\title{
Bonding and Reactivity of Gallium and Aluminium Coordination Complexes
}

By

Struan John Wright Cummins

\author{
A thesis \\ submitted to Victoria University of Wellington \\ in fulfilment of the requirements for the degree of \\ Doctor of Philosophy
}

Victoria University of Wellington 


\section{Acknowledgements}

Firstly, I would like to thank Associate Professor Robin Fulton for her guidance, wisdom, support, patience, enthusiasm and relentless positive attitude. The past seven years under your tutelage have been incredibly rewarding, encouraging the growth of both my theoretical and practical skills while making the PhD process as fun as possible. This work would not have been nearly as enjoyable without you.

To Professor Martyn Coles, thank you for all your help and input over the years. You have been a fountain of knowledge in many areas, most of all with crystal structures and help in solving crystal data. The technical staff at Victoria University of Wellington deserve my heartfelt gratitude for all the effort they put in behind the scenes to keep equipment operational in difficult circumstances, particularly lan Vorster and David Flynn.

Thank you to the members of the Coles and Fulton research groups, both past and present, for all the entertaining and scientific discussion you provided to help ease the monotony of lab work. Thanks also to the various friends I made in the other groups at VUW for the support and comradery you provided. Special thanks to Teresa Gen for being a constant source of cute cat videos and interesting foods.

Thank you to the Curtis-Gordon research scholarship and the Victoria Doctoral submission scholarship for the financial aid provided, without which this work would not have been possible.

And finally thank you to my loving family for the constant encouragement and support throughout my entire time at university. Despite not having a clue what I was talking about and telling all your friends I'm a mad scientist, you were always there when I needed you with a smile and a hug. 


\section{Abstract}

This thesis describes the synthesis, structures and reactivities of gallium and aluminium complexes supported by $\beta$-diketiminato ligands $\left(\left[C R\left\{C(R) N\left(R^{\prime}\right)\right\}_{2}\right]^{-}\right.$, abbrev. $\left.\left[\left(B D I_{R^{\prime}}\right)\right]^{-}\right)$.

Chapter 1 gives a general introduction into the trends and properties that distinguish the heavier $p$-block elements from their lighter counterparts. An introduction into the theory of multiple bond formation, both homonuclear and heteronuclear, in the heavy $p$-block elements is provided and a summary of the sterically demanding ligands required to stabilise these complexes is introduced. The $\beta$-diketiminato ligand framework utilised in this study is introduced and the methods of generation of low valent gallium and aluminium complexes supported by the BDIDIPp ligand are discussed.

Chapter 2 discusses the reactivity of the complex BDIDIPPGa with diazo- compounds in the quest to isolate a complex with a formal gallium-carbon double bond. BDI DIPPGa reacts with two equivalents of both trimethylsilyldiazomethane and diazofluorene, presumably through the target gallium-carbon double bond intermediate. No reaction is observed with di-tert-

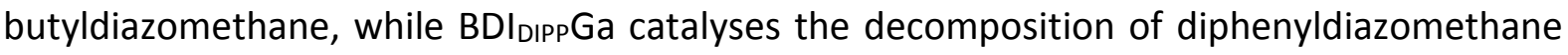
into tetraphenylethene. Three new $\beta$-diketiminato gallium(I) complexes were synthesised: $\operatorname{ArBDI}_{D I P P G a} \mathrm{BDI}_{\mathrm{Ar} * \mathrm{Ga}}$ and $\mathrm{BDI}_{\mathrm{Ar}} \mathrm{Ga}$. $\mathrm{ArBDI}_{\mathrm{DIPP} G a}$ also reacted with two equivalents of trimethylsilyldiazomethane, presumably through the target gallium-carbon double bond intermediate. $\mathrm{BDI}_{\mathrm{Ar}} * \mathrm{Ga}$ and $\mathrm{BDI}_{\mathrm{Ar}} \mathrm{Ga}$ both inserted into the $\mathrm{C}-\mathrm{H}$ bond of trimethylsilyldiazomethane to give $\mathrm{BDI}_{\mathrm{Ar}} * \mathrm{Ga}(\mathrm{H}) \mathrm{C}\left(\mathrm{N}_{2}\right) \mathrm{SiMe}_{3}$ and $\mathrm{BDI}_{\mathrm{Ar}} \mathrm{Ga}(\mathrm{H}) \mathrm{C}\left(\mathrm{N}_{2}\right) \mathrm{SiMe}_{3}$ respectively. Upon addition of diazofluorene to $B D I_{A r} * G a$, one of the aromatic protons of the $\mathrm{BDI}_{\mathrm{Ar}}$ ligand was abstracted by the diazofluorene, resulting in coordination of one of the flanking phenyl groups to the gallium centre.

Chapter 3 discusses an investigation into the formation of formal double bonds between aluminium and phosphorus, and gallium and phosphorus. The proposed 'deprotonation/elimination' method, reacting BDI $\mathrm{DIPPM}(\mathrm{PHAr}) \mathrm{Cl}(\mathrm{M}=\mathrm{Al}, \mathrm{Ga} \mathrm{Ar}=\mathrm{Ph}, \mathrm{Mes})$ with ${ }^{n} \mathrm{BuLi}$, resulted in the formation of intractable mixtures of products. Direct synthesis by the addition of $\mathrm{MesPLi}_{2}$ to $\mathrm{BDI}_{\mathrm{DIPPMCl}}$ ( $\mathrm{M}=\mathrm{Al}, \mathrm{Ga}$ ) resulted in the formation of $\mathrm{BDI}_{\mathrm{DIPP} M}(\mathrm{PHMes}) \mathrm{Cl}(\mathrm{M}=\mathrm{Al}, \mathrm{Ga})$. Changing the elimination product to $\mathrm{TMS}-\mathrm{Cl}$, through the

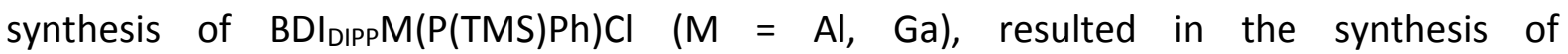


BDIDIPPAI(P(TMS)Ph)Cl, which showed no signs of elimination occurring upon heating to 110 ${ }^{\circ} \mathrm{C}$. BDI $\mathrm{BIPP}_{\mathrm{Pa}}(\mathrm{P}(\mathrm{TMS}) \mathrm{Ph}) \mathrm{Cl}$ could not be isolated, potentially as the complex was undergoing the desired elimination of TMS-Cl, but the resulting complex was decomposing. Changing the elimination product to ethane, through the synthesis of BDIDIPPAl(PHMes)Et, resulted in no sign of elimination occurring upon heating to $110^{\circ} \mathrm{C}$. Reduction of $\mathrm{BDI}_{\mathrm{DIPPMCl}}(\mathrm{M}=\mathrm{Al}, \mathrm{Ga})$ in the presence of bistrimethylsilylacetylene, as part of the synthesis of $\mathrm{BDI}_{\mathrm{DIPPM} M \mathrm{I}_{2}}(\mathrm{M}=\mathrm{Al}, \mathrm{Ga})$ salts, was unsuccessful, as was the reaction of BDIDIPpGa with bistrimethylsilylacetylene. Reduction of $\mathrm{MesPCl}_{2}$ with potassium metal in the presence of $\mathrm{BDI}_{\mathrm{DIPP}} \mathrm{Ga}$ resulted in an intractable mixture of products, reduction with magnesium resulted in the formation of $(\mathrm{MesP})_{3}$ and $(\mathrm{MesP})_{4}$. Addition of $\mathrm{MesPH}_{2}$ to $\mathrm{BDI}$ DIPPGa resulted in the formation of BDI DIPPGa(H)P(H)Mes, which did not undergo $\mathrm{H}_{2}$ elimination at $110{ }^{\circ} \mathrm{C}$. The synthesis of

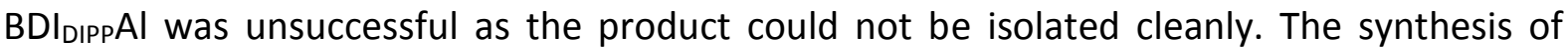
ArBDIDIPpAl resulted in the intramolecular rearrangement of the ligand to give a fivemembered aluminium containing ring. The synthesis of $\mathrm{BDI}_{A r} * \mathrm{Al}$ stalled at the formation of $\mathrm{BDI}_{\mathrm{Ar}} \mathrm{Al}(\mathrm{Me}) \mathrm{I}$ due to the steric bulk of the ligand blocking the second substitution of iodine from occurring.

Chapter 4 discusses the reactivity of the primary phosphanide complexes

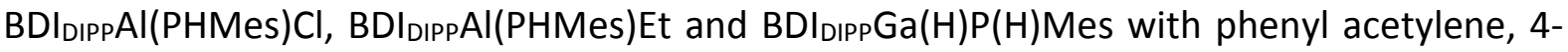
nitro-phenyl isocyanate, phenyl isothiocyanate, dicyclohexyl carbodiimide, cyclohexene, benzophenone, benzaldehyde, selenium, sulfur, and methyl iodide. Reactivity was not observed for phenyl acetylene, dicyclohexyl carbodiimide or benzophenone with any of the phosphanides. Reactivity with the phosphanides was observed with cyclohexene, however rapid decomposition of the products occurred and they were unable to be identified. $\mathrm{BDI}_{\mathrm{DIPP} A}(\mathrm{PHMes}) \mathrm{Cl}$ and $\mathrm{BDI}_{\mathrm{DIPP} G}(\mathrm{H}) \mathrm{P}(\mathrm{H}) \mathrm{Mes}$ showed no reactivity with benzaldehyde, however, the ethyl ligand of $\mathrm{BDI}_{\mathrm{DIPPA}} \mathrm{Al}(\mathrm{PHMes}) \mathrm{Et}$ reacted with the aldehyde proton, eliminating ethane and substituting the $\mathrm{PhC}(\mathrm{O})$ - ligand onto the aluminium centre. Reactivity with the phosphanides was observed with both sulfur and selenium, however multiple different products were formed, none of which were successfully isolated. Reactivity between the phosphanides and methyl iodide was observed, with the P-M bond appearing to be cleaved and formation of a $\mathrm{M}-\mathrm{I}$ bond occurring. 4-nitro-phenyl isocyanate and phenyl 
isothiocyanate underwent insertion reactions into the M-P bond, however only $\left.\mathrm{BDI}_{\text {DIPPAl }} \mathrm{Cl}\right) \mathrm{N}\left(4-\mathrm{NO}_{2}-\mathrm{Ph}\right) \mathrm{C}(\mathrm{O}) \mathrm{P}(\mathrm{H})$ Mes was able to be isolated and fully characterised.

Finally, chapter 5 summarises the results of this research and provides an outlook at the future direction of this field of research. 


\section{Table of Contents}

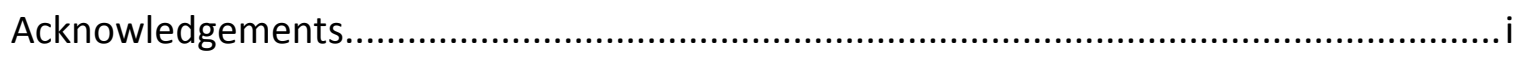

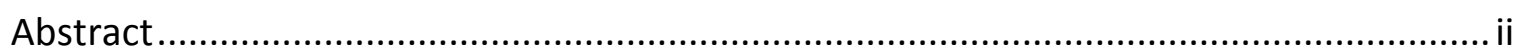

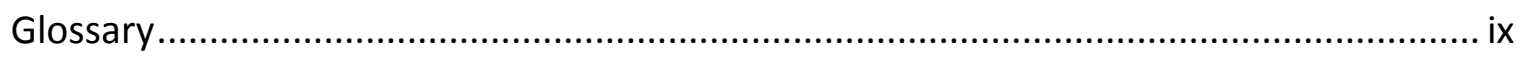

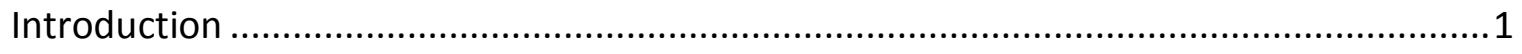

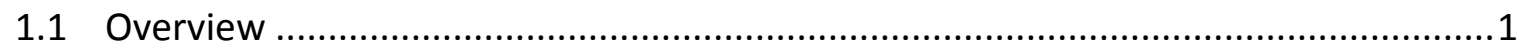

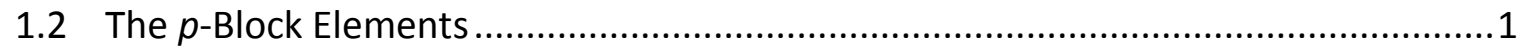

1.3 Stereochemical Lone Pairs and the Inert Pair Effect.............................................

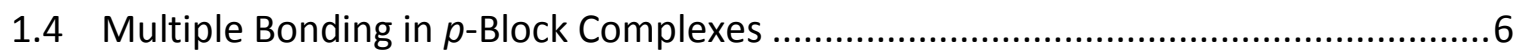

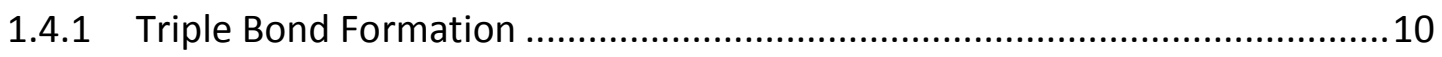

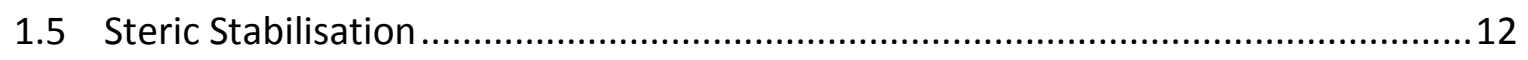

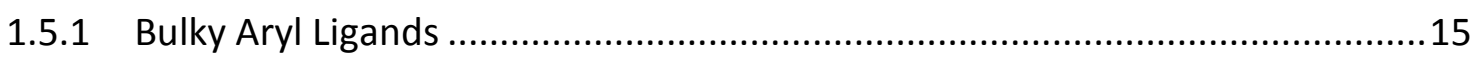

1.5.1.1 Low Valent Group 13 Aryl Complexes ...................................................16

1.5.1.2 Low Valent Group 14 Aryl Complexes ................................................18

1.5.1.3 Low Valent Group 15 Aryl Complexes ..................................................21

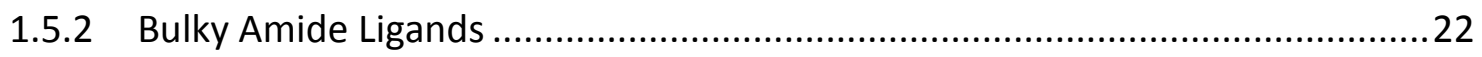

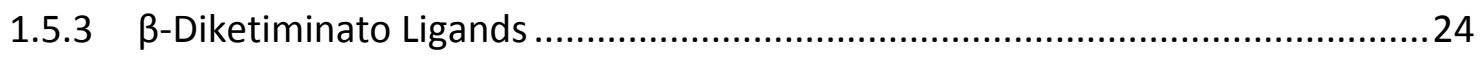

1.5.3.1 $\quad \beta$-Diketiminato Ligand Derivatives .......................................................26

1.5.3.2 $\quad \beta$-Diketiminato Metal Complexes........................................................2

1.6 Heteronuclear Multiple Bonding in the Main Group ..........................................28

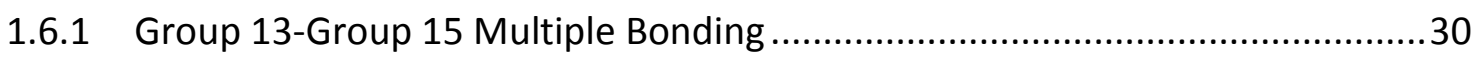

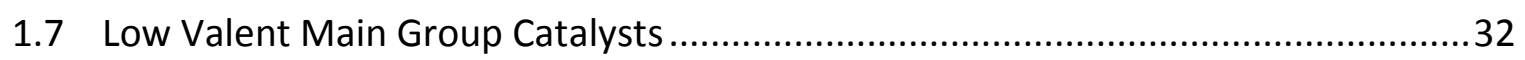

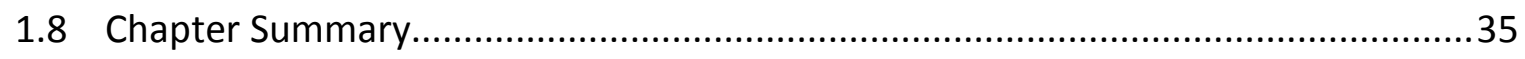

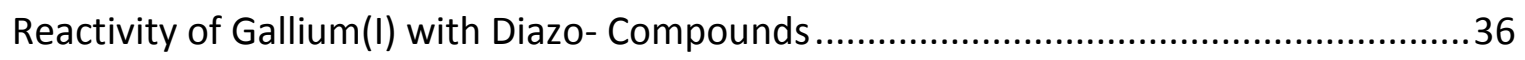

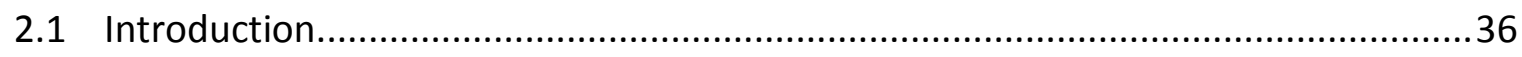

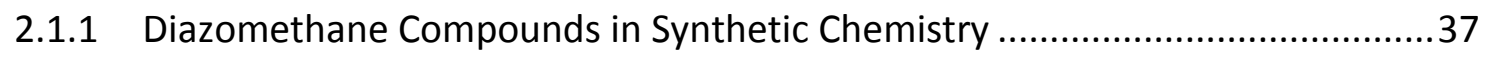




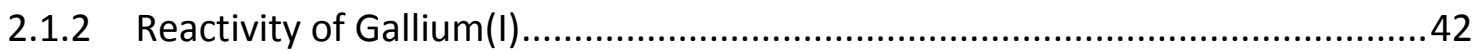

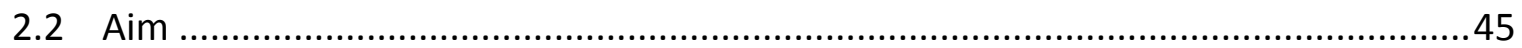

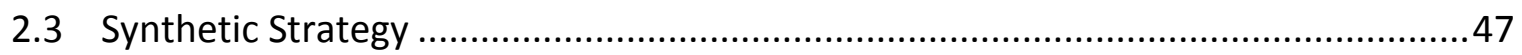

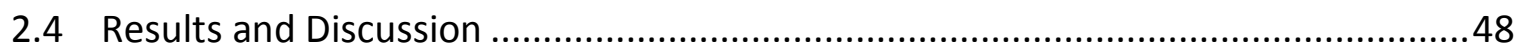

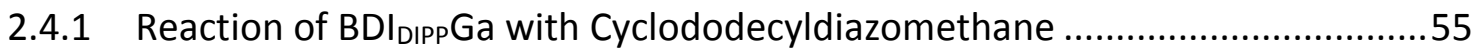

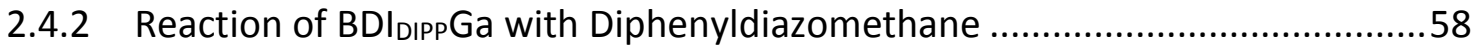

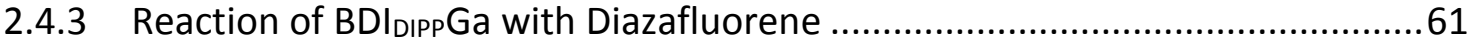

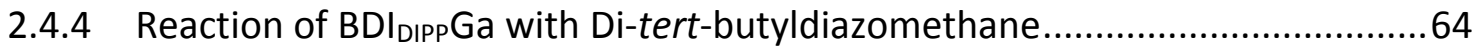

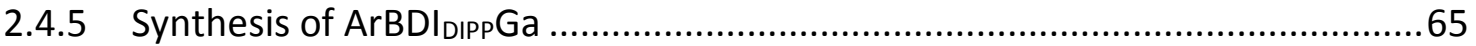

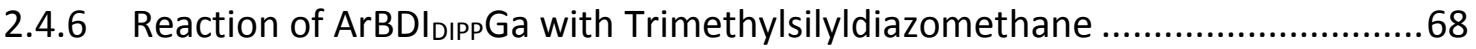

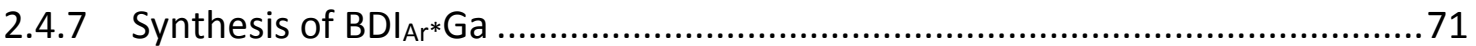

2.4.8 Reaction of $\mathrm{BDI}_{\mathrm{Ar}} * \mathrm{Ga}$ with Trimethylsilyldiazomethane .................................73

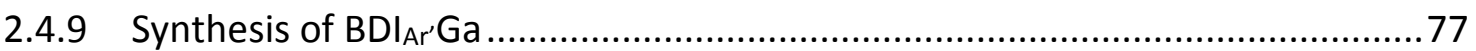

2.4.10 Reaction of $\mathrm{BDI}_{\mathrm{Ar}} \mathrm{Ga}$ with Trimethylsilyldiazomethane ...............................79

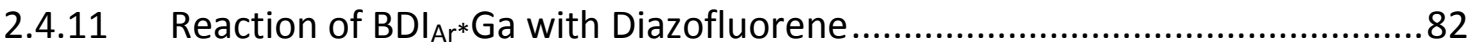

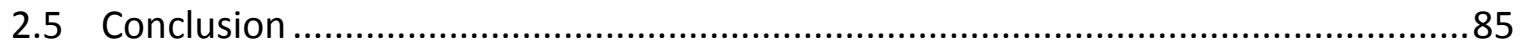

Attempted Synthesis of Group 13-Phosphorus Double Bonds .....................................87

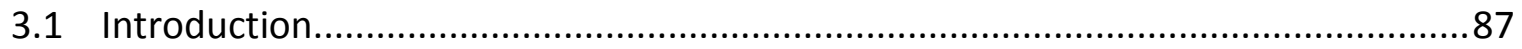

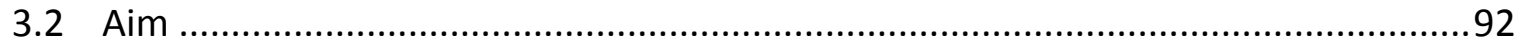

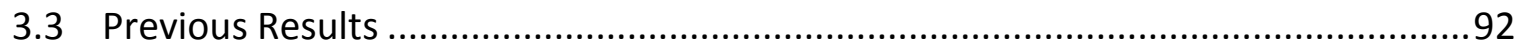

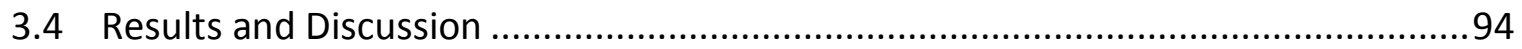

3.4.1 Increasing the Steric Bulk of the Phosphanide ...............................................95

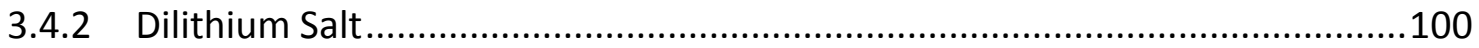

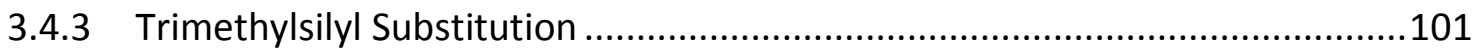

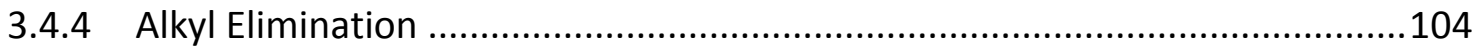

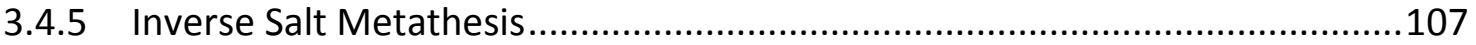




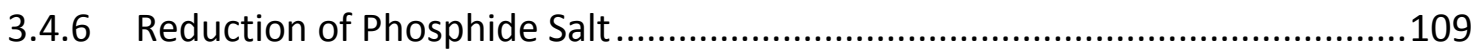

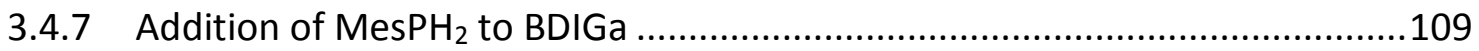

3.4.8 Attempted Synthesis of BDIAI Complexes .................................................113

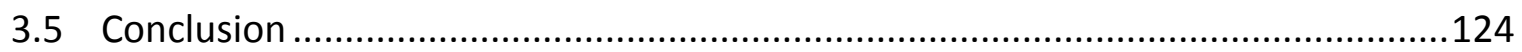

Reactivity of Primary Gallium and Aluminium Phosphanides .....................................126

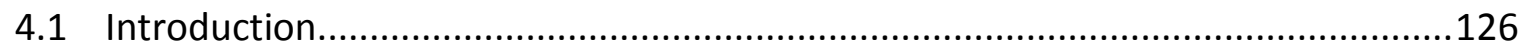

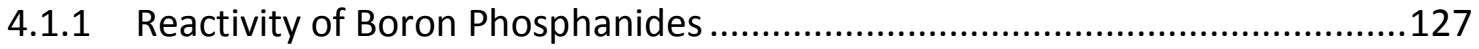

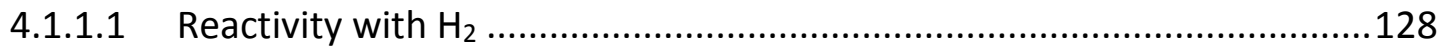

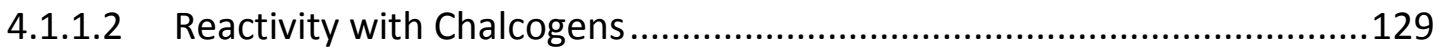

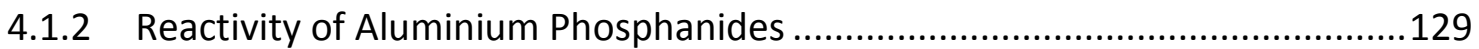

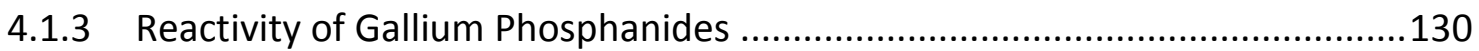

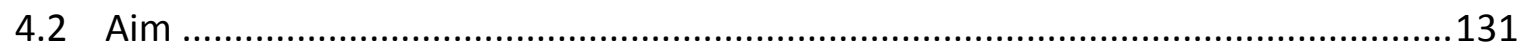

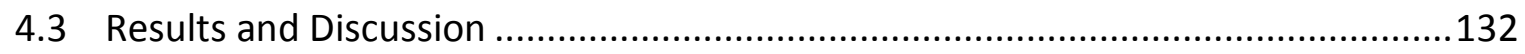

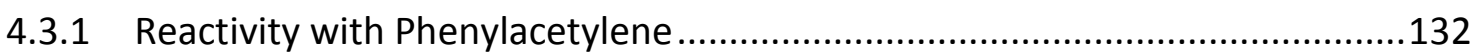

4.3.2 Reactivity with 4-Nitro-Phenyl Isocyanate ...............................................133

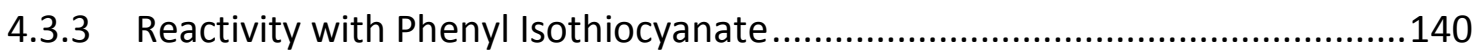

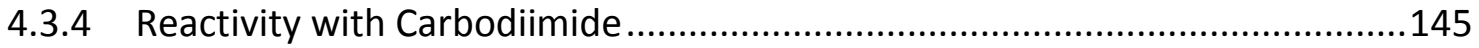

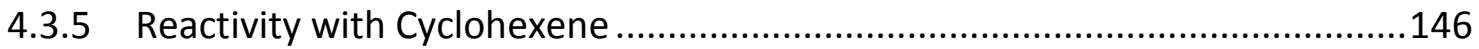

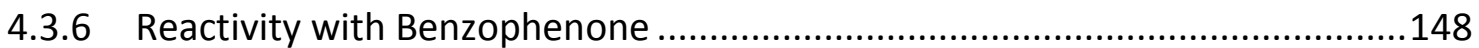

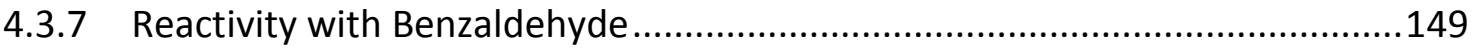

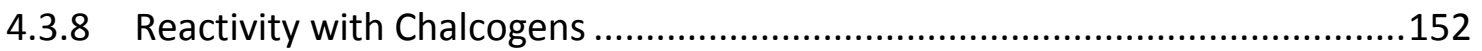

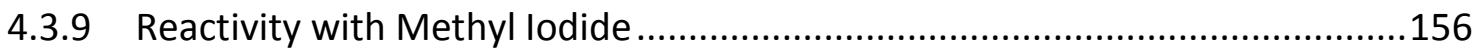

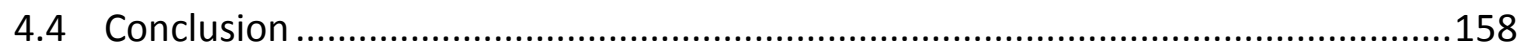

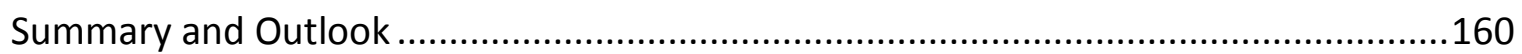

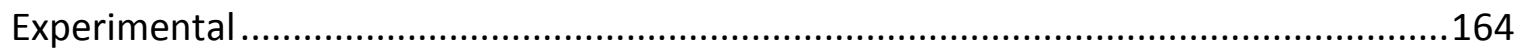

Appendix A: NMR Spectra of Novel Compounds........................................................190 


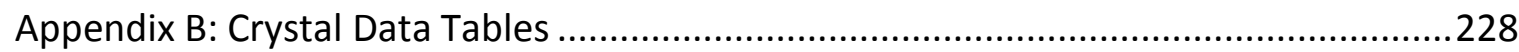

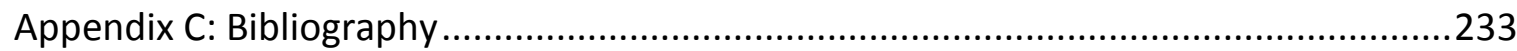




\section{Glossary}

\begin{tabular}{|c|c|}
\hline$\delta$ & Chemical shift (ppm) \\
\hline${ }^{1} \mathrm{H}$ NMR & Hydrogen nuclear magnetic resonance \\
\hline${ }^{13}$ C NMR & Carbon nuclear magnetic resonance \\
\hline${ }^{31}$ P NMR & Phosphorus nuclear magnetic resonance \\
\hline app & Apparent \\
\hline Ad & Adamantyl group \\
\hline Ar & 2,6-diisopropylphenyl (2,6-i $\left.\mathrm{Pr}_{2} \mathrm{C}_{6} \mathrm{H}_{3}\right)$ \\
\hline Ar* & $2,6-\left(\mathrm{CHPh}_{2}\right)_{2}-4-\mathrm{MeC}_{6} \mathrm{H}_{2}$ \\
\hline $\mathrm{Ar}^{\prime}$ & $2,6-\left(\mathrm{CHPh}_{2}\right)_{2}-4-{ }^{\mathrm{t}} \mathrm{BuC}_{6} \mathrm{H}_{2}$ \\
\hline Ar" & $\mathrm{C}_{6} \mathrm{H}_{3}-2,6-\left(\mathrm{C}_{6} \mathrm{H}_{3}-2,6-{ }^{\mathrm{i}} \mathrm{Pr}_{2}\right)_{2}$ \\
\hline$A r^{\prime \prime \prime}$ & $\mathrm{C}_{6} \mathrm{H}_{2}-2,6-\left(\mathrm{C}_{6} \mathrm{H}_{3}-2,6-{ }^{\mathrm{i}} \mathrm{Pr}_{2}\right)_{2}-4-\left(\mathrm{SiMe}_{3}\right)$ \\
\hline$\mu$ & Bridging \\
\hline br & Broad \\
\hline $\mathrm{C}_{6} \mathrm{D}_{6}$ & Deuterated benzene \\
\hline$C_{7} D_{8}$ & Deuterated toluene \\
\hline CGMT & Carter-Goddard-Malrieu-Trinquier theory \\
\hline COSY & Correlation spectroscopy $\left({ }^{1} \mathrm{H}\right.$ to $\left.{ }^{1} \mathrm{H}\right)$ \\
\hline$C p^{*}$ & 1,2,3,4,5-pentamethylcyclopentadienyl ligand \\
\hline CSD & Cambridge Structural Database \\
\hline d & Doublet \\
\hline dt & Doublet of triplets \\
\hline DBU & 1,8-Diazabicyclo[5.4.0]undec-7-ene \\
\hline DCM & Dichloromethane \\
\hline DFT & Density Functional Theory \\
\hline Dipp & 2,6-diisopropylphenyl group \\
\hline DME & 1,2-dimethoxyethane \\
\hline Dmp & 2,6-dimethylphenyl group \\
\hline EDG & Electron donating group \\
\hline Et & Ethyl \\
\hline EWG & Electron withdrawing group \\
\hline FI & Fluorene group \\
\hline FLP & Frustrated Lewis Pair \\
\hline $\mathrm{Hz}$ & Hertz, $\mathrm{s}^{-1}$ \\
\hline HМBC & Heteronuclear multiple-bond correlation $\left({ }^{1} \mathrm{H}\right.$ to $\left.{ }^{13} \mathrm{C}\right)$ \\
\hline HSQC & Heteronuclear single quantum coherence $\left({ }^{1} \mathrm{H}\right.$ to $\left.{ }^{13} \mathrm{C}\right)$ \\
\hline HOMO & Highest Occupied Molecular Orbital \\
\hline J & Scalar coupling constant $(\mathrm{Hz})$ \\
\hline kcal & Kilocalories \\
\hline kJ & Kilojoules \\
\hline LUMO & Lowest Unoccupied Molecular Orbital \\
\hline$m$ & Multiplet \\
\hline$m-$ & meta \\
\hline Mes & Mesityl ligand $\left(2,4,6-\mathrm{Me}_{3} \mathrm{C}_{6} \mathrm{H}_{2}\right)$ \\
\hline Mes* & 2,4,6-tri-tert-butylphenyl group \\
\hline MO & Molecular orbital \\
\hline NHC & $\mathrm{N}$-Heterocyclic carbene \\
\hline NMR & Nuclear magnetic resonance spectroscopy. \\
\hline
\end{tabular}




\begin{tabular}{|c|c|}
\hline${ }^{n} \mathrm{Bu}$ & n-Butyl \\
\hline $0-$ & ortho \\
\hline$p-$ & para \\
\hline ppm & Parts per million. \\
\hline Ph & Phenyl \\
\hline $\mathbf{s}$ & Singlet. \\
\hline sept & Septet. \\
\hline SOJT & Second order Jahn-Teller \\
\hline SOMO & Singly Occupied Molecular Orbital \\
\hline $\mathbf{t}$ & Triplet. \\
\hline tt & Triplet of triplets. \\
\hline THF & Tetrahydrofuran \\
\hline TMEDA & Tetramethyl ethylenediamine \\
\hline Tmp & 2,2,6,6-tetramethylpiperidino group \\
\hline TMS & Trimethylsilyl group \\
\hline Tol & Toluene \\
\hline Trip & 2,4,6-triisopropylphenyl group \\
\hline UV & Ultraviolet \\
\hline \multirow[t]{2}{*}{ WBI } & Wiberg bond index \\
\hline & Terminology of the $\beta$-diketiminate ligand \\
\hline BDI DIPP & $\mathrm{CH}\left\{\mathrm{C}(\mathrm{Me}) \mathrm{N}\left(\mathrm{C}_{6} \mathrm{H}_{3}-2,6-\mathrm{Pr}_{2}\right)\right\}_{2}$ \\
\hline ArBDIDIPP & $o-\mathrm{C}_{6} \mathrm{H}_{4}\left\{\mathrm{C}\left(\mathrm{CH}_{3}\right) \mathrm{N}-2,6-{ }^{\mathrm{i}} \mathrm{Pr}_{2} \mathrm{C}_{6} \mathrm{H}_{3}\right\}\left\{\mathrm{N}-2,6-\mathrm{P}_{2} \mathrm{C}_{6} \mathrm{H}_{3}\right\}$ \\
\hline tBuBDIDIPP & $\mathrm{CH}\left\{\mathrm{C}\left({ }^{\mathrm{t}} \mathrm{Bu}\right) \mathrm{N}\left(\mathrm{C}_{6} \mathrm{H}_{3}-2,6--^{\mathrm{i}} \mathrm{Pr}_{2}\right)\right\}_{2}$ \\
\hline $\mathrm{BDI}_{\mathrm{Ar} *}$ & $\mathrm{CH}\left\{\mathrm{C}(\mathrm{Me}) \mathrm{N}\left(\mathrm{C}_{6} \mathrm{H}_{2}-2,6-\left(\mathrm{CHPh}_{2}\right)_{2}-4-\mathrm{Me}\right)\right\}_{2}$ \\
\hline $\mathrm{BDI}_{\mathrm{Ar}}$ & $\mathrm{CH}\left\{\mathrm{C}(\mathrm{Me}) \mathrm{N}\left(\mathrm{C}_{6} \mathrm{H}_{2}-2,6-\left(\mathrm{CHPh}_{2}\right)_{2}-4-{ }^{\mathrm{t}} \mathrm{Bu}\right)\right\}_{2}$ \\
\hline$v-H / v-$ & Refers to the hydrogen substituent of carbon $2\left(R_{3}=H\right)$. \\
\hline $\mathrm{p}-\mathrm{C}$ & Refers to carbon 2. \\
\hline $\mathrm{NCCCN} / \mathrm{C}_{3} \mathrm{~N}_{2}$ & Refers to the plane defined by $N_{1}-C_{1}-C_{2}-C_{3}-N_{2}$ \\
\hline
\end{tabular}<smiles>[R5]N=C([R])/C([R3])=C(/[R])N([R7])N[R]</smiles> 


\section{Chapter 1}

\section{Introduction}

\subsection{Overview}

This thesis discusses an investigation into the bonding and reactivity of gallium and aluminium co-ordination complexes, specifically the reactivity of gallium(I) complexes with diazo compounds with the goal of forming a gallium-carbon double bonded species; the reactivity of both gallium and aluminium complexes with various phosphorus reagents with the goal of forming a metal-phosphorus double bonded species; and the reactivity of the metal phosphanide species obtained from the attempted synthesis of the metal-phosphorus double bonds, as the reactivity of primary gallium and aluminium phosphanides is not represented currently in literature.

\subsection{The $p$-Block Elements}

The heavier $p$-block elements exhibit significantly different properties and behaviour to $p$-block elements in the first row, with the divergence from the predictable behaviour of the first row caused by the introduction of $p, d$ and $f$ core-shell electrons descending the group, with each new type of core-shell introduced affecting their properties. ${ }^{1}$ For instance, the atomic radii of the $p$-block elements (Table 1, 2 d.p.) are heavily influenced by the core electron configurations. The relatively large increase in atomic radii between the $2^{\text {nd }}$ and $3^{\text {rd }}$ row $p$-block elements can be rationalised by the increasing size of the $3 s / 3 p$ versus $2 s / 2 p$ atomic orbitals. The size difference between the $3^{\text {rd }}$ and $4^{\text {th }}$ row $p$-block elements is small due to the introduction of core $d$-orbitals (Ga onwards) causing a much smaller increase in atomic radii due to the contraction by the $d$-orbitals, whereby the core $d$ electrons are not as effective at shielding the valence electrons from the nucleus, causing the valence shell electrons to be 
attracted closer to the nucleus. ${ }^{1-3} \mathrm{~A}$ significant increase in atomic radii is observed between the $4^{\text {th }}$ row and the $5^{\text {th }}$, when a second set of core $d$-orbitals is added (In onwards) with yet another small increase in atomic radius between the $5^{\text {th }}$ and $6^{\text {th }}$ row upon addition of core $f$ orbitals ( $\mathrm{Tl}$ onwards) due to the 'lanthanide contraction' - whereby the core $f$-orbitals are even worse at shielding the valence electrons from the effect of the nucleus than the $d$ orbitals.

Table 1: Atomic radii of the $p$-block elements in $\AA$. Data is crystallographically determined ${ }^{2}$ vs (calculated) ${ }^{3}$

\begin{tabular}{|c|c|c|c|c|}
\hline B: $1.91(2.05)$ & C: $1.77(1.90)$ & N: $1.66(1.79)$ & O: $1.50(1.71)$ & F: $1.46(1.63)$ \\
\hline Al: $2.25(2.39)$ & Si: $2.19(2.32)$ & P: $1.90(2.23)$ & S: $1.89(2.14)$ & Cl: $1.82(2.06)$ \\
\hline Ga: $2.32(2.33)$ & Ge: $2.29(2.34)$ & As: $1.88(2.31)$ & Se: $1.82(2.24)$ & Br: $1.86(2.19)$ \\
\hline In: $2.43(2.46)$ & Sn: $2.42(2.48)$ & Sb: $2.47(2.46)$ & Te: $1.99(2.42)$ & I: $2.04(2.38)$ \\
\hline Tl: $2.47(2.42)$ & Pb: $2.60(2.49)$ & Bi: $2.54(2.50)$ & Po: N.D. (2.50) & At: N.D. (2.47) \\
\hline
\end{tabular}

This alternating large-small increase in radii is caused by the change in core electronic structure and potentially influences the relative separation energy of the valence $s$ and $p$ orbitals. ${ }^{1}$ This results in some unusual properties in the co-ordination chemistry of the heavier $p$-block elements. Trending down, the groups exhibit an increasing distortion from ideal geometries due to the increasing stability of non-bonding electron pairs ("s-electrons") and minimal hybridisation between the $s$ and $p$ orbitals. The energy gap between the $s$ and $p$ orbitals along with increasing relativistic effects ${ }^{4}$ in the heaviest elements also results in a trend for the heavier $p$-block elements in group 13-15 preferentially adopting lower $(n-2)$ oxidation states than their lighter counterparts. ${ }^{1,5}$ 


\subsection{Stereochemical Lone Pairs and the Inert Pair Effect}

The distortion from ideal geometries and preference for the $(n-2)$ oxidation state stem from the $s$ electrons of low-valent period 4, 5 and 6 elements in the $p$-block exhibiting two highly interesting traits. The electrons in the occupied s-orbital can be 'inert' and potentially 'stereochemically active'. The 'inert pair effect' describes the tendency of the heavier $p$-block elements to preferentially exist in lower oxidation states and rely on donor atoms such as oxygen, nitrogen and sulfur to stabilise them. This phenomenon arises because of both the relative difference in energy between the $4 s$ and $4 p$ (and by extension the $5 s / 5 p$ and $6 s / 6 p$ ), and the physical extension of the $4 p$ orbitals away from the nucleus relative to the $4 s$ orbital. ${ }^{5-}$ ${ }^{6}$ The relative extension of the $4 p$ orbitals also start experiencing significant increases in relativistic effects, with larger relativistic effects being observed in the period 6 elements. ${ }^{4,7}$ This effect occurs as outer shell electrons approaching the speed of light have a higher relative mass and therefore a reduced Bohr radius than core electrons, with the effects being larger in the higher energy levels and accounting for one third of the energy difference between the $6 s$ and $6 p$ orbitals, leading to the $s$ electrons becoming increasingly inert. ${ }^{7}$ This allows for the occupied $4 s / 5 s / 6 s$ orbital to behave as a pair of core electrons and, provided the element is sufficiently stabilised, allows the isolation of low oxidation state complexes such as the $\beta$ diketiminato $\mathrm{Ga}(\mathrm{I})$ complex $\mathbf{1}^{8}$ and bisamidosilyl Ge(II) complex $\mathbf{I}^{9}$ (Figure 1 ) and their heavier analogues.

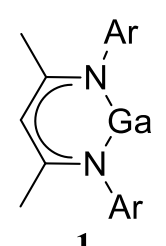

1

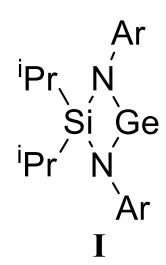

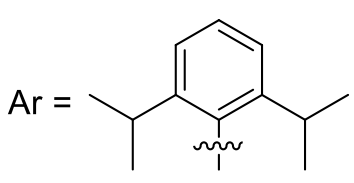

Figure 1: Stabilised Ga(I) and Ge(II) complexes.

The $6 s$ electrons are the main exhibiters of the inert pair effect, where the stability gained through hybridisation is offset by the significant difference in both size and relative energy of the $p$ orbitals and the destabilization caused by the contraction of the $s$ orbital upon oxidation 
to a higher charged metal ion. ${ }^{10}$ For example $\mathrm{PbX}_{4}(\mathrm{X}=\mathrm{Cl}, \mathrm{Br}, \mathrm{I})$ complexes are highly unstable, with the exception of $\mathrm{PbF}_{4}$, as the halogen removes electron density from the lead atom and causes the $s$ orbitals to contract, reducing their ability to hybridise and leading to shorter but weaker bonds (i.e. the bond shortens due to ionic radii contraction but weakens due to destabilisation of the $s$ orbital). ${ }^{10-11}$ In contrast, tetra-alkyl lead complexes $\mathrm{PbR}_{4}(\mathrm{R}=$ alkyl group) exhibit more of a covalent bond than an ionic one, which puts less of a positive charge on the metal centre and does not contract the $s$ orbital, enabling better hybridisation and making $\mathrm{Pb}(\mathrm{IV})$ the dominant oxidation state in organic lead complexes. ${ }^{11}$<smiles></smiles>

II<smiles></smiles>

III<smiles></smiles>

IV<smiles>CC(C)c1cccc(C(C)C)c1N(C)C</smiles>

Figure 2: Isostructural group $14 \mathrm{BDI}$ halide complexes

The term 'stereochemically active lone pair' describes the degree in which the $s$ orbitals hybridise with the $p$ orbitals. In general, as groups 13, 14 and 15 are descended, the level of hybridisation between the $s$ and $p$ orbitals decreases. For instance, in the series of isostructural $\beta$-diketiminate group 14 complexes (Figure 2 ) the s electrons remain 'inert'. In these complexes the lone pair is given directionality by the degree of $p$ character in the hybridisation. This imposes configurational constraints on the complex similar to a typical lone pair in that it occupies one of the co-ordination sites on the metal atom. ${ }^{10}$ As the heavier element (e.g. Ge/Sn/Pb) bonds, the hybridisation of the $4 s / 5 s / 6 s$ and $4 p / 5 p / 6 p$ orbitals can occur to a typically decreasing extent down the group when bonds form. This leads to complexes II-IV possessing increasingly distorted tetrahedral shapes where bond angles are between the $90^{\circ}$ of a true $p$-orbital and $109.5^{\circ}$ of a fully $s p^{3}$ hybrid orbital. Complexes IV and III both possess an angle of $92.2^{\circ}$ between the $\mathrm{N}-\mathrm{M}-\mathrm{N}$ plane and the $\mathrm{Cl}$ substituent, ${ }^{12-13}$ while complex II has an angle of $95.3^{\circ} .{ }^{12}$ While the $4 s / 5 s / 6 s$ electrons of complexes II-IV do not take part in bonding, the orbital does contribute towards the molecular orbitals involved in 
bonding, and the resulting non-bonding orbital is given directionality by the contributions from the $p$-orbitals. ${ }^{11}$ The resulting orbital behaves similar to a typical lone pair, repulsing other substituents and, in some cases, can act as a weak Lewis base. The gallium(I) complex 1 can act as a Lewis base with metallic Lewis acids such as $\mathrm{Ni}(\mathrm{CO})_{3}$ (Figure 3) to give heterobimetallic complex $\mathbf{V}$ and even heterotrimetallic complex VI. ${ }^{14}$ Complex $\mathbf{1}$ behaves analogous to a carbene ligand and has been used to form heterobimetallic complexes with other transition metals such as $\mathrm{Mn}, \mathrm{Fe}, \mathrm{Mo}$ and $\mathrm{W} .{ }^{15}$
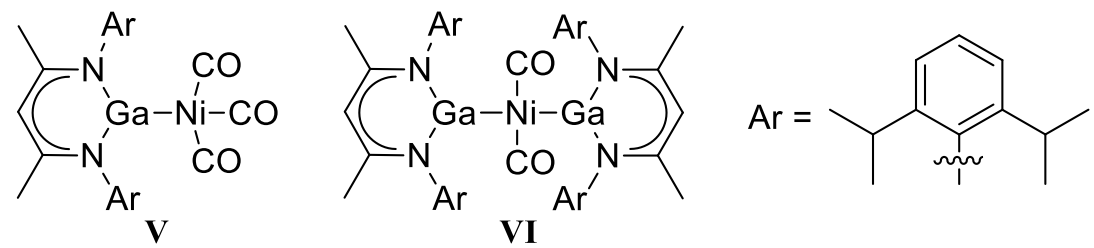

Figure 3: Gallium(I) nickel complexes.

The lone pair of the low valent heavier $p$-block elements is not always stereochemically active, and the ligands can be evenly dispersed (holodirected) around the coordination sphere as opposed to hemidirected (Figure 4) when the lone pair influences the coordination sphere and redistributes the ligands. For example, complexes of $\mathrm{Pb}(\mathrm{II})$ exhibit hemidirectionality at low coordination numbers (2-5), holodirectionality at high coordination numbers (9-10) and a combination of both, primarily holodirectionality, in the middle (6-8). ${ }^{10}$ In contrast, when the $s$ electrons are involved in the bonding (i.e. $\mathrm{Pb}$ (IV) complexes) there is no directionality imparted by the lone pair, and the ligands are holodirected around the coordination sphere for all known coordination complexes. ${ }^{10}$ From this it can be drawn that the lone pair is only stereochemically active when the steric constraints of the ligating atoms allows it to be or when the timescale of the investigation technique allows detection of it. 


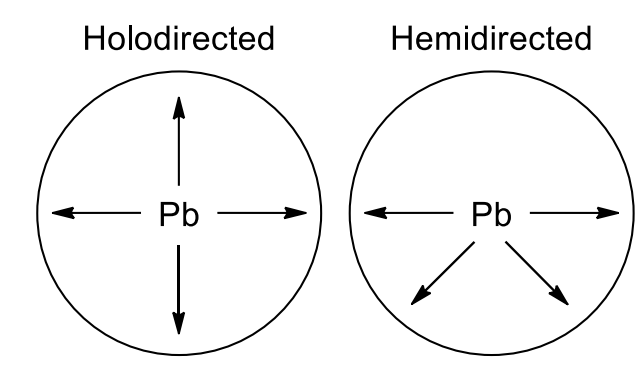

Figure 4: Different coordination spheres in $\mathrm{Pb}(\mathrm{II})$ complexes.

\subsection{Multiple Bonding in $p$-Block Complexes}

In order to understand multiple bonding between elements of different rows of the $p$ block, the effects introduced in multiple bonding between main group elements of the same type must first be discussed. The most common examples of multiple bonding in the $p$-block are the three classes of carbon-carbon bonds: alkanes, alkenes, and alkynes. These bonds are the textbook ${ }^{16}$ examples of a single, double and triple bond and are used to exemplify $s-p$ hybridisation theory, where bond angles between substituents are virtually identical to the expected values of $109.5^{\circ}, 120^{\circ}$, and $180^{\circ}$. However, below the first row of the $p$-block (Al onwards) the core electronic structure begins to distort the ability of the $s$ and $p$ orbitals to hybridise. ${ }^{17-18}$ The addition of core $p$ electrons and later (Ga onwards) core $d$ electrons results in the higher orbitals extending further away from the nucleus due to Pauli repulsion, which causes the higher level $p$ orbitals to physically overlap less with the corresponding $s$ orbitals, reducing their ability to hybridise. ${ }^{6}$ Another factor that changes between the first row elements is the electronic structure of the bond. For example, the lighter elements such as carbon typically adopt a triplet state, ${ }^{19}$ where one electron occupies a hybrid $s p^{2}$ orbital and another occupies a $\pi$ orbital (Figure 5 , left), two molecules in this configuration then combine in a $\sigma-\sigma$ and $\pi-\pi$ orientation to give one $\sigma$ bond and one $\pi$ bond to form the double bond. However, heavier elements such as tin typically adopt a singlet state and thus when two tin molecules bond, they cannot undergo the same $\sigma-\sigma$ bond overlap that carbon can as both $s p^{2}$ orbitals are fully occupied (Figure 5 , middle). Instead, the full $s p^{2}$ orbital bonds with the empty $p$ orbital to give a polar-dative bond instead (Figure 5, right). ${ }^{18}$ 


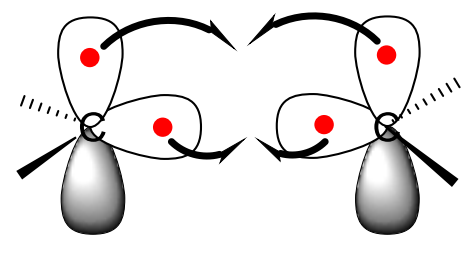

$s p^{2}-s p^{2}$ bonding

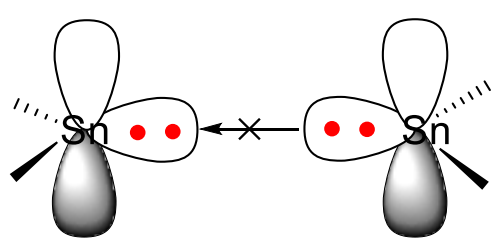

$s p^{2}-s p^{2}$ bonding

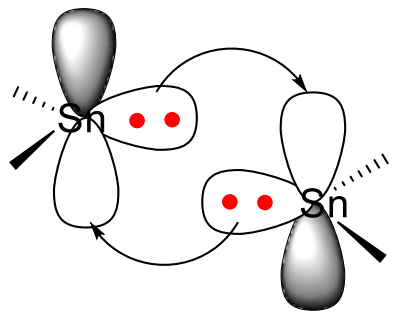

Polar dative bonding

Figure 5: Comparison between carbon double bond formation and tin double bond formation.

The rationale behind double bonds forming either carbon-type double bonds or polardative bonds can be explained through what is called the Carter-Goddard-Malrieu-Trinquier (CGMT) theory, ${ }^{19-22}$ which approaches bond formation in the $R_{2} E=E R_{2}$ systems as an association of each $\mathrm{R}_{2} \mathrm{E}$ : unit. This theory suggests the type of bonding modes present is strongly correlated with the singlet-triplet gap of the $\mathrm{R}_{2} \mathrm{E}$ : unit and the energy gained from bond formation (eq 1).

$$
E_{\sigma+\pi}=E_{I N T}-2 \Delta E_{S-T}
$$

The energy $\left(E_{\sigma+\pi}\right)$ is given by the energy of the double bond $\left(E_{I N T}\right)$ minus the energy difference between the triplet and singlet state $\left(\Delta E_{S-T}\right)$. This is illustrated in Figure 6 . While the $\Delta E_{S-T}$ term is positive for carbon as the triplet state is more stable, it is negative for the heavier elements (e.g. $\mathrm{Si}-\mathrm{Pb}$ ) as the singlet state is more stable. As such, Trinquier and Malrieu proposed the general rule that if $E_{\sigma+\pi}$ is $>2 \Delta E_{S-T}$ then a classical planar structure is observed ( $s p^{2}-s p^{2}$ bonding) whereas if $E_{\sigma+\pi}$ is $<2 \Delta E_{S-T}$, a trans bent structure is observed (polar dative bonding) and if $E_{\sigma+\pi}$ is $\left\langle\Delta E_{S-T}\right.$ then no bond formation will occur, leading to $\mathrm{R}_{2} E$ : monomers being the most stable state. ${ }^{20-22}$ Because the general trend is that the strength of the E-E bond decreases going down the group, the energy gained through bond formation is increasingly insufficient in heavier elements to counter the energy required to access the triplet state prior to bond formation, leading to heavier elements favouring discrete monomers. ${ }^{5}$ 


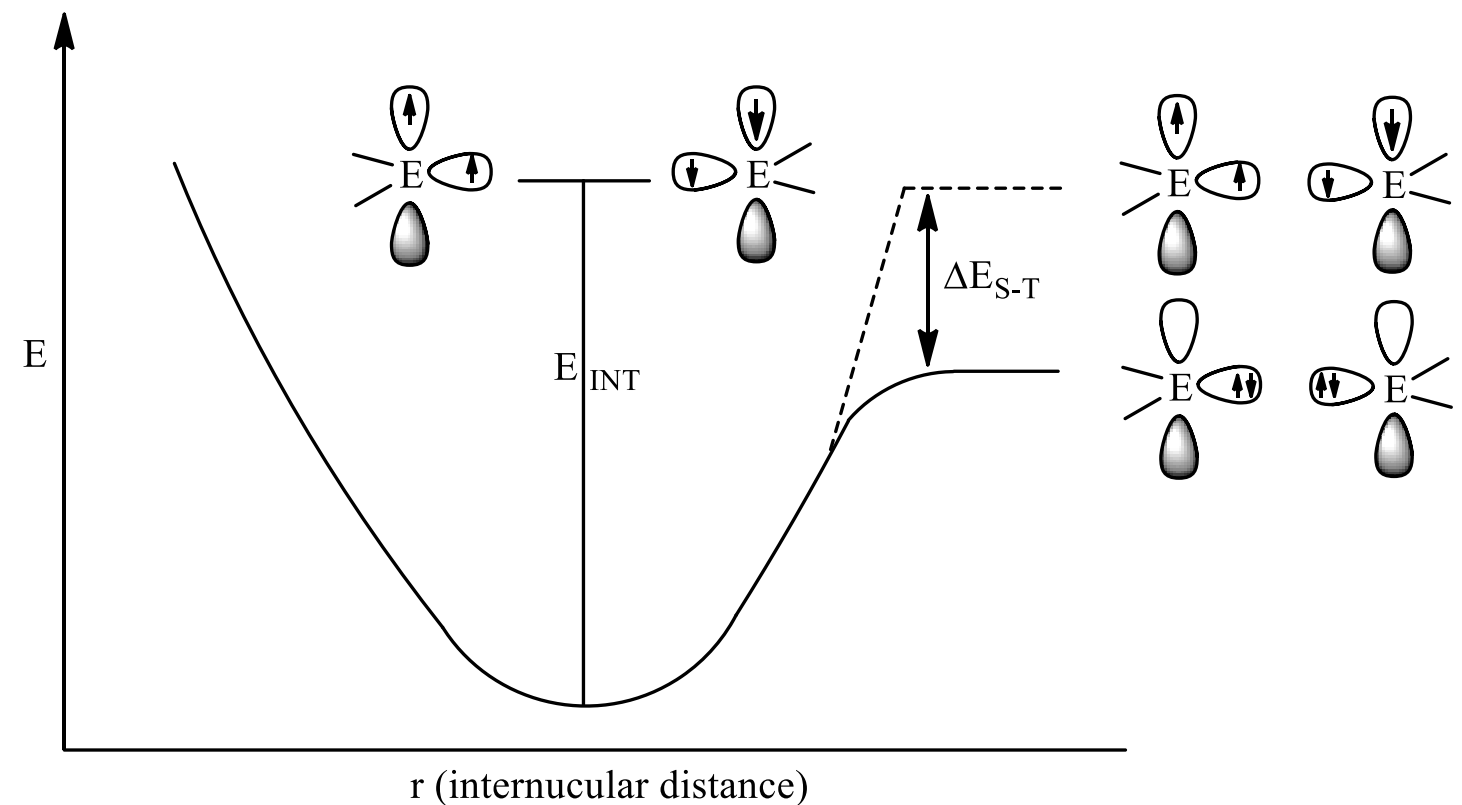

Figure 6: Generalized dissociation energy schematic of an olefinic double bond into two triplet fragments.

The presence of polar-dative bonding can be readily determined by the geometry at the central atom. Because the bond forms due to orbital overlap between the $s p^{2}$ orbital on one tin atom with the empty $p$ orbital on the neighbouring tin atom, the remaining substituents on the tin centre do not lie on the plane of the double bond as they do with carbon-carbon double bonds. Instead, the substituents are shifted out of plane by the angle defined as $\alpha$, which measures the angle between a plane equidistant from the four substituents that passes through both central atoms (Figure 7).

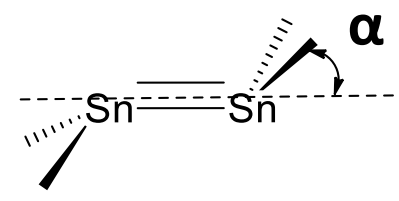

Figure 7: The dihedral angle between the double bond and substituents, $\alpha$. 
Because the double bond is formed through the overlap of two different types of orbitals, this gives rise to second order Jahn-Teller (SOJT) orbital mixing. Using the group 14 elements as the examples, instead of the standard molecular orbital (MO) diagram (Figure 8, left) the bonding orbitals (the occupied $s p^{2} \sigma$ orbital and the empty $p$ orbital) mix with the anti-bonding orbitals (the $\sigma^{*}$ and $\pi^{*}$ orbitals) to give the final molecular orbitals: an offset $\sigma$ bonding orbital and non-bonding orbital and their corresponding antibonding orbitals (Figure 8 , right). ${ }^{23-25}$

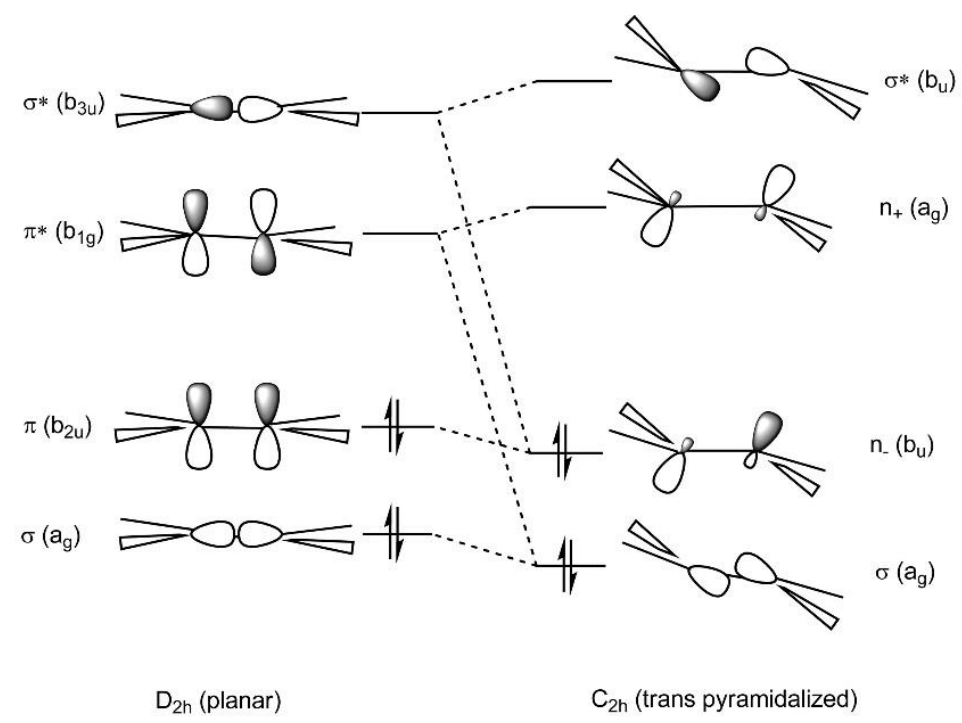

Figure 8: Energy level diagram illustrating second order Jahn-Teller orbital mixing for double bonded complexes. Figure reproduced from Fischer and Power. ${ }^{24}$

The formation of the $n$ - non-bonding orbital leads to a complete divergence from the traditional model of a double bond, where while there are 4 electrons involved in the bond between the two molecules, the bond is not necessarily any stronger or shorter than the corresponding single bond. ${ }^{5}$ In the heavier elements such as lead, the bond is actually longer than the corresponding single bond. ${ }^{26}$ This leads to debate over whether these electrons are involved in the bonding, or can be considered as a lone pair, shared across two atoms in different resonance forms (Figure 9) which will be discussed in detail in section 1.5 below. 


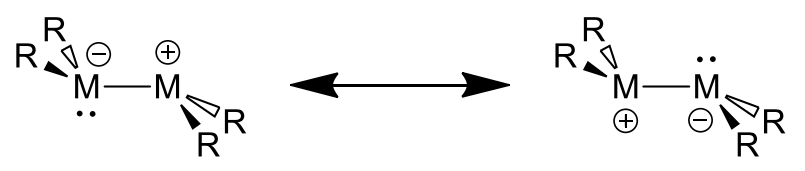

Figure 9: Resonance structures of heavier alkenes.

The electronic environment of the central atoms also has limited effect on the degree of bonding shown by the non-bonding $\mathrm{MO}$, which can be altered by changing the ancillary $\mathrm{R}$ groups. ${ }^{27}$ Structural factors such as the $\alpha$ angle cannot be used to directly measure the degree of involvement of the non-bonding $\mathrm{MO}$ in the double bond, but give a general indication as to what degree of a classical bond is present. In the context of the $p$-block, double bonds between the heavier elements adopt a trans-pyramidalized conformation, with larger values of $\alpha$ typically associated with the heavier elements where the bonding is thought to be weakest. Using the group 14 elements as an example, disilenes have angles ranging from $0^{\circ}$ $23^{\circ},{ }^{24}$ depending on the ligand system, with more sterically bulky ligands possessing an angle closer to the $0^{\circ}$ of classical bonding. Digermenes and distannenes have angles of about $50^{\circ}$ and $55^{\circ}$ respectively, ${ }^{24}$ while diplumbenes exemplify this effect with angles as high as $71^{\circ} .^{28}$

\subsubsection{Triple Bond Formation}

A similar SOJT effect is observed in the alkyne analogues of heavier $p$-block elements, where instead of the traditional $\sigma$-bond and two $\pi$-bonds (Figure 10, left) of an alkyne, the mixing between the bonding and anti-bonding orbitals forms the offset $\sigma$ bonding orbital and non-bonding orbital that the alkene analogues do, but also a $\pi$ bonding orbital (Figure 10, right) and their corresponding antibonding orbitals. 5,29 


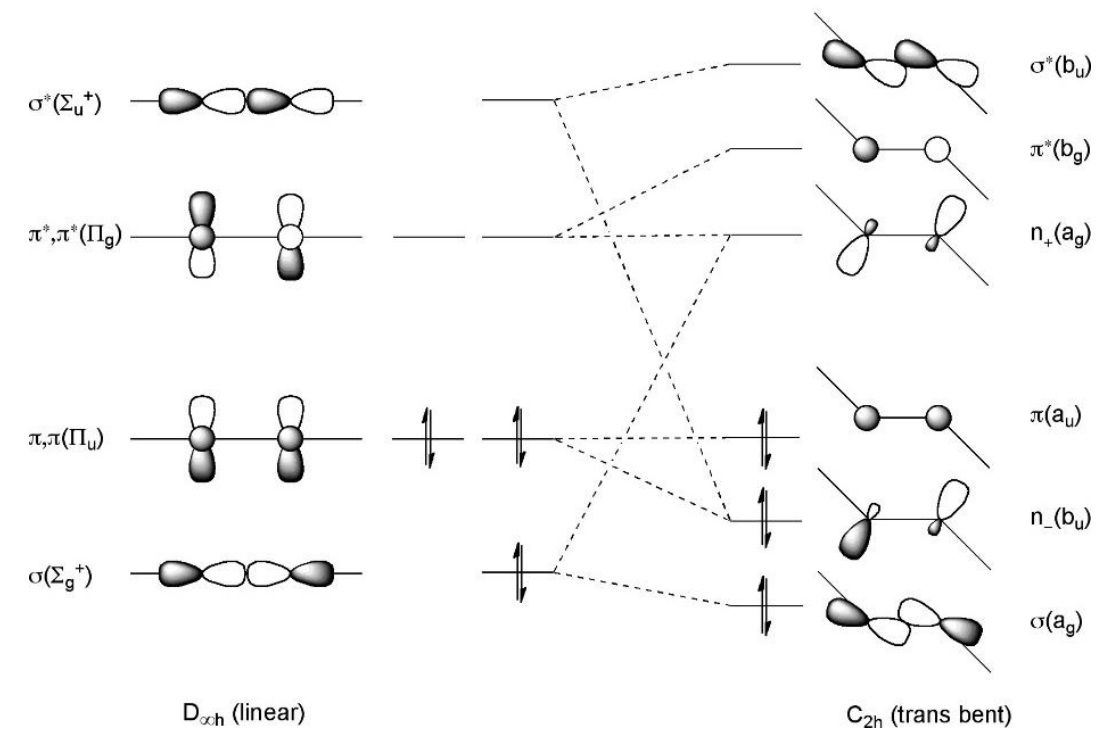

Figure 10: Energy level diagram illustrating second order Jahn-Teller orbital mixing for triple bonded complexes. Figure reproduced from Fischer and Power. ${ }^{24}$

The inclusion of the $\pi$ orbital in the bonding molecular orbitals suggests that the alkyne analogues of heavier main group elements should have an additional bonding interaction over the alkene analogues, and therefore the bonds should be stronger and shorter than the analogous alkene. However, this orbital is prone to 'slipping', where an increasing $\alpha$ angle in the trans bent structure correlates with reduced orbital overlap and decreasing bond order descending a group. ${ }^{24}$ In group 14 elements, the bond order of alkyne analogues decreases by about 0.5 for each element down the group, with alkynes having a bond order of 3 , silynes a bond order of 2.5 , and plumbynes having a bond order of about $1 .{ }^{24}$ This leads to the interesting situation where the bond lengths of alkyne analogues can be either longer and shorter than a standard single bond depending on the ancillary ligand used. For example, in the solid state the tin complex Ar"SnSnAr" (VII, Figure 11, $\left.\mathrm{Ar}^{\prime \prime}=\mathrm{C}_{6} \mathrm{H}_{3}-2,6\left(\mathrm{C}_{6} \mathrm{H}_{3}-2,6-{ }^{\mathrm{i}} \mathrm{Pr}_{2}\right)_{2}\right)^{30}$ has a Sn-Sn bond length of 2.6675(4) $\AA$ and an $\alpha$ angle of $125.24(7)^{\circ}$ (for reference the average Sn-Sn single bond is about $2.81 \AA$ ), however adding an $\mathrm{SiMe}_{3}$ group to the 4-position of the terphenyl ligand to give complex VIII results in a Sn-Sn bond length of 3.0660(10) $\AA$ and an $\alpha$ angle of $99.25(14)^{\circ} \cdot{ }^{31}$ DFT calculations on complexes VII and VIII show that both the multiple bonded structure of VII and the single bonded structure of VIII are local energy minimums. ${ }^{32}$ However, in both complex VII and VIII the multiple bonded form is the more 
stable form, being $5.3 \mathrm{kcal} / \mathrm{mol}$ and $5.4 \mathrm{kcal} / \mathrm{mol}$ lower in energy respectively. ${ }^{32}$ The UV-Vis spectra of both complexes support that the multiple bonded species of both complexes is present in solution phase, and the difference between the two structures in the solid state was attributed to crystal packing forces overcoming the small energy barrier between the two bonding modes. ${ }^{24,32-33} \mathrm{~A}$ similar result was also observed in germanium, where the triple bonded mode was observed in the solid state for 9 out of 10 synthesised terphenyl derivative ligands, and one $\left(\left[\left(\mathrm{C}_{6} \mathrm{H}_{3}-2,6\left(\mathrm{C}_{6} \mathrm{H}_{3}-2,6-\mathrm{Pr}_{2}\right)_{2}-4\left(\mathrm{GeMe}_{3}\right)\right) \mathrm{Ge}_{2}\right)\right.$ adopting the single bond structure. ${ }^{34}$ DFT calculations supported that the multiple bonded structure was the lowest in energy for all ten. ${ }^{33-34}$

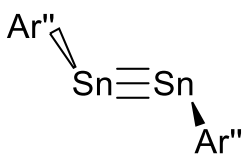

VII

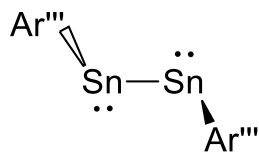

VIII

$$
\text { Ar" }=\mathrm{C}_{6} \mathrm{H}_{3}-2,6-\left(\mathrm{C}_{6} \mathrm{H}_{3}-2,6-\mathrm{i}^{\mathrm{i}} \mathrm{Pr}_{2}\right)_{2} \quad \text { Ar"' }=\mathrm{C}_{6} \mathrm{H}_{2}-2,6-\left(\mathrm{C}_{6} \mathrm{H}_{3}-2,6-\mathrm{Pr}_{2}\right)_{2}-4-\left(\mathrm{SiMe}_{3}\right)
$$

Figure 11: Different bonding structures of tin alkynes.

Interestingly, some gallium and indium alkyne analogues have shown that the nonbonding orbital can be converted into an additional bonding orbital occurs upon single electron reduction. ${ }^{35-36}$ The single electron reduction results in the formation of what has been calculated to be a singularly occupied molecular orbital (SOMO) $\pi$ bonding orbital that formally contributes 0.5 to the bond order, however further attempts at reduction to obtain an isoelectronic alkyne analogue leads to product decomposition into a cluster.

\subsection{Steric Stabilisation}

While the heaviest $p$ block elements $(\mathrm{Tl} / \mathrm{Pb} / \mathrm{Bi})$ are readily isolated in their $n-2$ oxidation state due to the relatively high inert pair effect in these elements, isolating the lighter $p$ block 
elements in their $n-2$ oxidation states was challenging due to their high reactivity and tendency to either polymerise/oligomerise, or to disproportionate into the $n$ oxidation state and elemental metal. ${ }^{37-39}$ The crucial breakthrough in the isolation of these compounds occurred in the 1970 s with the synthesis of $\left(\left(\mathrm{Me}_{3} \mathrm{Si}\right)_{2} \mathrm{CH}\right)_{2} \mathrm{Sn}(\mathbf{X}){ }^{40}$ a low valent tin(II) analogue of a carbene in solution, which in the solid state formed a dimer analogous to ethene, though possessing an unusual trans-bent geometry with pyramidal metal atoms. This was quickly followed by synthesis of $\left(\left(\mathrm{Me}_{3} \mathrm{Si}\right)_{2} \mathrm{CH}\right)_{2} \mathrm{~Pb}^{41}(\mathbf{X I})$ and $\left(\left(\mathrm{Me}_{3} \mathrm{Si}\right)_{2} \mathrm{CH}\right)_{2} \mathrm{Ge}(\mathbf{I X}$, Figure 12$),{ }^{42}$ and while these were prepared from the known, stable $M(I I)$ halide salts, they were the first examples of stable low valent tin and germanium organometallic compounds.

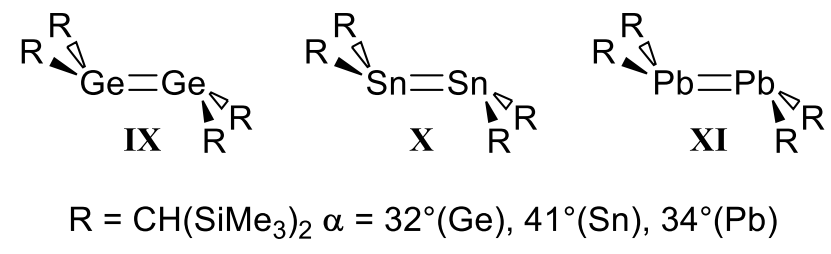

Figure 12: Initial low valent main group alkyl compounds.

This series of compounds exemplify the relative inability of the higher $s$ and $p$ orbitals to hybridise. The trans-pyramidalized structures of IX-XI form due to the second order JahnTeller mixing discussed in 1.4, where the $\sigma^{*}$ and $\pi^{*}$ orbitals mix with the $\sigma$ and $\pi$ orbitals to give a $\sigma\left(\mathrm{ag}_{\mathrm{g}}\right)$ orbital and a non-bonding $\mathrm{n}_{-}\left(\mathrm{b}_{\mathrm{u}}\right)$ orbital. This leads to these compounds typically being represented as resonance structures where the non-bonding pair is shared between the two metal atoms, resulting in a localised positive and negative charge across the species (Figure 13). ${ }^{40}$ The presence of the non-bonding pair is supported by the metal-metal distances in these complexes (single bond lengths in brackets), ${ }^{26}$ with the Ge-Ge distance of 2.3458(7) $\AA$ ( $2.44 \AA$ ) $)$, Sn-Sn distance of $2.7683(7) \AA ̊(2.80 \AA)$, and Pb-Pb distance of $4.129 \AA$ ( $2.90 \AA)$. The $\mathrm{Pb}-\mathrm{Pb}$ bond can be considered less of a bond and more as an associative interaction between the $\left(\left(\mathrm{Me}_{3} \mathrm{Si}\right)_{2} \mathrm{CH}\right)_{2} \mathrm{~Pb}$ : monomers in the solid state, while in solution they are discreet units. 


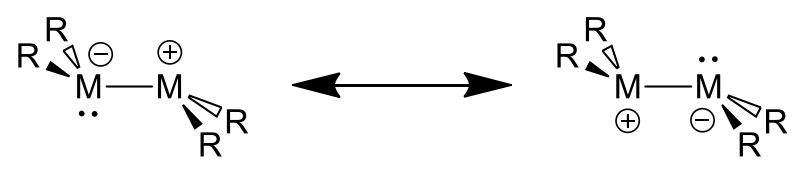

Figure 13: Resonance structures of heavier alkenes.

As discussed in section 1.4.1, the heavier alkyne analogues have a low energy difference between the single bonded form and the triple bonded form, and are typically represented as having their bond order reduced by 0.5 going down the group (Figure 14). Relative to the alkene analogues, the addition of the extra in plane $\pi$ orbital to the alkyne analogues XIIXIV leads to significant shortening of the Ge-Ge (2.2850(6) $\left.\AA, \alpha=128.27(8)^{\circ}\right)^{43}$ and Sn-Sn $\left(2.6675(4) \AA \text {, } \alpha=125.24(7)^{\circ}\right)^{30}$ bonds, while leading to a Pb-Pb bond $(3.1881(1) \AA, \alpha=$ $\left.94.26(4)^{\circ}\right)^{44}$ that is shorter than in $\left[\left(\left(\mathrm{Me}_{3} \mathrm{Si}\right)_{2} \mathrm{CH}\right)_{2} \mathrm{~Pb}\right]_{2}$ but still longer than a standard $\mathrm{Pb}-\mathrm{Pb}$ single bond.

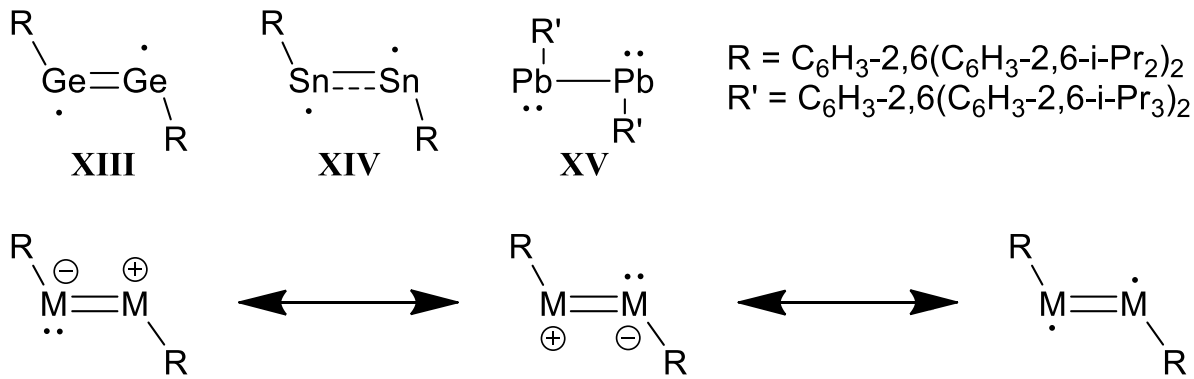

Figure 14: Heavier alkyne analogue compounds and their resonance forms.

With the $\left(\mathrm{Me}_{3} \mathrm{Si}\right)_{2} \mathrm{CH}$ - ligand setting the benchmark for how much steric bulk was necessary to stabilise low valent main group compounds, over the past 45 years stable compounds of most of the group 13-15 elements in their $n-2$ oxidation have been isolated and characterised using a wide variety of ligands. 


\subsubsection{Bulky Aryl Ligands}

Aryl ligands are the collection of ligands that bind to a metal through an aromatic carbon atom, such as those of benzene (Figure 15). The five available substitution positions allow for the ligand to be tailored both in terms of its steric environment and electronic properties. Suitable placement of electron withdrawing groups (EWG) or electron donating groups (EDG) around the ring alters the electronic environment at the bound metal centre, affecting the stability and reactivity of the complex. Aryl ligands that provide increasingly larger steric protection have been synthesised and used to isolate low valent main group species. ${ }^{24,39}$<smiles>[R]c1c([R])c([R])c([R])c([R])c1[R]</smiles>

Figure 15: Generic aryl ligand structure.

One of the most prevalent ligands of this class are the terphenyl ligands, typically derivatives of $m$-terphenyl $\mathbf{X V}$ that are bound to the metal through the carbon on the central benzene ring at the position ortho to both other phenyl substituents (Figure 16). Some of the common terphenyl derivatives include $-\mathrm{C}_{6} \mathrm{H}_{3}-2,6-\mathrm{Mes}_{2}$ XVI, $-\mathrm{C}_{6} \mathrm{H}_{3}-2,6-$ Dipp $_{2}$ XVII (Dipp = 2,6diisopropylphenyl), and - $\mathrm{C}_{6} \mathrm{H}_{3}-2,6$-Trip 2 XVIII (Trip = 2,4,6-triisopropylphenyl).

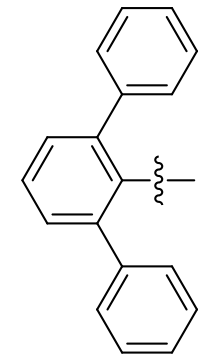

XV

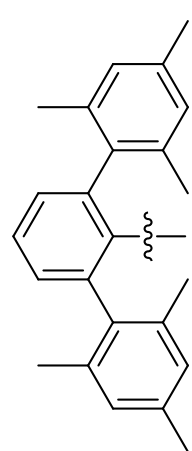

XVI

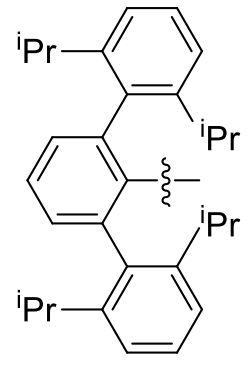

XVII

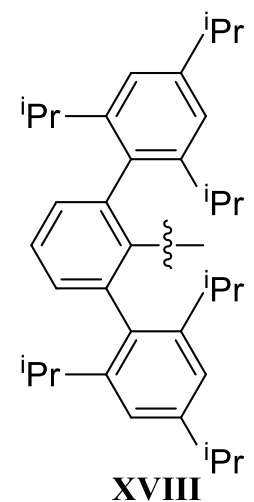

Figure 16: Common terphenyl ligands. 


\subsubsection{Low Valent Group 13 Aryl Complexes}

Some of the first stable monomeric low valent group 13 elements were the arene complexes of aluminium(I), ${ }^{45}$ gallium $(\mathrm{I}),{ }^{46}$ indium $(\mathrm{I}),{ }^{47}$ and thallium $(\mathrm{I})^{48}$ using the pentamethylcyclopentadienyl (Cp*) ligand (XIX, Figure 17). These complexes exhibited the reactivity of discrete $C p^{*} \mathrm{M}$ units, but in the solid state were found to be tetrameric $(\mathbf{X X})^{49}$ or hexameric $(\mathbf{X X I})^{46}$ units. For instance, the aluminium tetramers readily reduced elemental selenium and tellurium to give heterocubanes $\left[(\mathrm{Cp} * \mathrm{AlSe})_{4}\right]$ and $\left[(\mathrm{Cp} * \mathrm{AlTe})_{4}\right]$ through oxidation of the $\mathrm{Al}(\mathrm{I})$ to $\mathrm{Al}(\mathrm{III}) .^{50}$
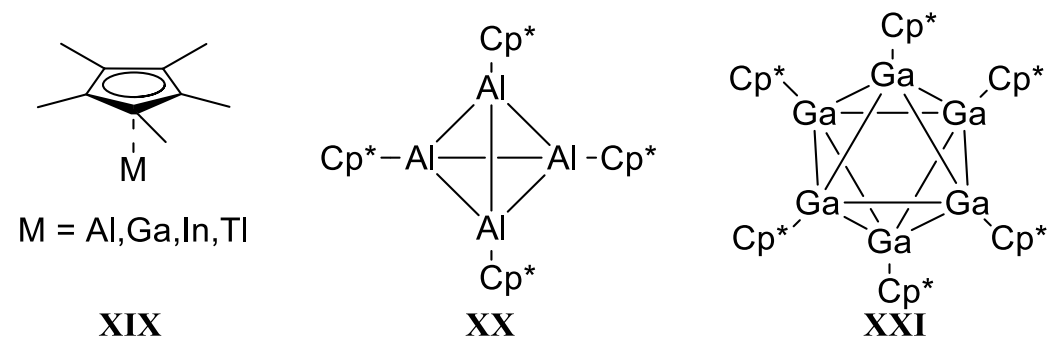

Figure 17: Low valent group 13 arene complexes.

When the bulkier terphenyl ligand XVIII (- $\mathrm{C}_{6} \mathrm{H}_{3}-2,6-$ Trip $\left._{2}\right)$, was coordinated to indium(I), the monomeric complex $\mathrm{In}-\mathrm{C}_{6} \mathrm{H}_{3}-2,6-\mathrm{Trip}_{2}$ (XXII) was isolated in the solid state. ${ }^{51}$ Complex XXII is the third example of a monodentate $\ln (\mathrm{I})$ species and the first that was monomeric in the solid state. However, by altering the steric constraints of the ligand and changing from the Trip groups of ligand XVIII to the Dipp groups of ligand XVII, the steric environment changes enough such that the indium dimer XXIII is isolated in the solid state (Figure 18). ${ }^{52}$ Cryoscopy of dimer XXIII in cyclohexane solution shows extensive dissociation of the In-In bond, indicating that the In-In bond is very weak and the monomer may be favoured in the solution state. ${ }^{52}$ These results highlight how small changes in the steric design of terphenyl ligands can dramatically alter the coordination around the metal centre. 

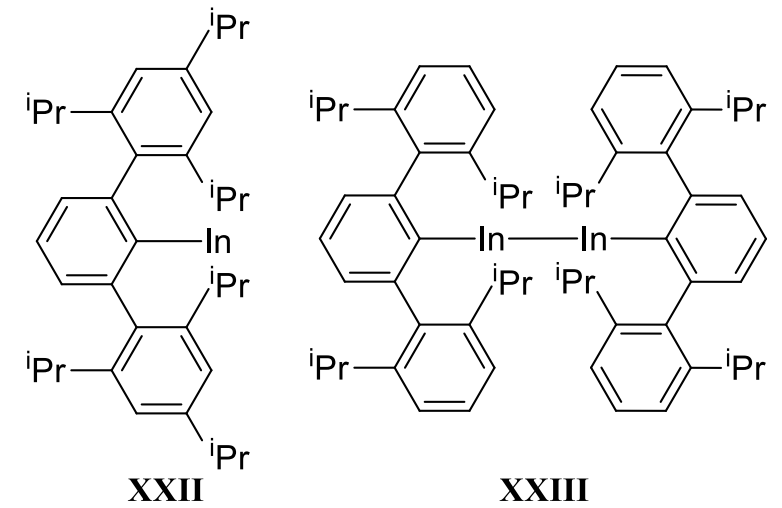

Figure 18: Indium terphenyl complexes.

Similarly, series of thallium(I) complexes bearing the terphenyl ligand was also generated. The influence of the flanking aryl groups of the terphenyl ligand has a major effect on the coordination at the metal centre. When the $-\mathrm{C}_{6} \mathrm{H}_{3}-2,6-\mathrm{Trip}_{2}$ ligand XVIII is used the monomer XXIV was isolated (Figure 19), ${ }^{53}$ the first stable aryl thallium complex. However, when the steric bulk of the ligand is decreased by utilising the $-\mathrm{C}_{6} \mathrm{H}_{3}-2,6-$ Dipp 2 ligand XVII, the thallium dimer XXV was found. ${ }^{54}$ Further reduction of the steric bulk of the flanking aryl groups to the $-\mathrm{C}_{6} \mathrm{H}_{3}-2,6-\mathrm{Dmp}_{2}$ ligand ( $\mathrm{Dmp}=2,6$-dimethylphenyl), resulted in the formation of the thallium trimer XXVI (Figure 19). ${ }^{54}$
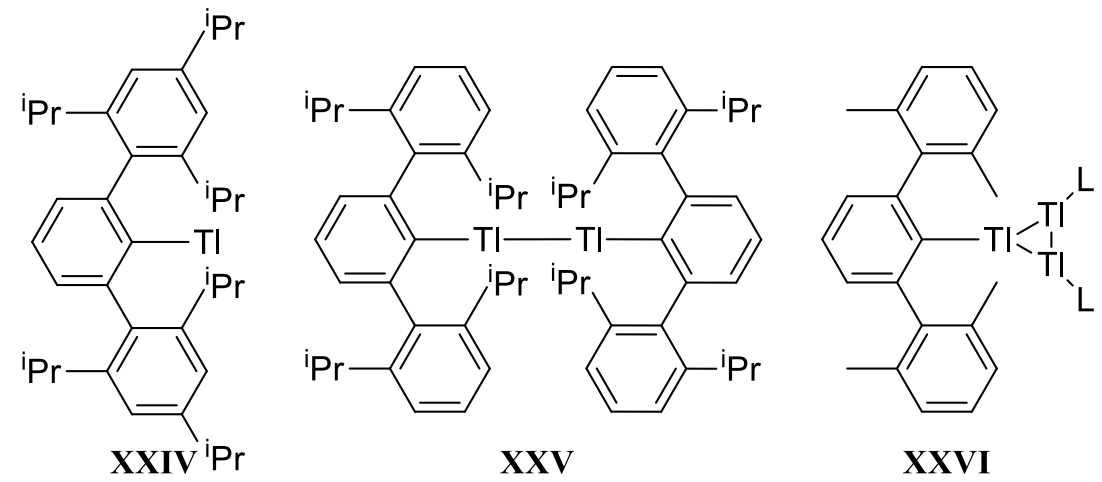

Figure 19: Thallium terphenyl complexes, $\mathrm{L}=-\mathrm{C}_{6} \mathrm{H}_{3}-2,6-\mathrm{Dmp}_{2}$. 
The utilisation of terphenyl ligands also allowed the formation of the first monovalent, monocoordinated species of gallium(I). While $\mathrm{Ga}_{-} \mathrm{C}_{6} \mathrm{H}_{3}-2,6-\mathrm{Trip}_{2}{ }^{55}$ was shown to be a monomer in hydrocarbon solution, the solid state structure was unable to be determined. Increasing the size of the ligand by adding isopropyl groups to the 3 and 5 positions of the central aryl ring allowed for the isolation of $\left[\mathrm{Ga}-\left(\mathrm{C}_{6} \mathrm{H}_{1}-3,5-{ }^{\mathrm{i}} \mathrm{Pr}-2,6-\mathrm{Trip}_{2}\right)\right]^{56}$ (XXVII, Figure 20) which was observed as being both monomeric in hydrocarbon solution and the solid state. Interestingly, when the 4-position of the central aryl ring is substituted with a ${ }^{\mathrm{t}} \mathrm{Bu}$ group instead (the $-\mathrm{C}_{6} \mathrm{H}_{2}-4-{ }^{\mathrm{t}} \mathrm{Bu}-2,6-$ Trip $_{2}$ ligand), the resulting gallium complex XXVIII is a dimer in the solid state. ${ }^{56}$ Further reduction in steric bulk to the $-\mathrm{C}_{6} \mathrm{H}_{3}-2,6-\mathrm{Dipp} 2$ ligand forms complex XXIX, which is a dimer in the solid state and only partially dissociates to a monomer in hydrocarbon solution. ${ }^{57}$

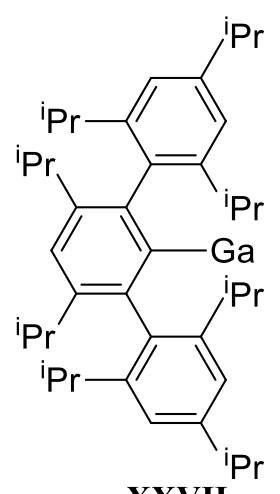

XXVII

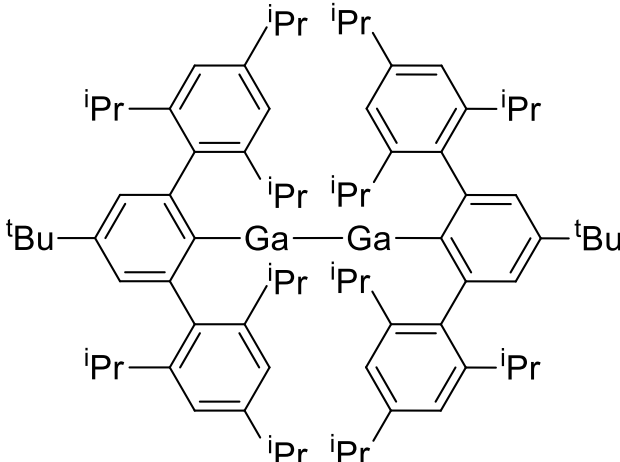

XXVIII

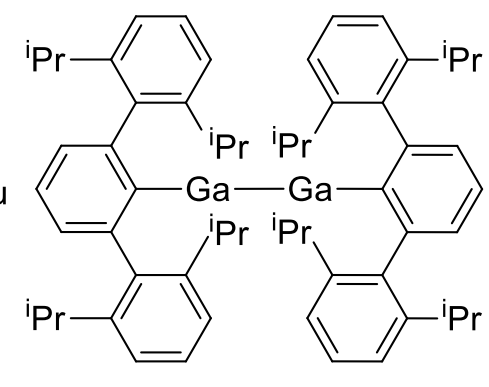

XXIX

Figure 20: Gallium terphenyl complexes.

\subsubsection{Low Valent Group 14 Aryl Complexes}

The low valent group 14 complexes were the targets of many research groups in the late $20^{\text {th }}$ century in the quest to generate heavier carbene, alkene, and alkyne analogues (Figure 21), as discussed in sections 1.4 and 1.5 previously. These objectives led to a wide variety of aryl ligands being utilised and the isolation of many interesting low valent group 14 complexes. 

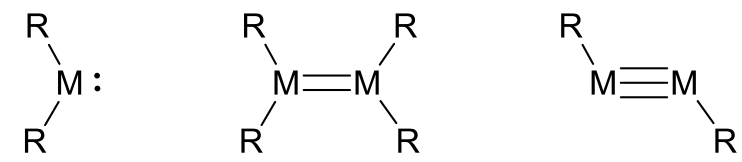

Figure 21: Group 14 carbene, alkene and alkyne analogues.

The chemistry of alkyl and aryl $\mathrm{Pb}$ (II) was plagued by their tendency to disproportionate into $\mathrm{Pb}(\mathrm{IV})$ and elemental lead, for example when organolithium reagents or Grignard reagents are reacted with $\mathrm{PbCl}_{2} \cdot{ }^{58}$ However, by utilising both the steric and electronic properties of the 2,4,6-tris(trifluoromethyl)phenyl ligand, the monomeric $\mathrm{Pb}$ (II) aryl complex $\left(2,4,6-\mathrm{CF}_{3}-\mathrm{C}_{6} \mathrm{H}_{2}\right)_{2} \mathrm{~Pb}\left(\mathbf{X X X}\right.$, Figure 22) was isolated in $1991 .{ }^{59}$ While this was the second characterised example of a stable $\mathrm{Pb}(\mathrm{II})$ monomeric complex after $\left(\left(\mathrm{Me} \mathrm{Si}_{2}\right)_{2} \mathrm{CH}\right)_{2} \mathrm{~Pb}$, it was the first characterised $\sigma$-aryl $\mathrm{Pb}$ (II) complex. The unusual thermal and photochemical stability of XXX was attributed to the four nearby fluoride atoms, as one fluoride atom from each of the $\mathrm{CF}_{3}$ groups in the 2 and 6 positions has a short (2.79-2.97 $\AA$ ) contact with the central $\mathrm{Pb}$ atom. The subsequent synthesis of the monomeric Sn(II) complex XXXI was the first example of monomeric $\mathrm{Sn}(\mathrm{II})$, as previous synthesises of $\mathrm{Sn}$ (II) complexes had only isolated and characterised polymeric Sn(II). ${ }^{60}$ Complex XXXI also possessed the short (2.66-2.83 $\left.⿱ 亠 ⿻ ⿰ 丿 亅 八\right)$ fluoride contacts, and the later synthesis of $\left(2,4,6-\mathrm{CF}_{3}-\mathrm{C}_{6} \mathrm{H}_{2}\right)_{2} \mathrm{Ge}^{61}$ rounded out this series (XXXII, Figure 22). Complex XXXII also possessed similar short (2.55-2.79 ̊̊) contacts with the flanking fluoride atoms. The importance of this electronic stabilisation can be seen by the much higher stability of $\left(2,4,6-\mathrm{CF}_{3}-\mathrm{C}_{6} \mathrm{H}_{2}\right)_{2} \mathrm{Ge}$ compared to $\left(2,4,6-{ }^{-} \mathrm{Bu}_{3}-\mathrm{C}_{6} \mathrm{H}_{2}\right)_{2} \mathrm{Ge},{ }^{62}$ the latter of which decomposes at temperatures above $-30^{\circ} \mathrm{C}$, while the former is stable up to its melting point of $58{ }^{\circ} \mathrm{C}$. While it is stable to UV exposure in the solid state, it will degrade during UV exposure in the solution state. 

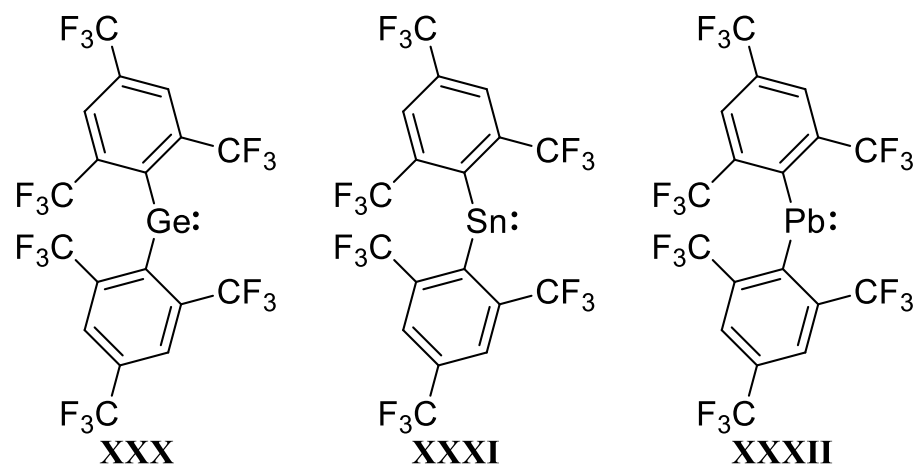

Figure 22: Group 14 bis-2,4,6-tris(trifluoromethyl)phenyl complexes.

Other heavy element carbene analogues have since been prepared bearing aryl ligands such as 2,4,6-triphenylphenyl $\mathbf{X X X I I I}^{63}$ 2,6-bis-1'-napthylphenyl $\mathbf{X X X I V}{ }^{63}$ 2,6-(NMe $)_{2} \mathrm{C}_{6} \mathrm{H}_{3}-\quad \mathbf{X X X V}, 64-65 \quad$ 2,6-bis(bis-(trimethylsilyl)methyl)-4tris(trimethylsilyl)methyl)phenyl $\quad \mathbf{X X X V I a}{ }^{66} \quad$ 2,4,6-tris(bis-(trimethylsilyl)methyl)phenyl XXXVIb, ${ }^{67}$ 1,1,3,3,5,5,7,7-octaethyl-s-hydrindacen-4-yl XXXVII, ${ }^{68}$ and terphenyl derivatives $-\mathrm{C}_{6} \mathrm{H}_{3}-2,6-\mathrm{Mes}_{2},{ }^{69}$ and $-\mathrm{C}_{6} \mathrm{H}_{3}-2,4-\left({ }^{\mathrm{i}} \mathrm{Pr}_{2} \mathrm{C}_{6} \mathrm{H}_{3}\right)_{2}{ }^{66}$
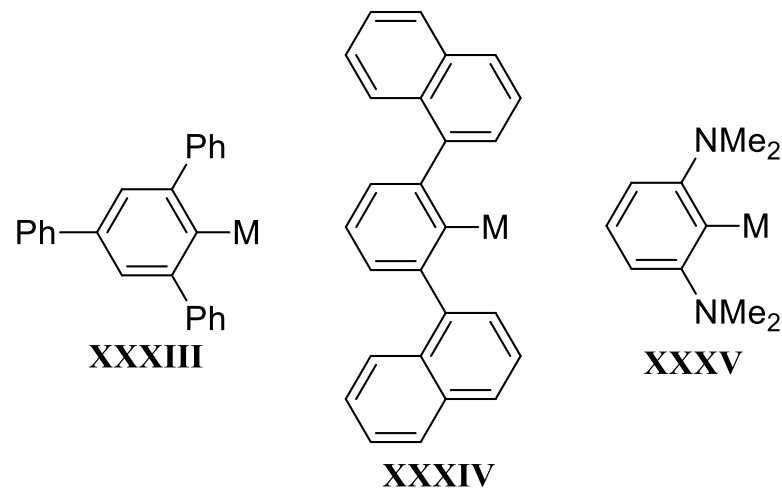

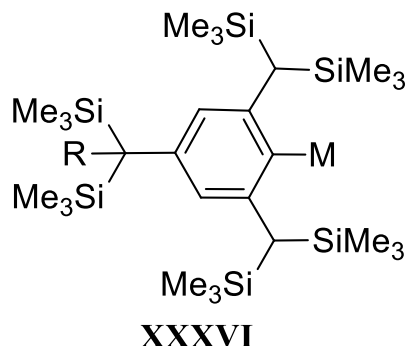

a: $\mathbf{R}=\mathrm{SiMe}_{3}$

b: $\mathbf{R}=\mathbf{H}$<smiles>[M]c1c2c(cc3c1C(CC)(CC)CC3(CC)CC)CC2(CC)CC</smiles>

XXXVII

Figure 23: Heavy element aryl carbene complexes.

The heavier alkene analogues (Figure 24) have been prepared utilising a large range of aryl ligands ranging from the simple tetramers using mesityl (XXXVIII), ${ }^{70-71}$ 2,6diethylphenyl, ${ }^{72-73}$ 2,4,6-triisopropylphenyl, ${ }^{74-75}$ and adamantyl ${ }^{76}$ ligands, to systems with two 
aryl ligands, such as 2,4,6-tris(bis-(trimethylsilyl)methyl)phenyl, ${ }^{77}$ 1,1,3,3,5,5,7,7-octaethyl-shydrindacen-4-yl (XXXIX) $)^{78}$ or terphenyl ligands, ${ }^{79-82}$ and two other substituents $(R=H, M e$, $\mathrm{Et}, \mathrm{Cl}, \mathrm{Br}, \mathrm{I}, \mathrm{SiMe}_{3}, \mathrm{PCy}_{2}$ ) to allow for derivatisation of the metal-metal double bond. The alkyne analogues have been prepared using terphenyl ligands for the full heavier group 14 series, $^{30,}$ 43-44 while the 2,6-bis(bis-(trimethylsilyl)methyl)-4-tris(trimethylsilyl)methyl)phenyl ligand has been used to prepare the silicon ${ }^{83}$ and germanium ${ }^{84}$ alkynes (XL).

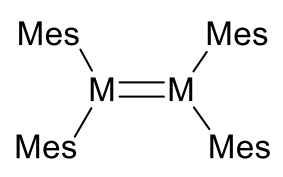

XXXVIII

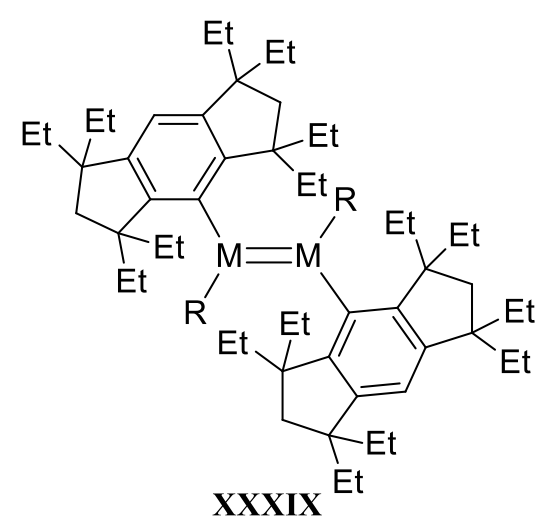

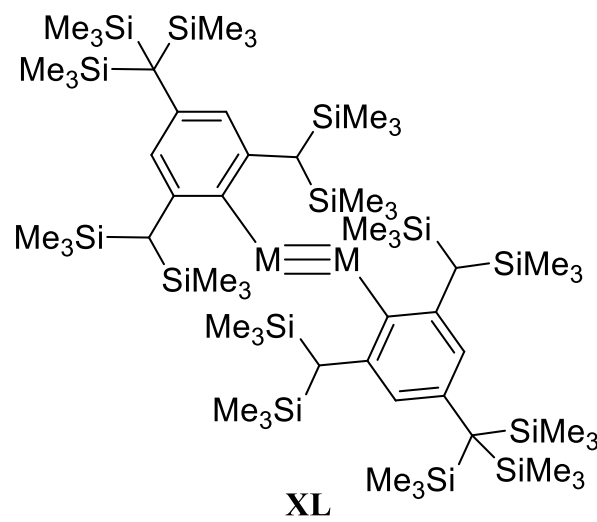

XL

Figure 24: Heavier group 14 alkene and alkyne analogues.

\subsubsection{Low Valent Group 15 Aryl Complexes}

Heavy group 15 complexes typically adopt either the +3 or +5 oxidation states, having access to two $s$ and three $p$ electrons for bonding. Complexes in the +1 or +2 oxidation states can be prepared, but the additional $p$ electrons result in a high tendency for the monomeric units to form dimers, trimers, rings, clusters, and covalent networks. Sterically bulky aryl ligands such as 2,4,6-tritertbutylphenyl, ${ }^{85-89}$ 2,4,6-tris(bis-(trimethylsilyl)methyl)phenyl,,90-93 2,6-bis(bis-(trimethylsilyl)methyl)-4-tris(trimethylsilyl)methyl)phenyl, ${ }^{91-92,} \quad 94 \quad-\mathrm{C}_{6} \mathrm{H}_{3}-2,6-$ $\mathrm{Mes}_{2},{ }^{95}$ and $-\mathrm{C}_{6} \mathrm{H}_{3}-2,6-\mathrm{Trip}_{2},{ }^{88,95-97}$ produce homologous or heterogenous double bonds when used as the ancillary ligands on group 15 low valent complexes. Very few examples of monomeric low valent aryl complexes exist, and require ligands such as NCN pincer ligands ${ }^{98-}$ 100 (Figure 25) to discourage dimer formation. 

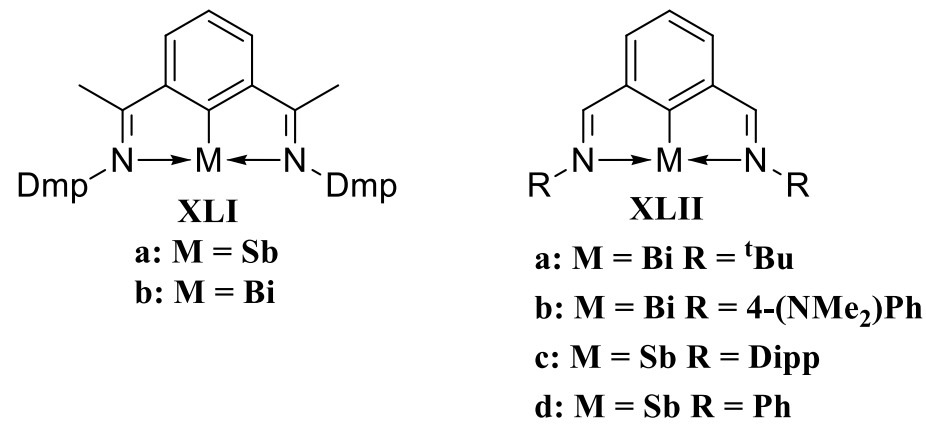

Figure 25: NCN Pincer ligand complexes.

\subsubsection{Bulky Amide Ligands}

Amide ligands comprise a significant portion of metal coordination compounds, ${ }^{101}$ ranging from the simplistic monoanionic amide $\left[\mathrm{R}_{2} \mathrm{~N}\right]^{-}$ligand $\mathbf{X L I I I}$, through amidinates $\mathrm{XLIV}$, guanindiantes XLV, $\beta$-diketiminates XLVI to dianionic di(amido) ligands XLVII and XLVIII (Figure 26). This allows for fine tuning of the steric bulk of the protecting groups employed, the degree of chelation, size of the ring, charge of the complex, and electrostatic properties of the nitrogen atom(s).

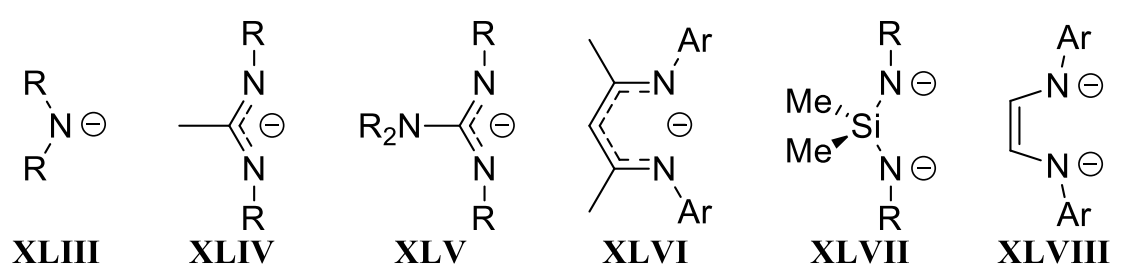

Figure 26: Common type of amide ligand.

Much of the initial metal-amide chemistry was pioneered using the bis(trimethylsilyl)amide ligand $\left[\mathrm{N}\left(\mathrm{SiMe}_{3}\right)_{2}\right]^{-} \mathbf{X L I X}$ as it could be readily synthesised, lacked the reactive $\beta$-hydrogens of similar amide ligands such as diisopropylamide, and possessed reasonable steric bulk. ${ }^{102-103}$ As the field progressed, new amide ligands with larger, bulkier 
groups emerged and asymmetric amide ligands $\left[N(R)\left(R^{\prime}\right)\right]^{-} \mathbf{L}$ with larger alkyl and aryl substituents were used to isolate more reactive species (Figure 27). ${ }^{104}$

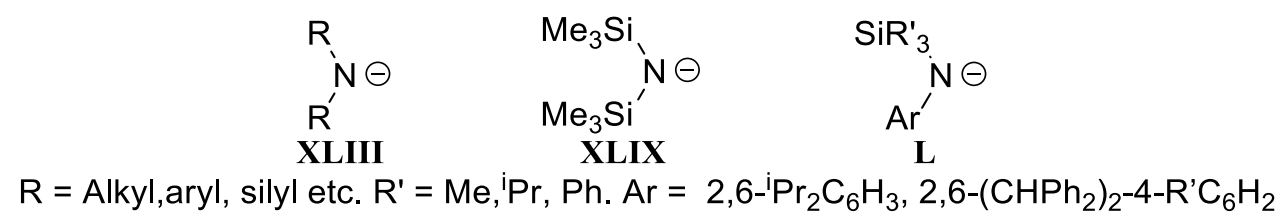

Figure 27: Common monomeric amide ligands.

The bulky, asymmetric amide ligand $-\mathrm{N}\left(\mathrm{SiMe}_{3}\right)\left(-\mathrm{C}_{6} \mathrm{H}_{3}-2,6-\mathrm{Mes}_{2}\right)$ was used to stabilise the first example of a monomeric gallium amide complex (LI, Figure 28). ${ }^{105}$ While complex $\mathbf{L I}$ is drawn with a single bond between the nitrogen and gallium, the bond length of $1.980(2) \AA$ and calculated Wiberg bond index (WBI) of 1.39 indicates that there is some degree of donation from the lone pair on the nitrogen into the empty $p$-orbital on the gallium(I) centre. ${ }^{105}$ The similar $-\mathrm{N}(\mathrm{Me})\left(-\mathrm{C}_{6} \mathrm{H}_{3}-2,6-\mathrm{Mes}_{2}\right)$ ligand was used to stabilise monomeric thallium amide complex LII, which was the first monomeric thallium amide isolated in the solid state, ${ }^{106}$ as previous attempts had yielded tetramers and aggregates. ${ }^{107}$ Complex LII possesses a TI-N bond length of 2.364(3) $\AA$, which is longer than the TI-N bond length of 2.307(6) $\AA$ observed in the $\left[2,6-\mathrm{Pr}_{2} \mathrm{C}_{6} \mathrm{H}_{3}\left(\mathrm{SiMe}_{3}\right) \mathrm{NTI}\right]_{4}$ tetramer previously synthesised, presumably due to the $\mathrm{Tl}$-arene interactions with one of the mesityl groups present in the solid state. ${ }^{106-107}$ An attempt was made to synthesise the full set of heavier group 13 (Al-TI) monomeric amides utilising the $\mathrm{N}\left(\mathrm{SiMe}_{3}\right)\left(2,6-\left(\mathrm{CHPh}_{2}\right)_{2}-4-\mathrm{MeC}_{6} \mathrm{H}_{2}\right)$ ligand. All but the aluminium complexes LIIIa-c were able to be generated. ${ }^{108}$ In these complexes, there was again a small degree of multiple bonding present (1.35 WBI) between the metal and the nitrogen ligand and the lone pair on the metal centre has almost entirely ( 99\%) $s$ character, ${ }^{108}$ indicating limited $s-p$ hybridisation is occurring in these complexes. 


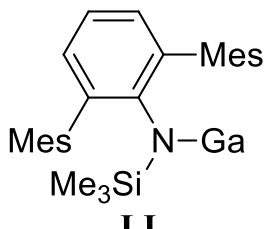

LI

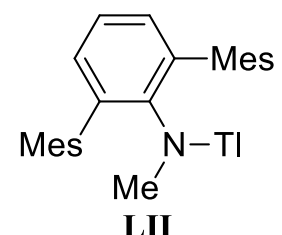

LII<smiles>[M]C(c1ccccc1)c1cc(C)cc(C(c2ccccc2)c2ccccc2)c1N([Si])[Si]</smiles>

LIII

a: $\mathbf{M}=\mathbf{G a}$

b: $\mathbf{M}=\mathbf{I n}$

c: $\mathbf{M}=\mathbf{T l}$

Figure 28: Monomeric amide metal complexes.

\subsection{3 $\beta$-Diketiminato Ligands}

The $\beta$-diketiminato ligand (BDI/NacNac) is a monoanionic, 4 electron ligand that benefits from the chelate effect, a delocalised electronic backbone, and formation of a six-membered ring upon co-ordination to a metal centre. Much like the terphenyl ligand, the R groups 1-5 can all be varied in order to tune the steric and electronic properties of the ligand, though by far the most common form of the BDI ligand is $\mathrm{BDI}_{\mathrm{DIPP}} \mathrm{H}$ (2, Figure 29). ${ }^{109-110}$<smiles>[R]N=C([R])/C([R])=C(/[R])N[R5]</smiles><smiles>CC1=CC(C)=N[Al]N1[Al]</smiles><smiles>CC(C)c1cccc(C(C)C)c1N(C)C</smiles>

Figure 29: The $\beta$-diketiminato ligand.

While the condensation of acetylacetone with an amine and an amine hydrochloride salt to give an aminoimine has been known since the turn of the century, ${ }^{111}$ the first derivatives of the BDI ligand weren't used as ligands until the late 1960's when their co-ordination to nickel was investigated. ${ }^{112}$ It wasn't until the mid 1990's when the BDIDIPP variant was first synthesised and used, as a neutral ligand to co-ordinate nickel, with the goal of creating new polymerisation catalysts. ${ }^{113}$ The addition of 2 to $(\mathrm{DME}) \mathrm{NiBr}_{2}$ in dichloromethane (Figure 30) 
resulted in the formation of complex LIV, where $\mathbf{2}$ has rearranged into its $\beta$-diimine tautomeric form via a 1-3 hydride shift of the amine proton to $C_{2}$ of the BDI ligand (referred to as the $\gamma$-position $(\gamma$-carbon), coordinating to the nickel centre through both imine moieties resulting in the complex adopting a boat conformation. ${ }^{113}$

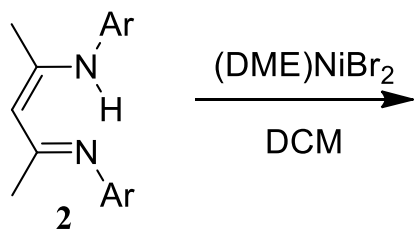

2<smiles>CC1=CC(C)=C([Al])N(Br)N1Br</smiles>

LIV<smiles>CC(C)c1cccc(C(C)C)c1C(C)(C)C</smiles>

Figure 30: Formation of a BDI nickel(II) complex.

The monoanionic form of the BDI ligand is typically installed on a metal centre through one of three main routes. The first uses alkyl lithium reagents, such as $n$-butyllithium, to generate BDI-Li (3, Figure 31), which then undergoes salt metathesis with a metal salt $(X=F$, $\mathrm{Cl}, \mathrm{Br}, \mathrm{I}, \mathrm{OAc}$ etc.) to give the $\beta$-diketiminato metal complex. ${ }^{114}$ Alternatively, sodium ${ }^{115}$ and potassium ${ }^{116}$ salts of the BDI ligand have been used in the same manner. The second route to installing the BDI ligand uses either alkyl or amido metal complexes as the metal source $\left(\mathrm{AlMe}_{3}, \mathrm{ZnEt}_{2}, \mathrm{Cd}(\mathrm{HMDS})_{2}, \mathrm{Y}(\mathrm{HMDS})_{3}\right.$ etc.) which will deprotonate 2, with the driving force of the reaction being the elimination of a fully saturated alkane or amine (Figure 32). ${ }^{114,117}$

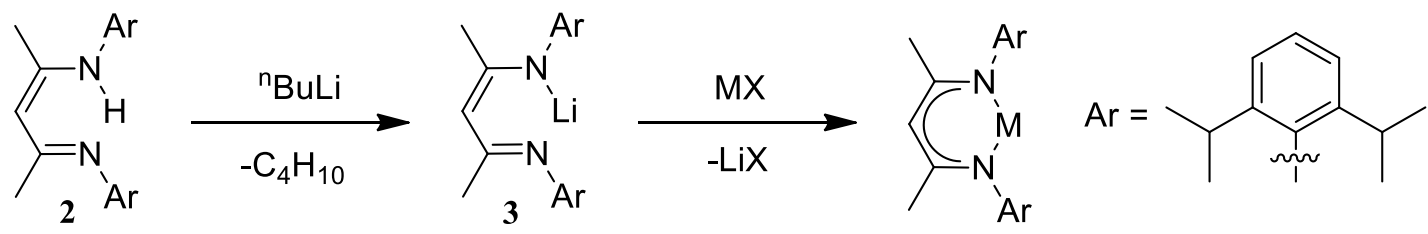

Figure 31: Generation of BDI-Li and BDI metal complexes. 


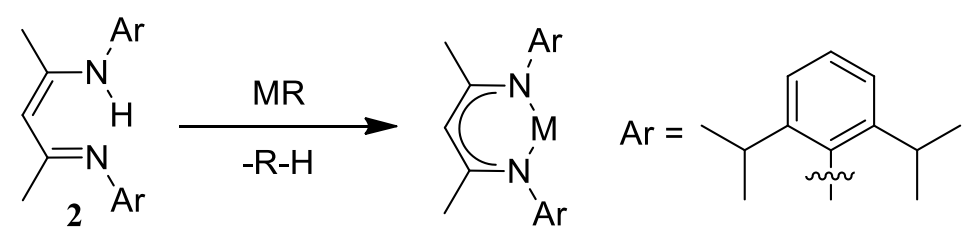

Figure 32: Generation of alkyl BDI metal complexes.

The third route is to synthesise the alkali salt of the ligand ( $\mathbf{L V}$ ) directly using the insertion of a nitrile into a metal-alkyl bond (metal = lithium or potassium), then attach it to the metal centre via the same salt metathesis reaction as the first route (Figure 33). ${ }^{118}$

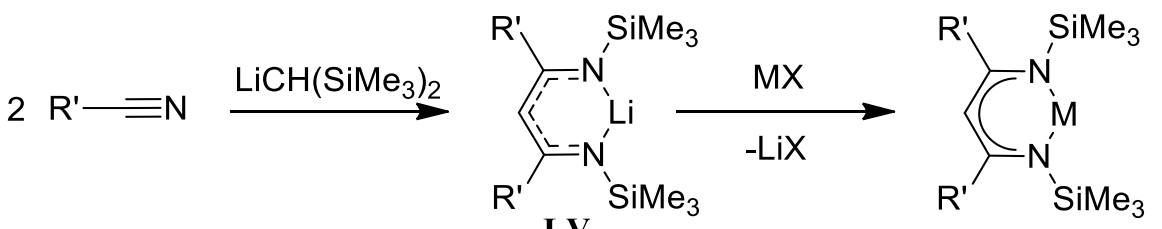

Figure 33: Generation of BDI metal complexes via nitrile insertion.

\subsubsection{1 $\quad \beta$-Diketiminato Ligand Derivatives}

As shown in Figure 29 above, the BDI ligand can be varied at each position on the ring to tune the steric and electronic properties of the ligand. Three derivatives of this ligand utilised in this thesis that are depicted in Figure 34 are $\mathrm{ArBDI}_{\mathrm{DIPP}-\mathrm{H}}(\mathbf{1 3}),{ }^{119} \mathrm{BDI}_{\mathrm{Ar}} *-\mathrm{H}(\mathbf{1 4})^{120}$ and $\mathrm{BDI}_{A r^{\prime}-\mathrm{H}}$ (15). Ligand $\mathbf{1 3}$ is an asymmetric derivative of the BDI ligand, adopting an anilido/imino bonding mode with metals, while the phenyl ring incorporated into the ligand backbone allows for increased delocalisation of electron density upon formation of the metal complex. Ligands 14 and $\mathbf{1 5}$ are newer derivatives of the BDI ligand, with larger diphenyl methyl groups replacing the diisopropyl groups of the standard BDI ligand to provide even more steric protection to the metal centre. 


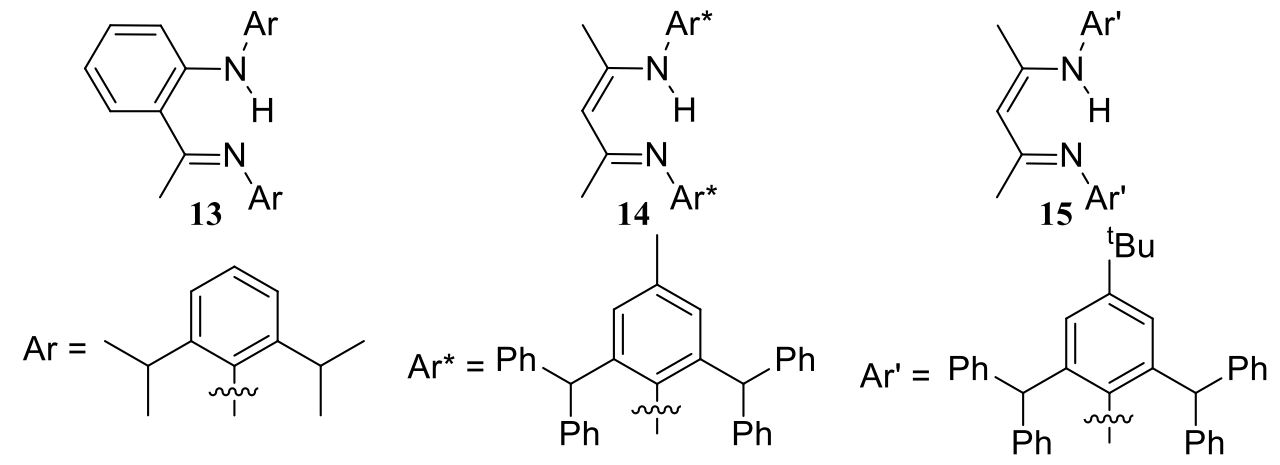

Figure 34: $\mathrm{ArBDI}_{\mathrm{DIPP}}-\mathrm{H}, \mathrm{BDI}_{\mathrm{Ar}} \mathrm{H}^{-\mathrm{H}}$ and $\mathrm{BDI} \mathrm{Ar}^{\prime}-\mathrm{H}$ ligands.

\subsubsection{2 $\quad \beta$-Diketiminato Metal Complexes}

The use of the BDI ligand as an ancillary ligand was driven initially by its role as a spectator ligand for the catalysis of ethene, as it possesses a large degree of steric tunability and strong metal-ligand bonds. ${ }^{121}$ The BDI DIPP ligand has been used as an ancillary ligand on nearly all of the 63 natural metals, with only $\mathrm{Rb}, \mathrm{Cs}, \mathrm{Au}, \mathrm{Hg}$, and Dy complexes left to be isolated. ${ }^{121}$ The number of BDI metal complexes has grown from 475 when the field was last reviewed in $2002^{121}$ to $\sim 2400$ individual entries in the CSD (Cambridge Structural Database, Aug 2018 database) for BDIDIPPM complexes alone. The use of the BDI ligand in the $p$ block began after Coles and Jordan ${ }^{122}$ reported that cationic aluminium complexes supported by amidinate ligands (LVI, Figure 35) were active in ethene polymerisation. The BDI ligand was proposed as a potentially better ancillary ligand than an amidinate, and aluminium dimethyl complex 4 soon followed, which could undergo methyl abstraction using $\left[\mathrm{Ph}{ }_{3} \mathrm{C}\right]\left[\mathrm{B}\left(\mathrm{C}_{6} \mathrm{~F}_{5}\right)_{4}\right]$ to yield ion pair LVII, though catalysis studies of LVII were not reported. ${ }^{123}$
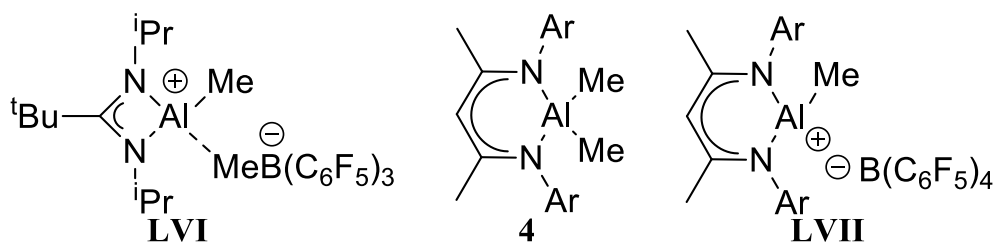<smiles>CC(C)c1cccc(C(C)C)c1N(C)C</smiles>

Figure 35: Aluminium coordination complexes. 
Complex 4 could be readily converted into the diiodide 5 (Figure 36) by treatment with two equivalents of iodine, which, when treated with two equivalents of potassium metal, is reduced to give complex $6 .{ }^{124}$ Complex 6 was the first example of a monomeric aluminium(I) complex $\left(\mathrm{Cp}^{*} \mathrm{Al},\left(\mathrm{CMe}_{3}\right)_{3} \mathrm{SiAl},\left(\mathrm{SiMe}_{3}\right)_{3} \mathrm{CAl}\right.$, and $\left(\mathrm{SiMe}_{3}\right)_{3} \mathrm{SiAl}$ are all tetramers in the solid state and room temperature solution state) $)^{124}$ and also the first example of two coordinate aluminium. The unusual stability of complex $\mathbf{6}$ stems from the BDI ligand, as unlike in complex 4 and 5 where the Al atom sits above the NCCCN plane in a pseudo-tetrahedral coordination mode, the Al atom in complex $\mathbf{6}$ is located in the NCCCN plane. Calculations show that the lone pair extends away from the metal centre in the same plane, forming a pseudo-trigonal aluminium centre as part of a six membered aromatic ring system. ${ }^{124}$ The electrons adopt a singlet state, indicating they could act as a Lewis base, while the presence of an empty $p$ orbital on the aluminium centre could act as a Lewis acid. This reactive centre is then shielded by the Ar groups of the BDI ligand to prevent the complex form forming dimers or tetramers. Complex 6 has been shown to oxidatively insert into $\mathrm{H}-\mathrm{H},{ }^{125} \mathrm{H}-\mathrm{B},{ }^{125} \mathrm{H}-\mathrm{C},{ }^{125} \mathrm{H}-\mathrm{N},{ }^{125} \mathrm{H}-\mathrm{O},{ }^{125} \mathrm{H}-$ $\mathrm{Si}^{125} \mathrm{H}-\mathrm{P},{ }^{125} \mathrm{C}-\mathrm{F},{ }^{126} \mathrm{C}-\mathrm{S},{ }^{127} \mathrm{C}-\mathrm{O},{ }^{126} \mathrm{O}=\mathrm{O},{ }^{128} \mathrm{P}-\mathrm{P},{ }^{127} \mathrm{~S}-\mathrm{S},{ }^{127} \mathrm{Sb}-\mathrm{Sb},{ }^{129} \mathrm{Bi}-\mathrm{Bi}^{129}$ and $\mathrm{Bi}-\mathrm{C}^{130}$ bonds, as well as oxidatively add across the $\pi$-system of alkene and alkyne bonds. ${ }^{131}$

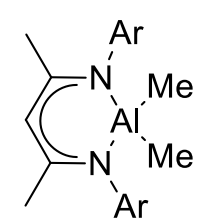

4

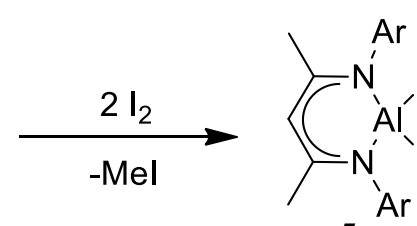

5

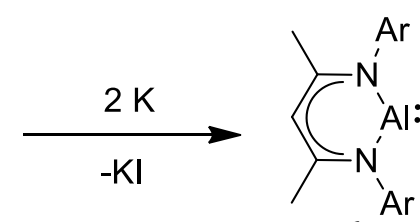

6<smiles>CC(C)c1cccc(C(C)C)c1N(C)C</smiles>

Figure 36: Synthesis of BDIDIPP aluminium(I).

\subsection{Heteronuclear Multiple Bonding in the Main Group}

While the bonding models discussed in 1.4 offer great insight into the molecular orbitals of the heavier $p$-block alkene and alkyne analogues, additional considerations are introduced when switching from the homonuclear alkene and alkyne analogues to heteronuclear ones. ${ }^{17}$ The major considerations are the difference in the energies of the molecular orbitals, the 
electronegativity difference of the two species, and the electronic structures of the different groups.<smiles>[R]C([R])=[Si]([R])=[Al]</smiles>

LVIII<smiles>[R]C(=[O+])[Si]([R])(O)=C([R])[R]</smiles>

LIX

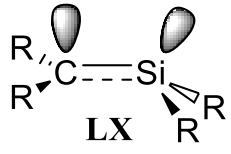

Figure 37: Orbital overlap of silenes depending on conformation.

The simplest heteronuclear heavier $p$-block alkene analogues are the silenes (LVIII, Figure 37), which are alkenes in which one of the two atoms of the carbon-carbon double bond is replaced with silicon. The strength of the C-Si $\pi$ bond is strongly influenced by the geometry of the silicon atom, which can adopt either the planar structure of LIX or the tetrahedral structure of $\mathbf{L X} .{ }^{132}$ Which geometry is preferred is determined by the singlettriplet energy gap (as discussed in 1.4), but in heteronuclear species this gap is also influenced by the $\pi \rightarrow \sigma^{*}$ energy separation and the electronegativity of the two species and their substituents. ${ }^{133}$ Using silenes as the example, changing from a $\mathrm{C}=\mathrm{C}$ bond to a $\mathrm{C}=\mathrm{Si}$ bond decreases the $\pi \rightarrow \sigma^{*}$ gap by $44 \%$ (when $R=H$ ), ${ }^{133}$ allowing for increased SOJT orbital mixing upon the Si adopting a tetrahedral conformation, which in turn lowers the energy of the transpyramidalized conformation relative to the planar conformation. ${ }^{132}$

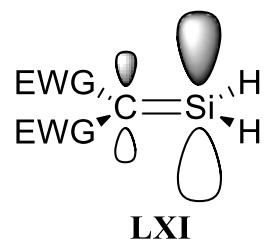

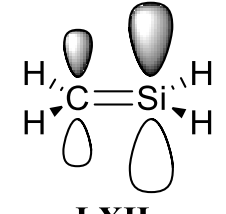

LXII

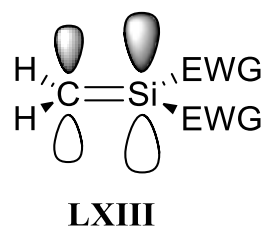

Figure 38: Effect of electron withdrawing groups on orbital overlap of silenes. 
The $\mathrm{H}_{2} \mathrm{Si}=\mathrm{CH}_{2}$ bond (LXII, Figure 38 ) is calculated to have a dipole moment of $0.693 \mathrm{D}$, which is indicative of $\mathrm{Si}^{\delta+}=\mathrm{C}^{\delta-}$ polarisation across the bond in line with the electronegativities of silicon and carbon. ${ }^{134}$ However, upon substitution of the ligands on the silicon for electron withdrawing groups (EWGs) in complex LXIII, the $3 p$ orbital on the silicon contracts and the effective nuclear charge on the silicon decreases, leading to an even more pronounced $\mathrm{Si}^{\delta+}=\mathrm{C}^{\delta-}$ polarisation across the bond and better orbital overlap between the $2 p$ and $3 p$ orbitals of the $\pi$ bond, making the bond more ionic and, as a result, shorter and stronger. ${ }^{132}$ Conversely, substituting the ligands on the carbon for EWGs in complex LXI results in a decrease in both the $\mathrm{Si}^{\delta+}=\mathrm{C}^{\delta-}$ polarisation across the bond (and can even lead to a $\mathrm{Si}^{\delta-}=\mathrm{C}^{\delta+}$ polarisation instead) and the orbital overlap between the $2 p$ and $3 p$ orbitals of the $\pi$ bond, which results in a longer, weaker bond. ${ }^{132}$ Another notable effect in complex LXI is that as the silicon becomes more anionic through resonance structures with the EWGs, it is more likely to adopt a tetrahedral conformation, leading to a trans-bent silene over a classical planar silene. ${ }^{132}$

\subsubsection{Group 13-Group 15 Multiple Bonding}

With group 13 complexes typically possessing an empty $p$-orbital and group 15 complexes possessing a lone pair of electrons, the two groups are intrinsic Lewis pairs that readily form adducts (LXIV, Figure 39). ${ }^{16,} 135$ When the group 15 and group 13 elements are directly bound to each other, a degree of $\pi$ bonding can occur (LXV) if there is sufficient orbital overlap between the lone pair and the empty orbital. ${ }^{5}$ In the formally double bonded complex LXVI, there is also the potential for lone pair donation to give triple bonding character. ${ }^{5}$

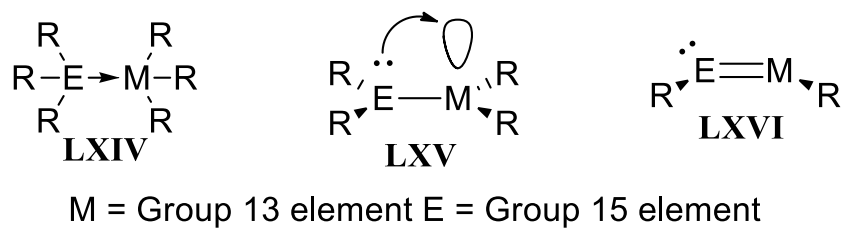

Figure 39: Different bonding types of group 13-group 15 complexes. 
While heavy element complexes of type LXIV an LXV are well known, ${ }^{24}$ the heavy element complexes of type LXVI are limited to the products of the reaction between aluminium(I), ${ }^{136}$ gallium(I), ${ }^{105,137}$ or indium(I) ${ }^{137}$ and a sterically demanding azide to give a metal-nitrogen double bond (LXVII, Figure 40). The aluminium nitrogen double bond is highly unstable in this form and will react readily with the ancillary ligands, either inserting into $\mathrm{C}-\mathrm{H}$ bonds or undergoing cycloaddition across aromatic $\mathrm{C}=\mathrm{C}$ bonds. ${ }^{136}$ Interestingly, while testing the reactivity of complex LXVIII with $N$-heterocyclic carbenes, a stable aluminium nitrogen double bond (LXIX, Figure 41) was obtained as the product, after the aluminium inserted into the $\mathrm{C}=\mathrm{N}$ bond of the ligand. ${ }^{138}$ Recently, complexes containing $\mathrm{Ga}=\mathrm{Sb}^{139}$ and $\mathrm{Ga}=\mathrm{As}^{140}$ bonds have been successfully isolated through the addition of $\mathrm{SbX}_{3}(\mathrm{X}=\mathrm{F}, \mathrm{Cl}, \mathrm{Br}, \mathrm{I})$ or $\mathrm{Cp}^{*} \mathrm{AsCl}_{2}$ to two equivalents of $\mathrm{BDI}_{\mathrm{DIPP}} \mathrm{Ga} \mathbf{1}$.

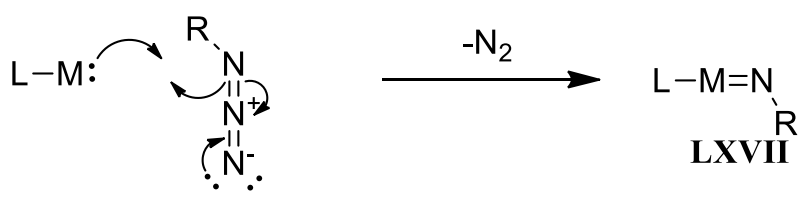

Figure 40: Formation of group 13 imides using azides.
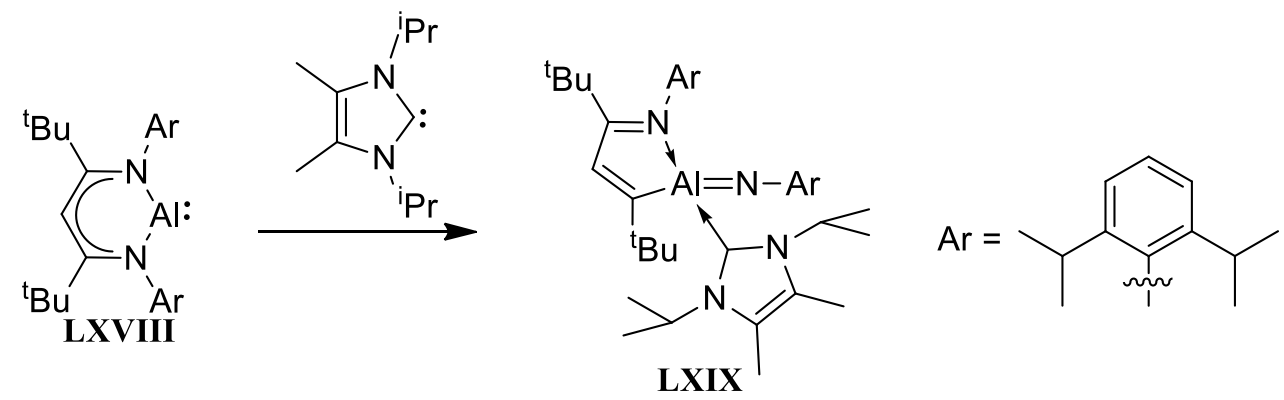

Figure 41: Formation of aluminium imide by addition of an $\mathrm{N}$-heterocyclic carbene.

There are three fully structurally characterised gallium imides (Figure 42) which each have a unique coordination at the metal centre. Complex LXX was the first synthesised monomeric heavy group 13 imide, requiring the bulky BDIDIPP and terphenyl ligands to protect 
the double bond and prevent dimerization. ${ }^{141}$ The gallium-imide bond length of $1.742(3) \AA$ is shorter than a gallium nitrogen single bond (1.82-1.94 $\AA$ ) with the reduction in length being attributed mostly to the $\mathrm{Ga}^{\delta+}=\mathrm{N}^{\delta-}$ dipole, while $\pi$ backdonation from nitrogen to gallium results in a $\sim 49 \mathrm{~kJ} / \mathrm{mol}$ barrier to rotation around the Ga-N bond. ${ }^{141}$ Complex LXXIa was

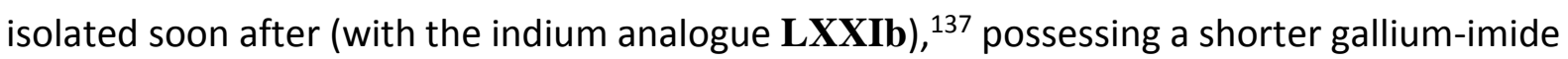
bond length of 1.701(3) ^ than that of complex LXX. This is attributed to the change from a three coordinate gallium centre in $\mathbf{L X X}$ to a two-coordinate gallium centre in LXXIa, which both removes the occupation of the $p$ orbital of the gallium and increases the effective charge at the gallium, creating a stronger $\mathrm{Ga}^{\delta+}=\mathrm{N}^{\delta-}$ dipole ${ }^{137}$ and resulting in a calculated Pauling bond order of $1.98 .{ }^{142}$ Complex LXXII is also a two coordinate gallium imide, with a gallium-imide bond length of 1.743(5) $\AA$ almost identical to complex $\mathbf{L X X}$, however there is also a close contact $(2.395(6) \AA)$ with one of the mesityl groups that may be influencing the coordination at the gallium centre. ${ }^{105}$

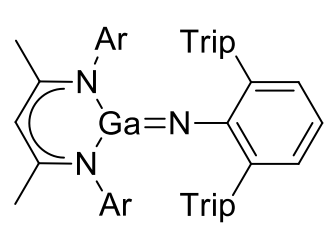
LXX<smiles>Cc1cc(C(C)(C)C)cc(C)c1-c1cccc(-c2c(C)cc(C(C)(C)C)cc2C)c1N=[X]c1c(Br)cccc1Br</smiles>

${ }^{\mathrm{t}} \mathrm{Bu}$<smiles>CCCC=Nc1c(C)cccc1S(C)(=O)=O</smiles><smiles>CC(C)c1cccc(C(C)C)c1N(C)C</smiles>

Figure 42: Group 13 imide complexes.

\subsection{Low Valent Main Group Catalysts}

Once thought to be redox inactive, the main group metals have now been shown to activate small molecules in a similar manner to the transition metals. ${ }^{143}$ One of the challenges of low valent main group catalysis is that while they can be very strong reductants, reducing them back to the low valent state can be a challenge, requiring harsh reagents such as 
potassium. ${ }^{144}$ One potential area of interest in low valent main group catalysis is bond activation, such as the activation of $\mathrm{P}_{4}$ or $\mathrm{CO}_{2}$. The low valent group 14 hydrides have been investigated for their potential use in sequestering atmospheric $\mathrm{CO}_{2}$, with germanium hydride LXXIII readily inserting $\mathrm{CO}_{2}$ gas into the $\mathrm{Ge}-\mathrm{H}$ bond to form the germanium formate LXXIV. ${ }^{145}$ Subsequent investigation found that LXXIV could be converted back to hydride LXXIII through the use of $\mathrm{LiH}_{2} \mathrm{NBH}_{3}$ at the hydride source to liberate lithium formate, while when excess $\mathrm{H}_{3} \mathrm{NBH}_{3}$ was used methanol could be isolated as the product. ${ }^{146}$ Unfortunately, these steps have been carried out independently of each other, so a full catalytic cycle has not been performed, but the potential for catalysis with germanium hydrides has been successfully demonstrated. ${ }^{146}$
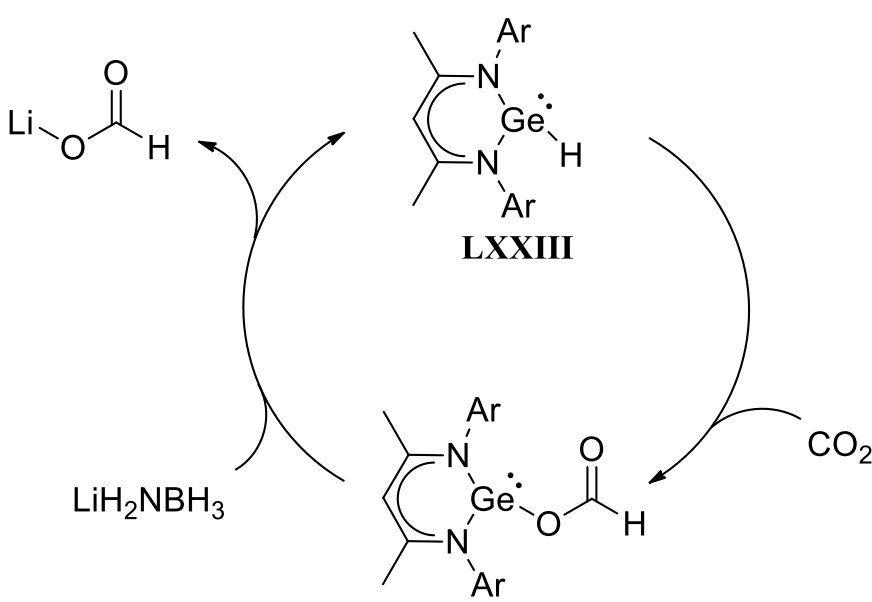

LXXIV

Figure 43: Germanium hydride activating $\mathrm{CO}_{2}$ and regeneration of the starting hydride.

The reactivity of the low valent heavier group 13 elements has been extensively investigated over the last 20 years, with a particularly strong focus on aluminium. ${ }^{144}$ The reactivity of complex 6 (BDI DIPPAl) was discussed in 1.5.3.2, and of particular note in the list is the ability to activate C-F bonds ${ }^{126}$ which was previously the sole domain of the transition metals. While the catalytic prospects of aluminium have previously been limited to oxidative addition/reductive elimination and $\sigma$ bond metathesis, ${ }^{144}$ the recent synthesis of the nucleophilic aluminyl LXXV (Figure 44) opens up an entirely new field of aluminium 
chemistry to investigate, with addition of methyl triflate or methyl iodide resulting in the formation of an aluminium carbon bond to give complex LXXVI instead of the usual salt expected in electrophilic aluminium. ${ }^{147}$
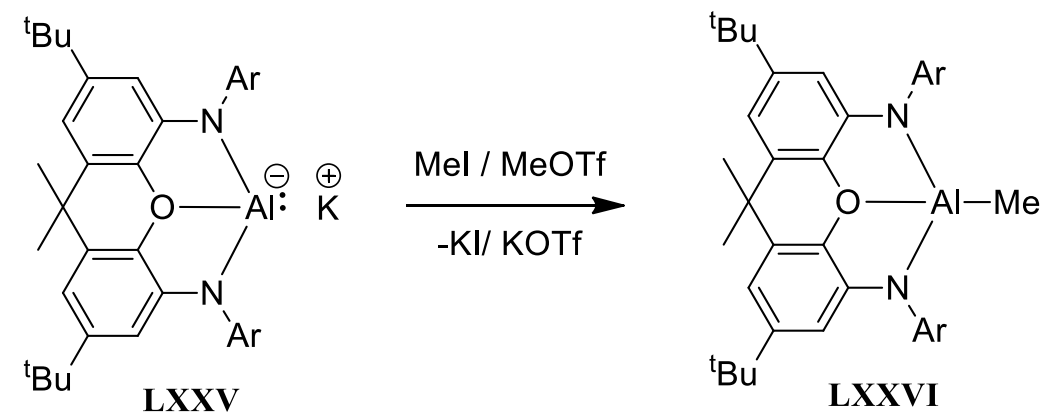

Figure 44: Nucleophilic aluminium complex reactivity with Mel and MeOTf. 


\subsection{Chapter Summary}

- Chapter 2 investigates the reactivity of BDIDIPPGa 1 with the diazo- compounds trimethylsilyldiazomethane, cyclododecyldiazomethane, diphenyldiazomethane, diazofluorene, and di-tert-butyldiazomethane, which resulted in a broad spectrum of different reactivities that potentially involved a gallium-carbon double bonded intermediate. Attempts to isolate this intermediate and confirm the reactivity of these diazomethanes included changing the ligand to $\operatorname{ArBDI}_{\mathrm{DIPP}}\left(\mathrm{o}-\mathrm{C}_{6} \mathrm{H}_{4}\left\{\mathrm{C}\left(\mathrm{CH}_{3}\right) \mathrm{N}-2,6-\right.\right.$ $\left.\left.{ }^{i} \mathrm{Pr}_{2} \mathrm{C}_{6} \mathrm{H}_{3}\right\}\left\{\mathrm{NH}-2,6-\mathrm{Pr}_{2} \mathrm{C}_{6} \mathrm{H}_{3}\right\}\right)$ and $\mathrm{BDI}_{\mathrm{Ar}} * \quad\left(\mathrm{CH}\left\{\mathrm{C}(\mathrm{Me}) \mathrm{N}\left(\mathrm{C}_{6} \mathrm{H}_{2}-2,6-\left(\mathrm{CHPh}_{2}\right)_{2}-4-\mathrm{Me}\right)\right\}_{2}\right)$, however instead of confirming the existing reactivity this revealed new reactivities including both alkyl and aryl C-H bond activation.

- Chapter 3 summarises the attempts made to synthesise a complex containing a formal double bond between phosphorus and either aluminium or gallium, while no such complexes were isolated, several novel gallium phosphanides were synthesised during the attempts.

- Chapter 4 investigates the reactivity of the gallium and aluminium phosphanides isolated in chapter 3 with small molecules, as the reactivity of primary aluminium and gallium phosphanides is not represented currently in the literature.

- Chapter 5 is the summary, conclusions and future outlook of this thesis.

- Chapter 6 is the experimental section of this thesis. 


\section{Chapter 2}

\section{Reactivity of Gallium(I) with Diazo- Compounds}

\subsection{Introduction}

Diazo- compounds are a diverse class of molecules with uses in both organic and inorganic chemistry. These compounds can be difficult to handle as the $\mathrm{C}=\mathrm{N}^{+}=\mathrm{N}^{-}$unit can spontaneously decompose to dinitrogen, with the rapid evolution of gas causing an explosion. Their explosive potential is determined by the substituents, for instance, diazomethane (LXXVII, Figure 45), can explode upon heating, mechanical shock or if exposed to intense light. ${ }^{148}$ Extreme care is taken upon synthesising this compound, with special diazomethane kits used that do not contain any mechanical joints and the compound is never isolated in its pure form. In contrast, substituting one or more of the hydrogen atoms makes the compound much more stable, with trimethylsilyldiazomethane (7) stable enough in hexane solution such that it is commercially available, while diphenyldiazomethane $(\mathbf{8})$ is a stable solid, though it decomposes in solution. ${ }^{149}$
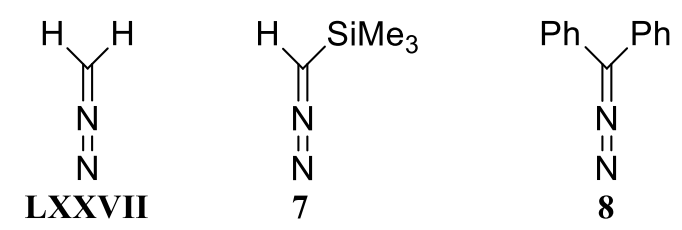

Figure 45: Common diazo- compounds. 
Diazo- compounds are stabilised by their resonance forms, depicted in Figure 46, which delocalises the positive and negative charge across the diazo- unit. ${ }^{150}$ Diazo- compounds can liberate a carbene through the loss of the $\mathrm{N}_{2}$ unit, however they can also react directly with metal centres to form nitrilimine ligands, which is discussed below.

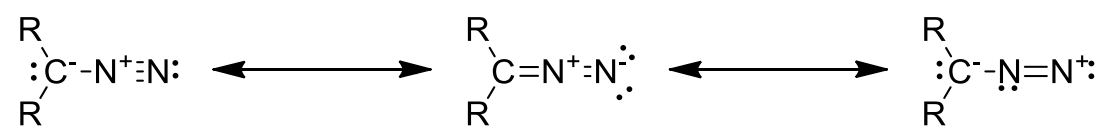

Figure 46: Resonance forms of diazo- compounds.

\subsubsection{Diazomethane Compounds in Synthetic Chemistry}

In organic chemistry, diazomethane is typically used as a methylation reagent to transform alcohols and carboxylic acids to methyl ethers and esters respectively, and diazomethane can also be used to substitute a halide in an acid halide, insert into aldehyde $\mathrm{C}-\mathrm{H}$ bonds, and undergo $3+2$ dipolar cycloadditions to prepare cyclopropanes. ${ }^{148,} 150$ The higher substituted diazo- compounds increase the versatility of diazo- compounds as a reagent, with the different combination of substituents and broad use for a range or reactions allowing millions of reactions that utilize diazo- compounds, ${ }^{148}$ while also improving the stability of the reagent. ${ }^{150}$

In inorganic chemistry, the reactivity of diazo- compounds varies significantly depending on the metal centre they are reacting with and its steric and electronic environment. One of the key differences is that metals can oxidatively add to the carbon of the diazo- unit, eliminating dinitrogen and forming a metal-carbon double bond (Figure 47). In transition metals diazo- compounds have been used to generate carbene complexes of osmium, ${ }^{151-153}$ ruthenium, ${ }^{154-155}$ palladium, ${ }^{156-157}$ platinum, ${ }^{157}$ copper, ${ }^{158}$ nickel, ${ }^{159-160}$ cobalt, ${ }^{161}$ rhodium, ${ }^{162}$ iron, ${ }^{163}$ and also germanium. ${ }^{164}$ 


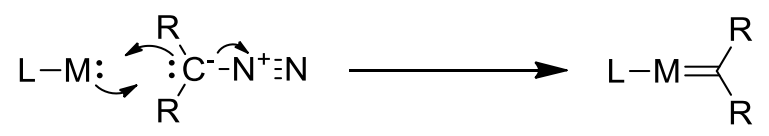

Figure 47: Formation of metal-carbon double bonds with diazo- compounds.

The dependency of the product on the steric environment of the transition metal was best exemplified by the dimethylphenyl (Dmp) and mesityl (Mes) derivatives of the BDI ligand on copper (Figure 48). ${ }^{165-166}$ When the more sterically restrictive mesityl derivative LXXVIII is reacted with diphenyldiazomethane, the terminal carbene complex LXXIX is isolated, whereas when the diphenylmethyl derivative $\mathbf{L X X X}$ is used, the bridged carbene complex LXXXI is formed instead.
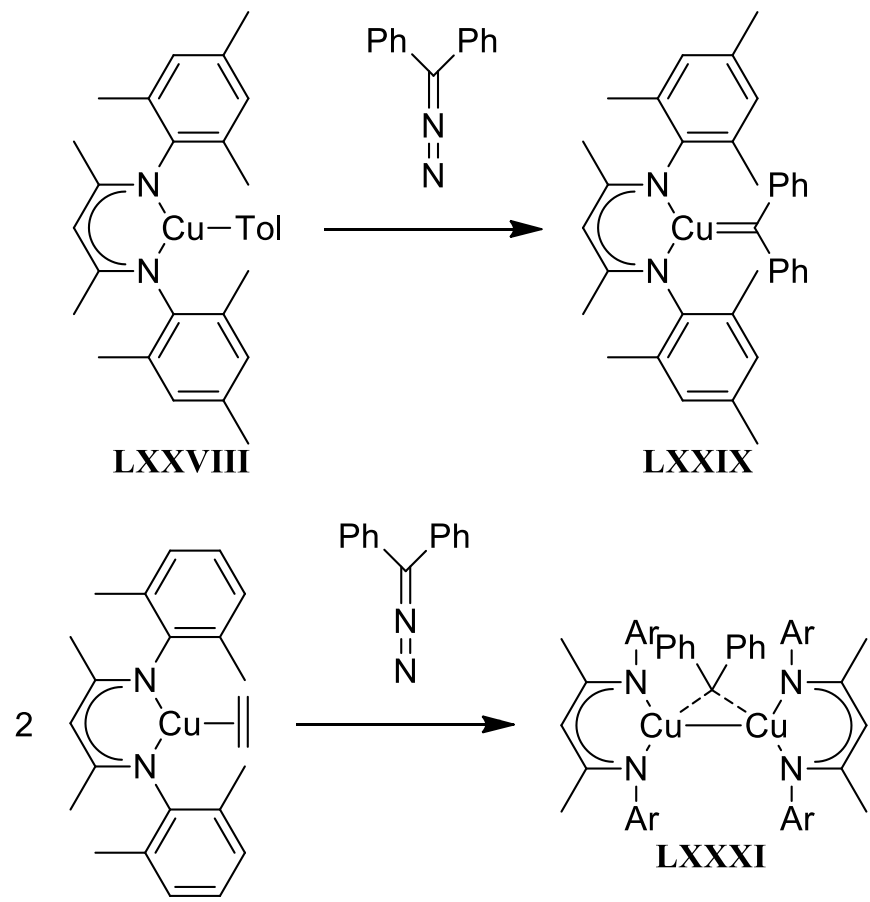

LXXX

Figure 48: BDI copper carbene complexes. 
The addition of a diazomethane to a metal complex does not always eliminate dinitrogen. For example lluc and Hillhouse ${ }^{160}$ found that the addition of 2,6-dimesitylphenyl diazomethane to nickel complex LXXXII resulted in coordination of the dinitrogen unit to the nickel centre (LXXXIII, Figure 49). The stable intermediate LXXXIII could then be converted to their desired carbene product LXXXIV upon exposure to UV light. Similar reactivity was observed upon changing the ethane bridged diphosphine ligands of complex LXXXII to naphthalene bridged diphosphine ligands, indicating that the formation of the intermediate was most likely due to electronic effects rather than steric ones. ${ }^{160}$

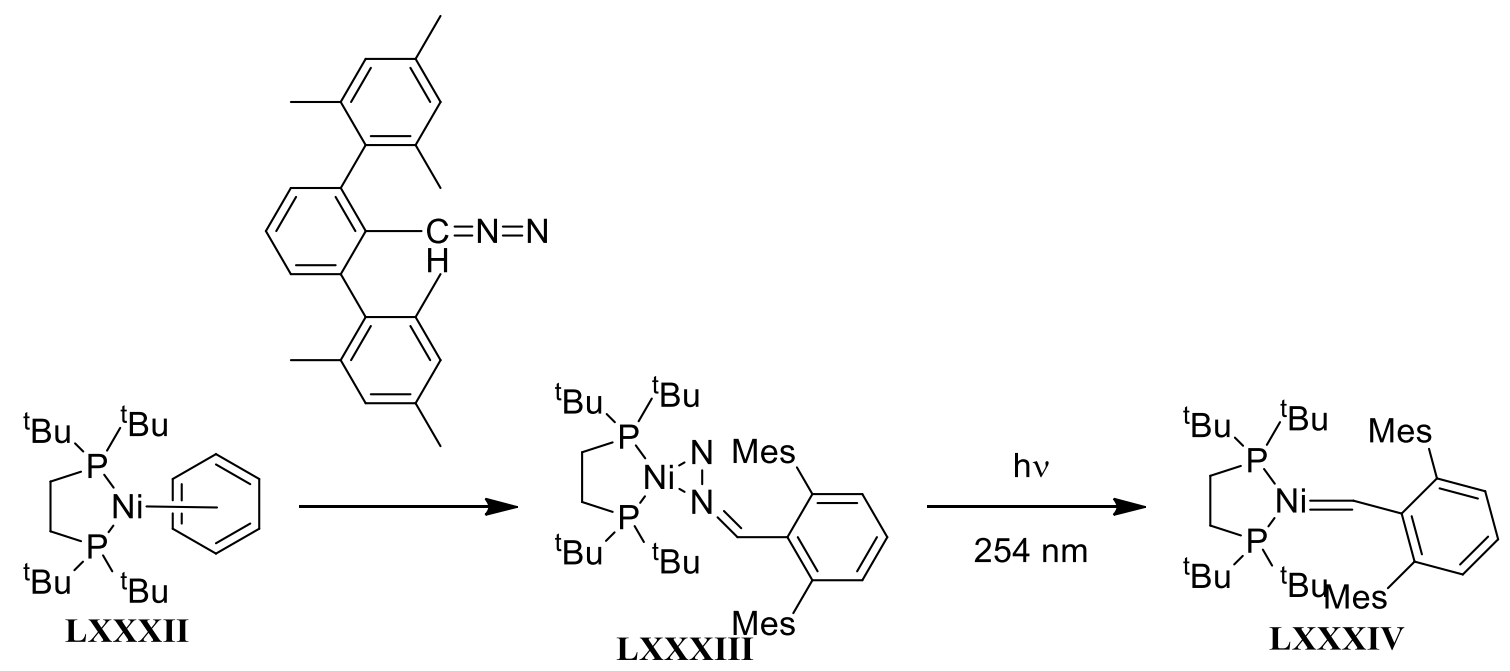

Figure 49: Dinitrogen coordination intermediate.

The $N$ - heterocyclic carbene nickel complex LXXXV, ${ }^{167}$ also does not react with diazocompounds to generate a carbene, but instead the diazo- compound coordinates through the terminal nitrogen (LXXXVI, Figure 50). Complex LXXXVI is stable and will not lose $\mathrm{N}_{2}$ upon exposure to UV irradiation unlike complex LXXXIII. ${ }^{167}$ This binding mode, in which the terminal nitrogen of the diazo- compound binds to the metal centre resulting in delocalisation of the diazo- electrons as in complex LXXXVI, has also been observed with iridium, ${ }^{168}$ scandium, ${ }^{169}$ germanium,${ }^{75}$ gallium, ${ }^{170}$ and aluminium. ${ }^{170-171}$ 


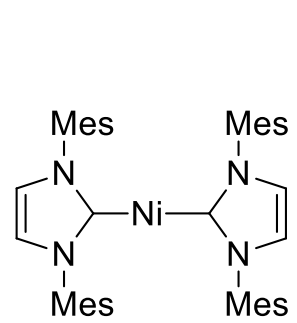

LXXXV

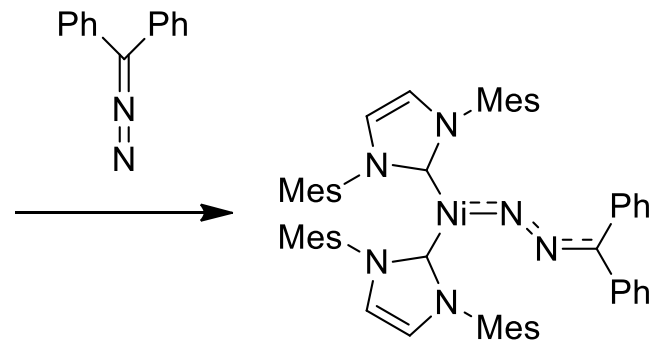

LXXXVI

Figure 50: Terminal nitrogen coordination of diazomethane.

Monosubstituted diazo- compounds can be used to install a nitrilimine unit on a metal centre via a salt metathesis reaction. In these reactions, the diazo- unit was deprotonated with ${ }^{n} \mathrm{BuLi}$ to yield the lithium salt of the diazo- compound, this latter compound is then reacted with a metal halide to give a nitrilimine (Figure 51). The carbanion of the deprotonated diazo- compound is stabilised by delocalisation of the charge with the adjacent nitrogen atoms, and thus the anion can adopt multiple resonance structures. The resulting nitrilimine group binds through the terminal nitrogen atom in complexes LXXXVII and LXXXVIII (Figure 52), ${ }^{170,172}$ binds through the carbon atom in complex XC, ${ }^{166}$ or binds through both the terminal nitrogen and carbon atom in complex LXXXIX. ${ }^{170}$

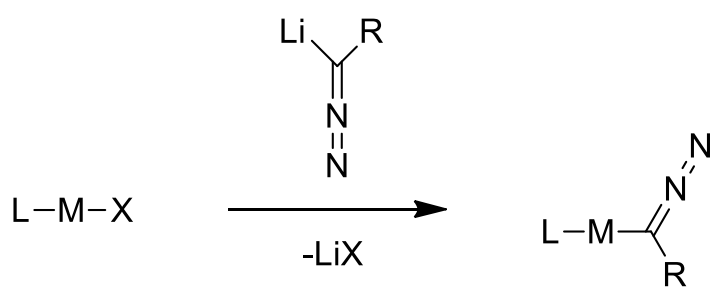

Figure 51: Installation of a nitrilimine via salt metathesis 

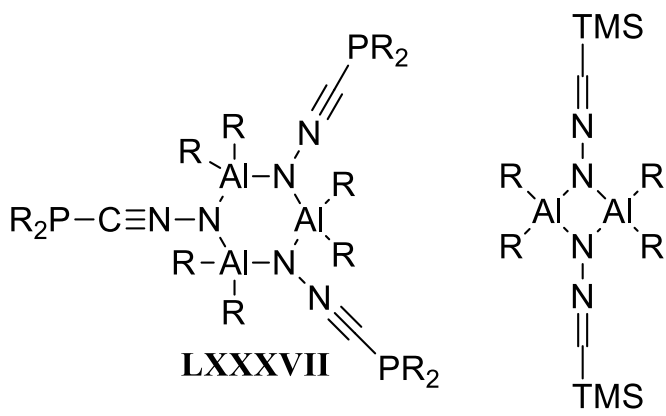

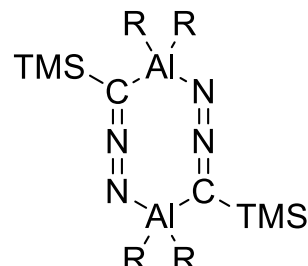

LXXXIX

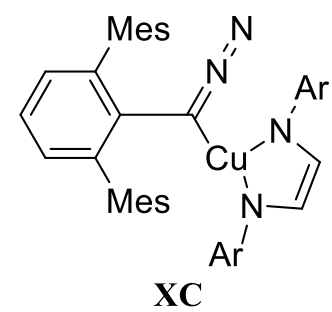

$\mathrm{XC}$

LXXXVIII

Figure 52: Different binding modes of the nitrilimine unit.

Interestingly, in rare cases the $\mathrm{C}-\mathrm{H}$ bond on monosubstituted diazo- compounds can be activated by the metal complex itself. For instance, addition of trimethylsilyldiazomethane to scandium imido complex XCI (Figure 53) ${ }^{169}$ resulted in the formation of complex XCII. Presumably, this complex forms through deprotonation of the diazo-compound by the imido ligand and coordination of the resulting nitrilimine unit via the terminal nitrogen to the scandium centre. Similarily, Tsui et al. ${ }^{173}$ found that gold hydride XCIII will react with the diazo- proton of ethyldiazoacetate to eliminate dihydrogen gas and form a gold-carbon bond with the diazomethane carbon to give complex XCIV (Figure 54).
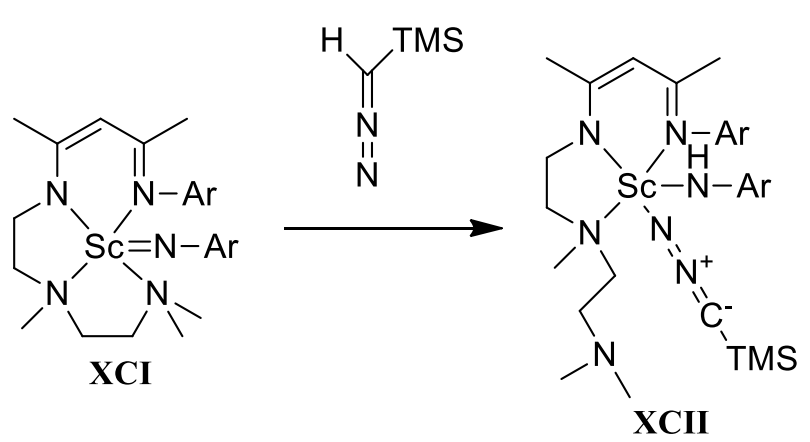

Figure 53: Deprotonation of diazomethane by a scandium imine. 


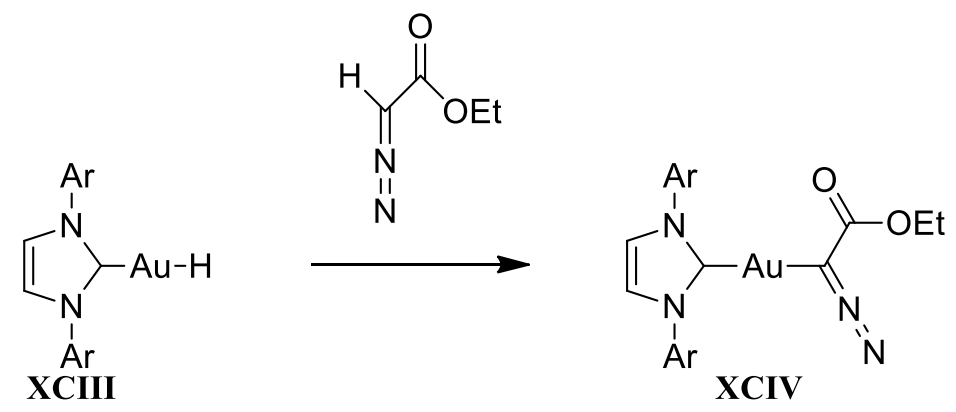

Figure 54: Deprotonation of diazomethane by gold hydride.

\subsubsection{Reactivity of Gallium(I)}

Gallium(I) complexes were first synthesised using cyclopentadiene ligands in 1992 after "GaCl" and "Gal" reagents could be reliably synthesised. ${ }^{174}$ While the initially isolated gallium(I) complexes could be isolated as monomers in the solution and gas phases, these gallium(I) complexes formed hexamers, tetramers and dimers in the solid state. Monomeric gallium(I) complexes were first generated by employing the bulky tris(3,5-di-tertbutylpyrazolyl)hydroborato ligand. ${ }^{175}$ The generation of other gallium(I) complexes quickly followed, with the synthesis of gallium(I) complexes supported by bulky enamine (1), ${ }^{8}$ aryl (XCVI and XXIX), ${ }^{55}$ and bis-imine (XCV) ${ }^{176}$ ligands. Depending on the ancillary ligand used to stabilise the $\mathrm{Ga}(\mathrm{I})$ centre, they typically exist as either neutral (1) or anionic (XCV) complexes. As mentioned in section 1.5.1.1, subtle changes in the ligands influence the coordination at the metal centre, with complex XXVII being monomeric in the solid state, but the removal of the extra steric protection of one isopropyl group on the flanking ligand results in complex XXIX being a dimer in the solid state (Figure 55). 

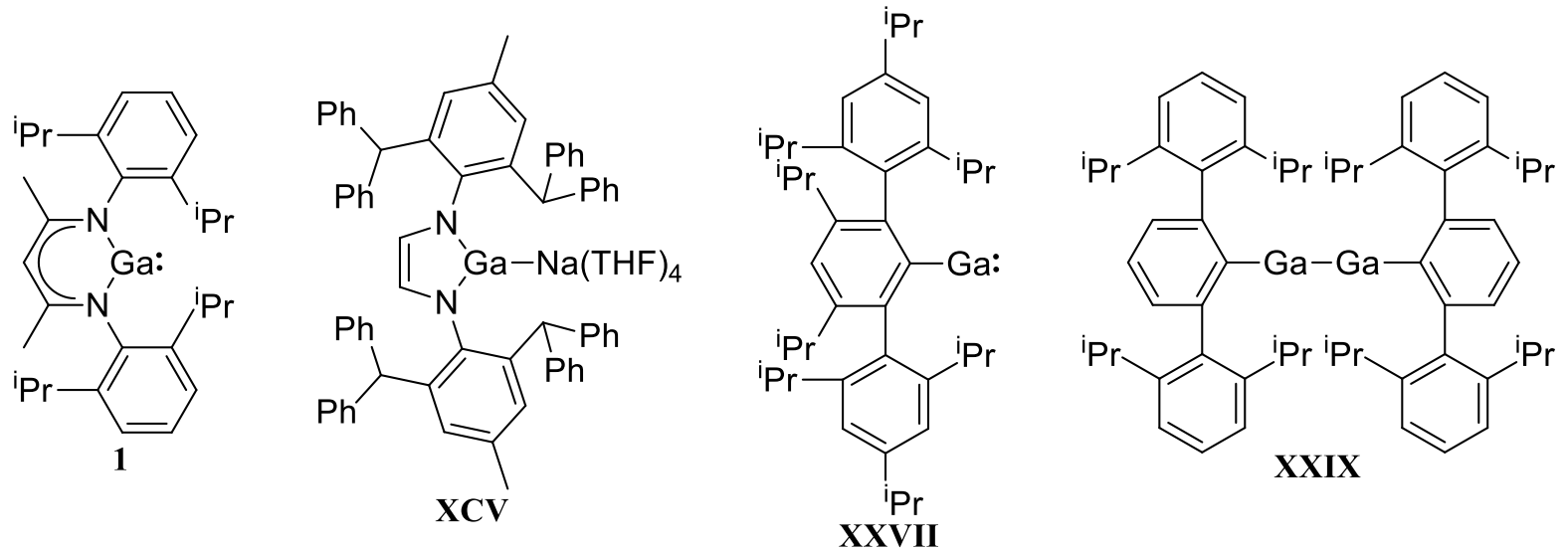

Figure 55: Common gallium(I) complexes.

Gallium(I) complexes such as complex 1 possess the interesting quality of being able to behave as both an electrophile and a nucleophile, due to having both an empty $p$ orbital and a lone pair of electrons. This makes them effectively group 13 carbene analogues. Complex $\mathbf{1}$ will donate its lone electron pair into empty orbitals of Lewis acids (Figure 56), resulting in complexes of type XCVI where $\mathrm{M}=$ boron, ${ }^{177-178}$ aluminium, ${ }^{178}$ gallium, ${ }^{178}$ phosphorus, ${ }^{179-180}$ nickel, ${ }^{14,}{ }^{181-183}$ platinum, ${ }^{184}$ palladium, ${ }^{184}$ copper, ${ }^{185}$ silver, ${ }^{185}$ germanium, ${ }^{186}$ chromium, ${ }^{187}$ molybdenum, ${ }^{187}$ tungsten, ${ }^{187}$ and cobalt. ${ }^{187}$ While complex $\mathbf{1}$ can act as an ancillary ligand, it also readily undergoes redox chemistry to form complexes of type XCVII, and has been shown to insert into $\mathrm{Au}-\mathrm{Cl},{ }^{180} \mathrm{Rh}-\mathrm{Cl},{ }^{188} \mathrm{Zn}-\mathrm{Cl},{ }^{189} \mathrm{Zn}-\mathrm{Me},{ }^{189} \mathrm{Ga}-\mathrm{Cl},{ }^{190} \mathrm{Ga}-\mathrm{Me},{ }^{190} \mathrm{Sn}-\mathrm{Cl},{ }^{190-191} \mathrm{Si}-$ $\mathrm{Cl},{ }^{190} \mathrm{C}-\mathrm{Cl},{ }^{190} \mathrm{Bi}-\mathrm{O},{ }^{192} \mathrm{Bi}-\mathrm{C},{ }^{130} \mathrm{Bi}-\mathrm{N},{ }^{193} \mathrm{H}-\mathrm{H},{ }^{194} \mathrm{O}-\mathrm{H},{ }^{194-195} \mathrm{P}-\mathrm{H},{ }^{194} \mathrm{P}-\mathrm{P},{ }^{196} \mathrm{P}-\mathrm{Cl},{ }^{193} \mathrm{~N}-\mathrm{H},{ }^{194} \mathrm{Sn}-\mathrm{H},{ }^{194}$ $\mathrm{Pb}-\mathrm{Cl},{ }^{197} \mathrm{~Pb}-\mathrm{O},{ }^{197} \mathrm{Hg}-\mathrm{S},{ }^{197} \mathrm{Rh}-\mathrm{O},{ }^{198} \mathrm{Pt}-\mathrm{Cl},{ }^{199} \mathrm{Te}-\mathrm{C},{ }^{200} \mathrm{Te}-\mathrm{Te},{ }^{200} \mathrm{In}-\mathrm{C},{ }^{201} \mathrm{Sb}-\mathrm{N},{ }^{202} \mathrm{As}-\mathrm{Cl},{ }^{193}$ and As$\mathrm{N}^{193}$ bonds. Complex 1 has even been shown to reversibly insert into $\mathrm{Bi}-\mathrm{Bi}$ and $\mathrm{Sb}-\mathrm{Sb}$ bonds. ${ }^{203}$

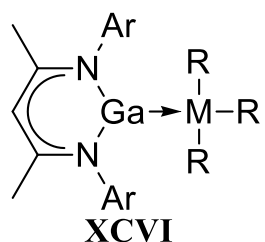<smiles></smiles>

XCVII

Figure 56: Donation vs insertion into $\mathrm{R}-\mathrm{X}$ bonds by gallium(I). 
Terphenyl gallium(I) 'dimers', such as complex XXIX, react with a wide variety of olefins in both [n+2] and [2n+2] cycloadditions. In the case of [n+2] cycloadditions with ethene, propene, hex-1-ene and styrene (Figure 57), the gallium-gallium bond of complex XXIX is broken and two equivalents of the alkene react to form the 6 membered metallacycle complex XCVIII. ${ }^{204}$ In contrast, when [2n+2] cycloaddition reactions were attempted with cyclopentadiene, cycloheptatriene, and norbornadiene, the gallium-gallium bond was preserved and the expected cycloaddition products XCIX or C was obtained (Figure 58)..$^{205}$ This gives support that the gallium-gallium 'dimer' can behave as both a diradical monomer and an ethene analogue. Both complex 1 (BDIDIPPGa) and XXVII will react with $\mathrm{N}_{2} \mathrm{O}$ and $\mathrm{S}_{8}$ in typical oxidation reactions, with complex 1 forming $(\mathrm{LGaO})_{2}$ and $(\mathrm{LGaS})_{2}$ respectively. ${ }^{206}$ Complex 1 and XXVII will also react with small azides to form tetrazoles ${ }^{207}$ and bulky azides to form formal gallium-nitrogen double bonds. ${ }^{141}$ As discussed in section 1.6.1, these compounds were the first monomeric imides of group 13 elements heavier than boron, and were quickly followed by their aluminium ${ }^{138}$ and indium ${ }^{137}$ analogues. Complex $\mathbf{1}$ has also been used to synthesise the second known gallium-arsenic double bond ${ }^{140}$ and the first gallium-antimony double bond. ${ }^{208}$<smiles>CCCc1cccc(C(C)C)c1-c1cccc(-c2c(C(C)C)cccc2C(C)C)c1CCCc1c(-c2c(C(C)C)cccc2C(C)C)cccc1-c1c(C(C)C)cccc1C(C)C</smiles>

XXIX

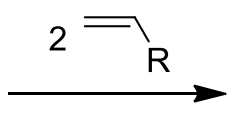

Figure 57: $n+2$ cycloaddition reactions with terphenyl gallium(I). 
<smiles>CCCc1cccc(C(C)C)c1-c1cccc(-c2c(C(C)C)cccc2C(C)C)c1[Ge](Cl)Cc1c(-c2c(C(C)C)cccc2C(C)C)cccc1-c1c(C(C)C)cccc1C(C)C</smiles>

XXIX
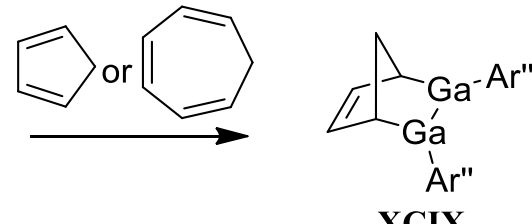

XCIX

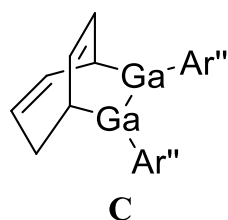

C

Figure 58: $2 n+2$ cycloaddition reactions with terphenyl gallium(I).

\subsection{Aim}

The objective of this project was to investigate the reactivity of BDI DIPPGa (1) with diazocompounds, with the goal of isolating a neutral complex containing a formal gallium-carbon double bond similar to complex 9 . These complexes are rare, and their isolation would allow for the investigation of any potential catalytic ability the gallium-carbon double bond could possess. One of the restrictions on this synthesis is that $R_{1}$ and $R_{2}$ are not group 15 elements, as these have previously been shown to prefer the double bond over gallium. For instance, in complex CI, the stable canonical form of the bond was actually $\mathrm{P}=\mathrm{C}-\mathrm{GaMe}_{2}$ instead of $\mathrm{P}$ $\mathrm{C}=\mathrm{GaMe}_{2}$, supported by the shortened P-C bond length of $1.658(7) \AA$ which is indicative of strong P-C $\pi$ bonding. ${ }^{209}$ The presence of a limited degree of $\mathrm{Ga}-\mathrm{C} \pi$ bonding is supported by the shortening of the Ga-C bond by $0.056 \AA$ and a planar conformation at the gallium and carbon centres. ${ }^{209}$ The only existing gallium carbon double bond is the anionic metallobenzene complex CII (Figure 59), which, similar to complex CI, possesses a delocalised electronic system incorporating the gallium, making the bonding less of a formal double bond and more of an allylic interaction..$^{210}$ The synthesis of a complex similar to 9 would require promoting the gallium from its usual singlet state into the triplet state, and will therefore require the energy gained from the formation of the double bond to be larger than the singlet-triplet promotion energy. 
<smiles>[R]C(=[V])[Te]</smiles>

9

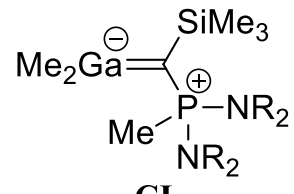
CI

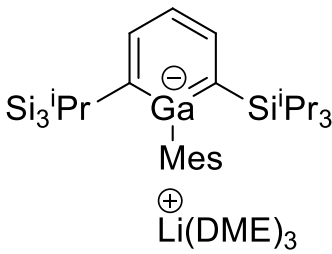

CII

Figure 59: Gallium metallobenzene complex.

The initial key compound in this project is the known complex, BDIDIPPa 1 (Scheme 1). ${ }^{8}$ The BDI DIPP-H ligand 2 was prepared according to literature procedures, ${ }^{113}$ and converted to lithium salt 3 via addition of 'BuLi in hexane. A suspension of 'gallium(I) iodide' was prepared following literature procedure. ${ }^{8}$ This involved combining gallium metal with one molar equivalent of iodine in toluene under $\mathrm{N}_{2}$ and placing the mixture in an ultrasonic bath at 40 ${ }^{\circ} \mathrm{C}$ for 3 hours. The dark green suspension was used immediately by cooling to $-78{ }^{\circ} \mathrm{C}$ after which a solution of $\mathbf{3}$ in toluene was added slowly dropwise and the resulting mixture was left to warm to room temperature overnight. The reaction mixture was filtered through celite and concentrated in vacuo then cooled in the freezer at $-30^{\circ} \mathrm{C}$, resulting in the formation of yellow crystals of $\mathbf{1}$.

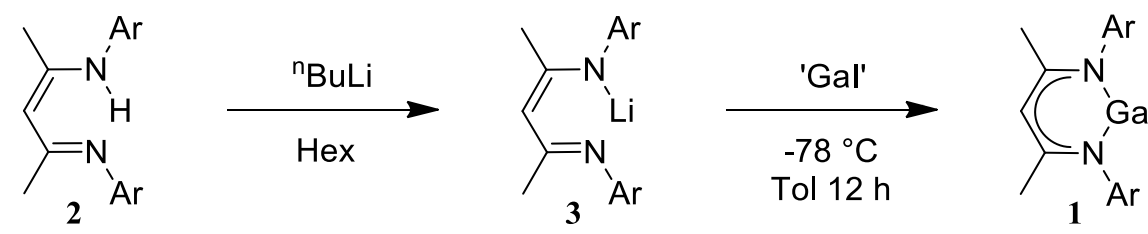<smiles>CC(C)c1cccc(C(C)C)c1C(C)(C)C</smiles>

Scheme 1: Synthesis of BDI DIPPGa.

To increase the scope of the investigation to include the reactivity of other gallium(I) complexes, three additional ligand derivatives, including two bulky $\beta$-diketiminate ligands and an anilido/imino ligand, were also used to generate three new gallium(I) species $\operatorname{ArBDI}_{\mathrm{DIPP} G a}$ 
$10, \mathrm{BDI}_{\mathrm{Ar} * \mathrm{Ga}} 11$ and $\mathrm{BDI}_{\mathrm{Ar}} \mathrm{Ga} 12$ (Figure 60 ). The reactivity of these complexes with diazocompounds was also examined.

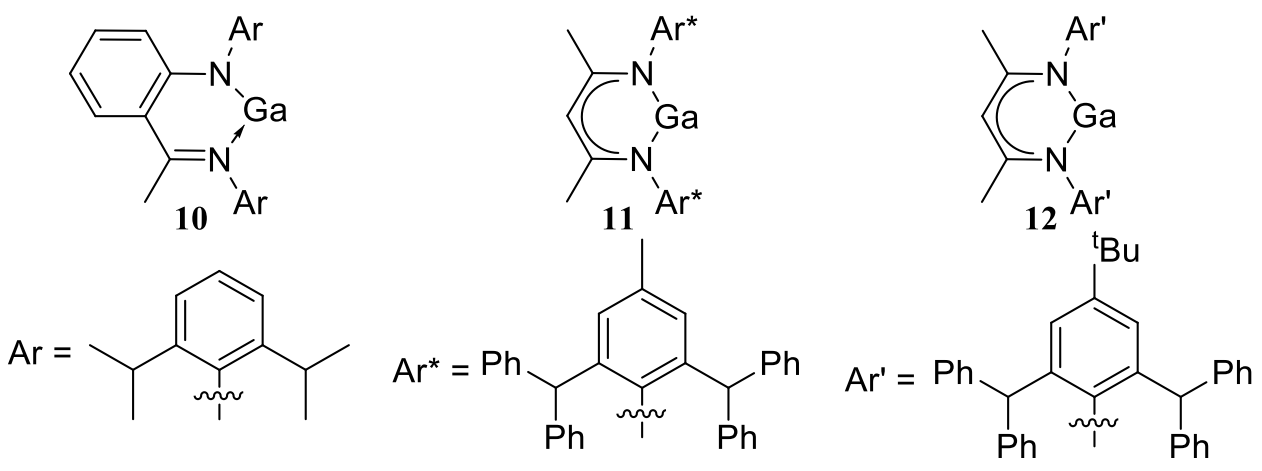

Figure 60: New gallium(I) synthetic targets for investigation.

\subsection{Synthetic Strategy}

The reactivity of complex $\mathbf{1}$ towards a range of diazo- compounds, including trimethylsilyldiazomethane, diphenyldiazomethane, cyclododecyldiazomethane, diazofluorene, and di-tert-butyldiazomethane (Figure 61) was examined to determine if the gallium(I) centre would undergo oxidative addition to form a carbene complex as observed with transition metals and germanium (Scheme 2).

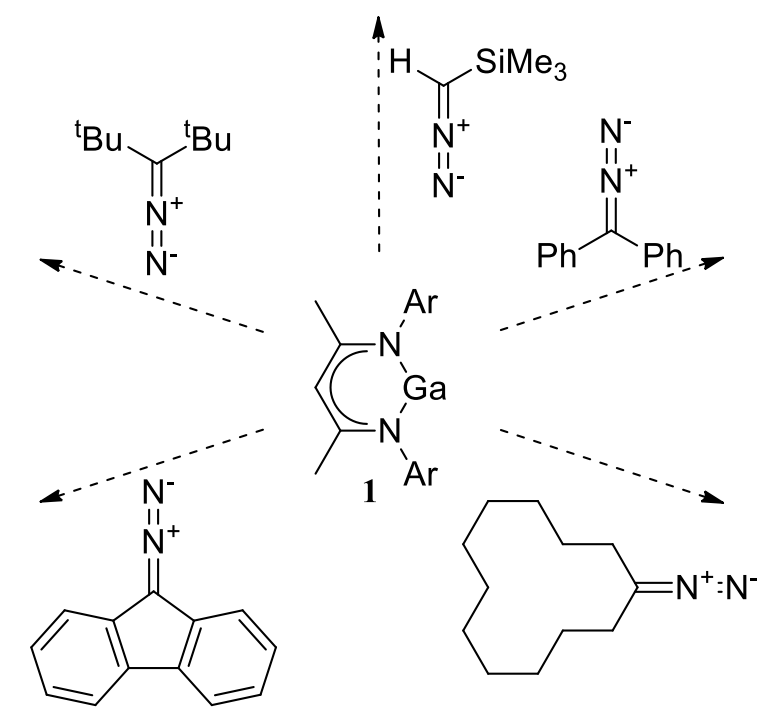

Figure 61: Diazo- compound reactivity diagram. 


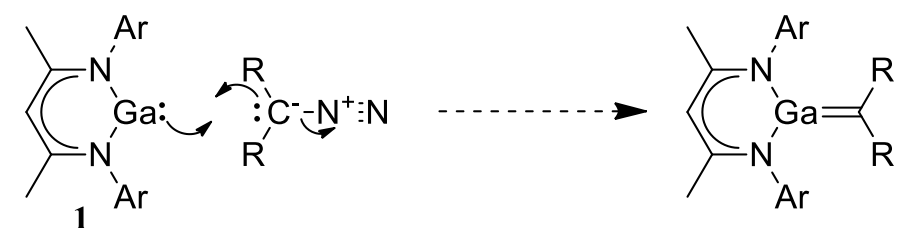

Scheme 2: Proposed double bond formation mechanism.

The second part of this project investigated the synthesis and isolation of new gallium(I) complexes using the ArBDI $I_{D P P}-\mathrm{H} 13, \mathrm{BDI}_{A r^{*}-\mathrm{H}} 14$ and $\mathrm{BDI}_{A r^{\prime}-\mathrm{H}} 15$ ligands following a similar method used in the synthesis of $\mathbf{1}$ (Scheme 3), isolating the lithium salt of the ligand and reacting it with a solution of 'Gal' at $-78^{\circ} \mathrm{C}$ overnight, resulting in the formation of $A$ BBDI 10, $\mathrm{BDI}_{\mathrm{Ar} * \mathrm{Ga}} 11$ and $\mathrm{BDI}_{\mathrm{Ar}} \mathrm{Ga} 12$ respectively. The reactivity of these new gallium(I) complexes with a range of diazo- compounds was examined with the goal of forming a gallium-carbon double bond.

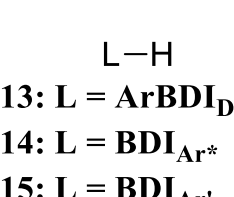
${ }_{\mathrm{n}}^{\mathrm{n} u}$
$\underset{\mathrm{Hex}}{\stackrel{\mathrm{BuLi}}{\longrightarrow}}$
$\mathrm{L}-\mathrm{Li}$ 16: $\mathrm{L}=\mathrm{ArBDI}_{\mathrm{DIPP}}$ 17: $\mathbf{L}=$ BDI $_{\mathbf{A r}^{*}}$ 18: $\mathbf{L}=\mathbf{B D I}_{\mathbf{A r}^{\prime}}$

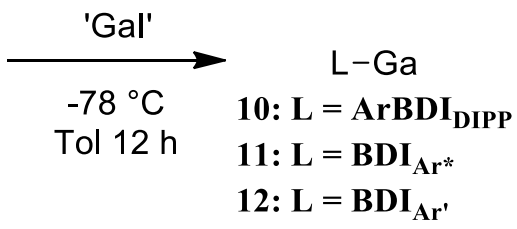

Scheme 3: Synthesis of other BDI gallium(I) complexes.

\subsection{Results and Discussion}

The first diazo- compound examined was the commercially available trimethylsilyldiazomethane. Addition of one equivalent of trimethylsilyldiazomethane solution to a toluene solution of complex 1 at $-30{ }^{\circ} \mathrm{C}$ resulted in the evolution of gas, presumably $\mathrm{N}_{2}$, and the formation of one new product in a 50:50 ratio with $\mathbf{1}$ as determined by ${ }^{1} \mathrm{H}$ NMR spectroscopy. Subsequent addition of a second equivalent of trimethylsilyldiazomethane solution to the reaction mixture led to the formation of a single 
product. The ${ }^{1} \mathrm{H}$ NMR spectrum of isolated product revealed a signal at $\delta-0.81 \mathrm{ppm}$ integrating for two protons. Two signals $(\delta 0.22,-0.21 \mathrm{ppm})$ integrating to 9 protons each are assigned to two trimethylsilyl groups, the presence of which is consistent with two equivalents of trimethylsilyldiazomethane adding to complex $\mathbf{1}$. An X-ray diffraction study on crystals grown from toluene at $-30{ }^{\circ} \mathrm{C}$ revealed that this assumption was correct with a fourcoordinate gallium centre bound, in addition to the $\mathrm{BDI}$ ligand, to a $\mathrm{CH}_{2} \mathrm{SiMe}_{3}$ moiety and a nitrilimine unit to reveal the product to be BDI

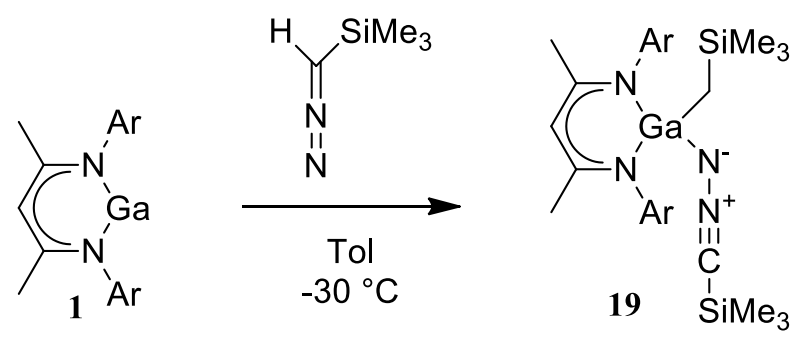

Scheme 4: Reaction of BDIDIPPGa with TMSC(H) $\mathrm{N}_{2}$. 


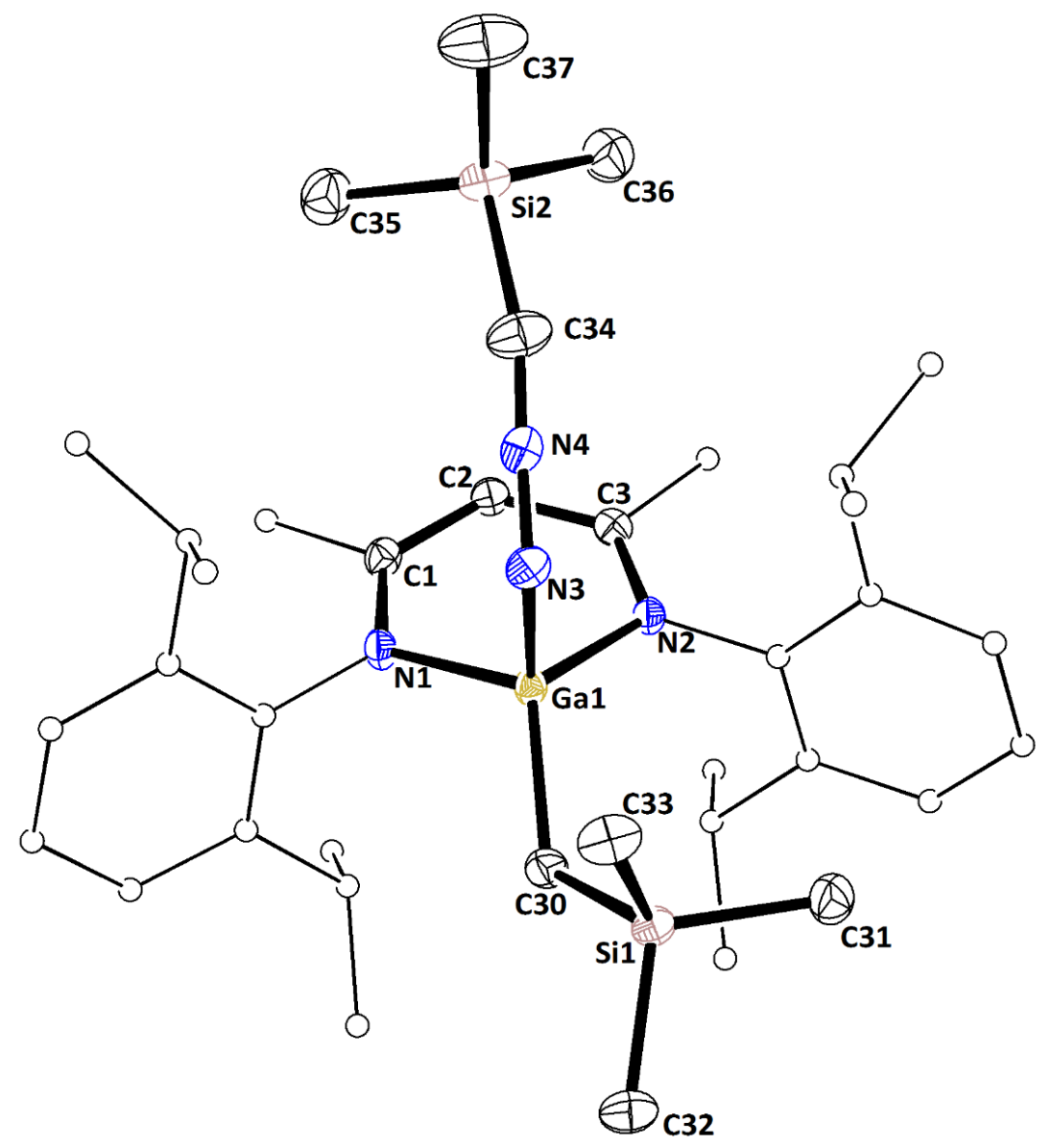

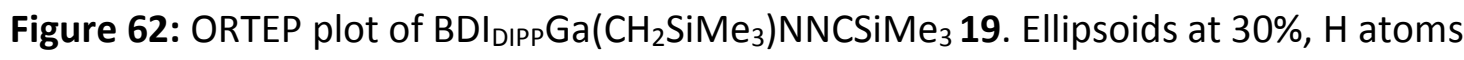
omitted and selected $\mathrm{C}$ atoms in wire frame for clarity.

Table 2: Selected bond lengths and angles for BDI ${ }_{\text {DIPPGa }}\left(\mathrm{CH}_{2} \mathrm{SiMe}_{3}\right) \mathrm{NNCSiMe}_{3} 19$.

Bond Lengths $(\AA)$

$\begin{array}{cc}\mathrm{Ga}(1)-\mathrm{N}(1) & 1.971(1) \\ \mathrm{Ga}(1)-\mathrm{N}(2) & 1.958(1) \\ \mathrm{N}(1)-\mathrm{C}(1) & 1.333(2) \\ \mathrm{N}(2)-\mathrm{C}(3) & 1.334(2) \\ \mathrm{C}(1)-\mathrm{C}(2) & 1.399(2) \\ \mathrm{C}(2)-\mathrm{C}(3) & 1.399(2) \\ \mathrm{Ga}(1)-\mathrm{N}(3) & 1.902(1) \\ \mathrm{N}(3)-\mathrm{N}(4) & 1.236(2) \\ \mathrm{N}(4)-\mathrm{C}(34) & 1.187(2) \\ \mathrm{C}(34)-\mathrm{Si}(2) & 1.818(2) \\ \mathrm{Ga}(1)- & 1.955(2) \\ \mathrm{C}(30)-\mathrm{Si}(1) & 1.861(1)\end{array}$

\section{Bond Angles ( ${ }^{\circ}$ )}

$\mathrm{N}(1)-\mathrm{Ga}(1)-\mathrm{N}(2) \quad 94.89(4)$

$\mathrm{Ga}(1)-\mathrm{N}(1)-\mathrm{C}(1) \quad 121.05(9)$

$\mathrm{Ga}(1)-\mathrm{N}(2)-\mathrm{C}(3) \quad 120.78(8)$

$\mathrm{N}(1)-\mathrm{C}(1)-\mathrm{C}(2) \quad 123.4(1)$

$\mathrm{C}(1)-\mathrm{C}(2)-\mathrm{C}(3) \quad 128.4(1)$

$\mathrm{C}(2)-\mathrm{C}(3)-\mathrm{N}(2) \quad 123.6(1)$

$\mathrm{Ga}(1)-\mathrm{C}(30)-\mathrm{Si}(1) \quad 121.47(7)$

$\mathrm{Ga}(1)-\mathrm{N}(3)-\mathrm{N}(4) \quad 118.48(9)$

$\mathrm{N}(3)-\mathrm{N}(4)-\mathrm{C}(34) \quad 174.7(1)$

$\mathrm{N}(4)-\mathrm{C}(34)-\mathrm{Si}(2) \quad 160.8(1)$ 
The N-N-C angle of $174.7(1)^{\circ}$ and an N-C-Si angle of $160.8(1)^{\circ}$, combined with an N-N bond length of $1.236(2) \AA$, an N-C bond length of 1.187(2) $\AA$, and a C-Si bond length of $1.818(2) \AA$ are consistent with the presence of a $\mathrm{M}-\mathrm{N}-\mathrm{N} \equiv \mathrm{C}-\mathrm{TMS}$ nitrilimine unit as opposed to a $\mathrm{N}=\mathrm{N}=\mathrm{C}(\mathrm{M})-\mathrm{TMS}$ nitrilimine unit. This unit has two potential resonance forms (Figure 63) in which the negative charge can be on either the terminal nitrogen or carbon atoms. The N-N, $\mathrm{C}-\mathrm{N}$ and $\mathrm{C}-\mathrm{Si}$ bond lengths are nearly identical to the nitrogen bridged dimer $\left(\left(\mathrm{CH}\left(\mathrm{SiMe}_{3}\right)_{2}\right)_{2} \mathrm{GaNNCSiMe}_{3}\right)_{2}{ }^{170}$ and similar to those observed in scandium complex XCII (N$\mathrm{N}: 1.188(5) \AA ̊ \Omega, C-N: 1.199(6) \AA ̊ ., S c-N-N$ angle of $149.5(3)^{\circ}, N-N-C$ angle of $176.5(5)^{\circ}$ and N-C-Si angle of $157.4(5)^{\circ}$ ) which described the $\mathrm{N}=\mathrm{N}=\mathrm{C}$ unit as an allenic interaction. ${ }^{169}$ This allenic interaction is indicated by the longer than average $\mathrm{N} \equiv \mathrm{C}$ bond and a shorter than average $\mathrm{N}-\mathrm{N}$ bond length due to resonance of the negative charge between the nitrogen (19a) and the carbon (19b).
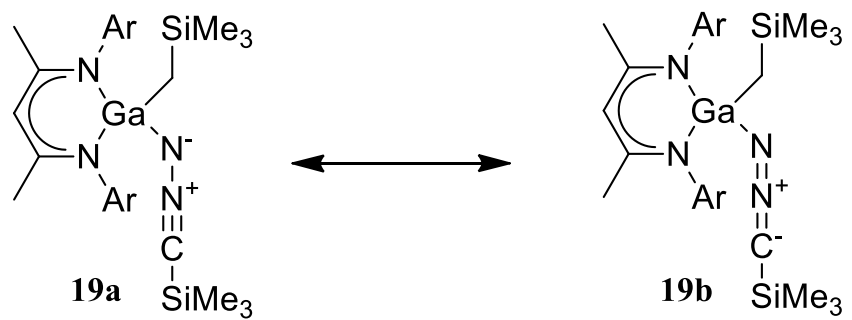

Figure 63: Resonance structures of $\mathrm{BDI}_{\mathrm{DIPP}} \mathrm{Ga}\left(\mathrm{CH}_{2} \mathrm{SiMe}_{3}\right) \mathrm{NNCSiMe}_{3}$.

The formation of complex $\mathbf{1 9}$ is the net result of the addition of two equivalents of trimethylsilyldiazomethane to gallium(I) complex 1. Addition of the first equivalent presumably results in the simultaneous loss of $\mathrm{N}_{2}$ gas and generation of a carbene that bonds with the metal centre resulting in the formation of the desired gallium-carbene complex $\mathbf{2 0}$ (Scheme 5). This intermediate has two potential resonance forms, one in which there is a formal $\mathrm{Ga}=\mathrm{C}$ double bond $\mathbf{2 0 a}$, the other in which there is a Ga-C single bond, and there is a positive charge on the gallium and a negative charge on the carbon $\mathbf{2 0 b}$. As there is expected to be poor $\pi$-orbital overlap between the gallium and carbene, the resonance form $\mathbf{2 0 b}$ is expected to dominate. This negatively charged carbon centre is the postulated to then 
deprotonate a second equivalent of trimethylsilyldiazomethane to form a nitrilimine unit, which coordinates to the positively charged gallium through the negatively charged terminal nitrogen atom, resulting in the formation of a tetracoordinate gallium complex ligated by the BDIDIPP ligand, an alkyl $\mathrm{CH}_{2} \mathrm{SiMe}_{3}$ ligand and a nitrilimine ligand (complex 19).

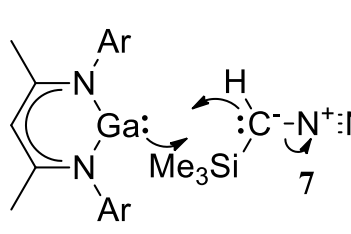

1

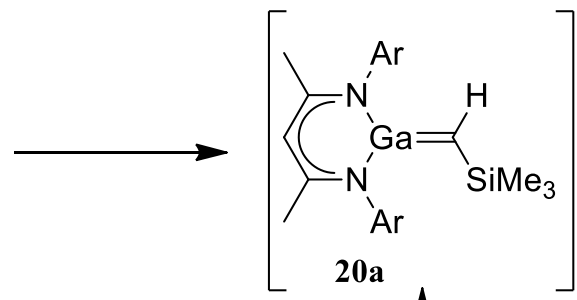

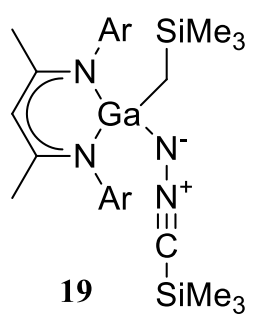
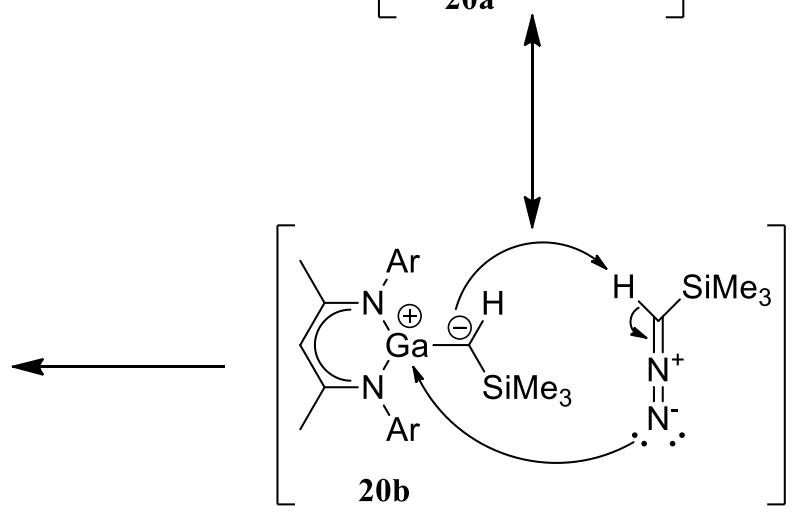

Scheme 5: Proposed formation mechanism of BDIDIPPGa( $\left.\mathrm{CH}_{2} \mathrm{SiMe}_{3}\right) \mathrm{NNCSiMe}_{3}$.

Attempts to study the mechanism of formation of this product by NMR were unsuccessful due to the rapid reaction, with complete conversion to 19 in $<1$ minute, even if the reaction was cooled to $-78{ }^{\circ} \mathrm{C}$ prior to NMR analysis. Attempts at trapping the intermediate were hindered by the BDI ${ }_{D I P P G a}$ starting material directly reacting with the trapping agents such as bistrimethylsilylacetylene and dichloromethane.

Interestingly, crystals obtained from one reaction mixture at $-78{ }^{\circ} \mathrm{C}$ were identified via Xray diffraction as $\mathrm{BDI}_{\mathrm{DIPPG}}\left(\mathrm{CH}_{2} \mathrm{SiMe}_{3}\right) \mathrm{N}(\mathrm{H}) \mathrm{NC} 21$ (Figure 64), which appears to be complex 19 following loss of the $\mathrm{SiMe}_{3}$ group from the nitrilimine ligand and protonation of the ligating nitrogen atom. The ${ }^{1} \mathrm{H}$ NMR spectrum of $\mathbf{2 1}$ shows the $\gamma$-proton as a singlet resonance at $\delta$ $4.85 \mathrm{ppm}$, with a singlet resonance at $\delta 3.64 \mathrm{ppm}$ in a 1:1 ratio to the $\gamma$-proton corresponding to the $\mathrm{N}-\mathrm{H}$ proton. Two singlet resonances in a 1:9:2 ratio to the $\gamma$-proton at $\delta-0.49$ and -0.90 
ppm correspond to the TMS group and $\mathrm{CH}_{2}$ group protons respectively. Two septet resonances in a 1:2:2 ratio with the $\psi$-proton at $\delta 3.87$ and $3.16 \mathrm{ppm}$ corresponding to the methine protons of the isopropyl groups and four doublet resonances each in a 1:6 ratio with the $\mathrm{y}$-proton at $\delta 1.51,1.39,1.28$ and $1.02 \mathrm{ppm}$ corresponding to methyl protons of the isopropyl groups of the ancillary ligand. The coordinating atom is assigned as an $\mathrm{N}$ as opposed to $\mathrm{Ga}-\mathrm{C}(\mathrm{H})-\mathrm{N} \equiv \mathrm{N}$ based on the singlet resonance at $\delta 3.64 \mathrm{ppm}$ having no correlations in the HSQC spectrum, and a weak $\mathrm{HMBC}$ correlation to the resonance in the ${ }^{13} \mathrm{C}$ NMR spectrum at $\delta 131.0 \mathrm{ppm}$, which has been assigned as the $\mathrm{C}^{-}$. An X-ray diffraction study of $\mathbf{2 1}$ shows a very short C-N bond of 1.157(2) $\AA$, similar to other terminal $\mathrm{R}-\mathrm{N}^{+} \equiv \mathrm{C}^{-}$bonds $\mathrm{s}^{211}$ and shorter than in complex 19 (1.187(2) $\AA$ ). The gallium sits in a pseudo-tetrahedral conformation above the NCCCN plane of the ligand, with a bite angle of $95.66(4)^{\circ}$ and similar bond lengths and angles for the ligand as complex 19. The Ga-C bond length of 1.953(1) $\AA$, C-Si bond length of 1.858(1) $\AA$ and Ga-C-Si angle of $123.21(8)^{\circ}$ are comparable to those in 19 (1.955(2) $\AA, 1.861(1) \AA$ and $121.47(7)^{\circ}$ respectively).

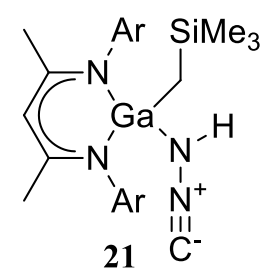

Figure 64: Isolated by-product BDIDIPPGa $\left(\mathrm{CH}_{2} \mathrm{SiMe}_{3}\right) \mathrm{N}(\mathrm{H}) \mathrm{NC}$. 


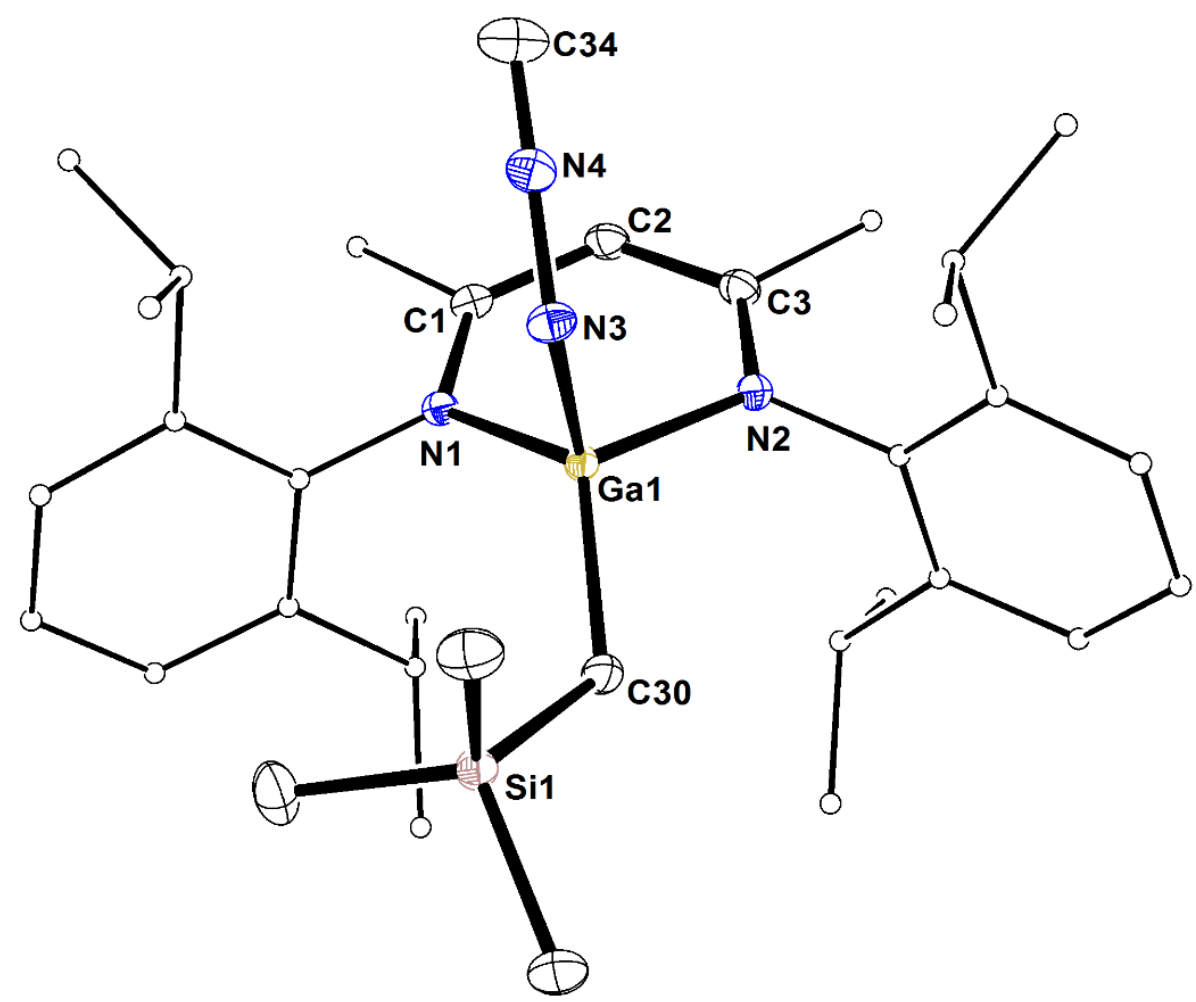

Figure 65: ORTEP plot of $\mathrm{BDI}_{\mathrm{DIPP} G a}\left(\mathrm{CH}_{2} \mathrm{SiMe}\right) \mathrm{N}(\mathrm{H}) \mathrm{NC}$ 21. Ellipsoids at $30 \%, \mathrm{H}$ atoms omitted and selected $\mathrm{C}$ atoms in wire frame for clarity.

Table 3: Selected bond lengths and angles for BDIDIPPGa( $\left.\mathrm{CH}_{2} \mathrm{SiMe}_{3}\right) \mathrm{N}(\mathrm{H}) \mathrm{NC} 21$.

\begin{tabular}{|c|c|c|c|}
\hline \multicolumn{2}{|c|}{ Bond Lengths ( $\AA$ ) } & \multicolumn{2}{|c|}{ Bond Angles $\left({ }^{\circ}\right)$} \\
\hline $\mathrm{Ga}(1)-\mathrm{N}(1)$ & $1.954(1)$ & $N(1)-G a(1)-N(2)$ & $95.66(4)$ \\
\hline $\mathrm{Ga}(1)-\mathrm{N}(2)$ & $1.948(1)$ & $\mathrm{Ga}(1)-\mathrm{N}(1)-\mathrm{C}(1)$ & $121.04(8)$ \\
\hline$N(1)-C(1)$ & $1.335(2)$ & $\mathrm{Ga}(1)-\mathrm{N}(2)-\mathrm{C}(3)$ & $120.19(8)$ \\
\hline$N(2)-C(3)$ & $1.339(2)$ & $N(1)-C(1)-C(2)$ & 123.3(1) \\
\hline$C(1)-C(2)$ & $1.396(2)$ & $C(1)-C(2)-C(3)$ & $128.2(1)$ \\
\hline$C(2)-C(3)$ & $1.395(2)$ & $C(2)-C(3)-N(2)$ & $124.2(1)$ \\
\hline $\mathrm{Ga}(1)-\mathrm{N}(3)$ & $1.914(1)$ & $\mathrm{Ga}(1)-\mathrm{C}(30)-\mathrm{Si}(1)$ & $123.21(8)$ \\
\hline$N(3)-N(4)$ & $1.339(2)$ & $\mathrm{Ga}(1)-\mathrm{N}(3)-\mathrm{N}(4)$ & $122.86(9)$ \\
\hline$N(4)-C(34)$ & $1.157(2)$ & $N(3)-N(4)-C(34)$ & $178.5(2)$ \\
\hline $\mathrm{Ga}(1)-$ & $1.953(1)$ & & \\
\hline$C(30)-S i(1)$ & $1.858(1)$ & & \\
\hline
\end{tabular}

The synthesis of complex $\mathbf{2 1}$ was repeated to determine what had happened to the trimethylsilyl group, however these attempts resulted in the synthesis of complex 19, and complex $\mathbf{2 1}$ could not be reproduced. 


\subsubsection{Reaction of BDI IIPPGa with Cyclododecyldiazomethane}

As previously discussed, when trimethylsilyldiazomethane is added to scandium complex $\mathbf{X C I}^{169}$ deprotonation of the diazo- compound by the scandium imido complex is observed. The activation barrier for this reaction was calculated to be $13.6 \mathrm{kcal} / \mathrm{mol}$. Unfortunately, the $\mathrm{pK}_{\mathrm{a}}$ values of diazo- compounds are unknown. ${ }^{212}$ As it appears that similar reactivity was occurring with complex 1 , we decided to investigate the reactivity of diazo-compounds that did not contain an $\alpha$-proton. To that end, cyclododecyldiazomethane $\mathbf{2 4}$ was prepared following adapted literature procedure (Scheme 6$)^{213}$ from cyclododecanone through condensation with $p$-toluenesufonyl hydrazide to give hydrazide $22 .{ }^{214}$ Treatment of 22 with sodium methoxide in methanol resulted in conversion to sodium hydrazide salt $\mathbf{2 3}$, finally thermal pyrolysis of the sodium salt $\mathbf{2 3}$ yielded $\mathbf{2 4}$ as bright red crystals that were used without further purification.

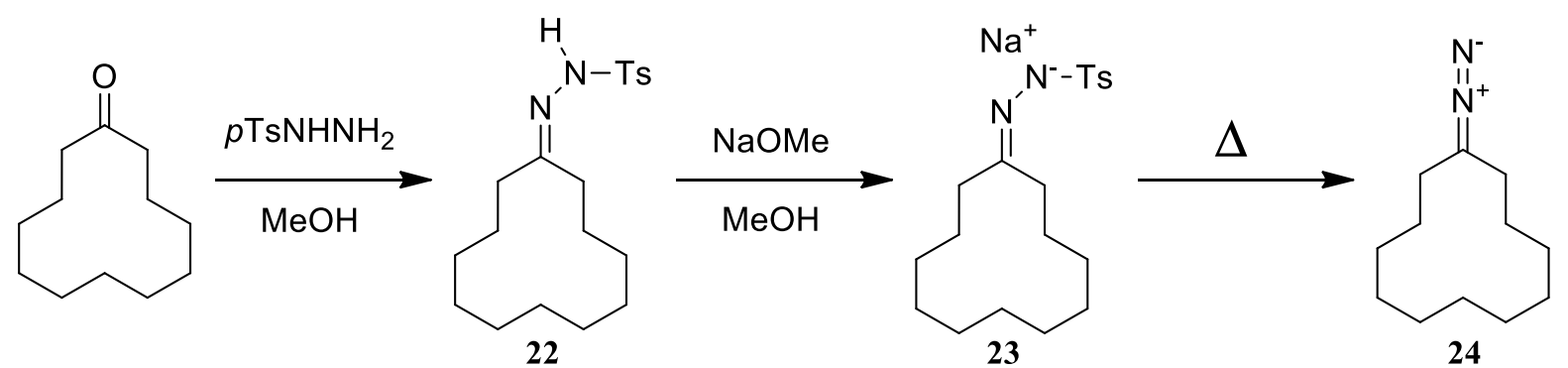

Scheme 6: Preparation of cyclododecyldiazomethane.

Addition of one equivalent of a solution of cyclododecyldiazomethane $\mathbf{2 4}$ in hexane to a solution of $\mathrm{BDI}$ DIPPGa 1 in toluene cooled to $-30^{\circ} \mathrm{C}$ resulted in the formation of one new $\mathrm{BDI}$ DIPP containing product (as determined from the presence of a new $\mathrm{y}$-proton resonance in the crude ${ }^{1} \mathrm{H}$ NMR spectrum) in a less than 50:50 ratio. On the assumption that a similar product to 19 was again forming, a second equivalent of 24 was added to the reaction mixture, which increased the ratio of product:starting material to approximately 80:20. Removal of the solvent and crystallisation from toluene at $-30^{\circ} \mathrm{C}$ yielded crystals suitable for $X$-ray diffraction, with the resulting data indicating that the product of the reaction was most likely 
$\mathrm{BDI}_{\text {DIPPGa}}\left(\mathrm{C}_{12} \mathrm{H}_{21}\right) \mathrm{N}(\mathrm{H}) \mathrm{N}(\mathrm{H}) \mathrm{C}_{12} \mathrm{H}_{21}$ (25) (Scheme 7). The presence of two short (1.325(7) and $1.346(7) \AA ̊ \AA), s p^{2}$ carbon bonds in the cyclododecane rings indicate that the $\mathrm{CH}_{2}$ unit adjacent to the diazo- carbon has been deprotonated and a double bond has formed between the two carbon centres. The C-N bond length of 1.369(6) A indicates the presence of a shortened C-N single bond, while the N-N bond length of 1.420(5) $\AA$ indicates a lengthened N-N single bond. Additionally, the loss of the two protons from the two cyclododecane moieties requires accounting for, and electron density accounting for a single proton can be found near both nitrogen atoms. Both nitrogen atoms adopt a planar orientation, leading to the $\mathrm{M}-\mathrm{N}-\mathrm{N}-\mathrm{C}=\mathrm{C}-$ $\mathrm{R}$ sub unit sitting in the same plane, indicating that the $\pi$-system is potentially delocalised across all atoms involved. While a clean ${ }^{1} \mathrm{H}$ NMR spectrum would confirm the presence of the $\mathrm{N}-\mathrm{H}$ protons, one has not successfully been obtained due potentially to the presence of the decomposition products of $\mathbf{2 4}$ also being present in the reaction mixture.
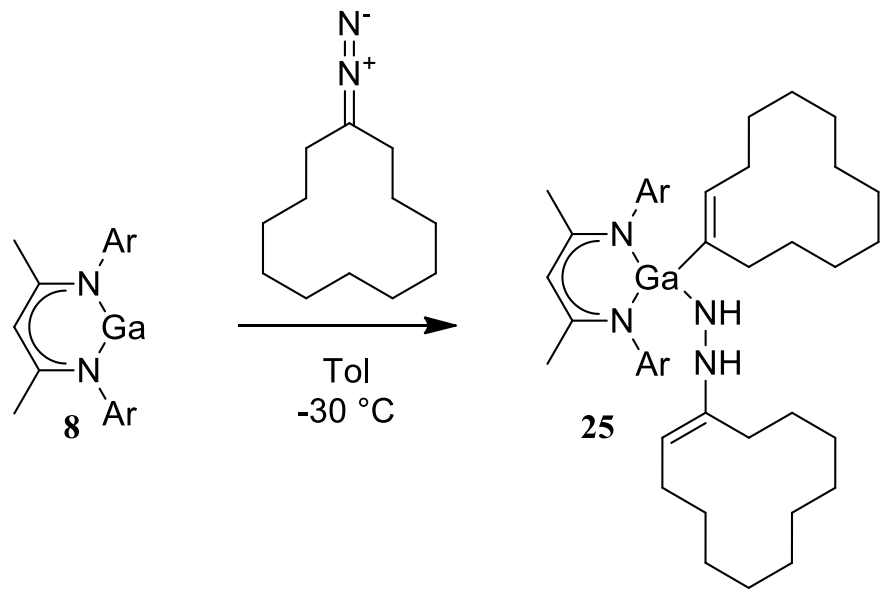

Scheme 7: Reaction of BDIDIPPGa with $\mathrm{C}_{12} \mathrm{H}_{22} \mathrm{~N}_{2}$. 


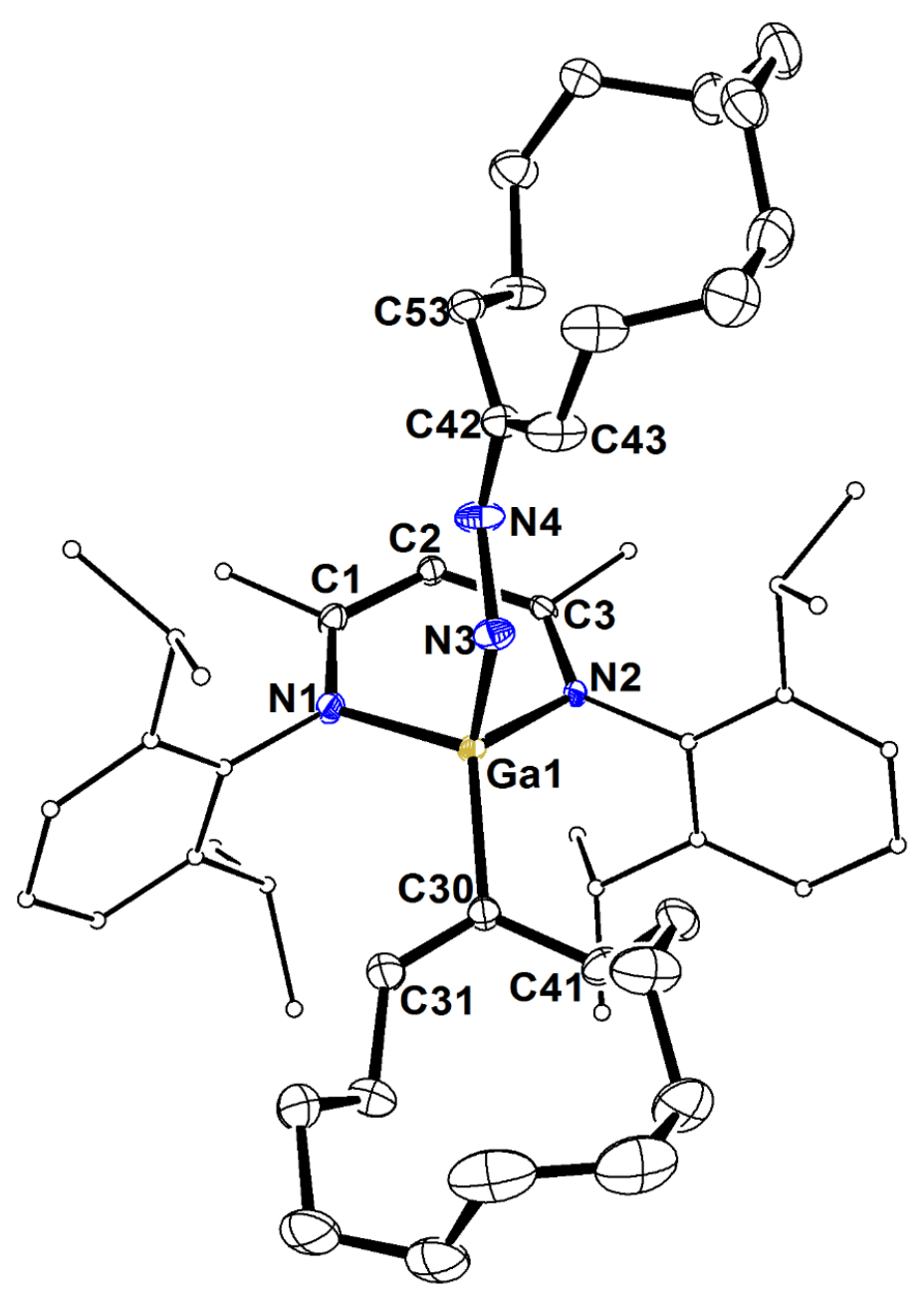

Figure 66: ORTEP plot of $B D I_{D I P P G a}\left(\mathrm{C}_{12} \mathrm{H}_{21}\right) \mathrm{N}(\mathrm{H}) \mathrm{N}(\mathrm{H}) \mathrm{C}_{12} \mathrm{H}_{21}$ 25. Ellipsoids at $30 \%, \mathrm{H}$ atoms omitted and selected $\mathrm{C}$ atoms in wire frame for clarity.

Table 4: Selected bond lengths and angles for BDIDIPPGa $\left(\mathrm{C}_{12} \mathrm{H}_{21}\right) \mathrm{N}(\mathrm{H}) \mathrm{N}(\mathrm{H}) \mathrm{C}_{12} \mathrm{H}_{21} 25$.

\begin{tabular}{cccc}
\multicolumn{3}{c}{ Bond Lengths (离) } & \multicolumn{2}{c}{ Bond Angles ( ${ }^{\circ}$ ) } \\
$\mathrm{Ga}(1)-\mathrm{N}(1)$ & $1.989(3)$ & $\mathrm{N}(1)-\mathrm{Ga}(1)-\mathrm{N}(2)$ & $94.2(1)$ \\
$\mathrm{Ga}(1)-\mathrm{N}(2)$ & $1.974(3)$ & $\mathrm{Ga}(1)-\mathrm{N}(1)-\mathrm{C}(1)$ & $119.5(3)$ \\
$\mathrm{N}(1)-\mathrm{C}(1)$ & $1.333(5)$ & $\mathrm{Ga}(1)-\mathrm{N}(2)-\mathrm{C}(3)$ & $119.8(3)$ \\
$\mathrm{N}(2)-\mathrm{C}(3)$ & $1.326(5)$ & $\mathrm{N}(1)-\mathrm{C}(1)-\mathrm{C}(2)$ & $123.9(4)$ \\
$\mathrm{C}(1)-\mathrm{C}(2)$ & $1.393(6)$ & $\mathrm{C}(1)-\mathrm{C}(2)-\mathrm{C}(3)$ & $128.2(2)$ \\
$\mathrm{C}(2)-\mathrm{C}(3)$ & $1.408(6)$ & $\mathrm{C}(2)-\mathrm{C}(3)-\mathrm{N}(2)$ & $124.0(4)$ \\
$\mathrm{Ga}(1)-\mathrm{N}(3)$ & $1.873(3)$ & $\mathrm{Ga}(1)-\mathrm{C}(30)-\mathrm{C}(31)$ & $118.4(4)$ \\
$\mathrm{N}(3)-\mathrm{N}(4)$ & $1.420(5)$ & $\mathrm{Ga}(1)-\mathrm{C}(30)-\mathrm{C}(41)$ & $119.1(3)$ \\
$\mathrm{N}(4)-\mathrm{C}(42)$ & $1.369(6)$ & $\mathrm{C}(31)-\mathrm{C}(30)-\mathrm{C}(41)$ & $122.4(5)$ \\
$\mathrm{C}(42)-\mathrm{C}(43)$ & $1.346(7)$ & $\mathrm{Ga}(1)-\mathrm{N}(3)-\mathrm{N}(4)$ & $114.6(3)$ \\
$\mathrm{C}(42)-\mathrm{C}(53)$ & $1.502(7)$ & $\mathrm{N}(3)-\mathrm{N}(4)-\mathrm{C}(42)$ & $120.0(4)$ \\
$\mathrm{Ga}(1)-\mathrm{C}(30)$ & $1.966(3)$ & $\mathrm{N}(4)-\mathrm{C}(42)-\mathrm{C}(43)$ & $122.4(4)$ \\
$\mathrm{C}(30)-\mathrm{C}(31)$ & $1.325(7)$ & $\mathrm{N}(4)-\mathrm{C}(42)-\mathrm{C}(53)$ & $112.7(4)$ \\
$\mathrm{C}(30)-\mathrm{C}(41)$ & $1.480(7)$ & $\mathrm{C}(43)-\mathrm{C}(42)-\mathrm{C}(53)$ & $124.7(4)$
\end{tabular}


The formation of complex $\mathbf{2 5}$ is presumed to occur via the mechanism depicted in Scheme 8, simultaneous carbene formation, loss of $\mathrm{N}_{2}$ and attack of the gallium(I) centre gives the desired gallium carbene complex $\mathbf{2 6}$. As with complex $\mathbf{2 0}$, there are two resonance forms $\mathbf{2 6 a}$ and $\mathbf{2 6 b}$, with $\mathbf{2 6 b}$ being expected to dominate. Intermediate $\mathbf{2 6} \mathbf{b}$ then reacts with a second equivalent of cyclododecyldiazomethane in a concerted process in which the $\beta$-proton of the cyclododecyl ligand is transferred to one of the two nitrogen atoms of the cyclododecyldiazomethane, coordination of the terminal nitrogen to the gallium centre occurs, and a C-C double bond is formed to give a cyclododecene ligand. Intermediate $\mathbf{2 7}$ then undergoes an allylic 1,3 hydride shift to form the second $\mathrm{C}$-C double bond and protonate the second nitrogen atom to give complex 25.
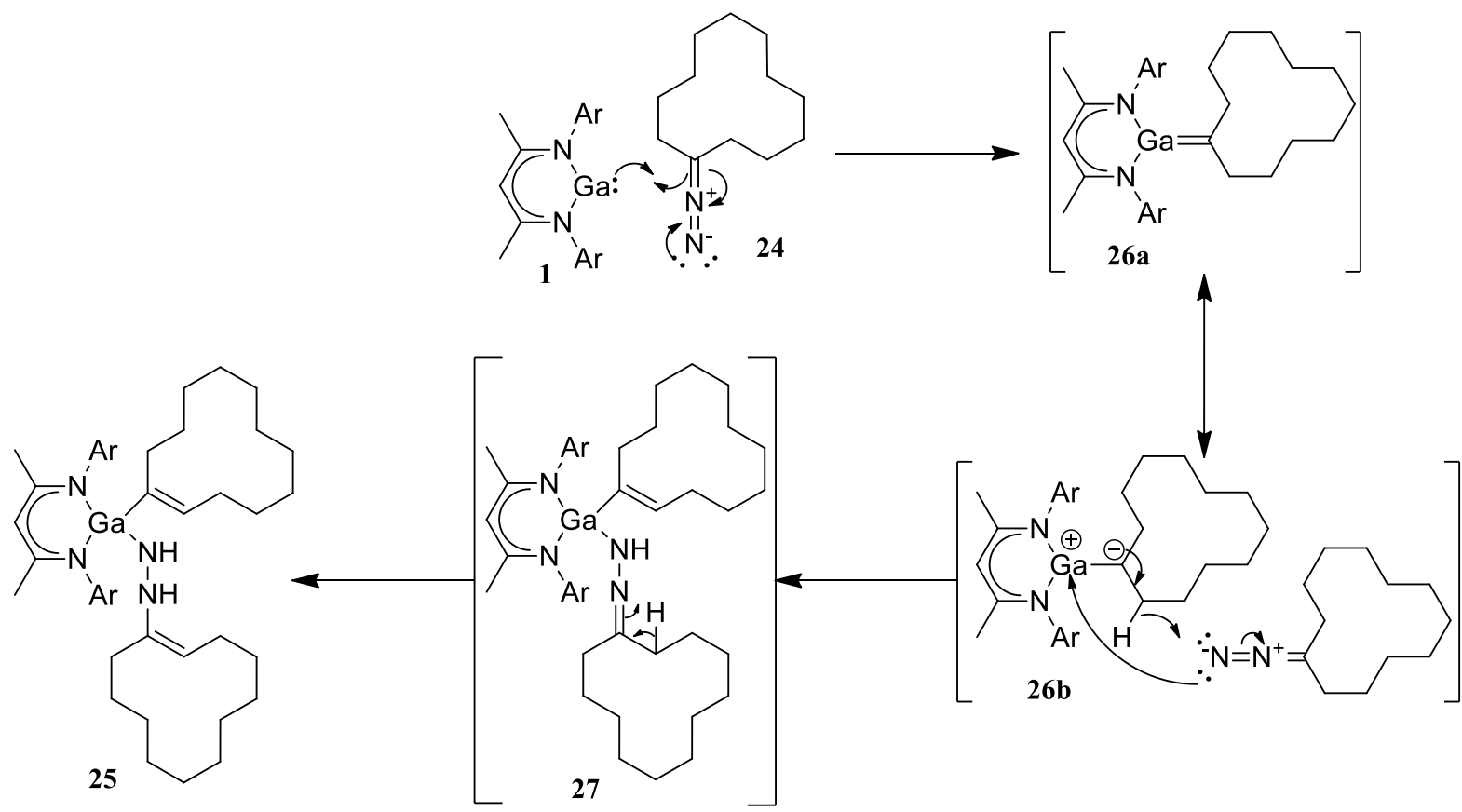

Scheme 8: Proposed mechanism for the formation of BDIDIPPGa $\left(\mathrm{C}_{12} \mathrm{H}_{21}\right) \mathrm{N}(\mathrm{H}) \mathrm{N}(\mathrm{H}) \mathrm{C}_{12} \mathrm{H}_{21}$.

\subsubsection{Reaction of BDIDIPPGa with Diphenyldiazomethane}

The unexpected $\alpha$-deprotonation of trimethylsilyldiazomethane and $\beta$-deprotonation of cyclododecyldiazomethane required a change in the diazo- compound. In order reduce the potential for $\beta$-elimination during the reaction, diphenyldiazomethane $\mathbf{8}$ was prepared from 
benzophenone following literature procedures (Scheme 9). ${ }^{149}$ Benzophenone was converted to hydrazone $\mathbf{2 8}$ via condensation with hydrazine monohydrate, followed by reduction using mercuric oxide to give 8 as a red/purple solid.<smiles>COc1cccc(C(=O)c2ccccc2)c1N=C(c1ccccc1)c1ccccc1</smiles>

Scheme 9: Synthesis of diphenyldiazomethane.

Upon addition of diphenyldiazomethane $\mathbf{8}$ to BDIDIPPGa $\mathbf{1}$, the solution immediately changed colour from dark red/purple to pale yellow. The ${ }^{1} \mathrm{H}$ NMR spectral analysis of the solution showed that the only BDI containing compound present was complex $\mathbf{1}$, however the resonances corresponding to $\mathbf{8}$ were no longer present. Instead resonances corresponding to tetraphenylethene $\mathbf{3 0}$ were observed, the decomposition product of the diazo- compound. Diphenyldiazomethane is known to be unstable in solution, ${ }^{149}$ and upon dissolving it in $\mathrm{C}_{6} \mathrm{D}_{6}$ a small amount $(<5 \%)$ of decomposition was observed after $24 \mathrm{~h}$. In the presence of BDIDIPPGa, complete decomposition was observed immediately. Presumably, either the proposed carbanion 29 forms, but then attacks another equivalent of diazomethane (Scheme 10) or simply co-ordination of the diazomethane unit to the gallium centre $\mathbf{3 1}$ is enough to catalyse the decomposition of diphenyldiazomethane to tetraphenylethene (Scheme 11).

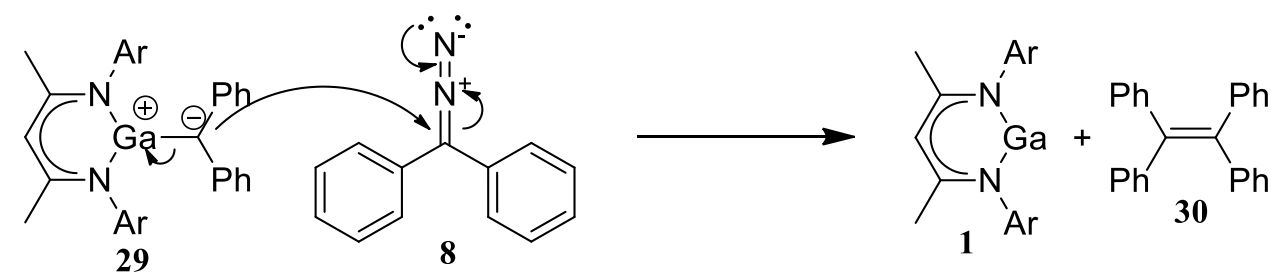

Scheme 10: Tetraphenylethene formation via carbanion. 


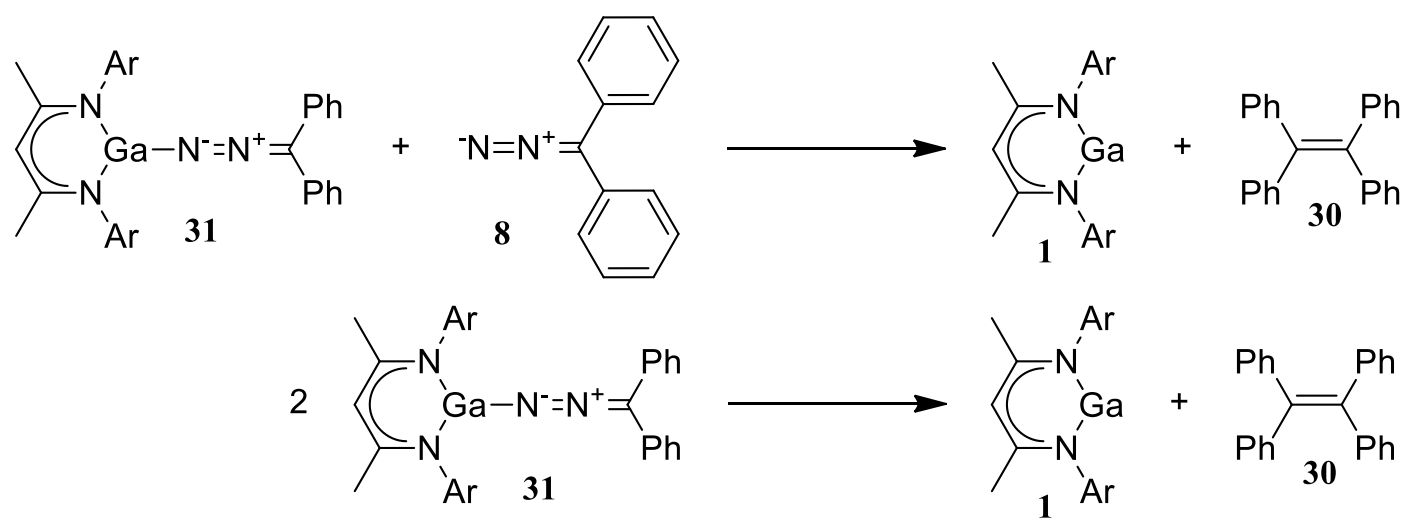

Scheme 11: Tetraphenylethene formation via co-ordination.

Previous work has demonstrated that the analogous complex BDI DIPPAl (6) reacts with diphenyldiazomethane in a very different manner, with the formation of $\mathrm{Ph}_{2} \mathrm{C}=\mathrm{N}-\mathrm{N}=\mathrm{CPh}_{2}$ followed by aluminium insertion into the $\mathrm{N}-\mathrm{N}$ bond (Figure 67 ) to give diiminylaluminium complex CIII as the product. ${ }^{215} \mathrm{Ph}_{2} \mathrm{C}=\mathrm{N}-\mathrm{N}=\mathrm{CPh}_{2}$ is another decomposition product of the parent diphenyldiazomethane, however the reaction was carried out at $60^{\circ} \mathrm{C}$, a temperature at which spontaneous decomposition of diphenyldiazomethane occurs in solution. ${ }^{149}$ Therefore, it is unclear if complex $\mathbf{6}$ played a role in the decomposition of diphenyldiazomethane in a similar manner as proposed for complex $\mathbf{1}$.
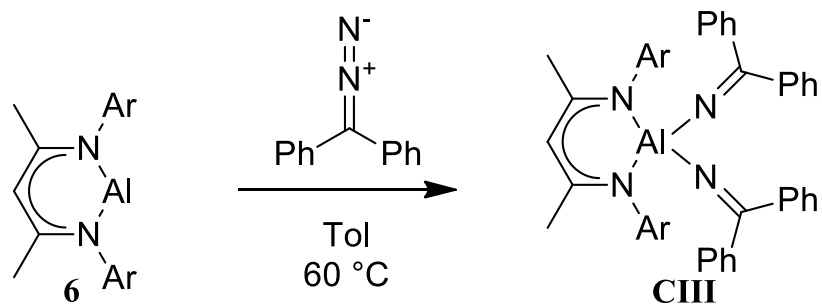

Figure 67: Reaction of BDIDIPPAl with diphenyldiazomethane. 


\subsubsection{Reaction of BDIDIPPGa with Diazafluorene}

As the formation of tetraphenylethene showed that consideration of the ease of dimer formation between two monomers of the diazo- compound was required, diazofluorene was selected as the next reagent to be examined due to the relative difficulty of formation of bifluorene compared to tetraphenylethene. ${ }^{216}$ Diazofluorene $\mathbf{3 3}$ was synthesised following literature procedure (Scheme 12). ${ }^{149}$ Fluorenone was converted into hydrazone 32 via condensation with hydrazine monohydrate, subsequent reduction of hydrazone $\mathbf{3 2}$ with mercuric oxide yielded diazofluorene $\mathbf{3 3}$ as red crystals.

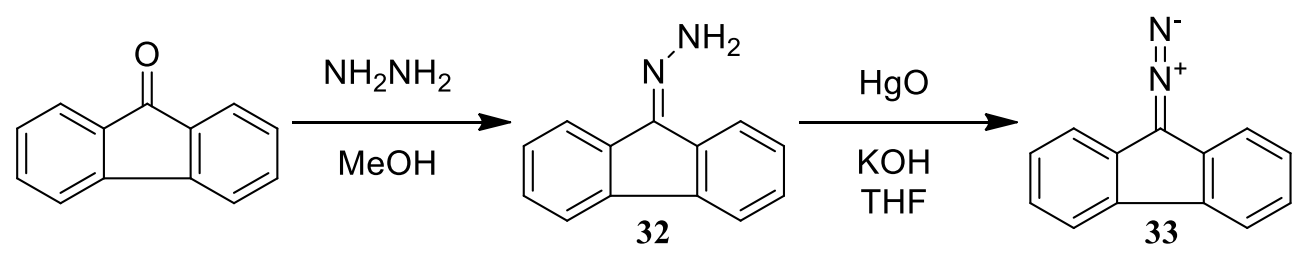

Scheme 12: Synthesis of diazofluorene.

In contrast to the reaction of $\mathbf{1}$ with diphenyldiazomethane, upon addition of $\mathbf{3 3}$ to a solution of $\mathbf{1}$ the toluene solution turned intense blue, which over the course of 5 minutes converted to a dark green solution. The ${ }^{1} \mathrm{H}$ NMR spectrum of the reaction mixture showed three BDI-containing species were present, complex 1 and two new signals in a 50:47:3 ratio. Assuming that a subsequent reaction with a second unit of the diazo-compound was once again occurring as with $\mathbf{1 9}$ and $\mathbf{2 5}$, a second equivalent of $\mathbf{3 3}$ was added to the reaction mixture resulting in nearly complete consumption of $\mathbf{1}$. Concentration of the solution and storage in the freezer at $-30{ }^{\circ} \mathrm{C}$ resulted in the formation of crystals suitable for $\mathrm{X}$-ray diffraction, which identified the product as BDIDIPPGaFINNFI 34 (Scheme 13). 

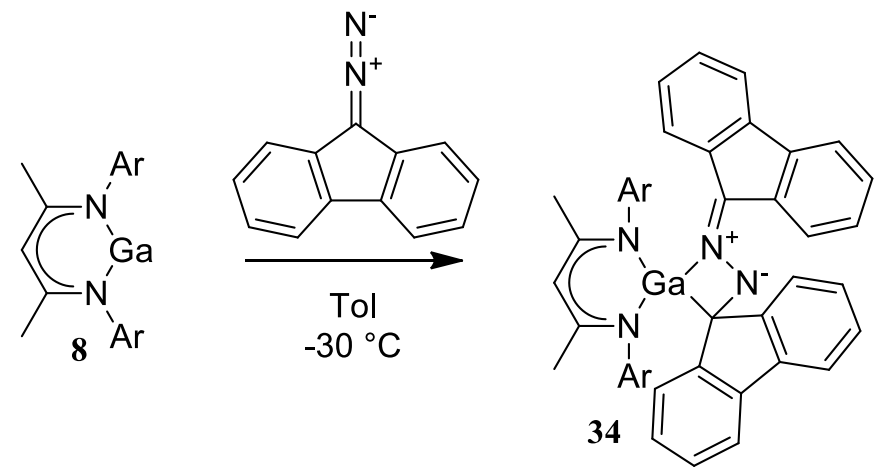

Scheme 13: Reaction of BDIDIPPGa with diazofluorene.

Complex 34 appears to be the product of a [2+2] cycloaddition reaction between the desired gallium-carbon double bonded species $\mathbf{3 5}$ and a second equivalent of diazofluorene. A fully clean ${ }^{1} \mathrm{H}$ and ${ }^{13} \mathrm{C}$ NMR spectrum of complex 34 could not be obtained due to the presence of an impurity with overlapping $\gamma$-proton resonances (potentially the opposite cycloaddition product). However, visible resonances of the major product at $\delta 8.26,7.91$, $7.43,6.72$ and 6.54 ppm supported the presence of multiple fluorene rings in the product. No visible $\mathrm{N}-\mathrm{H}$ resonances were identified from the HSQC spectrum, supporting the presence of the $\mathrm{C}=\mathrm{N}^{+}-\mathrm{N}^{-}$moiety. The $\mathrm{X}$-ray diffraction study supports this, with a longer $\mathrm{C}=\mathrm{N}$ double bond length of $1.334(3) \AA$, shortened N-N single bond length of $1.332(3) \AA$, and $\mathrm{C}-\mathrm{N}-\mathrm{N}$ angle of $122.3(2)^{\circ}$ supporting the presence of an allylic C-N-N interaction. The gallium sits $0.243 \AA$ above the NCCCN plane of the ligand in an almost planar conformation with $N(1), N(2)$ and $\mathrm{C}(30)$ (sum of angles $355.8^{\circ}$ ), while the bound fluorene ligand is at a $54.47^{\circ}$ angle to the NCCCN plane. The Ga-N(3) bond length of 2.023(2) A is longer than a standard Ga-N bond, potentially due to the positive charge on the nitrogen atom. The $\mathrm{Ga}-\mathrm{C}(30)-\mathrm{N}(4)$ angle of $90.1(1)^{\circ}$ and $\mathrm{C}-\mathrm{N}$ bond length of $1.477(3) \AA ̊$ is comparable to similar 4-membered ring systems, while the $C(30)$ Ga-N(3) angle of $67.34(6)^{\circ}$ is comparable to transition metal complexes ( $\mathrm{Y}, \mathrm{Mo}, \mathrm{Sc}, \mathrm{Ru}$ ) containing similar 4-membered ring systems. ${ }^{217-219}$ 


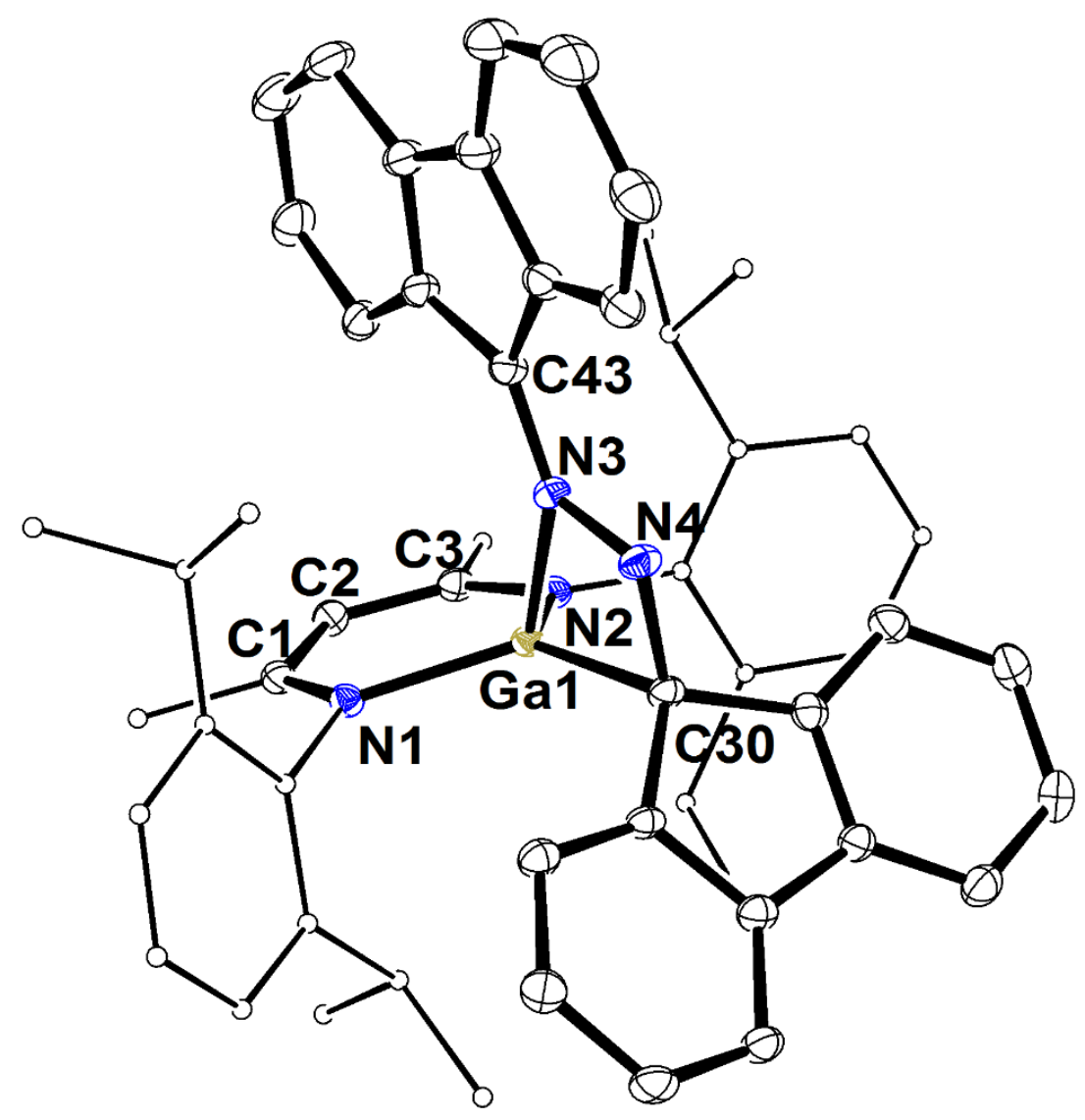

Figure 68: ORTEP plot of BDIDIPPGaFINNFI 34. Ellipsoids at 30\%, $\mathrm{H}$ atoms omitted and selected $\mathrm{C}$ atoms in wire frame for clarity.

Table 5: Selected bond lengths and angles for BDIDIPPGaFINNFI 34.

Bond Lengths ( $\AA$ )

$\mathrm{Ga}(1)-\mathrm{N}(1)$

$1.931(2)$

$\mathrm{Ga}(1)-\mathrm{N}(2)$

$\mathrm{N}(1)-\mathrm{C}(1)$

$\mathrm{N}(2)-\mathrm{C}(3)$

$\mathrm{C}(1)-\mathrm{C}(2)$

$C(2)-C(3)$

$\mathrm{Ga}(1)-\mathrm{N}(3)$

$\mathrm{N}(3)-\mathrm{N}(4)$

$\mathrm{N}(4)-\mathrm{C}(30)$

$\mathrm{N}(3)-\mathrm{C}(43)$

$\mathrm{Ga}(1)-\mathrm{C} 30)$
$1.930(2)$

$1.337(3)$

$1.347(3)$

$1.400(3)$

$1.391(3)$

2.023(2)

$1.332(3)$

$1.477(3)$

1.334(3)

2.048(2)

\section{Bond Angles $\left({ }^{\circ}\right)$}

$\begin{array}{cc}\mathrm{N}(1)-\mathrm{Ga}(1)-\mathrm{N}(2) & 97.95(7) \\ \mathrm{Ga}(1)-\mathrm{N}(1)-\mathrm{C}(1) & 122.4(1) \\ \mathrm{Ga}(1)-\mathrm{N}(2)-\mathrm{C}(3) & 121.3(1) \\ \mathrm{N}(1)-\mathrm{C}(1)-\mathrm{C}(2) & 123.7(2) \\ \mathrm{C}(1)-\mathrm{C}(2)-\mathrm{C}(3) & 128.4(2) \\ \mathrm{C}(2)-\mathrm{C}(3)-\mathrm{N}(2) & 124.7(2) \\ \mathrm{Ga}(1)-\mathrm{C}(30)-\mathrm{N}(4) & 90.1(1) \\ \mathrm{Ga}(1)-\mathrm{N}(3)-\mathrm{N}(4) & 95.6(1) \\ \mathrm{N}(3)-\mathrm{N}(4)-\mathrm{C}(30) & 106.8(2) \\ \mathrm{C}(30)-\mathrm{Ga}(1)-\mathrm{N}(3) & 67.34(8) \\ \mathrm{Ga}(1)-\mathrm{N}(3)-\mathrm{C}(43) & 142.1(1) \\ \mathrm{C}(43)-\mathrm{N}(3)-\mathrm{N}(4) & 122.3(2)\end{array}$


The proposed mechanism for the formation of complex $\mathbf{3 4}$ is the initial formation of the desired gallium-carbene complex 35 through attack of the gallium(I) centre and loss of $N_{2}$, followed by a [2+2] cycloaddition reaction between the desired gallium-carbon double bonded species $\mathbf{3 5}$ and a second equivalent of diazofluorene 33 (Scheme 14). The formation of complex $\mathbf{3 4}$ gives a good indication that the gallium-carbon double bond may indeed be formed, but is highly reactive.

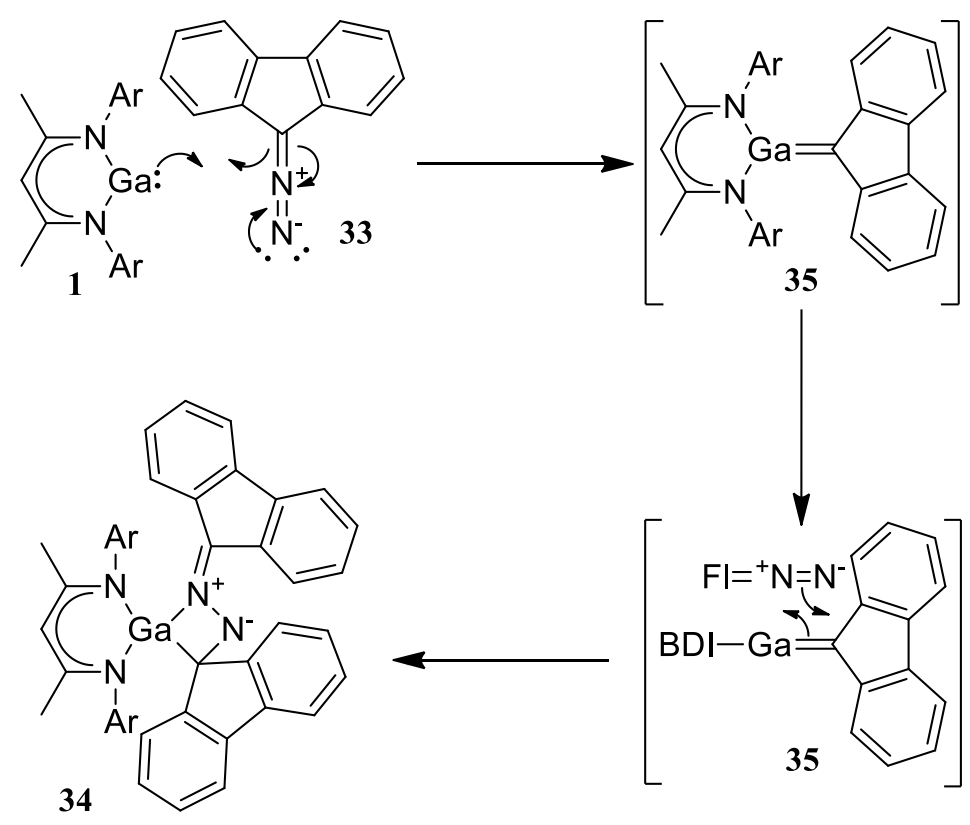

Scheme 14: Proposed mechanism of reaction of BDI DIPPGa with diazofluorene.

\subsubsection{Reaction of BDIDIPPGa with Di-tert-butyldiazomethane}

With the list of complications to isolating a gallium-carbon double bond now including both $\alpha$ and $\beta$ protons, decomposition to dimers, and [2+2] cycloaddition, the next diazocompound attempted was di-tert-butyldiazomethane 38. This compound lacks $\alpha$ and $\beta$ protons, dimer formation is relatively difficult ${ }^{220}$ and the ${ }^{\mathrm{t}} \mathrm{Bu}$ groups make the compound significantly more sterically hindered. Di-tert-butyldiazomethane $\mathbf{3 8}$ was synthesised from pivalonitrile following literature procedures (Scheme 15). ${ }^{221-222}$ Sodium mediated radical reduction of pivalonitrile resulted in the formation of imine $\mathbf{3 6}$, imine substitution of $\mathbf{3 6}$ with 
hydrazine resulted in the formation of imine $\mathbf{3 7}$, subsequent reduction of imine $\mathbf{3 7}$ with mercuric oxide yielded di-tert-butyldiazomethane $\mathbf{3 8}$ as a red oil.

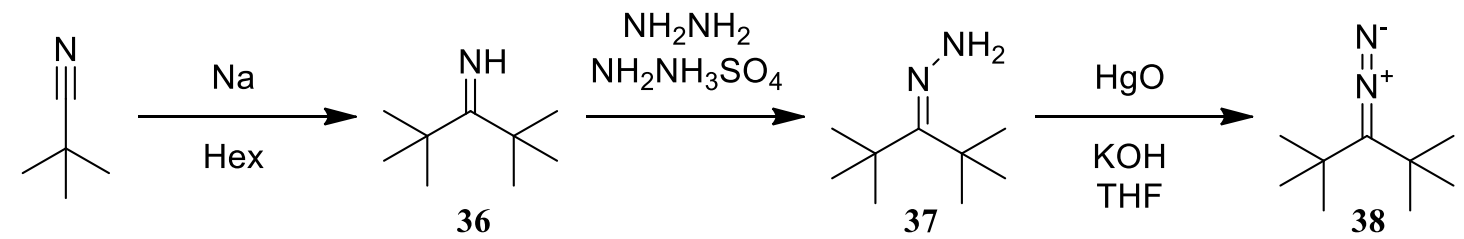

Scheme 15: Synthesis of di-tert-butyldiazomethane.

Addition of di-tert-butyldiazomethane $\mathbf{3 8}$ to $\mathrm{BDI}_{\mathrm{DIPP}} \mathrm{Ga} \mathbf{1}$ was rather uneventful in that absolutely nothing happened, no reaction was observed by ${ }^{1} \mathrm{H}$ NMR spectroscopy and the two reagents remained unreactive in $\mathrm{C}_{6} \mathrm{D}_{6}$, toluene, and THF, while heating of all samples above $60{ }^{\circ} \mathrm{C}$ resulted in degradation of 1 with no observable formation of target 39 (Scheme 16). Presumably, the steric bulk of the ${ }^{\text {t}} \mathrm{Bu}$ groups, intended to prevent dimerization, also prevented the two reagents from getting close enough to react in the first place.<smiles>CC1=CC(C)=NN([AlH2])C1</smiles><smiles>CC(C)(C)C(=[N+]=[N-])C(C)(C)C</smiles><smiles>CCCC</smiles>

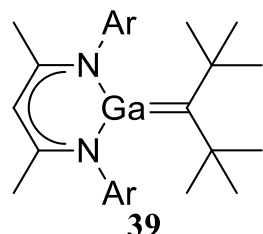

Scheme 16: Attempted reaction with di-tert-butyldiazomethane.

\subsubsection{Synthesis of ArBDIDIPPGa}

The BDIDIPp ligand proved unsuitable at stabilising a complex with a gallium-carbon double bond. Although the reactivity suggests that the target $\mathrm{Ga}=\mathrm{C}$ double bonded complex is formed, it is kinetically unstable and reacts rapidly with a second equivalent of diazo- 
compounds. As such, other variations of the BDI ligand were used, both to generate new gallium(I) complexes and investigate their reactivity towards diazo- compounds. In order to examine if the orbital overlap between the proposed carbanion and the gallium centre could be improved, and thus stabilise the $\mathrm{Ga}=\mathrm{C}$ double bond, the anilido/imino analogue of the BDI ligand $\left(A r B D I_{D I P P}-H, 13\right)$ was prepared following literature procedure. ${ }^{119}$ Treatment of the ligand $\mathbf{1 3}$ with $n$-butyllithium resulted in the formation of lithium salt $\mathbf{1 6}$ (Scheme 17), which was isolated and added to a solution of 'Gal' in toluene, resulting in the formation of a vivid yellow solution. Upon concentrating and storing at $-30^{\circ} \mathrm{C}$, bright yellow crystals of $\mathrm{ArBDI}_{\mathrm{DIPP}} \mathrm{Ga}$ 10 formed.

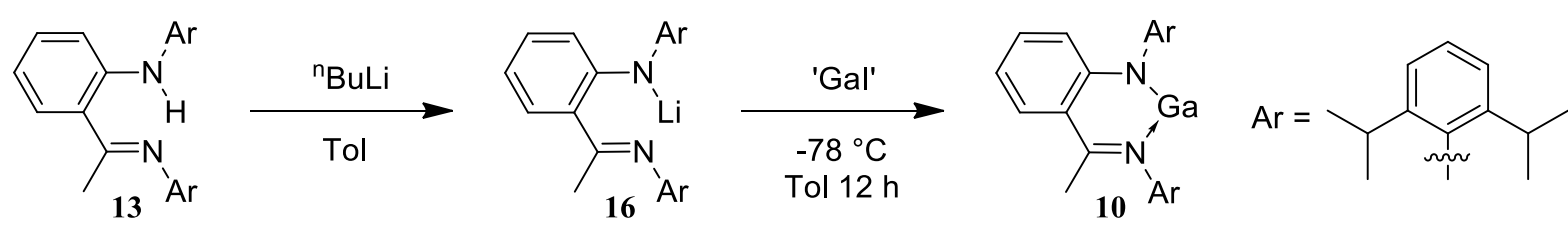

Scheme 17: Synthesis of ArBDI DIPPGa.

Analysis of $\mathbf{1 0}$ by NMR spectroscopy and X-Ray diffraction showed that the gallium had inserted nearly perfectly into the plane of the ligand, with all the backbone carbon atoms, nitrogen atoms, and gallium forming a plane. This plane creates an element of symmetry in a molecule that was expected to be asymmetric. The ${ }^{1} \mathrm{H}$ NMR spectrum shows the backbone methyl group as a singlet resonance at $\delta 2.06 \mathrm{ppm}$, two septet resonances in a 3:2:2 ratio with the backbone methyl group at $\delta 3.33$ and $2.90 \mathrm{ppm}$ corresponding to the methine protons of the isopropyl groups and four doublet resonances each in a 3:6 ratio with the backbone methyl group at $\delta 1.33,1.25,1.13$ and 1.03 ppm corresponding to the methyl protons of the isopropyl groups of the ancillary ligand. The bite angle of the ligand is $85.0(1)^{\circ}$ which is smaller than both the $87.5^{\circ}$ observed in $\mathrm{BDI}_{\mathrm{DIPP} G a}{ }^{8}$ and the $89.0^{\circ}$ in ${ }^{\mathrm{B}}{ }^{\mathrm{Bu}} \mathrm{BD} \mathrm{DIPPG}_{\mathrm{DIP}}{ }^{223}$ The imide dative bond is $6 \%$ longer than the amide bond to the gallium centre $(2.114(4) \AA$ and $1.988(3) \AA$ respectively) however the carbon nitrogen bond distances of the imide and amide are nearly

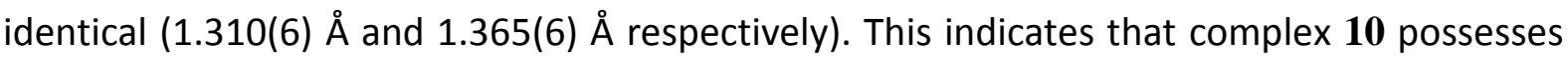
similar delocalised aromaticity of the ligand backbone to $\mathbf{1}$, but with a slight skewing of the 
gallium towards the amide nitrogen, reflecting the change in binding from the diimine ligand $\mathbf{2}$ to the anilido/imino ligand $\mathbf{1 3}$.

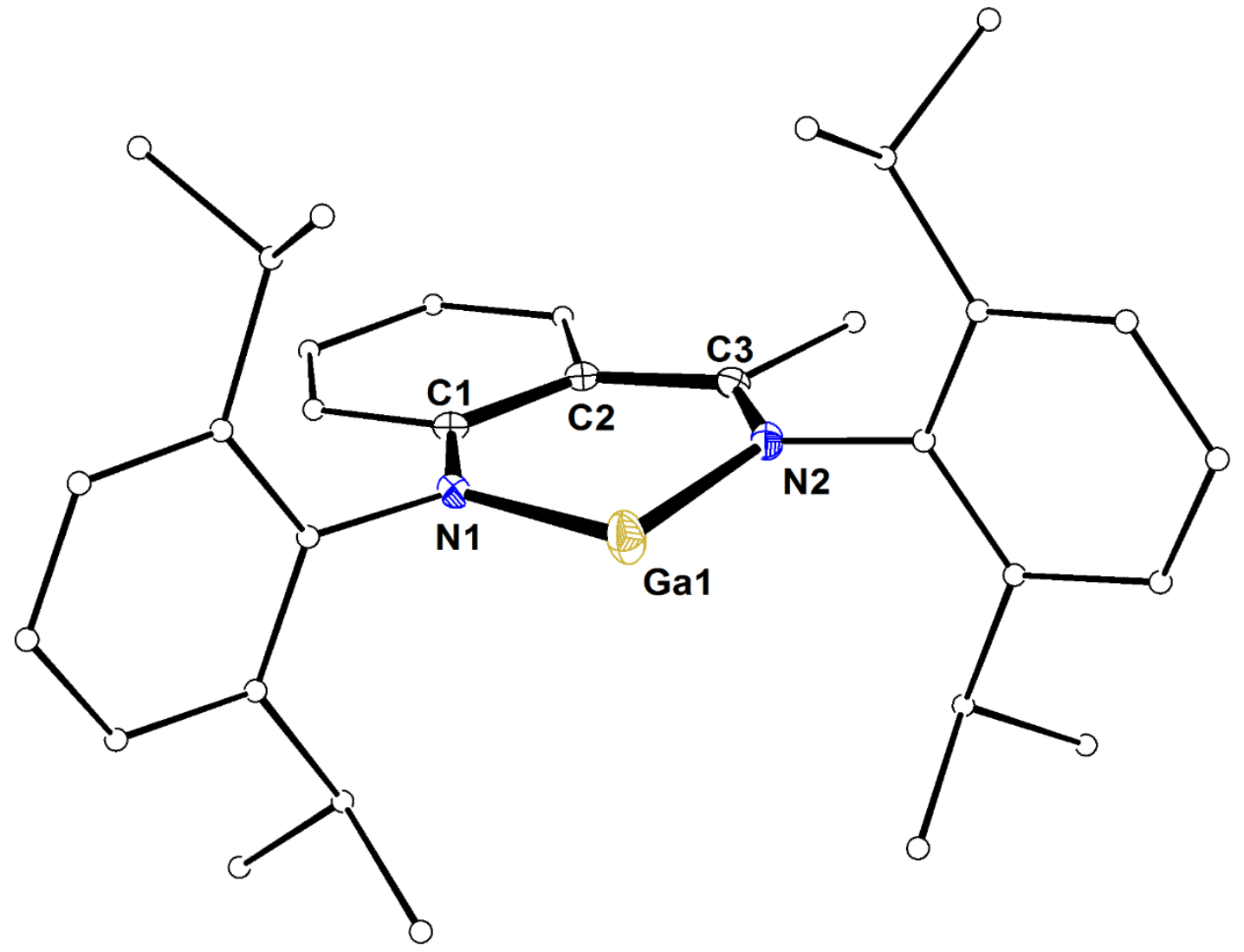

Figure 69: ORTEP plot of ArBDIDIPPGa 10. Ellipsoids at 30\%, $\mathrm{H}$ atoms and solvent omitted and selected $\mathrm{C}$ atoms in wire frame for clarity.

Table 6: Selected bond lengths and angles for $\operatorname{ArBDI}_{\mathrm{DIPP}} \mathrm{Ga} 10$.

\begin{tabular}{|c|c|c|c|}
\hline \multicolumn{2}{|c|}{ Bond Lengths ( $\AA$ ) } & \multicolumn{2}{|c|}{ Bond Angles ( $\left(^{\circ}\right)$} \\
\hline $\mathrm{a}(1)-\mathrm{N}(1)$ & $1.988(3)$ & $N(1)-G a(1)-N(2)$ & $85.0(1)$ \\
\hline$(1)-N(2)$ & $2.114(4)$ & $\mathrm{Ga}(1)-\mathrm{N}(1)-\mathrm{C}(1)$ & $133.5(3)$ \\
\hline 1)-C(1) & $1.365(6)$ & $\mathrm{Ga}(1)-\mathrm{N}(2)-\mathrm{C}(3)$ & $132.0(3)$ \\
\hline (2)-C(3) & $1.310(6)$ & $N(1)-C(1)-C(2)$ & $122.8(3)$ \\
\hline 1)-C(2) & $1.438(6)$ & $C(1)-C(2)-C(3)$ & $124.2(3)$ \\
\hline$(2)-C(3)$ & $1.450(5)$ & $C(2)-C(3)-N(2)$ & $122.4(3)$ \\
\hline
\end{tabular}




\subsubsection{Reaction of ArBDIDIPPGa with Trimethylsilyldiazomethane}

Addition of trimethylsilyldiazomethane 7 to $A r B D I_{D I P P G a} 10$ in toluene at $-30{ }^{\circ} \mathrm{C}$ (Scheme 18) resulted in the evolution of gas however, as with the previous attempt with $\mathrm{BDI}_{\mathrm{DIPP} G a} \mathbf{1}$, a 50:50 ratio of product:starting material was observed in the ${ }^{1} \mathrm{H}$ NMR spectrum. A second equivalent of trimethylsilyldiazomethane $\mathbf{7}$ was added to the reaction mixture and full consumption of the starting material was observed. Concentration of the solvent and cooling to $-30{ }^{\circ} \mathrm{C}$ yielded $\mathrm{ArBDI}_{\mathrm{DIPP}} \mathrm{Ga}\left(\mathrm{CH}_{2} \mathrm{SiMe}_{3}\right) \mathrm{NNCSiMe}_{3} \mathbf{4 0}$ as vivid yellow crystals suitable for $\mathrm{X}$-ray diffraction.

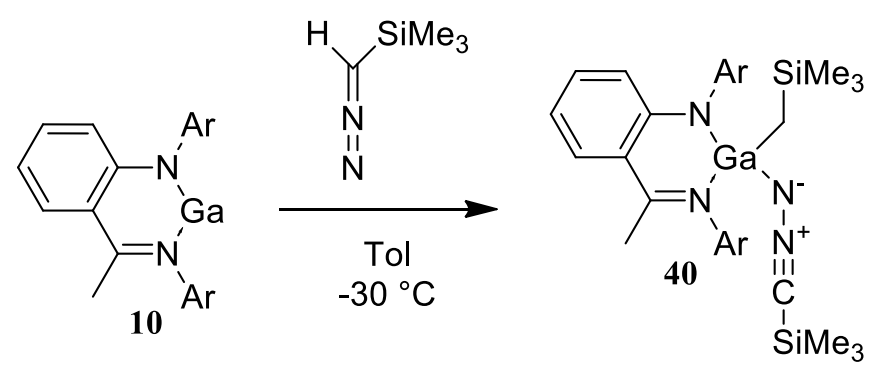

Scheme 18: Synthesis of $\mathrm{ArBDI}_{\mathrm{DIPP} G}\left(\mathrm{CH}_{2} \mathrm{SiMe}_{3}\right) \mathrm{NNCSiMe}_{3}$.

Unlike analogous complex $\mathbf{1 9}$, complex $\mathbf{4 0}$ appears to degrade in the solution state and liberate $\mathrm{ArBDI}_{\mathrm{DIPP}} \mathrm{H}$, complicating NMR analysis through the presence of the free ligand, however as the ligand signals are known the ${ }^{1} \mathrm{H}$ NMR spectrum can be mostly analysed. The asymmetry of $\mathbf{4 0}$ is visible in the ${ }^{1} \mathrm{H}$ NMR spectrum, with the backbone methyl resonance appearing as a singlet at $\delta 2.01 \mathrm{ppm}$, while eight doublet resonances appear each in a 1:1 ratio with the backbone methyl resonance at $\delta 1.75,1.71,1.43,1.36,1.34,1.29,1.05$, and $0.86 \mathrm{ppm}$ and four septet resonances are present at $\delta 3.73,3.52,3.39$, and $3.22 \mathrm{ppm}$ each in a 3:1 ratio with the backbone methyl resonance. This suggests that the isopropyl groups on the BDI ligand are restricted from rotating on an NMR timescale. The presence of two singlet resonances in a 3:9:9 ratio with the backbone methyl ligand at $\delta-0.01$ and $-0.19 \mathrm{ppm}$ corresponding to trimethylsilyl groups again supports that two equivalents of trimethylsilyldiazomethane $\mathbf{7}$ react with complex $\mathbf{1 0}$ to form 40. Further supporting the asymmetry in $\mathbf{4 0}$ is the $\mathrm{CH}_{2}$ unit appearing as two doublet resonances at $\delta-0.74$ and -0.84 
ppm as opposed to the singlet observed for complex 19. An X-ray diffraction study confirmed that $\mathbf{4 0}$ is asymmetric, with the amide-imide nature of the ligand creating two enantiomers of 40, and both $R$ and $S$ conformations are visible in the unit cell. The bond lengths and angles in the two molecules are nearly identical, so data for only one is listed in Table 7. While the bond lengths and angles in the ancillary ligand are expectedly different between complex $\mathbf{1 9}$ and 40, the lengths and angles of the NNCTMS and $\mathrm{CH}_{2} \mathrm{TMS}$ ligands are nearly identical, with the one exception being the $\mathrm{N}(4)-\mathrm{C}(37)-\mathrm{Si}(2)$ angle of $168.8(2)^{\circ}$ compared to $160.8(1)^{\circ}$ in complex 19. The amide-imide bonding is reflected in the Ga-N distances of 1.925(1) and 1.993(1) $\AA$ for $N(1)$ and $N(2)$ respectively, however this has not had the desired stabilising effect on the potential $\mathrm{Ga}=\mathrm{C}$ double bond intermediate, with the reactivity being identical to BDI DIPPGa. 


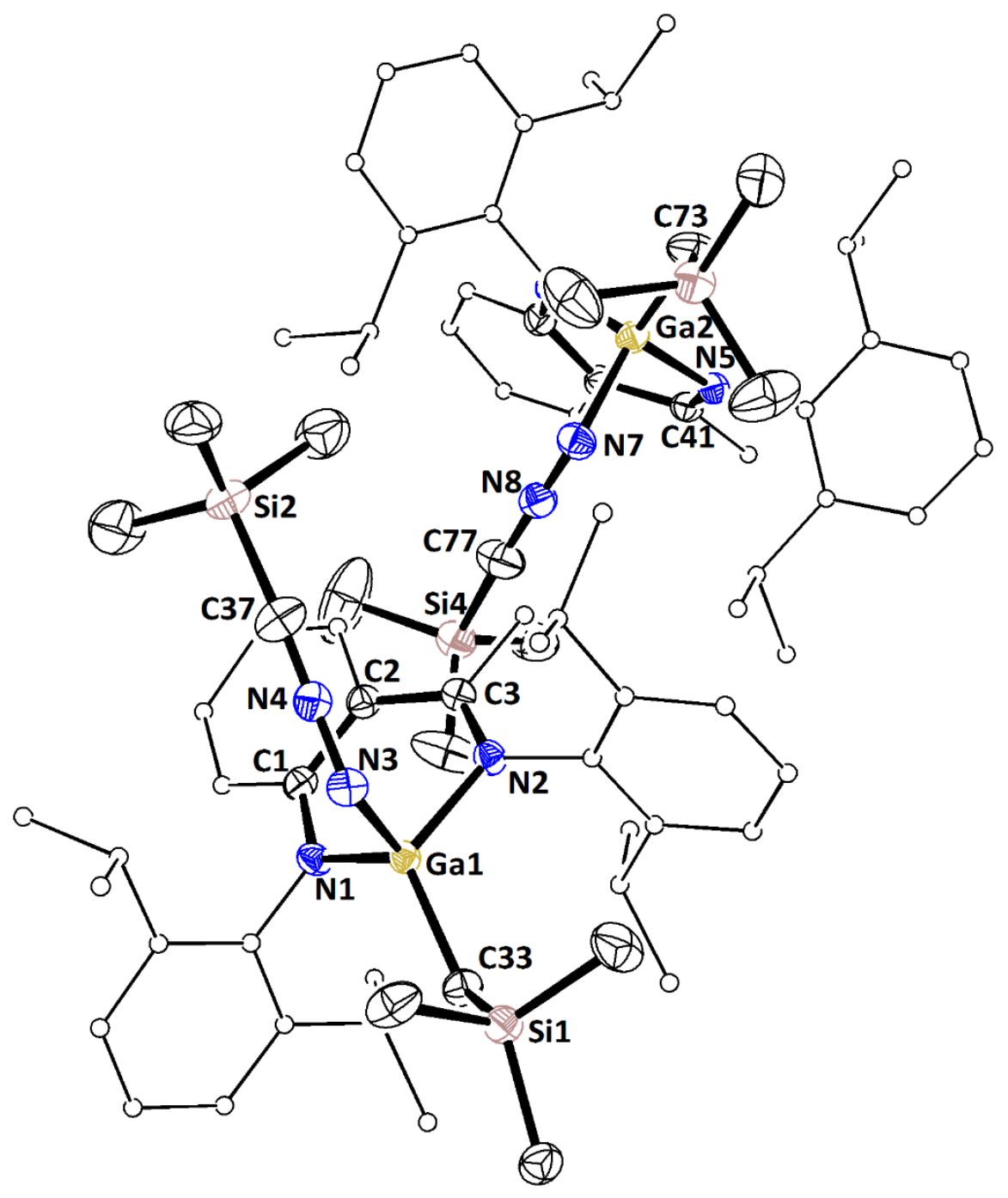

Figure 70: ORTEP plot of $\mathrm{ArBDI}_{\mathrm{DIPP}} \mathrm{Ga}\left(\mathrm{CH}_{2} \mathrm{SiMe}_{3}\right) \mathrm{NNCSiMe}_{3}$ 40. Ellipsoids at 30\%, $\mathrm{H}$ atoms and disorder in $\mathrm{Si}(3) \mathrm{Me}_{3}$ group omitted and selected $\mathrm{C}$ atoms in wire frame for clarity.

Table 7: Selected bond lengths and angles for $\mathrm{ArBDI}$ DIPPGa( $\left(\mathrm{CH}_{2} \mathrm{SiMe}_{3}\right) \mathrm{NNCSiMe}_{3} 40$.

\begin{tabular}{|c|c|c|c|}
\hline \multicolumn{2}{|c|}{ Bond Lengths ( $\mathrm{A})$} & \multicolumn{2}{|c|}{ Bond Angles $\left({ }^{\circ}\right)$} \\
\hline $\mathrm{Ga}(1)-\mathrm{N}(1)$ & $1.925(1)$ & $N(1)-G a(1)-N(2)$ & $92.67(6)$ \\
\hline $\mathrm{Ga}(1)-\mathrm{N}(2)$ & $1.993(1)$ & $\mathrm{Ga}(1)-\mathrm{N}(1)-\mathrm{C}(1)$ & $124.0(1)$ \\
\hline$N(1)-C(1)$ & $1.362(2)$ & $\mathrm{Ga}(1)-\mathrm{N}(2)-\mathrm{C}(3)$ & $124.6(1)$ \\
\hline$N(2)-C(3)$ & $1.315(2)$ & $N(1)-C(1)-C(2)$ & $123.2(2)$ \\
\hline$C(1)-C(2)$ & $1.439(3)$ & $C(1)-C(2)-C(3)$ & $125.0(2)$ \\
\hline$C(2)-C(3)$ & $1.459(2)$ & $C(2)-C(3)-N(2)$ & $122.3(2)$ \\
\hline $\mathrm{Ga}(1)-\mathrm{N}(3)$ & $1.904(2)$ & $\mathrm{Ga}(1)-\mathrm{C}(33)-\mathrm{Si}(1)$ & $120.7(1)$ \\
\hline$N(3)-N(4)$ & $1.241(2)$ & $\mathrm{Ga}(1)-\mathrm{N}(3)-\mathrm{N}(4)$ & $119.0(1)$ \\
\hline$N(4)-C(37)$ & $1.176(3)$ & $N(3)-N(4)-C(37)$ & $174.9(2)$ \\
\hline$C(37)-S i(2)$ & $1.824(2)$ & $N(4)-C(37)-S i(2)$ & $168.8(2)$ \\
\hline $\mathrm{Ga}(1)-\mathrm{C}(33)$ & $1.955(2)$ & & \\
\hline$C(33)-\operatorname{Si}(1)$ & $1.857(2)$ & & \\
\hline
\end{tabular}




\subsubsection{Synthesis of $\mathrm{BDI}_{\mathrm{Ar}} * \mathrm{Ga}$}

As two equivalents of diazo- compound reacted with both BDI ${ }_{D I P P G a} 1$ and ArBDIDIPPGa 10, a more sterically hindering ligand was thought to be the solution to this problem, with the goal of blocking the second equivalent of diazo- compound from being able to react with the presumed carbanion intermediate. The $\mathrm{BDI}_{\mathrm{Ar}}$ ligand was selected as the eight flanking phenyl groups of the ligand offer significantly more steric protection than the methyl groups of the $\mathrm{BDI}_{\mathrm{DIPP}}$ ligand. $\mathrm{BDI}_{\mathrm{Ar}^{*}-\mathrm{H}} 14$ was synthesised following literature procedure (Scheme 19), 120 treatment of the ligand $\mathbf{1 4}$ with $n$-butyllithium resulted in the formation of lithium salt $\mathbf{1 7}$, which was isolated and added to a solution of 'Gal' in toluene, resulting in the formation of an orange solution. Filtration of this solution through celite, concentrating to c.a. $10 \mathrm{~mL}$ and storing at $-30{ }^{\circ} \mathrm{C}$ yielded crystals of $\mathrm{BDI}_{\mathrm{Ar}} * \mathrm{Ga} \mathbf{1 1}$ suitable for analysis by $\mathrm{X}$-ray diffraction.
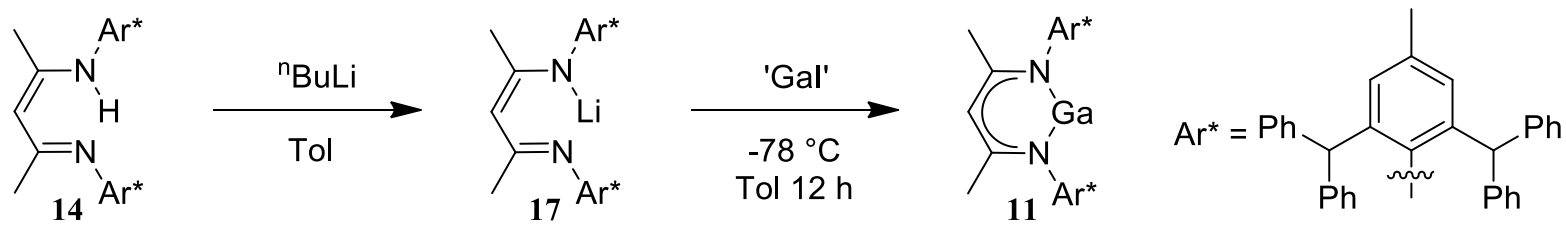

Scheme 19: Synthesis of $B D I_{A r} * G a$.

Analysis of 11 by ${ }^{1} \mathrm{H}$ NMR spectroscopy showed that the BDI $\gamma$-proton is significantly more shielded at $\delta 4.80 \mathrm{ppm}$ than that of BDIDIPPGa 1 ( $\delta 5.20 \mathrm{ppm})$, similarly the backbone methyl groups are also significantly more shielded at $\delta 1.02 \mathrm{ppm}$ than in $\mathbf{1}(\delta 1.72 \mathrm{ppm})$, though they are deshielded relative to ligand $\mathbf{1 4}(\delta 0.25 \mathrm{ppm})$. The presence of aromatic resonances in a ratio of 1:8:8:12:4:8:4 relative to the $\gamma$-proton indicate that the ligand is symmetric, along with the singlet resonance in a 1:4 ratio relative to the $\psi$-proton at $\delta 6.00 \mathrm{ppm}$ corresponding to the methine protons and singlet resonance in a 1:6 ratio relative to the $\psi$-proton at $\delta 1.93$ ppm corresponding to the methyl protons on the aromatic groups of the ancillary ligand. The X-ray diffraction study confirmed that the product was $\mathrm{BDI}_{\mathrm{Ar}} * \mathrm{Ga} 11$ and not the $\mathrm{BDI}_{\mathrm{Ar}} * \mathrm{Gal}_{2}$ byproduct also isolated from the reaction mixture. The Ga-N bond lengths of 2.072(2) and 2.074(2) A are slightly longer than those of $\mathbf{1}$ (2.053 and $2.056 \AA$ ) while the bite angle of the 
ligand is also slightly larger $\left(88.05(9)^{\circ}\right.$ compared to $87.5^{\circ}$ in $\left.\mathbf{1}\right)$. The NCCCN bond lengths and angles are nearly identical to those of $\mathbf{1}$ and the gallium atom sits in the plane of the ligand as with 1 and 10. Unfortunately, a large amount of disorder is present in the ligand and two toluene molecules of the asymmetric unit, and while one of the two solid state orientations of the ligand does effectively block the top face of the molecule, the other orientation does not, so the effectiveness of the ligand at blocking a second diazo- equivalent cannot be determined from the structure alone.

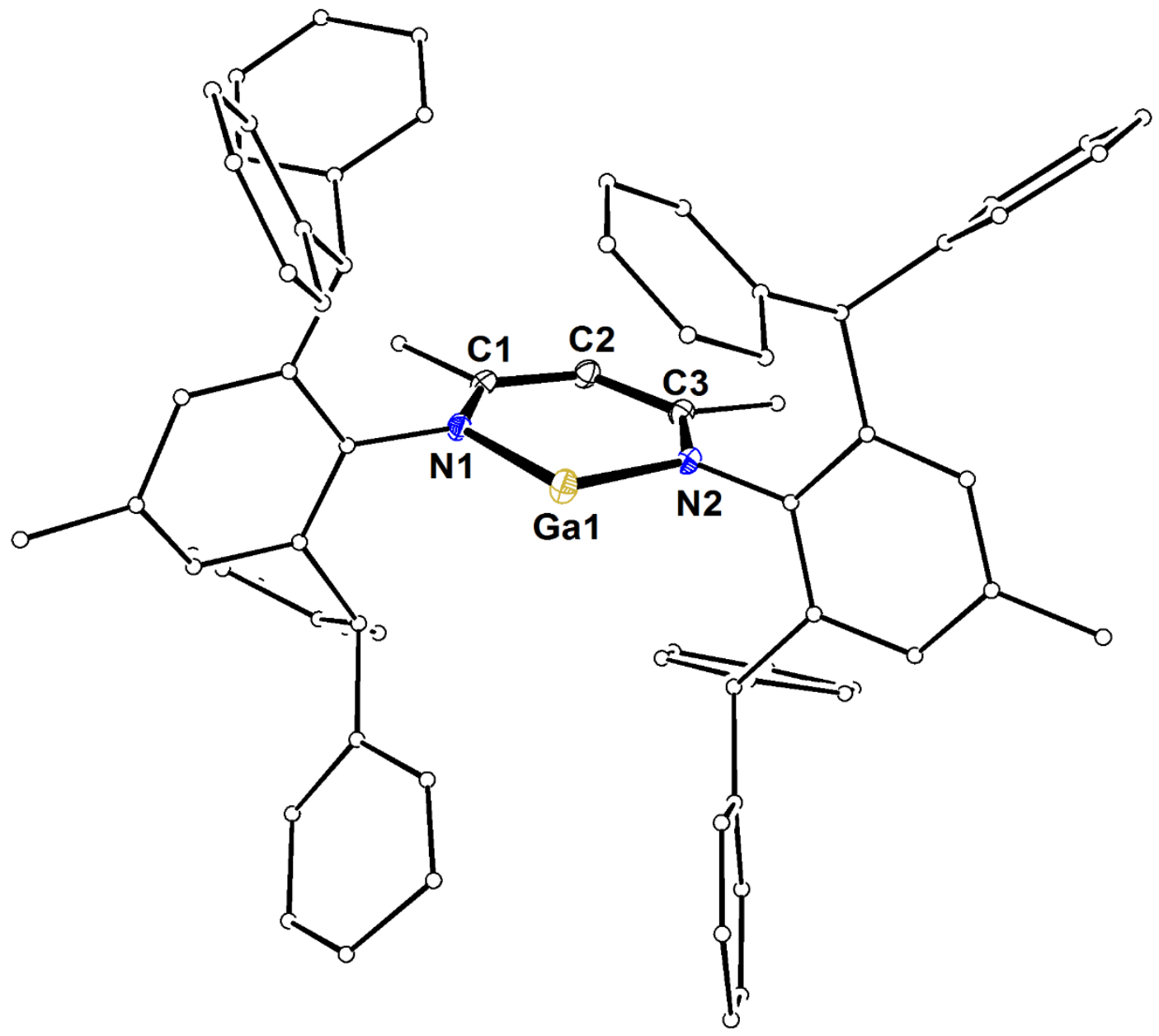

Figure 71: ORTEP plot of $\mathrm{BDI}_{\mathrm{Ar}} * \mathrm{Ga}$ 11. Ellipsoids at $30 \%, \mathrm{H}$ atoms, ligand disorder and solvent omitted and selected $\mathrm{C}$ atoms in wire frame for clarity. 
Table 8: Selected bond lengths and angles for $\mathrm{BDI}_{\mathrm{Ar} * \mathrm{Ga}} 11$.

\begin{tabular}{|c|c|c|c|}
\hline \multicolumn{2}{|c|}{ Bond Lengths ( $\AA$ ) } & \multicolumn{2}{|c|}{ Bond Angles $\left({ }^{\circ}\right)$} \\
\hline $\mathrm{Ga}(1)-\mathrm{N}(1)$ & $2.072(2)$ & $N(1)-G a(1)-N(2)$ & $88.05(9)$ \\
\hline $\mathrm{Ga}(1)-\mathrm{N}(2)$ & $2.074(2)$ & $\mathrm{Ga}(1)-\mathrm{N}(1)-\mathrm{C}(1)$ & $128.2(2)$ \\
\hline$N(1)-C(1)$ & $1.328(3)$ & $G a(1)-N(2)-C(3)$ & $127.9(2)$ \\
\hline$N(2)-C(3)$ & $1.333(3)$ & $N(1)-C(1)-C(2)$ & $123.3(2)$ \\
\hline$C(1)-C(2)$ & $1.404(4)$ & $C(1)-C(2)-C(3)$ & $128.5(2)$ \\
\hline$C(2)-C(3)$ & $1.400(4)$ & $C(2)-C(3)-N(2)$ & $123.4(2)$ \\
\hline
\end{tabular}

\subsubsection{Reaction of $\mathrm{BDI}_{\mathrm{Ar}} * \mathrm{Ga}$ with Trimethylsilyldiazomethane}

Addition of one equivalent of trimethylsilyldiazomethane 7 to $\mathbf{1 1}$ (Scheme 20) resulted in a near instant fading from the bright yellow colour of the starting materials to a very pale yellow. Unlike the reaction with $\mathbf{1}$ and 10, only one equivalent of $\mathbf{7}$ was needed for full consumption of $\mathbf{1 1}$ to be observed by ${ }^{1} \mathrm{H}$ NMR spectroscopy. Concentration of the solution and storage at $-30^{\circ} \mathrm{C}$ yielded colourless blocks, that upon investigation by ${ }^{1} \mathrm{H} N M R$ spectroscopy, possessed a broad resonance at $\delta 5.72 \mathrm{ppm}$, which is the typical chemical shift of a gallium hydride. ${ }^{224}$ This, coupled with no observable evolution of gas, indicated that a similar reaction to scandium complex XCI was occurring, where the metal centre was directly deprotonating the diazo- compound and forming a nitrilimine unit, an X-ray diffraction study

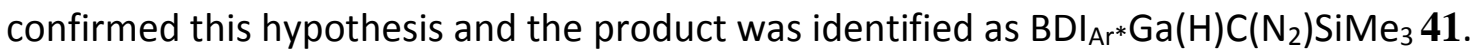

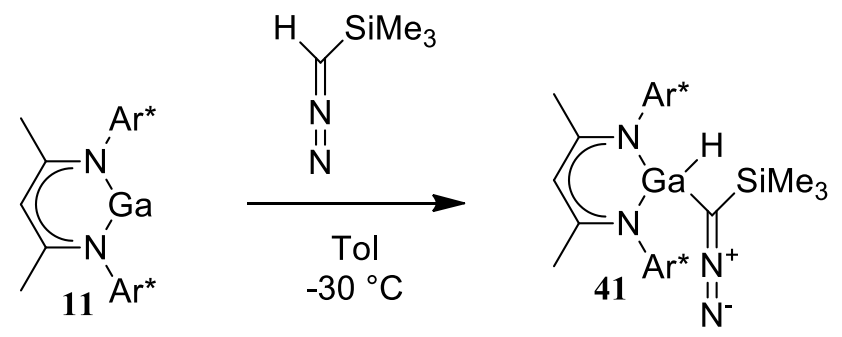

Scheme 20: Synthesis of $B_{D I} I_{A r} G a(H) C\left(N_{2}\right) S_{i M e}$.

A similar activation of the $\mathrm{C}-\mathrm{H}$ bond in the diazo- compound has been previously reported for the BDI germanium(II) complex CIV, in which the ligand deprotonated the diazo- 
compound and the resulting nitrilimine unit bound to the germanium centre to give complex CV (Figure 72). ${ }^{225}$ While the reactivity of gallium(I) has been investigated, complex $\mathbf{4 1}$ is the first instance of $\mathrm{C}-\mathrm{H}$ bond activation by gallium(I). It should be noted that the nitrilimine unit is typically installed on a metal centre via the lithium salt of trimethylsilyldiazomethane, whereas in complex $\mathbf{4 1}$ it can be directly formed.
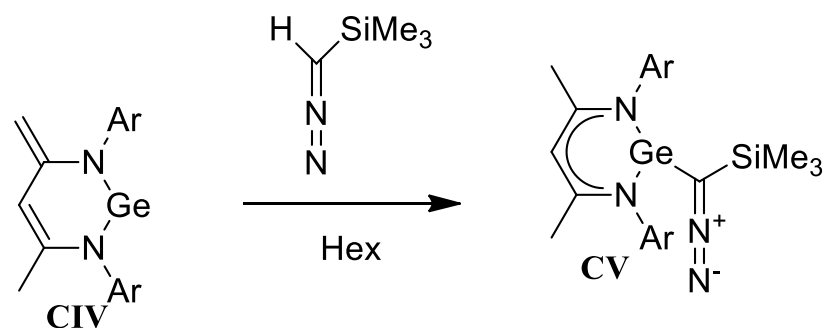

Figure 72: Reactivity of BDIGe(II) with trimethylsilyldiazomethane.

Complex 41 shows even more shielding of the BDI $\gamma$-proton ( $\delta 4.24 \mathrm{ppm}$ ) relative to $\mathbf{1 1}$ ( $\delta 4.80 \mathrm{ppm}$ ) while the backbone methyl substituents have lost the deshielding effect present in 11 ( $\delta 1.02 \mathrm{ppm}$ ) and now appear at $\delta 0.29 \mathrm{ppm}$, a similar shift to that observed in the free ligand 14 ( $\delta 0.25 \mathrm{ppm})$. The $\mathrm{Ga}-\mathrm{H}$ resonance appears at $\delta 5.72 \mathrm{ppm}$ as a broad signal, similar to the $\delta 5.49$ ppm shift observed in $\mathrm{BDI}_{\mathrm{DIPP}} \mathrm{Ga}(\mathrm{Me}) \mathrm{H}$, and deshielded relative to $\mathrm{BDI}_{\mathrm{DIPP}} \mathrm{GaH}_{2}(\delta$ $4.58 \mathrm{ppm}) .{ }^{224}$ An X-ray diffraction study of $\mathbf{4 1}$ shows a short $\mathrm{N}-\mathrm{N}$ bond distance in the nitrilimine unit of 1.163(3) $\AA$, which is in the realm of $\mathrm{N}-\mathrm{N}$ triple bond lengths, presumably due to the $\mathrm{N}^{+}-\mathrm{N}^{-}$attraction shortening the bond. One of the most interesting structural features of 41 is that the gallium, while tetrahedral, still sits within the NCCCN plane of the ligand, which is rare for four-coordinate BDI-gallium(III) complexes; this planar geometry has only been observed in the dihydride complexes $\left(\mathrm{BDIGaH}_{2}\right) .224,226-227$ There is a significantly increased bite angle of the ligand from $88.05(9)^{\circ}$ in 11 to $97.97(6)^{\circ}$ in 41 , along with the reduction in Ga-N bond length from 2.072(2)/2.074(2) $\AA$ in 11 to 1.961(2)/1.937(1) $\AA$ in 41. This data indicates that the $\mathrm{BDI}_{\mathrm{Ar}}$ ligand imposes a different conformational arrangement on the gallium centre than observed in other BDI-gallium(III) complexes, which is unusual as even 
a methyl substituent $\left(\mathrm{BDI}_{\mathrm{DIPP}} \mathrm{Ga}(\mathrm{H}) \mathrm{Me}\right)$ results in the gallium centre sitting out of the plane of the ligand. ${ }^{224}$

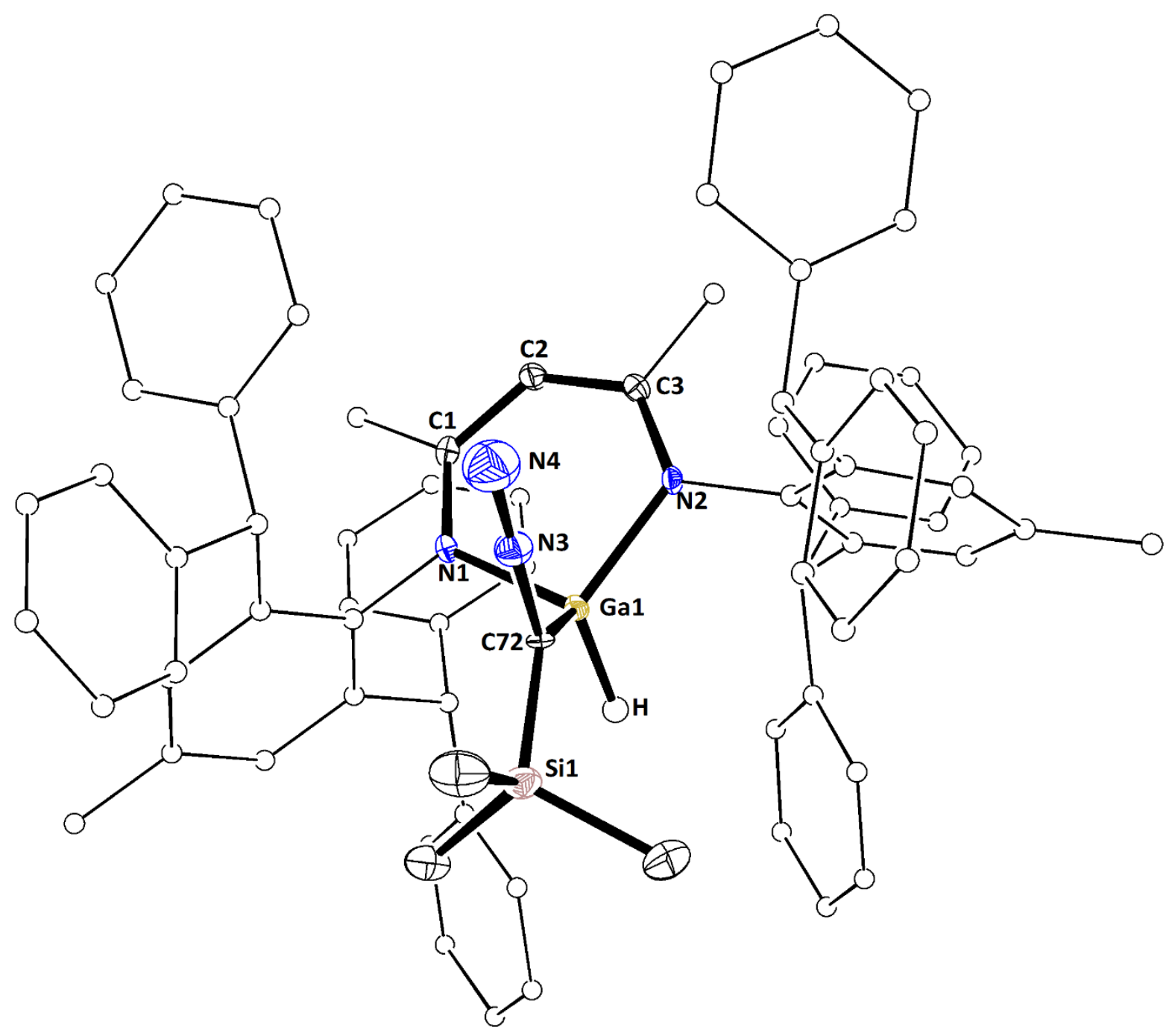

Figure 73: ORTEP plot of $\mathrm{BDI}_{\mathrm{Ar}} * \mathrm{Ga}(\mathrm{H}) \mathrm{C}\left(\mathrm{N}_{2}\right) \mathrm{SiMe}_{3}$ 41. Ellipsoids at $30 \%, \mathrm{H}$ atoms omitted and selected $\mathrm{C}$ atoms in wire frame for clarity. 
Table 9: Selected bond lengths and angles for $B D I_{A r} * G a(H) C\left(N_{2}\right) S_{i M e} 41$.

\begin{tabular}{|c|c|c|c|}
\hline \multicolumn{2}{|c|}{ Bond Lengths ( $\AA$ ) } & \multicolumn{2}{|c|}{ Bond Angles ( $\left(^{\circ}\right)$} \\
\hline $\mathrm{Ga}(1)-\mathrm{N}(1)$ & $1.961(2)$ & $N(1)-G a(1)-N(2)$ & $97.97(6)$ \\
\hline $\mathrm{Ga}(1)-\mathrm{N}(2)$ & $1.937(1)$ & $\mathrm{Ga}(1)-N(1)-C(1)$ & $122.4(1)$ \\
\hline$N(1)-C(1)$ & $1.325(2)$ & $\mathrm{Ga}(1)-\mathrm{N}(2)-\mathrm{C}(3)$ & $121.8(1)$ \\
\hline$N(2)-C(3)$ & $1.346(3)$ & $N(1)-C(1)-C(2)$ & $123.3(2)$ \\
\hline$C(1)-C(2)$ & $1.407(2)$ & $C(1)-C(2)-C(3)$ & $129.7(2)$ \\
\hline$C(2)-C(3)$ & $1.388(3)$ & $C(2)-C(3)-N(2)$ & $124.4(2)$ \\
\hline $\mathrm{Ga}(1)-\mathrm{C}(72)$ & $1.903(2)$ & $\mathrm{Ga}(1)-\mathrm{C}(72)-\mathrm{Si}(1)$ & $124.32(9)$ \\
\hline$N(3)-C(72)$ & $1.357(2)$ & $\mathrm{Ga}(1)-\mathrm{C}(72)-\mathrm{N}(3)$ & 118.1(1) \\
\hline$N(3)-N(4)$ & $1.163(3)$ & $N(4)-N(3)-C(72)$ & $178.1(2)$ \\
\hline$C(72)-S i(1)$ & $1.759(2)$ & $\mathrm{H}-\mathrm{Ga}(1)-\mathrm{C}(72)$ & $107(1)$ \\
\hline \multirow[t]{4}{*}{$\mathrm{Ga}(1)-\mathrm{H}$} & $1.44(2)$ & $\mathrm{H}-\mathrm{Ga}(1)-\mathrm{N}(1)$ & $114(1)$ \\
\hline & & H-Ga(1)-N(2) & 116(1) \\
\hline & & $N(1)-G a(1)-C(72)$ & $109.84(7)$ \\
\hline & & $N(2)-G a(1)-C(72)$ & $112.33(7)$ \\
\hline
\end{tabular}

The insertion of $\mathbf{1 1}$ into the $\mathrm{C}-\mathrm{H}$ bond of the diazo- group was unexpected, though not entirely unprecedented as both $\mathrm{N}-\mathrm{H}$ and $\mathrm{O}-\mathrm{H}$ bonds have been activated by BDIDIPpGa. However, this does call into question the proposed mechanism of formation of the other observed results, as no carbanion was isolated, and potentially the mechanism of formation involves a gallium hydride intermediate $\mathbf{4 2}$ instead (Scheme 21). The migration of the hydride from the gallium to a carbon would likely require a carbocation intermediate $\mathbf{4 3}$ instead of a carbanion, which can be rationalised as forming through deprotonation of the second equivalent of diazomethane by the carbon atom of the first, elimination of $\mathrm{N}_{2}$ gas followed by hydride migration to the formed carbocation and co-ordination of the nitrogen of the deprotonated diazomethane unit $\mathbf{4 4}$ to the gallium centre. However, this mechanism seems unlikely due to the secondary carbocation intermediate which are typically unstable, though the silicon and gallium are both electron donating so may stabilise such a species. Attempts to study the mechanism by NMR were again hampered by the speed of the reaction, with complete conversion being observed by ${ }^{1} \mathrm{H}$ NMR spectroscopy in $<1$ minute, even if the reaction mixture was cooled to $-78^{\circ} \mathrm{C}$ prior to analysis. 


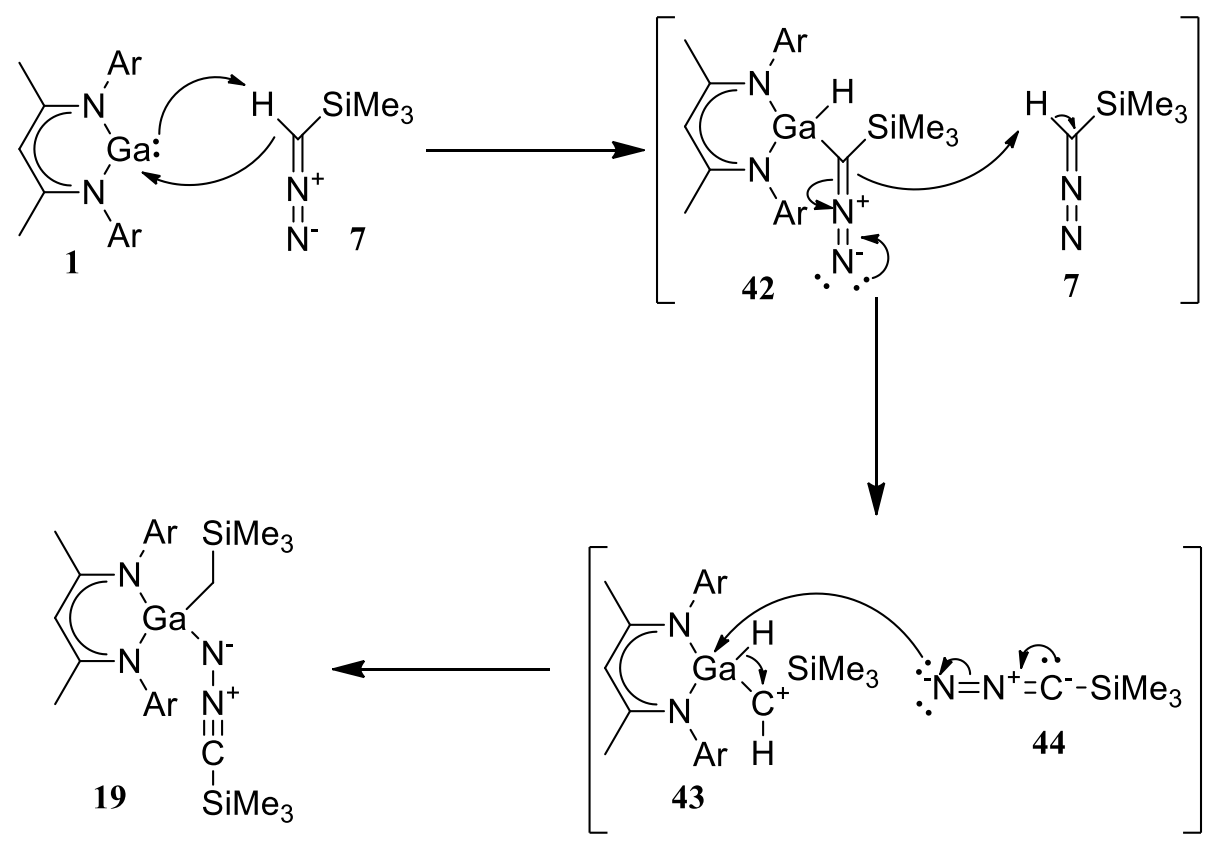

Scheme 21: $\mathrm{BDI}_{\mathrm{DIPP} G a}\left(\mathrm{CH}_{2} \mathrm{SiMe}_{3}\right) \mathrm{NNCSiMe}_{3}$ formation via carbocation.

\subsubsection{Synthesis of $\mathrm{BDI}_{\mathrm{Ar}} \mathrm{Ga}$}

As the $\mathrm{BDI}_{\mathrm{Ar}}$ ligand had proven successful at blocking a second equivalent of diazocompound from reacting and provided an example of $\mathrm{C}-\mathrm{H}$ bond activation by a gallium(I) complex, the slightly more sterically hindering $\mathrm{BDI}_{\mathrm{Ar}}$ ligand was chosen to investigate if this $\mathrm{C}-\mathrm{H}$ bond activation could be reproduced. $\mathrm{BDI}_{\mathrm{Ar}}-\mathrm{H} 15$ was synthesised by adapting the literature procedure used in the synthesis of $\mathrm{BDI}_{\mathrm{Ar} *-\mathrm{H}} .{ }^{120}$ Substituting 4-methylaniline for 4tert-butylaniline resulted in the isolation of $\mathrm{BDI}_{\mathrm{Ar}^{\prime}-\mathrm{H}}(\mathbf{1 5})$, as colourless crystals. X-ray diffraction confirmed that the diketiminate form of the ligand had been isolated as opposed to the diimine form, the unit cell of $\mathbf{1 5}$ possessing five discrete toluene molecules emphasising the degree of $\pi$-stacking the ligand can undergo. The ligand $\mathbf{1 5}$ was converted to lithium salt 18 by addition of $n$-butyllithium (Scheme 22), the lithium salt was isolated and added to a solution of 'Gal' at $-78{ }^{\circ} \mathrm{C}$ in toluene, subsequent workup, concentration of the solution and storage at $-30{ }^{\circ} \mathrm{C}$ gave $\mathrm{BDI}_{\mathrm{Ar}} \mathrm{Ga} \mathbf{1 2}$ as yellow crystals. 
$\sum_{15}^{N} N^{A}{ }^{\prime} r^{\prime}$

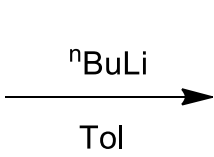

Tol

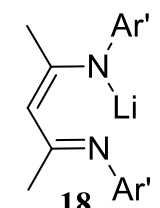

$18 \mathrm{Ar}^{\prime}$

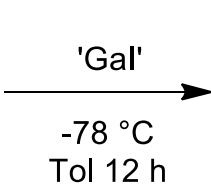

Tol $12 \mathrm{~h}$<smiles></smiles><smiles>CC(C)(C)c1cc(C(c2ccccc2)c2ccccc2)c(C(C)(C)C)c(C(c2ccccc2)c2ccccc2)c1</smiles>

Scheme 22: Synthesis of BDI $\mathrm{Ar}^{\prime} \mathrm{Ga}$.

Analysis of 12 by ${ }^{1} \mathrm{H}$ NMR spectroscopy revealed near identical resonances to those in complex 11, with BDI $\gamma$-proton resonances of $\delta 4.80$ in both complexes, with the only distinction being the change from the methyl peak at $\delta 1.93 \mathrm{ppm}$ in $\mathbf{1 1}$ to the ${ }^{\mathrm{t}} \mathrm{Bu}$ peak at $\delta$ $1.15 \mathrm{ppm}$ in 12. X-ray diffraction analysis confirms that the isolated product is $\mathrm{BDI}_{\mathrm{Ar}} \mathrm{Ga} \mathbf{1 2}$ rather than the alternative $\mathrm{BDI}_{\mathrm{Ar}} \mathrm{Gal}_{2}$ by-product which can also be isolated from the reaction. The ligand possesses a bite angle of $87.3(1)^{\circ}$, narrower than that of $87.5^{\circ}$ and $88.05(9)^{\circ}$ for $\mathrm{BDI}_{\mathrm{DIPPG}} 1$ and $\mathrm{BDI}_{\mathrm{Ar}} * \mathrm{Ga} 11$ respectively. Again, the gallium sits within the NCCCN plane of the ligand in accordance with the other BDI gallium(I) complexes. The solid state structure shows the flanking phenyl substituents crowding both the top and bottom face of the complex, indicating that, as with complex 11, a second equivalent of diazo- compound should not be able to coordinate to the gallium centre. 


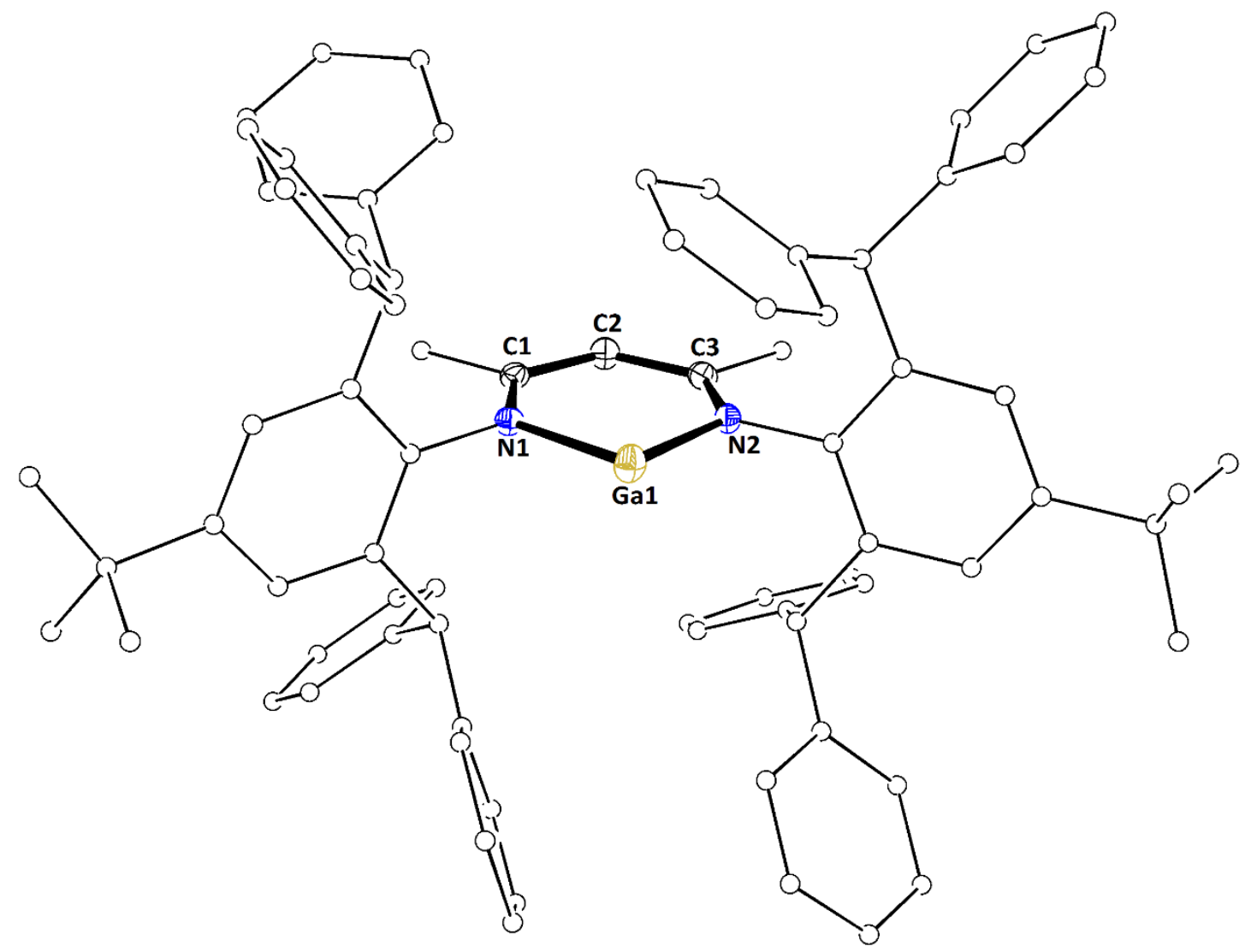

Figure 74: ORTEP plot of $\mathrm{BDI}_{A r^{\prime}} \mathrm{Ga}$ 12. Ellipsoids at $30 \%, \mathrm{H}$ atoms omitted and selected $\mathrm{C}$ atoms in wire frame for clarity.

Table 10: Selected bond lengths and angles for $B D I_{A r^{\prime}} G a 12$.

\begin{tabular}{llll}
\multicolumn{3}{c}{ Bond Lengths (立) } & \multicolumn{2}{c}{ Bond Angles ( ${ }^{\circ}$ ) } \\
$\mathrm{Ga}(1)-\mathrm{N}(1)$ & $2.081(3)$ & $\mathrm{N}(1)-\mathrm{Ga}(1)-\mathrm{N}(2)$ & $87.3(1)$ \\
$\mathrm{Ga}(1)-\mathrm{N}(2)$ & $2.076(3)$ & $\mathrm{Ga}(1)-\mathrm{N}(1)-\mathrm{C}(1)$ & $129.1(2)$ \\
$\mathrm{N}(1)-\mathrm{C}(1)$ & $1.334(5)$ & $\mathrm{Ga}(1)-\mathrm{N}(2)-\mathrm{C}(3)$ & $128.1(2)$ \\
$\mathrm{N}(2)-\mathrm{C}(3)$ & $1.340(5)$ & $\mathrm{N}(1)-\mathrm{C}(1)-\mathrm{C}(2)$ & $122.7(3)$ \\
$\mathrm{C}(1)-\mathrm{C}(2)$ & $1.401(5)$ & $\mathrm{C}(1)-\mathrm{C}(2)-\mathrm{C}(3)$ & $128.5(3)$ \\
$\mathrm{C}(2)-\mathrm{C}(3)$ & $1.393(5)$ & $\mathrm{C}(2)-\mathrm{C}(3)-\mathrm{N}(2)$ & $123.7(3)$
\end{tabular}

\subsubsection{Reaction of $\mathrm{BDI}_{\mathrm{Ar}}$ Ga with Trimethylsilyldiazomethane}

Addition of one equivalent of trimethylsilyldiazomethane 7 slowly to a toluene solution of 12 (Scheme 23) once again lead to the bright yellow colour fading nearly instantly to give a pale yellow solution and no observable evolution of gas. As with the reaction of 11, full consumption of 12 was observed by ${ }^{1} \mathrm{H}$ NMR spectroscopy upon addition of only one 
equivalent of 7 . Concentration of the reaction mixture and storage at $-30{ }^{\circ} \mathrm{C}$ lead to the formation of colourless crystals of $\mathrm{BDI}_{\mathrm{Ar}} \mathrm{Ga}(\mathrm{H}) \mathrm{C}\left(\mathrm{N}_{2}\right) \mathrm{SiMe}_{3} 45$.

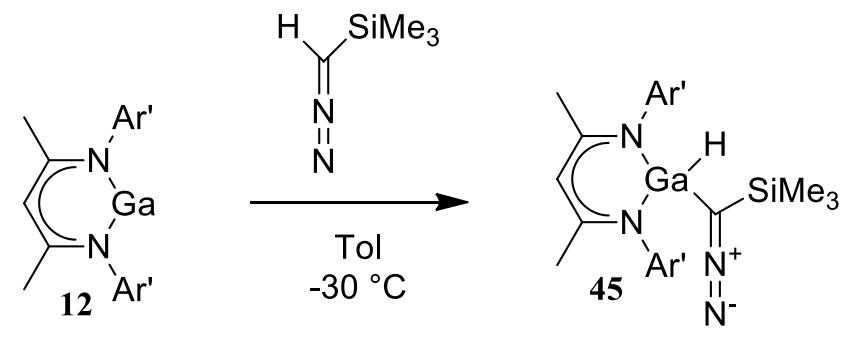

Scheme 23: Synthesis of $B D I_{A r} \mathrm{Ga}(\mathrm{H}) \mathrm{C}\left(\mathrm{N}_{2}\right) \mathrm{SiMe}_{3}$.

As with complex 41, the insertion of the gallium into the $\mathrm{C}-\mathrm{H}$ bond of the diazo- compound was confirmed in the ${ }^{1} \mathrm{H}$ NMR spectrum by the presence of a broad hydride peak at $\delta 5.72$ $\mathrm{ppm}$ in a 1:0.7 ratio with the $\psi$-proton, and the presence of a singlet resonance at $\delta 1.09 \mathrm{ppm}$ in a 1:18 ratio corresponding to the ${ }^{\mathrm{t}} \mathrm{Bu}$ groups indicated that the product had the same symmetry as complex 41. The BDI $\gamma$-proton of $\mathbf{4 5}$ is once again shielded at $\delta 4.27 \mathrm{ppm}$ relative to 12 ( $\delta 4.80 \mathrm{ppm})$ as are the singlet resonances at $\delta 0.34 \mathrm{ppm}$ in a 1:6 ratio the correspond to the backbone methyl groups. The X-ray diffraction study of $\mathbf{4 5}$ shows that the ligand possesses an almost identical bite angle of $97.8(1)^{\circ}$ compared to $97.97(6)^{\circ}$ in the $\mathrm{BDI}_{\mathrm{Ar}}$ variant 41, as well as comparable bond lengths and angles in the ligand backbone and the nitrilimine ligand. Again, the nitrilimine unit contains a very short (1.162(5) $\AA$ ) N-N bond due to the $\mathrm{N}^{+}-$ $\mathrm{N}^{-}$resonance form of the nitrilimine unit being preferred. Further analysis of the X-ray diffraction study was hindered by disorder present in both the TMS group and the ligand. Changing from ligand $\mathbf{1 4}$ to ligand $\mathbf{1 5}$ did not have the desired effect of slowing the reaction rate sufficiently to see if there is an intermediary in the reaction, such as the diazomethane unit coordinated to the gallium(I) centre, and unfortunately the full conversion is observed by ${ }^{1} \mathrm{H}$ NMR spectroscopy in $<1$ minute. 


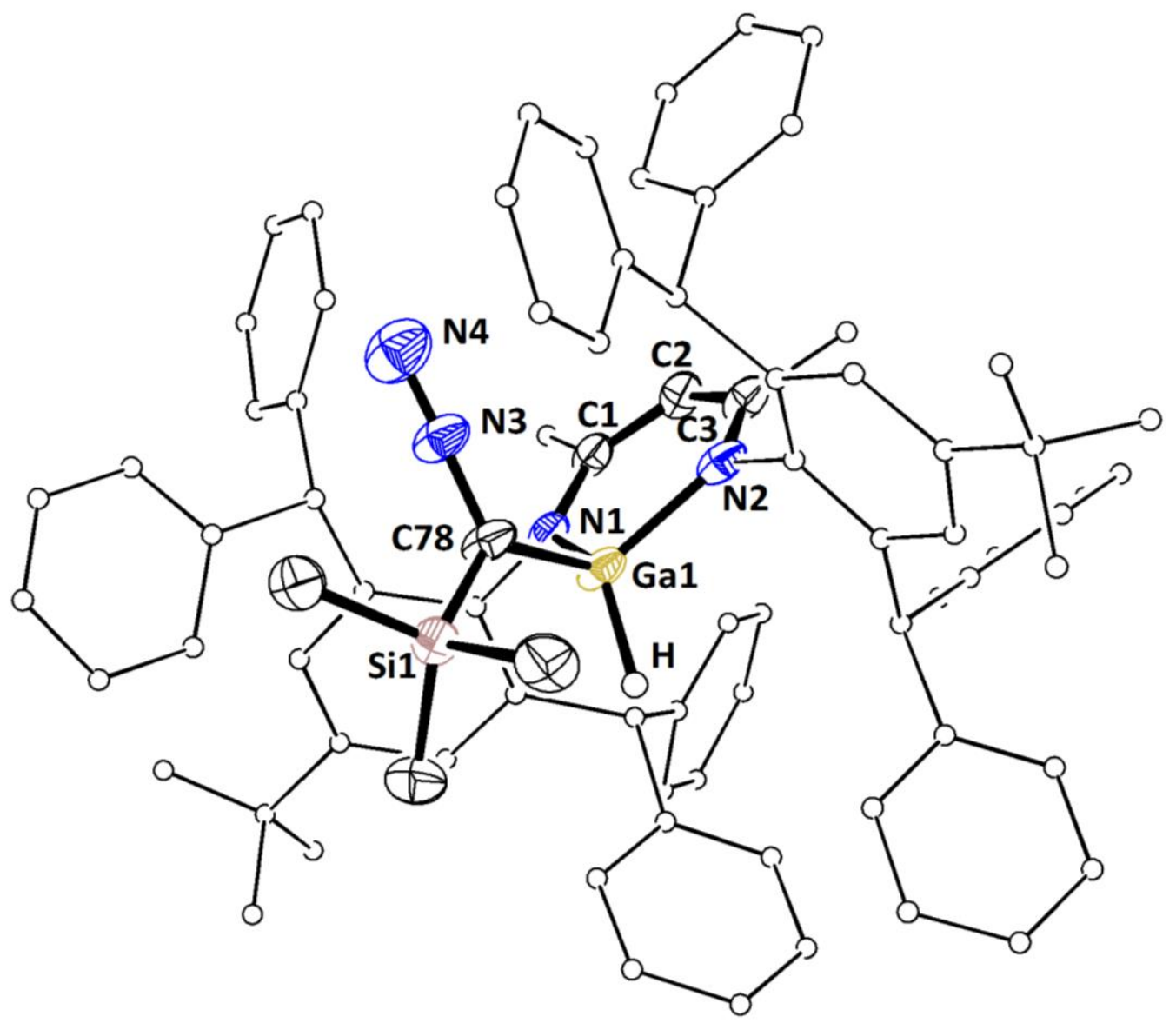

Figure 75: ORTEP plot of $\mathrm{BDI}_{\mathrm{Ar}} \mathrm{Ga}(\mathrm{H}) \mathrm{C}\left(\mathrm{N}_{2}\right) \mathrm{SiMe}_{3}$ 45. Ellipsoids at $30 \%, \mathrm{H}$ atoms, solvent and disorder in the $\mathrm{SiMe}_{3}$ and ${ }^{\mathrm{t}} \mathrm{Bu}$ group omitted, and selected $\mathrm{C}$ atoms in wire frame for clarity.

Table 11: Selected bond lengths and angles for $\mathrm{BDI} \mathrm{Ar}_{\mathrm{A}} \mathrm{Ga}(\mathrm{H}) \mathrm{C}\left(\mathrm{N}_{2}\right) \mathrm{SiMe}_{3} 45$.

\begin{tabular}{|c|c|c|c|}
\hline \multicolumn{2}{|c|}{ Bond Lengths $(\AA)$} & \multicolumn{2}{|c|}{ Bond Angles $\left({ }^{\circ}\right)$} \\
\hline $\mathrm{Ga}(1)-\mathrm{N}(1)$ & $1.937(3)$ & $N(1)-G a(1)-N(2)$ & $97.8(1)$ \\
\hline $\mathrm{Ga}(1)-\mathrm{N}(2)$ & $1.954(3)$ & $\mathrm{Ga}(1)-\mathrm{N}(1)-\mathrm{C}(1)$ & $122.3(2)$ \\
\hline$N(1)-C(1)$ & $1.345(5)$ & $\mathrm{Ga}(1)-N(2)-C(3)$ & $122.8(2)$ \\
\hline$N(2)-C(3)$ & $1.343(5)$ & $N(1)-C(1)-C(2)$ & $123.7(3)$ \\
\hline$C(1)-C(2)$ & $1.390(5)$ & $C(1)-C(2)-C(3)$ & $130.6(3)$ \\
\hline$C(2)-C(3)$ & $1.401(6)$ & $C(2)-C(3)-N(2)$ & $122.4(3)$ \\
\hline $\mathrm{Ga}(1)-\mathrm{C}(78)$ & $1.913(4)$ & $\mathrm{Ga}(1)-\mathrm{C}(78)-\mathrm{Si}(1)$ & $125.7(2)$ \\
\hline$N(3)-C(78)$ & $1.354(5)$ & $\mathrm{Ga}(1)-\mathrm{C}(78)-\mathrm{N}(3)$ & $118.7(3)$ \\
\hline$N(3)-N(4)$ & $1.162(5)$ & $N(4)-N(3)-C(78)$ & $178.1(4)$ \\
\hline$C(78)-S i(1)$ & $1.771(4)$ & $\mathrm{H}-\mathrm{Ga}(1)-\mathrm{C}(78)$ & $105(1)$ \\
\hline $\mathrm{Ga}(1)-\mathrm{H}$ & $1.47(4)$ & & \\
\hline
\end{tabular}




\subsubsection{Reaction of $\mathrm{BDI}_{\mathrm{Ar}} * \mathrm{Ga}$ with Diazofluorene}

With the $\mathrm{Ar}^{*}$ ligand successfully blocking the second equivalent of diazomethane from reacting with the gallium(I), but the $\alpha$-proton of trimethylsilyldiazomethane reacting instead of carbene formation via loss of $\mathrm{N}_{2}$, a new approach was attempted. As the reaction between

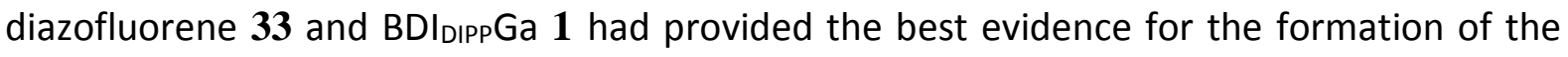
desired gallium-carbon double bonded complex, and diazofluorene lacks both $\alpha$ and $\beta$ protons, its reactivity with $\mathbf{1 1}$ was investigated. Addition of a solution of diazofluorene to a solution of $\mathbf{1 1}$ in toluene resulted in the yellow colour of the solution fading. The concentration of the reaction mixture and storage in the freezer at $-30{ }^{\circ} \mathrm{C}$ lead to the formation of colourless crystals of $\mathrm{BDI_{Ar } * G a N}(H) N F I 46$.
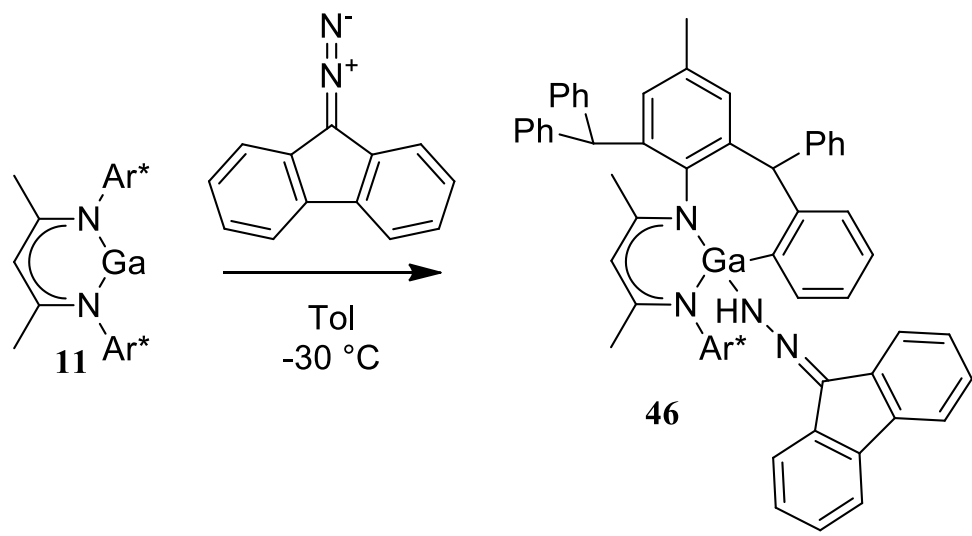

Scheme 24: Synthesis of $B D I_{A r} * G a N(H) N F I$.

The ${ }^{1} \mathrm{H}$ NMR spectrum of $\mathbf{4 6}$ reveals the $\gamma$-proton resonance at $\delta 4.57 \mathrm{ppm}$, shifted upfield compared to 11 ( $\delta 4.79 \mathrm{ppm}$ ) but not to the same extent as 41 ( $\delta 4.24 \mathrm{ppm})$. Four singlet resonances each in a 1:3 ratio to the $\psi$-proton at $\delta 1.80,1.74,1.37$ and 0.38 ppm correspond to the methyl protons on the aromatic groups and the methyl protons of the backbone of the ancillary ligand. Four singlet resonances each in a 1:1 ratio to the $\psi$-proton at $\delta 7.20,6.86$, 6.46 and $6.02 \mathrm{ppm}$ correspond to the methine protons of the ancillary ligand, and support that the symmetry of the ligand has been lost, with each one in a different environment. $A$ singlet resonance in a 1:1 ratio to the $\gamma$-proton at $\delta 7.80 \mathrm{ppm}$ with no correlations in the HSQC 
spectrum is assigned to the $\mathrm{N}-\mathrm{H}$ proton. The X-ray diffraction study shows that the gallium again remains in the NCCCN plane of the ligand, with N-Ga bond lengths of 1.945(2)/1.948(2) $\AA ̊$ and a bite angle of $98.07(7)^{\circ}$, comparable to $41\left(1.961(2) / 1.937(1) \AA\right.$ and $\left.97.97(6)^{\circ}\right)$. The Ga$\mathrm{N}(3)$ bond length of $1.888(3) \AA, N-N$ bond length of $1.305(3) \AA$ and $N-C$ bond length of $1.302(4)$ $\AA$ are consistent with a shortened N-N single bond and lengthened N-C double bond, indicating that the bonding may have an allylic component. The Ga-C bond length of 1.973(2) $\AA$ is longer than that observed in $\mathbf{1 9}(1.955(2) \AA)$, shorter than that observed $\mathbf{4 0}(2.048(2) \AA)$, and forms part a seven-membered ring system in which the gallium has formed a bond with one of the ortho- carbon atoms of a phenyl group of the ancillary ligand.

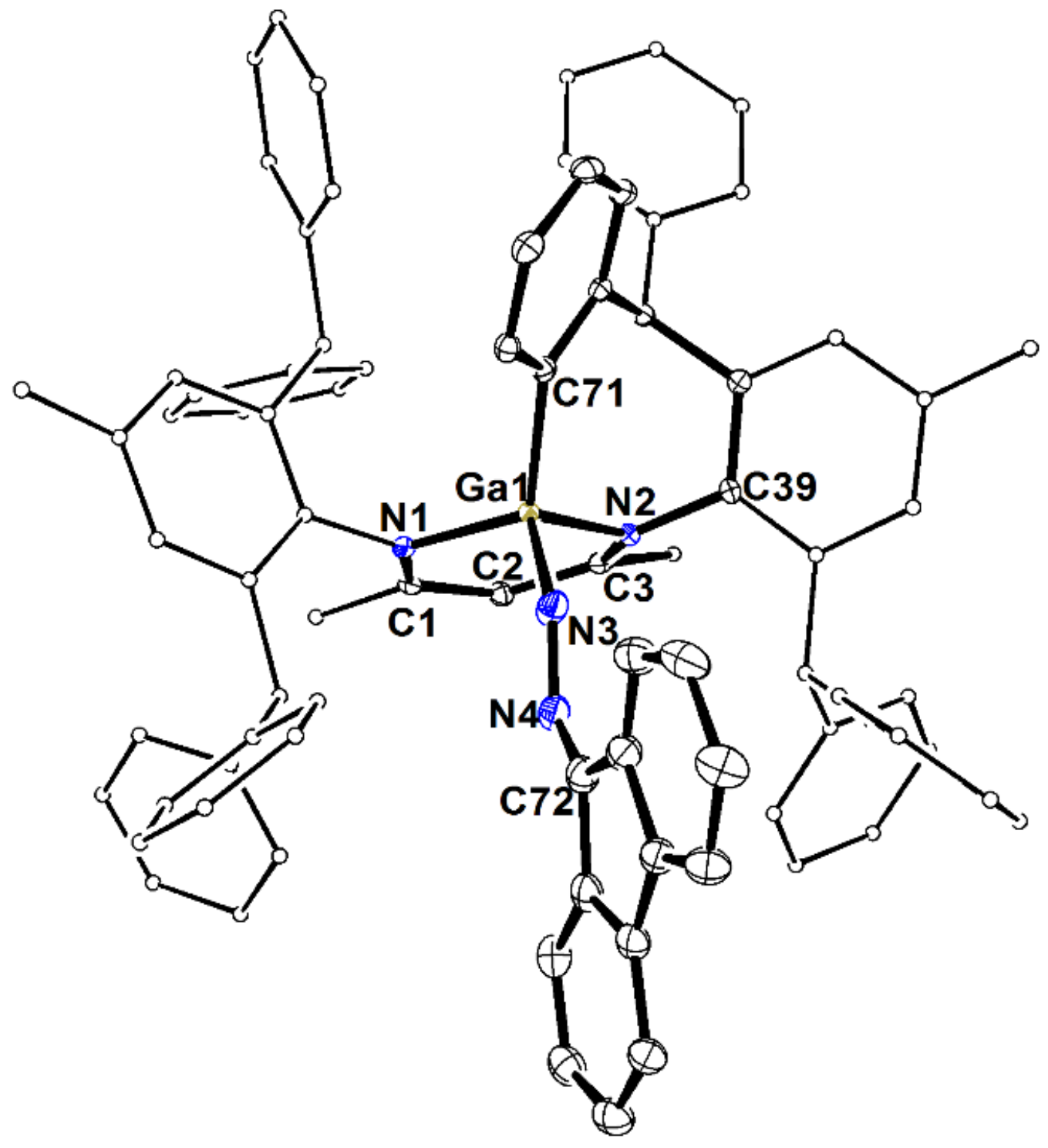

Figure 76: ORTEP plot of $\mathrm{BDI}_{\mathrm{Ar}_{\mathrm{r}} * \mathrm{GaN}}(\mathrm{H}) \mathrm{NFI}$ 46. Ellipsoids at $30 \%, \mathrm{H}$ atoms omitted and selected $\mathrm{C}$ atoms in wire frame for clarity. 
Table 12: Selected bond lengths and angles for BDI $\mathrm{Ar}_{\mathrm{Ar}} \mathrm{GaN}(\mathrm{H}) \mathrm{NFI} 46$.

\begin{tabular}{|c|c|c|c|}
\hline \multicolumn{2}{|c|}{ Bond Lengths ( $\AA$ ) } & \multicolumn{2}{|c|}{ Bond Angles $\left({ }^{\circ}\right)$} \\
\hline $\mathrm{Ga}(1)-\mathrm{N}(1)$ & $1.945(2)$ & $N(1)-G a(1)-N(2)$ & $98.07(7)$ \\
\hline $\mathrm{Ga}(1)-\mathrm{N}(2)$ & $1.948(2)$ & $\mathrm{Ga}(1)-\mathrm{N}(1)-\mathrm{C}(1)$ & $121.5(1)$ \\
\hline$N(1)-C(1)$ & $1.341(3)$ & $\mathrm{Ga}(1)-\mathrm{N}(2)-\mathrm{C}(3)$ & $122.6(1)$ \\
\hline$N(2)-C(3)$ & $1.332(3)$ & $N(1)-C(1)-C(2)$ & $124.1(2)$ \\
\hline$C(1)-C(2)$ & $1.403(3)$ & $C(1)-C(2)-C(3)$ & $129.4(2)$ \\
\hline$C(2)-C(3)$ & $1.403(3)$ & $C(2)-C(3)-N(2)$ & $122.9(2)$ \\
\hline $\mathrm{Ga}(1)-\mathrm{C}(71)$ & $1.973(2)$ & $N(3)-G a(1)-C(71)$ & $105.2(1)$ \\
\hline $\mathrm{Ga}(1)-\mathrm{N}(3)$ & $1.888(3)$ & $\mathrm{Ga}(1)-\mathrm{N}(3)-\mathrm{N}(4)$ & $126.8(2)$ \\
\hline$N(3)-N(4)$ & $1.305(3)$ & $N(4)-N(3)-C(72)$ & $122.3(2)$ \\
\hline$N(4)-C(72)$ & $1.302(4)$ & $\mathrm{Ga}(1)-\mathrm{N}(2)-\mathrm{C}(39)$ & $114.3(1)$ \\
\hline
\end{tabular}

Complex 46 appears to be the result of an aryl $\mathrm{C}-\mathrm{H}$ bond activation by diazofluorene (Scheme 25), which presumably proceeds via coordination of the diazo- group to the gallium centre via the terminal nitrogen atom to give complex 47. Complex 47 then undergoes $\sigma$-bond metathesis with a nearby $\mathrm{C}-\mathrm{H}$ bond on one of the flanking aryl groups to form complex $\mathbf{4 6}$. This indicates that $\mathrm{BDI}_{\mathrm{Ar}} * \mathrm{Ga}$ is able to activate alkyl C-H bonds of diazo- compounds, and diazocompounds are able to activate the aryl $\mathrm{C}-\mathrm{H}$ bond of the ancillary ligand of $\mathrm{BDI}_{\mathrm{Ar}} * \mathrm{Ga}$ upon coordination.

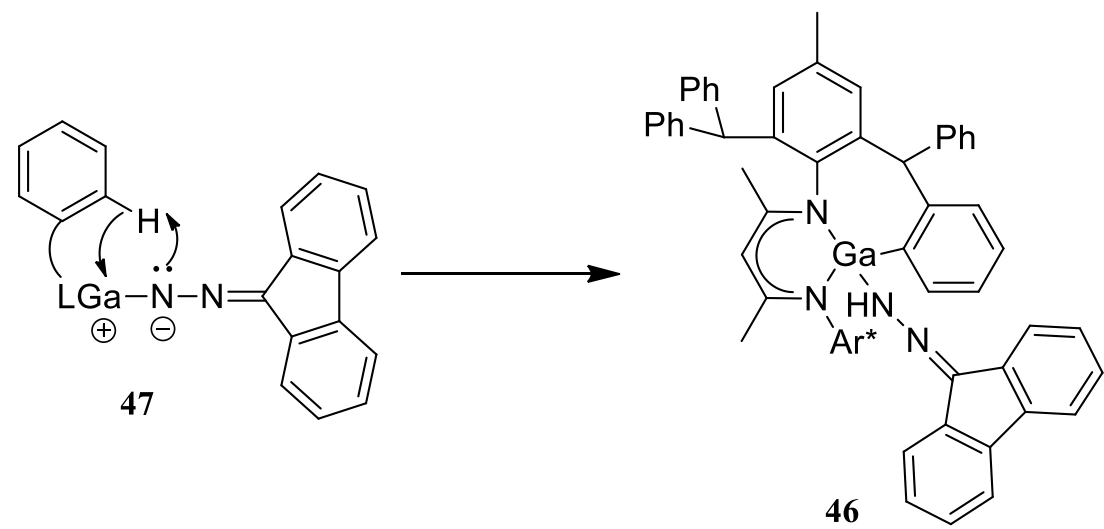

Scheme 25: Proposed mechanism of reaction of $\mathrm{BDI}_{\mathrm{Ar}} * \mathrm{Ga}$ with diazofluorene. 


\subsection{Conclusion}

The reactivity of diazo- compounds with gallium(I) changes depending both on the diazocompound and the ancillary ligand used on the gallium(I). We have shown that when $\mathrm{BDI}_{\mathrm{DIPPGa}}$ is reacted with trimethylsilyldiazomethane, two equivalents of the diazocompound react, one losing the $\mathrm{N}_{2}$ unit as expected but then deprotonating the second equivalent to give a $\mathrm{CH}_{2} \mathrm{SiMe}_{3}$ ligand and a nitrilimine ligand, potentially going through the target $\mathrm{Ga}=\mathrm{C}$ intermediate. When the diazo- compound is changed to cyclododecyldiazomethane, again two equivalents of the diazo- compound react, with one losing $\mathrm{N}_{2}$ as expected and coordinating to the gallium centre, but this time the nitrilimine unit of the second equivalent appears to have deprotonated the $\alpha$-carbon of both cyclododecane rings, giving a $\mathrm{C}_{12} \mathrm{H}_{21}$ ligand and a $\mathrm{N}(\mathrm{H}) \mathrm{N}(\mathrm{H}) \mathrm{C}_{12} \mathrm{H}_{21}$ ligand. Changing the diazo- compound to diphenyldiazomethane lead to the isolation of the $\mathrm{BDI}_{\mathrm{DIPP}} \mathrm{Ga}$ starting material and tetraphenylethene, with BDIDIPpGa apparently catalysing the decomposition of the diazocompound. Switching the diazo- compound to diazofluorene results in an apparent [2+2] cycloaddition reaction of a second equivalent of diazofluorene with the proposed $\mathrm{Ga}=\mathrm{C}$ intermediate, though the intermediate could not be successfully isolated. The final diazocompound attempted was di-tert-butyldiazomethane, which surprisingly did not react with BDIDIPPGa at all.

Upon changing the ligand and forming $A r B D I_{D I P P G a}$, the same reactivity with trimethylsilyldiazomethane was observed, with the asymmetric nature of the ligand resulting in the formation of two enantiomers with a $\mathrm{CH}_{2} \mathrm{SiMe}_{3}$ ligand and a nitrilimine ligand. The change in electronic structure was insufficient to stabilise the proposed gallium-carbon double bond intermediate.

Increasing the steric bulk of the ligand to form $\mathrm{BDI}_{\mathrm{Ar}} * \mathrm{Ga}$ and $\mathrm{BDI}_{\mathrm{Ar}} \mathrm{Ga}$ successfully stopped the second equivalent of diazo- compound reacting with the gallium(I) species, however the gallium(I) species now inserted into the $\mathrm{C}-\mathrm{H}$ bond of trimethylsilyldiazomethane to give a gallium hydride and a nitrilimine ligand coordinated through the carbon atom. When diazofluorene was added to $\mathrm{BDI}_{\mathrm{Ar}} * \mathrm{Ga}$, it resulted in the activation of an aryl $\mathrm{C}-\mathrm{H}$ bond in one of the ancillary phenyl groups of the $\mathrm{BDI}_{\mathrm{Ar}}$ ligand, with the complex possessing a $\mathrm{Ga}-\mathrm{C}$ bond to the ancillary phenyl group and a $\mathrm{N}(\mathrm{H}) \mathrm{N}=\mathrm{Fl}$ ligand. 
It cannot be conclusively stated that the desired gallium-carbon double bond exists as an intermediate in these reactions. While the deprotonation of trimethylsilyldiazomethane and apparent [2+2] cycloaddition of a second equivalent of diazofluorene support its formation, the direct insertion into $\mathrm{C}-\mathrm{H}$ bonds and activation of both alkyl and aryl $\mathrm{C}-\mathrm{H}$ bonds do not result in the formation of the desired gallium-carbon double bond. This illustrates that the reactivity of gallium(I) with diazo- compounds varies and is heavily dependent on both the ancillary ligand and diazo- compound. 


\section{Chapter 3}

\section{Attempted Synthesis of Group 13-Phosphorus Double Bonds}

\subsection{Introduction}

One of the major goals of research groups over the past 50 years was the synthesis and characterisation of compounds that possess multiple bonds between the various elements of the $p$-block, essentially creating a library of all possible homonuclear and heteronuclear analogues of alkenes and alkynes. ${ }^{24,} 38$ The 1999 review by Power ${ }^{5}$ and the 2010 review by Fischer and Power ${ }^{24}$ catalogued the existing examples of these complexes, dividing them into 12 categories of homonuclear and heteronuclear double bonded species and five categories of homonuclear and heteronuclear triple bonded species. One of the gaps identified by these reviews was the lack of examples of multiple bonding between the heavier group 13 and group 15 elements that was not a result of the lone pair on the group 15 element donating electron density into the empty $p$-orbital of the group 13 element (Figure 77, as discussed in section 1.6.1).

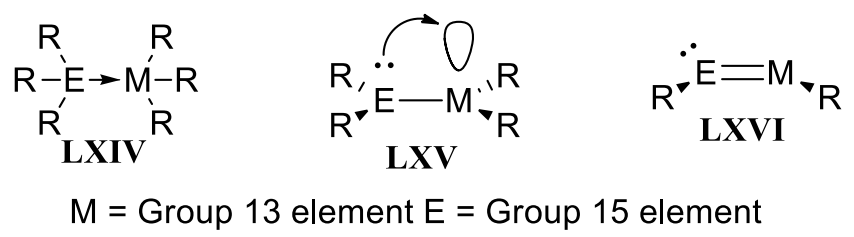

Figure 77: Different bonding types between group 13 and group 15 complexes. 
Examples of complexes of type LXVI were limited to the imides of aluminium, gallium and indium (as discussed in section 1.6.1) until 2018, when the gallaarsene complex CVI was synthesised through the addition of two equivalents of $\mathrm{BDI}$ DIPPGa 1 to $\mathrm{Cp}^{*} \mathrm{AsCl}_{2}$ (Figure 78). ${ }^{140}$ While addition of one equivalent of $\mathbf{1}$ led to the insertion of the gallium into the $\mathrm{As}-\mathrm{Cl}$ bond, the addition of a two equivalents of $\mathbf{1}$ lead to the formation of CVI via dechlorination of the $\mathrm{BDI}_{\mathrm{DIPPGa}}(\mathrm{Cl}) \mathrm{As}(\mathrm{Cl}) \mathrm{Cp}^{*}$ complex into $\mathrm{CVI}$ and $\mathrm{BDI}_{\mathrm{DIPP}} \mathrm{GaCl}_{2} \cdot{ }^{140}$ Complex $\mathrm{CVI}$ is the second example of a gallaarsene after $\left[\left\{\mathrm{Li}(\mathrm{THF})_{3}\right\}_{2} \mathrm{Ga}_{2}\left\{\mathrm{As}\left(\mathrm{Si}^{\mathrm{i}} \mathrm{Pr}_{3}\right)\right\}_{4}\right]^{228}$ and the first that was monomeric of type LXVI.
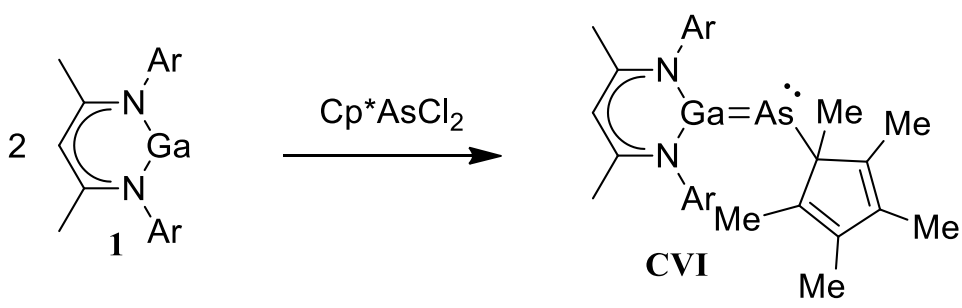

Figure 78: Synthesis of a gallaarsene.

Soon after the synthesis of the gallaarsene CVI was reported, the gallastibenes CVIIa-d were also reported. ${ }^{139}$ Complexes CVIIa-d were generated in a similar manner to complex

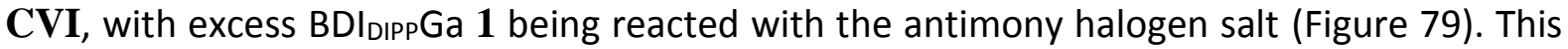
reaction is presumed to go through a $\mathrm{BDI} \mathrm{IIPP}_{\mathrm{DP}}(\mathrm{X}) \mathrm{Sb}(\mathrm{X}) \mathrm{Ga}(\mathrm{X})_{\mathrm{DIPP}} \mathrm{BDI}$ intermediate, with loss of $\mathrm{BDI}_{\text {DIPPGaX}}$ leaving the antimony open to coordination by the third equivalent of gallium(I). ${ }^{139}$<smiles></smiles>

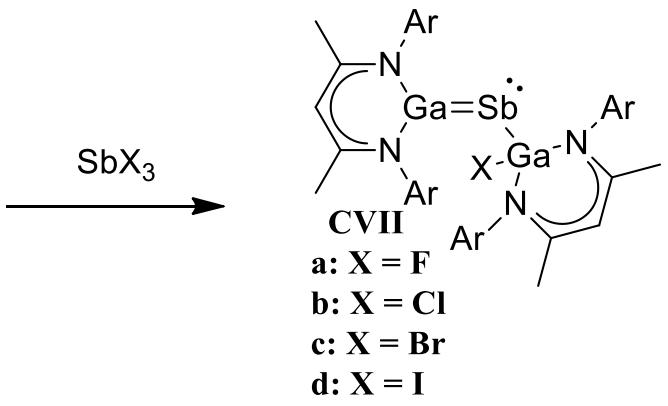

Figure 79: Synthesis of gallastibenes. 
The successful isolation of complexes CVI and CVII leave only the group 13-phosphorus and group 13-bismuth double bonded species left to be isolated in this category. Of the former, several previous attempts at their isolation have been reported. ${ }^{229}$ One attempt at the synthesis of gallium and indium phosphorus double bonds was reported by Rotter et al.,229 who synthesised Mes* ${ }_{2} \mathrm{MP}(\mathrm{H}) \mathrm{SiR}_{3}$ (CVIIIa-c, Figure 80). This complex underwent spontaneous elimination of the Mes* ligand upon warming to room temperature, presumably through the desired double bonded intermediate CIX, however this intermediate immediately dimerised to form CX. ${ }^{229}$ A previous study of similar dimers by the same group, in which the Mes* ligand of complex $\mathbf{C X b}$ was substituted with a $\mathrm{P}(\mathrm{H}) \mathrm{SiMe}_{3}$ group. X-ray diffraction, NMR and computational studies indicated that there was an allylic $\pi$-interaction between the gallium and the phosphorus centres of these dimers, contributing a small degree of multiple bonding. ${ }^{230}$

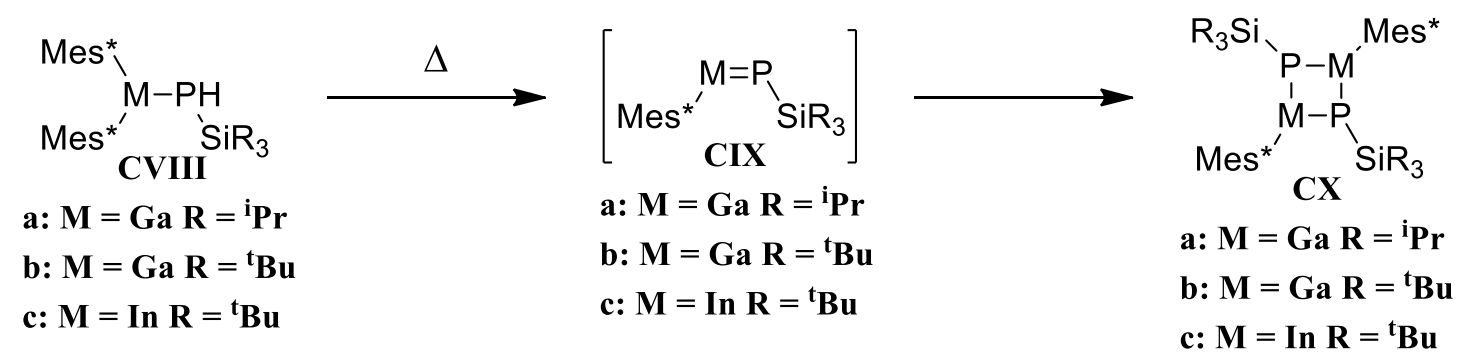

Figure 80: Attempted synthesis of group 13-15 double bond via elimination.

Another attempt by Baker et al. ${ }^{231}$ investigated the reactivity of complex CXI (Figure 81), a gallium(I) analogue of an $\mathrm{N}$-heterocyclic carbene (NHC), with a cyclophosphane. This chemistry was inspired by the reaction of $\mathrm{NHCs}$ with $(\mathrm{PhP})_{5}$ which form pnictogen adducts. ${ }^{232}$ Upon addition of cyclo-(PPh) $)_{5}$ to CXI, the spirocyclic complex CXII was isolated, in which the gallene has substituted for one of the PPh groups in the cyclophosphane ring. Addition of the phosphinidene transfer reagent $\mathrm{Et}_{3} \mathrm{P}=\mathrm{P}\left(-\mathrm{C}_{6} \mathrm{H}_{3}-2,6-\mathrm{Mes}_{2}\right)$ to complex $\mathbf{C X I}$ resulted in an intractable mixture of products. ${ }^{231}$ As the gallene successfully inserted into a P-P single bond, Mes*P=PMes* was also added to complex $\mathbf{C X I}$ to investigate if it could insert into a $\mathrm{P}=\mathrm{P}$ double bond, however complex CXI was unreactive with the diphosphene. Finally, the 
gallium diiodide complex CXIII (Figure 82 ) underwent salt metathesis with LiP(H)Mes* to yield gallium phosphide CXIV. Upon addition of DBU to abstract $\mathrm{HI}$ and form the phosphinidene, it instead underwent single electron reduction of the ligand to give complex CXV. ${ }^{144}$

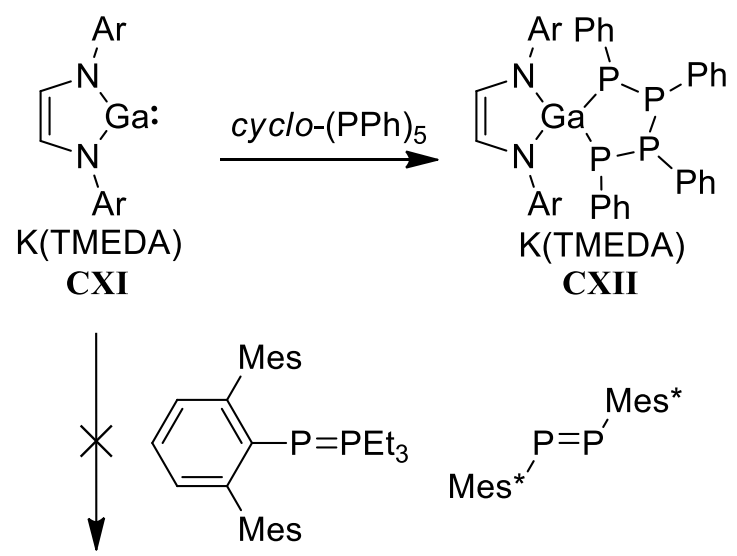

Figure 81: Reactivity of $\mathrm{N}$-heterocyclic gallium(I) with phosphorus compounds.

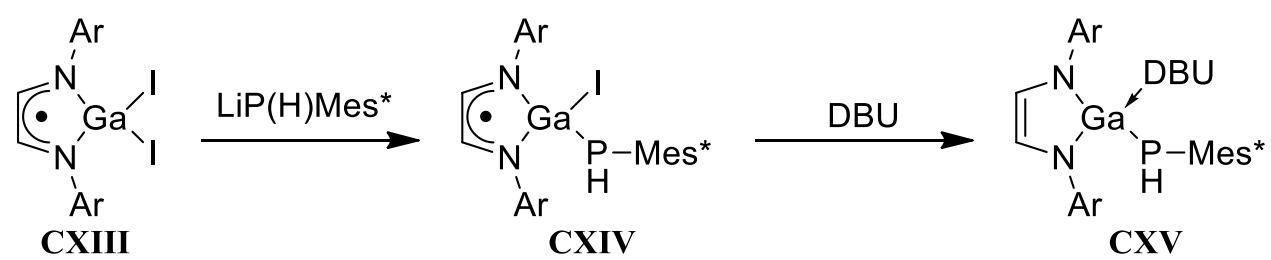

Figure 82: Attempted phosphinidene formation by $\mathrm{HI}$ elimination.

Another complex worth noting is that of Petrie and Power, ${ }^{233}$ who attempted to prepare the gallium analogue of the borylphosphanides $\left(\mathrm{R}_{2} \mathrm{BPR}^{\prime} \mathrm{Li}\right)$ through the reaction of $\operatorname{Trip}_{2} \mathrm{GaCl}$ with $\mathrm{MesPLi}_{2}$ (Figure 83). Instead, upon addition of the gallium chloride CXVI to dilithiummesitylphosphine, the digallylphosphane CXVII was isolated. Complex CXVII possesses a planar phosphorus instead of a typical pyramidal coordination which, combined with the short Ga-P bond length of $2.257(3) \AA$, indicates that there is a degree of $\pi$-bonding between the gallium and phosphorus centres. 


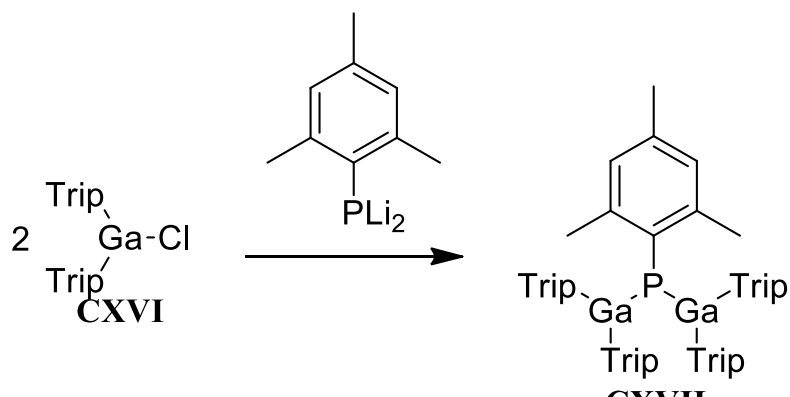

CXVII

Figure 83: Reaction of $\operatorname{Trip}_{2} \mathrm{GaCl}$ with dilithium phosphine salt.

The reactivity of elemental aluminium, gallium and indium with phosphine in an argon matrix has also been investigated (Figure 84), ${ }^{234}$ with the initial product identified as the metal phosphine adduct CXVIII. This adduct then tautomerized to the insertion product CXIX, which is formally an unstable $\mathrm{M}(\mathrm{II})$ species that interconverts into the $\mathrm{M}(\mathrm{III})$ species $\mathbf{C X X}$ or the adduct form CXVIII.

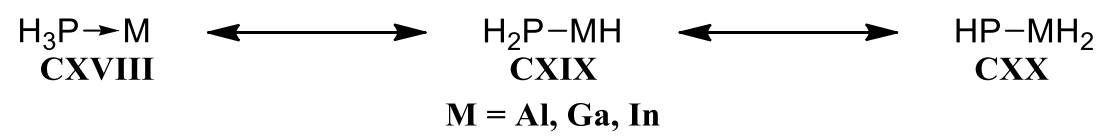

Figure 84: Argon matrix products of metal addition to phosphine.

Theoretical studies have been performed on the target phosphinidene species in their most basic forms (HAIPH and HGaPH) with idealised M-P double ${ }^{235}$ and triple ${ }^{236}$ bonding. The $\mathrm{HMPH}$ species is $177.7 \mathrm{~kJ} \mathrm{~mol}^{-1}$ and $188.4 \mathrm{~kJ} \mathrm{~mol}^{-1}$ higher in energy than tautomers $\mathrm{AlPH}_{2}$ and $\mathrm{GaPH}_{2}$ respectively, significantly higher in comparison with the $\mathrm{H}_{3} \mathrm{MPH}_{3}, \mathrm{H}_{2} \mathrm{MPH}_{2}, \mathrm{HMPH}_{2}$ and MP compounds also modelled. ${ }^{235}$ The HMPH complexes adopt a bent configuration and boast short Al-P and Ga-P (2.1535 $\AA$ and $2.1445 \AA$ respectively) bond lengths relative to $\mathrm{H}_{2} \mathrm{PMH}_{2}$ species ( $2.3379 \AA$ and $2.3310 \AA$ for $\mathrm{Al}$ and Ga respectively). An investigation into the energetic parameters of $\mathrm{HPGaH}$ returned the singlet-triplet gap of $\Delta \mathrm{E}_{\mathrm{Ga}}=45.66 \mathrm{kcal} / \mathrm{mol}$ and $\Delta \mathrm{E}_{\mathrm{p}}=$ - 
$33.16 \mathrm{kcal} / \mathrm{mol}$, with a HOMO-LUMO gap of $228 \mathrm{kcal} / \mathrm{mol}$ and a binding energy of 93.76 $\mathrm{kcal} / \mathrm{mol}$, resulting in a WBO of $1.68 .^{236}$

\subsection{Aim}

The aim of this project was to synthesize complexes bearing formal double bonds between either gallium or aluminium and phosphorus, trying to fill in the gap in known multiple bonded species of the $p$ block. These target complexes could then be investigated for potential catalytic activity. The target complexes would ideally possess bonding of type LXVI (Figure 85), with the lone pair on the phosphorus atom not participating in the bonding orbitals. To address the issue of lone pair donation by the phosphorus atom into the empty $p$ orbital on the metal atom, the BDI ligand was chosen as the chelating nature of the ligand occupies the empty $p$ orbital on the metal centre, leaving only two orbitals to take part in any bonding with the phosphorus. This would ideally generate a complex of type CXXI, where the phosphorus adopts a planar conformation with one of the three coordination sites being the lone pair and the metal-phosphorus bond length of $\sim 2.15 \AA$ to agree with theoretical calculations.

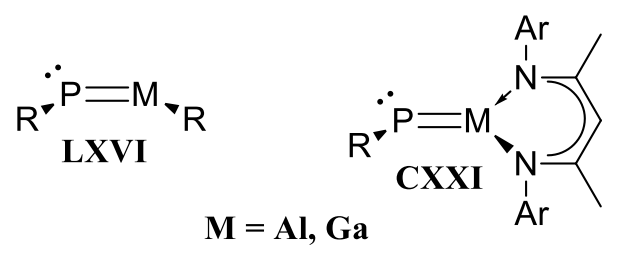

Figure 85: Target phosphinidene complexes.

\subsection{Previous Results}

Previous work in the group ${ }^{237}$ found that treatment of $\mathrm{BDI}_{\mathrm{DIPP} G} \mathrm{G}(\mathrm{PHPh}) \mathrm{Cl} \mathbf{4 8}$ with ${ }^{\mathrm{n}} \mathrm{BuLi}$ resulted in the formation of $\mathbf{5 0}$, in which one of the isopropyl groups on the BDI ligand has 
lost a proton and is bound to the gallium centre. The formation of this product was postulated to proceed via a phosphinidene intermediate 49 , which was formed after deprotonation of the phosphanide $\mathbf{4 8}$ by 'BuLi followed by elimination of $\mathbf{L i C l}$, or 'deprotonation/elimination' pathway.

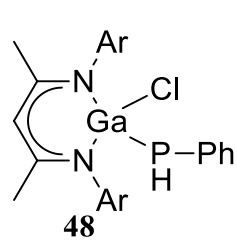<smiles></smiles>

49

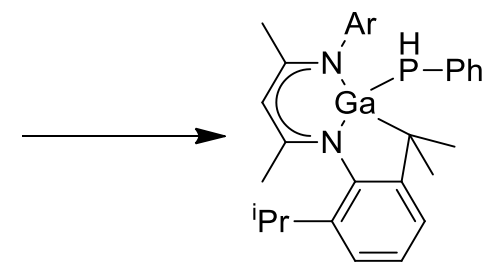

50<smiles>CC(C)c1cccc(C(C)C)c1N(C)C</smiles>

Scheme 26: Potential reaction pathway of $B D I_{D I P P G a}(\mathrm{PHPh}) \mathrm{Cl}$ with ${ }^{\mathrm{n}} \mathrm{BuLi}$.

Unfortunately, compound $\mathbf{5 0}$ was only initially generated on a small scale and only characterised by NMR spectroscopy. In an effort to reproduce these results and fully characterise complex $\mathbf{5 0}$, the known starting material $\mathrm{BDI}_{\mathrm{DIPP}} \mathrm{GaCl}_{2}{ }^{238} \mathbf{5 1}$ was prepared by the addition of $\mathrm{BDI}_{\mathrm{DIPP}} \mathrm{Li} 3$ to a solution of $\mathrm{GaCl}_{3}$ in toluene (Scheme 27 ), the isolated product was then treated with PhPHLi in THF to give BDIDIPPGa(PHPh)Cl 48. To investigate the aluminium analogue, $\mathrm{BDI}_{\mathrm{DIPP}} \mathrm{AlCl}_{2}^{238} \mathbf{5 2}$ was prepared and converted into $\mathrm{BDI}_{\mathrm{DIPP}} \mathrm{Al}(\mathrm{PHPh}) \mathrm{Cl} \mathbf{5 3}$ following similar methodology.<smiles>CC(=[Al])C=C(C)N([Al])[Al]</smiles><smiles></smiles><smiles></smiles>

$48 \mathrm{M}=\mathbf{G a}$

Scheme 27: Synthesis of gallium and aluminium phosphanides. 


\subsection{Results and Discussion}

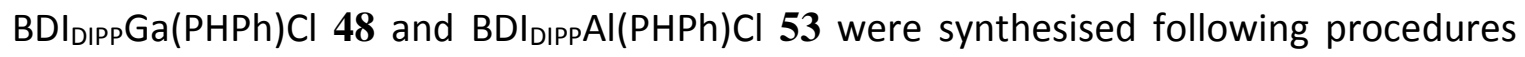
previously developed within the group. Addition of ${ }^{n} \mathrm{BuLi}$ to $\mathbf{4 8}$ or $\mathbf{5 3}$ at room temperature resulted in a complex mixture of products (Scheme 28 ). The ${ }^{1} \mathrm{H}$ NMR spectrum of the reaction between 48 and ${ }^{\mathrm{n}} \mathrm{BuLi}$ revealed complex $\mathbf{5 0}$ to be present within the reaction mixture among other unidentifiable products. However, as crystals suitable for X-ray diffraction could not be obtained, the product was not fully characterised. These reactions were attempted at $-30{ }^{\circ} \mathrm{C}$ or $-78{ }^{\circ} \mathrm{C}$, however multiple products were always observed. On one occasion, an average quality single crystal of the reaction mixture at $-78{ }^{\circ} \mathrm{C}$ was obtained. Unfortunately, the data was not of sufficient quality to conclusively determine a structure, but indicated the presence of $\mathrm{GaBu}_{3}, \mathrm{PhPHLi}$ and $\mathrm{BDI}_{\mathrm{DIPPG}} \mathrm{G}(\mathrm{Bu}) \mathrm{PHPh}$ in the structure. This gave some insight into one reaction pathway occurring where ${ }^{\mathrm{n}} \mathrm{BuLi}$ was reacting directly with the gallium-chloride to form an organogallium complex which underwent either disproportion or decomposition into lithium salts of the ligands. Similarly, the reaction between aluminium complex $\mathbf{5 3}$ and ${ }^{\mathrm{n} B u L i}$ also yielded an intractable mixture of products, none of which could be identified or separated.

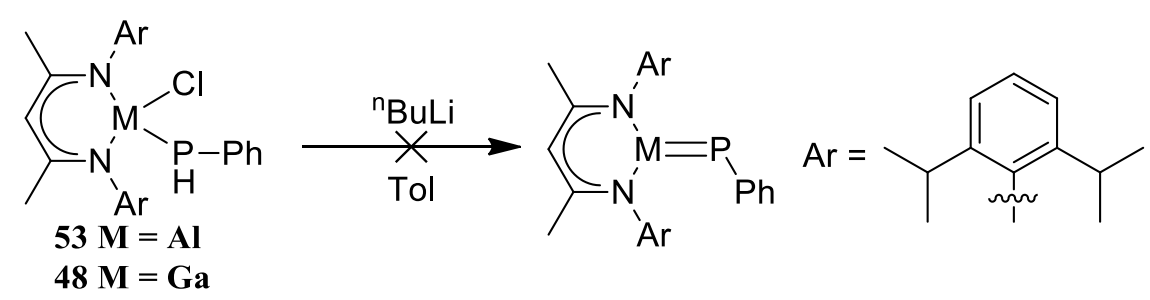

Scheme 28: Addition of n'BuLi to the chlorophosphanides.

Complexes 48 and $\mathbf{5 3}$ were also treated with tBuLi as an alternative reagent (Scheme 29). This stronger base would potentially react with the phosphanide proton preferentially over the metal-chloride. Unfortunately, the reactions also resulted in a similar intractable mixture of products. 


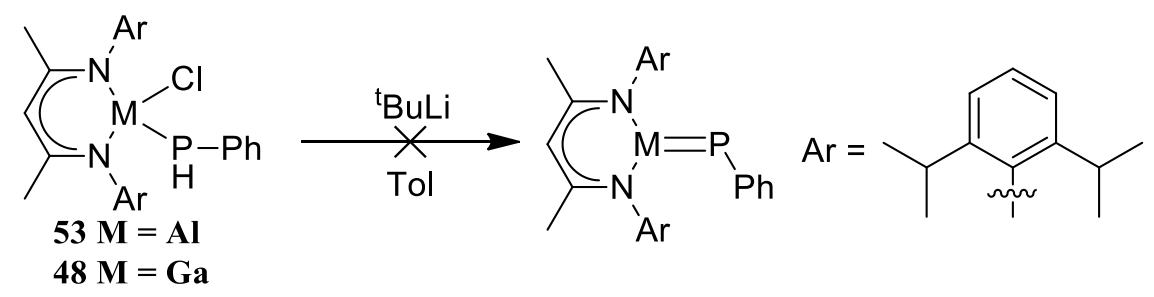

Scheme 29: Addition of tBuLi to the chlorophosphanides.

\subsubsection{Increasing the Steric Bulk of the Phosphanide}

With the deprotonation/elimination pathway forming intractable mixtures of products when ${ }^{\mathrm{n}} \mathrm{BuLi}$ was added to either of complex $\mathbf{4 8}$ or $\mathbf{5 3}$, the effect of the steric bulk of the phosphanide was examined. As such, the phenylphosphine ligand was changed to the mesitylphosphine ligand to increase the steric protection around the metal-phosphorus bond (and to remove the complaints about the noxious odours permeating in the lab). Mesitylphosphine was generated in the same manner as phenylphosphine, bromomesitylene 54 was converted the Grignard reagent mesitylmagnesiumbromide $\mathbf{5 5}$ by stirring over magnesium metal under $\mathrm{N}_{2}$ (Scheme 30). The Grignard reagent was then added dropwise to a solution of $\mathrm{PCl}_{3}$ at $-78{ }^{\circ} \mathrm{C}$ to favour formation of the monosubstituted product $\mathrm{MesPCl}_{2} \mathbf{5 6}$, which was separated from the disubstituted product $\mathrm{Mes}_{2} \mathrm{PCl}$ via distillation under $\mathrm{N}_{2}$. $\mathrm{A}$ solution of $\mathrm{MesPCl}_{2}$ was then added slowly to a suspension of $\mathrm{LiAlH}_{4}$ at $-78{ }^{\circ} \mathrm{C}$, careful distillation lead to the isolation of the pyrophoric $\mathrm{MesPH}_{2} \mathbf{5 7}$ as a colourless liquid that solidified on standing at room temperature. ${ }^{239}$<smiles>Cc1cc([AlH2])cc(C)c1Br</smiles>

Scheme 30: Synthesis of mesitylphosphine. 
Aluminium dichloride $\mathbf{5 2}$ and gallium dichloride $\mathbf{5 1}$ were treated with one equivalent of the lithium salt of mesitylphosphine (Scheme 31), and subsequent workup lead to the isolation of the chloromesitylphosphanides BDI ${ }_{\text {DIPPAI (PHMes)Cl } \mathbf{5 8} \text { and BDI }}$ DIPPGa(PHMes)Cl 59 respectively.

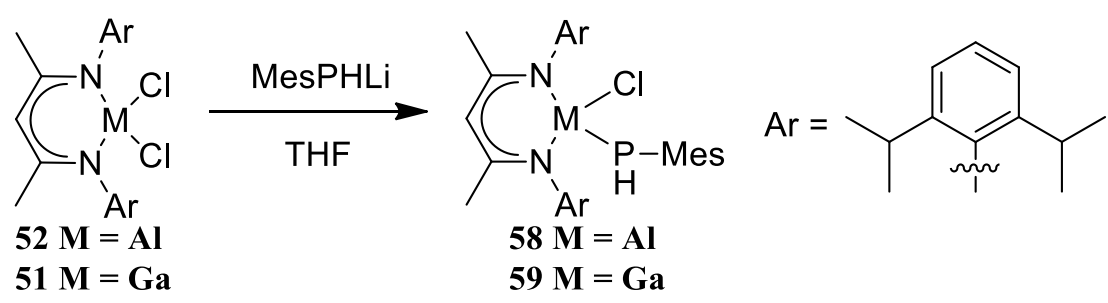

Scheme 31: Synthesis of chloromesitylphosphanides.

The ${ }^{1} \mathrm{H}$ NMR spectrum of complex 58 revealed the $\gamma$-proton resonance at $\delta 4.95 \mathrm{ppm}$ has shifted upfield from dichloride $\mathbf{5 2}(\delta 5.01 \mathrm{ppm})$ but to a lesser extent than complex $\mathbf{5 3}(\delta 4.85$ ppm). Two resonances are observed in a 1:2:2 ratio to the $\psi$-proton at $\delta 3.50$ and $3.24 \mathrm{ppm}$ corresponding to the methine protons of the isopropyl group, while four doublet resonances are observed each in a 1:6 ratio to the $y$-proton at $\delta 1.54,1.26,1.12$ and $1.01 \mathrm{ppm}$ that correspond to the methyl protons of the isopropyl group. The presence of three singlet resonances in a 1:3:6:6 ratio to the $\psi$-proton at $\delta 2.01,1.79$ and $1.54 \mathrm{ppm}$ correspond to the methyl groups on the mesityl group and BDI backbone. The phosphanide proton appears as a doublet at $\delta 2.73 \mathrm{ppm}$ with a ${ }^{1} J_{\mathrm{PH}}$ coupling constant of $199 \mathrm{~Hz}$, while the ${ }^{31} \mathrm{P}$ NMR spectrum reveals a singlet at $\delta-196.2 \mathrm{ppm}$ that splits into a doublet with a ${ }^{1} J_{\mathrm{PH}}$ coupling constant of 200 $\mathrm{Hz}$ when run with the ${ }^{1} \mathrm{H}$ decoupling turned off. This indicates that the mesitylphosphanide ligand successfully coordinated to the aluminium centre, and that there is a plane of symmetry in the molecule. Crystals of $\mathbf{5 8}$ suitable for an X-ray diffraction study were grown from toluene at $-30{ }^{\circ} \mathrm{C}$, which confirmed the proposed connectivity of the ligands. The aluminium atom sits above the NCCCN plane of the ligand in a pseudo-tetrahedral conformation, with Al-N bond lengths of 1.895(1)/ 1.892(2) A identical to complex 53, and comparable to those in $\mathrm{BDI}_{\mathrm{DIPPAI}}\left(\mathrm{PPh}_{2}\right)_{2}(1.902(1) / 1.9254(10) \AA)^{127}$ and $\mathrm{BDI}_{\mathrm{DIPP} A I}(\mathrm{H}) \mathrm{PPh}_{2}$ (1.9070(13)/1.8963(13) Å). ${ }^{125}$ The Al-P bond length of $2.3435(7) \AA$ is identical to complex 53, 
and slightly shorter than that of the diphenylphosphine complexes $(2.3775(5) / 2.3979(5) \AA$ and $2.3971(6) \AA$ respectively), presumably due to the reduced steric repulsion of a monosubstituted phosphide ligand compared to a disubstituted phosphide ligand. The Al-Cl bond length of $2.1402(7) \AA$ is identical to complex 53, and slightly longer than that of 2.1344(4)/2.1185(4) A in the starting material $\mathrm{BDI}_{\mathrm{DIPPAICl}} \mathbf{5 2}^{238}$

The ${ }^{1} \mathrm{H}$ NMR spectrum of complex 59 shows the $\psi$-proton at $\delta 4.87 \mathrm{ppm}$, nearly identical to complex 48 ( $\delta 4.88 \mathrm{ppm}$ ). The presence of eight doublet resonances each in a 1:3 ratio with the $\mathrm{y}$-proton at $\delta 1.61,1.46,1.33,1.24,1.15,1.14,1.09$ and $1.05 \mathrm{ppm}$ corresponding to the methyl protons of the isopropyl group combined with the presence of three resonances in a 1:2:1:1 ratio with the $y$-proton at $\delta 3.64,3.32$ and $3.16 \mathrm{ppm}$ corresponding to the methine protons of the isopropyl group, indicate that the iPr groups of the BDI ligand are inequivalent, presumably due to restricted rotation on an NMR timescale. A similar splitting pattern is observed to that of complex 48 . The backbone methyl resonance at $\delta 1.58 \mathrm{ppm}(6 \mathrm{H})$ and mesityl group methyl resonances at $\delta 2.00(3 \mathrm{H})$ and $1.81(6 \mathrm{H})$ ppm retain their symmetrical equivalence in the ${ }^{1} \mathrm{H}$ NMR spectrum, supporting that parts of the BDI ligand are restricted in their rotation. The phosphanide proton presents as a doublet in a 1:1 ratio with the $\gamma$-proton at $\delta 3.13 \mathrm{ppm}$ with a ${ }^{1} \mathrm{~J}_{\mathrm{PH}}$ coupling constant of $202 \mathrm{~Hz}$, while the ${ }^{31} \mathrm{P}$ NMR spectrum shows a singlet at $\delta-190.3 \mathrm{ppm}$ which splits into a doublet with a ${ }^{1} J_{\mathrm{PH}}$ coupling constant of $201 \mathrm{~Hz}$ when run with the ${ }^{1} \mathrm{H}$ decoupling turned off. An X-ray diffraction study of $\mathbf{5 9}$ reveals nearly identical bond lengths and angles to 48 , with a pseudo-tetrahedral gallium atom sitting above the NCCCN plane of the ligand. The Ga-P bond length of $2.3138(5) \AA$ is expectedly slightly shorter than that of 2.363(1) $\AA$ in $\mathrm{BDI}_{\mathrm{DIPPGa}}(\mathrm{H}) \mathrm{PPh}_{2} \cdot{ }^{194}$ In both complex $\mathbf{5 8}$ and $\mathbf{5 9}$, the $\mathrm{P}-\mathrm{H}$ is disordered over two positions due to the pseudo-tetrahedral conformation of the phosphorus atom, with the complexes having both $\mathrm{R}$ and $\mathrm{S}$ configuration present in the unit cell. 


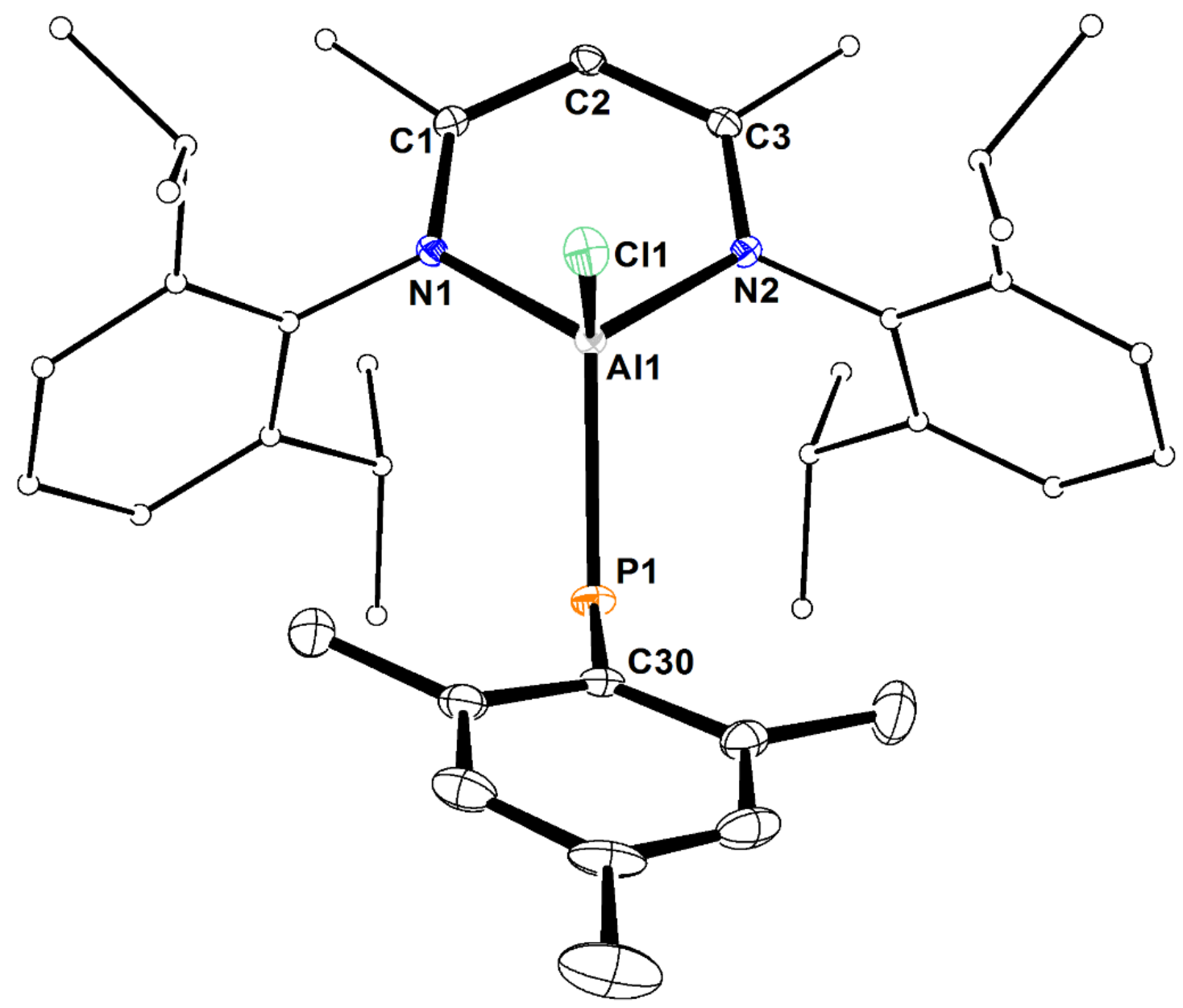

Figure 86: ORTEP plot of BDIDIPPAl(PHMes)Cl 58. Ellipsoids at 30\%, $\mathrm{H}$ atoms omitted and selected $\mathrm{C}$ atoms in wire frame for clarity.

Table 13: Selected bond lengths and angles for BDIDIPPAI(PHMes)Cl 58.

\begin{tabular}{|c|c|c|c|}
\hline \multicolumn{2}{|c|}{ Bond Lengths ( $\AA$ ) } & \multicolumn{2}{|c|}{ Bond Angles $\left({ }^{\circ}\right)$} \\
\hline $\mathrm{Al}(1)-\mathrm{N}(1)$ & $1.895(1)$ & $N(1)-A I(1)-N(2)$ & $97.60(7)$ \\
\hline $\mathrm{Al}(1)-\mathrm{N}(2)$ & $1.892(2)$ & $A l(1)-N(1)-C(1)$ & $120.4(1)$ \\
\hline$N(1)-C(1)$ & $1.336(2)$ & $A l(1)-N(2)-C(3)$ & $120.0(1)$ \\
\hline$N(2)-C(3)$ & $1.343(2)$ & $N(1)-C(1)-C(2)$ & $122.6(2)$ \\
\hline$C(1)-C(2)$ & $1.400(2)$ & $C(1)-C(2)-C(3)$ & $128.0(2)$ \\
\hline$C(2)-C(3)$ & $1.393(2)$ & $C(2)-C(3)-N(2)$ & $123.1(2)$ \\
\hline $\mathrm{Al}(1)-\mathrm{P}(1)$ & $2.3435(7)$ & $\mathrm{Cl}(1)-\mathrm{Al}(1)-\mathrm{P}(1)$ & $113.93(3)$ \\
\hline$P(1)-C(30)$ & $1.843(2)$ & $\mathrm{Al}(1)-\mathrm{P}(1)-\mathrm{C}(30)$ & $105.71(6)$ \\
\hline $\mathrm{Al}(1)-\mathrm{Cl}(1)$ & $2.1402(7)$ & & \\
\hline
\end{tabular}



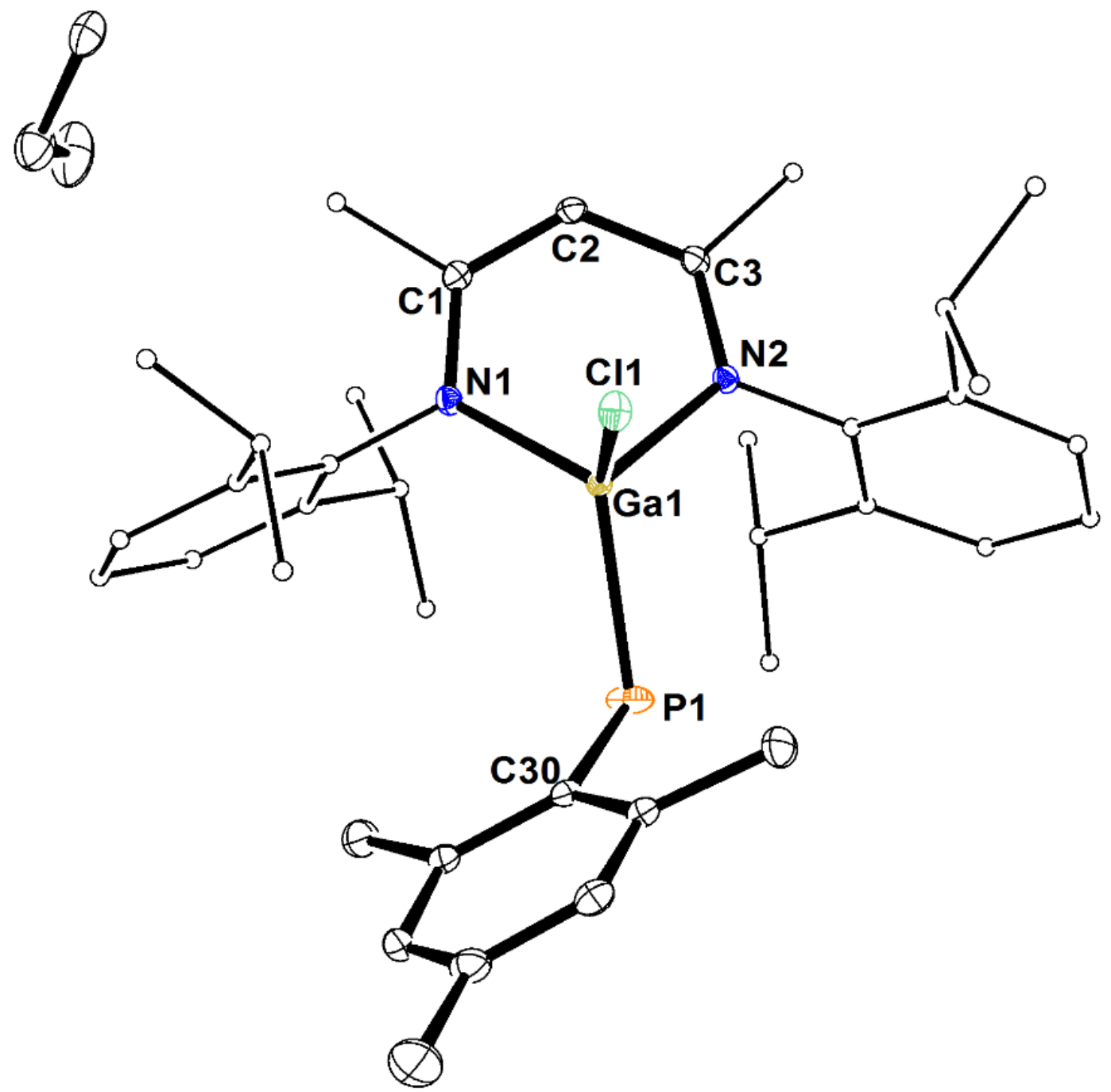

Figure 87: ORTEP plot of $\mathrm{BDI}_{\mathrm{DIPP}} \mathrm{Ga}(\mathrm{PHMes}) \mathrm{Cl}$ 59. Ellipsoids at $30 \%, \mathrm{H}$ atoms omitted and selected $\mathrm{C}$ atoms in wire frame for clarity.

Table 14: Selected bond lengths and angles for BDI ${ }_{\mathrm{DIPP}} \mathrm{Ga}$ (PHMes)Cl 59.

\begin{tabular}{|c|c|c|c|}
\hline \multicolumn{2}{|c|}{ Bond Lengths ( $\AA$ ) } & \multicolumn{2}{|c|}{ Bond Angles $\left({ }^{\circ}\right)$} \\
\hline $\mathrm{Ga}(1)-\mathrm{N}(1)$ & $1.942(1)$ & $N(1)-G a(1)-N(2)$ & $96.43(5)$ \\
\hline $\mathrm{Ga}(1)-\mathrm{N}(2)$ & $1.965(1)$ & $\mathrm{Ga}(1)-\mathrm{N}(1)-\mathrm{C}(1)$ & $117.8(1)$ \\
\hline$N(1)-C(1)$ & $1.340(2)$ & $\mathrm{Ga}(1)-\mathrm{N}(2)-\mathrm{C}(3)$ & $118.4(1)$ \\
\hline$N(2)-C(3)$ & $1.328(2)$ & $N(1)-C(1)-C(2)$ & $123.8(1)$ \\
\hline$C(1)-C(2)$ & $1.394(2)$ & $C(1)-C(2)-C(3)$ & $128.2(1)$ \\
\hline$C(2)-C(3)$ & $1.408(2)$ & $C(2)-C(3)-N(2)$ & $123.6(1)$ \\
\hline $\mathrm{Ga}(1)-\mathrm{P}(1)$ & $2.3138(5)$ & $\mathrm{Cl}(1)-\mathrm{Ga}(1)-\mathrm{P}(1)$ & $118.15(2)$ \\
\hline$P(1)-C(30)$ & $1.839(2)$ & $G a(1)-P(1)-C(30)$ & $106.21(5)$ \\
\hline $\mathrm{Ga}(1)-\mathrm{Cl}(1)$ & $2.2223(4)$ & & \\
\hline
\end{tabular}


Complexes 58 and $\mathbf{5 9}$ were independently treated with ${ }^{\mathrm{n} B u L i}$ (Scheme 32) with the goal of isolating the target phosphinidene complex or its decomposition product, via the proposed deprotonation/elimination pathway. In the case of both aluminium and gallium, this resulted in a similar mixture of products forming. One of these products present in both the reactions of aluminium and gallium could readily be identified by ${ }^{1} \mathrm{H}$ NMR spectroscopy as the known complex BDI DIPP-Li, indicating that the switch from phenylphosphine to mesitylphosphine now lead to the decomposition of both aluminium complex $\mathbf{5 8}$ and gallium complex $\mathbf{5 9}$ when treated with nBuLi. Similar reactivity with both complex $\mathbf{5 8}$ and $\mathbf{5 9}$ was also observed when tBuLi was used as a reagent instead, indicating that increasing the steric bulk at the phosphanide potentially reduced the reactivity of the $\mathrm{P}-\mathrm{H}$ bond.

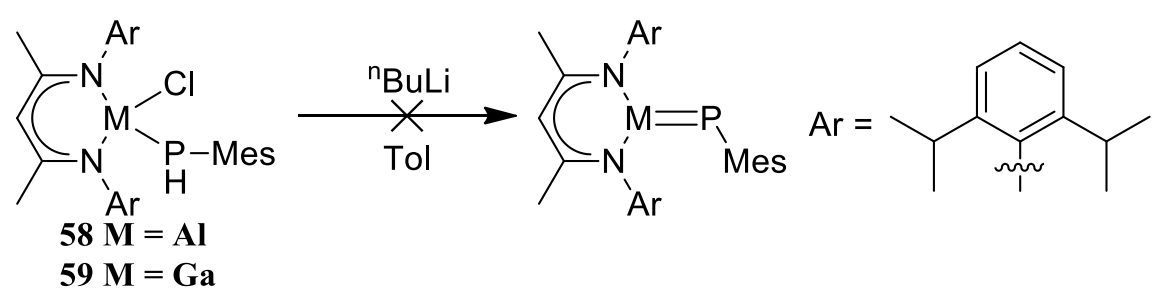

Scheme 32: Addition of ${ }^{\mathrm{n}} \mathrm{BuLi}$ to the chloromesitylphosphanides.

\subsubsection{Dilithium Salt}

As mentioned in section 3.1, the dilithium salt MesPLi 2 is a known compound that has previously been used by Petrie and Power ${ }^{240}$ to install a bridging phosphanide onto two units of $\mathrm{Ga}$ (Trip) ${ }_{2}$ by the addition of (Trip) ${ }_{2} \mathrm{Ga}-\mathrm{Cl}$ to a slurry of $\mathrm{MesPLi}_{2}$. As MesPLi can react with two metal chloride bonds, it was thought that addition of either $\mathrm{BDI}_{\mathrm{DIPP}} \mathrm{AlCl}_{2} \mathbf{5 2}$ or $\mathrm{BDI}_{\mathrm{DIPP}} \mathrm{GaCl}_{2}$ 51 to $\mathrm{MesPLi}_{2}$ could potentially eliminate both chloride ligands from the metal centre and potentially lead to the metal-phosphorus double bond (Scheme 33). 


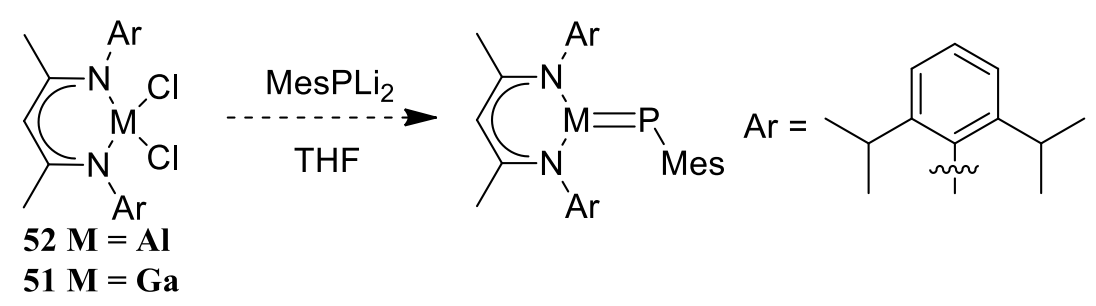

Scheme 33: Attempted substitution with MesPLi2.

Unfortunately, attempts to prepare the dilithium salt were unsuccessful, as despite following the literature procedure (slow addition of two equivalents of ${ }^{n} \mathrm{BuLi}$ to $\mathrm{MesPH}_{2}$ at 0 ${ }^{\circ} \mathrm{C}$, let warm to room temp and stir for 1 hour, filter off yellow ppt of the dilithium salt), upon addition of $\mathbf{5 2}$ or $\mathbf{5 1}$ to the yellow powder obtained, the only products isolated were BDIDIPPAl(PHMes)Cl 58 and BDIDIPPGa(PHMes)Cl 59. This indicates that the yellow precipitate being obtained was likely MesPHLi instead of MesPLiz. Repeated attempts at the synthesis of MesPLi 2 were done using fresh reagents and after thorough drying of solvents. Unfortunately, the only isolable products from these reaction mixtures were aluminium complex $\mathbf{5 8}$ and gallium complex 59. Either the dilithium salt was not generated, or the dilithium salt was formed but could only react with one of the chloride ligands on the metal centre and the phosphorus became protonated during purification/isolation.

\subsubsection{Trimethylsilyl Substitution}

As the deprotonation/elimination pathway proved unsuccessful at generating the mealphosphorus double bond using ${ }^{\mathrm{n}} \mathrm{BuLi}$, alternative elimination pathways were investigated. As trimethylsilylchloride is a common elimination product in organic chemistry, it was thought that installing a trimethylsilyl group on the phosphanide ligand could lead to $\mathrm{TMS}-\mathrm{Cl}$ elimination with the chloride on the adjacent metal centre, as occurs in spontaneous $\mathrm{Sb}=\mathrm{C}$ bond formation from [2-Pyr $\left.\left(\mathrm{SiMe}_{3}\right)_{2} \mathrm{C}\right]_{2} \mathrm{SbCl}\left(\mathrm{Pyr}=\mathrm{C}_{5} \mathrm{H}_{4} \mathrm{~N}\right)$ losing $\mathrm{Me}_{3} \mathrm{SiCl}$ to form [2$\operatorname{Pyr}\left(\mathrm{SiMe}_{3}\right)_{2} \mathrm{CSb}=\mathrm{C}\left(\mathrm{SiMe}_{3}\right)_{2}-\mathrm{Pyr} .^{241}$ Phenylphosphine was converted into trimethylsilylphenylphosphine through the addition of ${ }^{n}$ BuLi to phenylphosphine and addition of TMS-Cl. The lithium salt of trimethylsilylphenylphosphine was then added to complex $\mathbf{5 2}$ 
and 51 in THF (Scheme 34) leading to the formation of the disubstituted phosphanide complexes 60 and 61.

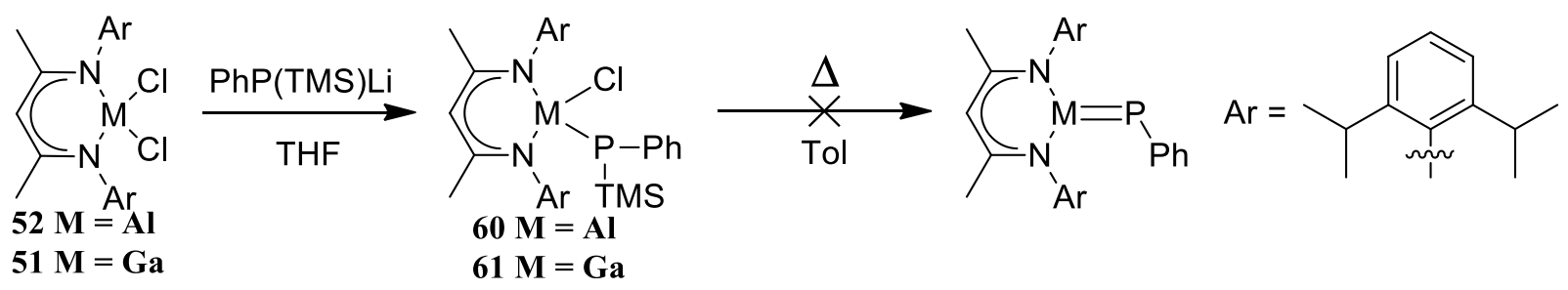

Scheme 34: Attempted TMS-Cl elimination.

Complex 60 was isolated from the reaction mixture as colourless crystals. The ${ }^{1} \mathrm{H}$ NMR spectrum revealed the $\gamma$-proton at $\delta 4.96$ ppm, similar to $\mathbf{5 3}$ and $\mathbf{5 8}$ ( $\delta 4.85$ and 4.95 ppm respectively). The presence of two overlapping resonances at $\delta 3.67-3.53 \mathrm{ppm}$ in a $1: 4$ ratio with the $\gamma$-proton corresponding to the methine protons of the isopropyl group, combined with four doublet resonances at $\delta 1.62,1.49,1.15$ and 1.01 in a 1:6:6:6:6 ratio with the $\gamma$ proton corresponding to the methyl protons of the isopropyl group, show a similar splitting pattern as $\mathbf{5 3}$ and $\mathbf{5 8}$. The presence of a doublet resonance at $\delta-0.07 \mathrm{ppm}$ with a ${ }^{2} J_{\mathrm{PH}}$ coupling constant of $4.6 \mathrm{~Hz}$ in a 1:9 ratio with the $\gamma$-proton corresponds to the TMS group, which is bound to the phosphanide ligand. The ${ }^{31} \mathrm{P}$ NMR spectrum shows a singlet at $\delta-160.0 \mathrm{ppm}$, similar to the resonance of the protonated phosphanide $\mathbf{5 3}$ at $\delta-158.2 \mathrm{ppm}$. An X-ray diffraction study of $\mathbf{6 0}$ reveals the complex has nearly identical bond lengths and angles to $\mathbf{5 3}$, with the aluminium sitting above the NCCCN plane of the ligand in a pseudo-tetrahedral conformation. The trimethylsilyl group is present on the phosphanide ligand, with a torsional angle to the chloride ligand of $36.40(5)^{\circ}$ and an interspatial distance of $4.3839(8) \AA$ in the solid state an indication that an elimination reaction is possible. The P-Si bond length of 2.254(1) $\AA$ is comparable to $2.255 \AA$ observed in $\left(\mathrm{Me}_{2} \mathrm{AIP}\left(\mathrm{SiMe}_{3}\right)_{2}\right)_{2}{ }^{242}$

Complex 61 could not be isolated, with the ${ }^{1} \mathrm{H}$ NMR spectrum of the crude reaction mixture possessing multiple $\boldsymbol{\gamma}$-proton resonances, numerous overlapping doublet resonances and multiple resonances around $0 \mathrm{ppm}$. This indicated that the complex may have formed, 
however the presence of other products (potentially the desired gallium-phosphorus double bond complex or its decomposition products) hindered the efforts to isolate it.

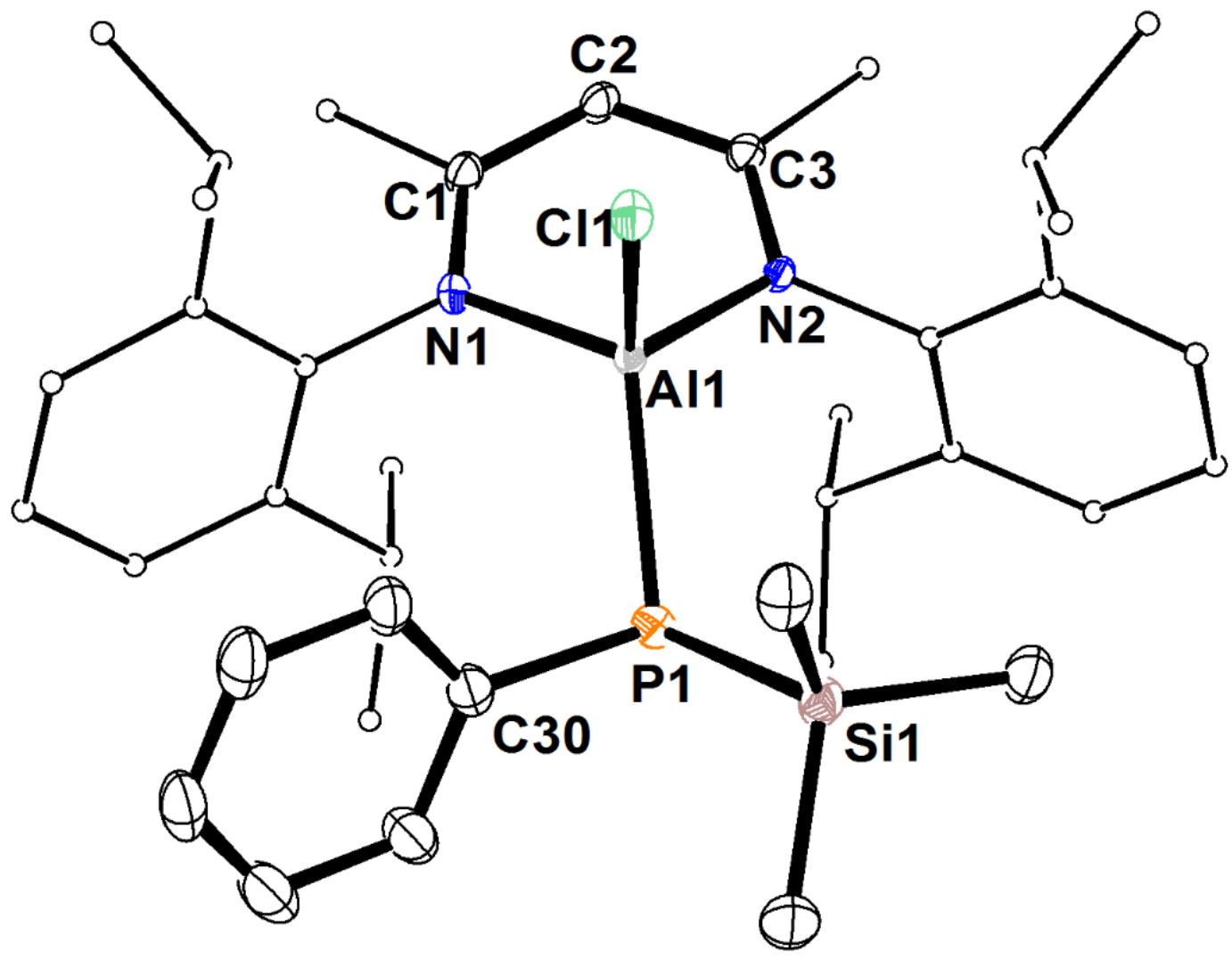

Figure 88: ORTEP plot of $\mathrm{BDI}_{\mathrm{DIPP}} \mathrm{Al}(\mathrm{PPhTMS}) \mathrm{Cl}$ 60. Ellipsoids at $30 \%, \mathrm{H}$ atoms and solvent omitted and selected $\mathrm{C}$ atoms in wire frame for clarity.

Table 15: Selected bond lengths and angles for BDIDIPPAI(PPhTMS)Cl 60.

\begin{tabular}{|c|c|c|c|}
\hline \multicolumn{2}{|c|}{ Bond Lengths ( $\AA$ ) } & \multicolumn{2}{|c|}{ Bond Angles $\left({ }^{\circ}\right)$} \\
\hline $\mathrm{Al}(1)-\mathrm{N}(1)$ & $1.901(2)$ & $N(1)-A l(1)-N(2)$ & $98.32(8)$ \\
\hline $\mathrm{Al}(1)-\mathrm{N}(2)$ & $1.887(2)$ & $A I(1)-N(1)-C(1)$ & $119.5(1)$ \\
\hline$N(1)-C(1)$ & $1.333(3)$ & $A l(1)-N(2)-C(3)$ & 119.9(1) \\
\hline$N(2)-C(3)$ & $1.339(3)$ & $N(1)-C(1)-C(2)$ & $123.5(2)$ \\
\hline$C(1)-C(2)$ & $1.401(3)$ & $C(1)-C(2)-C(3)$ & $128.1(2)$ \\
\hline$C(2)-C(3)$ & $1.393(3)$ & $C(2)-C(3)-N(2)$ & $122.7(2)$ \\
\hline $\mathrm{Al}(1)-\mathrm{P}(1)$ & $2.3447(7)$ & $\mathrm{Cl}(1)-\mathrm{Al}(1)-\mathrm{P}(1)$ & $118.56(3)$ \\
\hline$P(1)-C(30)$ & $1.855(2)$ & $A l(1)-P(1)-C(30)$ & $103.64(8)$ \\
\hline$P(1)-S i(1)$ & $2.254(1)$ & Al(1)-P(1)-Si(1) & $111.38(3)$ \\
\hline $\mathrm{Al}(1)-\mathrm{Cl}(1)$ & $2.1578(8)$ & & \\
\hline
\end{tabular}


Complex 60 was heated to reflux in $C_{6} D_{6}$, toluene and THF (Scheme 35 ) to encourage elimination of TMS-Cl, however no reaction was observed under these conditions. This could be attributed to the $\mathrm{Al}-\mathrm{Cl}$ bond having an inherently higher bond dissociation energy than the $\mathrm{Si}-\mathrm{Cl}$ bond $(420 \mathrm{~kJ} / \mathrm{mol}$ versus $381 \mathrm{~kJ} / \mathrm{mol}),{ }^{243}$ as such, the entire premise for this pathway is flawed. However, the $\mathrm{Ga}-\mathrm{Cl}$ bond dissociation energy $(354 \mathrm{~kJ} / \mathrm{mol})$ is weaker than the $\mathrm{Si}-\mathrm{Cl}$ bond. Thus, it could explain why complex $\mathbf{6 1}$ was unable to be isolated, as it may have undergone the desired elimination.
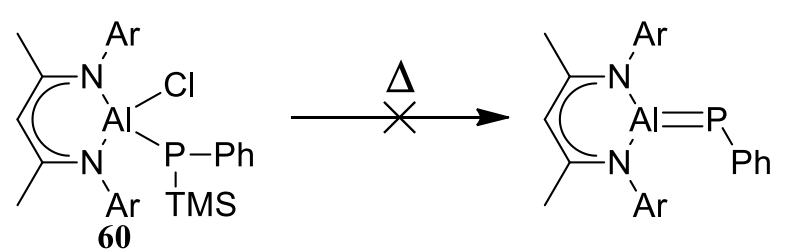<smiles>CC(C)c1cccc(C(C)C)c1C(C)(C)C</smiles>

Scheme 35: Attempted aluminium phosphinidene formation.

\subsubsection{Alkyl Elimination}

With the attempt at eliminating TMS-Cl to form the metal phosphorus double bond hindered presumably by the strength of the aluminium-chlorine bond of $420 \mathrm{~kJ} / \mathrm{mol}$, the aluminium-carbon bond was investigated next as a potential elimination reaction pathway as it is significantly weaker at $255 \mathrm{~kJ} / \mathrm{mol}^{243}$ The known complex BDIDIPPAlEtCl 62 was

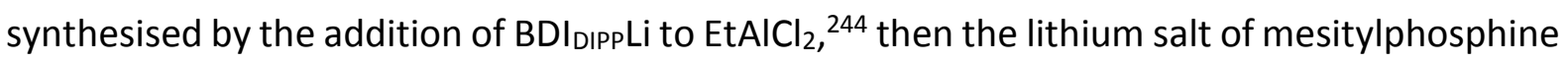
was added to $\mathbf{6 2}$ (Scheme 36) resulting in the formation of the alkylphosphide complex $\mathbf{6 3}$, with the aim to eliminate ethane and form the aluminium phosphinidene complex.

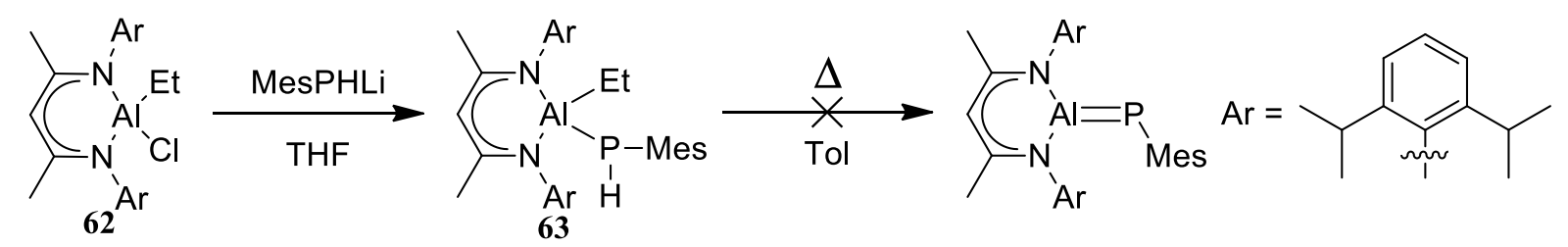

Scheme 36: Attempted alkyl elimination route. 
Complex 63 was isolated from toluene at $-30{ }^{\circ} \mathrm{C}$ as colourless crystals. The ${ }^{1} \mathrm{H}$ NMR spectrum revealed that the $\gamma$-proton was upfield at $\delta 4.72 \mathrm{ppm}$ compared to BDIDIPPAI(PHMes)Cl 58 ( $\delta 4.94$ ppm). The presence of four doublet resonances each in a 1:6 ratio with the $y$-proton at $\delta 1.57,1.21,1.13$ and $1.03 \mathrm{ppm}$ corresponding to the methine protons of the isopropyl group and two resonances in a 1:2:2 ratio with the $\gamma$-proton at $\delta 3.35$ and $3.25 \mathrm{ppm}$ corresponding to the methyl protons of the isopropyl group indicate that the molecule is symmetric. The presence of three singlet peaks in a 1:3:6:6 ratio with the $\gamma$-proton at $\delta 1.99,1.75$ and $1.49 \mathrm{ppm}$ correspond to the methyl substituents on the mesityl group and the backbone methyl peaks of the BDIDIPP ligand. The ethyl ligand is identified by the presence of a triplet resonance at $\delta 1.29 \mathrm{ppm}$ and a quartet resonance at $\delta-0.09 \mathrm{ppm}$ in a 1:3:2 ratio with the $\gamma$-proton. The phosphanide proton shows as a doublet resonance at $\delta 2.57 \mathrm{ppm}$ with a ${ }^{1} J_{\mathrm{PH}}$ coupling constant of $196 \mathrm{~Hz}$ in a 1:1 ratio with the $\psi$-proton, while the ${ }^{31} \mathrm{P}$ NMR spectrum shows a singlet at $\delta-189.9 \mathrm{ppm}$ which splits into a doublet with a ${ }^{1} \mathrm{JPH}_{\mathrm{PH}}$ coupling constant of $196 \mathrm{~Hz}$ when run with the ${ }^{1} \mathrm{H}$ decoupling turned off. An X-ray diffraction study of $\mathbf{6 3}$ reveals a similar structure to $\mathbf{5 8}$, with a pseudo-tetrahedral aluminium sitting above the NCCCN plane of the ligand. The Al-N bond lengths of 1.928(1)/1.911(1) $\AA$ are longer than those of $\mathbf{5 8}$ $(1.895(1) / 1.892(2) \AA ̊ \Omega)$, with a bite angle of the ligand of $96.08(5)^{\circ}$, slightly smaller than that of $\mathbf{5 8}\left(97.60(7)^{\circ}\right)$. The Al-P bond length of $2.390(5) \AA$ is slightly longer than $\mathbf{5 8}(2.3435(7) \AA$ ) and the P-C bond length of $1.844(1) \AA ̊$ is nearly identical (1.843(2) $\AA$ ). Similar to $\mathbf{5 8}$, the phosphorus atom of complex $\mathbf{6 3}$ adopts a distorted tetrahedral conformation, with the proton disordered over two positions as either the R or S enantiomer of the complex. The mesityl group and the ethyl ligand are eclipsed with just a $3.2^{\circ}$ torsion angle and an interspatial distance of $3.47 \AA$ between $\mathrm{C} 30-\mathrm{C} 32$. The $\mathrm{Al}(1)-\mathrm{P}(1)-\mathrm{C}(32)$ angle of $100.12(5)^{\circ}$ is sharper than the $105.71(6)^{\circ}$ observed in 58, and results in the mesityl ligand effectively blocking one face of the ethyl ligand. 


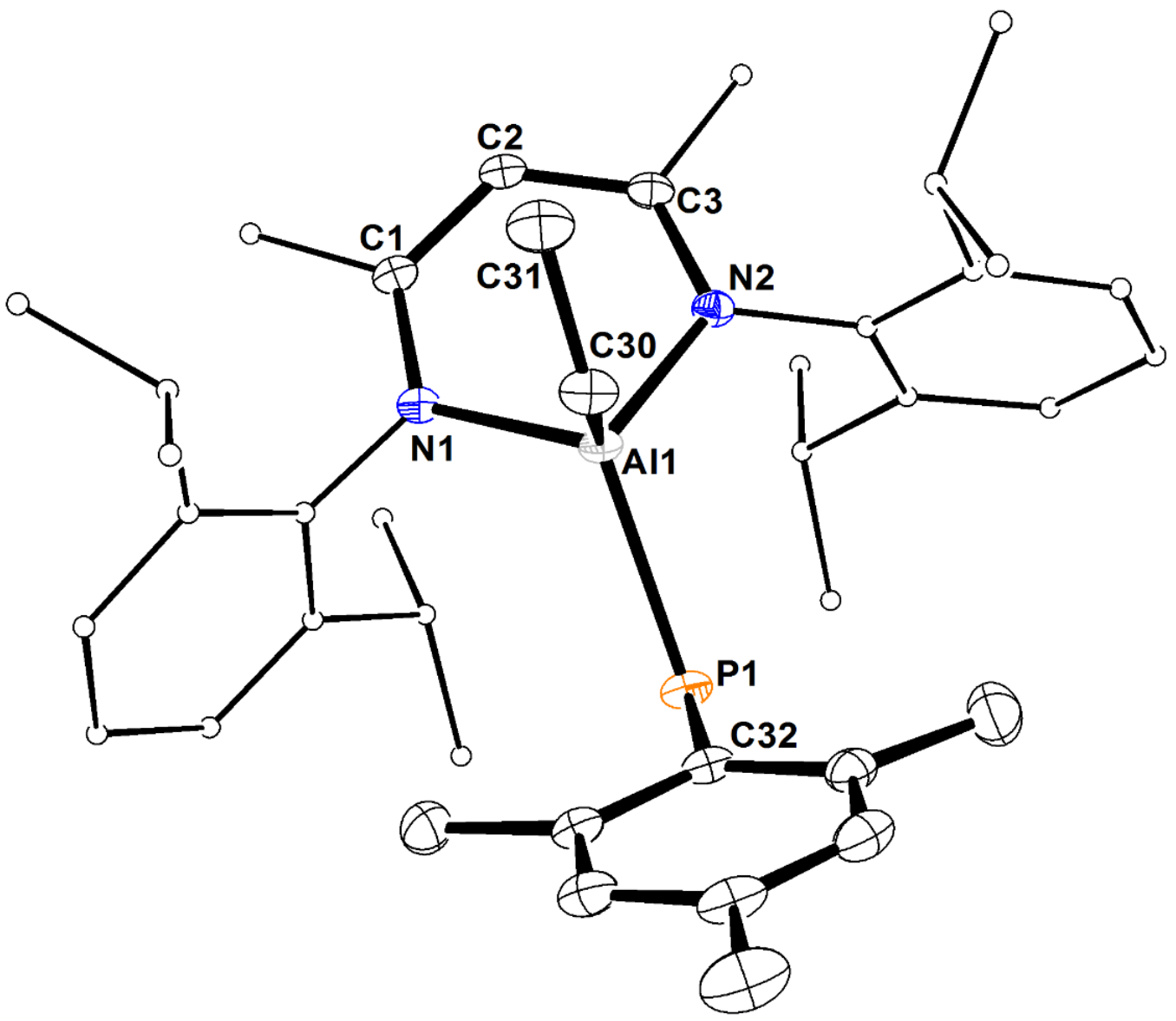

Figure 89: ORTEP plot of BDIDIPPAIEtP(H)Mes 63. Ellipsoids at $30 \%, \mathrm{H}$ atoms omitted and selected $\mathrm{C}$ atoms in wire frame for clarity.

Table 16: Selected bond lengths and angles for BDIDIPPAI(PHMes)Cl 63.

\begin{tabular}{|c|c|c|c|}
\hline \multicolumn{2}{|c|}{ Bond Lengths ( } & \multicolumn{2}{|c|}{ Bond Angles $\left({ }^{\circ}\right)$} \\
\hline $\operatorname{Al}(1)-N(1)$ & $1.928(1)$ & $N(1)-A l(1)-N(2)$ & $96.08(5)$ \\
\hline $\mathrm{Al}(1)-\mathrm{N}(2)$ & $1.911(1)$ & $A l(1)-N(1)-C(1)$ & $120.21(9)$ \\
\hline$N(1)-C(1)$ & $1.338(2)$ & $\mathrm{Al}(1)-\mathrm{N}(2)-\mathrm{C}(3)$ & 120.1(1) \\
\hline$N(2)-C(3)$ & $1.342(2)$ & $N(1)-C(1)-C(2)$ & $123.0(1)$ \\
\hline$C(1)-C(2)$ & $1.400(2)$ & $C(1)-C(2)-C(3)$ & $127.6(1)$ \\
\hline$C(2)-C(3)$ & $1.391(2)$ & $C(2)-C(3)-N(2)$ & $123.5(1)$ \\
\hline $\mathrm{Al}(1)-\mathrm{P}(1)$ & $2.390(5)$ & $C(30)-A l(1)-P(1)$ & $112.64(5)$ \\
\hline $\mathrm{Al}(1)-\mathrm{C}(30)$ & $1.970(1)$ & $\mathrm{Al}(1)-\mathrm{C}(30)-\mathrm{C}(31)$ & $117.6(1)$ \\
\hline$P(1)-C(32)$ & $1.844(1)$ & $\mathrm{Al}(1)-\mathrm{P}(1)-\mathrm{C}(32)$ & $100.12(5)$ \\
\hline
\end{tabular}

Complex 63 was heated to reflux in $C_{6} D_{6}$, toluene and THF (Scheme 35 ) to encourage elimination of ethane, however no reaction occurred under these conditions. While the Al-C bond dissociation energy is lower than that of $\mathrm{Al}-\mathrm{Cl},{ }^{243}$ the energy gained from the $\mathrm{Al}=\mathrm{P}$ double 
bond would need to offset the energy required to break both the $\mathrm{Al}-\mathrm{C}$ and $\mathrm{P}-\mathrm{H}$ bonds for the formation of the phosphinidene complex to be energetically favourable. Therefore, the complex likely did not form either due to the mesityl group preventing the complex from adopting one conformation required for elimination to occur, or the elimination reaction is not energetically favourable.

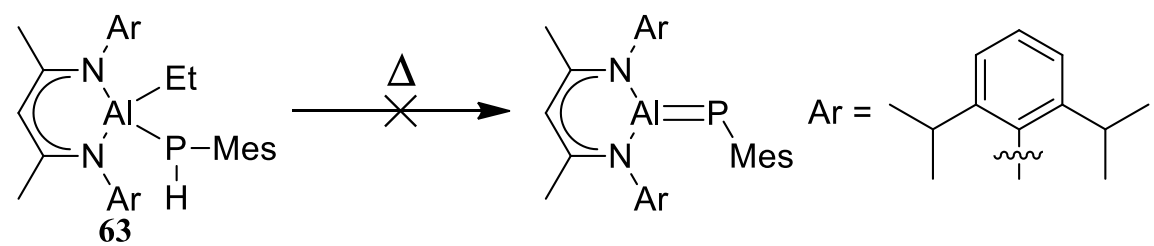

Scheme 37: Attempted aluminium phosphinidene formation.

\subsubsection{Inverse Salt Metathesis}

Similar to carbon and silicon, germanium can also form lithium salts with a metal-lithium bond that can undergo salt metathesis with metal chlorides to form a metal-metal bond. For instance, reduction of germanium dichloride CXXII with potassium metal in the presence of bistrimethylsilylacetylene (Scheme 38$)^{245}$ generates the coordination complex CXXIII. Further reduction with lithium metal generates the dilithium salt CXXIV which can then be added to a metal dichloride salt to form a germanium-metal multiple bond.

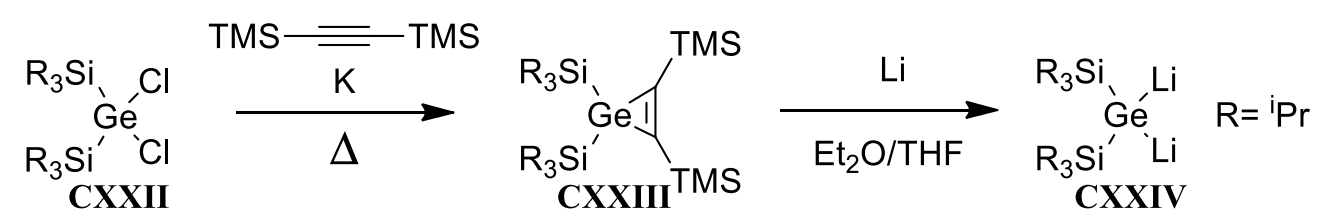

Scheme 38: Synthesis of a germanium dilithium salt. 
This methodology was applied to aluminium and gallium, with the idea to add the resulting dilithium salt to $\mathrm{MesPCl}_{2}$ to attempt to create the metal-phosphorus double bond (Scheme 39). Both $\mathbf{5 2}$ and $\mathbf{5 1}$ were heated to reflux in bistrimethylsilylacetylene with potassium metal in an attempt to form 64 and 65 , however no reaction was observed with either of the metal dichloride salts.
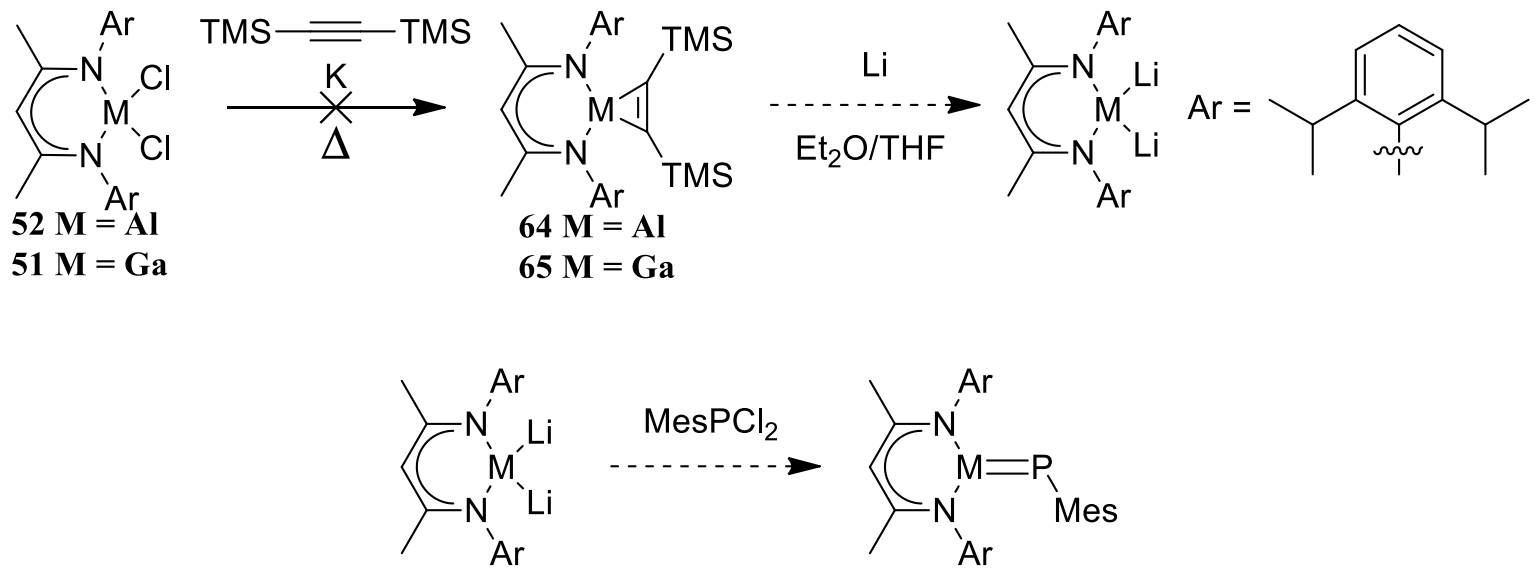

Scheme 39: Attempted use of a metal dilithium salt to form a double bond.

Synthesis of bistrimethylsilylacetylene co-ordination complex $\mathbf{6 5}$ was investigated by the reflux of BDIIIPGa 1 in bistrimethylsilylacetylene (Scheme 40), however the desired oxidative addition of $\mathbf{1}$ did not occur with bistrimethylsilylacetylene, and the complexes remained unreactive towards each other.
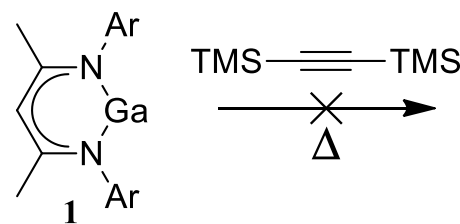

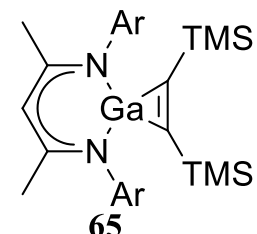

Scheme 40: Attempted reaction of $\mathrm{Ga}(\mathrm{I})$ with bistrimethylsilylacetylene. 


\subsubsection{Reduction of Phosphide Salt}

Another route investigated was the in-situ reduction of $\mathrm{MesPCl}_{2} 56$ in the presence of $\mathrm{BDI}_{\mathrm{DIPP} G a} \mathbf{1}$ with either magnesium or potassium (Scheme 41). As complex $\mathbf{1}$ is known to insert into $\mathrm{P}-\mathrm{Cl}$ bonds, ${ }^{193}$ it was postulated that mixing $\mathrm{MesPCl}_{2}$ and $\mathbf{1}$ in solution with potassium or magnesium metal would result in the formation of the desired phosphinidene complex through insertion of $\mathbf{1}$ into the $\mathrm{P}-\mathrm{Cl}$ bond followed by reduction of the two chloride moieties to give the double bonded complex. However, upon addition of $\mathrm{MesPCl}_{2}$ to 1 no reaction was observed. Addition of potassium metal to the mixture lead to a mixture of products, one of which was the known complex BDIDIPPK, indicating that ligand exchange between gallium and potassium was occurring. Addition of magnesium metal to a mixture of $\mathrm{MesPCl}_{2}$ and $\mathbf{1}$ lead to the formation of the known compounds $(\mathrm{MesP})_{3}$ and $(\mathrm{MesP})_{4}{ }^{246}$

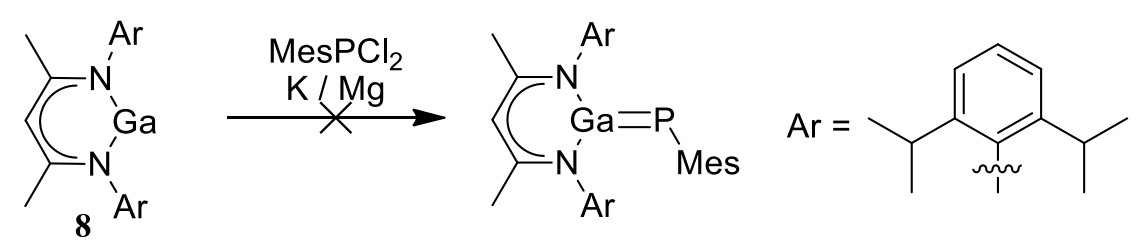

Scheme 41: Attempted in situ reduction route.

\subsubsection{Addition of $\mathrm{MesPH}_{2}$ to BDIGa}

The next method attempted was the elimination of dihydrogen, as it had been shown previously that BDIDIPPGa 1 can insert into the P-H bond of diphenylphosphine ${ }^{194}$ and that complexes such as CXXV (Figure 90) with a group 13-group 15 bond can react with $\mathrm{H}_{2}$ in a similar manner to Frustrated Lewis Pairs (FLPs). ${ }^{247}$ For instance, aluminium complex CXXV underwent hydrogenolysis upon addition of $\mathrm{H}_{2}$ gas at room temperature, forming the intermediate CXXVI, which immediately disproportionated to CXXVII and CXXVIII. 


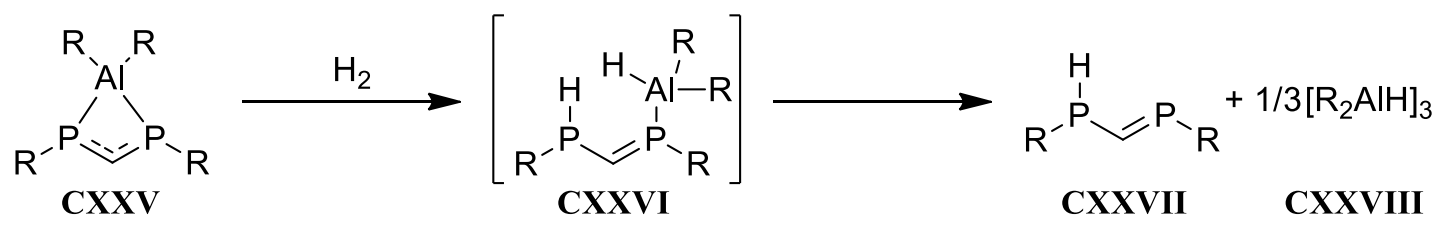

Figure 90: Hydrogenolysis of an Al-P bond.

FLPs can also reversibly bind dihydrogen, with complex CXXIX reacting with dihydrogen gas at room temperature to form complex CXXX. Complex CXXX will then liberate dihydrogen gas upon heating to $100{ }^{\circ} \mathrm{C} .{ }^{248}$ Because the gallium-phosphorus double bond is predicted to likely have poor $\pi$ orbital overlap, this may allow for a similar FLP interaction as complex CXXX, which could libertate dihydrogen at high temperatures.<smiles>[18OH]c1c(F)c([18OH])c(F)c(F)c1F</smiles>

Figure 91: Reversible binding of $\mathrm{H}_{2}$ by FLPS.

Similar to the reactivity reported between $\mathrm{BDI}_{\mathrm{DIPP}} \mathrm{Ga} \mathbf{1}$ and diphenylphosphine, addition of mesitylphosphine to 1 resulted in the oxidative addition of the phosphine onto the gallium centre to form the phosphanide hydride complex 66 (Scheme 42).

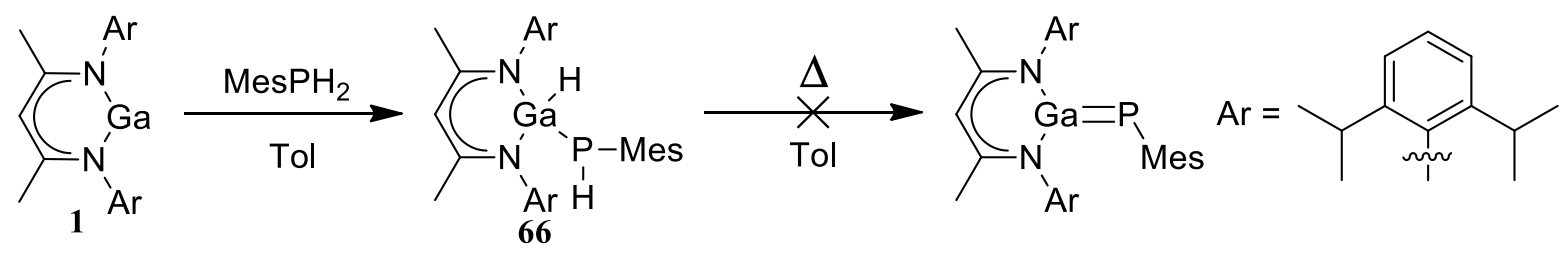

Scheme 42: Addition of $\mathrm{MesPH}_{2}$ to $B \mathrm{BDI}_{\mathrm{DIPP}} \mathrm{Ga}$. 
Complex 66 was isolated as colourless crystals. The ${ }^{1} \mathrm{H}$ NMR spectrum revealed that the $\gamma$ proton resonance appears at $\delta 4.78 \mathrm{ppm}$, nearly identical to $\mathrm{BDI}_{\mathrm{DIPP} G a}(\mathrm{H}) \mathrm{PPh}_{2}(\delta 4.79 \mathrm{ppm}) .{ }^{194}$ The presence of broad doublet at $\delta 5.65 \mathrm{ppm}$ is consistent with the presence of a gallium hydride, comparable to complex 41 ( $\delta 5.72 \mathrm{ppm}), \mathrm{BDI}_{\mathrm{DIPPG}}(\mathrm{H}) \mathrm{PPh}_{2}(\delta 6.01 \mathrm{ppm})^{194}$ and

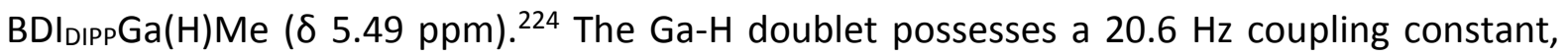
consistent with a ${ }^{2} J_{\mathrm{PH}}$ interaction. Three resonances in a 1:1:1:2 ratio to the $\gamma$-proton at $\delta 3.56$, 3.34 and $3.21 \mathrm{ppm}$ account for the methine protons of the isopropyl group, while six resonances (some overlapping doublets) in a 1:3:3:6:3:3:6 ratio to the $\gamma$-proton at $\delta 1.72$, $1.53,1.25,1.19,1.15$ and $1.10 \mathrm{ppm}$ correspond to the methyl protons of the isopropyl group. Three resonances at $\delta 2.03,1.73$ and $1.58 \mathrm{ppm}$ in a 1:3:6:6 ratio to the $\psi$-proton correspond to the mesityl ligand methyl groups and the backbone methyl groups. This indicates that the restricted rotation in the $\operatorname{Pr}$ groups present in $\mathrm{BDI}_{\text {DIPP }}$ gallium complex $\mathbf{5 9}$ is also present in $\mathbf{6 6 .}$ The phosphide proton appears as a doublet at $\delta 2.90 \mathrm{ppm}$ with a $200 \mathrm{~Hz}{ }^{1} J_{\mathrm{PH}}$ coupling constant, while the ${ }^{31} \mathrm{P}$ NMR spectrum possesses a doublet resonance at $\delta-187.5 \mathrm{ppm}$ with a $5.1 \mathrm{~Hz}$ coupling constant, presumably to the Ga-H proton. The phosphorus resonance splits into a doublet of doublets with a ${ }^{1} J_{\mathrm{PH}}$ coupling constant of $200 \mathrm{~Hz}$ and a ${ }^{2} J_{\mathrm{PH}}$ coupling constant of $20.6 \mathrm{~Hz}$ when run with the ${ }^{1} \mathrm{H}$ decoupling turned off.

An X-ray diffraction study of $\mathbf{6 6}$ showed it crystallises in the $\mathrm{P} 2_{1} / \mathrm{m}$ space group with $1 / 2$ the molecule in the asymmetric unit. The gallium atom sits above the CNNNC plane of the ligand in a pseudo-tetrahedral conformation, with a Ga-N bond length of 1.942(1) A and a bite angle of $95.16(1)^{\circ}$, comparable to BDIDIPPGa(H)PPh $\left(1.946(2) / 1.960(2) \AA \AA, 93.7^{\circ}\right)$. The Ga-H bond length of 2.2223(4) $\AA$ is significantly longer than in complex 41 and 45 (1.44(2) $\AA$ and 1.47(4) $\AA$ respectively) while the Ga-P bond length of 2.3138(5) $\AA$ and P-C bond length of $1.839(2) \AA$ are identical to complex 59, with a narrower Ga-P-C angle of $102.9(2)^{\circ}$ compared with $106.21(5)^{\circ}$. The torsion angle between the gallium hydride and the phosphide proton is $106.1^{\circ}$, effectively a trans conformation. As such, while the long $\mathrm{Ga}-\mathrm{H}$ bond may indicate that the bond is weak and could potentially undergo elimination, the $\mathrm{P}-\mathrm{H}$ proton is in the trans conformation, and the mesityl ligand directly opposite the Ga-H bond would sterically inhibit any potential elimination reaction. 


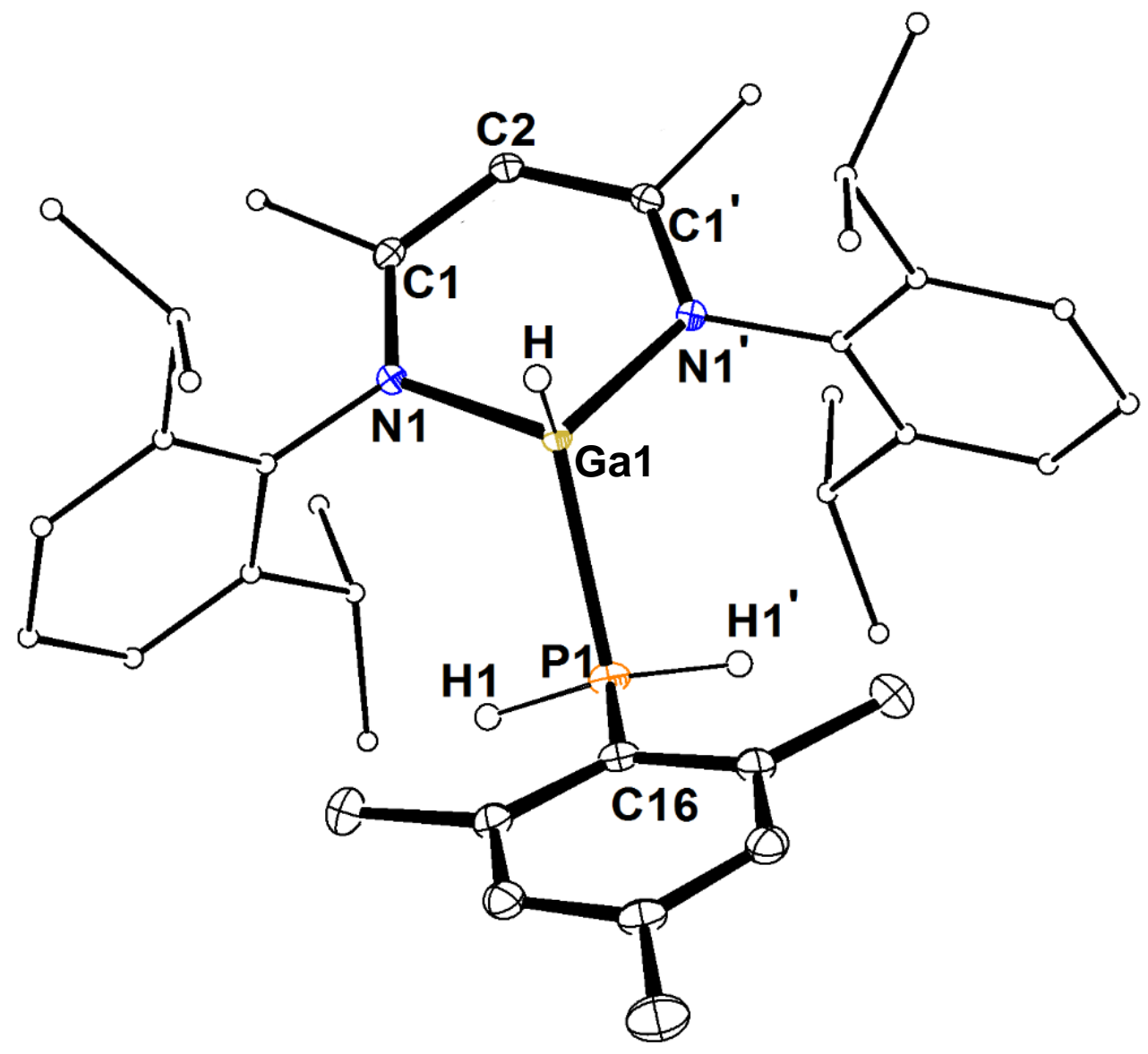

Figure 92: ORTEP plot of $B D I_{D I P P G a}(\mathrm{H}) \mathrm{P}(\mathrm{H})$ Mes 66 . Ellipsoids at $30 \%, \mathrm{H}$ atoms and solvent omitted and selected $\mathrm{C}$ atoms in wire frame for clarity.

Table 17: Selected bond lengths and angles for BDIDIPPGa(H)P(H)Mes 66.

\begin{tabular}{cccc}
\multicolumn{3}{c}{ Bond Lengths (迆 } & \multicolumn{2}{c}{ Bond Angles ( $\left.{ }^{\circ}\right)$} \\
$\mathrm{Ga}(1)-\mathrm{N}(1)$ & $1.942(1)$ & $\mathrm{N}(1)-\mathrm{Ga}(1)-\mathrm{N}\left(1^{\prime}\right)$ & $95.16(1)$ \\
$\mathrm{N}(1)-\mathrm{C}(1)$ & $1.340(2)$ & $\mathrm{Ga}(1)-\mathrm{N}(1)-\mathrm{C}(1)$ & $120.56(3)$ \\
$\mathrm{C}(1)-\mathrm{C}(2)$ & $1.394(2)$ & $\mathrm{N}(1)-\mathrm{C}(1)-\mathrm{C}(2)$ & $123.7(1)$ \\
$\mathrm{Ga}(1)-\mathrm{P}(1)$ & $2.3138(5)$ & $\mathrm{C}(1)-\mathrm{C}(2)-\mathrm{C}\left(1^{\prime}\right)$ & $128.5(1)$ \\
$\mathrm{P}(1)-\mathrm{C}(16)$ & $1.839(2)$ & $\mathrm{H}-\mathrm{Ga}(1)-\mathrm{P}(1)$ & $115.9(3)$ \\
$\mathrm{Ga}(1)-\mathrm{H}$ & $2.2223(4)$ & $\mathrm{Ga}(1)-\mathrm{P}(1)-\mathrm{C}(16)$ & $102.9(2)$ \\
$\mathrm{P}(1)-\mathrm{H}(1)$ & $1.28(2)$ & $\mathrm{Ga}(1)-\mathrm{P}(1)-\mathrm{H}(1)$ & $98(1)$
\end{tabular}

Complex 66 was heated to reflux in $\mathrm{C}_{6} \mathrm{D}_{6}$, toluene and THF (Scheme 43 ) to encourage elimination of dihydrogen, however the complex remained stable under these conditions. This indicates that the desired phosphinidene complex would not undergo reversible $\mathrm{H}_{2}$ 
addition in the same manner as known FLPs, though a different ligand system at either the phosphorus or gallium may enable this FLP behaviour.

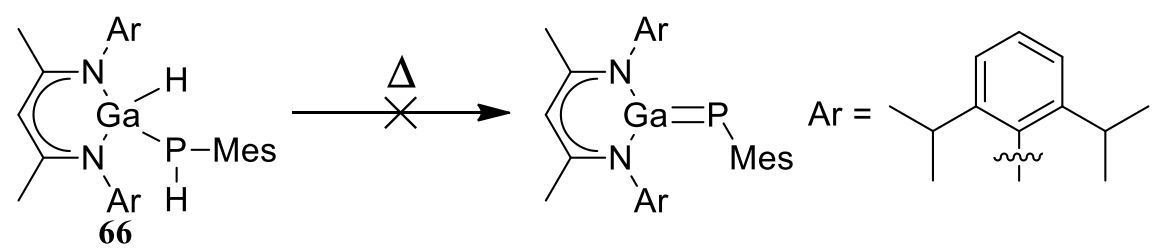

Scheme 43: Attempted gallium phosphinidene formation.

\subsubsection{Attempted Synthesis of BDIAl Complexes}

The methodology used in 3.4.7 was intended to also be applied to the known complex BDIDIPPAl 6, as the aluminium analogue of complex 1. Complex $\mathbf{6}$ was synthesised following a known literature procedure. ${ }^{124}$ Addition of BDIDIPP-H 2 to a solution of trimethylaluminium gives $\mathrm{BDI}_{\mathrm{DIPPAIMe}} \mathbf{4}$, which was converted to the diiodide 5 by stirring with elemental iodine (Scheme 44). Reduction of complex 5 with potassium metal resulted in the formation of BDIDIPPAl 6 qualitatively by ${ }^{1} \mathrm{H}$ NMR spectroscopy; however, attempts at isolating complex 6 from the reaction mixture were unsuccessful. The presence of unreacted diiodide $\mathbf{5}$ in the mixture lead to the co-crystallisation of $\mathbf{5}$ and $\mathbf{6}$ when following the literature method of crystallising from toluene. Attempts to crystallise $\mathbf{6}$ from hexane or THF were also unsuccessful. Using a slight excess of potassium metal for the reaction resulted in the overreduction of complex $\mathbf{6}$ and the formation of a small amount of $\mathrm{BDI}_{\mathrm{DIPPK}}$, which also was unable to be separated from the desired complex $\mathbf{6}$.

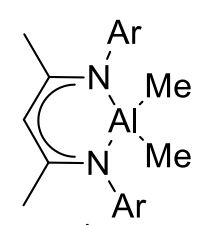

4

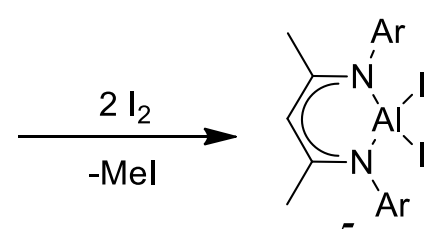

5

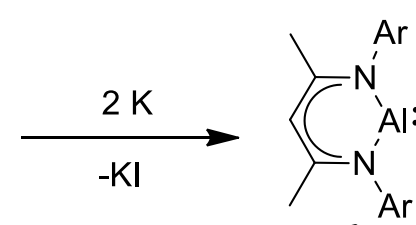

6<smiles>CC(C)c1cccc(C(C)C)c1N(C)C</smiles>

Scheme 44: Synthesis of BDIDIPP aluminium(I). 
With complex 6 proving difficult to isolate, the same methodology was attempted with the ArBDI aluminium(I) complex and examining the reactivity of 69 towards diazo- compounds and potential generation of an aluminium phosphinidene complex. It was thought that the extra delocalised electron density from the backbone phenyl group would assist in stabilising the target complex.

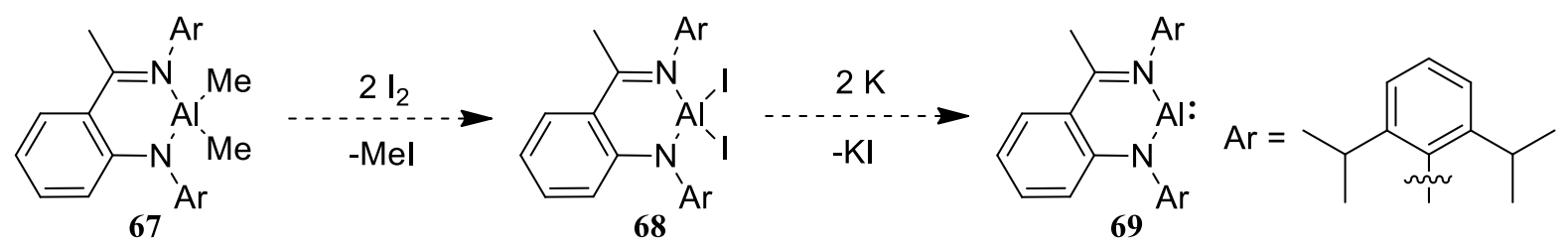

Scheme 45: Proposed synthesis of ArBDIDIPPAl.

To generate complex $\mathbf{6 7}$, reaction conditions similar to those used in the synthesis of 4 were followed. However, upon addition of trimethyl aluminium to a solution of $\mathrm{ArBDI}_{\mathrm{DIPP}}-\mathrm{H}$ 13 a new product was observed in the ${ }^{1} \mathrm{H}$ NMR spectrum that was in equilibrium with the starting materials. The presence of two N-H resonances at $\delta 11.60$ (ArBDIDIPP-H) and 5.02 ppm, along with two resonances at $\delta-0.37\left(\mathrm{AlMe}_{3}\right)$ and $-0.53 \mathrm{ppm}$ for the trimethylaluminium protons, indicated that the free ligand and trimethylaluminium were in equilibrium with a third complex. An X-ray diffraction study of crystals of the reaction mixture grown from toluene at $-30{ }^{\circ} \mathrm{C}$ identified the product as the adduct of $\mathrm{ArBDI}_{\mathrm{DIPP}}-\mathrm{H}$ and $\mathrm{AlMe}_{3} \mathbf{7 0}$ (Scheme 46) in which the imino nitrogen atom is coordinated to the aluminium centre and the anilido proton is still present.

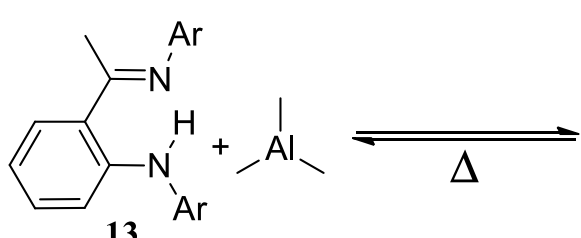<smiles>C/C(=N\[Al])c1ccccc1N[Al]</smiles><smiles>CC(C)c1cccc(C(C)C)c1C(C)C</smiles>
70

Scheme 46: Equilibrium between $\mathrm{ArBDI}_{\mathrm{DIPP}} \mathrm{H}, \mathrm{AlMe}_{3}$ and the adduct $\mathrm{ArBDI} \mathrm{DIPPH}_{\mathrm{H}} \mathrm{AlMe}$. 
The imino group of the ligand had rotated out of the usual NCCCN plane of the BDI ligand, with $C(3)$ sitting below the plane and $N(2)$ sitting above the plane. The imino nitrogen is coordinated to the aluminium with an Al-N bond distance of 2.072(1) $\AA$ and an average N-AlMe angle of $104.8^{\circ}$, similar to other imino adducts of $\mathrm{AlMe}_{3}\left(2.0418(19) \AA, 103.5^{\circ}\right) .{ }^{249}$ Due to the equilibrium between $\mathbf{1 3}$ and 70, and overlap of the methyl, methine and aromatic resonances of the two complexes, the ${ }^{1} \mathrm{H}$ NMR spectrum of $\mathbf{7 0}$ could not be fully assigned, with only the $\mathrm{N}-\mathrm{H}$ singlet resonance at $\delta 5.02 \mathrm{ppm}$ and bound $\mathrm{AlMe}_{3}$ resonance at $\delta-0.53 \mathrm{ppm}$ able to be definitively assigned. The $\mathrm{N}-\mathrm{H}$ resonance shifting upfield to $\delta 5.02 \mathrm{ppm}$ from $\delta 11.60$ $\mathrm{ppm}$ in the free ligand supports that the $\mathrm{N}-\mathrm{H}$ proton is no longer undergoing hydrogen bonding between two nitrogen atoms.

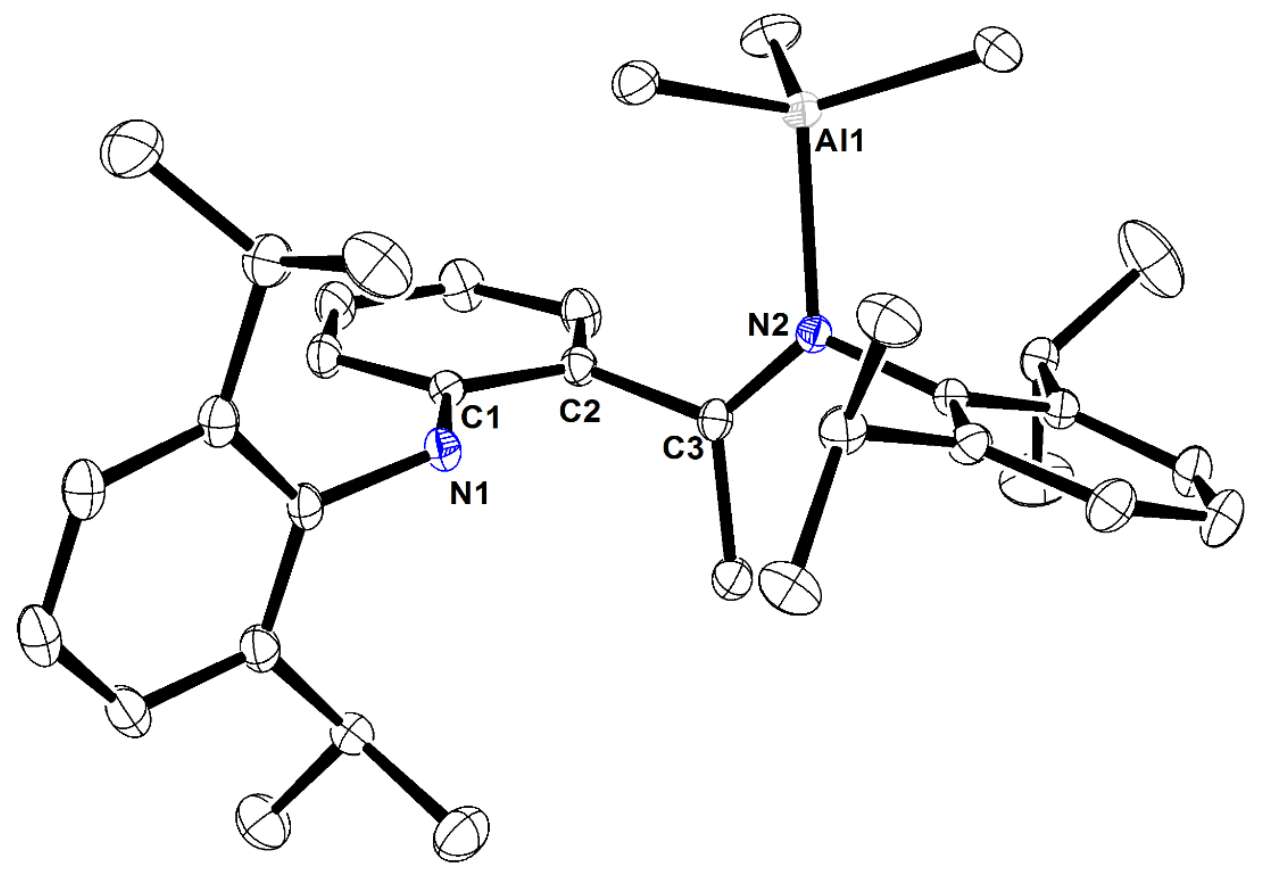

Figure 93: ORTEP plot of $\mathrm{ArBDI}_{\mathrm{DIPPH}}$.AIMe 3 70. Ellipsoids at $30 \%, \mathrm{H}$ atoms omitted for clarity.

Table 18: Selected bond lengths and angles for $\mathrm{ArBDI}_{\mathrm{DIPPH}} . \mathrm{AlMe}_{3} 70$.

\begin{tabular}{|c|c|c|c|}
\hline \multicolumn{2}{|c|}{ Bond Lengths ( $\mathrm{A})$} & \multicolumn{2}{|c|}{ Bond Angles $\left({ }^{\circ}\right)$} \\
\hline $\mathrm{Al}(1)-\mathrm{N}(2)$ & $2.072(1)$ & $\mathrm{Al}(1)-\mathrm{N}(2)-\mathrm{C}(3)$ & $128.3(1)$ \\
\hline$N(1)-C(1)$ & $1.409(2)$ & $N(1)-C(1)-C(2)$ & 119.1(1) \\
\hline$N(2)-C(3)$ & $1.284(2)$ & $C(1)-C(2)-C(3)$ & $120.7(1)$ \\
\hline$C(1)-C(2)$ & $1.409(2)$ & $C(2)-C(3)-N(2)$ & $121.5(1)$ \\
\hline$C(2)-C(3)$ & $1.496(2)$ & & \\
\hline
\end{tabular}


When crystals of $\mathbf{7 0}$ are dissolved in $\mathrm{C}_{6} \mathrm{D}_{6}$, the adduct ( $\mathrm{N}-\mathrm{H} \delta 5.02 \mathrm{ppm}, \mathrm{AlMe}_{3} \delta-0.53 \mathrm{ppm}$ ) is observed to be in equilibrium with $\mathrm{ArBDI}_{\mathrm{DIPP}}-\mathrm{H}(\mathrm{N}-\mathrm{H} \delta 11.60 \mathrm{ppm})$ and $\mathrm{AlMe}_{3}(\delta-0.37 \mathrm{ppm})$, with approximately an equal amount of starting materials and adduct present at $20{ }^{\circ} \mathrm{C}$ (red spectrum, Figure 94). The equilibrium favours free ligand and free $\mathrm{AlMe}_{3}$ upon heating to 30 ${ }^{\circ} \mathrm{C}$ (green spectrum, Figure 94), with no detectable trace of the adduct present at $40{ }^{\circ} \mathrm{C}$ (blue spectrum, Figure 94). Complex $\mathbf{7 0}$ was readily isolated as crystals at $-30{ }^{\circ} \mathrm{C}$ as lowering the temperature favours formation of the adduct. Refluxing the $\mathrm{C}_{6} \mathrm{D}_{6}$ solution for three days lead to the formation of a small amount of a new product, which was presumed to be the desired dimethyl complex 67.

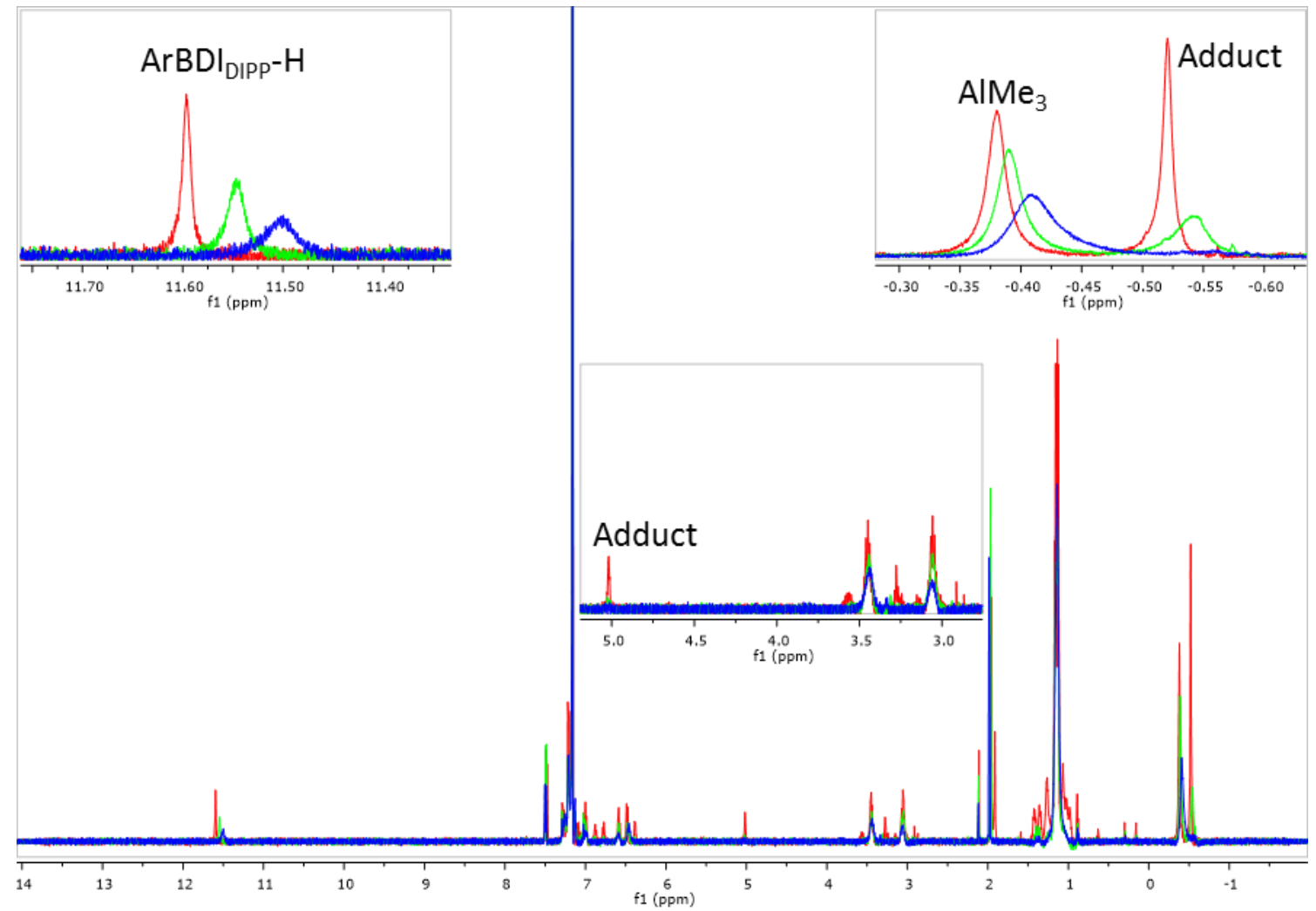

Figure 94: ${ }^{1} \mathrm{H}$ NMR spectra of 58 at $20^{\circ} \mathrm{C}, 30^{\circ} \mathrm{C}$ and $40^{\circ} \mathrm{C}$.

Refluxing a solution of $\mathbf{1 3}$ with $\mathrm{AlMe}_{3}$ in toluene for 24 hours resulted in the elimination of methane and formation of the dimethyl complex 67 (Scheme 47). A ${ }^{1} \mathrm{H}$ NMR spectroscopic 
study in $\mathrm{C}_{6} \mathrm{D}_{6}$ showed formation of a small amount of 67 after heating to $80{ }^{\circ} \mathrm{C}$ for three days, however heating to reflux in toluene affords near quantitative formation of $\mathbf{6 7}$ after 24 hours.

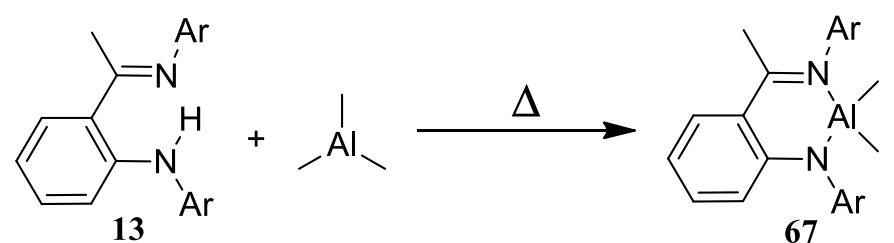

Scheme 47: Synthesis of ArBDI DIPPAIMe2.

The ${ }^{1} \mathrm{H}$ NMR spectrum of complex 67 displays the backbone methyl group as a singlet resonance at $\delta 1.86 \mathrm{ppm}$, which is in a 3:2:2 ratio with two resonances at $\delta 3.55$ and $3.21 \mathrm{ppm}$ corresponding to the methine protons of the isopropyl group. The presence of four doublet resonances each in a 3:6 ratio with the backbone methyl resonance at $\delta 1.37,1.30,1.14$ and $0.96 \mathrm{ppm}$ correspond to the methyl protons of the isopropyl group and indicates that the complex possesses one plane of symmetry, as opposed to the two planes of symmetry present in $\mathrm{BDI}_{\mathrm{DIPPAIMe}}$ 4. The aluminium bound methyl groups present as a single resonance in a 3:6 ratio with the backbone methyl at $\delta-0.55 \mathrm{ppm}$, deshielded compared to 4 ( $\delta-1.00$ ppm) indicating that the ArBDIDIPP ligand is less electron donating to aluminium than the $\mathrm{BDI}_{\mathrm{DIPP}}$ variant. An X-ray diffraction study of $\mathbf{6 7}$ showed that the aluminium sits above the NCCCN plane in a pseudo-tetrahedral conformation, with Al-Me bond lengths of $1.968(2) / 1.964(2) \AA$ identical to those in 4. The imide-amide bonding of the ligand is shown by the different Al-N bond lengths (1.966(2) $\AA$ and 1.876(1) A respectively) and the bite angle of $93.69(6)^{\circ}$ is larger than the $85.0(1)^{\circ}$ observed in $\operatorname{ArBDI}_{\text {DIPPGa }} \mathbf{1 0}$. 


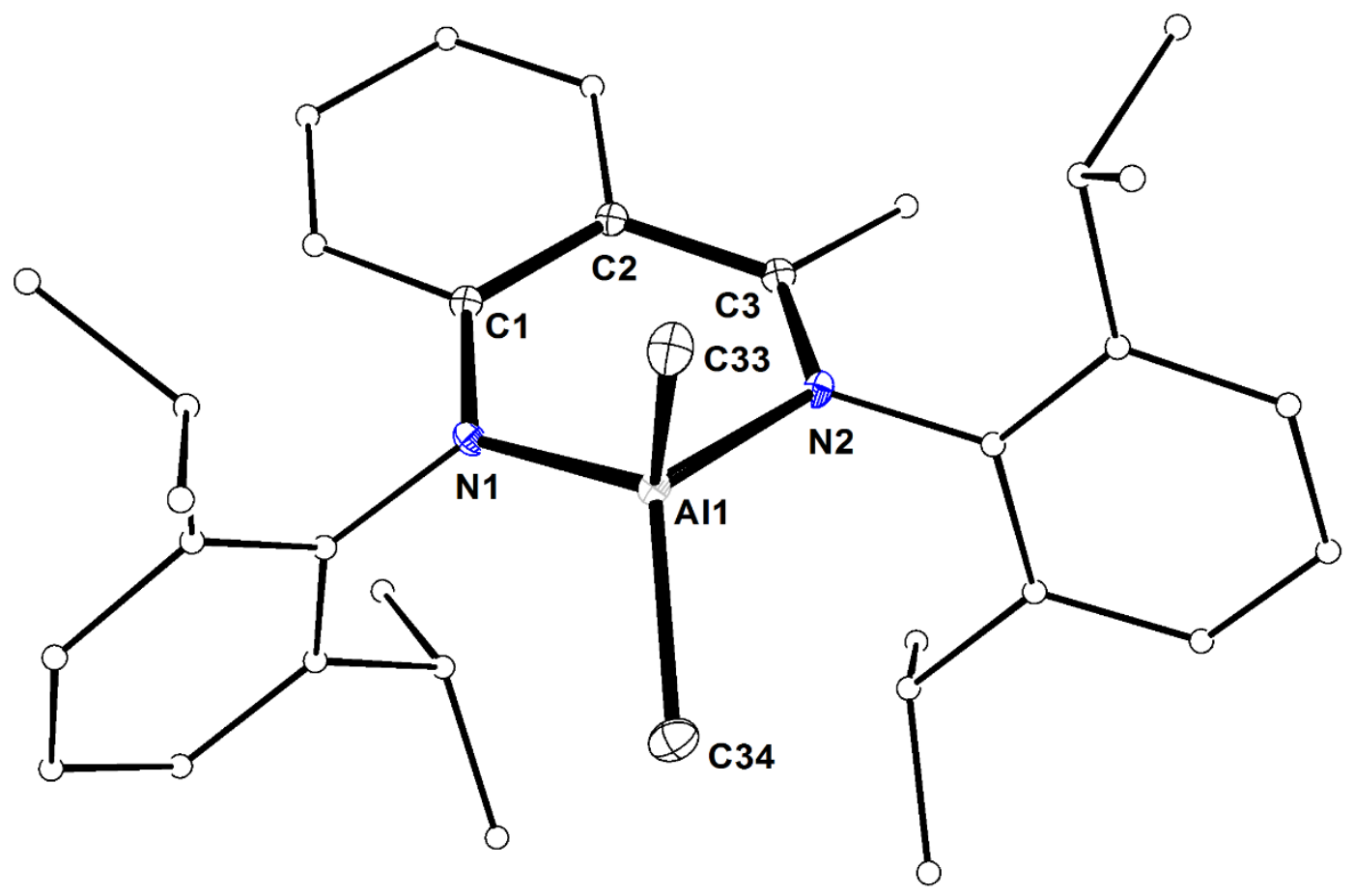

Figure 95: ORTEP plot of $\mathrm{ArBDI}_{\mathrm{DIPPAIMe}}$ 67. Ellipsoids at 30\%, $\mathrm{H}$ atoms omitted and selected C atoms in wire frame for clarity.

Table 19: Selected bond lengths and angles for ArBDI ${ }_{\text {IIPPAIMe }} 67$.

\begin{tabular}{|c|c|c|c|}
\hline \multicolumn{2}{|c|}{ Bond Lengths ( $\AA$ ) } & \multicolumn{2}{|c|}{ Bond Angles $\left({ }^{\circ}\right)$} \\
\hline $\operatorname{Al}(1)-N(1)$ & $1.876(1)$ & $N(1)-A I(1)-N(2)$ & $93.69(6)$ \\
\hline $\mathrm{Al}(1)-\mathrm{N}(2)$ & $1.966(2)$ & $A l(1)-N(1)-C(1)$ & $122.9(1)$ \\
\hline$N(1)-C(1)$ & $1.367(2)$ & Al(1)-N(2)-C(3) & $123.5(1)$ \\
\hline$N(2)-C(3)$ & $1.315(2)$ & $N(1)-C(1)-C(2)$ & $122.4(1)$ \\
\hline$C(1)-C(2)$ & $1.434(2)$ & $C(1)-C(2)-C(3)$ & $124.2(1)$ \\
\hline$C(2)-C(3)$ & $1.453(2)$ & $C(2)-C(3)-N(2)$ & $123.0(2)$ \\
\hline $\mathrm{Al}(1)-\mathrm{C}(33)$ & $1.968(2)$ & $C(33)-A l(1)-C(34)$ & $112.97(9)$ \\
\hline $\mathrm{Al}(1)-\mathrm{C}(34)$ & $1.964(2)$ & & \\
\hline
\end{tabular}

Addition of elemental iodine to a solution of $\mathbf{6 7}$ resulted in the purple colour disappearing over the course of 16 hours (Scheme 48) after which the volatiles were removed in vacuo, the residue dissolved in toluene and placed in the freezer at $-30{ }^{\circ} \mathrm{C}$, giving 68 as bright yellow crystals. 


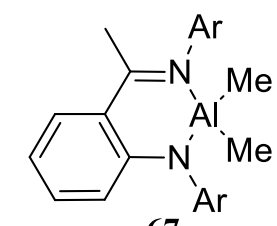

67

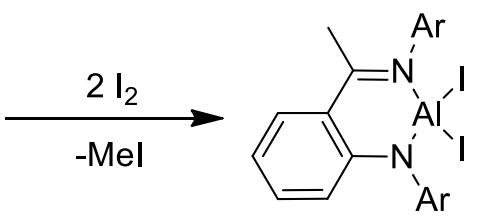

68

Scheme 48: Synthesis of ArBDIDIPPAll 2 .

The ${ }^{1} \mathrm{H}$ NMR spectrum of $\mathbf{6 8}$ shows the backbone methyl resonance as a singlet at $\delta 1.90$ ppm, which is in a 3:6 ratio with four doublet resonances at $\delta 1.46,1.43,1.07$ and $0.94 \mathrm{ppm}$ corresponding to the methyl protons of the isopropyl group. Two septet resonances in a 3:2:2 ratio with the backbone methyl at $\delta 3.71$ and $3.45 \mathrm{ppm}$ correspond to the methine protons of the isopropyl group, indicating that there is either one plane of symmetry in the molecule running through the ligand backbone; or that the Dipp groups are freely rotating. The aluminium methyl resonance of $\mathbf{6 7}$ at $\delta-0.55 \mathrm{ppm}$ is no longer present, supporting the formation of diiodide 68. An X-ray diffraction study of $\mathbf{6 8}$ showed the aluminium again adopting a pseudo-tetrahedral conformation, sitting above the NCCCN plane similar to 67 . The difference in imide-amide bond lengths is smaller (1.844(2) $\AA$ and 1.900(3) $\AA$ respectively) in 68 than in $67\left(1.876(1) \AA\right.$ and 1.966(2) $\AA$ respectively), and the bite angle in 68 of $98.0(1)^{\circ}$ is larger than the $93.69(6)^{\circ}$ observed in 67. The Al-I bond lengths of 2.528(1) $\AA$ and 2.5010(8) $\AA$ are comparable to those of $2.533 \AA$ and $2.511 \AA$ observed in $5,{ }^{238}$ indicating that complex $\mathbf{6 8}$ may be able to undergo the same reduction with potassium to form an aluminium(I) complex. 


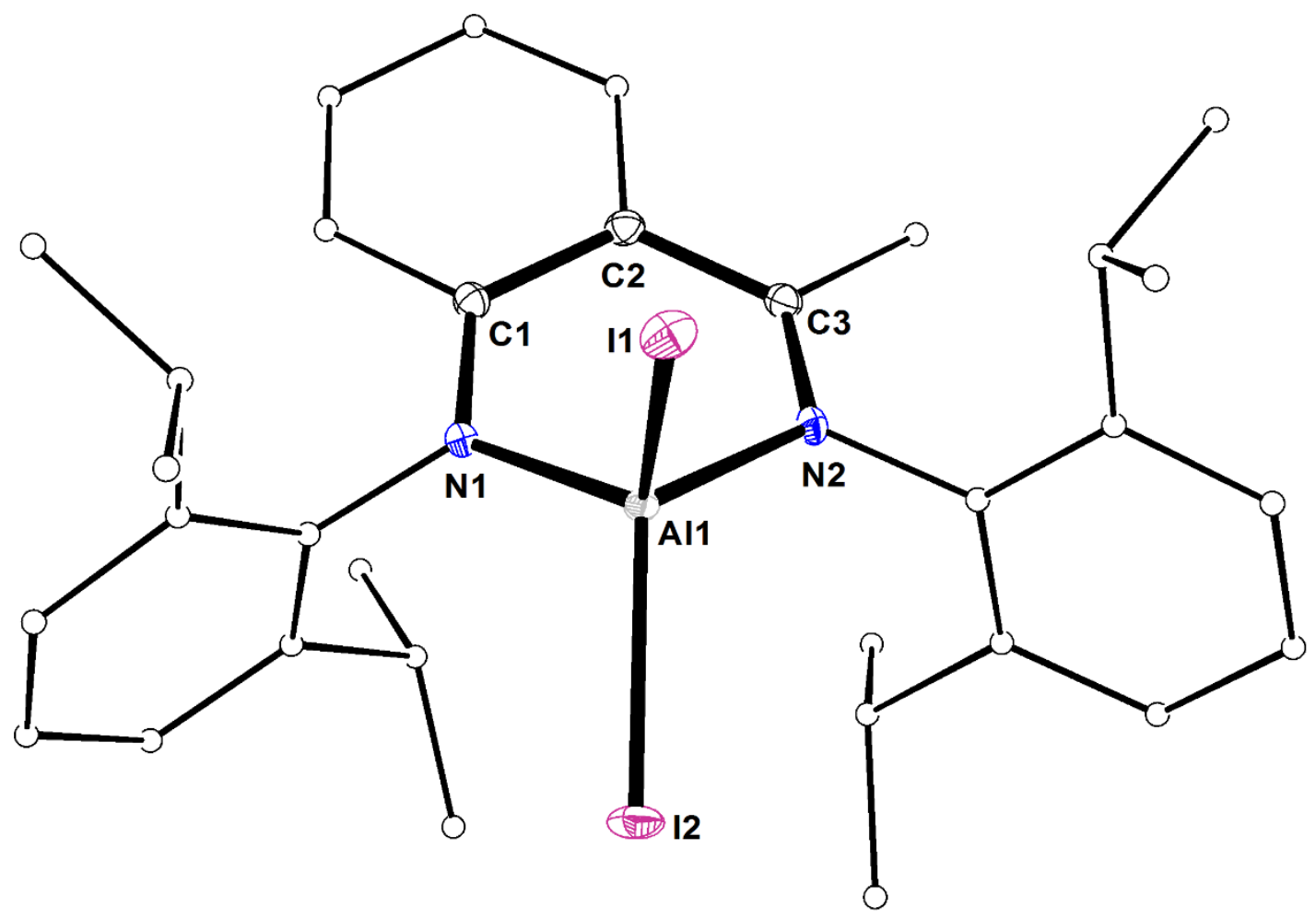

Figure 96: ORTEP plot of $\mathrm{ArBDI}_{\mathrm{DIPP}} \mathrm{All}_{2}$ 68. Ellipsoids at 30\%, $\mathrm{H}$ atoms omitted and selected $\mathrm{C}$ atoms in wire frame for clarity.

Table 20: Selected bond lengths and angles for $\mathrm{ArBDI}_{\mathrm{DIPP} A l} 68$.

\begin{tabular}{cccc}
\multicolumn{3}{c}{ Bond Lengths (̊) } & \multicolumn{2}{c}{ Bond Angles ( $\left.{ }^{\circ}\right)$} \\
$\mathrm{Al}(1)-\mathrm{N}(1)$ & $1.844(2)$ & $\mathrm{N}(1)-\mathrm{Al}(1)-\mathrm{N}(2)$ & $98.0(1)$ \\
$\mathrm{Al}(1)-\mathrm{N}(2)$ & $1.900(3)$ & $\mathrm{Al}(1)-\mathrm{N}(1)-\mathrm{C}(1)$ & $120.4(2)$ \\
$\mathrm{N}(1)-\mathrm{C}(1)$ & $1.362(4)$ & $\mathrm{Al}(1)-\mathrm{N}(2)-\mathrm{C}(3)$ & $120.8(2)$ \\
$\mathrm{N}(2)-\mathrm{C}(3)$ & $1.322(4)$ & $\mathrm{N}(1)-\mathrm{C}(1)-\mathrm{C}(2)$ & $122.3(3)$ \\
$\mathrm{C}(1)-\mathrm{C}(2)$ & $1.446(5)$ & $\mathrm{C}(1)-\mathrm{C}(2)-\mathrm{C}(3)$ & $124.3(3)$ \\
$\mathrm{C}(2)-\mathrm{C}(3)$ & $1.453(4)$ & $\mathrm{C}(2)-\mathrm{C}(3)-\mathrm{N}(2)$ & $123.3(3)$ \\
$\mathrm{Al}(1)-\mathrm{I}(1)$ & $2.528(1)$ & $\mathrm{I}(1)-\mathrm{Al}(1)-\mathrm{I}(2)$ & $108.92(3)$ \\
$\mathrm{Al}(1)-\mathrm{I}(2)$ & $2.5010(8)$ & &
\end{tabular}

Complex 68 was stirred over finely divided potassium metal (Scheme 49), the ${ }^{1} \mathrm{H} N M R$ spectrum of the reaction mixture showed multiple products had formed. Attempts to isolate these products from the mixture by crystallisation from toluene at $-30{ }^{\circ} \mathrm{C}$ resulted in the acquisition of an amber crystal of average quality for an X-ray diffraction study. While the Xray diffraction data could not be conclusively solved due to significant disorder in the structure, it indicated that the product was complex 71. Note, the bonding drawn in Scheme 
49 is indicative only, the data was of insufficient quality to distinguish any double bonds from single bonds. Complex $\mathbf{7 1}$ could have formed via a similar rearrangement of the aluminium centre as occurred in complex LXVIII (Figure 97), ${ }^{138}$ with the Al atom of 68 inserting into the imido $\mathrm{C}=\mathrm{N}$ bond to form a five-membered ring instead of a six-membered ring. It is possible that the target complex ArBDI IIPPAl 69 did form, but excess potassium in the reaction mixture lead to the subsequent formation of 71. Further attempts at synthesising $\mathbf{6 9}$ were performed, with more average/poor quality crystals of $\mathbf{7 1}$ being isolable from the reaction mixtures when potassium was used as the reducing agent. Upon changing the reducing agent to sodium, an intractable mixture of products was obtained. Changing the reducing agent to magnesium also yielded an intractable mixture of products.
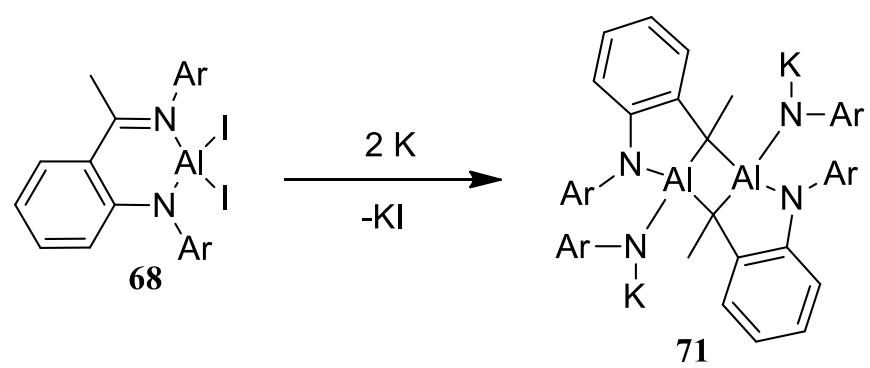

Scheme 49: Reduction of ArBDIDIPpAll 2 with potassium.
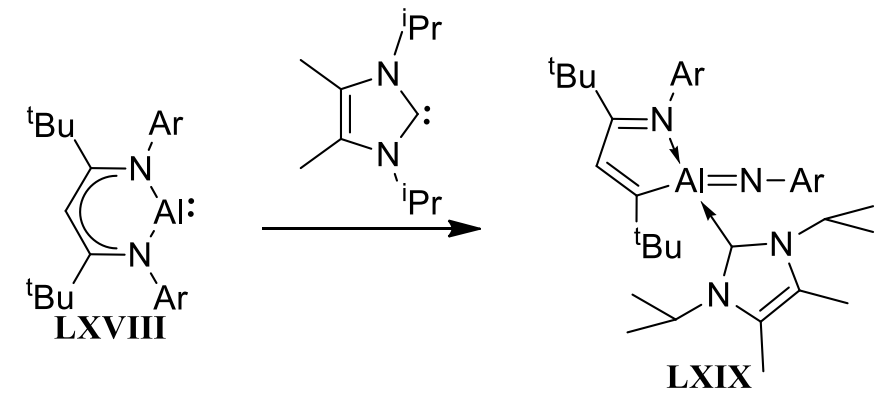<smiles>[Y]c1c(C(C)C)cccc1C(C)C</smiles>

Figure 97: Formation of aluminium imide by addition of an $\mathrm{N}$-heterocyclic carbene. 
With the synthesis of BDIDIPPAl 6 being unsuccessful due to problems with isolation, and the synthesis of ArBDI DIPPAl $\mathbf{6 9}$ being unsuccessful due to the complex potentially spontaneously rearranging, the synthesis of $\mathrm{BDI}_{\mathrm{Ar}} \mathrm{Al} \mathbf{7 4}$ (Scheme 50 ) was proposed using similar methodology. As the $\mathrm{BDI}_{\mathrm{Ar}}$ ligand possesses more steric protection than $\mathrm{BDI}_{\mathrm{DIPP}}$ or ArBDIDIPP, it was thought that this would help stabilise the aluminium(I) complex and therefore make it easier to synthesise and isolate.

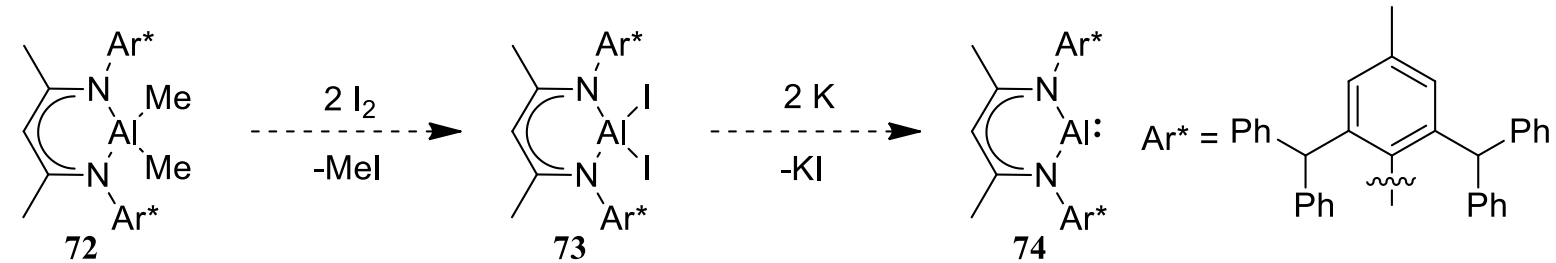

Scheme 50: Proposed synthesis of $\mathrm{BDI}_{\mathrm{Ar}}$ aluminium(I).

Addition of $\mathrm{BDI}_{\mathrm{Ar} *-\mathrm{H}} \mathbf{1 5}$ to trimethylaluminium in $\mathrm{C}_{6} \mathrm{D}_{6}$ indicated that no reaction occurred between the two at room temperature, therefore the reaction was carried out at reflux in toluene (Scheme 51), which resulted in the formation of the dimethyl complex $\mathbf{7 2}$ as a white powder. Attempts to grow crystals of $\mathbf{7 2}$ were unsuccessful, with the complex forming fibrous, semi-crystalline, rope-like aggregates of tiny needles upon slow evaporation of toluene. The ${ }^{1} \mathrm{H}$ NMR spectrum of 72 reveals the $\psi$-proton resonance as a singlet at $\delta 4.51 \mathrm{ppm}$, shielded relative to 15 ( $\delta 4.18 \mathrm{ppm}$ ). Two singlet resonances in a 1:6:6 ratio to the $\psi$-proton at $\delta 1.87$ and $0.39 \mathrm{ppm}$ correspond to the Ar-methyl resonance and the backbone methyl resonance respectively. A singlet resonance in a 1:6 ratio with the $\gamma$-proton corresponds to the aluminium methyl ligand resonance, which is deshielded relative to 4 and 67 ( $\delta-1.00$ and $0.55 \mathrm{ppm}$ respectively), indicating that the aluminium is drawing more electron density from the methyl ligands. A singlet resonance in a 1:4 ratio with the $y$-proton at $\delta 6.42 \mathrm{ppm}$ corresponds to the $\mathrm{CHPh}_{2}$ protons, additionally two doublet resonances at $\delta 7.36$ and 7.25 $\mathrm{ppm}$ and one triplet resonance at $\delta 6.93 \mathrm{ppm}$ in a 1:8:8:4 ratio with the $\gamma$-proton correspond to the resolvable resonances of the phenyl groups, with the other 20 presenting as overlapping resonances. 


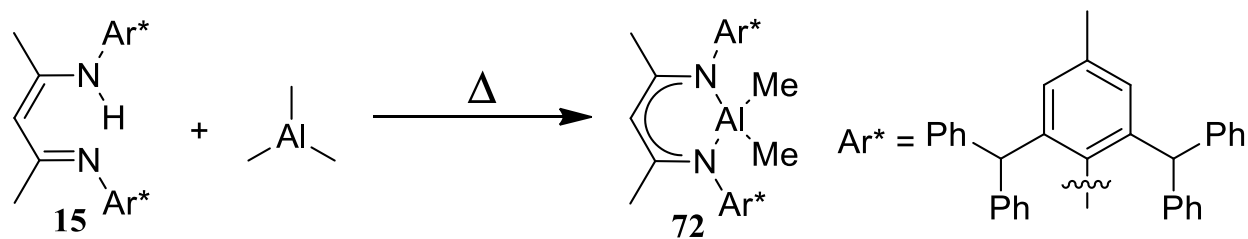

Scheme 51: Synthesis of $\mathrm{BDI}_{\mathrm{Ar}} * \mathrm{AlMe}_{2}$.

Complex 72 was stirred with elemental iodine in toluene for three days (Scheme 52) with the goal of forming the diiodide species 73. However, the ${ }^{1} \mathrm{H}$ NMR spectrum of the reaction mixture showed the presence of a new $\gamma$-proton resonance at $\delta 4.67 \mathrm{ppm}$, along with unreacted 72. Three new singlet resonances at $\delta 1.81,0.55$ and $0.43 \mathrm{ppm}$ in a 1:6:3:6 ratio with the $y$-proton are observed, and are assigned as the Ar-methyl resonance, Al-methyl resonance and the backbone methyl resonance respectively. This indicated that the product was the mixed methyl iodide complex 75. Refluxing the reaction mixture in a sealed ampule for a week resulted in a very small amount (c.a. 5\%) of a new product ( $\gamma$-proton $\delta 4.84 \mathrm{ppm}$ ) forming that potentially was the target diiodide $\mathbf{7 3}$, however this complex could not be isolated. The substitution of only one of the methyl ligands by iodide indicates that the BDI $\mathrm{Ar}$ * ligand is likely blocking the substitution of the second methyl ligand from occurring, due to the increased steric hinderance the ligand provides.

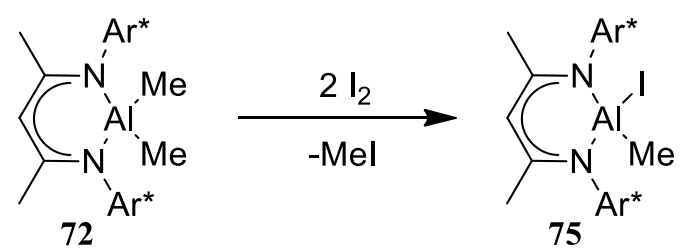

Scheme 52: Synthesis of $\mathrm{BDI}_{\mathrm{Ar}} * \mathrm{Al}(\mathrm{Me}) \mathrm{I}$. 


\subsection{Conclusion}

The attempts to form a formal double bond between either aluminium or gallium and phosphorus were not successful, the reactions of mixed chloro-phosphide substituted species with ${ }^{\mathrm{n}} \mathrm{BuLi}$ or ${ }^{\mathrm{t}} \mathrm{BuLi}$ did not result in the proposed elimination of $\mathrm{LiCl}$ and formation of metalphosphinidene species, but rather an intractable mixture of products that could not be successfully isolated. Increasing the steric bulk of the phosphide substituent from phenylphosphide to mesitylphosphide did not assist in isolating a metal-phosphinidene complex, but instead lead to the decomposition of the starting complexes and a mixture of unisolable products.

Changing the elimination product required for the proposed formation of a metalphosphinidene from $\mathrm{LiCl}$ to $\mathrm{TMS}-\mathrm{Cl}$ was also unsuccessful, though the intermediate species BDIDIPPAI(Cl)P(TMS)Ph was isolated successfully, it showed no signs of eliminating TMS-Cl upon heating. Changing the attempted elimination product to ethane lead to the synthesis of $\mathrm{BDI}_{\mathrm{DIPP}} \mathrm{Al}(\mathrm{Et}) \mathrm{P}(\mathrm{H}) \mathrm{Mes}$, which also showed no signs of undergoing elimination of ethane to form the target phosphinidene complex.

Attempts to reduce $\mathrm{MesPCl}_{2}$ with potassium in the presence of $\mathrm{BDI}_{\text {DIPPGa lead to the }}$ decomposition of the starting material, or formation of $(\mathrm{MesP})_{3}$ and $(\mathrm{MesP})_{4}$ when magnesium was used as the reducing agent. The attempt to make MesPLi 2 and react that with $\mathrm{BDI}_{\mathrm{DIPPM}} \mathrm{MX}_{2}(\mathrm{M}=\mathrm{Al}, \mathrm{Ga} \mathrm{X}=$ halogen) complexes should be investigated further, as it was likely that the MesPLi 2 was not successfully synthesised.

The attempt to eliminate dihydrogen from the complex $\mathrm{BDI}_{\mathrm{DIPP}} \mathrm{Ga}(\mathrm{H}) \mathrm{P}(\mathrm{H}) \mathrm{Mes}$ was also unsuccessful, indicating that the Ga-P interaction is not similar to known FLP interactions that can reversibly bind dihydrogen.

Attempts to investigate aluminium(I) species as reagents in the formation of an aluminium-phosphinidene complex were also unsuccessful, with BDIDIPPAl being successfully synthesised, but unable to be isolated/purified. The attempt to make a new BDI aluminium(I) complex using the ArBDIDIPP ligand was potentially successful, however the complex appears to undergo a similar insertion of the aluminium atom into the $\mathrm{C}=\mathrm{N}$ bond of the ligand to generate a five-membered ring previously reported. Another attempt using the $\mathrm{BDI}_{\mathrm{Ar}}$ ligand 
was unable to convert the dimethyl complex $\mathrm{BDI}_{\mathrm{Ar}} * \mathrm{AlMe}_{2}$ into the diiodide complex $\mathrm{BDI}_{\mathrm{Ar}} \mathrm{All}_{2}$, presumably due to the steric hinderance of the $\mathrm{BDI}_{\mathrm{Ar}}$ ligand preventing the second methyl ligand from undergoing substitution. 


\section{Chapter 4}

\section{Reactivity of Primary Gallium}

and Aluminium Phosphanides

\subsection{Introduction}

Compounds containing both group 13 and group 15 compounds are typically natural Lewis pairs, with group 15 compounds possessing a lone pair of electrons and group 13 compounds possessing an empty $p$ orbital allowing them to readily form adducts. One of the simplest adducts is ammonia borane (CXXXI, Figure 98) which was isolated as the monomeric form of $\mathrm{B}_{2} \mathrm{H}_{6} .2 \mathrm{NH}_{3}$ by the reaction of $\mathrm{LiBH}_{4}$ with $\mathrm{NH}_{4} \mathrm{Cl} .^{250}$ The strong compatibility of the two groups leads to adducts of many of the possible forms of CXXXII, even the inert pair effect does not prevent bismuth from forming adducts with aluminium and gallium. ${ }^{251}$
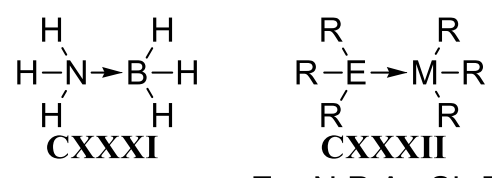

$\mathrm{E}=\mathrm{N}, \mathrm{P}, \mathrm{As}, \mathrm{Sb}, \mathrm{Bi}$

$M=B, A l, G a, I n, T I$

Figure 98: Adducts of group 13/15 elements.

This high tendency to form adducts creates difficulties in investigating the reactivity of group 13-15 bonds, as compounds with formal bonds (i.e. $\mathrm{R}_{2} \mathrm{E}-\mathrm{MR}_{2}$ ) are much rarer than adducts. ${ }^{24}$ Even when a group 13-group 15 bond is formed, the presence of the adjacent empty $p$ orbital and lone pair generally leads to either a degree of multiple bonding ( $\mathbf{L X V}$, 
Figure 99), ${ }^{24}$ or dimer/oligomer formation (CXXXIII) from electron donor-acceptor pairs between molecules. ${ }^{252-253}$

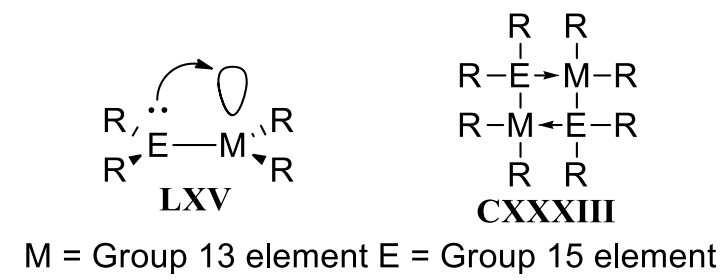

Figure 99: Group 13-group 15 lone pair donation.

Of the complexes possessing bond between group 13 and group 15 elements, the amidoboranes are by far the most common, followed by the boron phosphanides and the amidoalanes (Cambridge Structural Database, Aug 2018 database). While both aluminium phosphanides and gallium phosphanides are known compounds, the reactivity of these species is almost unknown, and the boron phosphanides must be used as a reference point to base a reactivity study on.

\subsubsection{Reactivity of Boron Phosphanides}

Boron phosphanides $\left(R_{2} B P R_{2}\right)$ are the most common of the group 13 phosphanides, however they are dwarfed in number by the boron-phosphine adducts $\left(R_{3} B . P R_{3}\right)$ which are widely used in both organic and inorganic chemistry. ${ }^{254}$ Boron phosphanides usually form dimers ${ }^{255}$ or trimers, ${ }^{256}$ but can exist as discrete units in which case they typically exhibit a degree of $\pi$ bonding between the valence pair of the phosphorus and the empty $p$ orbital on the boron. They can also be coordinated to a Lewis acid (CXXXIV, Figure 100), ${ }^{257}$ Lewis base $(\mathbf{C X X X V})^{258-259}$ or both, ${ }^{260}$ giving rise to reagents that possess just the empty $p$ orbital, just the lone pair, or both across the B-P bond (CXXXVI). 


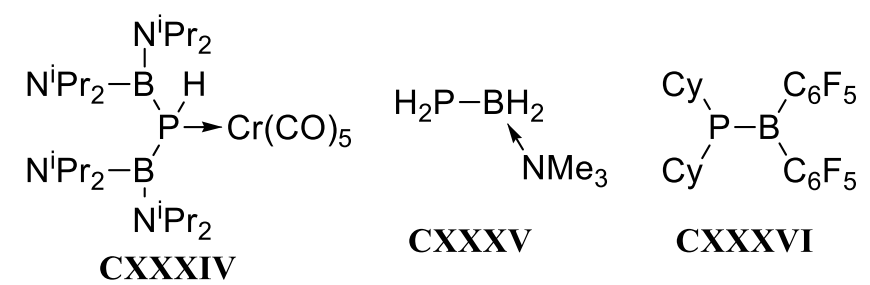

Figure 100: Different types of boron phosphanides.

Because of the poor orbital overlap between the boron and phosphorus $\pi$ orbitals, the lone pair on the phosphorus is both involved in bonding and can readily act as a nucleophile, ${ }^{261}$ and boron phosphanides will readily coordinate to transition metals such as chromium, ${ }^{257,262}$ tungsten, ${ }^{259}$ iron, ${ }^{259}$ and molybdenum. ${ }^{263}$

\subsubsection{Reactivity with $\mathrm{H}_{2}$}

Boron phosphanides can react in a similar manner to Frustrated Lewis Pairs (FLPs) in that they irreversibly cleave dihydrogen when both strong electron withdrawing groups and bulky steric ligands are utilised. The compounds $\left(\mathrm{C}_{6} \mathrm{~F}_{5}\right)_{2} \mathrm{BPCy}_{2} \mathbf{C X X X V I I a}$ and $\left(\mathrm{C}_{6} \mathrm{~F}_{5}\right)_{2} \mathrm{BP}^{t} \mathrm{Bu}_{2}$ CXXXVIIb have been shown to activate $\mathrm{H}_{2}$ at $60{ }^{\circ} \mathrm{C}$ to give full conversion to CXXXVIIIa and CXXXVIIIb respectively after 48 hours (Figure 101). ${ }^{264}$ While CXXXVIIa and CXXXVIIb possess B-P $\pi$ interactions giving a large degree of multiple bonding between the two, the poor orbital overlap between boron and phosphorus allows the complexes to behave in a similar manner to FLPs.

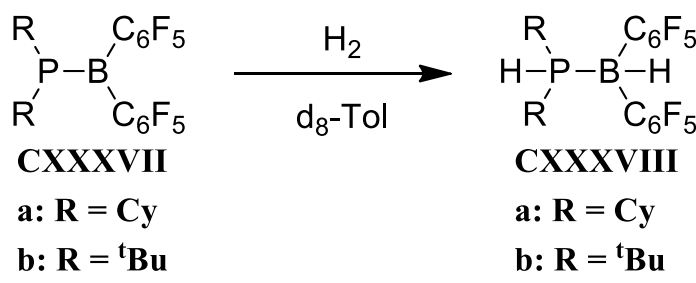

Figure 101: Reactivity of boron phosphanides with $\mathrm{H}_{2}$. 


\subsubsection{Reactivity with Chalcogens}

Elemental chalcogens react with the stabilised boron phosphanide CXXXV (Figure 102) by oxidising the phosphorus(III) to phosphorus(V) to give the sulphide CXXXIXa and selenide CXXXIXb complexes. In the case of dioxygen, insertion into the P-H bonds occurs in addition oxidation of the $\mathrm{P}(\mathrm{III})$ to $\mathrm{P}(\mathrm{V})$ to give phosphonic acid $\mathrm{CXL} .{ }^{259}$ Changing the $\mathrm{PH}_{2}$ group for $\mathrm{PPh}_{2}$ allowed for the tellurium analogue to be synthesised, which possesses similar reactivity however the reaction with $\mathrm{O}_{2}$ does not form the phosphonic acid and instead yields the phosphine oxide. ${ }^{265}$

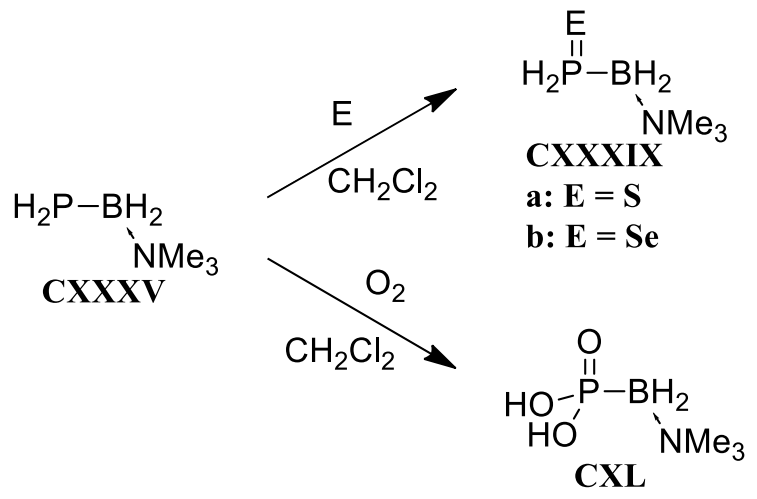

Figure 102: Boron phosphanide reactivity with chalcogens.

\subsubsection{Reactivity of Aluminium Phosphanides}

The reported reactivity of aluminium phosphanides is limited to the decomposition product of $\left(\mathrm{Me}_{3} \mathrm{SiCH}_{2}\right)_{2} \mathrm{AlPPh}_{2}$ reacting with THF to form $\mathrm{Ph}_{2} \mathrm{PC}_{4} \mathrm{H}_{8} \mathrm{OH} ;{ }^{266}$ and the insertion of $\mathrm{CO}_{2}, \mathrm{CS}_{2}$, and $\mathrm{CSO}$ into the aluminium-phosphorus bond of $(\mathrm{Tmp})_{2} \mathrm{AIP}\left(\mathrm{SiMe}_{3}\right)_{2}{ }^{267}$ This is because the majority of the investigated chemistry of aluminium-phosphorus bond reactivity typically involves a phosphine $\left(\mathrm{R}_{3} \mathrm{P}-\mathrm{Al} \mathrm{R}_{3}\right)$ Lewis donor-acceptor complex rather than an aluminium with a phosphide ligand $\left(R_{2} P-A l R_{2-3}\right)$. Complexes of the formula $R_{2} A I P R_{2}$, such as the landmark $\operatorname{Trip}_{2} \mathrm{AIP}\left(\mathrm{SiPh}_{3}\right) \mathrm{Ad}$ (CXLI, Figure 103), ${ }^{268}$ are relatively uncommon ${ }^{269}$ and almost all have not had any significant reactivity studies published on them. Recently the reactivity of aluminium phosphine complexes has been centred around their use as FLPs, with 
bridged $\mathrm{R}_{2} \mathrm{P}-\mathrm{X}-\mathrm{AlR} \mathrm{R}_{2}(\mathrm{X}=\mathrm{C}, \mathrm{N})$ complexes such as $\mathrm{CXLII}$ being used to activate alkynes, ${ }^{270}$ alkenes, ${ }^{271}$ isocyanates, ${ }^{271-273} \mathrm{CO}_{2},{ }^{271-274}$ and $\mathrm{H}_{2} .{ }^{247}$

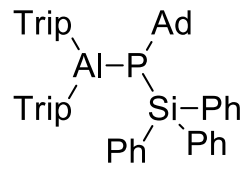

CXLI<smiles>CC[Al](CC)N(c1c(C(C)C)cccc1C(C)C)P(c1ccccc1)c1ccccc1</smiles>

CXLII

Figure 103: Aluminium phosphanide and FLP.

\subsubsection{Reactivity of Gallium Phosphanides}

Despite the diverse range of both monosubstituted ${ }^{231,} 275$ and disubstituted ${ }^{179,}$ 194, 240, 276 phosphanide ligands on gallium complexes, the reported reactivity of these gallium phosphanides is limited to their co-ordination complexes with transition metals, ${ }^{277}$ thermolysis of $\mathrm{P}-\mathrm{H}$ bonds to form $(\mathrm{RGaPR})_{2}$ dimers, ${ }^{278}$ and the attempted formation of a gallium-phosphorus double bond (discussed in section 3.1) through the attempted abstraction of $\mathrm{HI}$ with base from the mixed halo-phosphanide complex CXIV (Figure 104) which instead eliminated iodine through a single electron reduction of the ligand to give complex CXV. ${ }^{231}$

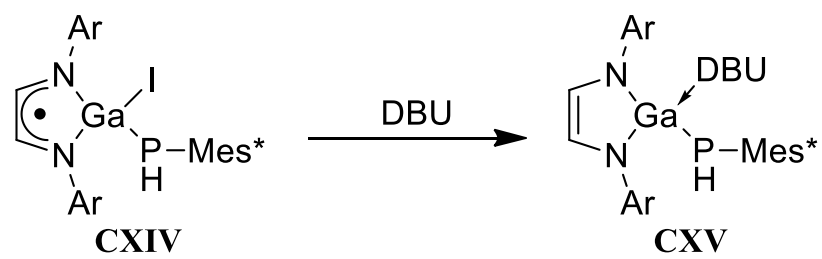

Figure 104: Attempted gallium phosphorus double bond formation. 


\subsection{Aim}

The objective of this study was to investigate the reactivity of the primary aluminium and gallium phosphanides isolated in Chapter 3, specifically $\mathrm{BDI}_{\mathrm{DIPP}} \mathrm{Al}(\mathrm{PHMes}) \mathrm{Cl} \mathbf{5 8}$, BDIDIPPAI(PHMes)Et 63, and BDIDIPPGa(H)P(H)Mes 66 (Figure 105). As mentioned previously, the reactivity of group 13 phosphanides has only been substantially investigated for the boron phosphanides. While the apparatus for investigating the reactivity with $\mathrm{H}_{2}$ and $\mathrm{CO}_{2}$ gas was unavailable at the time of this research, the reactivity with unsaturated small molecules such as phenyl acetylene, 4-nitro-phenyl isocyanate, phenyl isothiocyanate, dicyclohexyl carbodiimide, cyclohexene, benzophenone, benzaldehyde, methyl iodide and the chalcogens selenium and sulfur will be investigated (Figure 106).
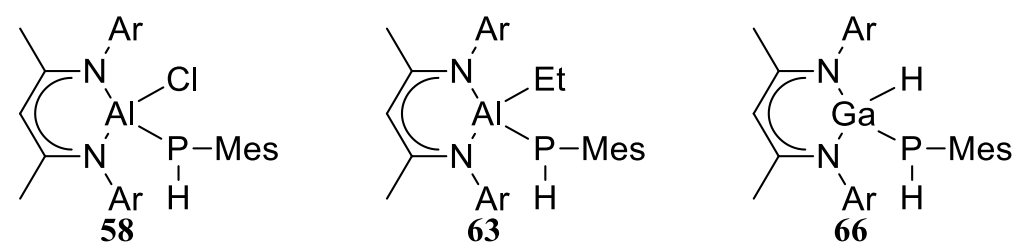

Figure 105: Primary aluminium and gallium phosphanides.

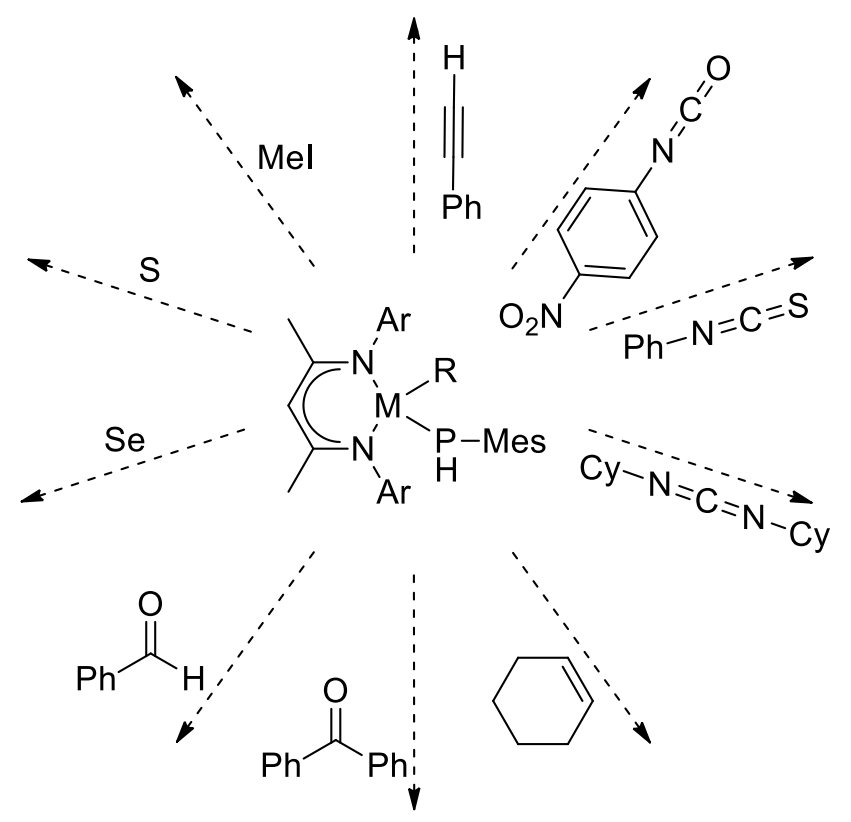

Figure 106: Reactivity diagram. 


\subsection{Results and Discussion}

Complexes 58, 63 and 66 are synthesised as described in chapter 3, with complexes 58 and $\mathbf{6 3}$ being formed through the addition of either $\mathrm{AlCl}_{3}{ }^{238}$ or $\mathrm{AlEtCl}_{2}{ }^{244}$ respectively to a solution of BDIDIPp-Li 3 (Scheme 53), followed by addition of the lithium salt of mesitylphosphine. Complex $\mathbf{6 6}$ was prepared by the addition of mesitylphosphine $\mathbf{5 7}$ to a solution of BDIDIPPGa 1 (Scheme 54). $\sum_{-N} N^{\prime}{ }^{\prime} \mathrm{Ar}$

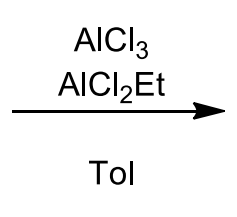<smiles></smiles>

$52 \mathbf{R}=\mathbf{C l}$

$62 \mathrm{R}=\mathbf{E t}$

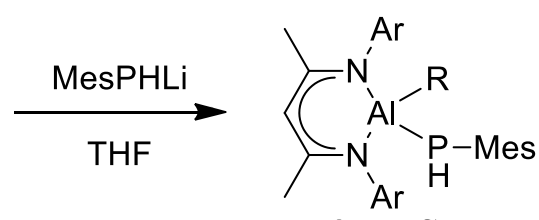

$58 \mathrm{R}=\mathbf{C l}$

$63 \mathrm{R}=\mathbf{E t}$<smiles>CC(C)c1cccc(C(C)C)c1C(C)(C)C</smiles>

Scheme 53: Synthesis of BDIDIPPAl phosphanides.

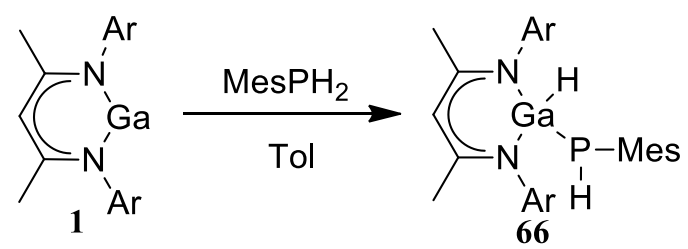

Scheme 54: Synthesis of BDIDIPPGa(H)P(H)Mes.

\subsubsection{Reactivity with Phenylacetylene}

Addition of phenyl acetylene to a solution of either phosphanide 58, 63 and 66 in $d_{6}$ benzene (Scheme 55) caused no visible change in either the ${ }^{1} \mathrm{H}$ or ${ }^{31} \mathrm{P}$ NMR spectrum of the mixture after 1 hour at room temperature. Upon heating to $40{ }^{\circ} \mathrm{C}$ for 2 hours, no reaction was observed and subsequent heating of the solution to $60{ }^{\circ} \mathrm{C}$ for 24 hours (Figure 107) still resulted in no change being observed. This implies that these phosphanides do not activate the acetylene bond. 

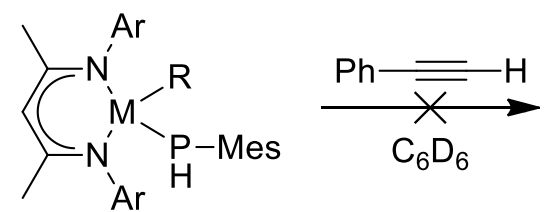<smiles>CC(C)c1cccc(C(C)C)c1C(C)C</smiles>

$58 \mathrm{M}=\mathrm{Al} \mathbf{R}=\mathbf{C l}$

$63 \mathrm{M}=\mathrm{Al} \mathrm{R}=\mathrm{Et}$

$66 \mathrm{M}=\mathrm{Ga} R=\mathbf{H}$

Scheme 55: Reactivity with phenyl acetylene.

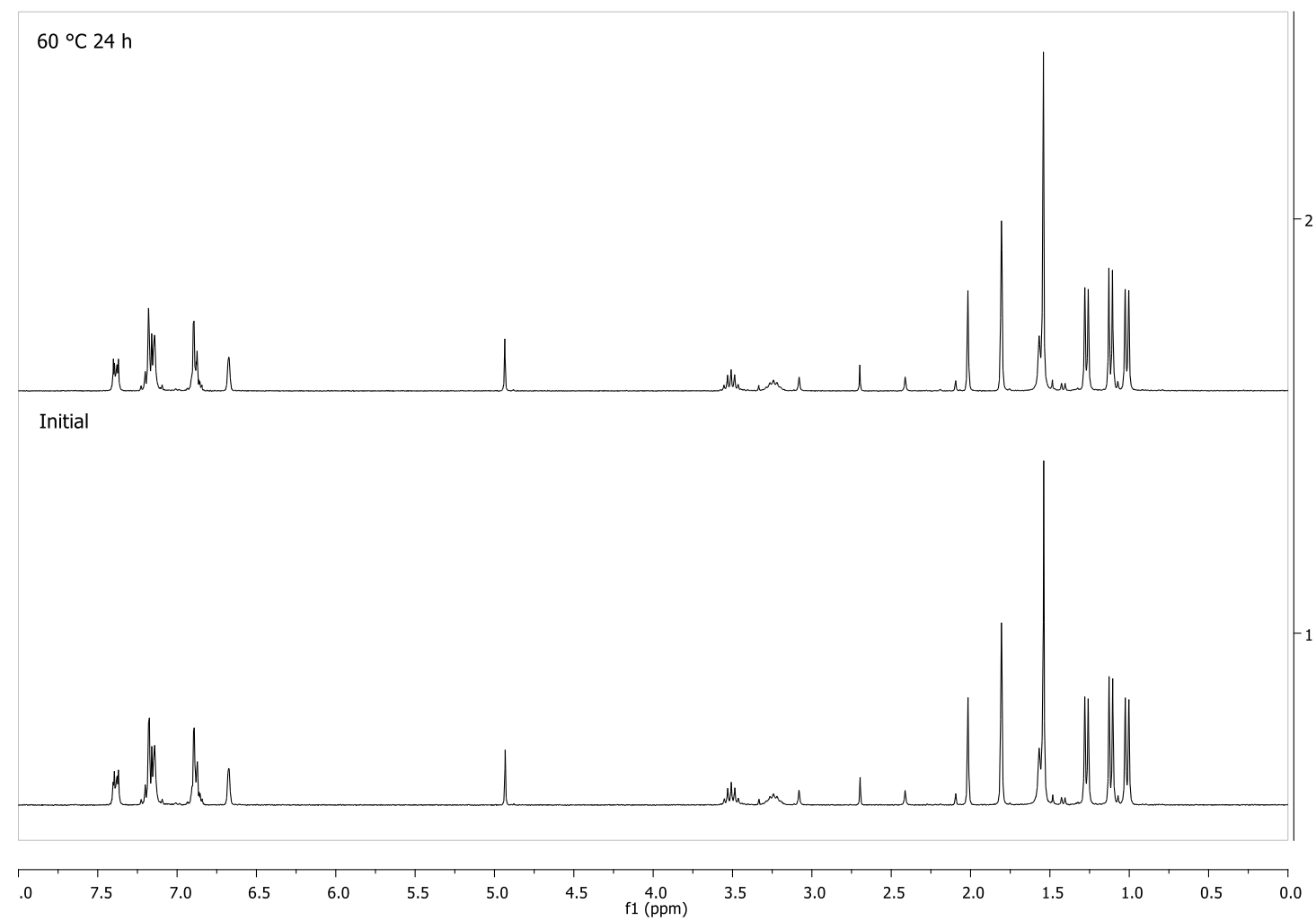

Figure 107: Comparison ${ }^{1} \mathrm{H}$ NMR spectra of $\mathrm{BDI}$ DIPPAI(PHMes)Cl 58 with phenyl acetylene, initial spectrum (bottom) and after heating to $60^{\circ} \mathrm{C}$ for 24 hours (top).

\subsubsection{Reactivity with 4-Nitro-Phenyl Isocyanate}

The addition of 4-nitrophenylisocyanate to BDIDIPPAI(PHMes)Cl 58 proceeded immediately (Figure 108), with formation of a new product observed in the ${ }^{1} \mathrm{H}$ and ${ }^{31} \mathrm{P}$ NMR spectra of the reaction mixture. Full conversion was observed after 16 hours, and the reaction was scaled up to attempt to isolate the product. 


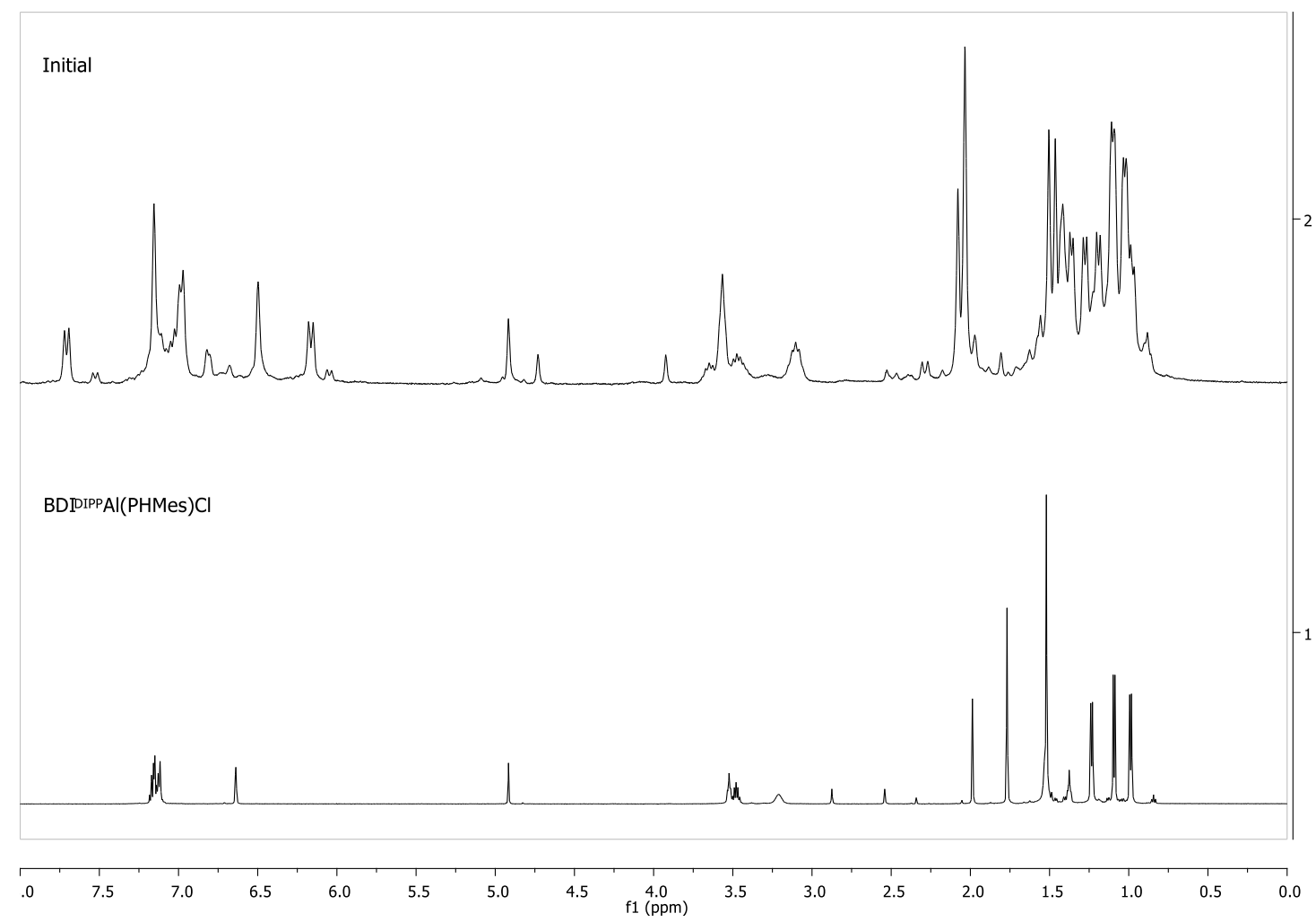

Figure 108: Comparison ${ }^{1} \mathrm{H}$ NMR spectra of BDIDIPPAl(PHMes)Cl 58 with 4-

nitrophenylisocyanate, reactivity was observed in the initial spectrum (top) compared to the starting material (bottom).

The large scale reaction between BDIDIPPAI(PHMes)Cl 58 and 4-nitrophenylisocyanate in toluene was complete after $16 \mathrm{~h}$ at room temperature, resulting in the formation of the

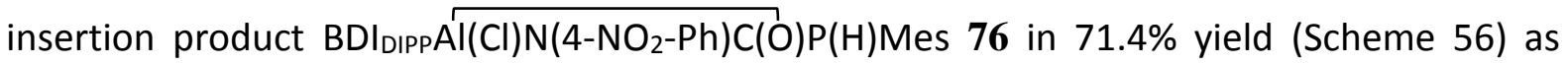
colourless crystals. 


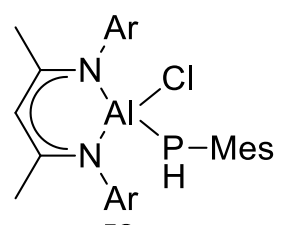

58
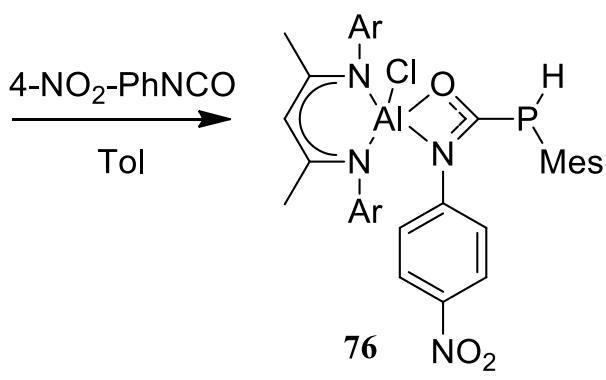

Scheme 56: Synthesis of $B D I_{D I P P} A l(C l) N\left(4-N_{2}-P h\right) C(O) P(H) M e s$.

The ${ }^{1} \mathrm{H}$ NMR spectrum of $\mathbf{7 6}$ reveals the $\nu$-proton as a singlet resonance at $\delta 4.91 \mathrm{ppm}$, comparable to that of starting material $\mathbf{5 8}(\delta 4.94 \mathrm{ppm})$. The presence of three resonances in a 1:1:1:2 ratio to the $\gamma$-proton at $\delta 3.67,3.48$ and $3.11 \mathrm{ppm}$ correspond to the methine protons of the isopropyl group, while the presence of five resonances in a 1:3:6:3:6:6 ratio to the $\gamma$ proton at $\delta 1.38,1.27,1.20,1.11$ and $1.03 \mathrm{ppm}$ correspond to the methyl protons of the isopropyl group. Four singlet resonances in a 1:3:6:3:3 ratio to the $y$-proton at $\delta 2.08,2.04$, 1.50 and 1.46 corresponding to the methyl protons of the mesityl group and ligand backbone respectively. The splitting of the ligand backbone methyl groups into two resonances, combined with the splitting of the iPr group resonances, indicate that there has been loss of the plane of symmetry in the ligand present in 58, while the mesityl group retains free rotation. Two doublet resonances in a 1:2:2 ratio to the $\psi$-proton at $\delta 7.71$ and $6.16 \mathrm{ppm}$ correspond to the protons on the 4- $\mathrm{NO}_{2}-\mathrm{Ph}$ group. A doublet resonance in a 1:1 ratio to the $\gamma$-proton at $\delta 4.31 \mathrm{ppm}$ corresponds to the phosphanide proton, with a ${ }^{1} \mathrm{~J}_{\mathrm{PH}}$ coupling constant of $240 \mathrm{~Hz}$, significantly downfield from the starting material at $\delta 2.73 \mathrm{ppm}$. The ${ }^{31} \mathrm{P}$ NMR spectrum reveals a singlet resonance at $\delta-91.2 \mathrm{ppm}$, shifted downfield from the starting material at $\delta-196.2 \mathrm{ppm}$.

An X-ray diffraction study of $\mathbf{7 6}$ reveals that the isocyanate has inserted into the Al-P bond, with an allylic N-C-O system coordinated to the aluminium through both the nitrogen and oxygen. The aluminium adopts a distorted trigonal bi-pyramidal conformation, with the $\mathrm{O}(1)$ $\mathrm{Al}(1)-\mathrm{N}(3)$ angle of $63.21(9)^{\circ}$ distorted from the idealised $90^{\circ}$. The $\mathrm{Al}-\mathrm{Cl}$ bond length of 2.1510(8) $\AA$ is comparable to 2.1402(7) $\AA$ in $\mathbf{5 8}$, while the Al-N bond of the BDIDIPp ligand are no longer identical (1.894(2) $\AA$ and 1.926(2) $\AA$ ) unlike in 58 (1.895(1)/1.892(2) $\AA$ ). The C(36)- 
$N(3)(1.280(4) \AA), C(36)-O(1)(1.311(4) \AA)$ and $C(36)-P(1)(1.850(3) \AA ̊)$ bonds are of comparable length to similar insertion products, ${ }^{279-280}$ and shorter than normal single bond lengths due to the delocalised electrons in the allylic system. This indicates that complex $\mathbf{5 8}$ could potentially be used as a catalyst for hydrophosphination reactions, if addition of $\mathrm{MesPH}_{2}$ to complex 76 results in the loss of the protonated insertion product and regeneration of $\mathbf{5 8 .}$

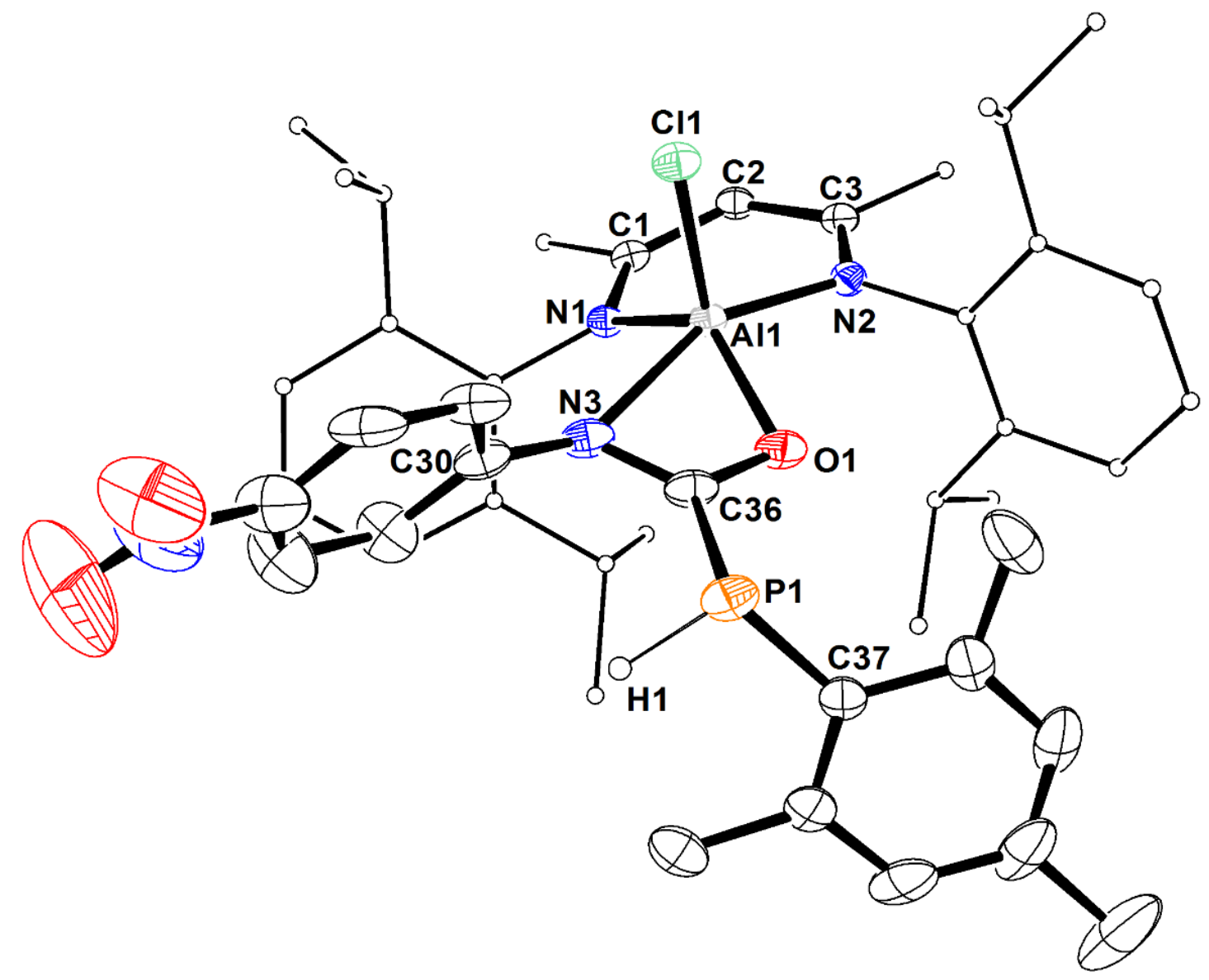

Figure 109: ORTEP plot BDIDIPPAl $(\mathrm{Cl}) \mathrm{N}\left(4-\mathrm{NO}_{2}-\mathrm{Ph}\right) \mathrm{C}(\mathrm{O}) \mathrm{P}(\mathrm{H}) \mathrm{Mes}$ 76. Ellipsoids at 30\%, $\mathrm{H}$ atoms and solvent omitted and selected $\mathrm{C}$ atoms in wire frame for clarity. 
Table 21: Selected bond lengths and angles for BDI $\mathrm{DIPP}_{\mathrm{Al}}(\mathrm{Cl}) \mathrm{N}\left(4-\mathrm{NO}_{2}-\mathrm{Ph}\right) \mathrm{C}(\mathrm{O}) \mathrm{P}(\mathrm{H}) \mathrm{Mes} 76$.

\begin{tabular}{|c|c|c|c|}
\hline \multicolumn{2}{|c|}{ Bond Lengths ( $\AA$ ) } & \multicolumn{2}{|c|}{ Bond Angles $\left({ }^{\circ}\right)$} \\
\hline $\operatorname{Al}(1)-N(1)$ & $1.894(2)$ & $N(1)-A l(1)-N(2)$ & $96.56(9)$ \\
\hline $\operatorname{Al}(1)-N(2)$ & $1.926(2)$ & $\mathrm{Al}(1)-\mathrm{N}(1)-\mathrm{C}(1)$ & $120.3(2)$ \\
\hline$N(1)-C(1)$ & $1.344(3)$ & $A l(1)-N(2)-C(3)$ & $121.2(2)$ \\
\hline$N(2)-C(3)$ & $1.328(3)$ & $N(1)-C(1)-C(2)$ & $123.8(2)$ \\
\hline$C(1)-C(2)$ & $1.397(4)$ & $C(1)-C(2)-C(3)$ & $127.7(2)$ \\
\hline$C(2)-C(3)$ & $1.402(3)$ & $C(2)-C(3)-N(2)$ & $122.3(2)$ \\
\hline $\mathrm{Al}(1)-\mathrm{Cl}(1)$ & $2.1510(8)$ & $\mathrm{N}(1)-\mathrm{Al}(1)-\mathrm{Cl}(1)$ & $111.48(7)$ \\
\hline $\mathrm{Al}(1)-\mathrm{O}(1)$ & $1.825(2)$ & $\mathrm{N}(2)-\mathrm{Al}(1)-\mathrm{Cl}(1)$ & $103.46(5)$ \\
\hline $\mathrm{Al}(1)-\mathrm{N}(3)$ & $2.265(3)$ & $\mathrm{N}(3)-\mathrm{Al}(1)-\mathrm{Cl}(1)$ & $91.25(7)$ \\
\hline $\mathrm{O}(1)-\mathrm{C}(36)$ & $1.311(4)$ & $N(2)-A l(1)-O(1)$ & $93.02(9)$ \\
\hline$N(3)-C(36)$ & $1.280(4)$ & $N(3)-A l(1)-O(1)$ & $63.21(9)$ \\
\hline$C(36)-P(1)$ & $1.850(3)$ & $N(1)-A l(1)-N(3)$ & $95.60(9)$ \\
\hline$P(1)-H(1)$ & $1.39(4)$ & $\mathrm{Al}(1)-\mathrm{N}(3)-\mathrm{C}(36)$ & $81.2(2)$ \\
\hline$P(1)-C(37)$ & $1.813(3)$ & $\mathrm{Al}(1)-\mathrm{O}(1)-\mathrm{C}(36)$ & $100.1(2)$ \\
\hline \multirow[t]{3}{*}{$N(3)-C(30)$} & $1.414(4)$ & $N(3)-C(36)-O(1)$ & $114.3(3)$ \\
\hline & & $C(36)-P(1)-C(37)$ & $101.3(1)$ \\
\hline & & $C(36)-N(3)-C(30)$ & $120.2(3)$ \\
\hline
\end{tabular}

Addition of 4-nitrophenylisocyanate a solution of BDIDIPPAI(PHMes)Et 63 in $\mathrm{C}_{6} \mathrm{D}_{6}$ resulted in an immediate colour change to intense dark red, the initial ${ }^{1} \mathrm{H}$ NMR spectrum showing formation of a new product with a $\gamma$-proton shift of $\delta 4.92 \mathrm{ppm}$. Full conversion to this product was observed after 1 hour at room temperature (Figure 110), however the peaks showed significant broadening, hampering efforts to assign them. 


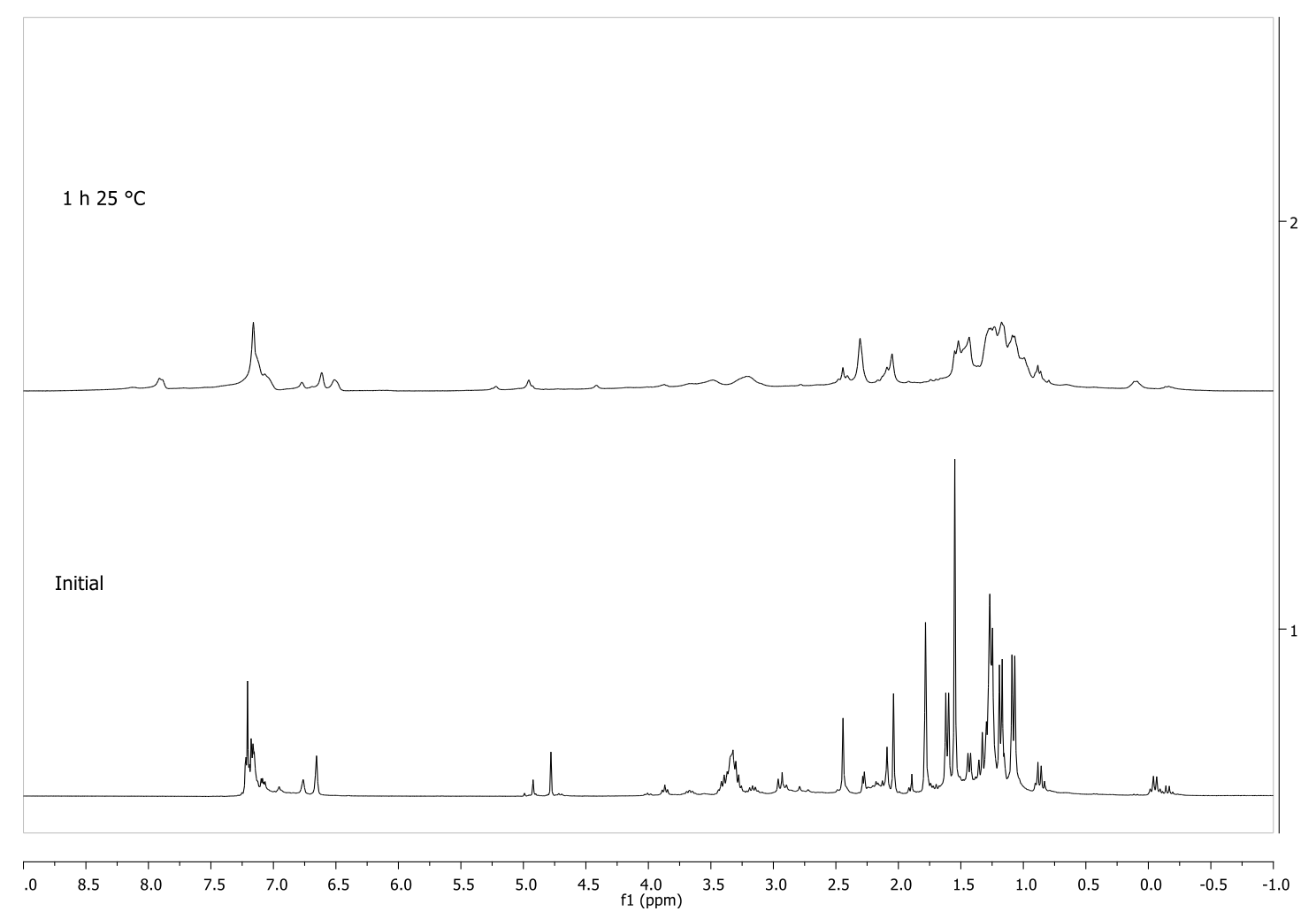

Figure 110: Comparison ${ }^{1} \mathrm{H}$ NMR spectra of BDIDIPPAl(PHMes)Et 63 with 4nitrophenylisocyanate, reactivity was observed in the initial spectrum (bottom) and complete after 1 hour at room temperature (top).

Repeating the reaction on a larger scale in toluene at room temperature overnight resulted in the formation of the same product, identified by ${ }^{1} \mathrm{H}$ NMR spectroscopy with the same broadening effect observed in the small scale reaction. This broadening prevented identification of the product by NMR spectroscopy, and crystals suitable for X-ray diffraction were unable to be obtained. The product is tentatively assigned as being the analogous insertion product 77 (Scheme 57), assuming similar reactivity as $\mathbf{7 6}$ was occurring. 


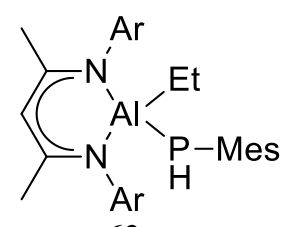

63
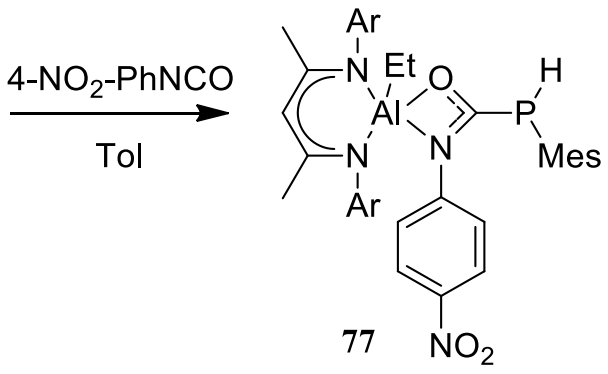

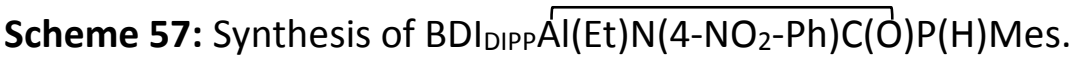

Addition of 4-nitrophenylisocyanate to a solution of BDIDIPPGa(H)P(H)Mes 66 in $d_{6}$ benzene showed the presence of three new resonances ( $\delta 4.93,4.85$ and $4.83 \mathrm{ppm}$ ) corresponding to the $y$-proton in the initial ${ }^{1} \mathrm{H}$ NMR spectrum in a 1:2:2 ratio. Likewise, the initial ${ }^{31} \mathrm{P}$ NMR spectrum showed three new resonances $(\delta-85.3,-155.9$ and $-186.4 \mathrm{ppm})$. After 16 hours at room temperature, the ${ }^{1} \mathrm{H}$ NMR spectrum showed an intractable mixture of multiple products.

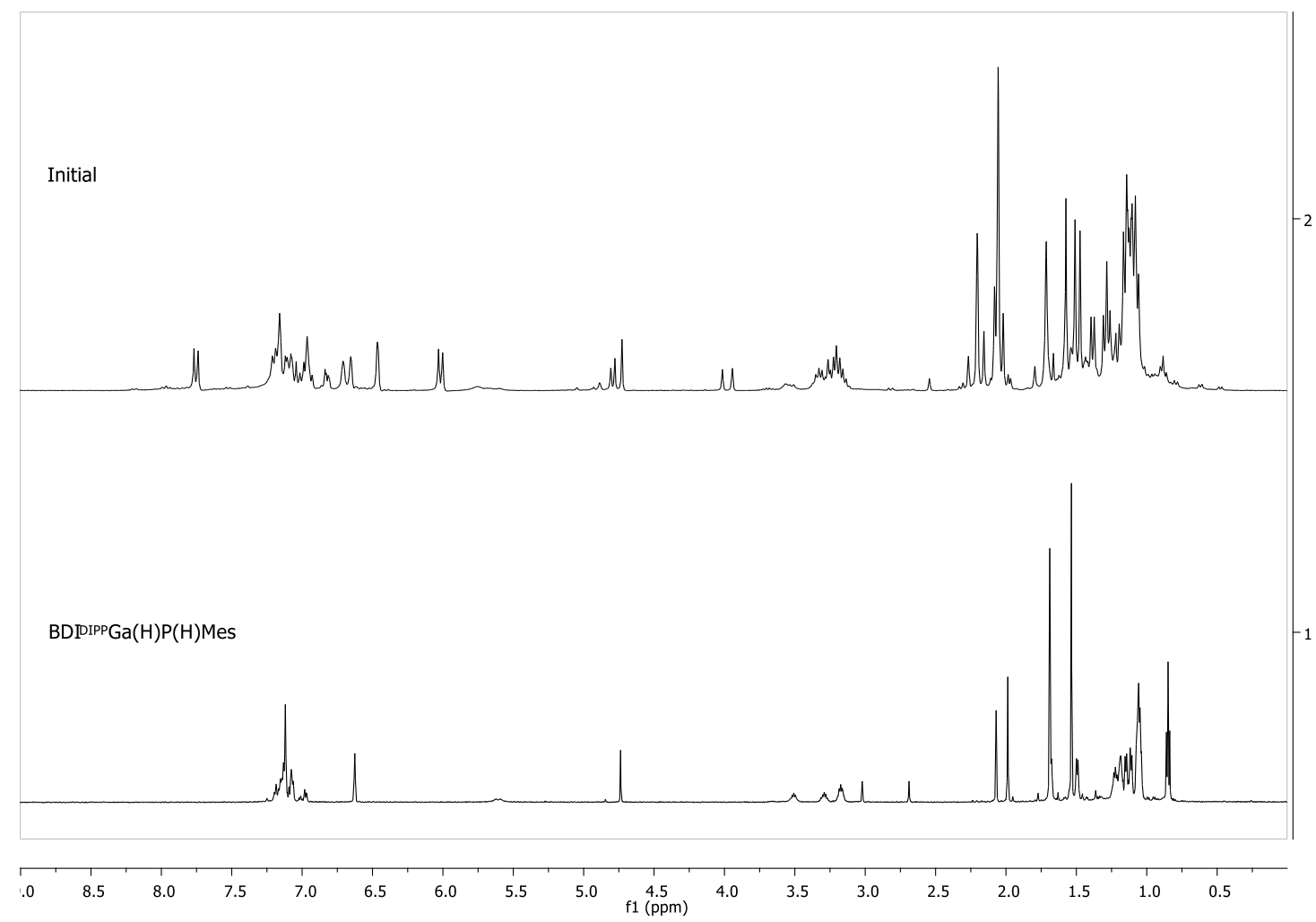

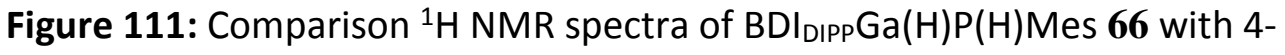
nitrophenylisocyanate, reactivity was observed in the initial spectrum (top) compared to the starting material (bottom). 
Repeating the reaction on a larger scale in toluene at room temperature overnight for 16 hours resulted in the formation of an intractable mixture of products. Attempts to crystallise and identify these products were unsuccessful. The analogous insertion product $\mathbf{7 8}$ may have formed (Scheme 58), however the presence of the gallium hydride may have resulted in decomposition of the complex into the various products observed by ${ }^{1} \mathrm{H}$ NMR spectroscopy.<smiles></smiles>
66

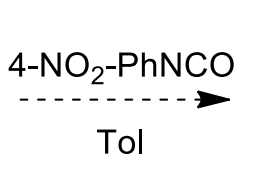

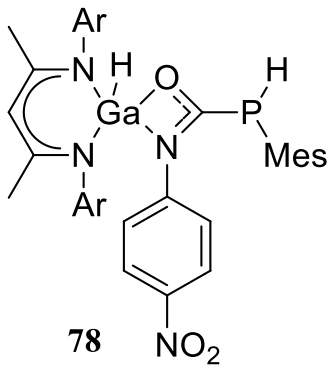

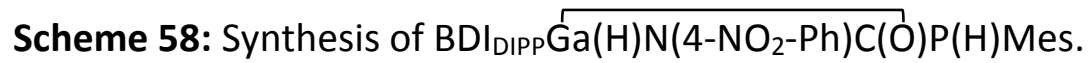

\subsubsection{Reactivity with Phenyl Isothiocyanate}

Upon addition of phenylisothiocyanate to $\mathrm{BDI}$ DIPPAI(PHMes) $\mathrm{Cl} \mathbf{5 8}$, no reaction was observed by ${ }^{1} \mathrm{H}$ NMR spectroscopy initially or at room temperature after 1 hour. Heating the solution to $40{ }^{\circ} \mathrm{C}$ for 16 hours (Figure 112) lead to the observation of a new resonance for the $\psi$-proton $(\delta 5.10 \mathrm{ppm})$ in a 1:4 ratio with the starting material. Heating the sample to $60^{\circ} \mathrm{C}$ for 90 hours increased the ratio of this new resonance to the starting material to $3: 1$. A new resonance for the phosphanide proton was observed at $\delta 4.51 \mathrm{ppm}$ with a ${ }^{1} J_{\mathrm{PH}}$ coupling constant of $250.6 \mathrm{~Hz}$. The initial four doublet resonances of the 'Pr methyl groups have split into multiple overlapping peaks, as have the resonances for the methine protons. 


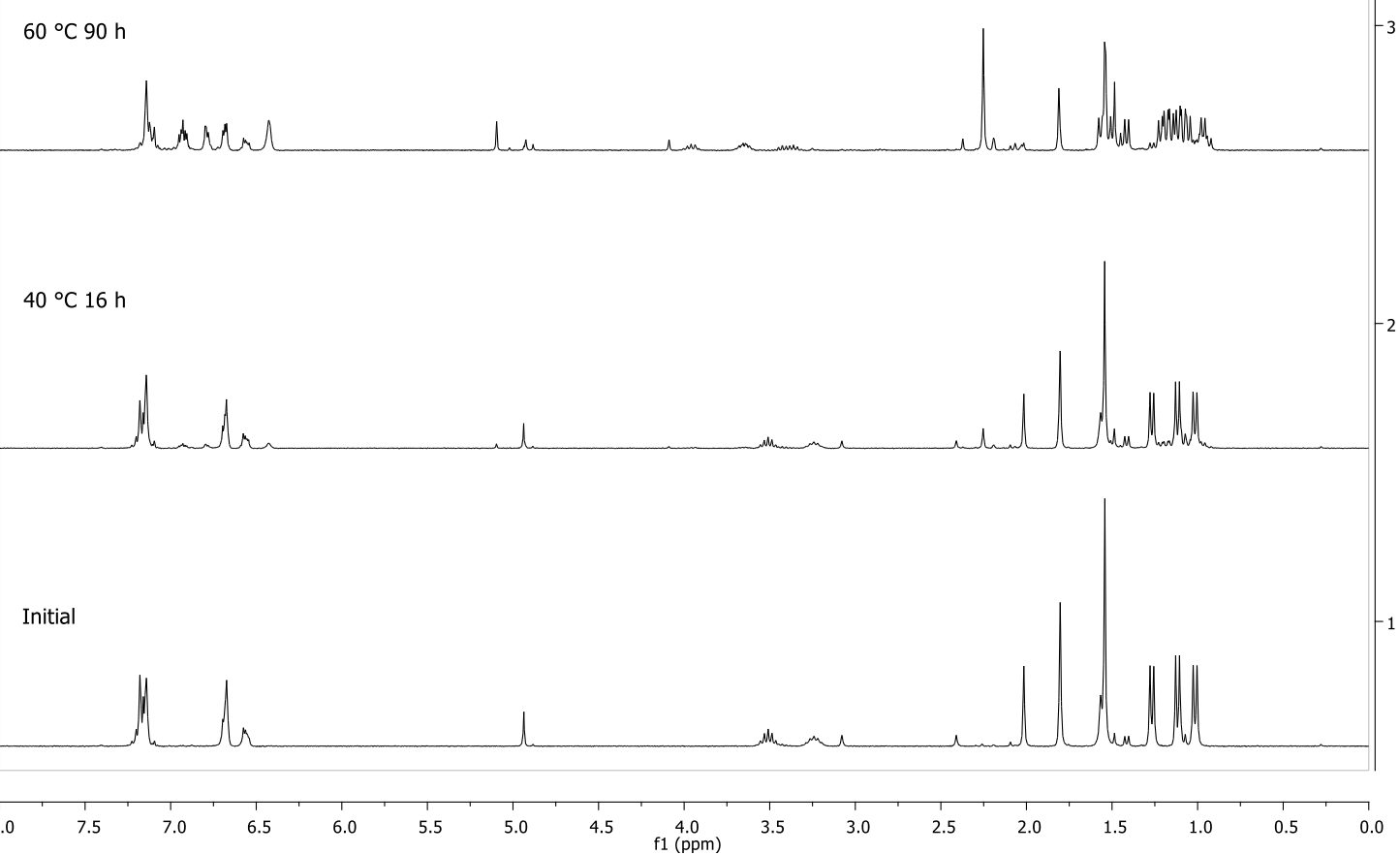

Figure 112: Comparison ${ }^{1} \mathrm{H}$ NMR spectra of $\mathrm{BDI}_{\mathrm{DIPP}} \mathrm{Al}(\mathrm{PHMes}) \mathrm{Cl} \mathbf{5 8}$ with phenylisothiocyanate, initial spectrum (bottom), after heating to $40{ }^{\circ} \mathrm{C}$ for 16 hours (middle) and after heating to $60^{\circ} \mathrm{C}$ for 90 hours (top).

Repeating the reaction on a larger scale in toluene heating to $60^{\circ} \mathrm{C}$ for seven days resulted in the formation of a product with the same resonances in the ${ }^{1} \mathrm{H}$ NMR spectrum as observed in the small-scale reaction. Attempts to isolate this product from the reaction mixture by crystallisation were unsuccessful, with the presence of starting material complicating the ${ }^{1} \mathrm{H}$ NMR spectrum and preventing full assignment of resonances. The presence of the phosphanide proton resonance at $\delta 4.51 \mathrm{ppm}$ with a ${ }^{1} \mathrm{JPH}_{\mathrm{PH}}$ coupling constant of $250.6 \mathrm{~Hz}$ does support that a similar reaction to 4- $\mathrm{NO}_{2}$-phenylisocyante has occurred, corresponding to insertion product 79 (Scheme 59). 


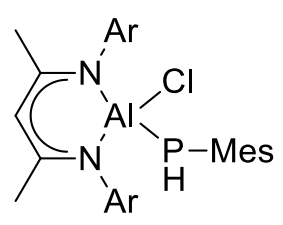

58

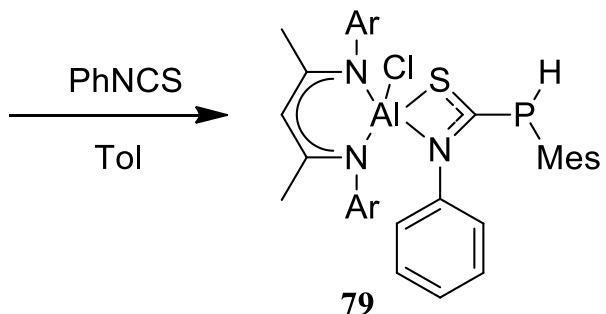

79

Scheme 59: Synthesis of BDIDIPPAl(Cl)N(Ph)C(S)P(H)Mes.

The addition of phenylisothiocyanate to a solution of $\mathrm{BDI}_{\text {DIPPAl}} \mathrm{AHMes}$ )Et $\mathbf{6 3}$ in $\mathrm{C}_{6} \mathrm{D}_{6}$ showed no reaction at room temperature or $40^{\circ} \mathrm{C}$, similar to 58 . Upon heating to $60^{\circ} \mathrm{C}$ for 2 hours, a new $\gamma$-proton resonance at $\delta 4.94 \mathrm{ppm}$ was observed by ${ }^{1} \mathrm{H}$ NMR spectroscopy (Figure 113 ) in a 3:1 ratio to the starting material. Subsequent heating for 90 hours results in complete conversion of the starting material to this new product. The resonances of the product however, show significant broadening similar to that observed in the reaction with 4-nitrophenylisocyanate, which hinders the effort to assign peaks to functionalities and determine the structure of the product. 


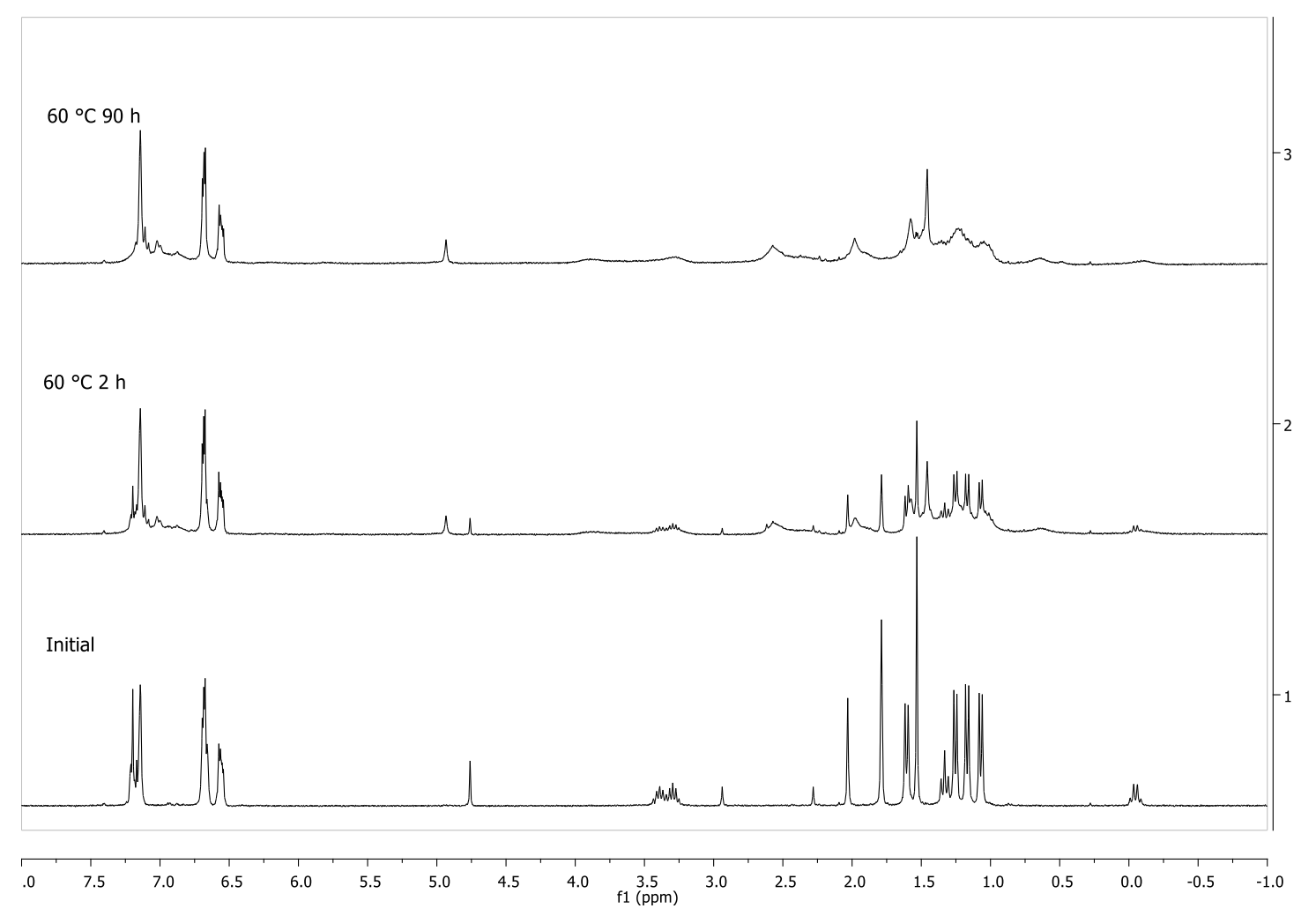

Figure 113: Comparison ${ }^{1} \mathrm{H}$ NMR spectra of BDIDIPPAl(PHMes)Et 63 with phenylisothiocyanate, initial (bottom), heating to $60^{\circ} \mathrm{C}$ for 2 hours (middle) and heating to $60{ }^{\circ} \mathrm{C}$ for 90 hours (top).

Repeating the reaction of $\mathbf{6 3}$ with phenylisothiocyanate on a larger scale in toluene lead to the formation of the same product identified by the NMR study, with the broadening of the peaks prohibiting assignment by ${ }^{1} \mathrm{H}$ NMR. Attempts to grow crystals from the reaction mixture failed to produce any of sufficient quality for an X-ray diffraction study. Therefore, the only conclusion that can currently be drawn is that $\mathbf{6 3}$ does undergo a reaction with phenylisothiocyanate (Scheme 60), but the product of that reaction has not currently been determined. 


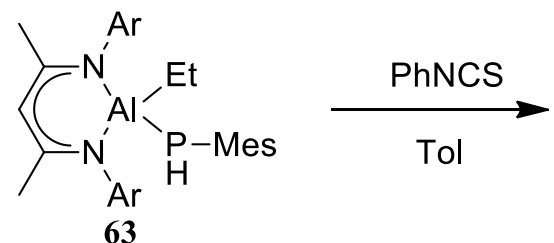

Scheme 60: Addition of phenylisothiocyanate to BDIDIPPAl(PHMes)Et.

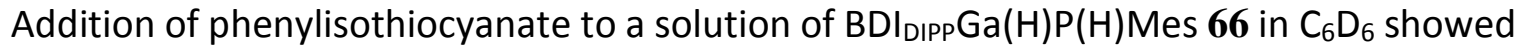
no reaction at room temperature after one hour or at $40{ }^{\circ} \mathrm{C}$ after 2 hours by ${ }^{1} \mathrm{H}$ NMR spectroscopy. Heating to $60^{\circ} \mathrm{C}$ for 2 hours resulted in the observation of a new $\mathrm{\gamma}$-proton peak in the ${ }^{1} \mathrm{H}$ NMR spectrum at $\delta 4.74 \mathrm{ppm}$ (Figure 114) and the $\mathrm{P}-\mathrm{H}$ resonance shifting to $\delta 4.91$ ppm with a ${ }^{1} J_{\mathrm{PH}}$ coupling constant of $237 \mathrm{~Hz}$. Continued heating at $60{ }^{\circ} \mathrm{C}$ for 16 hours showed $66 \%$ of the starting material had converted into this new product.

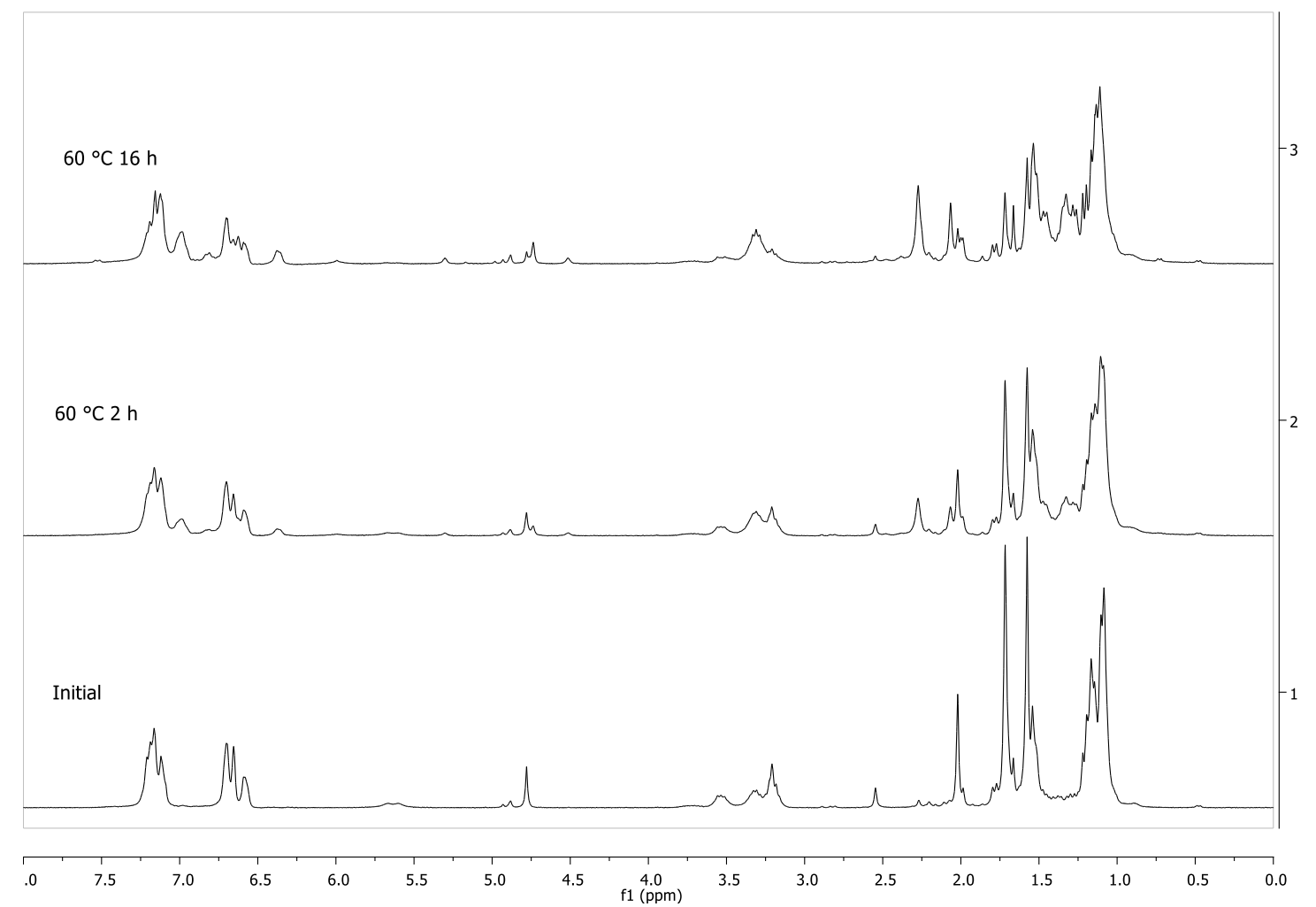

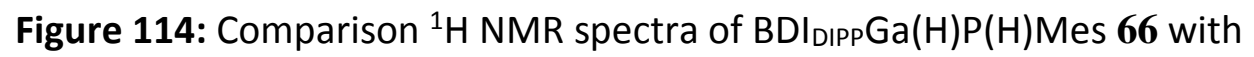
phenylisothiocyanate, initial (bottom), heating to $60^{\circ} \mathrm{C}$ for 2 hours (middle) and heating to $60{ }^{\circ} \mathrm{C}$ for 16 hours (top). 
Repeating the reaction of $\mathbf{6 6}$ with phenylisothiocyanate on a larger scale in toluene at 60 ${ }^{\circ} \mathrm{C}$ for 36 hours lead to the formation of the same product identified by the NMR study, however efforts to isolate this complex were unsuccessful. Crystals suitable for X-ray diffraction were unable to be obtained and assignment by ${ }^{1} \mathrm{H}$ NMR spectroscopy was prevented by the presence of a by-product in the reaction that was unable to be separated from the product. Therefore, the only conclusion that can currently be drawn is that $\mathbf{6 6}$ does undergo a reaction with phenylisothiocyanate (Scheme 61), but the product of that reaction has not currently been determined.

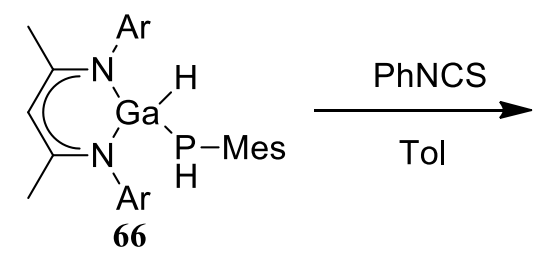

Scheme 61: Addition of phenylisothiocyanate to BDIDIPPGa(H)P(H)Mes.

\subsubsection{Reactivity with Carbodiimide}

One equivalent of dicyclohexylcarbodiimide was added to a solution of either phosphanide 58, 63 or 66 in $\mathrm{C}_{6} \mathrm{D}_{6}$ (Scheme 62). No reaction was observed by ${ }^{1} \mathrm{H}$ NMR spectroscopy for any of the phosphanides at room temperature after 1 hour. Upon heating to $40{ }^{\circ} \mathrm{C}$, no reaction was observed after 2 hours, subsequent heating to $60^{\circ} \mathrm{C}$ for 72 hours also lead to no reaction being observed by ${ }^{1} \mathrm{H}$ NMR spectroscopy (Figure 115). This suggests that phosphanides 58, $\mathbf{6 3}$ and $\mathbf{6 6}$ are all unreactive towards carbodiimides. 

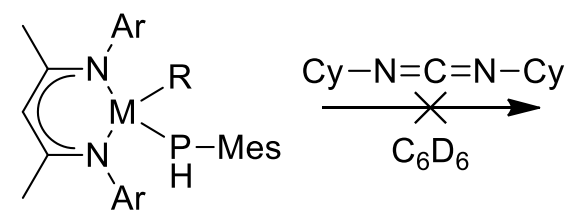<smiles>CC(C)c1cccc(C(C)C)c1N(C)C</smiles>

$58 \mathrm{M}=\mathrm{Al} \mathbf{R}=\mathbf{C l}$

$63 \mathrm{M}=\mathrm{Al} \mathbf{R}=\mathbf{E t}$

$66 \mathrm{M}=\mathrm{Ga} R=\mathrm{H}$

Scheme 62: Reactivity with dicyclohexyl carbodiimide.

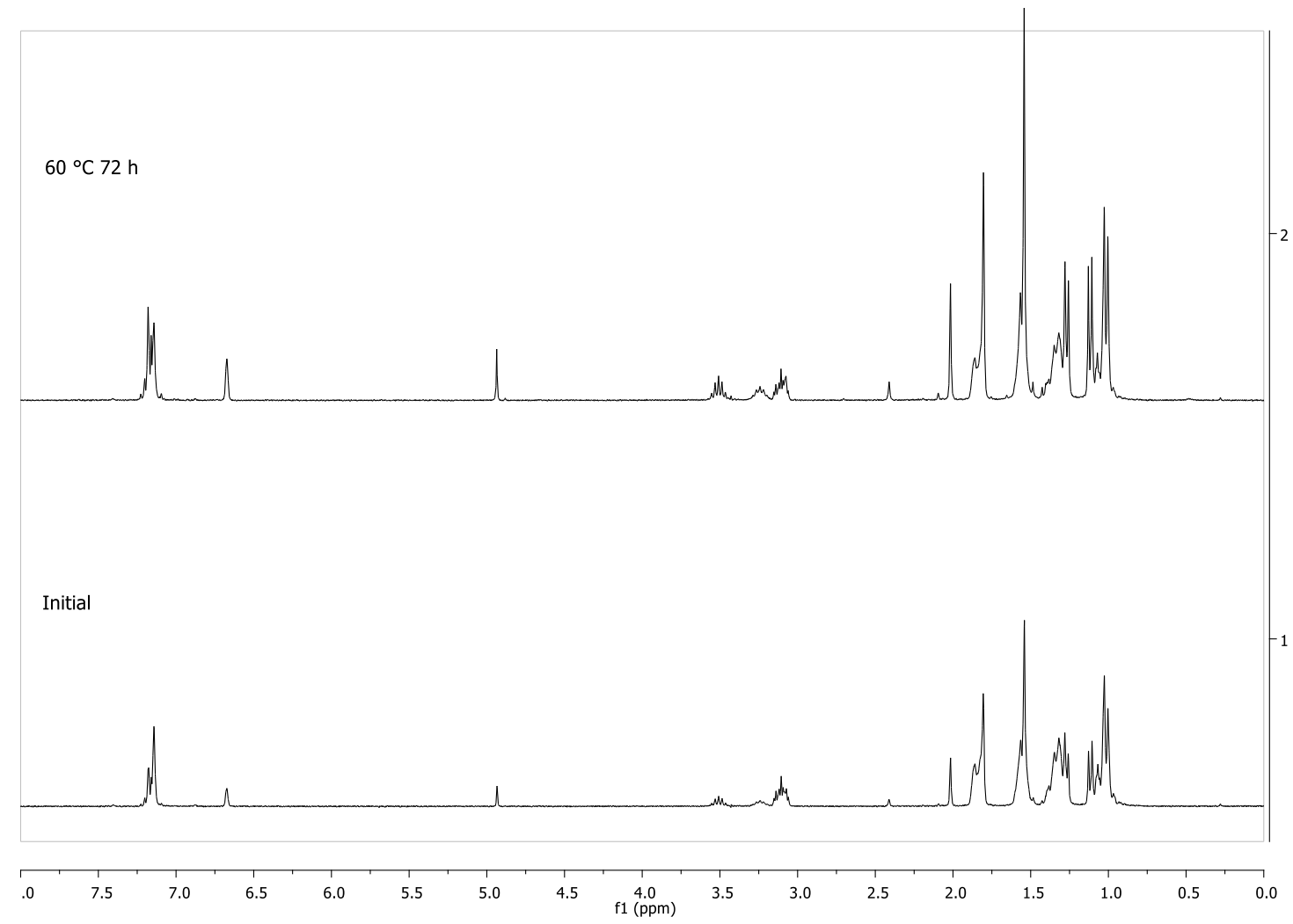

Figure 115: Comparison ${ }^{1} \mathrm{H}$ NMR spectra of BDIDIPPAI(PHMes)Cl $\mathbf{5 8}$ with dicyclohexyl carbodiimide, initial spectrum (bottom) and after heating to $60^{\circ} \mathrm{C}$ for 72 hours (top).

\subsubsection{Reactivity with Cyclohexene}

The addition of one equivalent of cyclohexene to a solution of either phosphanide $\mathbf{5 8 , 6 3}$ or 66 in $\mathrm{C}_{6} \mathrm{D}_{6}$ (Scheme 63) resulted in an intractable mixture of products in the initial ${ }^{1} \mathrm{H}$ NMR spectrum of the reaction with either complex $\mathbf{5 8}$ or $\mathbf{6 6}$, and the presence of three new $\mathrm{\gamma}$ proton resonances $(\delta 4.88,4.83$ and $4.79 \mathrm{ppm})$ in the initial ${ }^{1} \mathrm{H}$ NMR spectrum of the reaction with complex 63 (Figure 116). Subsequently, the presence of free ligand ( $\delta 12.41 \mathrm{ppm}$ ) was 
observed in an increasing ratio, indicating that the complexes forming were decomposing. While this indicates that phosphanides 58, 63 and 66 do react with cyclohexene, the nature of that reactivity could not be investigated due to the presence of multiple, short lived products.
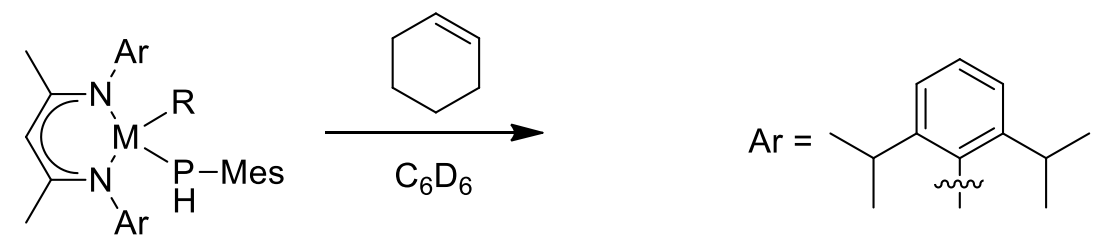

$$
\begin{aligned}
& 58 M=A l R=C l \\
& 63 M=A l R=E t \\
& 66 M=G a R=H
\end{aligned}
$$

Scheme 63: Reactivity with cyclohexene.

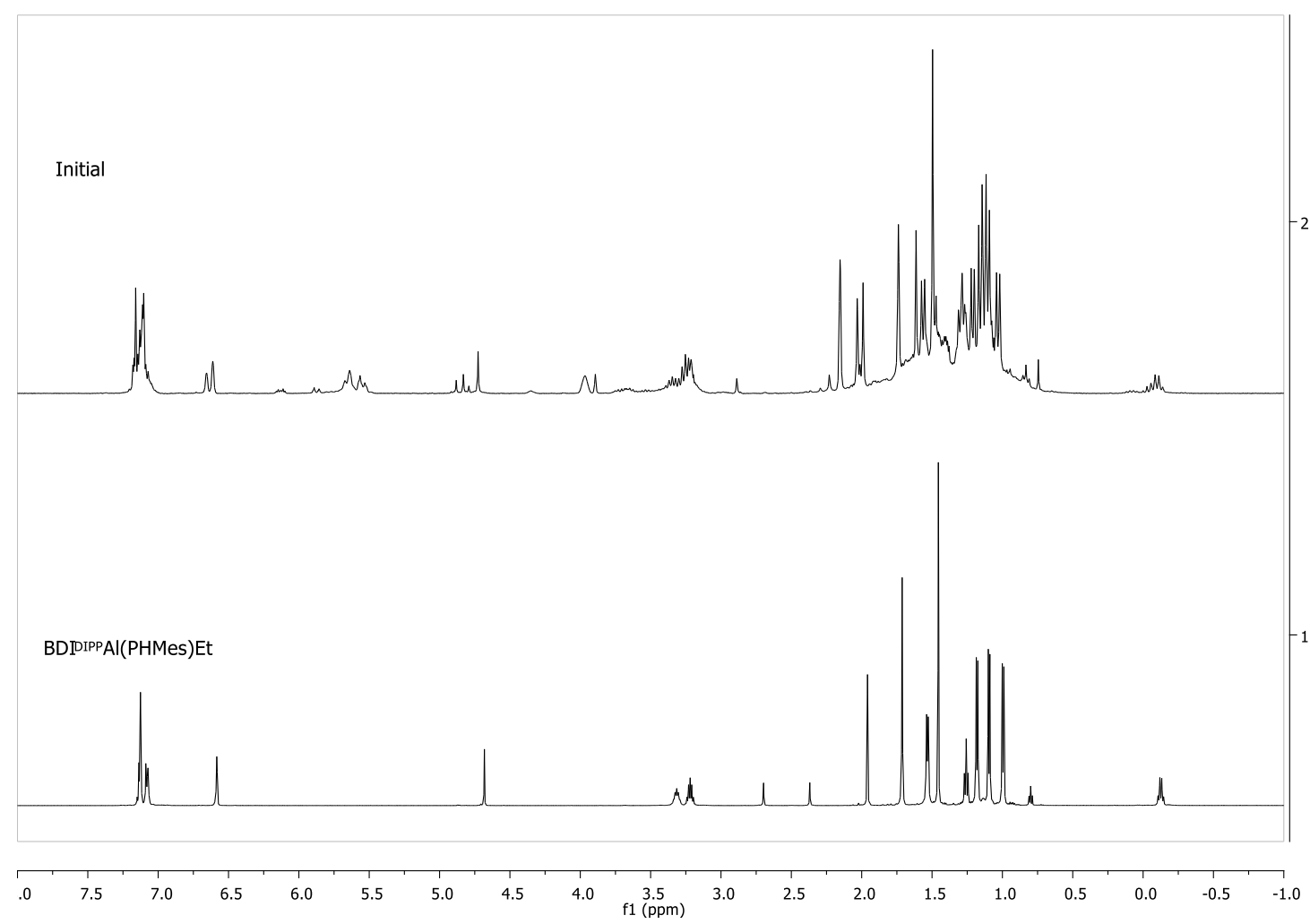

Figure 116: Comparison ${ }^{1} \mathrm{H}$ NMR spectra of BDIDIPPAI(PHMes)Et 63 with cyclohexene, reactivity was observed in the initial spectrum (top) compared to the starting material (bottom). 


\subsubsection{Reactivity with Benzophenone}

The addition of one equivalent of benzophenone to a solution of either phosphanide $\mathbf{5 8}$, 63 or 66 in $C_{6} D_{6}$ (Scheme 64 ) resulted in no observable change in the ${ }^{1} H$ NMR spectrum of the reaction at room temperature after 1 hour. Heating the solution to $40{ }^{\circ} \mathrm{C}$ also resulted in no reaction after 1 hour, with subsequent heating to $60^{\circ} \mathrm{C}$ also showing no reaction after 2 hours (Figure 117). After continuous heating for 90 hours the complexes remained unreactive towards each other, indicating that the phosphanides 58, 63 and 66 do not react with the ketone functionality of benzophenone.

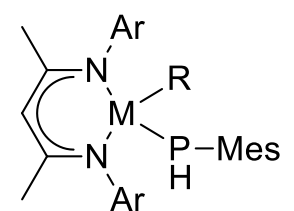<smiles>CC(C)(C)CCc1ccccc1C(=O)c1ccccc1</smiles><smiles>CC(C)c1cccc(C(C)C)c1C(C)C</smiles>

$58 \mathrm{M}=\mathrm{Al} \mathbf{R}=\mathbf{C l}$

$63 \mathrm{M}=\mathrm{Al} R=\mathrm{Et}$

$66 \mathrm{M}=\mathrm{Ga} R=\mathrm{H}$

Scheme 64: Reactivity with benzophenone. 


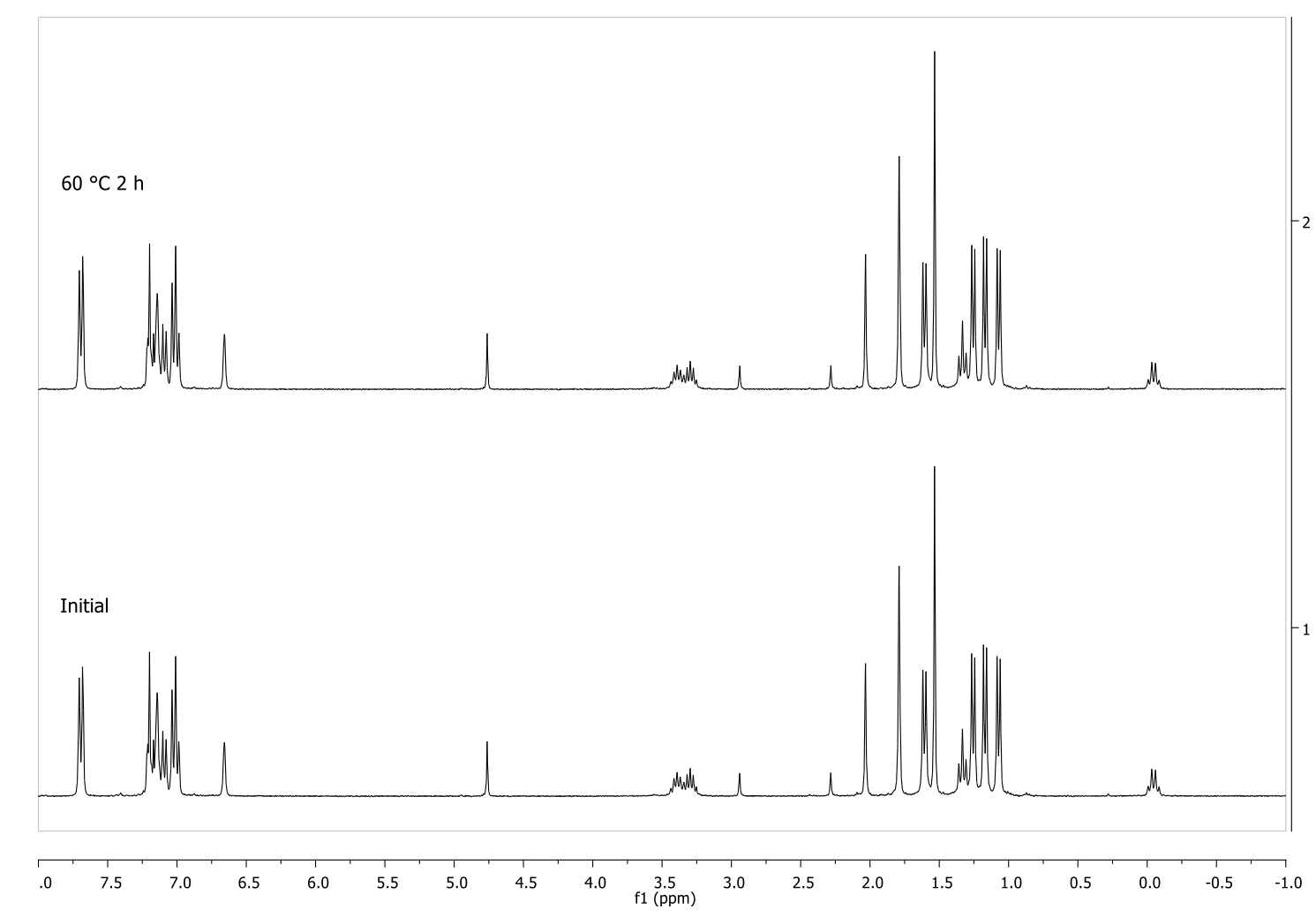

Figure 117: Comparison ${ }^{1} \mathrm{H}$ NMR spectra of BDIDIPPAI(PHMes)Et 63 with benzophenone, initial spectrum (bottom) and after heating to $60^{\circ} \mathrm{C}$ for 2 hours (top).

\subsubsection{Reactivity with Benzaldehyde}

One equivalent of benzaldehyde was added to a $C_{6} D_{6}$ solution of either phosphanide $\mathbf{5 8}$ or 66 (Scheme 65 ). The ${ }^{1} \mathrm{H}$ NMR spectrum showed no observable reaction was occurring at room temperature after 1 hour (Figure 118). Heating the solution to $40{ }^{\circ} \mathrm{C}$ for 2 hours also resulted in no reaction occurring, subsequent heating to $60^{\circ} \mathrm{C}$ for 72 hours also showing no reaction was occurring. This indicates that phosphanides 58 and $\mathbf{6 6}$ do not react with the aldehyde functionality of benzaldehyde. 


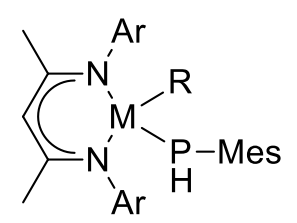<smiles>CCCCCCC(C)(C)C(=O)c1ccccc1</smiles><smiles>CC(C)c1cccc(C(C)C)c1N(C)C</smiles>

$58 \mathrm{M}=\mathbf{A l} \mathbf{R}=\mathbf{C l}$

$66 \mathrm{M}=\mathrm{Ga} R=\mathrm{H}$

Scheme 65: Reactivity with benzaldehyde.

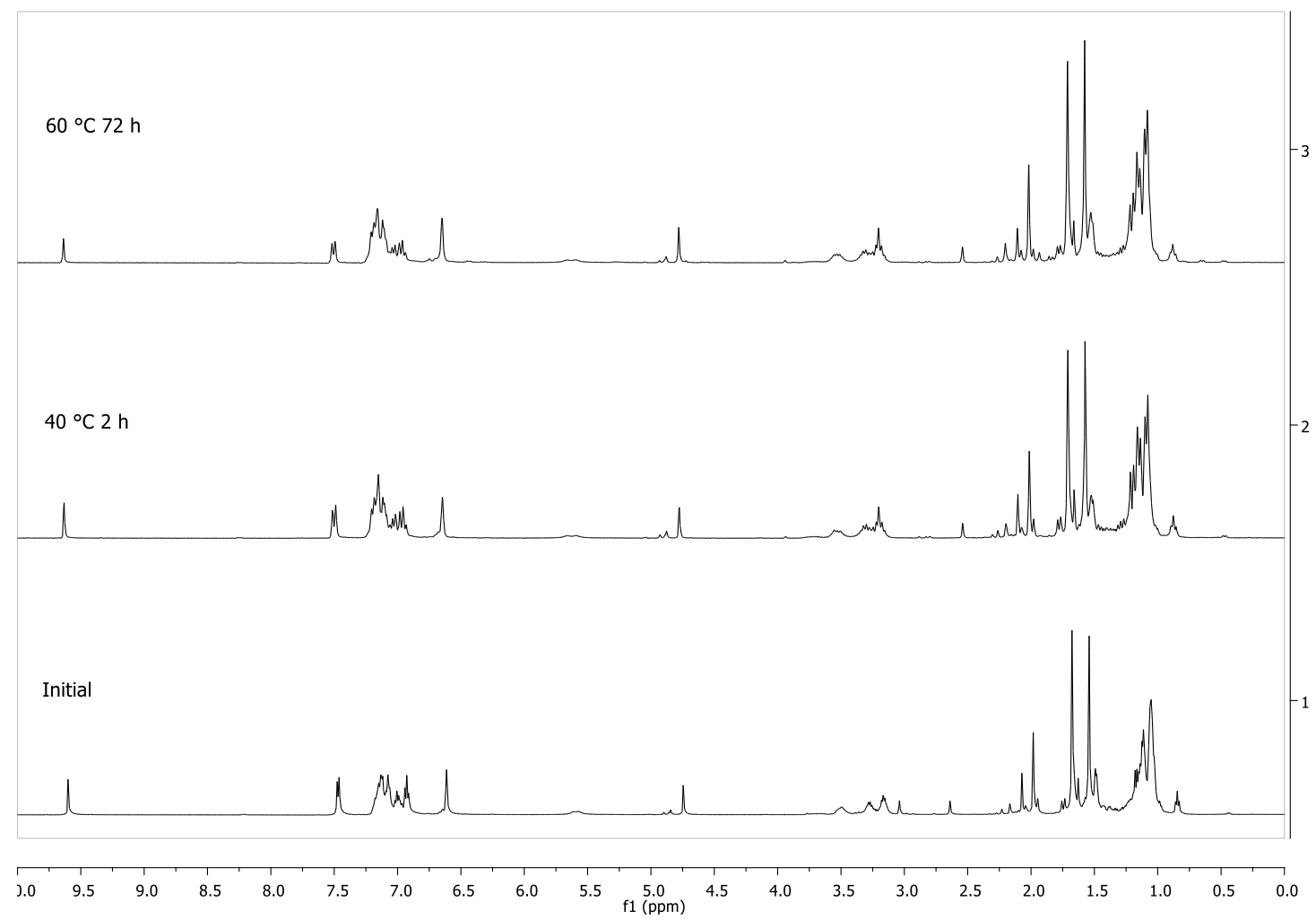

Figure 118: Comparison ${ }^{1} \mathrm{H}$ NMR spectra of $B \mathrm{BDIPP}_{\mathrm{DIP}}(\mathrm{H}) \mathrm{P}(\mathrm{H})$ Mes 66 with benzaldehyde, initial spectrum (bottom), after heating to $40^{\circ} \mathrm{C}$ for 2 hours (middle) and heating to $60^{\circ} \mathrm{C}$ for 2 hours (top).

Addition of benzaldehyde to a solution of phosphanide 63 in $C_{6} D_{6}$ appeared to result in the formation of a coordination complex of $\mathbf{6 3}$ and benzaldehyde (Figure 119), with the ${ }^{1} \mathrm{H}$ NMR spectrum showing resonances of both reagents appearing, but some having shifted 
significantly. The $\gamma$-proton resonance has shifted downfield from $\delta 4.72$ to $5.25 \mathrm{ppm}$, along with the phosphide proton shifting from $\delta 2.57$ to $3.52 \mathrm{ppm}$. No further change in the ${ }^{1} \mathrm{H}$ NMR spectrum was observed at room temperature after 1 hour, or upon heating the solution to 40 ${ }^{\circ} \mathrm{C}$ for 2 hours. However, upon heating the solution to $60^{\circ} \mathrm{C}$ for 16 hours, a new resonance for the $\psi$-proton was observed at $\delta 4.86 \mathrm{ppm}$. The presence of a singlet resonance at $\delta 0.78 \mathrm{ppm}$, combined with the loss of the ethyl ligand resonances ( $\delta 1.29$ and $-0.09 \mathrm{ppm}$ ) supports the formation of ethane, while the presence of the mesityl group methyl resonances $(\delta 2.18$ and $2.06 \mathrm{ppm}$ ) along with the phosphanide proton resonance ( $\delta 3.61 \mathrm{ppm})$ indicate that the phosphanide ligand is still present.

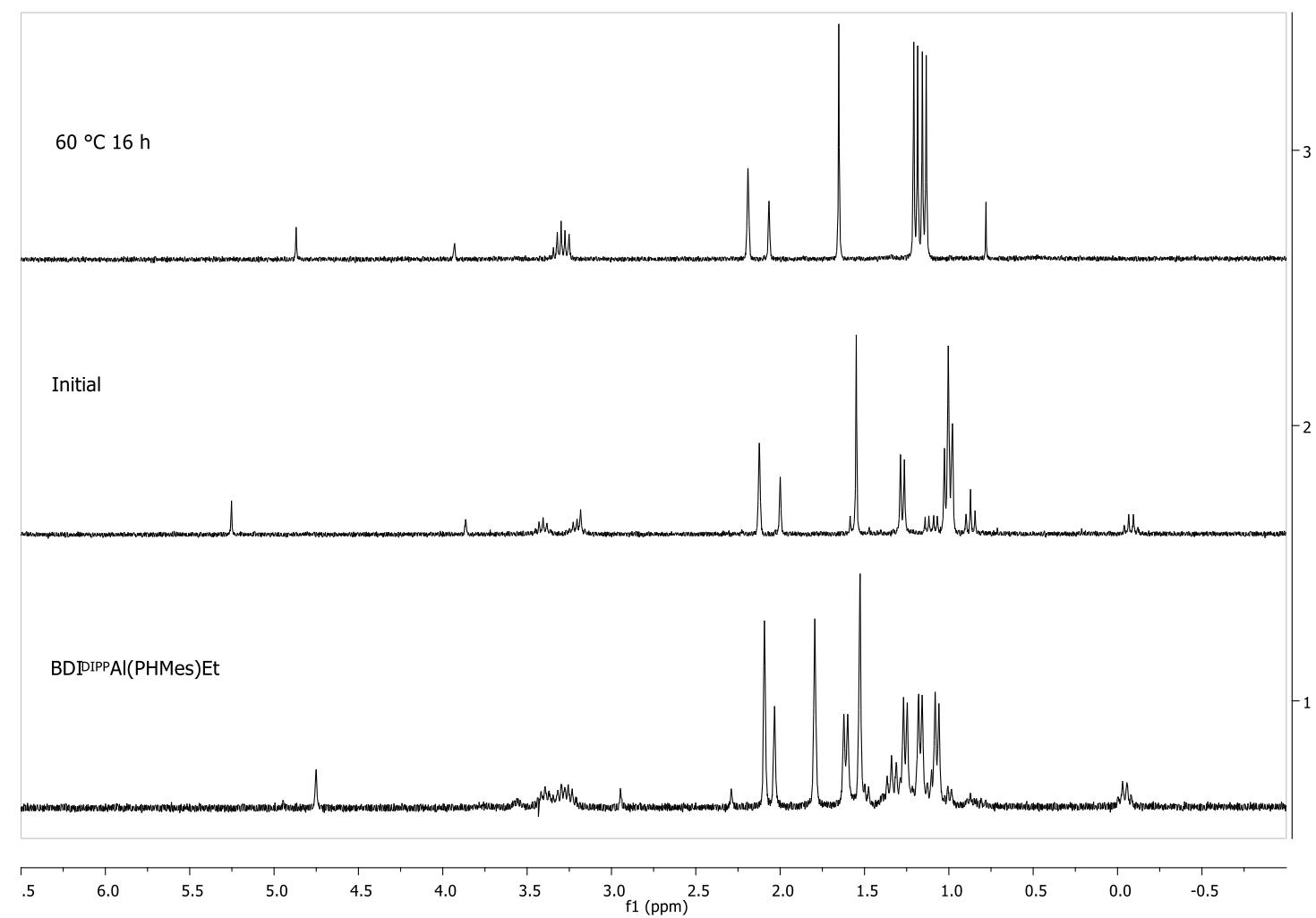

Figure 119: Comparison ${ }^{1} \mathrm{H}$ NMR spectra of BDIDIPPAI(PHMes)Et 63 (bottom) with benzaldehyde, initial spectrum (middle) and after heating to $60^{\circ} \mathrm{C}$ for 2 hours (top).

Repeating the reaction on a larger scale in toluene lead to the formation of the same product, however formation of other products was also observed by ${ }^{1} \mathrm{H} N M R$, which were 
unable to be separate by purification. Crystals suitable for X-ray diffraction could not be isolated from the reaction mixture, therefore only the ${ }^{1} \mathrm{H}$ NMR spectrum of the small-scale reaction in $\mathrm{C}_{6} \mathrm{D}_{6}$ could be used to infer the identity of the product. The presence of the singlet resonance at $\delta 0.78 \mathrm{ppm}$ supports the loss of ethane, potentially indicating that the product is complex 80 (Scheme 66), where benzaldehyde has lost the aldehyde proton and formed a bond to the aluminium through $\sigma$-bond metathesis of the $\mathrm{C}-\mathrm{H}$ and $\mathrm{Al}-\mathrm{C}$ bonds.

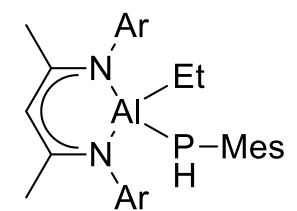

63<smiles>O=Cc1ccccc1</smiles>

$\mathrm{C}_{6} \mathrm{D}_{6}$

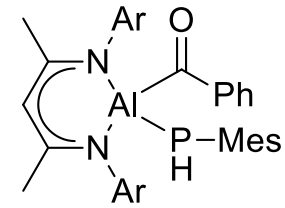

80<smiles>CC(C)c1cccc(C(C)C=[Zn])c1N(C)C</smiles>

Scheme 66: Proposed product of the addition of benzaldehyde to BDIDIPPAI(PHMes)Et.

\subsubsection{Reactivity with Chalcogens}

Upon addition of one equivalent of sulfur to a solution of BDIDIPPAl(PHMes) $\mathrm{Cl} \mathbf{5 8}$ in $\mathrm{C}_{6} \mathrm{D}_{6}$, no reaction was observed at room temperature after 1 hour. Following heating to $40{ }^{\circ} \mathrm{C}$ for 2 hours, the ${ }^{1} \mathrm{H}$ NMR spectrum showed a new $\gamma$-proton resonance at $\delta 4.90 \mathrm{ppm}$ in a 3:7 ratio to the starting material (Figure 120), heating to $60^{\circ} \mathrm{C}$ for 2 hours increased the amount of this product formed, however continued heating at $60^{\circ} \mathrm{C}$ for 16 hours lead to the formation of a second $\gamma$-proton resonance at $\delta 4.81 \mathrm{ppm}$, in addition to the first product observed, in a 65:35 ratio and complete consumption of the starting material. 


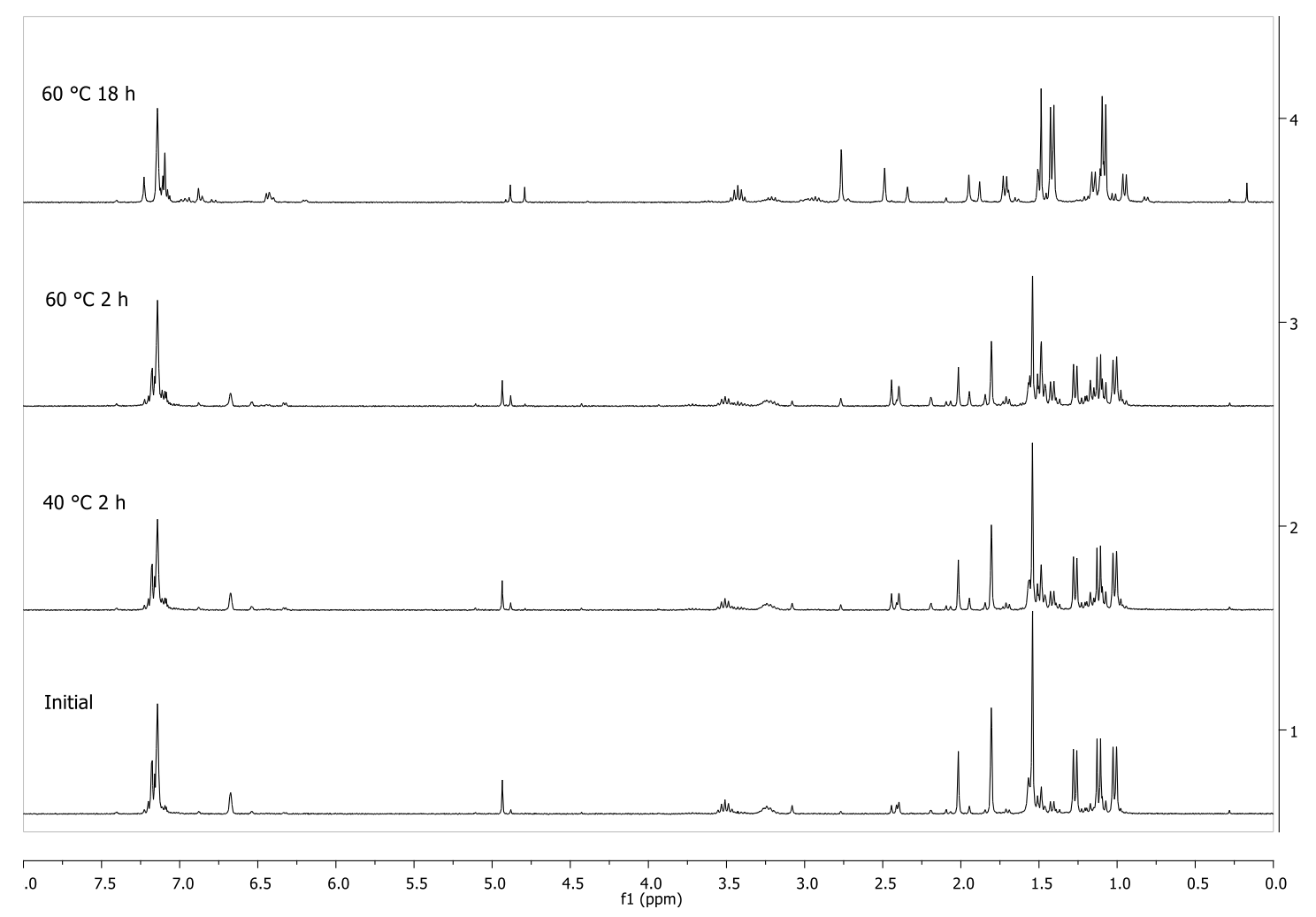

Figure 120: Comparison ${ }^{1} \mathrm{H}$ NMR spectra of BDIDIPPAI(PHMes)Cl 58 with sulfur, initial spectrum (bottom), heating to $40^{\circ} \mathrm{C}$ for 2 hours (lower middle), heating to $60^{\circ} \mathrm{C}$ for 2 hours (upper middle) and after heating to $60^{\circ} \mathrm{C}$ for 16 hours (top).

Chalcogens are known to insert into metal-phosphorus bonds, ${ }^{281}$ can oxidise $\mathrm{P}$ (III) complexes to $\mathrm{P}(\mathrm{V}),{ }^{281-282}$ and can also insert into phosphorus-hydrogen bonds, ${ }^{282}$ and any combination of these three reactions could account for the two products 81a-g (Scheme 67). Of all these different combinations of reactivities, $81 \mathrm{a}, \mathbf{8 1 b}$ and $81 \mathrm{c}$ are most likely to be the two products observed, due to the limited amount of sulfur used in the reaction. The reaction was repeated on a larger scale in toluene, however isolating the products of the reaction proved difficult, as neither a clean NMR sample or crystal suitable for X-ray diffraction could be obtained from the reaction mixture. Reactions with excess sulfur in an attempt to form only $\mathbf{8 1 g}$ resulted in an intractable mixture of products, with purification hindered by the remaining sulfur in the reaction mixture. 

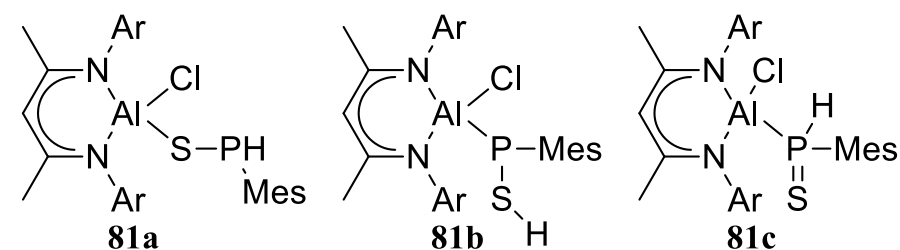

$\sum C_{\mathrm{Ar}}^{N^{\prime}} \mathrm{Al}_{\mathrm{Pr}}^{\mathrm{Ar}}-\mathrm{Cl}$

58

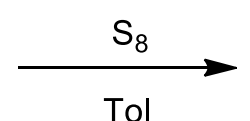

Tol<smiles></smiles>

81d<smiles></smiles>

81e

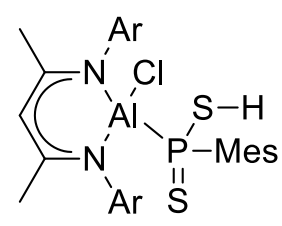

81f<smiles></smiles>

$81 \mathrm{~g}$

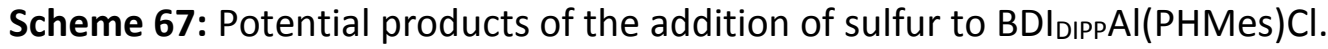

The addition of selenium to $\mathrm{BDI}_{\mathrm{DIPP}} \mathrm{Al}$ (PHMes) $\mathrm{Cl} \mathbf{5 8}$ in $\mathrm{C}_{6} \mathrm{D}_{6}$ proceeded in a similar fashion, with no reaction being observed immediately at room temperature by ${ }^{1} \mathrm{H}$ NMR spectroscopy. After two hours heating at $40{ }^{\circ} \mathrm{C}$, two new $\gamma$-proton resonances were observed at $\delta 4.97$ and 4.77 ppm, the former of which overlapped with the starting material making a ratio impossible to calculate. Subsequent heating to $60^{\circ} \mathrm{C}$ for 16 hours resulted in the formation of at least six different products based on the number of resonances in the $\gamma$-proton region (Figure 121). 


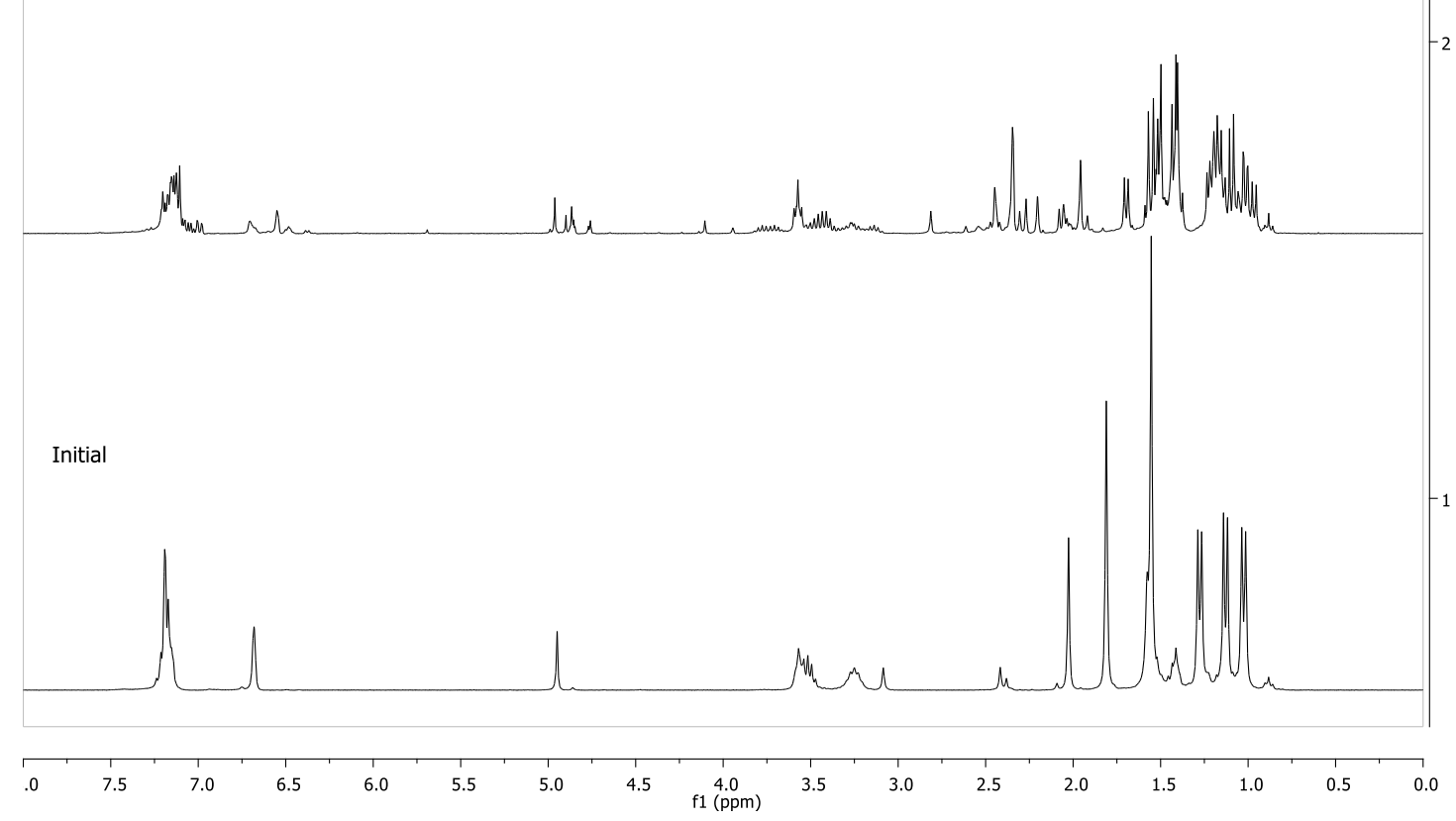

Figure 121: Comparison ${ }^{1} \mathrm{H}$ NMR spectra of BDIDIPPAI(PHMes)Cl 58 with selenium, initial spectrum (bottom), and after heating to $60^{\circ} \mathrm{C}$ for 16 hours (top).

As with the reaction of $\mathbf{5 8}$ with sulfur, there are multiple potential products $\mathbf{8 2} \mathbf{2}-\mathbf{g}$ due to the three different functional group reactivities with chalcogens (Scheme 68). Repeating the reaction in toluene on a larger scale lead to at least six product resonances being observed in the ${ }^{1} \mathrm{H}$ NMR spectrum and seven in the ${ }^{31} \mathrm{P}$ NMR spectrum. It is possible that all of the potential products formed to some degree, despite the limited amount of selenium, and none of these could be isolated from the reaction mixture. 


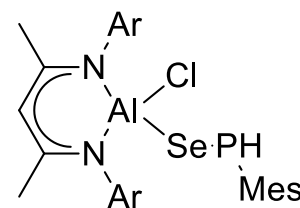

82a

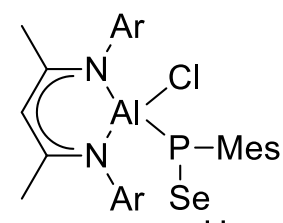

82b $H$

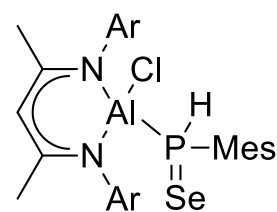

82c<smiles></smiles>

58

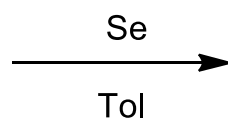

Tol

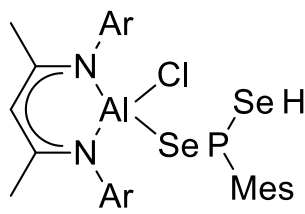

82d

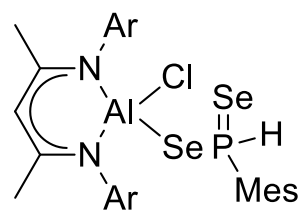

82e

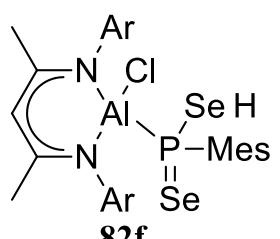

$82 f$<smiles></smiles>

$82 \mathrm{~g}$

Scheme 68: Proposed products of the addition of selenium to BDIDIPPAl(PHMes)Cl.

Addition of one equivalent of sulfur or selenium to a solution of phosphanide 63 or 66 in $\mathrm{C}_{6} \mathrm{D}_{6}$ encountered similar problems as $\mathbf{5 8}$, with the formation of multiple products occurring that were unable to be separated from each other. This indicates that phosphanides $\mathbf{5 8}, \mathbf{6 3}$ and 66 all react with chalcogens in multiple different ways, due to the presence of multiple reactive sites in the phosphanides.

\subsubsection{Reactivity with Methyl Iodide}

Addition of methyl iodide to a solution of phosphanide 58,63 or 66 in $C_{6} D_{6}$ resulted in no reaction at room temperature after 1 hour, or upon heating to $40^{\circ} \mathrm{C}$ for 2 hours (Figure 122). Subsequent heating to $60{ }^{\circ} \mathrm{C}$ lead to the loss of the resonances in the ${ }^{1} \mathrm{H}$ NMR spectrum $(\delta$ $6.67,2.73,2.02$ and $1.80 \mathrm{ppm}$ ) corresponding to the mesityl phosphide ligand and small changes in the resonances of the BDI DIPP ligand. This would indicate that methyl iodide cleaves the metal-phosphorus bond. The lack of a methyl resonance $<0 \mathrm{ppm}$ suggests the iodide substitutes onto the metal centre (Scheme 69) to give complexes 83-85 and the free phosphine. The reaction was repeated on a larger scale in toluene, however attempts to isolate the products were unsuccessful. 


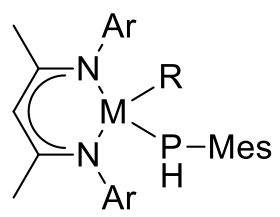

$58 \mathbf{M}=\mathbf{A l} \mathbf{R}=\mathbf{C l}$

$63 M=A l R=E t$

$66 M=G a R=H$<smiles>[R][Y4]1=C([Al])N([Al])C(C)=CC(C)=C1[Al]</smiles>

$83 \mathrm{M}=\mathrm{Al} R=\mathrm{Cl}$

$84 \mathrm{M}=\mathrm{Al} R=\mathbf{E t}$

$85 M=G a R=H$
+ MesPHMe $A r=$

Scheme 69: Proposed reactivity with methyl iodide.

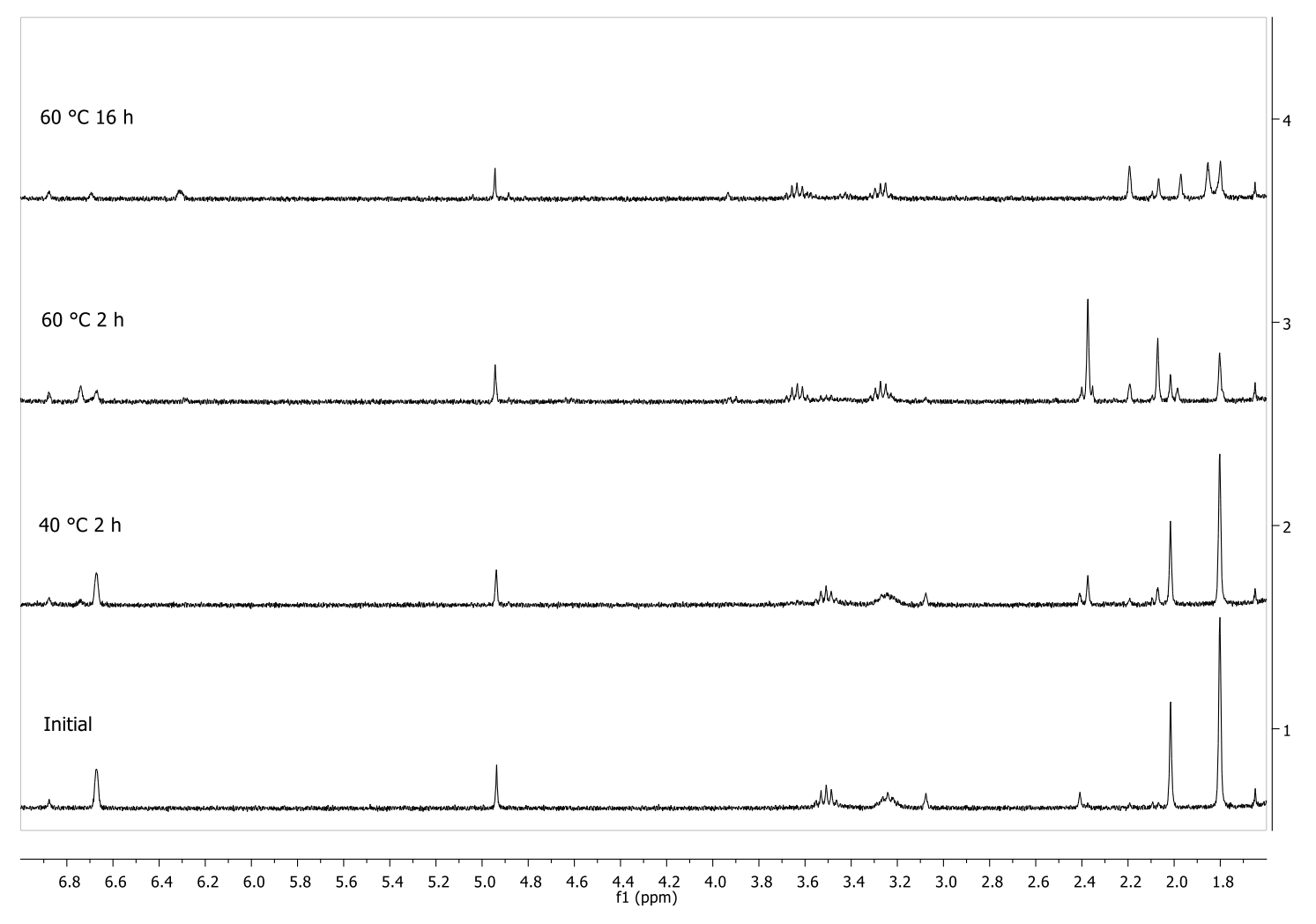

Figure 122: Comparison ${ }^{1} \mathrm{H}$ NMR spectra of BDI DIPPAI(PHMes)Cl 58 with methyl iodide, initial spectrum (bottom), heating to $40^{\circ} \mathrm{C}$ for 2 hours (lower middle), heating to $60^{\circ} \mathrm{C}$ for 2 hours (upper middle) and after heating to $60^{\circ} \mathrm{C}$ for 16 hours (top). 


\subsection{Conclusion}

The reactivity of the primary phosphanide complexes BDIDIPAI(PHMes)Cl 58,

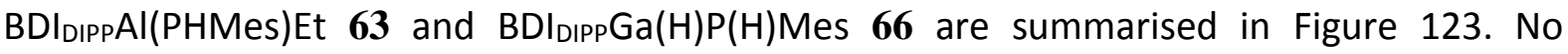
reactivity was observed for any phosphanide species with phenyl acetylene, dicyclohexylcarbodiimide, or benzophenone. The phosphanides reacted with cyclohexene to give intractable mixtures of products, none of which have been isolated. Of the three phosphanide species, only $\mathbf{6 3}$ reacted with benzaldehyde, however this reactivity was likely due to the presence of the ethyl ligand rather than the phosphide ligand. All three phosphanide species reacted with sulfur and selenium, however this yielded multiple products that could not be successfully isolated. The phosphanides were also reactive with methyl iodide, which likely cleaved the metal-phosphorus bond and substituted the metal with an iodide ligand, though the product could not be isolated to confirm this. All three phosphanides reacted with both 4-nitrophenylisocyanate and phenylisothiocyanate, while only one product (76) was able to be fully characterised, the similar splitting patterns in the ${ }^{1} \mathrm{H}$ NMR spectra of the other complexes strongly indicate that the same insertion product was formed. 


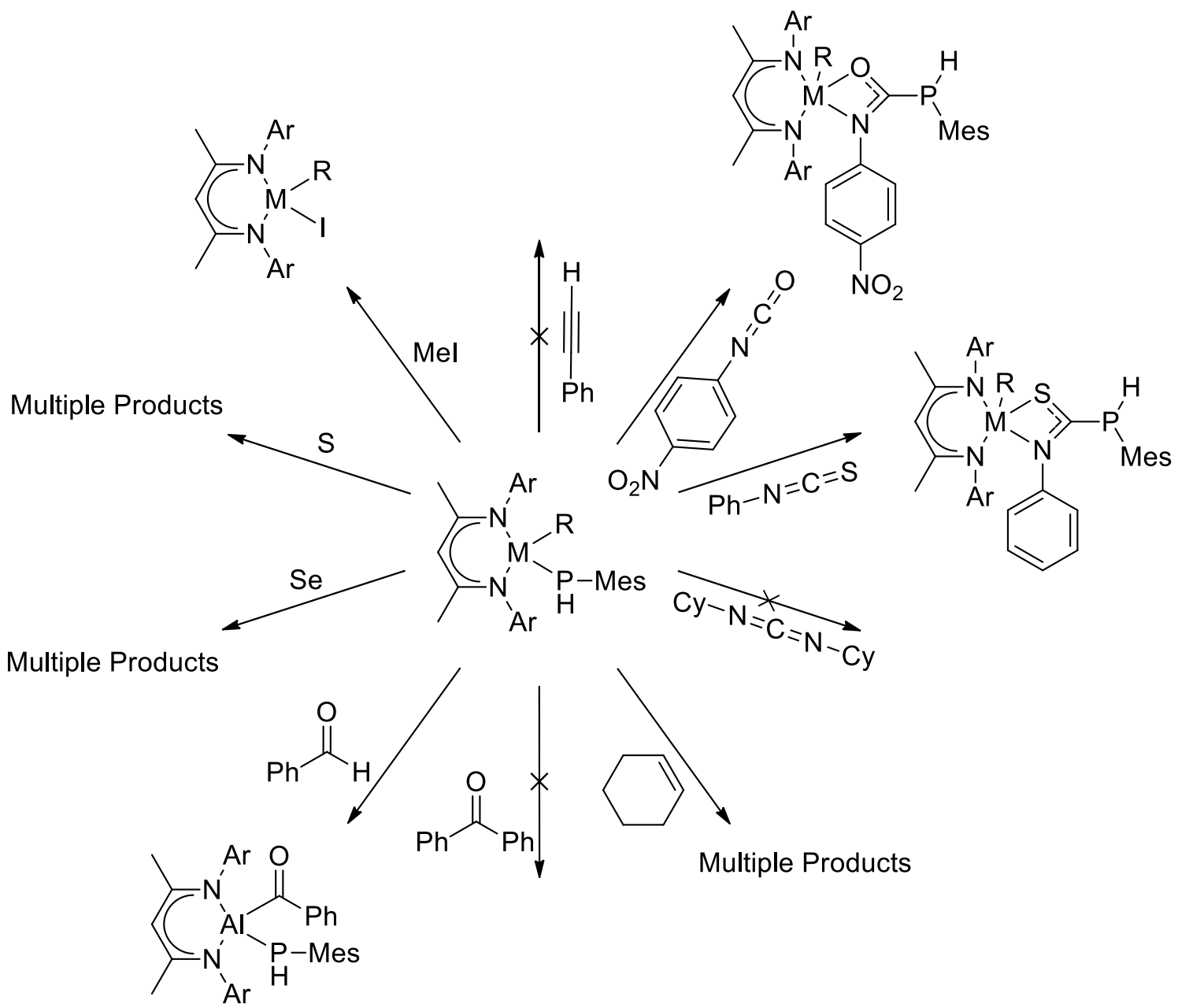

Figure 123: Reactivity summary of primary phosphanides.

Further work is needed to fully characterise the products of these reactions, and an investigation into if complex $\mathbf{7 6}$ will react with $\mathrm{MesPH}_{2}$ to regenerate the phosphanide complex is needed. If successful, complex $\mathbf{5 8}$ could potentially be used for catalytic hydrophosphination of isocyanates and isothiocyanates with primary phosphines, as opposed to secondary phosphines. 


\section{Chapter 5}

\section{Summary and Outlook}

The understanding of the structure and nature of bonding between the heavier $p$ block elements has increased rapidly over the past 50 years, to the point where $p$ block elements are no longer considered to lack the properties that make transition metals desirable for catalysis and organometallic chemistry. The heavier $p$ block elements have revealed that the structures and bonding observed in the first $\operatorname{row}(B, C, N, O)$ is actually the exception, rather than the normal for the block. This is due to the configuration at the metal centre and the degree of bonding between elements highly dependent on the energies of the valence orbitals used in bonding and the singlet-triplet energy gap of the two atoms involved in the bond. The use of sterically demanding ligands to both stabilise and protect the metal centre has allowed for the successful isolation of complexes in low oxidation states (n-2) and complexes analogous to alkenes and alkynes with multiple bonding present between different heavier elements of the $p$ block. The work presented in this thesis expands on the use of the $\beta$-diketiminato ligand with aluminium and gallium and the nature of the structure, bonding and reactivity of these complexes.

Chapter 2 describes the reactivity of BDIDIPPGa with a range of diazo- compounds in an effort to isolate a complex with a formal gallium-carbon double bond. The reaction of BDIDIPPGa with trimethylsilyldiazomethane resulted in two equivalents of the diazocompound reacting, one losing the $\mathrm{N}_{2}$ unit as expected but then deprotonating the second equivalent to give a $\mathrm{CH}_{2} \mathrm{SiMe}_{3}$ ligand and a nitrilimine ligand. When the diazo-compound is changed to cyclodoceyldiazomethane, again two equivalents of the diazo- compound react, with one losing $\mathrm{N}_{2}$ as expected and coordinating to the gallium centre, but this time the nitrilimine unit of the second equivalent appears to have deprotonated the $\alpha$-carbon of both cyclododecane rings, giving a $\mathrm{C}_{12} \mathrm{H}_{21}$ ligand and a $\mathrm{N}(\mathrm{H}) \mathrm{N}(\mathrm{H}) \mathrm{C}_{12} \mathrm{H}_{21}$ ligand. Changing the diazocompound to diphenyldiazomethane lead to the isolation of the BDI DIPPGa starting material and tetraphenylethylene, with BDI ${ }_{\text {DIPPGa }}$ apparently catalysing the decomposition of the 
diazo- compound. Switching the diazo- compound to diazofluorene results in an apparent $[2+2]$ cycloaddition reaction of a second equivalent of diazofluorene with the proposed $\mathrm{Ga}=\mathrm{C}$ intermediate, though the intermediate could not be successfully isolated. The final diazocompound attempted was di-tert-butyldiazomethane, which surprisingly did not react with $B I_{D I P P G a}$ at all. The preparation of three new gallium(I) complexes, $\operatorname{ArBDI}_{\mathrm{DIPP} G a}, \mathrm{BDI}_{\mathrm{Ar}} * \mathrm{Ga}$ and $\mathrm{BDI}_{\mathrm{Ar}} \mathrm{Ga}$ is also described. The reaction between $\mathrm{ArBDI}_{\mathrm{DIPP}} \mathrm{Ga}$ and trimethylsilyldiazomethane resulted in two equivalents of the diazo- compound reacting, forming two enantiomers with a $\mathrm{CH}_{2} \mathrm{SiMe}_{3}$ ligand and a nitrilimine ligand. $\mathrm{BDI}_{\mathrm{Ar}} * \mathrm{Ga}$ and $\mathrm{BDI}_{\mathrm{Ar}} \mathrm{Ga}$ successfully stopped the second equivalent of diazo- compound reacting with the gallium(I) species, however the gallium(I) species now inserted into the $\mathrm{C}-\mathrm{H}$ bond of trimethylsilyldiazomethane to give a gallium hydride and a nitrilimine ligand coordinated through the carbon atom. When diazofluorene was added to $\mathrm{BDI}_{\mathrm{Ar}} \mathrm{Ga}$, it resulted in the activation of an aryl $\mathrm{C}-\mathrm{H}$ bond in one of the ancillary phenyl groups of the $\mathrm{BDI}_{\mathrm{Ar}}$ ligand, with the complex possessing a $\mathrm{Ga}-\mathrm{C}$ bond to the ancillary phenyl group and a $\mathrm{N}(\mathrm{H}) \mathrm{N}=\mathrm{Fl}$ ligand.

Chapter 3 presents an investigation into the formation of an aluminium-phosphorus or gallium-phosphorus formal double bond. The attempted reduction/elimination strategy on $\mathrm{BDI}$ DIPPAI(PHPh)Cl and $\mathrm{BDI}$ DIPPGa(PHPh)Cl resulted in an intractable mixture of products. Increasing the steric bulk of the phosphanide substituent from phenylphosphide to mesitylphosphide did not assist in isolating a metal-phosphinidene complex, but instead lead to the decomposition of the starting complexes and a mixture of unisolable products. Changing the elimination product required for the proposed formation of a metalphosphinidene from $\mathrm{LiCl}$ to $\mathrm{TMS}-\mathrm{Cl}$ was unsuccessful. The intermediate species $\left.\mathrm{BDI}_{\text {DIPPAI}} \mathrm{Cl}\right) \mathrm{P}(\mathrm{TMS}) \mathrm{Ph}$ was isolated successfully, however showed no signs of eliminating TMS-Cl upon heating. Changing the attempted elimination product to ethane resulted in the synthesis of $\mathrm{BDI}_{\mathrm{DIPP} A I}(\mathrm{Et}) \mathrm{P}(\mathrm{H}) \mathrm{Mes}$, which showed no signs of undergoing elimination of ethane to form the target phosphinidene complex. Attempts to reduce $\mathrm{MesPCl}_{2}$ with potassium in the presence of BDIDIPPGa lead to the decomposition of the starting material, or formation of $(\mathrm{MesP})_{3}$ and $(\mathrm{MesP})_{4}$ when magnesium was used as the reducing agent. The attempt to make MesPLi $i_{2}$ and react that with $\mathrm{BDI}_{\mathrm{DIPPMX}}(\mathrm{M}=\mathrm{Al}, \mathrm{Ga} X=$ halogen) complexes should be investigated further, as it was likely that the MesPLi2 was not synthesised. The complex $\mathrm{BDI}_{\mathrm{DIPPGa}}(\mathrm{H}) \mathrm{P}(\mathrm{H})$ Mes was synthesised and subsequently heated to eliminate dihydrogen, 
however no elimination of dihydrogen occurred. Attempts to investigate aluminium(I) species as reagents in the formation of an aluminium-phosphinidene complex were also unsuccessful, with BDIDIPPAl being successfully synthesised, but unable to be isolated/purified. The attempt to make a new BDI aluminium(I) complex using the ArBDIDIPp ligand was potentially successful, however the complex appears to undergo a similar insertion of the aluminium atom into the $\mathrm{C}=\mathrm{N}$ bond of the ligand to generate a five-membered ring previously reported. Another attempt using the $\mathrm{BDI}_{\mathrm{Ar}}$ ligand was unable to convert the dimethyl complex $\mathrm{BDI}_{\mathrm{Ar}} \mathrm{AlMe}_{2}$ into the diiodide complex $\mathrm{BDI}_{\mathrm{Ar}} * \mathrm{All}_{2}$, presumably due to the steric hinderance of the $\mathrm{BDI}_{\mathrm{Ar}^{*}}$ ligand preventing the second methyl ligand from undergoing substitution.

Chapter 4 details an investigation into the reactivity of $\left.\left.\mathrm{BDI}\right|_{\mathrm{DIPPAl}} \mathrm{PHMes}\right) \mathrm{Cl}$, BDIDIPPAl(PHMes)Et and BDIDIPPGa(H)P(H)Mes with small molecules and chalcogens. No reactivity was observed for any of the phosphanide species with phenyl acetylene, dicyclohexylcarbodiimide, or benzophenone. The phosphanide complexes reacted with cyclohexene to give intractable mixtures of products, none of which have been isolated. Of the three phosphanide species, only BDIDIPPAI(PHMes)Et reacted with benzaldehyde, however this reactivity was likely due to the presence of the ethyl ligand rather than the phosphide ligand. All three phosphanide species reacted with sulfur and selenium, however this yielded multiple products that could not be successfully isolated. The phosphanides were also reactive with methyl iodide, which likely cleaved the metal-phosphorus bond and substituted the metal with an iodide ligand, though the product could not be isolated to confirm this. All three phosphanides reacted with both 4-nitrophenylisocyanate and phenylisothiocyanate, however the only product able to be fully characterised was

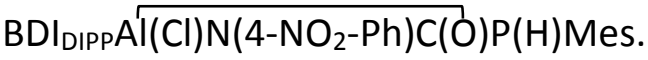

While the targeted multiple bonded compounds were not successfully isolated, the work presented in this thesis contributes several novel compounds and unprecedented reactivities. The activation of alkyl and aryl $\mathrm{C}-\mathrm{H}$ bonds by $\mathrm{BDI}_{\mathrm{Ar}} * \mathrm{Ga}$ warrants further investigation and expansion to other typically stable bonds, such as C-F bonds. The three examples of BDI $\mathrm{Ar}^{*}$ and $\mathrm{BDI}_{\mathrm{Ar}}$ gallium(III) complexes all showed the gallium(III) remaining in the CNNNC plane of the ligand, which is unusual for BDI bearing gallium(III) complexes and should be investigated by DFT to determine why this configuration is favourable. The reactivity should also be expanded to other diazo- compounds with harder to activate bonds, for example $\left(\mathrm{CF}_{3}\right)_{2} \mathrm{CNN}$, 
to investigate if the lack of $\beta$-hydrogen atoms allows the gallium-carbon double bond to form. Additionally, the reactivity with diazo- compounds should be expanded to the aluminium(I) complexes in pursuit of the aluminium-carbon double bond. The gallium-phosphorus and aluminium-phosphorus target complexes likely need larger, more sterically protecting ligands than $\mathrm{BDI}_{\mathrm{DIPP}}$ in order to be successfully isolated, and the $\mathrm{BDI}_{\mathrm{Ar}}$ and $\mathrm{BDI}_{\mathrm{Ar}}$ ligands should be investigated as ancillary ligands for the reactions attempted in chapter 3 , as they may prevent the decomposition to intractable mixtures so frequently observed. The reactivity of gallium and aluminium phosphanides with chalcogens could allow for the isolation of new, single source precursors for the synthesis of known Ga-E and Al-E nanomaterials used as semiconductors. The gallium and aluminium phosphanides may be able to be used as catalysts for hydrophosphination of isocyanates and isothiocyanates and their ability to react with $\mathrm{MesPH}_{2}$ to reform the starting materials should be investigated. 


\section{Chapter 6}

\section{Experimental}

\section{General}

All manipulations were carried out under dry nitrogen using standard Schlenk-line and cannula techniques, or in a conventional nitrogen-filled glovebox. Solvents were dried using a PureSolv. system (Innovative Technologies). NMR spectra were recorded in $C_{6} D_{6}$ at $298 \mathrm{~K}$ (unless otherwise stated), using a Bruker Avance DPX $300 \mathrm{MHz}$ spectrometer at $300.1\left({ }^{1} \mathrm{H}\right)$, $75.1\left({ }^{13} \mathrm{C}\right)$ and $121.1\left({ }^{31} \mathrm{P}\right) \mathrm{MHz}$ or a Varian DirectDrive $600 \mathrm{MHz}$ spectrometer at $600.1\left({ }^{1} \mathrm{H}\right)$ and $150.9\left({ }^{13} \mathrm{C}\right) \mathrm{MHz}$. Proton and carbon chemical shifts were referenced internally to residual solvent resonances. Crystals were covered in inert oil and suitable single crystals were selected under a microscope and mounted on an Agilent SuperNova diffractometer fitted with an Atlas or EOS S2 detector. Data were collected at the temperature indicated using

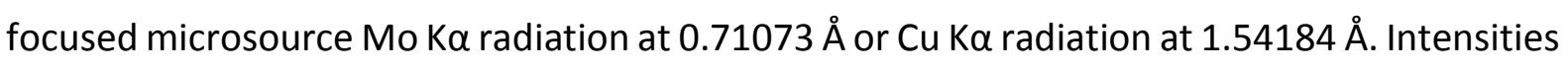
were corrected for Lorentz and polarisation effects and for absorption using multi-scan methods. Space groups were determined from systematic absences and checked for higher symmetry. All structures were solved using direct methods with SHELXS, 283 refined on $F^{2}$ using all data by full matrix least-squares procedures with SHELXL-97, ${ }^{284}$ within OLEX2.3. ${ }^{285}$ Nonhydrogen atoms were refined with anisotropic displacement parameters, unless stated otherwise. Hydrogen atoms were placed in calculated positions or manually assigned from residual electron density where appropriate. All compounds were purchased from SigmaAldrich chemical company. Anilines were distilled before use. Liquids were subjected to $3 \mathrm{x}$ freeze-pump-thaw cycles and stored under nitrogen in the glovebox. Phenylphosphine and Mesitylphosphine was prepared from bromobenzene and bromomesitylene respectively following literature procedures. ${ }^{239} \mathrm{Ar}^{*} \mathrm{NH}_{2}$ and $\mathrm{Ar}^{\prime} \mathrm{NH}_{2}$ were prepared according to literature procedures. $^{286}$ 


\section{'Gal'}

Suspensions of 'Gal' were prepared following literature procedures. ${ }^{8}$ Gallium metal 0.2 $\mathrm{g}, 2.8 \mathrm{mmol})$ and iodine $(0.36 \mathrm{~g}, 2.8 \mathrm{mmol})$ were placed in an ampule and toluene $(40 \mathrm{~mL})$ was added. The mixture was then placed in an ultrasonic bath that had been preheated to $40{ }^{\circ} \mathrm{C}$ and sonicated for 3 hours to give a dark green suspension which was used immediately without purification.

\section{$\mathrm{CH}\left\{\mathrm{C}(\mathrm{Me}) \mathrm{N}\left(\mathrm{C}_{6} \mathrm{H}_{3}-2,6-\mathrm{PPr}_{2}\right)\right\}_{2} \mathrm{Ga}\left(\mathrm{BDI}_{\mathrm{DIPP}} \mathrm{Ga}, 1\right)$}

This compound was synthesised by known literature procedures. ${ }^{8}$ A suspension of 'Gal' in toluene was then<smiles></smiles><smiles>CC(C)c1cccc(C(C)C)c1N(C)C</smiles>
cooled to $-78{ }^{\circ} \mathrm{C}$ and a solution of BDIDIPP-Li $(0.85 \mathrm{~g}, 2.0 \mathrm{mmol})$ in toluene $(10 \mathrm{~mL})$ was added slowly dropwise to give a bright yellow solution. The solution was warmed to room temperature and left to react for $16 \mathrm{~h}$, then filtered through celite and concentrated to c.a. $15 \mathrm{~mL}$ and placed in the freezer at $-30^{\circ} \mathrm{C}$, at which point yellow crystals of BDIDIPPGa 1 formed (0.45 g, 46\%). ${ }^{1} \mathrm{H}$ NMR (300 MHz, $\left.\mathrm{C}_{6} \mathrm{D}_{6}, 298 \mathrm{~K}\right) \delta 7.17(\mathrm{~m}, 6 \mathrm{H}, \mathrm{ArH}), 5.19$ (s, 1H, CH), 3.15 (sept, $\left.J=6.9 \mathrm{~Hz}, 4 \mathrm{H}, \mathrm{CH}\left(\mathrm{CH}_{3}\right)_{2}\right), 1.72\left(s, 6 \mathrm{H}, \mathrm{C}\left(\mathrm{CH}_{3}\right)\right), 1.29\left(d, J=6.9 \mathrm{~Hz}, 12 \mathrm{H}, \mathrm{CH}\left(\mathrm{CH}_{3}\right)_{2}\right), 1.15(d, J=$ $\left.6.9 \mathrm{~Hz}, 12 \mathrm{H}, \mathrm{CH}\left(\mathrm{CH}_{3}\right)_{2}\right)$. These values are in accordance with literature values.

\section{$\mathrm{CH}\left\{\mathrm{C}(\mathrm{Me}) \mathrm{NH}\left(\mathrm{C}_{6} \mathrm{H}_{3}-2,6-{ }^{-} \mathrm{Pr}_{2}\right)\right\}\left\{\mathrm{C}(\mathrm{Me}) \mathrm{N}\left(\mathrm{C}_{6} \mathrm{H}_{3}-2,6-\mathrm{Pr}_{2}\right)\right\}\left(B D I_{D I P P}-\mathrm{H}, 2\right)$}

This compound was prepared following literature procedure. ${ }^{113}$ Acetylacetone (10.2 $\mathrm{mL}, 100 \mathrm{mmol})$ and 2,6-diisopropylaniline (37.8 mL, $200 \mathrm{mmol}$ ) were added to

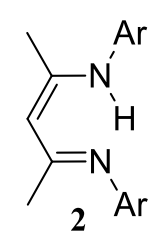
a stirring solution of ethanol $(100 \mathrm{~mL})$ in a $250 \mathrm{~mL}$ round bottom flask open to air fitted with a reflux condenser. $\mathrm{HCl}(9.0 \mathrm{~mL}, 100 \mathrm{mmol})$ was added drop-wise to the solution, and the mixture was then refluxed for $72 \mathrm{~h}$ to give a white precipitate. The solution was neutralised and extracted with $3 \times 50 \mathrm{~mL}$ of $1: 1$ sat. sodium carbonate solution : dichloromethane. The organic layer was isolated, and the solvent was reduced in vacuo till precipitation was observed. The solution was cooled to $0{ }^{\circ} \mathrm{C}$ and the resulting white crystals filtered off and recrystallized from dichloromethane/methanol to give $\mathrm{BDI}_{\mathrm{DIPP}} \mathbf{2}$ as colourless needles 
(31.65 g, 75.4\%). ${ }^{1} \mathrm{H}$ NMR (300 MHz, $\left.\mathrm{C}_{6} \mathrm{D}_{6}, 298 \mathrm{~K}\right) \delta 12.48(\mathrm{~s}, 1 \mathrm{H}, \mathrm{NH})$, 7.18-7.14 (m, 6H, ArH), $4.89(s, 1 \mathrm{H}, \mathrm{CH}), 3.32$ (sept, J = 4.2 Hz, 4H, $\left.\mathrm{CH}\left(\mathrm{CH}_{3}\right)_{2}\right), 1.67\left(s, 6 \mathrm{H}, \mathrm{C}\left(\mathrm{CH}_{3}\right)\right), 1.22(d, J=4.2 \mathrm{~Hz}$, $\left.12 \mathrm{H}, \mathrm{CH}\left(\mathrm{CH}_{3}\right)_{2}\right), 1.17\left(\mathrm{~d}, \mathrm{~J}=4.2 \mathrm{~Hz}, 12 \mathrm{H}, \mathrm{CH}\left(\mathrm{CH}_{3}\right)_{2}\right)$. The compound was also measured in $\mathrm{CDCl}_{3}$ to compare with literature values of: $\delta 12.12,7.12,4.84,3.10,1.72,1.22,1.12 .{ }^{113}$ When run in $\mathrm{CDCl}_{3}$, the resonances were of comparable chemical shift to the literature.

\section{$\mathrm{CH}\left\{\mathrm{C}(\mathrm{Me}) \mathrm{N}\left(\mathrm{C}_{6} \mathrm{H}_{3}-2,6^{-}{ }^{-} \mathrm{Pr}_{2}\right)\right\}_{2} \mathrm{AIMe}_{2}\left(\mathrm{BDI}_{\text {DIPPAIMe}}, 4\right)$}

This compound was prepared following literature procedure. ${ }^{287}$ Trimethylaluminium (1.2 mL, $2.4 \mathrm{mmol}$ ) $2.0 \mathrm{M}$ solution in toluene was added

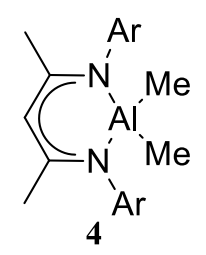
slowly to a solution of BDIDIPP-H $2(1.0 \mathrm{~g}, 2.4 \mathrm{mmol})$ in toluene $(20 \mathrm{~mL})$ and stirred for 2 hours. The solvent was concentrated to c.a. $5 \mathrm{~mL}$ and stored at $-30{ }^{\circ} \mathrm{C}$ at which point crystals of BDI DIPPAIMe $_{2} 4$ formed (1.1 g, 97\%). ${ }^{1} \mathrm{H}$ NMR (300 MHz, $\left.\mathrm{C}_{6} \mathrm{D}_{6}, 298 \mathrm{~K}\right) \delta$ 7.25-7.14 (m, 6H), 5.12 $(s, 1 \mathrm{H}), 3.22$ (sept, $J=6.9 \mathrm{~Hz}, 4 \mathrm{H}), 1.88(s, 6 \mathrm{H}), 1.23(d, J=6.9 \mathrm{~Hz}, 12 \mathrm{H}), 1.13(d, J=6.9 \mathrm{~Hz}$, $12 \mathrm{H}),-0.99(\mathrm{~s}, 6 \mathrm{H})$. These values are in accordance with literature values.

\section{$\mathrm{CH}\left\{\mathrm{C}(\mathrm{Me}) \mathrm{N}\left(\mathrm{C}_{6} \mathrm{H}_{3}-2,6-{ }^{\mathrm{i}} \mathrm{Pr}_{2}\right)\right\}_{2} \mathrm{All}_{2}\left(\mathrm{BDI}_{\mathrm{DIPP}} \mathrm{All}{ }_{2}, 5\right)$}

This compound was prepared following literature procedure. ${ }^{124}$ BDI DIPPAIMe $_{2} 4$ (500 mg, $1.1 \mathrm{mmol})$ was dissolved in toluene $(20 \mathrm{~mL})$ and iodine $(535 \mathrm{mg}, 2.1$

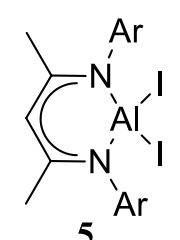

5 mmol) was added. The solution was stirred for 16 hours until the purple colour had disappeared to give a brown-yellow solution. Concentration of the solution to c.a. $5 \mathrm{~mL}$ and storage in the freezer at $-30{ }^{\circ} \mathrm{C}$ overnight afforded crystals of BDIDIPPAll $25(620 \mathrm{mg}, 84.5 \%) .{ }^{1} \mathrm{H}$ NMR (300 MHz, $\left.\mathrm{C}_{6} \mathrm{D}_{6}, 298 \mathrm{~K}\right) \delta 7.10(\mathrm{~m}, 6 \mathrm{H}), 5.04(\mathrm{~s}, 1 \mathrm{H}), 3.58(\mathrm{sept}, 4 \mathrm{H}), 1.49(\mathrm{~s}, 6 \mathrm{H}), 1.42(d$, $J=6.8 \mathrm{~Hz}, 12 \mathrm{H}), 1.09(d, J=6.8 \mathrm{~Hz}, 12 \mathrm{H})$. These values are in accordance with literature values.

\section{$\mathrm{CH}\left\{\mathrm{C}(\mathrm{Me}) \mathrm{N}\left(\mathrm{C}_{6} \mathrm{H}_{3}-2,6^{\mathrm{i}} \mathrm{Pr}_{2}\right)\right\}_{2} \mathrm{Al}$ (BDIDIPPAl, 6)}

This compound was prepared following literature procedure. ${ }^{124}$ A solution of $\mathrm{BDI}_{\text {DIPPAll }} \mathbf{5}$ (500 mg, $\left.0.7 \mathrm{mmol}\right)$ in toluene $(10 \mathrm{~mL}$ ) was added to a suspension of

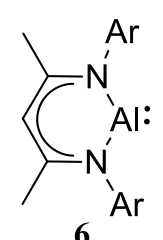

6 
finely divided potassium $(56 \mathrm{mg}, 1.4 \mathrm{mmol})$ in toluene $(10 \mathrm{~mL})$. The mixture was stirred for 3 days at room temperature, after which the solution developed a red colour and the potassium was consumed. The solution was filtered through celite and concentrated to c.a. $5 \mathrm{~mL}$ and placed in the freezer at $-30^{\circ} \mathrm{C}$. Crystals containing BDIDIPPAl 6 formed, but could not be purified from the $\mathrm{BDI}_{\mathrm{DIPP}}-\mathrm{K}$ and $\mathrm{BDI}_{\mathrm{DIPP}} \mathrm{All} \mathrm{I}_{2}$ impurities in the reaction mixture.

\section{$\mathrm{CH}\left\{\mathrm{C}(\mathrm{Me}) \mathrm{N}\left(\mathrm{C}_{6} \mathrm{H}_{3}-2,6-{ }^{\mathrm{i}} \mathrm{Pr}_{2}\right)\right\}_{2} \mathrm{Ga}\left(\mathrm{CH}_{2} \mathrm{SiMe}_{3}\right) \mathrm{NNCSiMe}_{3}$ (BDI $\left.\mathrm{BIPPa}\left(\mathrm{CH}_{2} \mathrm{TMS}\right) \mathrm{NNCTMS}, 19\right)$}

$\mathrm{BDI}_{\text {DIPPGa }}(0.1 \mathrm{~g}, 0.2 \mathrm{mmol})$ was dissolved in toluene $(5 \mathrm{~mL})$ and a solution of $2.0 \mathrm{M}$ trimethylsilyldiazomethane $(0.2 \mathrm{~mL}, 0.4 \mathrm{mmol})$ was added dropwise resulting in evolution of gas. Concentration of the solution gave $\mathbf{1 9}$ as yellow crystals (80 mg, 58.1\%). ${ }^{1} \mathrm{H}$ NMR (600 MHz, $\left.\mathrm{C}_{6} \mathrm{D}_{6}, 298 \mathrm{~K}\right) \delta 7.21(d, J=8.3 \mathrm{~Hz}$, $2 \mathrm{H}, \operatorname{Ar}-\boldsymbol{H}), 7.18-7.14(m, 2 \mathrm{H}, \operatorname{Ar}-\boldsymbol{H}), 7.08(d, J=7.8 \mathrm{~Hz}, 2 \mathrm{H}, \operatorname{Ar}-\boldsymbol{H}), 4.85(s, 2 \mathrm{H}$,

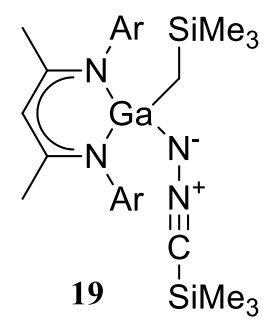
$\mathrm{CH}$ ), $3.87\left(\mathrm{sept}, \mathrm{J}=6.6 \mathrm{~Hz}, 2 \mathrm{H}, \mathrm{CH}\left(\mathrm{CH}_{3}\right)_{2}\right), 3.64(\mathrm{~s}, 1 \mathrm{H}, \mathrm{NH}), 3.16$ ( sept, J = $\left.6.9 \mathrm{~Hz}, 2 \mathrm{H}, \mathrm{CH}\left(\mathrm{CH}_{3}\right)_{2}\right)$, $1.73\left(d, J=6.3 \mathrm{~Hz}, 6 \mathrm{H}, \mathrm{CH}\left(\mathrm{CH}_{3}\right)_{2}\right), 1.69\left(s, 6 \mathrm{H}, \mathrm{CCH}_{3}\right), 1.40\left(d, J=6.8 \mathrm{~Hz}, 6 \mathrm{H}, \mathrm{CH}\left(\mathrm{CH}_{3}\right)_{2}\right), 1.35(d$, $\left.J=6.3 \mathrm{~Hz}, 6 \mathrm{H}, \mathrm{CH}\left(\mathrm{CH}_{3}\right)_{2}\right), 1.09\left(d, J=6.8 \mathrm{~Hz}, 6 \mathrm{H}, \mathrm{CH}\left(\mathrm{CH}_{3}\right)_{2}\right), 0.22\left(s, 9 \mathrm{H}, \mathrm{Si}\left(\mathrm{CH}_{3}\right)_{3}\right),-0.21(\mathrm{~s}, 9 \mathrm{H}$, $\left.\mathrm{Si}\left(\mathrm{CH}_{3}\right)_{3}\right),-0.81\left(\mathrm{~s}, 2 \mathrm{H}, \mathrm{CH}_{2}\right) .{ }^{13} \mathrm{C} \mathrm{NMR}\left(151 \mathrm{MHz}, \mathrm{C}_{6} \mathrm{D}_{6}\right) \delta 169.21,145.69,142.88,141.32$, $127.45,125.31,123.86,96.94,29.14,27.75,25.33,25.09,25.05,23.78,23.31,1.12,0.64$, 6.71. N.B. A strong correlation can be seen in the HMBC spectrum between the TMS peak at $0.22 \mathrm{ppm}$ and a carbon signal at $\sim 44 \mathrm{ppm}$, however upon running longer ${ }^{13} \mathrm{C}$ experiments and widening the window to between 400 and $-150 \mathrm{ppm}$ no signal for the $\mathrm{C}^{-}$could be resolved and this correlation is assumed to be from the $\mathrm{C}^{-}$in the compound.

\section{$\mathrm{CH}\left\{\mathrm{C}(\mathrm{Me}) \mathrm{N}\left(\mathrm{C}_{6} \mathrm{H}_{3}-2,6^{-}{ }^{-} \mathrm{Pr}_{2}\right)\right\}_{2} \mathrm{Ga}\left(\mathrm{CH}_{2} \mathrm{SiMe}_{3}\right) \mathrm{N}(\mathrm{H}) \mathrm{NC}\left(\mathrm{BDI}{ }_{\text {DIPPGa}}\left(\mathrm{CH}_{2} \mathrm{TMS}\right) \mathrm{N}(\mathrm{H}) \mathrm{NC}, 21\right)$}

BDI DIPPGa $(0.1 \mathrm{~g}, 0.2 \mathrm{mmol})$ was dissolved in toluene $(5 \mathrm{~mL})$ and cooled to $-78{ }^{\circ} \mathrm{C}$ in a dry ice/acetone bath, a solution of $2.0 \mathrm{M}$ trimethylsilyldiazomethane $(0.2 \mathrm{~mL}, 0.4 \mathrm{mmol})$ was diluted with hexane (5 $\mathrm{mL}$ ) and added dropwise, after which the solution was stirred for 1 hour then

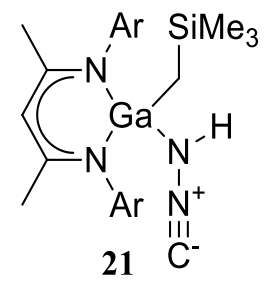
allowed to warm to room temperature. Concentration of the solution gave $\mathbf{2 1}$ as colourless 
crystals (10 mg, 7.3\%). ${ }^{1} \mathrm{H}$ NMR (600 MHz, $\left.\mathrm{C}_{6} \mathrm{D}_{6}, 298 \mathrm{~K}\right) \delta 7.17(d, J=1.5 \mathrm{~Hz}, 1 \mathrm{H}, \operatorname{Ar}-\boldsymbol{H}), 7.18-$ $7.14(m, 1 \mathrm{H}, \operatorname{Ar}-\boldsymbol{H}), 7.12(t, J=7.7 \mathrm{~Hz}, 2 \mathrm{H}, \operatorname{Ar}-\boldsymbol{H}), 7.02(d d, J=7.6,1.5 \mathrm{~Hz}, 2 \mathrm{H}, \operatorname{Ar}-\boldsymbol{H}), 4.72(s$, $2 \mathrm{H}, \mathrm{CH}$ ), 3.71 (app. sept, $J=6.8 \mathrm{~Hz}, 2 \mathrm{H}, \mathrm{CH}\left(\mathrm{CH}_{3}\right)_{2}$ ), 3.29 (app. sept, $J=6.9 \mathrm{~Hz}, 2 \mathrm{H}, \mathrm{CH}\left(\mathrm{CH}_{3}\right)_{2}$ ), $1.61\left(s, 6 \mathrm{H}, \mathrm{CCH}_{3}\right), 1.51\left(d, J=6.6 \mathrm{~Hz}, 6 \mathrm{H}, \mathrm{CH}\left(\mathrm{CH}_{3}\right)_{2}\right), 1.39\left(d, J=6.9 \mathrm{~Hz}, 6 \mathrm{H}, \mathrm{CH}\left(\mathrm{CH}_{3}\right)_{2}\right), 1.28(d$, $\left.J=6.9 \mathrm{~Hz}, 6 \mathrm{H}, \mathrm{CH}\left(\mathrm{CH}_{3}\right)_{2}\right), 1.02\left(d, J=6.6 \mathrm{~Hz}, 6 \mathrm{H}, \mathrm{CH}\left(\mathrm{CH}_{3}\right)_{2}\right),-0.49\left(s, 9 \mathrm{H}, \mathrm{Si}\left(\mathrm{CH}_{3}\right)_{3}\right),-0.90(s, 2 \mathrm{H}$, $\left.\mathrm{CH}_{2}\right) .{ }^{13} \mathrm{C}$ NMR $\left(151 \mathrm{MHz}, \mathrm{C}_{6} \mathrm{D}_{6}\right) \delta 170.33,146.02,143.03,140.88,131.02,128.47,127.66$, $125.33,123.95,98.05,29.12,27.43,25.62,24.94,24.87,23.85,23.55,1.09,-7.44$.

\section{$\mathrm{C}_{12} \mathrm{H}_{22} \mathrm{NN}(\mathrm{H}) \mathrm{Ts}(22)$}

This compound was prepared following literature procedures. ${ }^{214}$ Cyclododecanone $(2.5 \mathrm{~g}, 13.7 \mathrm{mmol})$ and $p$-toluenesulfonyl hydrazide $(2.6 \mathrm{~g}$, $13.7 \mathrm{mmol}$ ) were combined in a round bottom flask fitted with a Dean-Stark condenser, ethanol $(50 \mathrm{~mL})$ was added and the mixture refluxed for $16 \mathrm{~h}$ during

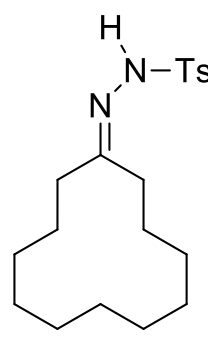

22 which a white precipitate formed. The precipitate was collected via filtration and washed with cold ethanol $(3 \times 15 \mathrm{~mL})$ to give Tosyl hydrazide salt 22 as a white solid (4.5 g, 93\%). ${ }^{1} \mathrm{H}$ NMR of the crude solid matched literature values ${ }^{214}$ and the solid was used without further purification.

\section{$\mathrm{C}_{12} \mathrm{H}_{22} \mathrm{NN}(\mathrm{Na}) \mathrm{Ts}(23)$}

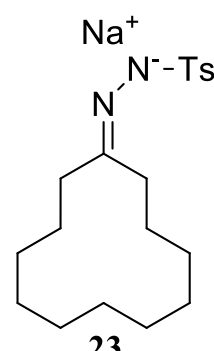

Tosyl hydrazide salt $22(2.0 \mathrm{~g}, 5.7 \mathrm{mmol})$ was added to a solution of $1.0 \mathrm{M}$ sodium hydroxide in ethanol $(50 \mathrm{~mL})$ and heated to $60^{\circ} \mathrm{C}$ for 4 hours then the solvent was removed in vacuo to give $\mathbf{2 3}$ as a white solid that was transferred to a sublimation vessel for pyrolysis immediately. ${ }^{1} \mathrm{H}$ NMR of a small sample showed the loss of the N-H peak present in $\mathbf{2 2}$. 
The sodium salt 23 was heated in a sublimation vessel at $90^{\circ} \mathrm{C}$ at $1.5 \times 10^{-5}$ mbar resulting in the deposition of red crystals of $\mathbf{2 4}$ on the cold finger, the sublimation vessel was transferred into a nitrogen glove box and the red crystals

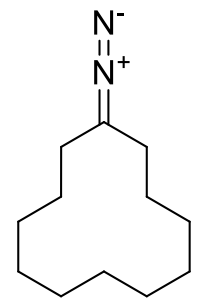

24 collected and stored at $-30{ }^{\circ} \mathrm{C} .{ }^{1} \mathrm{H}$ NMR $\left(300 \mathrm{MHz}, \mathrm{C}_{6} \mathrm{D}_{6}, 298 \mathrm{~K}\right) \delta 2.59(\mathrm{~m}, 2 \mathrm{H}), 2.25(\mathrm{~m}, 2 \mathrm{H})$, 1.48 (br m., 10H), 1.30 (br m., 8H).

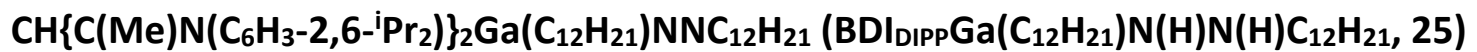

$\mathrm{BDI}_{\text {DIPPGa }}(0.1 \mathrm{~g}, 0.2 \mathrm{mmol})$ was dissolved in toluene $(5 \mathrm{~mL})$ and a solution of cyclododecyldiazomethane $(78 \mathrm{mg}, 0.4 \mathrm{mmol})$ in hexane $(5$ $\mathrm{mL}$ ) was added dropwise resulting in evolution of gas. Concentration of the solution gave 25 as off-yellow crystals (20 mg, 11.8\%). N.B. A clean NMR spectrum of this compound was unable to be obtained.

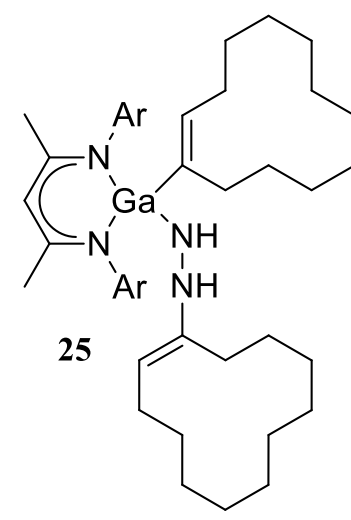

\section{$\mathrm{Ph}_{2} \mathrm{CNNH}_{2}(28)$}

This compound was prepared following literature procedures. ${ }^{149} \mathrm{~A}$ mixture of benzophenone $(5.0 \mathrm{~g}, 27.4 \mathrm{mmol})$, hydrazine monohydrate $(6.67$<smiles>NN=C(c1ccccc1)c1ccccc1</smiles>
$\mathrm{mL}, 137 \mathrm{mmol}$ ) and ethanol $(50 \mathrm{~mL})$ was heated at reflux for $16 \mathrm{~h}$ and concentrated in vacuo. The oily solid was extracted into DCM $(50 \mathrm{~mL})$ and washed with water $(3 \times 20 \mathrm{~mL})$. The organic phase was dried with $\mathrm{Na}_{2} \mathrm{SO}_{4}$ and concentrated to give hydrazone 28 as a white solid $(4.8 \mathrm{~g}$, $89 \%) .{ }^{1} \mathrm{H}$ NMR of the crude solid matched literature values ${ }^{149}$ and was used without further purification.

\section{$\mathrm{Ph}_{2} \mathrm{CNN}(8)$}

This compound was prepared following literature procedures. ${ }^{149}$ Hydrazone 28 (200 mg, $1 \mathrm{mmol}$ ) in THF ( $5 \mathrm{~mL}$ ) was added to a slurry of $\mathrm{HgO}$<smiles>[N-]=[N+]=C(c1ccccc1)c1ccccc1</smiles> 
(260 mg, $1.2 \mathrm{mmol})$ and $\mathrm{Na}_{2} \mathrm{SO}_{4}(200 \mathrm{mg}, 1.4 \mathrm{mmol})$ in THF $(10 \mathrm{~mL})$, followed by 5 drops of a saturated solution of $\mathrm{KOH}$ in $\mathrm{EtOH}$. The reaction vessel was wrapped in aluminium foil to exclude light and stirred for $16 \mathrm{~h}$. The red solution was filtered through celite and concentrated to give diphenyldiazomethane 8 as red/purple solid (180 mg, 93\%). ${ }^{1} \mathrm{H}$ NMR of the crude solid matched literature values ${ }^{149}$ and was used without further purification.

\section{Reaction of BDI ${ }_{\text {DIPPGa }}(1)$ with $\mathrm{Ph}_{2} \mathrm{CNN}(8)$}

BDI $_{\text {DIPPGa }}(0.1 \mathrm{~g}, 0.2 \mathrm{mmol})$ was dissolved in toluene $(5 \mathrm{~mL})$ and a solution of diphenyldiazomethane 8 (39 $\mathrm{mg}, 0.2 \mathrm{mmol}$ ) in hexane $(5 \mathrm{~mL})$ was added dropwise resulting in evolution of gas. Concentration of the solution and analysis by ${ }^{1} \mathrm{H} N M R\left(300 \mathrm{MHz}, \mathrm{CDCl}_{3}\right.$, $298 \mathrm{~K})$ showed the presence of $\mathrm{BDI}_{\mathrm{DIPP} G a}$ and peaks approximately matching tetraphenylethylene. ${ }^{288}$

\section{Fluoren-9-one Hydrazone (32)}

This compound was prepared following literature procedures. ${ }^{149} \mathrm{~A}$ mixture of Fluoren-9-one $(5.0 \mathrm{~g}, 27.7 \mathrm{mmol})$, hydrazine monohydrate $(6.78$<smiles>NN=C(c1ccccc1)c1ccccc1</smiles>
$\mathrm{mL}, 139 \mathrm{mmol}$ ) and methanol $(50 \mathrm{~mL})$ was heated at reflux for $16 \mathrm{~h}$ and concentrated in vacuo. The solid was extracted into DCM (50 mL) and washed with water $(3 \times 20 \mathrm{~mL})$. The organic phase was dried with $\mathrm{Na}_{2} \mathrm{SO}_{4}$ and concentrated to give hydrazone 32 as a white solid $(4.7 \mathrm{~g}$, $87 \%) .{ }^{1} \mathrm{H}$ NMR of the crude solid matched literature values ${ }^{149}$ and was used without further purification.

\section{9-Diazofluorene (33)}

This compound was prepared following literature procedures. ${ }^{149}$ Hydrazone 32 (200 mg, $1 \mathrm{mmol}$ ) in THF ( $5 \mathrm{~mL}$ ) was added to a slurry of $\mathrm{HgO}$

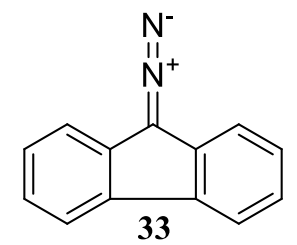
(260 mg, $1.2 \mathrm{mmol}$ ) and $\mathrm{Na}_{2} \mathrm{SO}_{4}(200 \mathrm{mg}, 1.4 \mathrm{mmol})$ in THF (10 mL), followed by 5 drops of a saturated solution of $\mathrm{KOH}$ in $\mathrm{EtOH}$. The reaction vessel was wrapped in aluminium foil to 
exclude light and stirred for $16 \mathrm{~h}$. The red solution was filtered through celite and concentrated to give 9-diazofluorene 33 as red solid (190 mg, 98\%). ${ }^{1} \mathrm{H}$ NMR of the crude solid matched literature values ${ }^{149}$ and was used without further purification.

\section{$\mathrm{CH}\left\{\mathrm{C}(\mathrm{Me}) \mathrm{N}\left(\mathrm{C}_{6} \mathrm{H}_{3}-2,6-\mathrm{P}^{\mathrm{i}} \mathrm{Pr}_{2}\right)\right\}_{2} \mathrm{GaC}_{13} \mathrm{H}_{10} \mathrm{NNC}_{13} \mathrm{H}_{10}$ (BDI DIPPGaFINNFI, 34)}

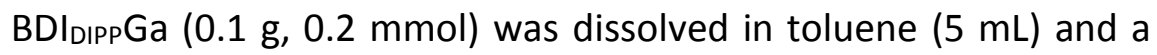
solution of diazofluorene 33 (78 $\mathrm{mg}, 0.4 \mathrm{mmol}$ ) in toluene $(5 \mathrm{~mL})$ was added dropwise resulting in evolution of gas. Concentration of the solution gave 34 as off-yellow crystals (20 mg, 11.8\%). ${ }^{1} \mathrm{H}$ NMR $\left(600 \mathrm{MHz}, \mathrm{C}_{6} \mathrm{D}_{6}, 298 \mathrm{~K}\right) \delta 8.26(d, J=7.6 \mathrm{~Hz}, 1 \mathrm{H} \mathrm{Ph}-\boldsymbol{H}), 7.91(d, J=5.2 \mathrm{~Hz}$, 1H, Ph- $\boldsymbol{H})$, 7.74-7.64 (m, 3H, Ph- $\boldsymbol{H}), 7.43(t, J=7.4 \mathrm{~Hz}, 1 \mathrm{H}, \mathrm{Ph}-\boldsymbol{H}), 7.30-$

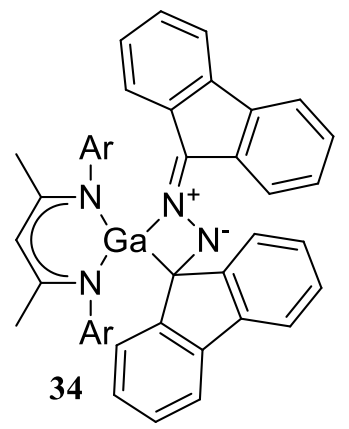
$7.18(m, 5 H, P h-H), 7.15-7.00(m, 8 H, P h-H$ Ar- $\boldsymbol{H}), 6.97-6.92(m, 1 H, P h-H), 6.72(d, J=7.7 \mathrm{~Hz}$, $1 \mathrm{H}, \mathrm{Ph}-\boldsymbol{H}), 6.54(d, J=7.6 \mathrm{~Hz}, 1 \mathrm{H}, \mathrm{Ph}-\boldsymbol{H}), 5.22(s, 1 \mathrm{H}, \mathrm{CH}), 3.84-3.75\left(m, 2 \mathrm{H}, \mathrm{CH}\left(\mathrm{CH}_{3}\right)_{2}\right), 3.35-$ $3.23\left(m, 2 \mathrm{H}, \mathrm{CH}\left(\mathrm{CH}_{3}\right)_{2}\right), 1.91\left(\mathrm{~s}, 3 \mathrm{H}, \mathrm{CCH}_{3}\right), 1.75-1.71\left(m, 6 \mathrm{H}, \mathrm{CCH}_{3} \mathrm{CH}\left(\mathrm{CH}_{3}\right)_{2}\right), 1.14(d, J=6.6 \mathrm{~Hz}$, $\left.6 \mathrm{H}, \mathrm{CH}\left(\mathrm{CH}_{3}\right)_{2}\right), 1.12-1.08\left(m, 6 \mathrm{H}, \mathrm{CH}\left(\mathrm{CH}_{3}\right)_{2}\right), 1.00\left(d, J=6.9 \mathrm{~Hz}, 3 \mathrm{H}, \mathrm{CH}\left(\mathrm{CH}_{3}\right)_{2}\right), 0.98-0.92(m$, $\left.6 \mathrm{H}, \mathrm{CH}\left(\mathrm{CH}_{3}\right)_{2}\right) .{ }^{13} \mathrm{C}$ NMR $\left(151 \mathrm{MHz}, \mathrm{C}_{6} \mathrm{D}_{6}, 298 \mathrm{~K}\right) \delta 170.14,145.89,143.67,141.86,139.69$, $138.01,136.85,136.50,130.81,129.33,128.67,128.57,127.61,127.25,126.66,125.70$, $125.31,124.05,123.98,120.52,119.70,119.41$, 97.63, 65.93, 29.24, 27.32, 25.47, 24.86, $24.10,24.07,23.57,23.54,23.36,21.44,15.62$.

\section{${ }^{\mathrm{t}} \mathrm{Bu}_{2} \mathrm{CNH}(36)$}

This compound was prepared following literature procedures. ${ }^{221}$ Pivalonitrile $(16.7 \mathrm{~g}, 0.2 \mathrm{~mol})$ was added dropwise to a solution of finely divided sodium (5.9

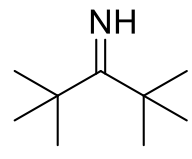
36 $\mathrm{g}, 0.25 \mathrm{~mol})$ in petroleum ether $(200 \mathrm{~mL})$, maintaining the temperature of the reaction vessel at $25{ }^{\circ} \mathrm{C}$. The reaction was stirred for $2 \mathrm{~h}$, then water $(200 \mathrm{~mL})$ was slowly added to quench the residual sodium metal. The organic layer was separated and dried over magnesium sulphate, filtered and distilled at $80{ }^{\circ} \mathrm{C}$ to give imine 36 as a colourless liquid $(12.4 \mathrm{~g}, 88 \%) .{ }^{1} \mathrm{H}$ 
NMR (300 MHz, $\left.\mathrm{CDCl}_{3}, 298 \mathrm{~K}\right) \delta 9.39$ (br. s, 1H), $1.26(s, 18 \mathrm{H})$. These values are in accordance with literature values.

\section{${ }^{\mathrm{t}} \mathrm{Bu}_{2} \mathrm{CNNH}_{2}$ (37)}

This compound was prepared following literature procedures. ${ }^{221} \mathrm{~A}$ mixture of imine 36 (7.0 g, $0.05 \mathrm{~mol})$, hydrazine monohydrate $(12.5 \mathrm{~g}, 0.25 \mathrm{~mol})$ and

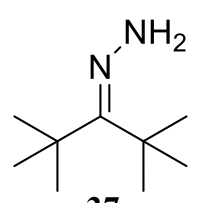

37 hydrazine sulphate $(6.5 \mathrm{~g}, 0.05 \mathrm{~mol})$ was heated at reflux for 4 days. The mixture was cooled and extracted into diethyl ether, the solvent was removed in vacuo and the resulting solid washed with methanol to give hydrazone 37 as a white solid $(7.5 \mathrm{~g}, 96 \%){ }^{1} \mathrm{H}$ NMR $(300 \mathrm{MHz}$, $\left.\mathrm{CDCl}_{3}, 298 \mathrm{~K}\right) \delta 5.26($ br. s, $2 \mathrm{H}), 1.39(\mathrm{~s}, 9 \mathrm{H}), 1.20(\mathrm{~s}, 9 \mathrm{H})$. These values are in accordance with literature values.

\section{${ }^{\mathrm{t}} \mathrm{Bu}_{2} \mathrm{CNN}(38)$}

This compound was prepared following literature procedures. ${ }^{222}$ Hydrazone 37 (150 mg, $1 \mathrm{mmol}$ ) in THF (5 mL) was added to a slurry of $\mathrm{HgO}$ (260 mg, 1.2<smiles>CC(C)(C)C(=[N+]=[N-])C(C)(C)C</smiles>
mmol) and $\mathrm{Na}_{2} \mathrm{SO}_{4}(200 \mathrm{mg}, 1.4 \mathrm{mmol})$ in THF $(10 \mathrm{~mL})$, followed by 5 drops of a saturated solution of $\mathrm{KOH}$ in $\mathrm{EtOH}$. The reaction vessel was wrapped in aluminium foil to exclude light and stirred for $16 \mathrm{~h}$. The red solution was filtered through celite and concentrated to give ditert-butyldiazomethane 38 as red oil (80 mg, 52\%) which was used without further purification.

\section{o- $\mathrm{C}_{6} \mathrm{H}_{4}\left\{\mathrm{C}\left(\mathrm{CH}_{3}\right) \mathrm{N}-2,6-\mathrm{Pr}_{2} \mathrm{C}_{6} \mathrm{H}_{3}\right\}$ NH-2,6-'Pr $\left.{ }_{2} \mathrm{C}_{6} \mathrm{H}_{3}\right\}($ ArBDIDIPP-H, 13)}

This compound was prepared following literature procedures. ${ }^{119}$ 2,6-diisopropylaniline (11.5 g, $65 \mathrm{mmol})$ was added to a solution of $\mathrm{TiCl}_{4}(2.0 \mathrm{~g}$,

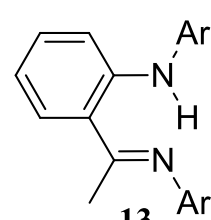
13 A $11 \mathrm{mmol})$ in hexane $(30 \mathrm{~mL})$ to give a brown precipitate. 2-fluroacetophenone $(2.6 \mathrm{~mL}, 22$ mmol) was added and the solution refluxed for 16 hours. The resulting solid was extracted with diethyl ether $(3 \times 30 \mathrm{~mL})$ and filtered through a celite/silica plug. The solution was 
concentrated to give an orange oil of $\left[0-\mathrm{C}_{6} \mathrm{H}_{4}\left\{\mathrm{C}\left(\mathrm{CH}_{3}\right) \mathrm{N}-2,6-{ }^{-} \mathrm{Pr}_{2} \mathrm{C}_{6} \mathrm{H}_{3}\right\}\{\mathrm{F}\}\right](5.2 \mathrm{~g}, 17 \mathrm{mmol})$ which

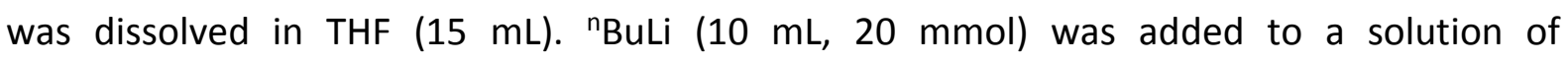
2,6-diisopropylaniline $(3.1 \mathrm{~g}, 18 \mathrm{mmol})$ in THF $(15 \mathrm{~mL})$, then added to the solution of [o$\left.\mathrm{C}_{6} \mathrm{H}_{4}\left\{\mathrm{C}\left(\mathrm{CH}_{3}\right) \mathrm{N}-2,6-\mathrm{Pr}_{2} \mathrm{C}_{6} \mathrm{H}_{3}\right\}\{\mathrm{F}\}\right]$ and refluxed for 72 hours. The solution was quenched with $\mathrm{H}_{2} \mathrm{O}$ $(50 \mathrm{~mL})$ and extracted with hexane $(3 \times 50 \mathrm{~mL})$, the organic fraction was dried with magnesium sulphate and concentrated to give an orange solid which was recrystallised from methanol/DCM to give ArBDIDIPP-H 13 as yellow crystals (7.6 g, 76\%). ${ }^{1} \mathrm{H} \mathrm{NMR} \mathrm{(300} \mathrm{MHz,} \mathrm{CDCl} 3$, $298 \mathrm{~K}) \delta 11.58(\mathrm{~s}, 1 \mathrm{H}, \mathrm{NH}), 7.48\left(d, J=8.2 \mathrm{~Hz}, 1 \mathrm{H}, \mathrm{C}_{6} \boldsymbol{H}_{4}\right), 7.28-7.18(m, 6 \mathrm{H}, \operatorname{Ar}-\boldsymbol{H}), 7.00(t, J=$ $\left.7.6 \mathrm{~Hz}, 1 \mathrm{H}, \mathrm{C}_{6} \boldsymbol{H}_{4}\right), 6.58\left(t, J=7.6 \mathrm{~Hz}, 1 \mathrm{H}, \mathrm{C}_{6} \boldsymbol{H}_{4}\right), 6.48\left(d, J=8.5 \mathrm{~Hz}, 1 \mathrm{H}, \mathrm{C}_{6} \boldsymbol{H}_{4}\right), 3.44$ (sept, J = 6.9 $\left.\mathrm{Hz}, 2 \mathrm{H}, \mathrm{CH}\left(\mathrm{CH}_{3}\right)_{2}\right), 3.05\left(\right.$ sept, $\left.\mathrm{J}=6.9 \mathrm{~Hz}, 2 \mathrm{H}, \mathrm{CH}\left(\mathrm{CH}_{3}\right)_{2}\right), 1.96\left(\mathrm{~s}, 3 \mathrm{H}, \mathrm{CCH}_{3}\right), 1.17(d, J=6.8 \mathrm{~Hz}$, $\left.6 \mathrm{H}, \mathrm{CH}\left(\mathrm{CH}_{3}\right)_{2}\right), 1.13\left(d, J=6.8 \mathrm{~Hz}, 6 \mathrm{H}, \mathrm{CH}\left(\mathrm{CH}_{3}\right)_{2}\right)$. These values are in accordance with literature values.

\section{o- $\left.\mathrm{C}_{6} \mathrm{H}_{4}\left\{\mathrm{C}\left(\mathrm{CH}_{3}\right) \mathrm{N}-2,6-{ }^{\mathrm{i}} \mathrm{Pr}_{2} \mathrm{C}_{6} \mathrm{H}_{3}\right\} \mathrm{N}-2,6-{ }^{-} \mathrm{Pr}_{2} \mathrm{C}_{6} \mathrm{H}_{3}\right\} \mathrm{Ga}$ (ArBDI IIPPGa, 10)}

A solution of 'Gal' in toluene ( $40 \mathrm{~mL}$ ) was prepared by sonicating gallium metal $(0.2 \mathrm{~g}, 2.8 \mathrm{mmol})$ and iodine $(0.36 \mathrm{~g}, 2.8 \mathrm{mmol})$ for $2 \mathrm{~h}$ at $45^{\circ} \mathrm{C}$, the

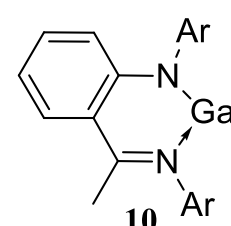
$10 \mathrm{Ar}$ solution was then cooled to $-78^{\circ} \mathrm{C}$ and a solution of ArBDIDIPP-Li (0.92 g, $\left.2.0 \mathrm{mmol}\right)$ in toluene $(10 \mathrm{~mL})$ was added slowly dropwise to give a bright green solution. The solution was warmed to room temperature and left to react for $16 \mathrm{~h}$, then filtered through celite and concentrated to c.a. $15 \mathrm{~mL}$ and placed in the freezer at $-30{ }^{\circ} \mathrm{C}$, at which point bright orange crystals of ArBDIDIPPGa 10 formed (0.32 g, 34\%). ${ }^{1} \mathrm{H}$ NMR (600 MHz, C $\left.6 \mathrm{D}_{6}, 298 \mathrm{~K}\right) \delta 7.54$ (dd, J = 8.4, 1.6 $\mathrm{Hz}, 1 \mathrm{H}, \operatorname{Ar}-\boldsymbol{H}), 7.33-7.28(m, 3 \mathrm{H}, \mathrm{Ar}-\boldsymbol{H})$, 7.15-7.12 (m, 3H, Ar-H), 7.00-6.95 (m, 1H, Ar-H), 6.67 $(d d, J=8.8,1.1 \mathrm{~Hz}, 1 \mathrm{H}, \mathrm{Ar}-\boldsymbol{H}), 6.51-6.47(m, 1 \mathrm{H}, \mathrm{Ar}-\boldsymbol{H}), 3.33\left(\mathrm{sept}, J=6.9 \mathrm{~Hz}, 2 \mathrm{H}, \mathrm{CH}\left(\mathrm{CH}_{3}\right)_{2}\right)_{\text {, }}$ 2.90 (sept, $\left.J=6.9 \mathrm{~Hz}, 2 \mathrm{H}, \mathrm{CH}\left(\mathrm{CH}_{3}\right)_{2}\right), 2.06\left(s, 3 \mathrm{H}, \mathrm{CH}_{3}\right), 1.33\left(d, J=6.9 \mathrm{~Hz}, 6 \mathrm{H}, \mathrm{CH}\left(\mathrm{CH}_{3}\right)_{2}\right), 1.25$ $\left(d, J=6.9 \mathrm{~Hz}, 6 \mathrm{H}, \mathrm{CH}\left(\mathrm{CH}_{3}\right)_{2}\right), 1.13\left(d, J=6.9 \mathrm{~Hz}, 6 \mathrm{H}, \mathrm{CH}\left(\mathrm{CH}_{3}\right)_{2}\right), 1.03\left(d, J=6.9 \mathrm{~Hz}, 6 \mathrm{H}, \mathrm{CH}\left(\mathrm{CH}_{3}\right)_{2}\right)$ ${ }^{13} \mathrm{C}$ NMR (151 MHz, C6 $\mathrm{D}_{6}, 298$ K) $\delta 170.00,153.32,145.85,144.56,143.39,140.69,133.62$, $132.66,129.33,128.57,127.06,126.50,125.70,124.62,124.33,118.66,117.91,114.47$, $29.10,28.61,25.68,24.77,24.72,23.74,21.03$. 


\section{o- $\mathrm{C}_{6} \mathrm{H}_{4}\left\{\mathrm{C}\left(\mathrm{CH}_{3}\right) \mathrm{N}-2,6^{\mathrm{i}} \mathrm{Pr}_{2} \mathrm{C}_{6} \mathrm{H}_{3}\right\}\left\{\mathrm{N}-2,6-{ }^{\mathrm{i}} \mathrm{Pr}_{2} \mathrm{C}_{6} \mathrm{H}_{3}\right\} \mathrm{Ga}\left(\mathrm{CH}_{2} \mathrm{SiMe}_{3}\right) \mathrm{NNCSiMe}_{3}$}

\section{(ArBDI DIPPGa(CH $\mathrm{CH}_{2}$ TMS)NNCTMS, 40)}

$\operatorname{ArBDI}_{\text {DIPPGa }}(0.1 \mathrm{~g}, 0.2 \mathrm{mmol})$ was dissolved in toluene $(5 \mathrm{~mL})$ and a solution of trimethylsilyldiazomethane $(0.2 \mathrm{~mL}, 0.4 \mathrm{mmol})$ was added dropwise resulting evolution of gas and the bright orange solution

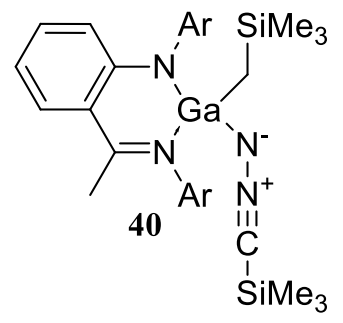
becoming bright yellow. Concentration of the solution gave $\mathbf{4 0}$ as yellow crystals $(120 \mathrm{mg}$, 82\%). ${ }^{1} \mathrm{H}$ NMR $\left(600 \mathrm{MHz}, \mathrm{C}_{6} \mathrm{D}_{6}, 298 \mathrm{~K}\right) \delta 7.36\left(d d, J=7.7,1.6 \mathrm{~Hz}, 1 \mathrm{H}, \mathrm{C}_{6} \boldsymbol{H}_{4}\right), 7.24-7.13(m, 6 \mathrm{H}$, $\operatorname{Ar}-\boldsymbol{H})$, 6.81-6.76 $\left(m, 1 \mathrm{H}, \mathrm{C}_{6} \boldsymbol{H}_{4}\right), 6.54-6.50\left(m, 1 \mathrm{H}, \mathrm{C}_{6} \boldsymbol{H}_{4}\right)$, 6.34-6.31 (m, $\left.1 \mathrm{H}, \mathrm{C}_{6} \boldsymbol{H}_{4}\right), 3.73(\mathrm{sept}, J=$ $\left.6.8 \mathrm{~Hz}, 1 \mathrm{H}, \mathrm{CH}\left(\mathrm{CH}_{3}\right)_{2}\right), 3.52\left(\right.$ sept $\left., J=6.8 \mathrm{~Hz}, 1 \mathrm{H}, \mathrm{CH}\left(\mathrm{CH}_{3}\right)_{2}\right), 3.39\left(\right.$ sept $\left., J=6.8 \mathrm{~Hz}, 1 \mathrm{H}, \mathrm{CH}\left(\mathrm{CH}_{3}\right)_{2}\right)$, $3.22\left(\operatorname{sept}, \mathrm{J}=6.8 \mathrm{~Hz}, 1 \mathrm{H}, \mathrm{CH}\left(\mathrm{CH}_{3}\right)_{2}\right), 2.01\left(\mathrm{~s}, 3 \mathrm{H}, \mathrm{CH}_{3}\right), 1.75\left(d, J=6.6 \mathrm{~Hz}, 3 \mathrm{H}, \mathrm{CH}\left(\mathrm{CH}_{3}\right)_{2}\right), 1.71$ $\left(d, J=6.8 \mathrm{~Hz}, 3 \mathrm{H}, \mathrm{CH}\left(\mathrm{CH}_{3}\right)_{2}\right), 1.43\left(d, J=6.8 \mathrm{~Hz}, 3 \mathrm{H}, \mathrm{CH}\left(\mathrm{CH}_{3}\right)_{2}\right), 1.36\left(d, J=6.8 \mathrm{~Hz}, 3 \mathrm{H}, \mathrm{CH}\left(\mathrm{CH}_{3}\right)_{2}\right)$, $1.34\left(d, J=6.8 \mathrm{~Hz}, 3 \mathrm{H}, \mathrm{CH}\left(\mathrm{CH}_{3}\right)_{2}\right), 1.29\left(d, J=6.8 \mathrm{~Hz}, 3 \mathrm{H}, \mathrm{CH}\left(\mathrm{CH}_{3}\right)_{2}\right), 1.05(d, J=6.8 \mathrm{~Hz}, 3 \mathrm{H}$, $\left.\mathrm{CH}\left(\mathrm{CH}_{3}\right)_{2}\right), 0.86\left(d, J=6.8 \mathrm{~Hz}, 3 \mathrm{H}, \mathrm{CH}\left(\mathrm{CH}_{3}\right)_{2}\right),-0.01\left(\mathrm{~s}, 9 \mathrm{H}, \mathrm{Si}\left(\mathrm{CH}_{3}\right)_{3}\right),-0.19\left(\mathrm{~s}, 9 \mathrm{H}, \mathrm{Si}\left(\mathrm{CH}_{3}\right)_{3}\right),-0.74$ $\left(d, J=13.4 \mathrm{~Hz}, 1 \mathrm{H}, \mathrm{CH}_{2}\right),-0.84\left(d, J=13.4 \mathrm{~Hz}, 1 \mathrm{H}, \mathrm{CH}_{2}\right)$. N.B. This complex degraded to 13 in solution and the resonances listed above are those that did not match the resonances for complex 13, a usable ${ }^{13} \mathrm{C}$ NMR spectrum of this compound was unable to be obtained.

\section{$\left.\mathrm{CH}\left\{\mathrm{C}(\mathrm{Me}) \mathrm{N}\left(\mathrm{C}_{6} \mathrm{H}_{2}-2,6-\left(\mathrm{CHPh}_{2}\right)_{2}-4-\mathrm{Me}\right)\right\} \mathrm{C}(\mathrm{Me}) \mathrm{NH}\left(\mathrm{C}_{6} \mathrm{H}_{2}-2,6-\left(\mathrm{CHPh}_{2}\right)_{2}-4-\mathrm{Me}\right)\right\}\left(\mathrm{BDI}_{\mathrm{Ar}}-\mathrm{H}, 14\right)$}

This compound was prepared following literature

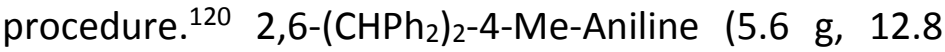
$\mathrm{mmol}),\left(\mathrm{C}_{6} \mathrm{H}_{2}-2,6-\left(\mathrm{CHPh}_{2}\right)_{2}-4-\mathrm{Me}\right)-\mathrm{NH}_{3} \mathrm{Cl}$.THF $(7.6 \mathrm{~g}, 12.8$

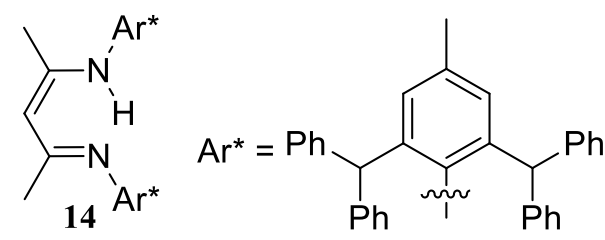
$\mathrm{mmol})$, and acetylacetone $(3.9 \mathrm{~mL}, 38.3 \mathrm{mmol})$ were combined in toluene $(80 \mathrm{~mL})$ and heated at reflux for 24 hours, cooled to room temperature and the solid collected by filtration. The solid was then dissolved in DCM $(200 \mathrm{~mL})$ and neutralised with aqueous sodium bicarbonate $(3 \times 50 \mathrm{~mL}$ ), the organic layer was dried with magnesium sulphate and concentrated to give 14 as a white solid (8.2 g, 68\%). ${ }^{1} \mathrm{H}$ NMR (300 MHz, $\left.\mathrm{CDCl}_{3}, 298 \mathrm{~K}\right) \delta 12.81(\mathrm{~s}, 1 \mathrm{H}, \mathrm{NH}), 7.28-7.26$ (m, 16H), 7.05-7.00 (m, 24H), $6.86(s, 4 \mathrm{H}, m-\mathrm{Ar}-\boldsymbol{H}), 5.95(s, 4 \mathrm{H}, \mathrm{CHPh} 2), 4.18(s, 1 \mathrm{H}, \mathrm{CH}), 2.25$ $\left(s, 6 \mathrm{H}, \mathrm{CH}_{3}\right), 0.25\left(s, 6 \mathrm{H}, \mathrm{CH}_{3}\right)$. These values are in accordance with the literature values. 


\section{$\mathrm{CH}\left\{\mathrm{C}(\mathrm{Me}) \mathrm{N}\left(\mathrm{C}_{6} \mathrm{H}_{2}-2,6-\left(\mathrm{CHPh}_{2}\right)_{2}-4-\mathrm{Me}\right)\right\}_{2} \mathrm{Ga}\left(\mathrm{BDI}_{\mathrm{Ar}} * \mathrm{Ga}, 11\right)$}

A solution of ' $G$ al' in toluene $(40 \mathrm{~mL})$ was prepared by sonicating gallium metal $(0.2 \mathrm{~g}, 2.8 \mathrm{mmol})$ and iodine $(0.36 \mathrm{~g}, 2.8 \mathrm{mmol})$ for $2 \mathrm{~h}$ at $45^{\circ} \mathrm{C}$, the solution was then cooled to $-78{ }^{\circ} \mathrm{C}$ and a solution of $\mathrm{BDI}_{\mathrm{Ar}}$-Li $(1.25 \mathrm{~g}, 1.3 \mathrm{mmol})$ in toluene $(10 \mathrm{~mL})$ was added dropwise to give an orange solution. The solution was warmed to room temperature and left to react for $16 \mathrm{~h}$, then filtered through celite and concentrated to c.a. $15 \mathrm{~mL}$ and placed in the freezer at $-30{ }^{\circ} \mathrm{C}$, at which point yellow crystals of $\mathrm{BDI}_{\mathrm{Ar}} * \mathrm{Ga} \mathbf{1 1}$ formed $(0.48 \mathrm{~g}$, 36 \%). ${ }^{1} \mathrm{H}$ NMR (600 MHz, C $\left.6 \mathrm{D}_{6}, 298 \mathrm{~K}\right) \delta 7.33(d, J=7.2 \mathrm{~Hz}, 8 \mathrm{H}, o-\mathrm{Ph}-\boldsymbol{H}), 7.30(d, J=7.8 \mathrm{~Hz}, 8 \mathrm{H}$, o-Ph-H), 7.12-7.09 (m, 12H, m-Ar- $\boldsymbol{H}, m-\mathrm{Ph}-\boldsymbol{H}), 7.03-7.01(m, 4 \mathrm{H}, p-\mathrm{Ph}-\boldsymbol{H}), 6.95(t, J=7.8 \mathrm{~Hz}$, $8 \mathrm{H}, m-\mathrm{Ph}-\boldsymbol{H}), 6.82(t, J=7.2 \mathrm{~Hz}, 4 \mathrm{H}, p-\mathrm{Ph}-\boldsymbol{H}), 6.00(s, 4 \mathrm{H}, \mathrm{CHPh}), 4.79(s, 1 \mathrm{H}, \mathrm{CH}), 1.93(s, 6 \mathrm{H}$, $\left.\mathrm{Ph}-\mathrm{CH}_{3}\right), 1.02$ (s, 6H, C(CH$\left.)\right) .{ }^{13} \mathrm{C}$ NMR (151 MHz, $\left.\mathrm{C}_{6} \mathrm{D}_{6}\right) \delta 165.34,144.73,144.09,143.02$, $139.87,134.74,130.59,130.35,130.20,128.71$, 128.57, 126.69, 126.68, 100.34, 53.08, 23.08, 21.44.

\section{$\mathrm{CH}\left\{\mathrm{C}(\mathrm{Me}) \mathrm{N}\left(\mathrm{C}_{6} \mathrm{H}_{2}-2,6-\left(\mathrm{CHPh}_{2}\right)_{2}-4-\mathrm{Me}\right)\right\}_{2} \mathrm{Ga}(\mathrm{H}) \mathrm{C}\left(\mathrm{N}_{2}\right) \mathrm{SiMe}_{3}\left(\mathrm{BDI}_{\mathrm{Ar}} * \mathrm{Ga}(\mathrm{H}) \mathrm{C}\left(\mathrm{N}_{2}\right) \mathrm{TMS}, 41\right)$}

$\mathrm{BDI}_{\mathrm{Ar}} * \mathrm{Ga}(0.2 \mathrm{~g}, 0.2 \mathrm{mmol})$ was dissolved in toluene $(5 \mathrm{~mL})$ and a solution of $2.0 \mathrm{M}$ trimethylsilyldiazomethane $(0.1 \mathrm{~mL}, 0.2 \mathrm{mmol})$ was added dropwise resulting in the solution fading to pale yellow.

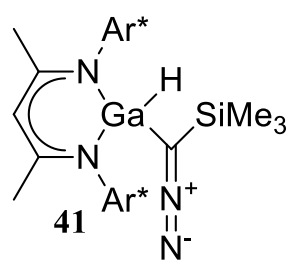
Concentration of the solution gave 41 as colourless crystals (222 mg, 97\%). ${ }^{1} \mathrm{H} \mathrm{NMR} \mathrm{(600} \mathrm{MHz,}$ $\left.\mathrm{C}_{6} \mathrm{D}_{6}, 298 \mathrm{~K}\right) \delta 7.81(d, J=7.8 \mathrm{~Hz}, 4 \mathrm{H}, o-\mathrm{Ph}-\boldsymbol{H}), 7.53(d, J=7.8 \mathrm{~Hz}, 4 \mathrm{H}, o-\mathrm{Ph}-\boldsymbol{H}), 7.31(d, J=7.2 \mathrm{~Hz}$, $4 \mathrm{H}, \mathrm{o}-\mathrm{Ph}-\boldsymbol{H}), 7.30(\mathrm{~s}, 2 \mathrm{H}, \mathrm{m}-\mathrm{Ar}-\boldsymbol{H}), 7.24-7.21(\mathrm{~m}, 8 \mathrm{H}), 7.14-7.08(m, 8 \mathrm{H}), 7.04-6.94(m, 14 \mathrm{H})$ 6.89 (s, 2H, CHPh), 6.18 (s, 2H, CHPh), 5.72 (br. s, 1H, GaH), 4.24 (s, 1H, CH), 1.86 (s, 6H, Ph$\left.\mathrm{CH}_{3}\right), 0.29\left(\mathrm{~s}, 6 \mathrm{H}, \mathrm{C}\left(\mathrm{CH}_{3}\right)\right), 0.26\left(\mathrm{~s}, 9 \mathrm{H}, \mathrm{Si}\left(\mathrm{CH}_{3}\right)_{3}\right) .{ }^{13} \mathrm{C} \mathrm{NMR}\left(151 \mathrm{MHz}, \mathrm{C}_{6} \mathrm{D}_{6}\right) \delta$ 174.29, 145.70, $145.26,142.98,142.77,142.71,141.47,139.46,136.39,131.73,131.25,131.02,130.78$, $130.46,129.77,129.34,128.90,128.69,128.57,128.35,127.19,126.89,126.58,126.41$, $126.37,96.86,52.07,51.11,22.91,21.21,1.79$. 


\section{$\left.\mathrm{CH}\left\{\mathrm{C}(\mathrm{Me}) \mathrm{N}\left(\mathrm{C}_{6} \mathrm{H}_{2}-2,6-\left(\mathrm{CHPh}_{2}\right)_{2}-4-{ }^{\mathrm{t}} \mathrm{Bu}\right)\right\} \mathrm{C}(\mathrm{Me}) \mathrm{NH}\left(\mathrm{C}_{6} \mathrm{H}_{2}-2,6-\left(\mathrm{CHPh}_{2}\right)_{2}-4-{ }^{\mathrm{t}} \mathrm{Bu}\right)\right\}\left(\mathrm{BDI}_{\mathrm{Ar}}-\mathrm{H}, 15\right)$}

This compound was prepared following adapted literature procedure. ${ }^{120} 2,6-\left(\mathrm{CHPh}_{2}\right)_{2}-4-{ }^{\mathrm{t}} \mathrm{Bu}-$ Aniline $(5.6$ g, $11.6 \mathrm{mmol}),\left(\mathrm{C}_{6} \mathrm{H}_{2}-2,6-\left(\mathrm{CHPh}_{2}\right)_{2}-4-{ }^{\mathrm{t}} \mathrm{Bu}\right)-\mathrm{NH}_{3} \mathrm{Cl}$.THF $(7.6$<smiles></smiles>
g, $11.6 \mathrm{mmol})$, and acetylacetone $(3.9 \mathrm{~mL}, 38.3 \mathrm{mmol})$ were combined in toluene $(80 \mathrm{~mL})$ and heated at reflux for 24 hours, cooled to room temperature and the solid collected by filtration. This was then dissolved in DCM $(200 \mathrm{~mL})$ and neutralised with aqueous sodium bicarbonate $(3 \times 50 \mathrm{~mL})$, the organic layer was dried with magnesium sulphate and concentrated to give 15 as a white solid $(6.5 \mathrm{~g}, 54 \%)$. Crystals suitable for X-Ray diffraction were grown from toluene at $-30{ }^{\circ} \mathrm{C} .{ }^{1} \mathrm{H}$ NMR $\left(600 \mathrm{MHz}, \mathrm{C}_{6} \mathrm{D}_{6}, 298 \mathrm{~K}\right) \delta 12.87(s, 1 \mathrm{H}, \mathrm{NH}), 7.51(d, J=7.2 \mathrm{~Hz}, 8 \mathrm{H}$, $\mathrm{Ph}-\boldsymbol{H}), 7.38(s, 4 \mathrm{H}, \boldsymbol{m}-\mathrm{Ar}-\boldsymbol{H}), 7.18-7.15(m, 8 \mathrm{H}, \mathrm{Ph}-\boldsymbol{H}), 7.11(t, J=7,4 \mathrm{~Hz}, 8 \mathrm{H}, \mathrm{Ph}-\boldsymbol{H}), 7.01-6.99$ $(m, 4 \mathrm{H}, p-\mathrm{Ph}-\boldsymbol{H}), 6.92-6.86(m, 12 \mathrm{H}, \mathrm{Ph}-\boldsymbol{H}), 6.37$ (s, 4H, CHPh), $4.38(s, 1 \mathrm{H}, \mathrm{CH}), 1.15$ (s, 18H, $\left.\mathrm{C}\left(\mathrm{CH}_{3}\right)_{3}\right), 0.57\left(\mathrm{~s}, 6 \mathrm{H} \mathrm{C}\left(\mathrm{CH}_{3}\right)\right) .{ }^{13} \mathrm{C} \mathrm{NMR}\left(151 \mathrm{MHz}, \mathrm{C}_{6} \mathrm{D}_{6}\right) \delta 164.71,147.16,145.37,143.23$, 141.86 , 139.14, 130.55, 129.98, 128.73, 128.44, 126.56, 126.54, 126.29, 95.24, 53.26, 34.68, $31.45,20.32$.

\section{$\mathrm{CH}\left\{\mathrm{C}(\mathrm{Me}) \mathrm{N}\left(\mathrm{C}_{6} \mathrm{H}_{2}-2,6-\left(\mathrm{CHPh}_{2}\right)_{2}-4-{ }^{\mathrm{t}} \mathrm{Bu}\right)\right\}_{2} \mathrm{Ga}\left(\mathrm{BDI}_{\mathrm{Ar}} \mathrm{Ga}, 12\right)$}

A solution of ' $G$ al' in toluene $(40 \mathrm{~mL})$ was prepared by sonicating gallium metal $(0.2 \mathrm{~g}, 2.8 \mathrm{mmol})$ and iodine $(0.36 \mathrm{~g}, 2.8 \mathrm{mmol})$ for $2 \mathrm{~h}$ at $45^{\circ} \mathrm{C}$, the solution was<smiles></smiles>
then cooled to $-78^{\circ} \mathrm{C}$ and a solution of $\mathrm{BDI} \mathrm{Ar}_{\mathrm{Ar}}-\mathrm{Li}(2.0 \mathrm{~g}, 2.0 \mathrm{mmol})$ in toluene $(10 \mathrm{~mL})$ was added dropwise to give an orange solution. The solution was warmed to room temperature and left to react for $16 \mathrm{~h}$, then filtered through celite and concentrated to c.a. $15 \mathrm{~mL}$ and placed in the freezer at $-30{ }^{\circ} \mathrm{C}$, at which point yellow crystals of $\mathrm{BDI}_{\mathrm{Ar}} \mathrm{Ga} 12$ formed $(0.86 \mathrm{~g}, 40 \%) .{ }^{1} \mathrm{H} \mathrm{NMR}$ $\left(300 \mathrm{MHz}, \mathrm{C}_{6} \mathrm{D}_{6}, 298 \mathrm{~K}\right) \delta 7.38(\mathrm{~m}, 12 \mathrm{H}, \boldsymbol{m}-\mathrm{Ar}-\boldsymbol{H} \mathrm{Ph}-\boldsymbol{H}), 7.33(d, J=7.2 \mathrm{~Hz}, 8 \mathrm{H}, \mathrm{Ph}-\boldsymbol{H}), 7.12(d, J$ $=7.6 \mathrm{~Hz}, 8 \mathrm{H}, \mathrm{Ph}-\boldsymbol{H}), 7.05(d, J=7.2 \mathrm{~Hz}, 4 \mathrm{H}, \mathrm{Ph}-\boldsymbol{H}), 6.97(t, J=7.6 \mathrm{~Hz}, 8 \mathrm{H}, \mathrm{Ph}-\boldsymbol{H}), 6.83(t, J=7.5$ $\mathrm{Hz}, 4 \mathrm{H}, \mathrm{Ph}-\boldsymbol{H}), 6.03(\mathrm{~s}, 4 \mathrm{H}, \mathrm{CHPh}), 4.80(\mathrm{~s}, 1 \mathrm{H}, \mathrm{CH}), 1.11\left(\mathrm{~s}, 18 \mathrm{H}, \mathrm{C}\left(\mathrm{CH}_{3}\right)_{3}\right), 1.04\left(\mathrm{~s}, 6 \mathrm{~h}, \mathrm{C}\left(\mathrm{CH}_{3}\right)\right)$. N.B. a usable ${ }^{13} \mathrm{C}$ NMR spectrum of this compound was unable to be obtained. 


\section{$\mathrm{CH}\left\{\mathrm{C}(\mathrm{Me}) \mathrm{N}\left(\mathrm{C}_{6} \mathrm{H}_{2}-2,6-\left(\mathrm{CHPh}_{2}\right)_{2}-4-{ }^{\mathrm{t}} \mathrm{Bu}\right)\right\}_{2} \mathrm{Ga}(\mathrm{H}) \mathrm{C}\left(\mathrm{N}_{2}\right) \mathrm{SiMe}_{3}\left(\mathrm{BDI}_{\mathrm{Ar}} \mathrm{Ga}(\mathrm{H}) \mathrm{C}\left(\mathrm{N}_{2}\right) \mathrm{TMS}, 45\right)$}

$\mathrm{BDI}_{\mathrm{Ar}} \mathrm{Ga}(0.24 \mathrm{~g}, 0.2 \mathrm{mmol})$ was dissolved in toluene $(5 \mathrm{~mL})$ and a solution of $2.0 \mathrm{M}$ trimethylsilyldiazomethane $(0.1 \mathrm{~mL}, 0.2 \mathrm{mmol})$ was added dropwise resulting in the solution fading to pale yellow.

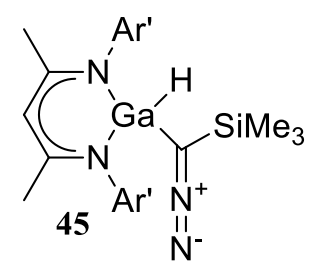
Concentration of the solution gave 45 as colourless crystals ( $210 \mathrm{mg}, 87 \%)$. ${ }^{1} \mathrm{H} \mathrm{NMR}(600 \mathrm{MHz}$, $\left.\mathrm{C}_{6} \mathrm{D}_{6}, 298 \mathrm{~K}\right) \delta 7.84(d, J=6.9 \mathrm{~Hz}, 4 \mathrm{H}, o-\mathrm{Ph}-\boldsymbol{H}), 7.57(d, J=6.9 \mathrm{~Hz}, 4 \mathrm{H}, o-\mathrm{Ph}-\boldsymbol{H}), 7.55(d, J=2.3$ $\mathrm{Hz}, 2 \mathrm{H}, o-\mathrm{Ph}-\boldsymbol{H}), 7.44(d, J=2.4 \mathrm{~Hz}, 2 \mathrm{H}, o-\mathrm{Ph}-\boldsymbol{H}), 7.36(d, J=7.0 \mathrm{~Hz}, 4 \mathrm{H}, o-\mathrm{Ph}-\boldsymbol{H}), 7.26-7.21$ $(\mathrm{m}, 8 \mathrm{H}), 7.13-7.10(m, 6 \mathrm{H}), 7.04(t, J=7.6 \mathrm{~Hz}, 4 \mathrm{H}, p-\mathrm{Ph}-\mathrm{H}), 6.97-6.93(m, 12 \mathrm{H}), 6.23(\mathrm{~s}, 2 \mathrm{H}$, $\mathrm{CHPh}), 5.72\left(\right.$ br. s, 1H, GaH), $4.27(s, 1 \mathrm{H}, \mathrm{CH}), 1.09\left(s, 18 \mathrm{H}, \mathrm{C}\left(\mathrm{CH}_{3}\right)_{3}\right), 0.34\left(s, 6 \mathrm{H} \mathrm{C}\left(\mathrm{CH}_{3}\right)\right), 0.23$ $\left(s, 9 H, \mathrm{Si}\left(\mathrm{CH}_{3}\right)_{3}\right) .{ }^{13} \mathrm{C}$ NMR $\left(151 \mathrm{MHz}, \mathrm{C}_{6} \mathrm{D}_{6}\right) \delta$ 174.19, 149.06, 145.72, 145.29, 143.01, 142.98, $142.43,141.24,138.98,131.15,130.70,130.47$, 129.73, 128.94, 128.75, 128.43, 127.39, $126.88,126.57,126.40,126.37,96.70,52.46,51.39,34.70,31.13,22.95,1.46$.

\section{$\mathrm{CH}\left\{\mathrm{C}(\mathrm{Me}) \mathrm{N}\left(\mathrm{C}_{6} \mathrm{H}_{2}-2,6-\left(\mathrm{CHPh}_{2}\right)_{2}-4-\mathrm{Me}\right)\right\} \mathrm{C}(\mathrm{Me}) \mathrm{N}\left(\mathrm{C}_{6} \mathrm{H}_{2}-\right.$}

\section{2-C(H)(Ph) $\left.\left.\left.\mathrm{C}_{6} \mathrm{H}_{4}\right)-4-\mathrm{Me}-6-\left(\mathrm{CHPh}_{2}\right)\right)\right\} \mathrm{GaN}(\mathrm{H}) \mathrm{NC}_{13} \mathrm{H}_{10}\left(\mathrm{BDI} \mathrm{Ar}_{\mathrm{Ar}} \mathrm{GaN}(\mathrm{H}) \mathrm{NFI}, 46\right)$}

$\mathrm{BDI}_{\mathrm{Ar}} \mathrm{Ga}(0.2 \mathrm{~g}, 0.2 \mathrm{mmol})$ was dissolved in toluene $(5 \mathrm{~mL})$ and a solution of diazofluorene ( $39 \mathrm{mg}, 0.2 \mathrm{mmol}$ ) in toluene $(5$ $\mathrm{mL}$ ) was added dropwise resulting in the orange coloured solution fading. Concentration of the solution gave $\mathbf{4 6}$ as offyellow crystals (40 mg, 16.6\%). ${ }^{1} \mathrm{H}$ NMR (600 MHz, $\mathrm{C}_{6} \mathrm{D}_{6}, 298 \mathrm{~K}$ ) $\delta 8.40(d, J=7.6 \mathrm{~Hz}, 1 \mathrm{H}), 8.36(d, J=7.9 \mathrm{~Hz}, 1 \mathrm{H}) 7.86(d, J=6.6$

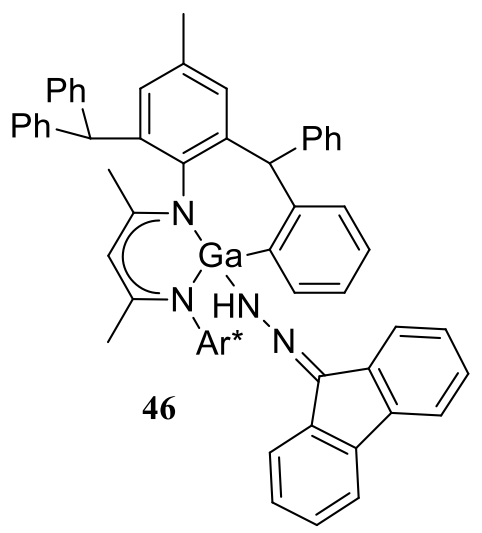
$\mathrm{Hz}, 1 \mathrm{H}), 7.80(s, 1 \mathrm{H}, \mathrm{NH}), 7.69(d, J=7.3 \mathrm{~Hz}, 2 \mathrm{H}), 7.67(d, J=7.3$ $\mathrm{Hz}, 2 \mathrm{H}), 7.51-7.44(m, 3 \mathrm{H}), 7.40(d, J=7.4 \mathrm{~Hz}, 1 \mathrm{H}), 7.37-7.31(m, 3 \mathrm{H}), 7.30-7.25(m, 4 \mathrm{H}), 7.20$ $(s, 1 \mathrm{H}, \mathrm{CHPh}), 7.15-6.88(m, 16 \mathrm{H}), 6.86(s, 1 \mathrm{H}, \mathrm{CHPh}), 6.78(t, J=7.7 \mathrm{~Hz}, 4 \mathrm{H}), 6.74(t, J=7.4 \mathrm{~Hz}$, 4H), $6.46(s, 1 \mathrm{H}, \mathrm{CHPh}), 6.41(t, J=7.8 \mathrm{~Hz}, 3 \mathrm{H}), 6.33(t, J=7.7 \mathrm{~Hz}, 2 \mathrm{H}) 6.02(s, 1 \mathrm{H}, \mathrm{CHPh}), 4.57$ $(s, 1 \mathrm{H}, \mathrm{CH}), 1.80\left(\mathrm{~s}, 3 \mathrm{H}, \mathrm{Ph}-\mathrm{CH}_{3}\right), 1.74\left(\mathrm{~s}, 3 \mathrm{H}, \mathrm{Ph}-\mathrm{CH}_{3}\right), 1.37\left(\mathrm{~s}, 3 \mathrm{H}, \mathrm{C}\left(\mathrm{CH}_{3}\right)\right), 0.38\left(\mathrm{~s}, 3 \mathrm{H}, \mathrm{C}\left(\mathrm{CH}_{3}\right)\right)$. ${ }^{13} \mathrm{C}$ NMR (151 MHz, C6 $\mathrm{D}_{6}, 298$ K) $\delta 173.29,170.79,154.58,146.08,145.46,145.27,143.10$, $142.50,142.42$, 142.16, 141.89, 141.35, 140.83, 140.68, 140.48, 140.33, 140.20, 140.02, 139.16, 138.80, 137.15, 136.54, 136.31, 131.35, 131.21, 131.04, 130.90, 130.86, 130.57, 
$129.97,129.93,129.69,129.40,128.97,128.89,128.70,128.62128 .51,127.65,127.40$, $127.17,127.15,126.84,126.68,126.49,126.43,126.29,126.18,125.88,125.48,123.88$, $120.20,119.98,119.45,97.11,53.19,52.42,51.53,50.62,30.24,23.00,22.84,21.45,21.20$.

\section{$\mathrm{CH}\left\{\mathrm{C}(\mathrm{Me}) \mathrm{N}\left(\mathrm{C}_{6} \mathrm{H}_{3}-2,6-\mathrm{Pr}_{2}\right)\right\}_{2} \mathrm{GaCl}_{2}\left(\mathrm{BDI}_{\mathrm{DIPP}} \mathrm{GaCl}_{2}, 51\right)$}

This compound was prepared following literature procedure. ${ }^{238} \mathrm{n} B \mathrm{Bui}(1.6 \mathrm{~mL}$, $3.1 \mathrm{mmol}$ ) in hexane was added drop-wise to a stirring solution of BDIDIPPH (1.19

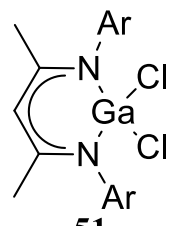
51

$\mathrm{g}, 2.8 \mathrm{mmol})$ in toluene $(10 \mathrm{~mL})$ that had been cooled to $-30{ }^{\circ} \mathrm{C}$. The solution rapidly turned yellow in colour. After $1 \mathrm{~h}$ this solution was added drop-wise to a solution of $\mathrm{GaCl}_{3}(500 \mathrm{mg}$, $2.8 \mathrm{mmol})$ in toluene $(10 \mathrm{~mL})$ that had been cooled to $-30^{\circ} \mathrm{C}$. This resulted in the rapid formation of a white precipitate. The slurry was stirred for $12 \mathrm{~h}$, filtered through celite, and the solvent removed in vacuo. The resulting solid was crystallized from toluene at $-30{ }^{\circ} \mathrm{C}$ to

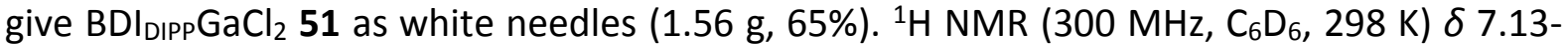
$7.07(m, 6 \mathrm{H}, \mathrm{Ar} \boldsymbol{H}), 4.75(s, 1 \mathrm{H}, \mathrm{CH}), 3.44$ (app. sept, J = 6.9, $\left.6.6 \mathrm{~Hz}, 4 \mathrm{H}, \mathrm{CH}\left(\mathrm{CH}_{3}\right)_{2}\right), 1.50(s, 6 \mathrm{H}$, $\left.\mathrm{C}\left(\mathrm{CH}_{3}\right)\right), 1.44\left(d, J=6.9 \mathrm{~Hz}, 12 \mathrm{H}, \mathrm{CH}\left(\mathrm{CH}_{3}\right)_{2}\right), 1.11\left(d, J=6.6 \mathrm{~Hz}, 12 \mathrm{H}, \mathrm{CH}\left(\mathrm{CH}_{3}\right)_{2}\right)$. These values are in accordance with literature values.

\section{$\mathrm{CH}\left\{\mathrm{C}(\mathrm{Me}) \mathrm{N}\left(\mathrm{C}_{6} \mathrm{H}_{3}-2,6-\mathrm{P}_{2}\right)\right\}_{2} \mathrm{Ga}\left(\mathrm{PH}\left(\mathrm{C}_{6} \mathrm{H}_{5}\right)\right) \mathrm{Cl}\left(\mathrm{BDI} \mathrm{DIPP}_{\mathrm{Pa}}(\mathrm{PHPh}) \mathrm{Cl}, 48\right)$}

This compound was prepared following known procedure. ${ }^{237} \mathrm{~A}$ solution of $\mathrm{PhP}(\mathrm{H}) \mathrm{Li}(18 \mathrm{mg}, 0.18 \mathrm{mmol})$ in THF $(10 \mathrm{~mL})$ was added drop-wise to a<smiles></smiles>
48 solution of $\mathrm{BDI}_{\mathrm{DIPP} G a C l}(100 \mathrm{mg}, 0.18 \mathrm{mmol})$ in $\mathrm{THF}(5 \mathrm{~mL})$ at $-30^{\circ} \mathrm{C}$. The solution was allowed to warm to room temperature and stirred for $12 \mathrm{~h}$, the solvent was removed in vacuo and the product extracted into toluene to give a cloudy yellow solution. This solution was filtered through celite to remove the precipitate. The volatiles were removed in vacuo and the resulting yellow solid crystallized from toluene/hexane at $-30{ }^{\circ} \mathrm{C}$ to give $B D I_{D I P P G a}(\mathrm{PHPh}) \mathrm{Cl} 48$ as yellow crystals (38 mg, 30.0\%). ${ }^{1} \mathrm{H}$ NMR $\left(300 \mathrm{MHz}, \mathrm{C}_{6} \mathrm{D}_{6}, 298 \mathrm{~K}\right) \delta$ 7.22-7.17 (m, 3H, $m$-ArH p-ArH), 7.12-7.09 (m, 2H, m-ArH), 7.06-7.02 (m, 1H, p-ArH), 6.95-6.89 (m, 1H, p-PhH), 6.86$6.78(m, 2 \mathrm{H}, m-\mathrm{PhH}), 6.76-6.71(m, 2 \mathrm{H}, \mathrm{o}-\mathrm{PhH}), 4.88(s, 1 \mathrm{H}, \mathrm{CH}), 3.77$ (app. sept, J = 6.9, 6.6 
$\left.\mathrm{Hz}, 2 \mathrm{H}, \mathrm{CH}\left(\mathrm{CH}_{3}\right)_{2}\right), 3.60$ (app. sept, J = 6.9, $\left.6.6 \mathrm{~Hz}, 2 \mathrm{H}, \mathrm{CH}\left(\mathrm{CH}_{3}\right)_{2}\right), 3.48-3.37\left(m, 1.5 \mathrm{H}, \mathrm{CH}\left(\mathrm{CH}_{3}\right)_{2}\right.$; $0.5 \mathrm{PH}$ ), 3.30 (app. sept, J = 6.9, $6.6 \mathrm{~Hz}, 1 \mathrm{H}, \mathrm{CH}\left(\mathrm{CH}_{3}\right)_{2}$ ), 3.09 (d, $\left.\mathrm{J}_{\mathrm{PH}}=195 \mathrm{~Hz}, 1 \mathrm{H}, \mathrm{PH}\right), 1.58-1.56$ $\left(m, 9 \mathrm{H}, 2 \mathrm{C}\left(\mathrm{CH}_{3}\right) ; 1 \mathrm{CH}\left(\mathrm{CH}_{3}\right)_{2}\right), 1.48\left(d, J=6.6 \mathrm{~Hz}, 3 \mathrm{H}, \mathrm{CH}\left(\mathrm{CH}_{3}\right)_{2}\right), 1.33(d, J=6.9 \mathrm{~Hz}, 3 \mathrm{H}$, $\left.\mathrm{CH}\left(\mathrm{CH}_{3}\right)_{2}\right), 1.19\left(d, J=6.9 \mathrm{~Hz}, 3 \mathrm{H}, \mathrm{CH}\left(\mathrm{CH}_{3}\right)_{2}\right), 1.14\left(d, J=6.9 \mathrm{~Hz}, 3 \mathrm{H}, \mathrm{CH}\left(\mathrm{CH}_{3}\right)_{2}\right), 1.10-1.06(m$, $\left.6 \mathrm{H}, \mathrm{CH}\left(\mathrm{CH}_{3}\right)_{2}\right), 1.03\left(d, J=6.9 \mathrm{~Hz}, 3 \mathrm{H}, \mathrm{CH}\left(\mathrm{CH}_{3}\right)_{2}\right)$. These values are in accordance with previously observed. ${ }^{237}$

\section{Attempted synthesis of BDIDIPPGaPPh (49)}

${ }^{\mathrm{n} B u L i}(32 \mu \mathrm{L}, 0.065 \mathrm{mmol})$ or ${ }^{\mathrm{t}} \mathrm{BuLi}(43 \mu \mathrm{L}, 0.065 \mathrm{mmol})$ in hexane was added drop-wise to a stirring solution of chlorophosphanide 48 (20 mg, 0.065

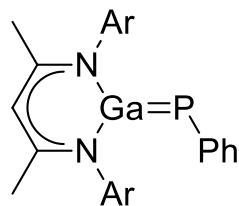

49 $\mathrm{mmol}$ ) in either toluene or THF, at either room temperature or cooled to $-30{ }^{\circ} \mathrm{C}$ or $-78{ }^{\circ} \mathrm{C}$ and the reaction mixture stirred for $1 \mathrm{~h}$. The mixture was then filtered through celite and the volatiles removed in vacuo. ${ }^{1} \mathrm{H}$ NMR of the residue typically contained the resonances associated with proposed decomposition product $\mathbf{5 0 ,}{ }^{237}$ however crystals suitable for X-ray diffraction to confirm the structure could not be obtained.

\section{$\mathrm{CH}\left\{\mathrm{C}(\mathrm{Me}) \mathrm{N}\left(\mathrm{C}_{6} \mathrm{H}_{3}-2,6-\mathrm{Pr}_{2}\right)\right\}_{2} \mathrm{AlCl}_{2}\left(\mathrm{BDI}_{\mathrm{DIPPAICl}}, 52\right)$}

This compound was prepared following literature procedure. ${ }^{238} \mathrm{n} B u L i(2.0 \mathrm{~mL}$, $4.0 \mathrm{mmol}$ ) in hexane was added drop-wise to a stirring solution of BDIDIPPH (1.57

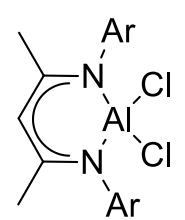
52 $\mathrm{g}, 3.7 \mathrm{mmol})$ in toluene $(10 \mathrm{~mL})$ that had been cooled to $-30^{\circ} \mathrm{C}$. The solution rapidly turned yellow in colour. After $1 \mathrm{~h}$ this solution was added drop-wise to a solution of $\mathrm{AlCl}_{3}(500 \mathrm{mg}$, $3.7 \mathrm{mmol})$ in toluene $(10 \mathrm{~mL})$ that had been cooled to $-30{ }^{\circ} \mathrm{C}$. This resulted in the rapid formation of a white precipitate. The slurry was stirred for $12 \mathrm{~h}$, filtered through celite, and the solvent removed in vacuo. The resulting solid was crystallized from toluene at $-30{ }^{\circ} \mathrm{C}$ to give $\mathrm{BDI}_{\mathrm{DIPPAICl}} 52$ as a colourless solid (1.71 g, 89\%). ${ }^{1} \mathrm{H} \mathrm{NMR}\left(600 \mathrm{MHz}, \mathrm{C}_{6} \mathrm{D}_{6}, 298 \mathrm{~K}\right) \delta 7.17-$ $7.07(m, 6 \mathrm{H}, \mathrm{Ar} \boldsymbol{H}), 5.01(\mathrm{~s}, 1 \mathrm{H}, \mathrm{CH}), 3.42\left(\right.$ sept, $\left.J=6.9 \mathrm{~Hz}, 4 \mathrm{H}, \mathrm{CH}\left(\mathrm{CH}_{3}\right)_{2}\right), 1.91\left(\mathrm{~s}, 6 \mathrm{H}, \mathrm{C}\left(\mathrm{CH}_{3}\right)\right)$, $1.28\left(d, J=6.9 \mathrm{~Hz}, 12 \mathrm{H}, \mathrm{CH}\left(\mathrm{CH}_{3}\right)_{2}\right), 1.18\left(d, J=6.9 \mathrm{~Hz}, 12 \mathrm{H}, \mathrm{CH}\left(\mathrm{CH}_{3}\right)_{2}\right)$. These values are in accordance with literature values. 


\section{$\mathrm{CH}\left\{\mathrm{C}(\mathrm{Me}) \mathrm{N}\left(\mathrm{C}_{6} \mathrm{H}_{3}-2,6 \text { - }^{\mathrm{i}} \mathrm{Pr}_{2}\right)\right\}_{2} \mathrm{Al}\left(\mathrm{PH}\left(\mathrm{C}_{6} \mathrm{H}_{5}\right)\right) \mathrm{Cl}(\mathrm{BDI} \mathrm{DIPAI}(\mathrm{PHPh}) \mathrm{Cl}, 53)$}

A solution of $\mathrm{PhP}(\mathrm{H}) \mathrm{Li}(20 \mathrm{mg}, 0.20 \mathrm{mmol})$ in THF $(10 \mathrm{~mL})$ was added drop-wise to a solution of $\mathrm{BDI}_{\mathrm{DIPP}} \mathrm{AlCl}_{2}(100 \mathrm{mg}, 0.20 \mathrm{mmol})$ in THF $(5 \mathrm{~mL})$ at<smiles></smiles>
53 $-30{ }^{\circ} \mathrm{C}$. The solution was allowed to warm to room temperature and stirred for $12 \mathrm{~h}$, the solvent was removed in vacuo and the product extracted into toluene to give a cloudy yellow solution. This solution was filtered through celite to remove the precipitate. The volatiles were removed in vacuo and the resulting yellow solid crystallized from toluene/hexane at -30 ${ }^{\circ} \mathrm{C}$ to give $\mathrm{BDI}$ DIPPAI(PHPh)Cl 53 as yellow crystals (45 mg, 43\%). ${ }^{1} \mathrm{H}$ NMR (300 MHz, $\mathrm{C}_{6} \mathrm{D}_{6}, 298$ K) $\delta$ 7.20-7.01 (m, 6H, ArH), 6.75-6.69 (m, 3H, p-PhH m-PhH), 6.63-6.58 (m, 2H,o-PhH), 4.85 $(s, 1 \mathrm{H}, \mathrm{CH}), 3.46$ (br. s, 2H, $\left.\mathrm{CH}\left(\mathrm{CH}_{3}\right)_{2}\right), 3.26$ (br. s, $\left.2 \mathrm{H}, \mathrm{CH}\left(\mathrm{CH}_{3}\right)_{2}\right), 2.64\left(d, \mathrm{~J}_{\mathrm{PH}}=192 \mathrm{~Hz}, 1 \mathrm{H}, \mathrm{PH}\right)$, $1.44\left(s, 6 \mathrm{H}, \mathrm{C}\left(\mathrm{CH}_{3}\right)\right), 1.04\left(d, J=6.9 \mathrm{~Hz}, 6 \mathrm{H}, \mathrm{CH}\left(\mathrm{CH}_{3}\right)_{2}\right), 0.93\left(d, J=6.6 \mathrm{~Hz}, 3 \mathrm{H}, \mathrm{CH}\left(\mathrm{CH}_{3}\right)_{2}\right) .{ }^{13} \mathrm{C}$ NMR $\left(75 \mathrm{MHz}, \mathrm{C}_{6} \mathrm{D}_{6}\right) \delta 171.24,146.13,143.42,139.41,134.06,133.86,129.34,127.98$, $125.71,124.99,124.39,99.11$, 29.74, 29.69, 28.12, 26.53, 25.06, 24.64, 24.32, 24.24, 23.40. ${ }^{31} \mathrm{P}$ NMR $\left(121 \mathrm{MHz}, \mathrm{C}_{6} \mathrm{D}_{6}, 298 \mathrm{~K}\right) \delta-158.15\left({ }^{1} \mathrm{H}\right.$ coupled $\left.-d, J_{\mathrm{PH}}=192 \mathrm{~Hz}\right)$.

\section{$\mathrm{CH}\left\{\mathrm{C}(\mathrm{Me}) \mathrm{N}\left(\mathrm{C}_{6} \mathrm{H}_{3}-2,6-\mathrm{PPr}_{2}\right)\right\}_{2} \mathrm{AIClP}(\mathrm{H}) \mathrm{Mes}$ (BDIDIPPAl(PHMes)Cl, 58)}

${ }^{n}$ BuLi (0.4 mL, $0.8 \mathrm{mmol}$ ) in hexane was added drop-wise to a stirring solution of $\mathrm{MesPH}_{2}(120 \mathrm{mg}, 0.8 \mathrm{mmol})$ in toluene $(10 \mathrm{~mL})$ that had been

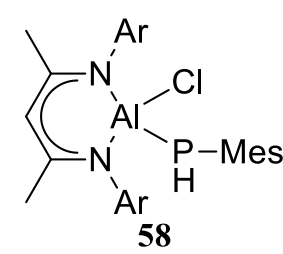
cooled to $-30^{\circ} \mathrm{C}$. The solution rapidly turned yellow in colour. After $1 \mathrm{~h}$ this solution was added drop-wise to a solution of $\mathrm{BDI}_{\mathrm{DIPP}} \mathrm{AlCl}_{2}(500 \mathrm{mg}, 0.8 \mathrm{mmol})$ in toluene $(10 \mathrm{~mL})$ that had been cooled to $-30^{\circ} \mathrm{C}$. This resulted in the rapid formation of a white precipitate. The slurry was stirred for $2 \mathrm{~h}$, filtered through celite, and the solvent removed in vacuo. The resulting solid was crystallized from toluene at $-30{ }^{\circ} \mathrm{C}$ to give $\mathrm{BDI}$ DIPPAl(PHMes) $\mathrm{Cl} 58$ as yellow crystals (326 mg, 65\%). ${ }^{1} \mathrm{H}$ NMR (600 MHz, $\left.\mathrm{C}_{6} \mathrm{D}_{6}, 298 \mathrm{~K}\right) \delta$ 7.21-7.14(m, 6H, ArH), $6.66(s, 2 \mathrm{H}, m-\boldsymbol{H}), 4.94(s$, $1 \mathrm{H}, \mathrm{CH}$ ), 3.50 (app. sept, J=6.9, $\left.6.6 \mathrm{~Hz}, 2 \mathrm{H}, \mathrm{CH}\left(\mathrm{CH}_{3}\right)_{2}\right), 3.24$ (br. s, $\left.2 \mathrm{H}, \mathrm{CH}\left(\mathrm{CH}_{3}\right)_{2}\right), 2.73\left(d, J_{P H}=\right.$ $199 \mathrm{~Hz}, 1 \mathrm{H}, \mathrm{PH}), 2.01\left(\mathrm{~s}, 3 \mathrm{H}, \mathrm{p}-\mathrm{Ph}-\mathrm{CH}_{3}\right), 1.79\left(\mathrm{~s}, 6 \mathrm{H}, \mathrm{o}-\mathrm{Ph}-\mathrm{CH}_{3}\right), 1.54\left(m, 12 \mathrm{H}, \mathrm{C}\left(\mathrm{CH}_{3}\right) \mathrm{CH}\left(\mathrm{CH}_{3}\right)_{2}\right)$, $1.26\left(d, J=6.6 \mathrm{~Hz}, 6 \mathrm{H}, \mathrm{CH}\left(\mathrm{CH}_{3}\right)_{2}\right), 1.12\left(d, J=6.9 \mathrm{~Hz}, 6 \mathrm{H}, \mathrm{CH}\left(\mathrm{CH}_{3}\right)_{2}\right), 1.01(d, J=6.9 \mathrm{~Hz}, 6 \mathrm{H}$, $\left.\mathrm{CH}\left(\mathrm{CH}_{3}\right)_{2}\right) .{ }^{13} \mathrm{C}$ NMR $\left(151 \mathrm{MHz}, \mathrm{C}_{6} \mathrm{D}_{6}\right) \delta 171.06,146.15,143.78,140.68,140.61,140.01,134.14$, 
$128.54,128.52,125.65,124.37,99.03,67.86,30.19,30.16,28.12,26.49,25.05,24.82,23.81$, 21.01. ${ }^{31} \mathrm{P}$ NMR $\left(121 \mathrm{MHz}, \mathrm{C}_{6} \mathrm{D}_{6}, 298 \mathrm{~K}\right) \delta-196.2\left({ }^{1} \mathrm{H}\right.$ coupled $\left.-d, J_{\mathrm{PH}}=200 \mathrm{~Hz}\right)$.

\section{$\mathrm{CH}\left\{\mathrm{C}(\mathrm{Me}) \mathrm{N}\left(\mathrm{C}_{6} \mathrm{H}_{3}-2,6-\mathrm{P}_{2}\right)\right\}_{2} \mathrm{GaClP}(\mathrm{H}) \mathrm{Mes}$ (BDI DIPPGa(PHMes)Cl, 59)}

${ }^{\mathrm{n} B u L i}(0.38 \mathrm{~mL}, 0.74 \mathrm{mmol})$ in hexane was added drop-wise to a stirring solution of $\mathrm{MesPH}_{2}(113 \mathrm{mg}, 0.74 \mathrm{mmol})$ in toluene $(10 \mathrm{~mL})$ that had been

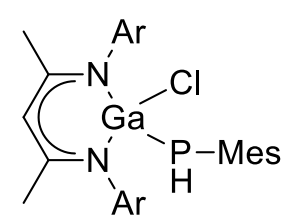

59 cooled to $-30^{\circ} \mathrm{C}$. The solution rapidly turned yellow in colour. After $1 \mathrm{~h}$ this solution was added drop-wise to a solution of $\mathrm{BDI}_{\mathrm{DIPP}} \mathrm{GaCl}_{2}(500 \mathrm{mg}, 0.74 \mathrm{mmol})$ in toluene $(10 \mathrm{~mL})$ that had been cooled to $-30{ }^{\circ} \mathrm{C}$. This resulted in the rapid formation of a white precipitate. The slurry was stirred for $2 \mathrm{~h}$, filtered through celite, and the solvent removed in vacuo. The resulting solid was crystallized from hexane at $-30{ }^{\circ} \mathrm{C}$ to give $\mathrm{BDI} \mathrm{DIPP}_{\mathrm{Pa}}(\mathrm{PHMes}) \mathrm{Cl} 59$ as yellow crystals (280 mg, 56\%). ${ }^{1} \mathrm{H}$ NMR (600 MHz, $\left.\mathrm{C}_{6} \mathrm{D}_{6}, 298 \mathrm{~K}\right) \delta$ 7.20-7.18 (m, 6H, ArH), $6.67(s, 2 \mathrm{H}, \boldsymbol{m}-\boldsymbol{H}), 4.87(s$, $1 \mathrm{H}, \mathrm{CH}$ ), 3.64 (sext, $J=6.6 \mathrm{~Hz}, 2 \mathrm{H}, \mathrm{CH}\left(\mathrm{CH}_{3}\right)_{2}$ ), 3.32 (app. sept, $J=6.9,6.6 \mathrm{~Hz}, 1 \mathrm{H}, \mathrm{CH}\left(\mathrm{CH}_{3}\right)_{2}$ ), 3.16 (app. sept, $\left.J=6.9,6.6 \mathrm{~Hz}, 1 \mathrm{H}, \mathrm{CH}\left(\mathrm{CH}_{3}\right)_{2}\right), 3.13\left(d, J_{P H}=202 \mathrm{~Hz}, 1 \mathrm{H}, \mathrm{PH}\right), 2.00(s, 3 \mathrm{H}, p-\mathrm{Ph}-$ $\left.\mathrm{CH}_{3}\right), 1.81\left(\mathrm{~s}, 6 \mathrm{H}, 0-\mathrm{Ph}-\mathrm{CH}_{3}\right), 1.63-1.58\left(\mathrm{~m}, 9 \mathrm{H}, \mathrm{C}\left(\mathrm{CH}_{3}\right) \mathrm{CH}\left(\mathrm{CH}_{3}\right)_{2}\right), 1.46(d, J=6.9 \mathrm{~Hz}, 3 \mathrm{H}$, $\left.\mathrm{CH}\left(\mathrm{CH}_{3}\right)_{2}\right), 1.33\left(d, J=6.6 \mathrm{~Hz}, 3 \mathrm{H}, \mathrm{CH}\left(\mathrm{CH}_{3}\right)_{2}\right), 1.24\left(d, J=6.6 \mathrm{~Hz}, 3 \mathrm{H}, \mathrm{CH}\left(\mathrm{CH}_{3}\right)_{2}\right), 1.16-1.13(m$, $\left.6 \mathrm{H}, \mathrm{CH}\left(\mathrm{CH}_{3}\right)_{2}\right), 1.10-1.03\left(m, 6 \mathrm{H}, \mathrm{CH}\left(\mathrm{CH}_{3}\right)_{2}\right) .{ }^{13} \mathrm{CNMR}\left(151 \mathrm{MHz}, \mathrm{C}_{6} \mathrm{D}_{6}\right) \delta$ 169.47, 169.18, 146.31, $146.19,143.51,143.22,141.62,141.54,140.85$, 140.79, 137.90, 135.69, 129.34, 128.75, $128.73,128.57,127.85,126.96,126.82,125.71,125.70,125.53,124.89,124.24,123.95$, $97.36,30.12$, 30.08, 29.92, 29.90, 28.07, 28.05, 26.49, 26.44, 25.12, 25.03, 24.76, 24.72, 23.96, 23.91, 23.82, 23.65, 23.63, 23.55, 23.47, 21.00. ${ }^{31} \mathrm{P} N M R\left(121 \mathrm{MHz}, \mathrm{C}_{6} \mathrm{D}_{6}, 298 \mathrm{~K}\right) \delta-$ $190.3\left({ }^{1} \mathrm{H}\right.$ coupled $\left.-d, J_{\mathrm{PH}}=201 \mathrm{~Hz}\right)$.

\section{Synthesis of MesPLi2}

This compound was prepared following literature procedure. ${ }^{233}$ To a solution of $\mathrm{MesPH}_{2}$ $(1.0 \mathrm{~g}, 6.6 \mathrm{mmol})$ in $\mathrm{Et}_{2} \mathrm{O}(50 \mathrm{~mL})$ cooled to $0{ }^{\circ} \mathrm{C}$ a solution of ${ }^{\mathrm{n}} \mathrm{BuLi}(6.8 \mathrm{~mL}, 13.6 \mathrm{mmol})$ in hexanes was slowly added. The solution was allowed to warm to room temperature and 
stirred for a further 1 hour. The resulting yellow solid was collected by filtration, dried under vacuum and used without further purification.

\section{Synthesis of $\mathrm{PhP}(\mathrm{H}) \mathrm{TMS}$}

${ }^{\text {nBuLi }}(2.4 \mathrm{~mL}, 4.8 \mathrm{mmol})$ in hexane was added drop-wise to a stirring solution of $\mathrm{PhPH}_{2}$ (500 mg, $4.5 \mathrm{mmol})$ in toluene $(10 \mathrm{~mL})$ that had been cooled to $-30^{\circ} \mathrm{C}$. The solution rapidly turned yellow in colour, after 1 hour a solution of TMS-Cl (495 mg, $4.5 \mathrm{mmol}$ ) in toluene (10 $\mathrm{mL}$ ) was added and a white precipitate formed. The solution was stirred for $2 \mathrm{~h}$, filtered through celite, and the solvent removed in vacuo to give $\mathrm{PhP}(\mathrm{H}) \mathrm{TMS}$ as a colourless oil that was used without further purification.

\section{$\mathrm{CH}\left\{\mathrm{C}(\mathrm{Me}) \mathrm{N}\left(\mathrm{C}_{6} \mathrm{H}_{3}-2,6-\mathrm{i}^{\mathrm{i}} \mathrm{Pr}_{2}\right)\right\}_{2} \mathrm{AIClP}\left(\mathrm{SiMe}_{3}\right) \mathrm{Ph}$ (BDIDIPPAI(PPhTMS)Cl, 60)}

${ }^{\mathrm{n} B u L i}(0.4 \mathrm{~mL}, 0.8 \mathrm{mmol})$ in hexane was added drop-wise to a stirring solution of $\mathrm{PhP}(\mathrm{H}) \mathrm{TMS}(145 \mathrm{mg}, 0.8 \mathrm{mmol})$ in toluene $(10 \mathrm{~mL})$ that had been

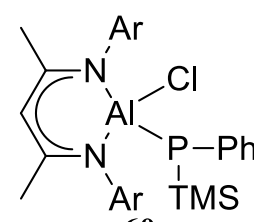
60 cooled to $-30^{\circ} \mathrm{C}$. The solution rapidly turned yellow in colour. After $1 \mathrm{~h}$ this solution was added drop-wise to a solution of ( $\left.\mathrm{BDI}_{\text {DIPP }}\right) \mathrm{AlCl}_{2}(500 \mathrm{mg}, 0.8 \mathrm{mmol})$ in toluene $(10 \mathrm{~mL})$ that had been cooled to $-30{ }^{\circ} \mathrm{C}$. This resulted in the rapid formation of a white precipitate. The slurry was stirred for $2 \mathrm{~h}$, filtered through celite, and the solvent removed in vacuo. The resulting solid was crystallized from toluene at $-30{ }^{\circ} \mathrm{C}$ to give BDIDIPPAI(PPhTMS)Cl 60 as colourless crystals (280 mg, 55\%). ${ }^{1} \mathrm{H}$ NMR (600 MHz, $\left.\mathrm{C}_{6} \mathrm{D}_{6}, 298 \mathrm{~K}\right) \delta 7.41(t, J=7.0 \mathrm{~Hz}, 2 \mathrm{H}, m-\mathrm{Ph}-\boldsymbol{H}), 7.00-6.94$ $(m, 6 \mathrm{H}, \mathrm{Ar} \boldsymbol{H}), 6.85(d d, J=10.6,4.0 \mathrm{~Hz}, 1 \mathrm{H}, \boldsymbol{p}-\mathrm{Ph}-\boldsymbol{H}), 6.79(t, J=7.3 \mathrm{~Hz}, 2 \mathrm{H}, \boldsymbol{o}-\mathrm{Ph}-\boldsymbol{H}), 4.96(s, 1 \mathrm{H}$, $\mathrm{CH})$, 3.67-3.53 (m, 4H, $\left.\mathrm{CH}\left(\mathrm{CH}_{3}\right)_{2}\right), 1.62\left(d, J=6.9 \mathrm{~Hz}, 6 \mathrm{H}, \mathrm{CH}\left(\mathrm{CH}_{3}\right)_{2}\right), 1.52\left(\mathrm{~s}, 6 \mathrm{H}, \mathrm{C}\left(\mathrm{CH}_{3}\right)\right), 1.49$ $\left(d, J=6.6 \mathrm{~Hz}, 6 \mathrm{H}, \mathrm{CH}\left(\mathrm{CH}_{3}\right)_{2}\right), 1.15\left(d, J=6.9 \mathrm{~Hz}, 6 \mathrm{H}, \mathrm{CH}\left(\mathrm{CH}_{3}\right)_{2}\right), 1.01\left(d, J=6.9 \mathrm{~Hz}, 6 \mathrm{H}, \mathrm{CH}\left(\mathrm{CH}_{3}\right)_{2}\right)$, $-0.07\left(d, J_{\mathrm{PH}}=4.7 \mathrm{~Hz}, 9 \mathrm{H}, \mathrm{CH}\left(\mathrm{CH}_{3}\right)_{2}\right) .{ }^{13} \mathrm{C} \mathrm{NMR}\left(151 \mathrm{MHz}, \mathrm{C}_{6} \mathrm{D}_{6}\right) \delta 170.89,145.37,143.47$, 140.12 , 139.14, 139.04, 129.34, 128.57, 127.33, 127.29, 125.72, 125.70, 125.52, 124.54, $98.85,29.81,29.76,28.04,26.30,25.21,25.09,24.02,23.97,23.78,1.22,1.13 .{ }^{31}$ P NMR (121 $\left.\mathrm{MHz}, \mathrm{C}_{6} \mathrm{D}_{6}, 298 \mathrm{~K}\right) \delta-160.0$. 
$\mathrm{CH}\left\{\mathrm{C}(\mathrm{Me}) \mathrm{N}\left(\mathrm{C}_{6} \mathrm{H}_{3}-2,6^{\mathrm{i}} \mathrm{Pr}_{2}\right)\right\}_{2} \mathrm{GaClP}\left(\mathrm{SiMe}_{3}\right) \mathrm{Ph}\left(\mathrm{BDI}_{\mathrm{DIPP}} \mathrm{Ga}(\mathrm{PPhTMS}) \mathrm{Cl}, 61\right)$

${ }^{\mathrm{n} B u L i}(0.38 \mathrm{~mL}, 0.74 \mathrm{mmol})$ in hexane was added drop-wise to a stirring solution of $\mathrm{PhP}(\mathrm{H}) \mathrm{TMS}(135 \mathrm{mg}, 0.74 \mathrm{mmol})$ in toluene $(10 \mathrm{~mL})$ that had been

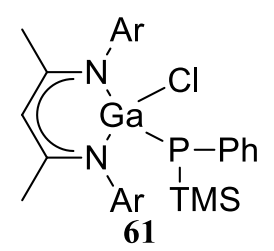
cooled to $-30^{\circ} \mathrm{C}$. The solution rapidly turned yellow in colour. After $1 \mathrm{~h}$ this solution was added drop-wise to a solution of ( $\left.B D I_{\text {DIPP }}\right) \mathrm{GaCl}_{2}(500 \mathrm{mg}, 0.74 \mathrm{mmol})$ in toluene $(10 \mathrm{~mL})$ that had been cooled to $-30{ }^{\circ} \mathrm{C}$. This resulted in the rapid formation of a white precipitate. The slurry was stirred for $2 \mathrm{~h}$, filtered through celite, and the solvent removed in vacuo. Analysis of the resulting solid showed the presence of multiple products, one of which was attributed to the presence of $\mathrm{BDI}_{\mathrm{DIPPG}} \mathrm{G}(\mathrm{PPhTMS}) \mathrm{Cl} \mathbf{6 1}$ however a clean NMR spectrum of this compound could not be obtained.

\section{$\mathrm{CH}\left\{\mathrm{C}(\mathrm{Me}) \mathrm{N}\left(\mathrm{C}_{6} \mathrm{H}_{3}-2,6 \text { - }^{\mathrm{P}} \mathrm{Pr}_{2}\right)\right\}_{2} \mathrm{AlEtCl}$ (BDI DIPPAIEtCl, 62)}

This compound was prepared following literature procedure. ${ }^{244 \mathrm{n}} \mathrm{BuLi}(1.2 \mathrm{~mL}$,

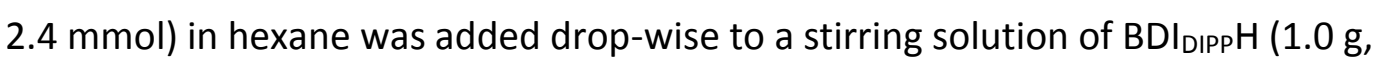

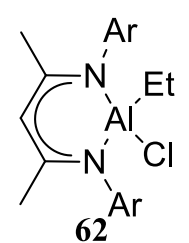
$2.3 \mathrm{mmol})$ in toluene $(10 \mathrm{~mL})$ that had been cooled to $-30{ }^{\circ} \mathrm{C}$. The solution rapidly turned yellow in colour. After $1 \mathrm{~h}$ a solution of $1.8 \mathrm{M} \mathrm{AlEtCl} 2(1.3 \mathrm{~mL}, 2.3 \mathrm{mmol})$ was added drop-wise. This resulted in the rapid formation of a white precipitate. The slurry was stirred for $12 \mathrm{~h}$, filtered through celite, and the solvent removed in vacuo. The resulting solid was crystallized from toluene at $-30{ }^{\circ} \mathrm{C}$ to give BDI DIPPAlEtCl 62 as colourless crystals $(1.56 \mathrm{~g}, 65 \%) .{ }^{1} \mathrm{H}$ NMR (300 MHz, $\left.\mathrm{C}_{6} \mathrm{D}_{6}, 298 \mathrm{~K}\right)$ ס 7.15-7.04 (m, 6H, ArH), 4.97 (s, 1H, CH), 3.77 (app. sept, J = 6.9, 6.6 $\left.\mathrm{Hz}, 2 \mathrm{H}, \mathrm{CH}\left(\mathrm{CH}_{3}\right)_{2}\right), 3.22$ (app. sept, J = 6.9, $\left.6.6 \mathrm{~Hz}, 2 \mathrm{H}, \mathrm{CH}\left(\mathrm{CH}_{3}\right)_{2}\right), 1.56\left(\mathrm{~s}, 6 \mathrm{H}, \mathrm{C}\left(\mathrm{CH}_{3}\right)\right), 1.50(d, J$ $\left.=6.6 \mathrm{~Hz}, 6 \mathrm{H}, \mathrm{CH}\left(\mathrm{CH}_{3}\right)_{2}\right), 1.31\left(d, J=6.9 \mathrm{~Hz}, 6 \mathrm{H}, \mathrm{CH}\left(\mathrm{CH}_{3}\right)_{2}\right), 1.20\left(d, J=6.9 \mathrm{~Hz}, 6 \mathrm{H}, \mathrm{CH}\left(\mathrm{CH}_{3}\right)_{2}\right)$, $1.01\left(d, J=6.9 \mathrm{~Hz}, 6 \mathrm{H}, \mathrm{CH}\left(\mathrm{CH}_{3}\right)_{2}\right), 0.82\left(t, J=8.1 \mathrm{~Hz}, 3 \mathrm{H}, \mathrm{AlCH}_{2} \mathrm{CH}_{3}\right),-0.03(q, J=8.1 \mathrm{~Hz}, 2 \mathrm{H}$, AlCH $\mathrm{CH}_{3}$ ). These values are in accordance with literature values.

\section{$\mathrm{CH}\left\{\mathrm{C}(\mathrm{Me}) \mathrm{N}\left(\mathrm{C}_{6} \mathrm{H}_{3}-2, \text { 6- }^{\mathrm{i}} \mathrm{Pr}_{2}\right)\right\}_{2}$ AlEtP(H)Mes (BDIDIPPAIEtP(H)Mes, 63)}

nBuLi $(0.4 \mathrm{~mL}, 0.8 \mathrm{mmol})$ in hexane was added drop-wise to a stirring solution of $\mathrm{MesPH}_{2}(120 \mathrm{mg}, 0.8 \mathrm{mmol})$ in toluene $(10 \mathrm{~mL})$ that had been

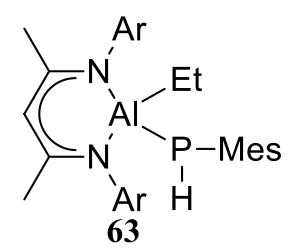


cooled to $-30^{\circ} \mathrm{C}$. The solution rapidly turned yellow in colour. After $1 \mathrm{~h}$ this solution was added drop-wise to a solution of BDI DIPPAIEtCl $62(500 \mathrm{mg}, 0.8 \mathrm{mmol})$ in toluene $(10 \mathrm{~mL})$ that had been cooled to $-30{ }^{\circ} \mathrm{C}$. This resulted in the rapid formation of a white precipitate. The slurry was stirred for $2 \mathrm{~h}$, filtered through celite, and the solvent removed in vacuo. The resulting solid was crystallized from toluene at $-30{ }^{\circ} \mathrm{C}$ to give (BDIDIPPAIEtP(H)Mes $63(280 \mathrm{mg}, 56 \%) .{ }^{1} \mathrm{H}$ NMR (300 MHz, $\left.\mathrm{C}_{6} \mathrm{D}_{6}, 298 \mathrm{~K}\right) \delta$ 7.17-7.10 (m, 6H, ArH), $6.62(s, 2 \mathrm{H}, m-\boldsymbol{H}), 4.72(s, 1 \mathrm{H}, \mathrm{CH}), 3.35$ $\left(m, 2 \mathrm{H}, \mathrm{CH}\left(\mathrm{CH}_{3}\right)_{2}\right), 3.25\left(\right.$ sept $\left., J=6.6 \mathrm{~Hz}, 2 \mathrm{H}, \mathrm{CH}\left(\mathrm{CH}_{3}\right)_{2}\right), 2.57\left(d, J_{P H}=196 \mathrm{~Hz}, 1 \mathrm{H}, \mathrm{PH}\right), 1.99(\mathrm{~s}$, $\left.3 \mathrm{H}, p-\mathrm{Ph}-\mathrm{CH}_{3}\right), 1.75\left(s, 6 \mathrm{H}, o-\mathrm{Ph}-\mathrm{CH}_{3}\right), 1.57\left(d, J=6.6 \mathrm{~Hz}, 6 \mathrm{H}, \mathrm{CH}\left(\mathrm{CH}_{3}\right)_{2}\right), 1.49\left(s, 6 \mathrm{H}, \mathrm{C}\left(\mathrm{CH}_{3}\right)\right.$, $1.29\left(t, J=7.9 \mathrm{~Hz}, 3 \mathrm{H}, \mathrm{CH}_{2} \mathrm{CH}_{3}\right), 1.21\left(d, J=6.6 \mathrm{~Hz}, 6 \mathrm{H}, \mathrm{CH}\left(\mathrm{CH}_{3}\right)_{2}\right), 1.13(d, J=6.9 \mathrm{~Hz}, 6 \mathrm{H}$, $\left.\mathrm{CH}\left(\mathrm{CH}_{3}\right)_{2}\right), 1.03\left(d, J=6.9 \mathrm{~Hz}, 6 \mathrm{H}, \mathrm{CH}\left(\mathrm{CH}_{3}\right)_{2}\right),-0.09\left(q, J=7.9 \mathrm{~Hz}, 2 \mathrm{H}, \mathrm{CH}_{2} \mathrm{CH}_{3}\right) .{ }^{13} \mathrm{C} \mathrm{NMR}(151$ $\left.\mathrm{MHz}, \mathrm{C}_{6} \mathrm{D}_{6}\right) \delta 171.08,145.28,144.23,141.35,139.95,139.88,133.06,132.92,132.76,128.32$, $128.30,127.70,125.03,124.73,98.37,29.89,29.85,27.45,25.26,25.21,25.15,24.39,24.35$, 23.95, 23.81, 23.72, 21.00, 9.94, 4.32. ${ }^{31}$ P NMR (121 MHz, $\left.\mathrm{C}_{6} \mathrm{D}_{6}, 298 \mathrm{~K}\right) \delta$-189.9 ( ${ }^{1} \mathrm{H}$ coupled $\left.d, J_{\mathrm{PH}}=196 \mathrm{~Hz}\right)$

Attempted synthesis of BDI DIPPAI( $\eta^{2}$-1,2-ethynediylbistrimethylsilyl) 64

BDI $_{\text {DIPPAICl}}(100 \mathrm{mg}, 0.2 \mathrm{mmol})$ and potassium metal $(15 \mathrm{mg}, 0.4 \mathrm{mmol})$ were stirred in bistrimethylsilylacetylene $\left(5 \mathrm{~mL}, 22 \mathrm{mmol}\right.$ ) heated to $140{ }^{\circ} \mathrm{C}$

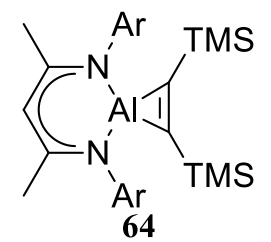
for 72 hours. ${ }^{1} \mathrm{H}$ NMR of the reaction mixture showed no reaction was occurring.

Attempted synthesis of BDI DIPPGa(n²-1,2-ethynediylbistrimethylsilyl) 65

a) $\mathrm{BDI}_{\mathrm{DIPP}} \mathrm{GaCl}_{2}(100 \mathrm{mg}, 0.18 \mathrm{mmol})$ and potassium metal $(15 \mathrm{mg}, 0.4$ $\mathrm{mmol}$ ) were stirred in bistrimethylsilylacetylene $(5 \mathrm{~mL}, 22 \mathrm{mmol})$

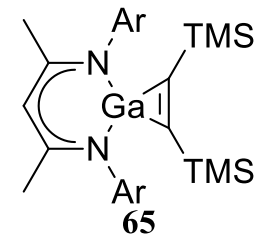
heated to $140{ }^{\circ} \mathrm{C}$ for 72 hours. ${ }^{1} \mathrm{H}$ NMR of the reaction mixture showed no reaction was occurring.

b) $\mathrm{BDI}_{\mathrm{DIPP} G a}(100 \mathrm{mg}, 0.2 \mathrm{mmol}$ ) was stirred in bistrimethylsilylacetylene ( $5 \mathrm{~mL}, 22 \mathrm{mmol})$ heated to $140{ }^{\circ} \mathrm{C}$ for 72 hours. ${ }^{1} \mathrm{H}$ NMR of the reaction mixture showed no reaction was occurring. 


\section{Attempted reduction of $\mathrm{MesPCl}_{2}$ in the presence of $\mathrm{BDI}_{\mathrm{DIPPGa}}$}

a) $\mathrm{BDI}_{\mathrm{DIPP}} \mathrm{Ga}\left(100 \mathrm{mg}, 0.2 \mathrm{mmol}\right.$ ) was added to a solution of $\mathrm{MesPCl}_{2}$ (44 mg, $0.2 \mathrm{mmol}$ ) in toluene $(10 \mathrm{~mL})$ and potassium metal $(15 \mathrm{mg}, 0.4 \mathrm{mmol})$ was added and the solution stirred for 72 hours. ${ }^{1} \mathrm{H}$ NMR of the reaction mixture showed an intractable mixture of products.

b) $\mathrm{BDI}_{\mathrm{DIPP}} \mathrm{Ga}(100 \mathrm{mg}, 0.2 \mathrm{mmol})$ was added to a solution of $\mathrm{MesPCl}_{2}$ (44 mg, $0.2 \mathrm{mmol}$ ) in toluene $(10 \mathrm{~mL})$ and magnesium metal $(5 \mathrm{mg}, 0.2 \mathrm{mmol})$ was added and the solution stirred for 72 hours. ${ }^{1} \mathrm{H}$ NMR of the reaction mixture showed an intractable mixture of products.

\section{$\mathrm{CH}\left\{\mathrm{C}(\mathrm{Me}) \mathrm{N}\left(\mathrm{C}_{6} \mathrm{H}_{3}-2,6 \text { - }^{\mathrm{i}} \mathrm{Pr}_{2}\right)\right\}_{2} \mathrm{Ga}(\mathrm{H}) \mathrm{P}(\mathrm{H}) \mathrm{Mes}\left(\mathrm{BDI}_{\mathrm{DIPP}} \mathrm{Ga}(\mathrm{H}) \mathrm{P}(\mathrm{H}) \mathrm{Mes}, 66\right)$}

A solution of $\mathrm{MesPH}_{2}(156 \mathrm{mg}, 1 \mathrm{mmol})$ in toluene $(10 \mathrm{~mL})$ was added drop-wise to a solution of (BDI DIPP)Ga $(500 \mathrm{mg}, 1 \mathrm{mmol})$ in toluene $(10 \mathrm{~mL})$,

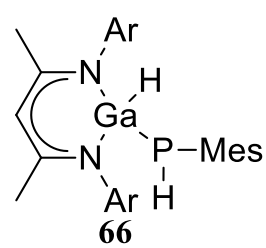
resulting in the loss of the yellow colour. The solution was stirred for $2 \mathrm{~h}$, and the solvent removed in vacuo. The resulting solid was crystallized from toluene at $-30{ }^{\circ} \mathrm{C}$ to give

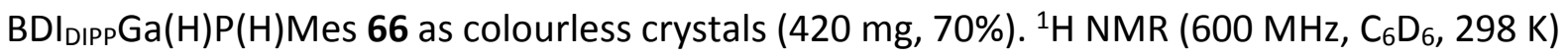
$\delta$ 7.25-7.16 (m, 6H, ArH), $6.67(s, 2 \mathrm{H}, m-\boldsymbol{H}), 5.65(d, J=20.6 \mathrm{~Hz}, 1 \mathrm{H}, \mathrm{GaH}), 4.78(s, 1 \mathrm{H}, \mathrm{CH})$, 3.60-3.51 $\left(m, 1 \mathrm{H}, \mathrm{CH}\left(\mathrm{CH}_{3}\right)_{2}\right), 3.37-3.29\left(m, 1 \mathrm{H}, \mathrm{CH}\left(\mathrm{CH}_{3}\right)_{2}\right), 3.26-3.17\left(m, 2 \mathrm{H}, \mathrm{CH}\left(\mathrm{CH}_{3}\right)_{2}\right), 2.90(d$, $\left.J_{P H}=200 \mathrm{~Hz}, 1 \mathrm{H}, \mathrm{PH}\right), 2.03\left(s, 3 \mathrm{H}, p-\mathrm{Ph}-\mathrm{CH}_{3}\right), 1.73-1.72\left(m, 9 \mathrm{H}, o-\mathrm{Ph}-\mathrm{CH}_{3} \mathrm{CH}\left(\mathrm{CH}_{3}\right)_{2}\right), 1.58(s, 6 \mathrm{H}$, $\left.\mathrm{C}\left(\mathrm{CH}_{3}\right)\right), 1.53\left(d, J=6.6 \mathrm{~Hz}, 3 \mathrm{H}, \mathrm{CH}\left(\mathrm{CH}_{3}\right)_{2}\right), 1.30-1.20\left(m, 6 \mathrm{H}, \mathrm{CH}\left(\mathrm{CH}_{3}\right)_{2}\right), 1.19(d, J=6.6 \mathrm{~Hz}, 3 \mathrm{H}$, $\left.\mathrm{CH}\left(\mathrm{CH}_{3}\right)_{2}\right), 1.15\left(d, J=6.9 \mathrm{~Hz}, 3 \mathrm{H}, \mathrm{CH}\left(\mathrm{CH}_{3}\right)_{2}\right), 1.12-1.07\left(m, 6 \mathrm{H}, \mathrm{CH}\left(\mathrm{CH}_{3}\right)_{2}\right) .{ }^{13} \mathrm{C} \mathrm{NMR}(151 \mathrm{MHz}$, $\left.\mathrm{C}_{6} \mathrm{D}_{6}\right) \delta 176.28,140.61,134.29,129.34,128.59,128.57,125.70,125.01,95.52,31.98,28.08$, 23.53, 23.46, 23.08, 20.97, 14.38. ${ }^{31}$ P NMR $\left(121 \mathrm{MHz}, \mathrm{C}_{6} \mathrm{D}_{6}, 298 \mathrm{~K}\right) \delta-187.5(d, J=5.1 \mathrm{~Hz})\left({ }^{1} \mathrm{H}\right.$ coupled - $d d, J_{P H}=200,20.6 \mathrm{~Hz}$ ). 


\section{o- $\mathrm{C}_{6} \mathrm{H}_{4}\left\{\mathrm{C}\left(\mathrm{CH}_{3}\right) \mathrm{N}-2,6-\mathrm{Pr}_{2} \mathrm{C}_{6} \mathrm{H}_{3}\right\}\left\{\mathrm{N}-2,6-{ }^{\mathrm{i}} \mathrm{Pr}_{2} \mathrm{C}_{6} \mathrm{H}_{3}\right\} A I M \mathrm{Me}_{2}$ (ArBDIDIPPAIMe 2,67 )}

ArBDIDIPP-H 13 (500 mg, $1.1 \mathrm{mmol})$ was dissolved in toluene $(10 \mathrm{~mL}$ ) and $2.0 \mathrm{M}$ trimethylaluminium $(0.55 \mathrm{~mL}, 1.1 \mathrm{mmol})$ was added. The solution was heated to $110{ }^{\circ} \mathrm{C}$ and stirred for 24 hours, the solvent was concentrated to

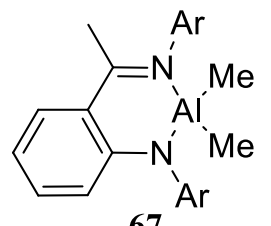
67 c.a. $3 \mathrm{~mL}$ and placed in the freezer at $-30^{\circ} \mathrm{C}$, at which point bright yellow crystals of ArBDI DIPPAIMe $_{2} 67$ formed (520 mg, 93\%). ${ }^{1} \mathrm{H}$ NMR (600 MHz, $\left.\mathrm{C}_{6} \mathrm{D}_{6}, 298 \mathrm{~K}\right) \delta$ 7.28-7.25 (m, 3H, $\operatorname{Ar}-\boldsymbol{H}), 7.21(d d, J=8.4,1.6 \mathrm{~Hz}, \operatorname{Ar}-\boldsymbol{H}), 7.13-7.07(m, 3 \mathrm{H}, \operatorname{Ar}-\boldsymbol{H}), 6.84(m, 1 \mathrm{H}, \operatorname{Ar}-\boldsymbol{H}), 6.50(d d, J=$ 8.8, 1.0 Hz, Ar-H), 6.38-6.33 (m, $1 \mathrm{H}, \mathrm{Ar}-\boldsymbol{H}$ ), 3.55 (app. sept, J = 6.9, $\left.6.6 \mathrm{~Hz}, 2 \mathrm{H}, \mathrm{CH}\left(\mathrm{CH}_{3}\right)_{2}\right), 3.21$ (app. sept, J = 6.9, 6.6 Hz, 2H, $\left.\mathrm{CH}\left(\mathrm{CH}_{3}\right)_{2}\right), 1.86\left(\mathrm{~s}, 3 \mathrm{H}, \mathrm{C}\left(\mathrm{CH}_{3}\right)\right), 1.37\left(d, \mathrm{~J}=6.9 \mathrm{~Hz}, 6 \mathrm{H}, \mathrm{CH}\left(\mathrm{CH}_{3}\right)_{2}\right)$, $1.30\left(d, J=6.6 \mathrm{~Hz}, 6 \mathrm{H}, \mathrm{CH}\left(\mathrm{CH}_{3}\right)_{2}\right), 1.14\left(d, J=6.9 \mathrm{~Hz}, 6 \mathrm{H}, \mathrm{CH}\left(\mathrm{CH}_{3}\right)_{2}\right), 0.96(d, J=6.9 \mathrm{~Hz}, 6 \mathrm{H}$, $\left.\mathrm{CH}\left(\mathrm{CH}_{3}\right)_{2}\right),-0.55\left(s, 6 \mathrm{H}, \mathrm{Al}\left(\mathrm{CH}_{3}\right)_{2}\right) .{ }^{13} \mathrm{C} \mathrm{NMR}\left(151 \mathrm{MHz}, \mathrm{C}_{6} \mathrm{D}_{6}\right) \delta 177.31,157.62,146.49,142.53$, 142.22 , 140.49, 134.12, 132.74, 126.56, 124.96, 124.94, 120.90, 118.21, 114.82, 28.67, 28.61, $25.64,25.24,24.75,24.61,23.10,-9.71$.

\section{$\left.0-\mathrm{C}_{6} \mathrm{H}_{4}\left\{\mathrm{C}\left(\mathrm{CH}_{3}\right) \mathrm{N}-2,6-{ }^{\mathrm{i}} \mathrm{Pr}_{2} \mathrm{C}_{6} \mathrm{H}_{3}\right\} \mathrm{N}-2,6-{ }^{\mathrm{i}} \mathrm{Pr}_{2} \mathrm{C}_{6} \mathrm{H}_{3}\right\} A \mathrm{Al}_{2}$ (ArBDI DIPPAll $_{2}, 68$ )}

Solid iodine (246 mg, $0.97 \mathrm{mmol}$ ) was added to a solution of ArBDIDIPPAIMe $_{2} 67$ (250 mg, $\left.0.48 \mathrm{mmol}\right)$ in toluene $(20 \mathrm{~mL})$ and stirred until

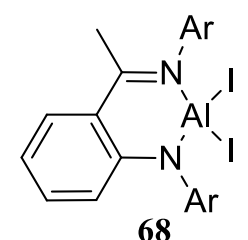

68 the purple colour faded (c.a. 16 hours). The volatiles were removed in vacuo and the residue was crystallised from toluene to give ArBDI $_{\text {DIPPAll }} 68$ as bright yellow crystals (310 mg, 83\%). ${ }^{1} \mathrm{H}$ NMR $\left(600 \mathrm{MHz}, \mathrm{C}_{6} \mathrm{D}_{6}, 298 \mathrm{~K}\right) \delta 7.25(\mathrm{~s}, 3 \mathrm{H}, \mathrm{Ar}-\boldsymbol{H}), 7.14-7.08(m, 4 \mathrm{H}, \mathrm{Ar}-\boldsymbol{H}), 6.80(d d d, J=$ 8.56, 6.81, $1.55 \mathrm{~Hz}, 1 \mathrm{H}, \operatorname{Ar}-\boldsymbol{H}), 6.59(d d, J=8.80,0.98 \mathrm{~Hz}, 1 \mathrm{H}, \operatorname{Ar}-\boldsymbol{H}), 6.37$ (ddd, J = 8.14, 6.83, $1.10 \mathrm{~Hz}, 1 \mathrm{H}, \mathrm{Ar}-\boldsymbol{H}$ ), 3.71 (app. sept, $J=6.9,6.6 \mathrm{~Hz}, 2 \mathrm{H}, \mathrm{CH}\left(\mathrm{CH}_{3}\right)_{2}$ ), 3.45 (app. sept, J = 6.9, 6.6 $\left.\mathrm{Hz}, 2 \mathrm{H}, \mathrm{CH}\left(\mathrm{CH}_{3}\right)_{2}\right), 1.90\left(\mathrm{~s}, 3 \mathrm{H}, \mathrm{C}\left(\mathrm{CH}_{3}\right)\right), 1.46\left(d, J=6.9 \mathrm{~Hz}, 6 \mathrm{H}, \mathrm{CH}\left(\mathrm{CH}_{3}\right)_{2}\right), 1.43(d, J=6.6 \mathrm{~Hz}, 6 \mathrm{H}$, $\left.\mathrm{CH}\left(\mathrm{CH}_{3}\right)_{2}\right), 1.07\left(d, J=6.9 \mathrm{~Hz}, 6 \mathrm{H}, \mathrm{CH}\left(\mathrm{CH}_{3}\right)_{2}\right), 0.94\left(d, J=6.9 \mathrm{~Hz}, 6 \mathrm{H}, \mathrm{CH}\left(\mathrm{CH}_{3}\right)_{2}\right) .{ }^{13} \mathrm{C} \mathrm{NMR}$ (151 $\left.\mathrm{MHz}, \mathrm{C}_{6} \mathrm{D}_{6}\right) \delta 181.03,156.55,146.90,143.18,140.25,138.80,135.54,132.90,129.30,127.70$, 125.59, 125.42, 121.85, 118.58, 117.56, 29.68, 29.53, 25.95, 25.79, 25.45, 24.53, 24.27. 


\section{Attempted synthesis of $o-\mathrm{C}_{6} \mathrm{H}_{4}\left\{\mathrm{C}\left(\mathrm{CH}_{3}\right) \mathrm{N}-2,6-\mathrm{Pr}_{2} \mathrm{C}_{6} \mathrm{H}_{3}\right\}$ NN-2,6- $\left.\mathrm{Pr}_{2} \mathrm{C}_{6} \mathrm{H}_{3}\right\} \mathrm{Al}$ (ArBDIDIPpAl, 69)}

ArBDIDIPPAll $_{2} 68(250 \mathrm{mg}, 0.34 \mathrm{mmol})$ in toluene $(10 \mathrm{~mL})$ was added to a suspension of finely divided potassium metal $(27 \mathrm{mg}, 0.68 \mathrm{mmol}$ ) in toluene $(10 \mathrm{~mL})$ and stirred for 2 hours. The solution was filtered through celite and

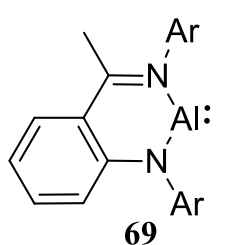
69 concentrated in vacuo to c.a. $2 \mathrm{~mL}$ and stored in the freezer at $-30^{\circ} \mathrm{C} .{ }^{1} \mathrm{H}$ NMR of the reaction showed a mixture of products had formed, and average quality crystals postulated as complex 71 were obtained from the reaction mixture, but complex 69 was not successfully isolated.

\section{o- $\mathrm{C}_{6} \mathrm{H}_{4}\left\{\mathrm{C}\left(\mathrm{CH}_{3}\right) \mathrm{N}\left(\mathrm{AlMe}_{3}\right)-2,6-\mathrm{Pr}_{2} \mathrm{C}_{6} \mathrm{H}_{3}\right\}$ NH-2,6-i $\left.\mathrm{Pr}_{2} \mathrm{C}_{6} \mathrm{H}_{3}\right\}$ (ArBDIDIPP-H.AlMe, 70$)$}

This compound was prepared following adapted literature procedures. ${ }^{287}$ ArBDIDIPP-H 13 (500 mg, $1.1 \mathrm{mmol}$ ) was dissolved in toluene $(10 \mathrm{~mL})$ and $2.0 \mathrm{M}$ trimethylaluminium $(0.55 \mathrm{~mL}, 1.1 \mathrm{mmol})$ was added. The solution was stirred for 2 hours, the solvent was concentrated to c.a. $2 \mathrm{~mL}$

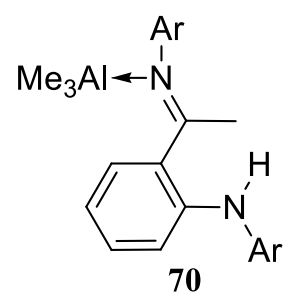
and placed in the freezer at $-30{ }^{\circ} \mathrm{C}$, at which point colourless crystals of $\mathrm{ArBDI}_{\mathrm{DIPPH}} \mathrm{AlMe}_{3} \mathbf{7 0}$ formed (385 mg, 67\%). A clean ${ }^{1} \mathrm{H}$ NMR spectrum of 70 could not be obtained as it partially dissociates to 13 and $\mathrm{AlMe}_{3}$ in solution at room temperature, but key peaks include: ${ }^{1} \mathrm{H}$ NMR $\left(600 \mathrm{MHz}, \mathrm{C}_{6} \mathrm{D}_{6}, 298 \mathrm{~K}\right) \delta 5.02$ (br. s, $\left.1 \mathrm{H}, \mathrm{NH}\right)$ and $-0.53\left(\mathrm{~s}, 9 \mathrm{H}, \mathrm{Al}\left(\mathrm{CH}_{3}\right)_{3}\right.$ bound)

\section{$\mathrm{CH}\left\{\mathrm{C}(\mathrm{Me}) \mathrm{N}\left(\mathrm{C}_{6} \mathrm{H}_{2}-2,6-\left(\mathrm{CHPh}_{2}\right)_{2}-4-\mathrm{Me}\right)\right\}_{2} \mathrm{AlMe}_{2}\left(\mathrm{BDI}_{\mathrm{Ar}} * \mathrm{AlMe}, \mathrm{M}_{2}\right)$}

$\mathrm{BDI}_{\mathrm{Ar} *-\mathrm{H}}(1.0 \mathrm{~g}, 1.0 \mathrm{mmol})$ was dissolved in toluene $(15 \mathrm{~mL})$ in an ampule and 2.0M AlMe $(0.5 \mathrm{~mL}, 1.0 \mathrm{mmol})$ was added. The solution was refluxed for $16 \mathrm{~h}$ to

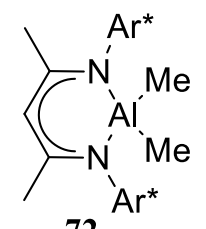

72 give a white precipitate, the solvent was removed to give 72 as a white powder (1.02 g, 94\%). ${ }^{1} \mathrm{H}$ NMR $\left(600 \mathrm{MHz}, \mathrm{C}_{6} \mathrm{D}_{6}, 298 \mathrm{~K}\right) \delta 7.36(d, J=7.2 \mathrm{~Hz}, 8 \mathrm{H}, \mathrm{Ph}-\boldsymbol{H}), 7.25(d, J=7.9 \mathrm{~Hz}, 8 \mathrm{H}, \mathrm{Ph}-\boldsymbol{H})$, 7.06-7.00 (m, 8H, Ph-H), 6.97-6.94 (m, 12H, Ph-H), $6.93(t, J=7.17 \mathrm{~Hz}, 4 \mathrm{H}, \boldsymbol{p}-\mathrm{Ph}-\boldsymbol{H}), 6.42(s, 4 \mathrm{H}$, $\left.\mathrm{CHPh}_{2}\right), 4.51(s, 1 \mathrm{H}, \mathrm{CH}), 1.87\left(\mathrm{~s}, 6 \mathrm{H}, \mathrm{Ph}-\mathrm{CH}_{3}\right), 0.39\left(\mathrm{~s}, 6 \mathrm{H}, \mathrm{C}\left(\mathrm{CH}_{3}\right)\right), 0.11\left(\mathrm{~s}, 6 \mathrm{H}, \mathrm{Al}\left(\mathrm{CH}_{3}\right)_{2}\right) .{ }^{13} \mathrm{C}$ NMR $\left(151 \mathrm{MHz}, \mathrm{C}_{6} \mathrm{D}_{6}\right) \delta 173.36,145.80,142.82,142.59,141.34,135.58,131.73,130.95$, $130.10,128.72,126.74,126.26,51.78,23.03,21.44,-5.01$. 


\section{Attempted synthesis of $\mathrm{CH}\left\{\mathrm{C}(\mathrm{Me}) \mathrm{N}\left(\mathrm{C}_{6} \mathrm{H}_{2}-2,6-\left(\mathrm{CHPh}_{2}\right)_{2}-4-\mathrm{Me}\right)\right\}_{2} \mathrm{All}_{2}\left(\mathrm{BDI}_{\mathrm{Ar}} * \mathrm{AlI}_{2}, 73\right)$}

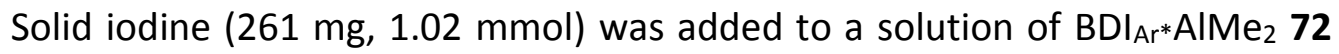
$(500 \mathrm{mg}, 0.51 \mathrm{mmol})$ in toluene $(20 \mathrm{~mL})$ and stirred for 3 days at room temperature. ${ }^{1} \mathrm{H}$ NMR of the reaction mixture showed that the mixed methyl

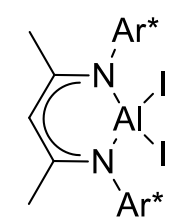
73 iodide species $\mathrm{BDI}_{\mathrm{Ar}} \mathrm{Al}(\mathrm{Me}) \mathrm{I}(\mathbf{7 5})$ had formed (based on integration of the Al-Me resonance). Refluxing the solution in a sealed ampule for 1 week did not result in a measurable formation of 73, though a small amount (c.a. 5\%) of a new product was observed in the reaction mixture by ${ }^{1} \mathrm{H}$ NMR spectroscopy.

\section{General procedure for reactivity studies}

Complex 58, 63 or $66(20 \mathrm{mg})$ and 1 equivalent of the reagent being investigated were weighed into a vial in a glove box, $\mathrm{C}_{6} \mathrm{D}_{6}(500 \mu \mathrm{L})$ was added and the reagents dissolved and transferred to an NMR tube sealed with a Youngs tap and monitored by ${ }^{1} \mathrm{H}$ and ${ }^{31} \mathrm{P} N M R$ compared to an NMR spectrum at the initial time. The NMR tubes were heated (if required) in a custom aluminium NMR tube heating block, controlled by thermo-probe.

\section{$\mathrm{CH}\left\{\mathrm{C}(\mathrm{Me}) \mathrm{N}\left(\mathrm{C}_{6} \mathrm{H}_{2}-2,6-\left(\mathrm{CHPh}_{2}\right)_{2}-4-\mathrm{Me}\right)\right\}_{2} \mathrm{Al}(\mathrm{Cl}) \mathrm{N}\left(4-\mathrm{NO}_{2}-\mathrm{C}_{6} \mathrm{H}_{4}\right) \mathrm{C}(\mathrm{O}) \mathrm{P}(\mathrm{H}) \mathrm{Mes}$} (BDI $\left.\left.{ }_{\text {DIPPAI(Cl)N(4-NO }}-\mathrm{Ph}\right) \mathrm{C}(\mathrm{O}) \mathrm{P}(\mathrm{H}) \mathrm{Mes}, 76\right)$

4-Nitrophenylisocyanate $(52 \mathrm{mg}, 0.32 \mathrm{mmol}$ ) was added to a solution of BDIDIPPAl(PHMes)Cl $58(200 \mathrm{mg}, 0.32 \mathrm{mmol})$ in toluene $(10$ $\mathrm{mL}$ ). The mixture was stirred for $16 \mathrm{~h}$ and the solvent concentrated to c.a. $3 \mathrm{~mL}$ and placed in the freezer at $-30{ }^{\circ} \mathrm{C}$, at which point colourless

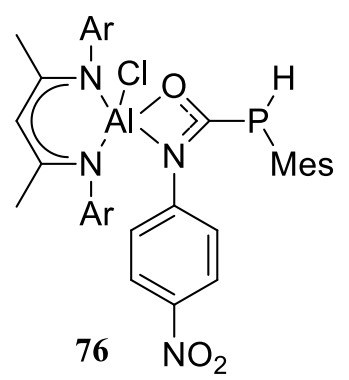
crystals of 76 formed (180 mg, 71.4\%). ${ }^{1} \mathrm{H}$ NMR (600 MHz, $\left.\mathrm{C}_{6} \mathrm{D}_{6}, 298 \mathrm{~K}\right) \delta 7.71(d, J=8.6 \mathrm{~Hz}$, 2H, Ph-H), 7.06-6.96 (m, 6H, Ar-H), $6.50(s, 2 \mathrm{H}, m-\operatorname{Ar}-\boldsymbol{H}), 6.16(d, J=8.6 \mathrm{~Hz}, 2 \mathrm{H}, \mathrm{Ph}-\boldsymbol{H}), 4.91(s$, $1 \mathrm{H}, \mathrm{CH}), 4.31\left(d, J_{\mathrm{PH}}=240 \mathrm{~Hz}, 1 \mathrm{H}, \mathrm{PH}\right), 3.71-3.62\left(m, 1 \mathrm{H}, \mathrm{CH}\left(\mathrm{CH}_{3}\right)_{2}\right), 3.48($ sept $, J=6.9 \mathrm{~Hz}, 1 \mathrm{H}$, $\left.\mathrm{CH}\left(\mathrm{CH}_{3}\right)_{2}\right), 3.16-3.06\left(m, 2 \mathrm{H}, \mathrm{CH}\left(\mathrm{CH}_{3}\right)_{2}\right), 2.08\left(s, 3 \mathrm{H}, \mathrm{Ar}-p-\mathrm{CH}_{3}\right), 2.04\left(s, 6 \mathrm{H}, \mathrm{Ar}-0-\mathrm{CH}_{3}\right), 1.50(s$, $\left.3 \mathrm{H}, \mathrm{C}\left(\mathrm{CH}_{3}\right)\right), 1.46\left(\mathrm{~s}, 3 \mathrm{H}, \mathrm{C}\left(\mathrm{CH}_{3}\right)\right), 1.38\left(d, J=6.6 \mathrm{~Hz}, 3 \mathrm{H}, \mathrm{CH}\left(\mathrm{CH}_{3}\right)_{2}\right), 1.29-1.25\left(m, 6 \mathrm{H}, \mathrm{CH}\left(\mathrm{CH}_{3}\right)_{2}\right)$, 
$1.20\left(d, J=6.9 \mathrm{~Hz}, 3 \mathrm{H}, \mathrm{CH}\left(\mathrm{CH}_{3}\right)_{2}\right), 1.12-1.09\left(m, 6 \mathrm{H}, \mathrm{CH}\left(\mathrm{CH}_{3}\right)_{2}\right), 1.04-1.02\left(m, 6 \mathrm{H}, \mathrm{CH}\left(\mathrm{CH}_{3}\right)_{2}\right) .{ }^{31} \mathrm{P}$ NMR (121 MHz, $\left.\mathrm{C}_{6} \mathrm{D}_{6}, 298 \mathrm{~K}\right) \delta$-91.2. 


\section{Appendix A: NMR Spectra of Novel Compounds}

\section{A.1 $\mathrm{CH}\left\{\mathrm{C}(\mathrm{Me}) \mathrm{N}\left(\mathrm{C}_{6} \mathrm{H}_{3}-2,6-{ }^{\mathrm{i}} \mathrm{Pr}_{2}\right)\right\}_{2} \mathrm{Ga}\left(\mathrm{CH}_{2} \mathrm{TMS}\right) \mathrm{NNCTMS}$ (19)}
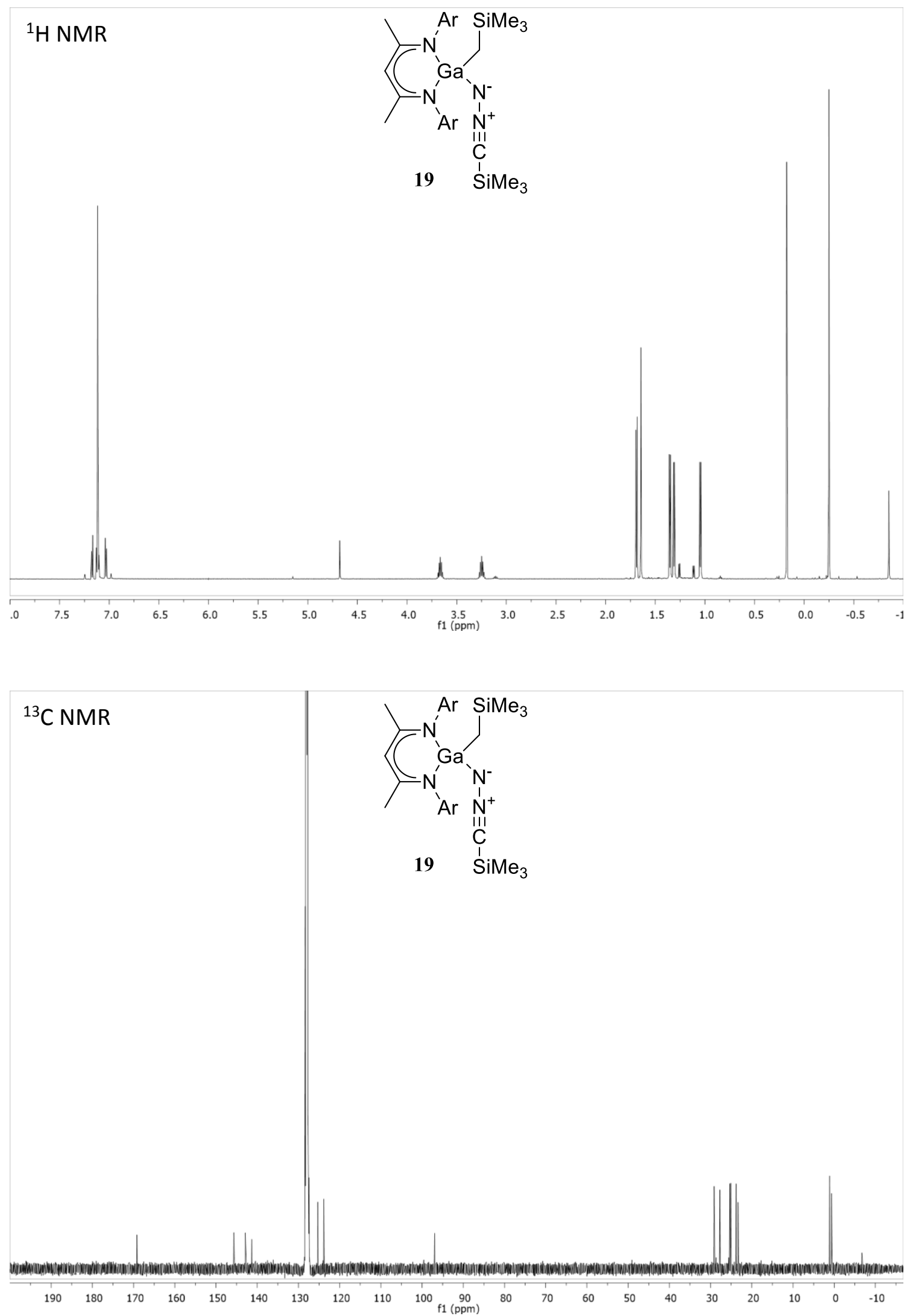


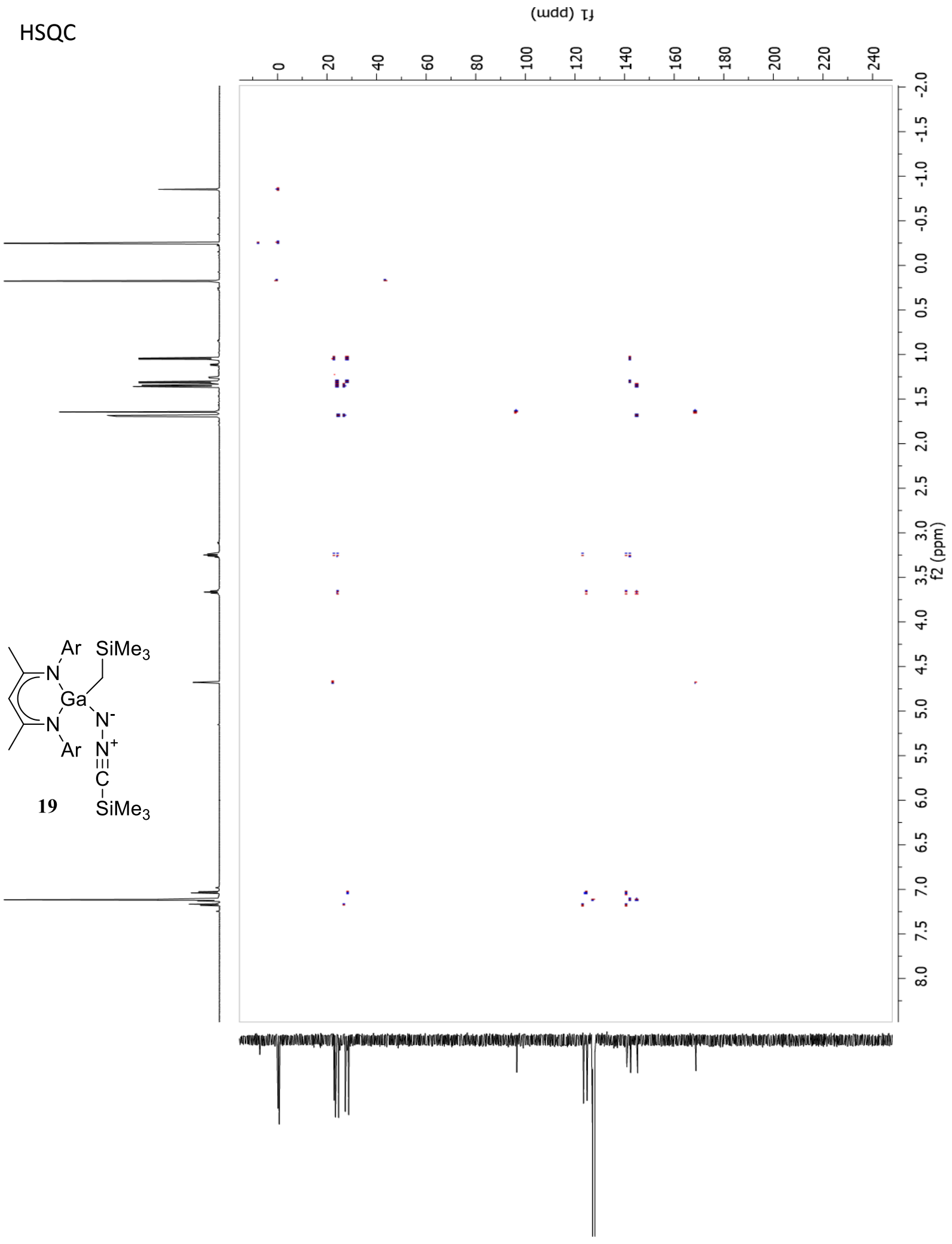


A.2 BDIDIPPGa(CH ${ }_{2}$ TMS)N(H)NC (21)
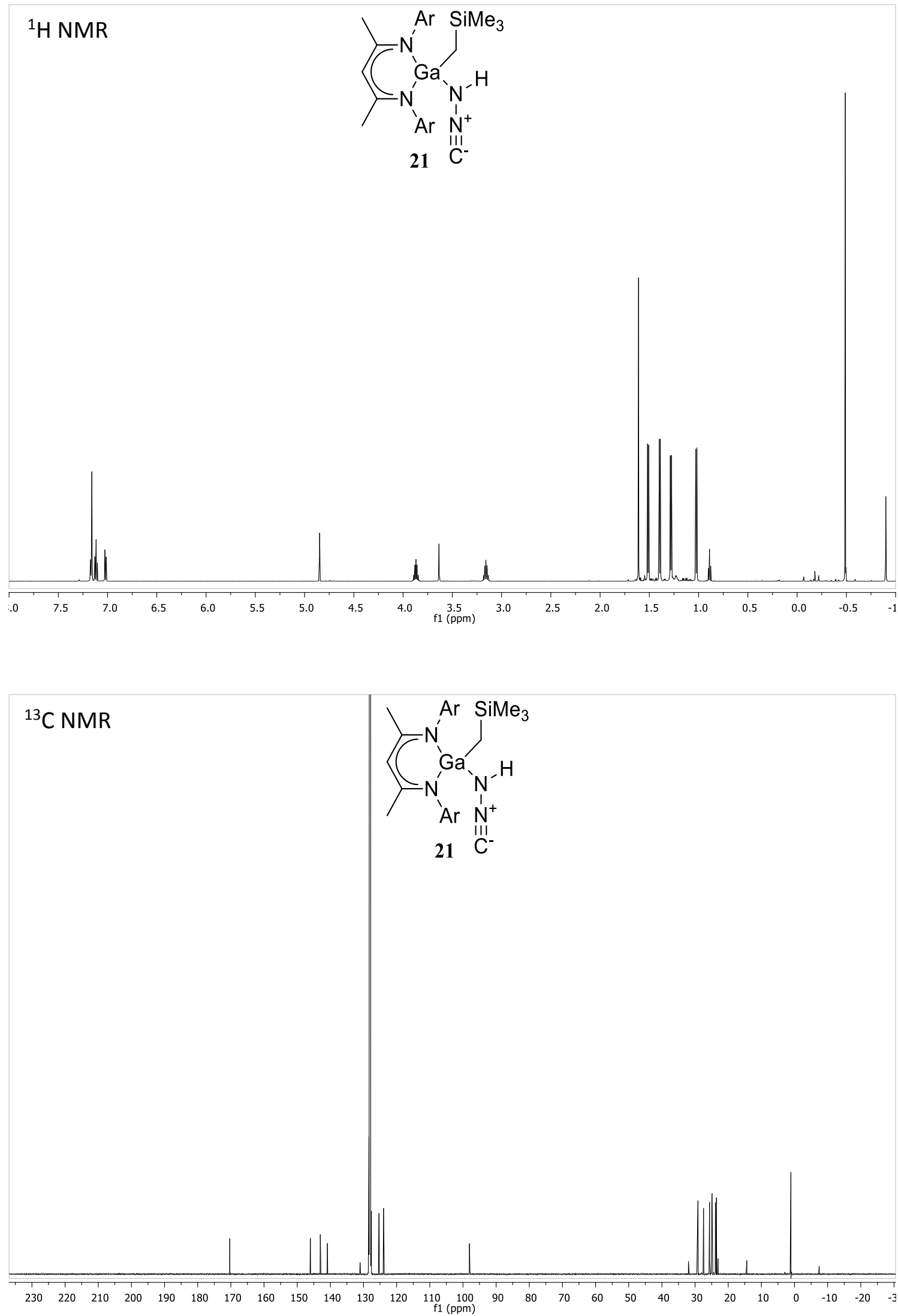


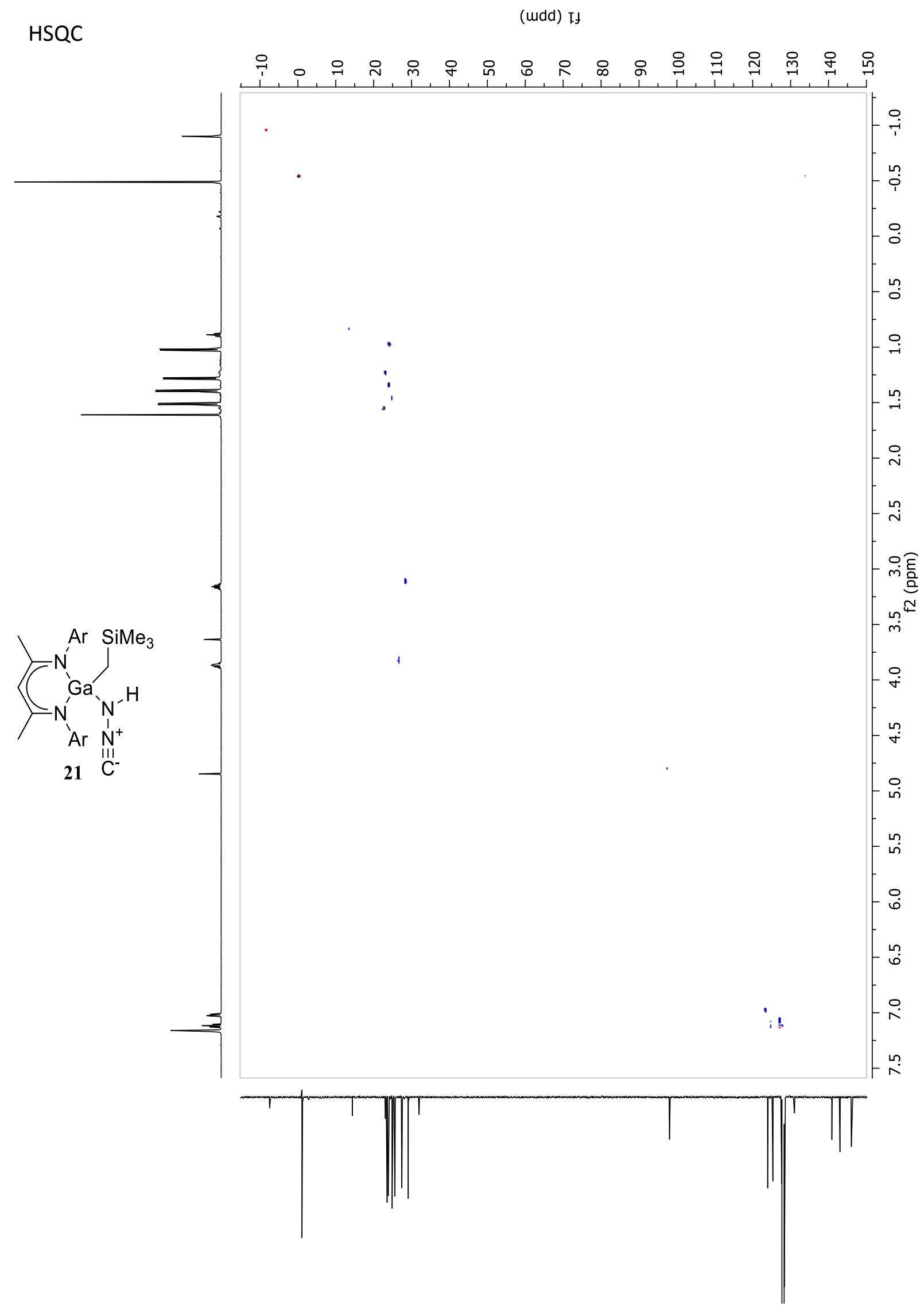




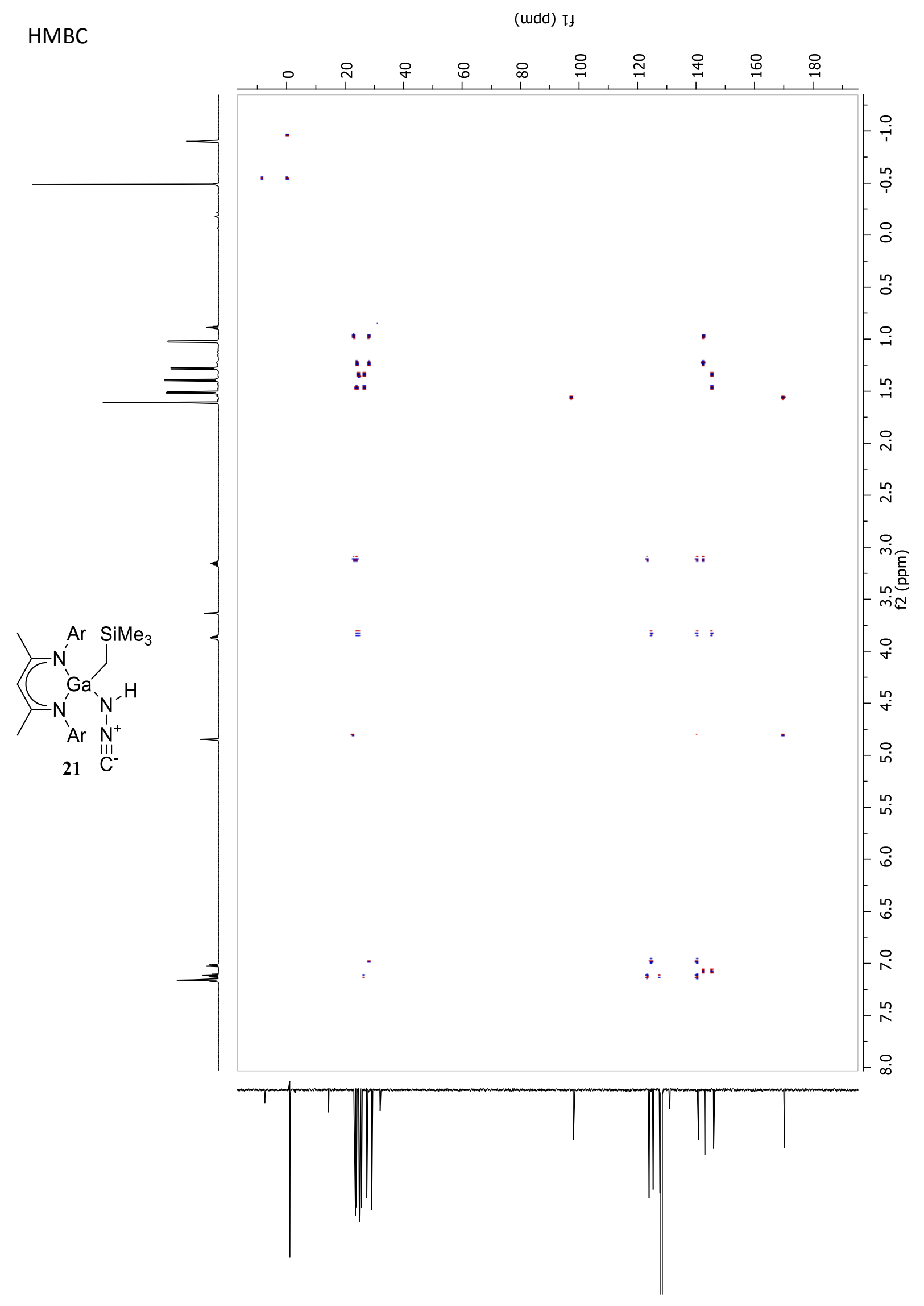




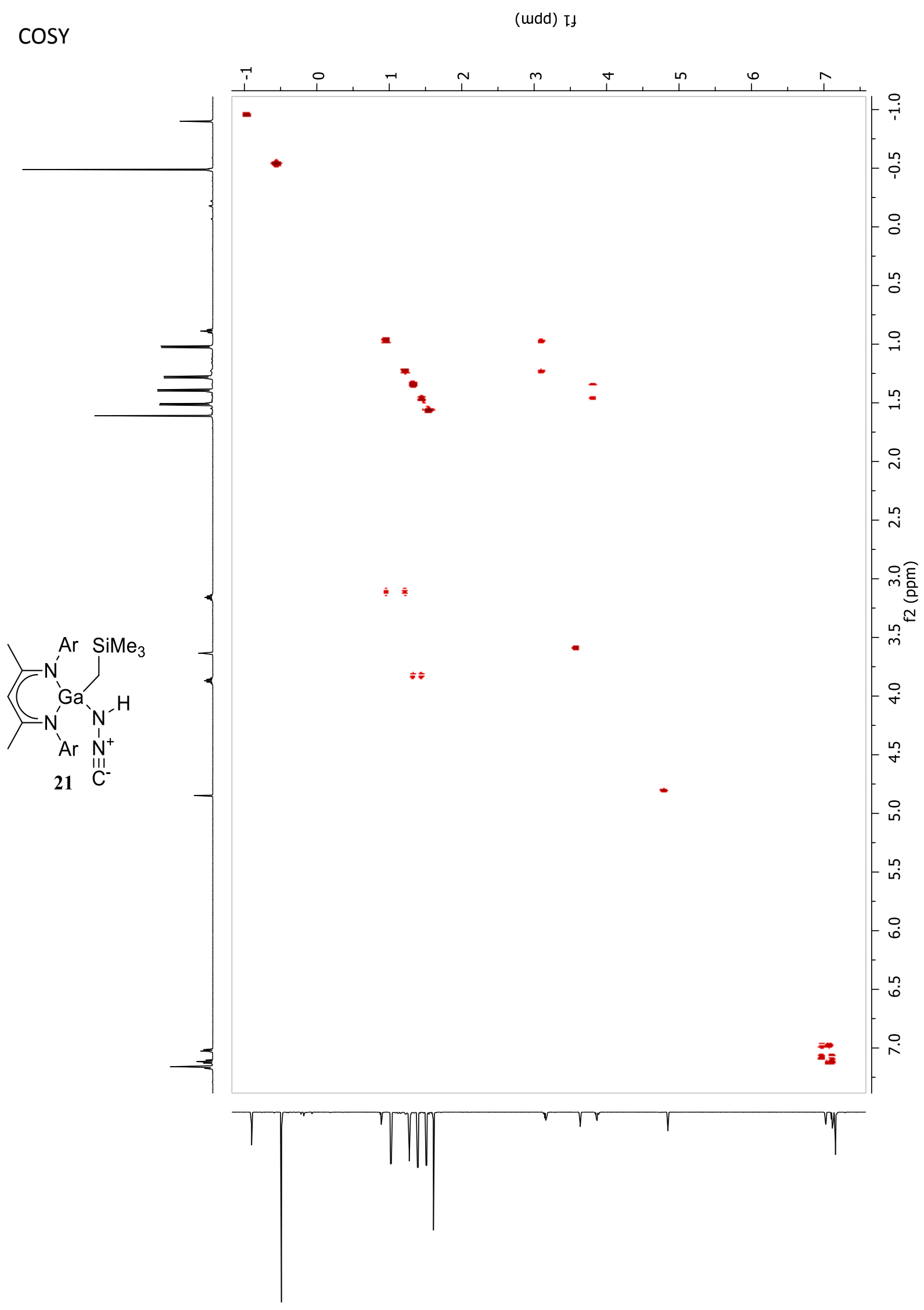




\section{A.3 BDIDIPPGa(FI)NNFI (34)}
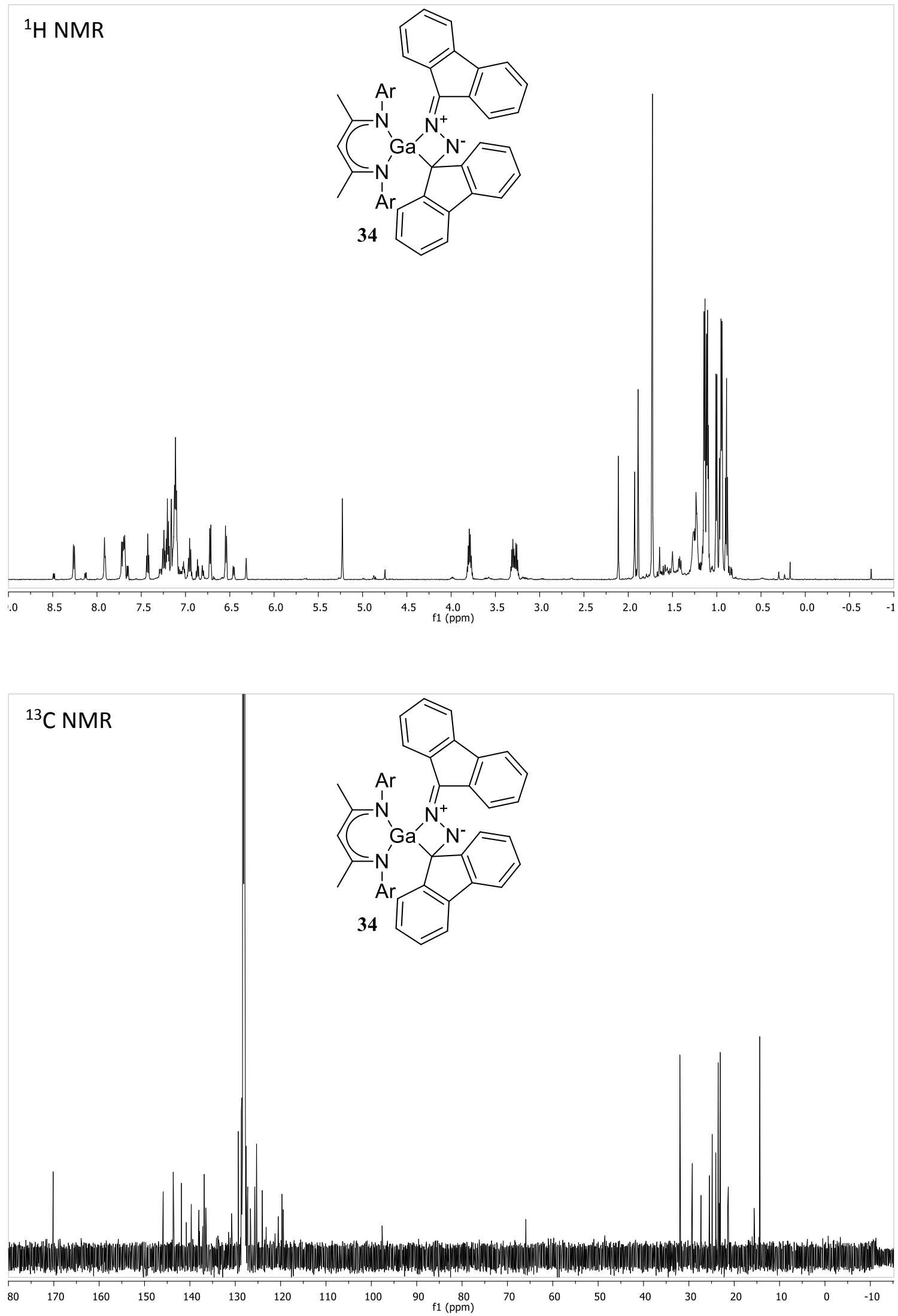
A.4 ArBDIDIPPGa (10)
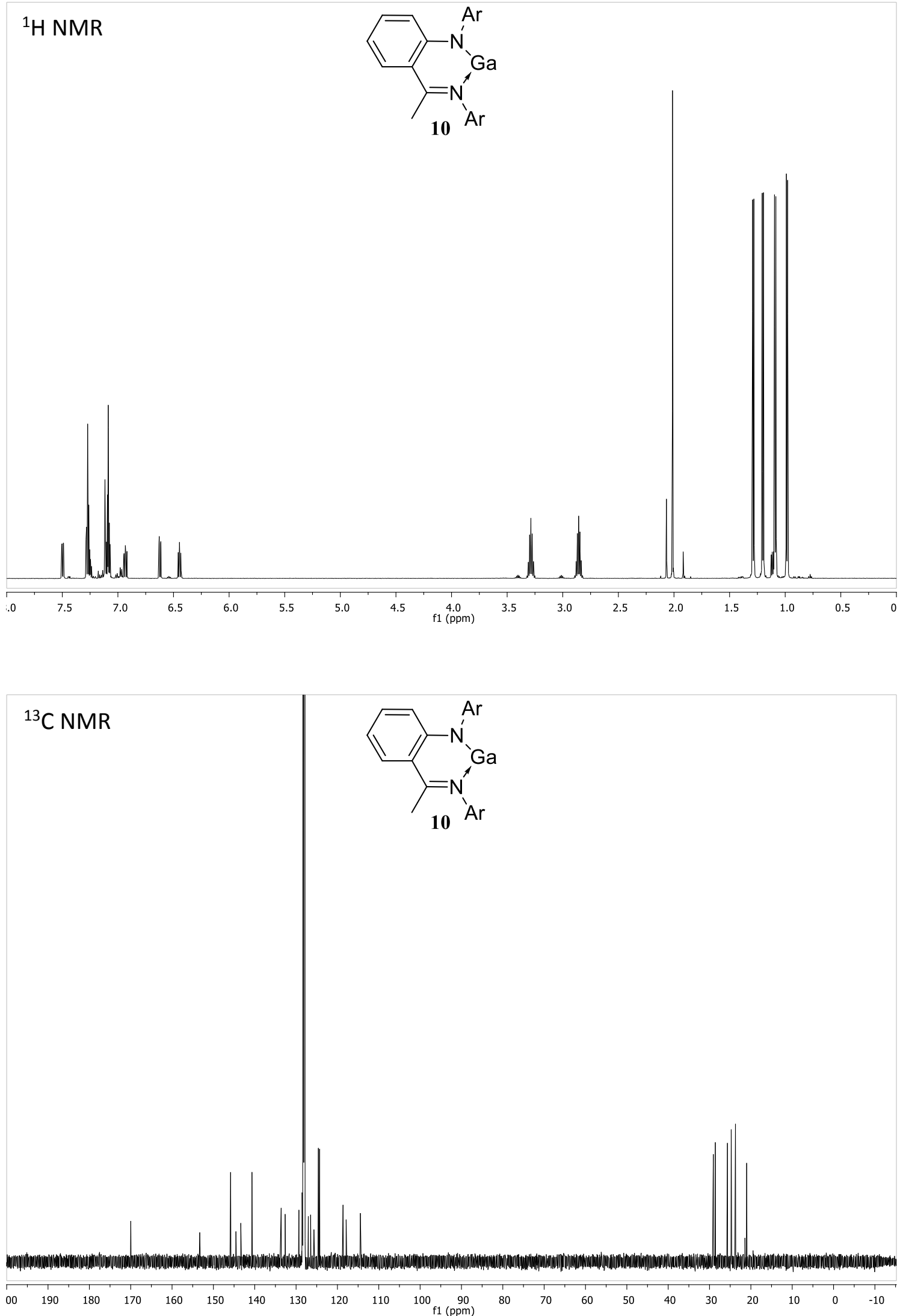


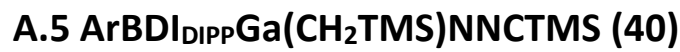

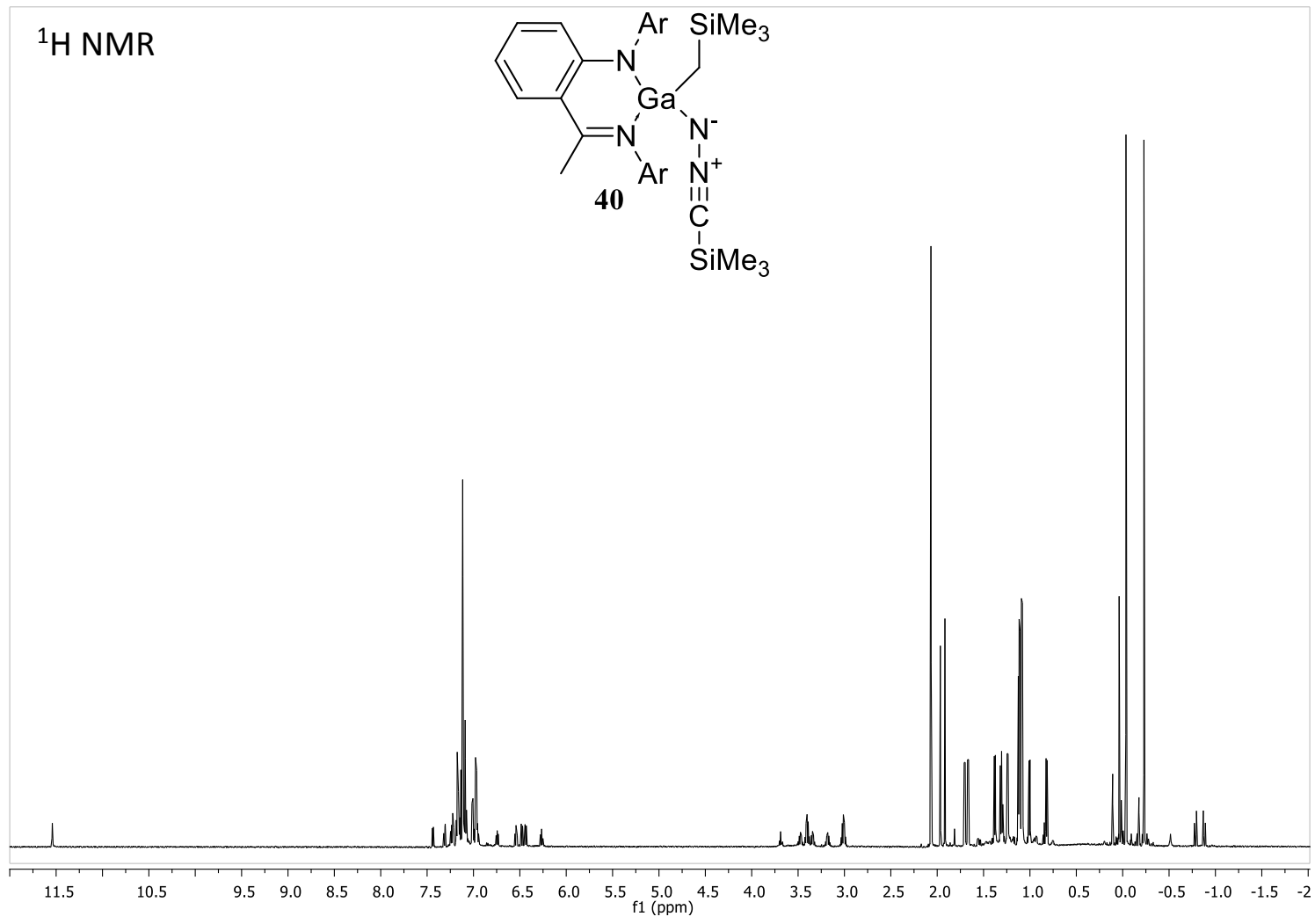

*NMR contains ArBDIDIPP-H decomposition 


\section{A. $6 \mathrm{BDI}_{\mathrm{Ar}} * \mathrm{Ga}$ (11)}
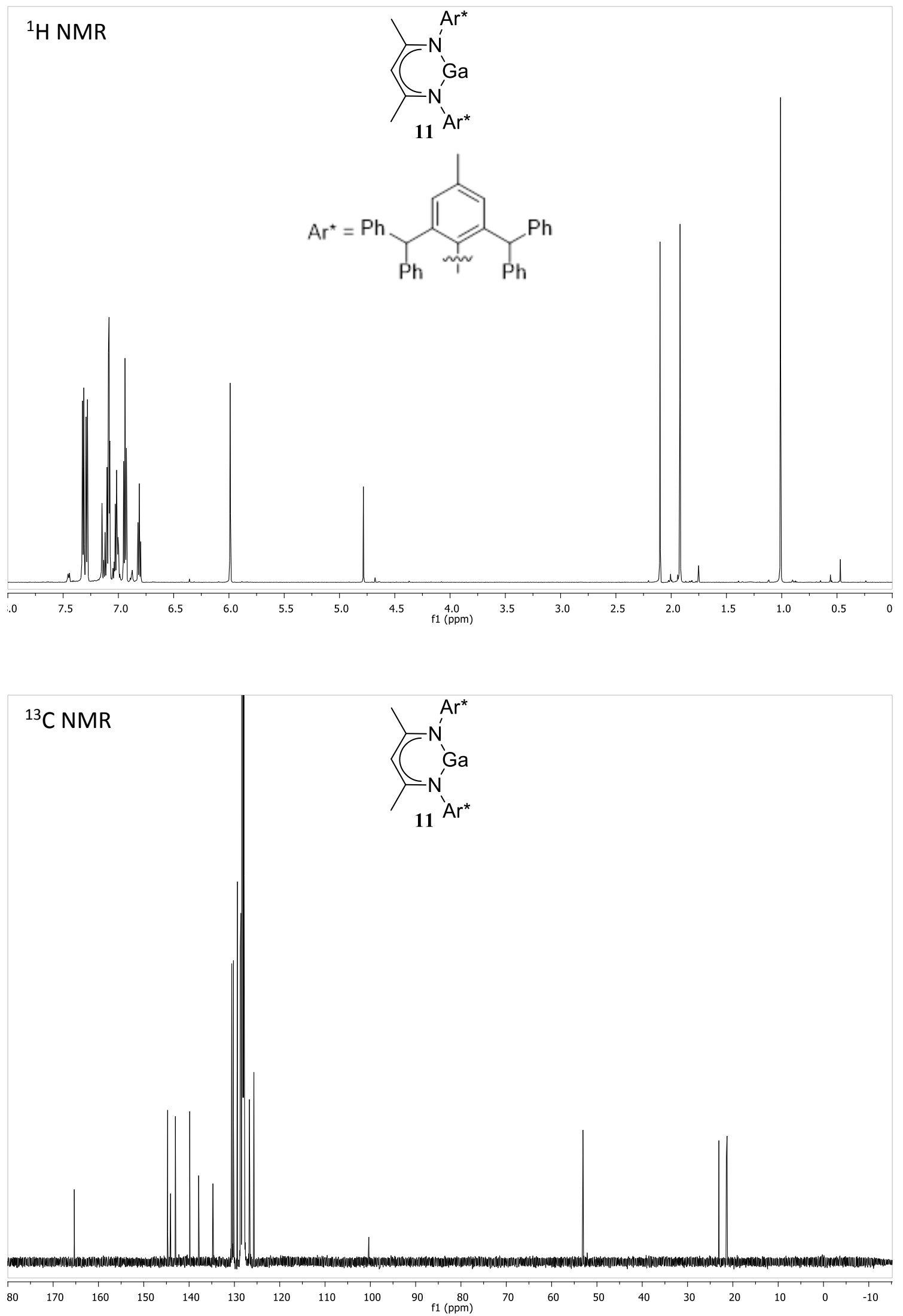
A.7 $\mathrm{BDI}_{\mathrm{Ar}} * \mathrm{Ga}(\mathrm{H}) \mathrm{C}\left(\mathrm{N}_{2}\right) \mathrm{TMS}(41)$
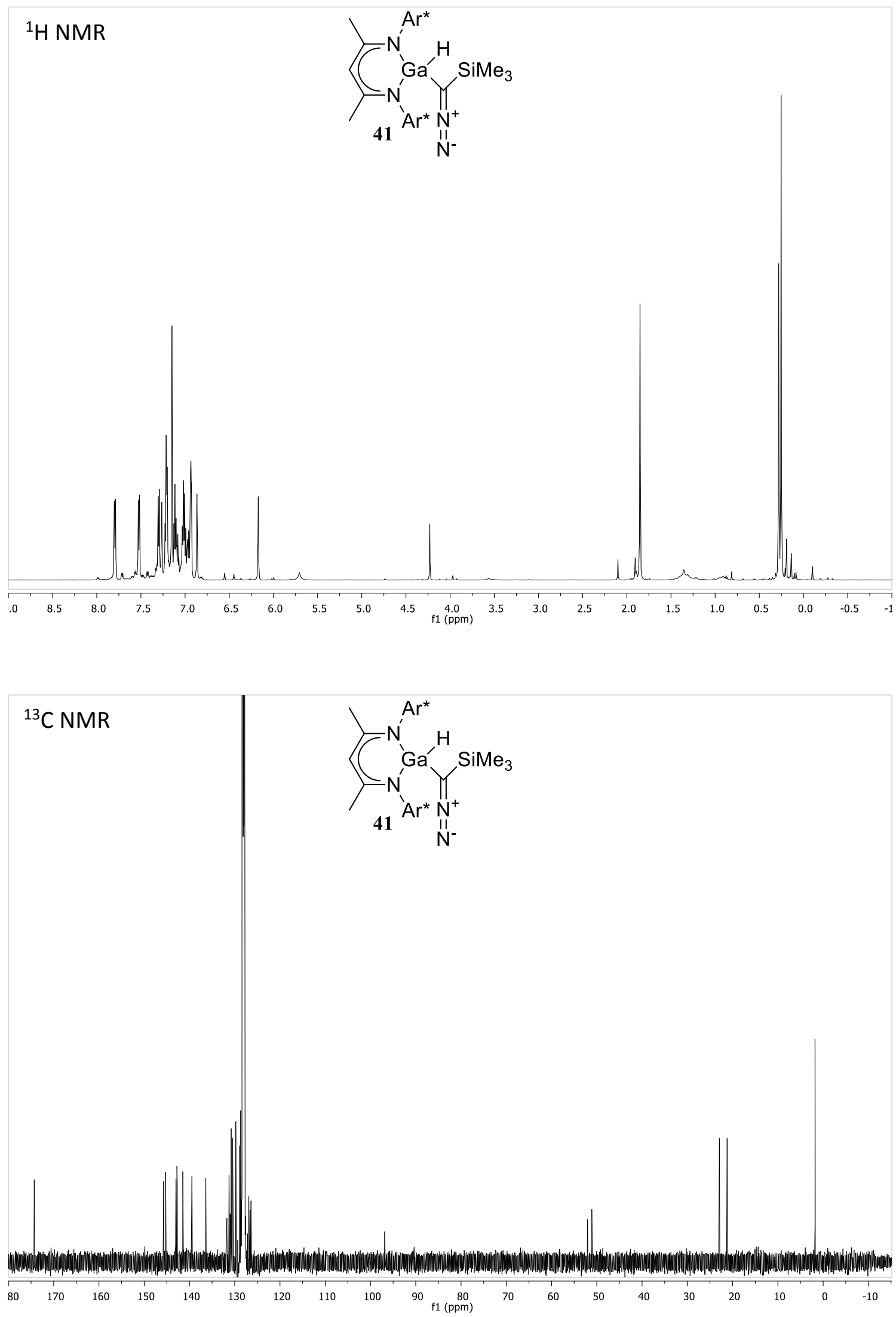
A.8 $\mathrm{BDI}_{A \mathrm{Ar}}-\mathrm{H}(15)$
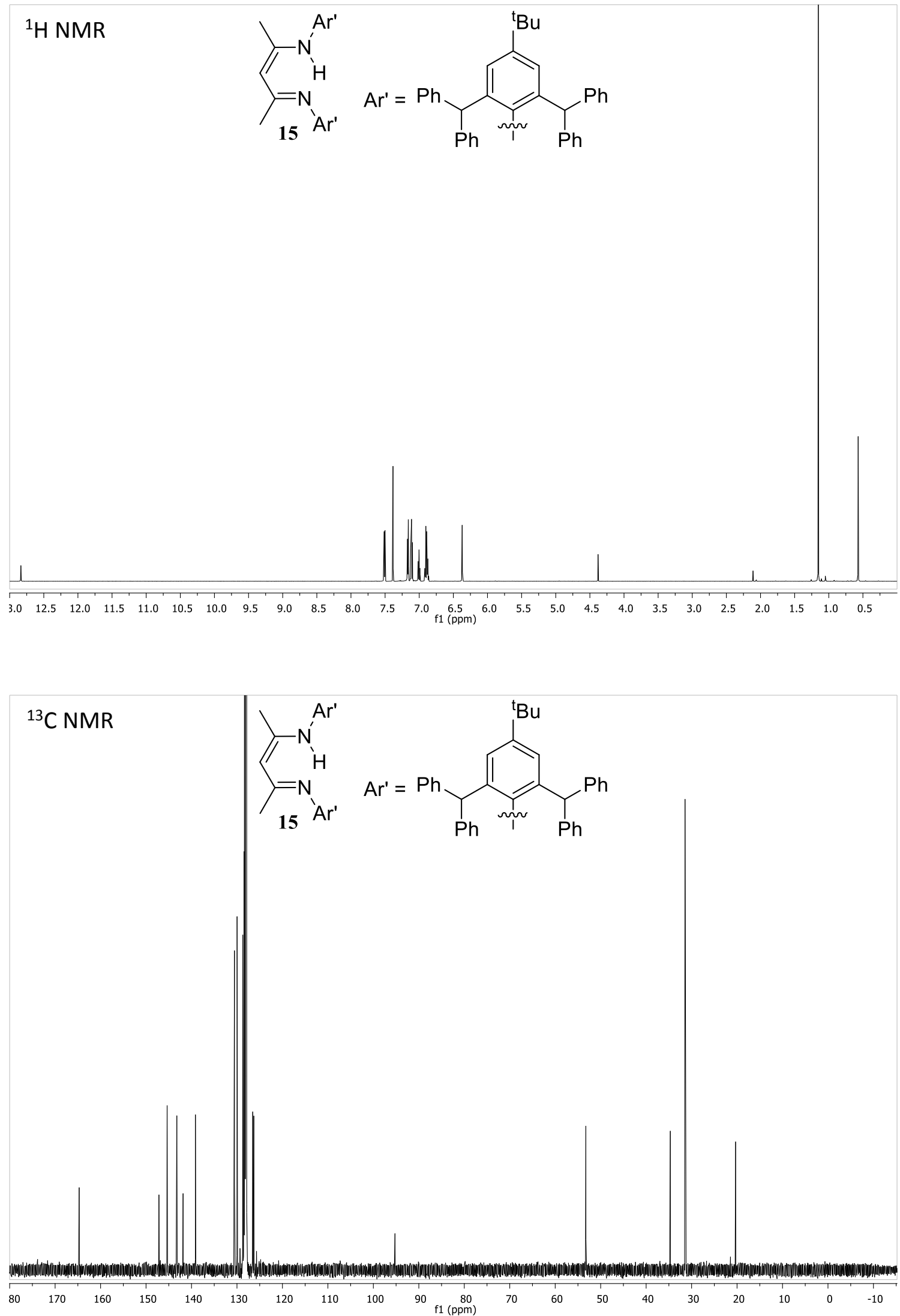


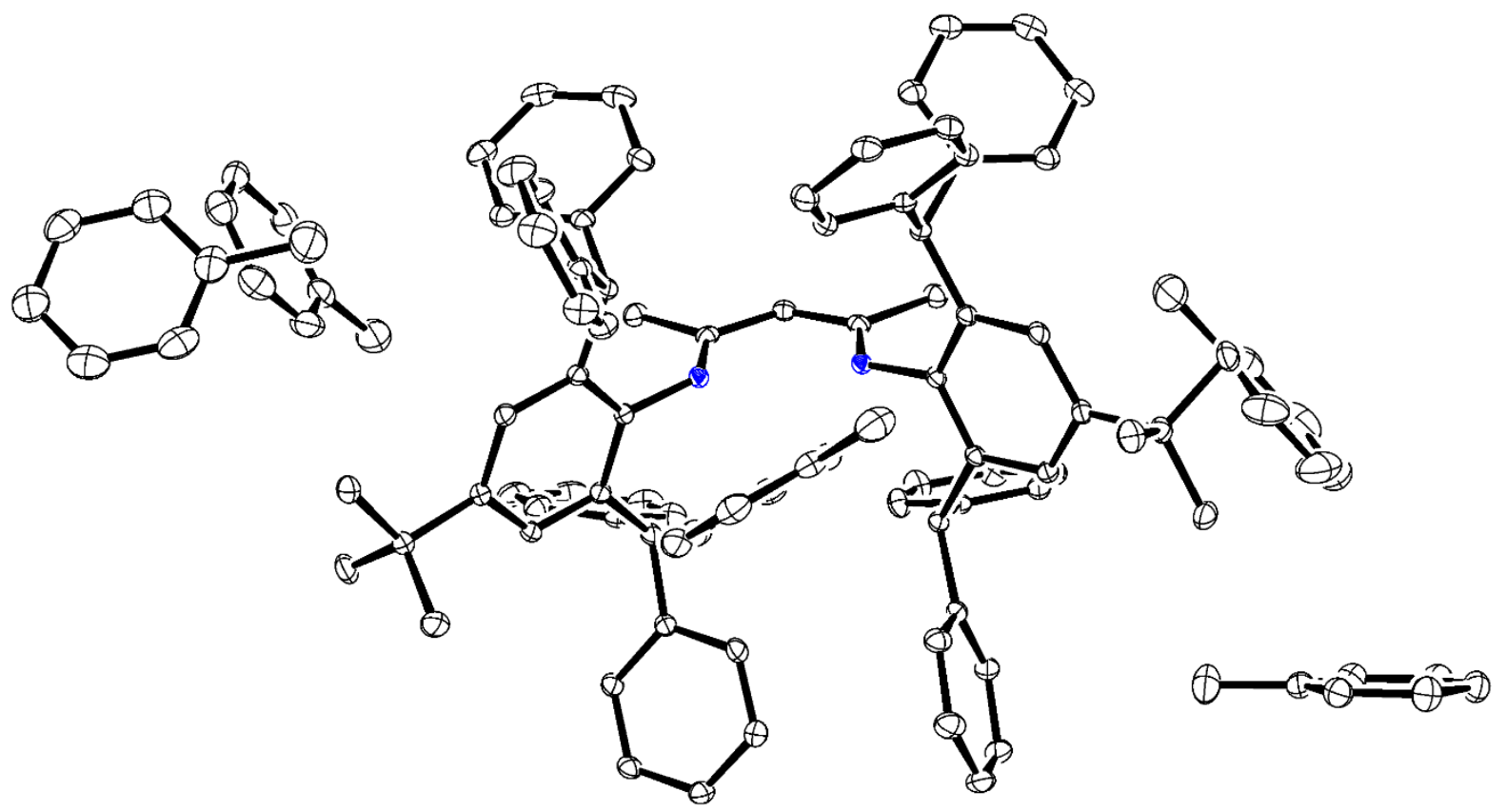

ORTEP plot of $\mathrm{BDI}_{\mathrm{Ar}}-\mathrm{H}$ 15. Ellipsoids at $30 \%, \mathrm{H}$ atoms omitted and selected $\mathrm{C}$ atoms in wire frame for clarity. 
A.9 $\mathrm{BDI}_{\mathrm{Ar}} \mathrm{Ga}$ (12)

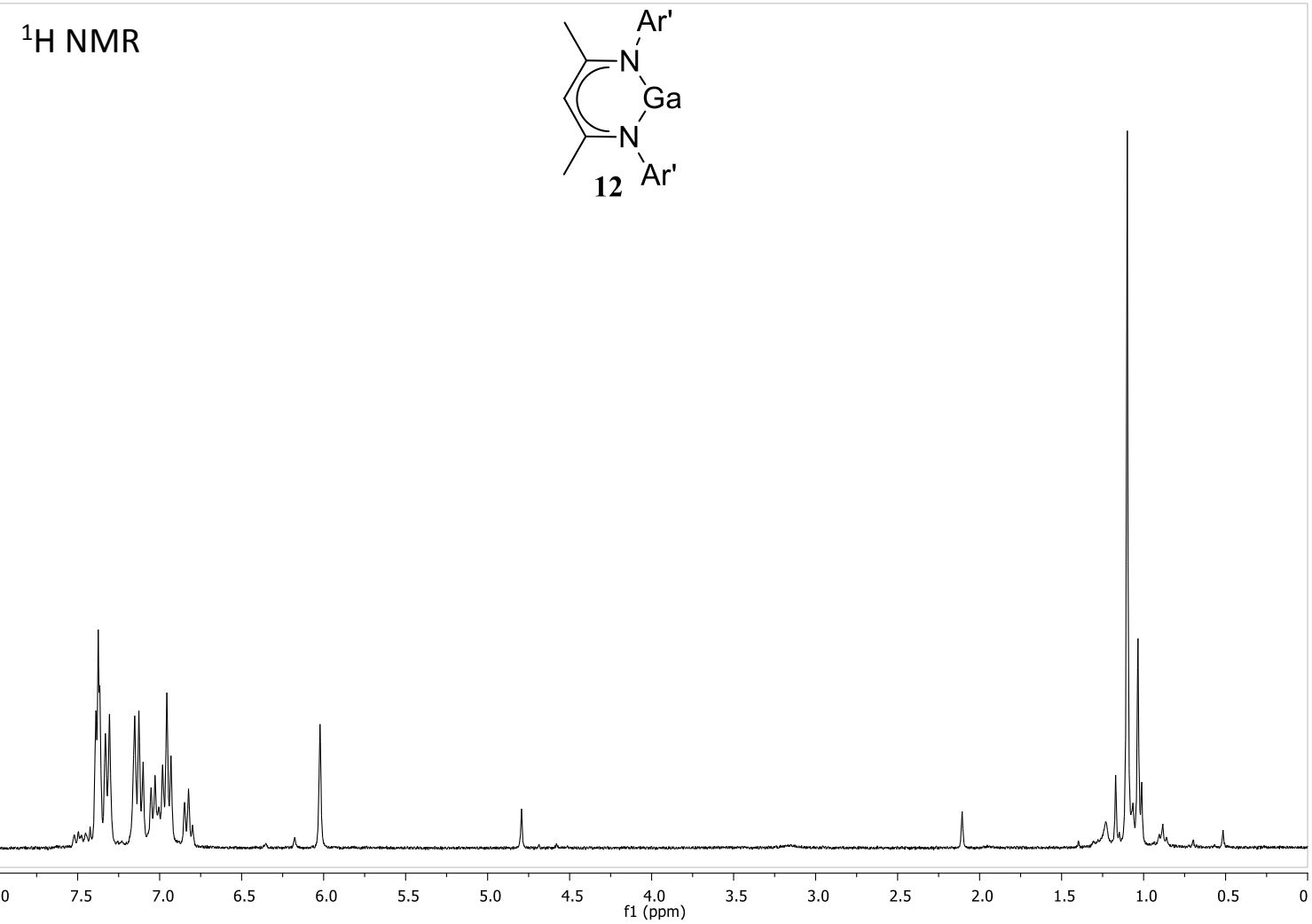




\section{A.10 BDI ${ }_{\mathrm{Ar}} \mathrm{Ga}(\mathrm{H}) \mathrm{C}\left(\mathrm{N}_{2}\right) \mathrm{TMS}(45)$}
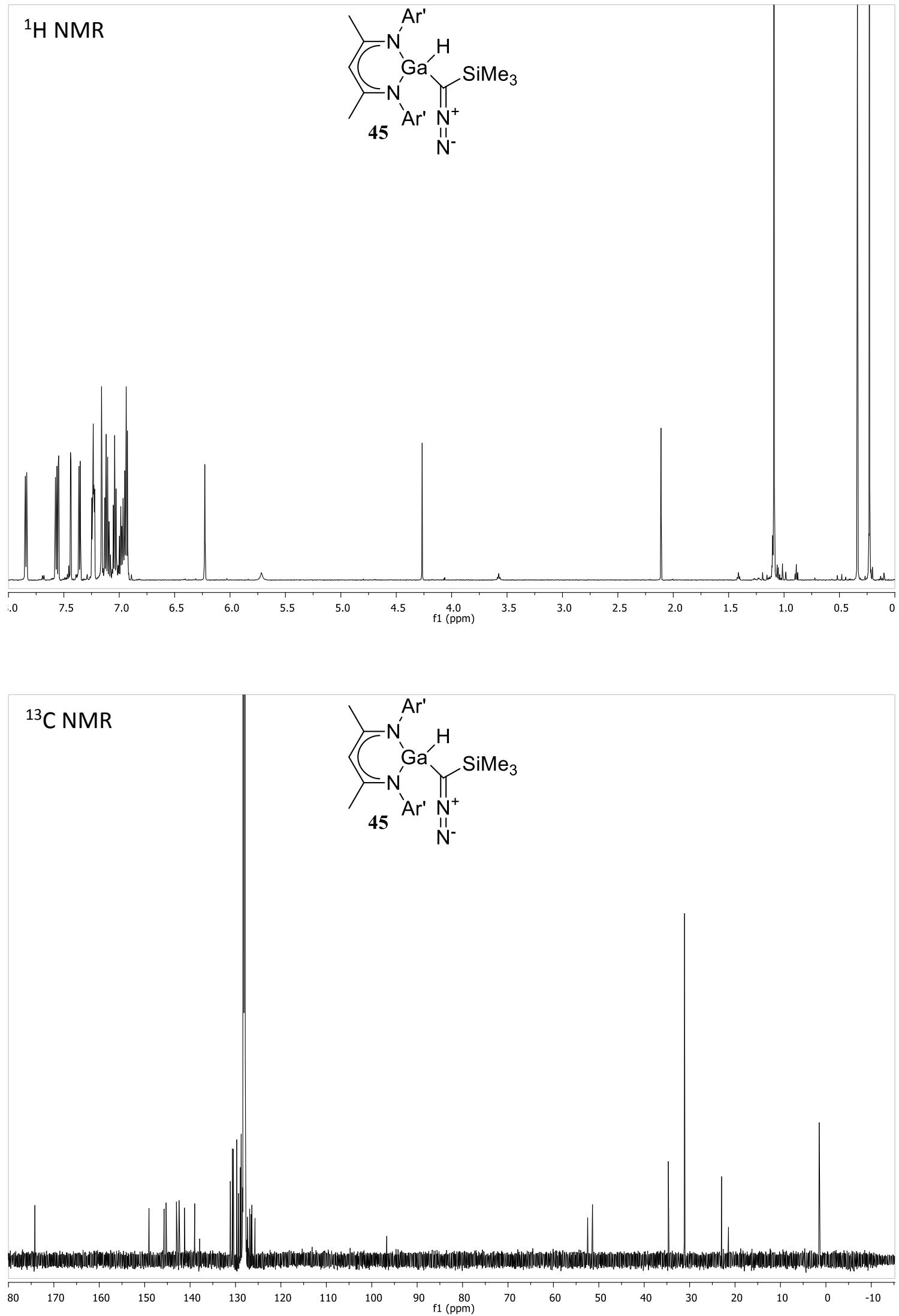


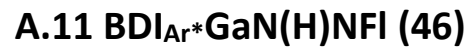
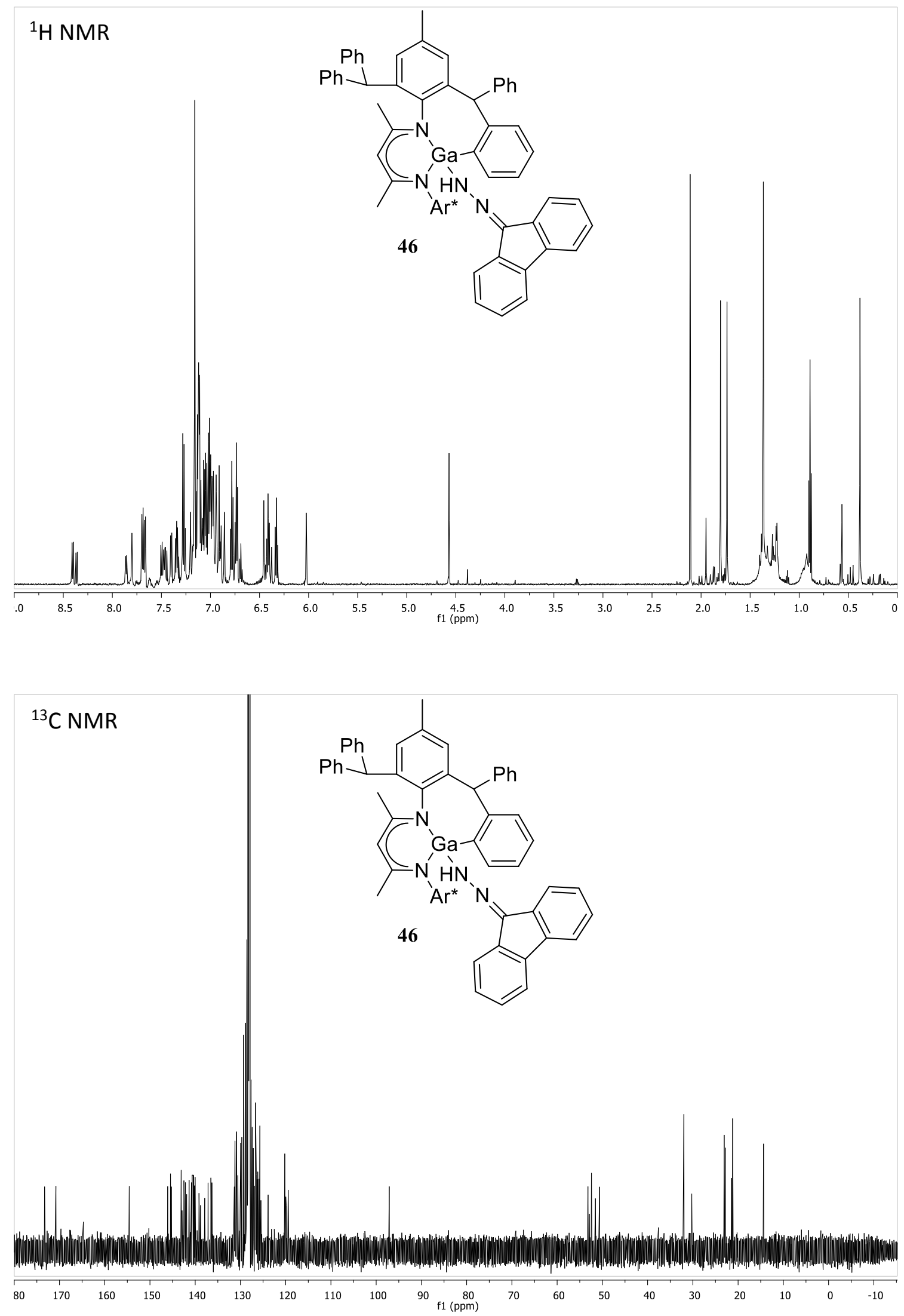


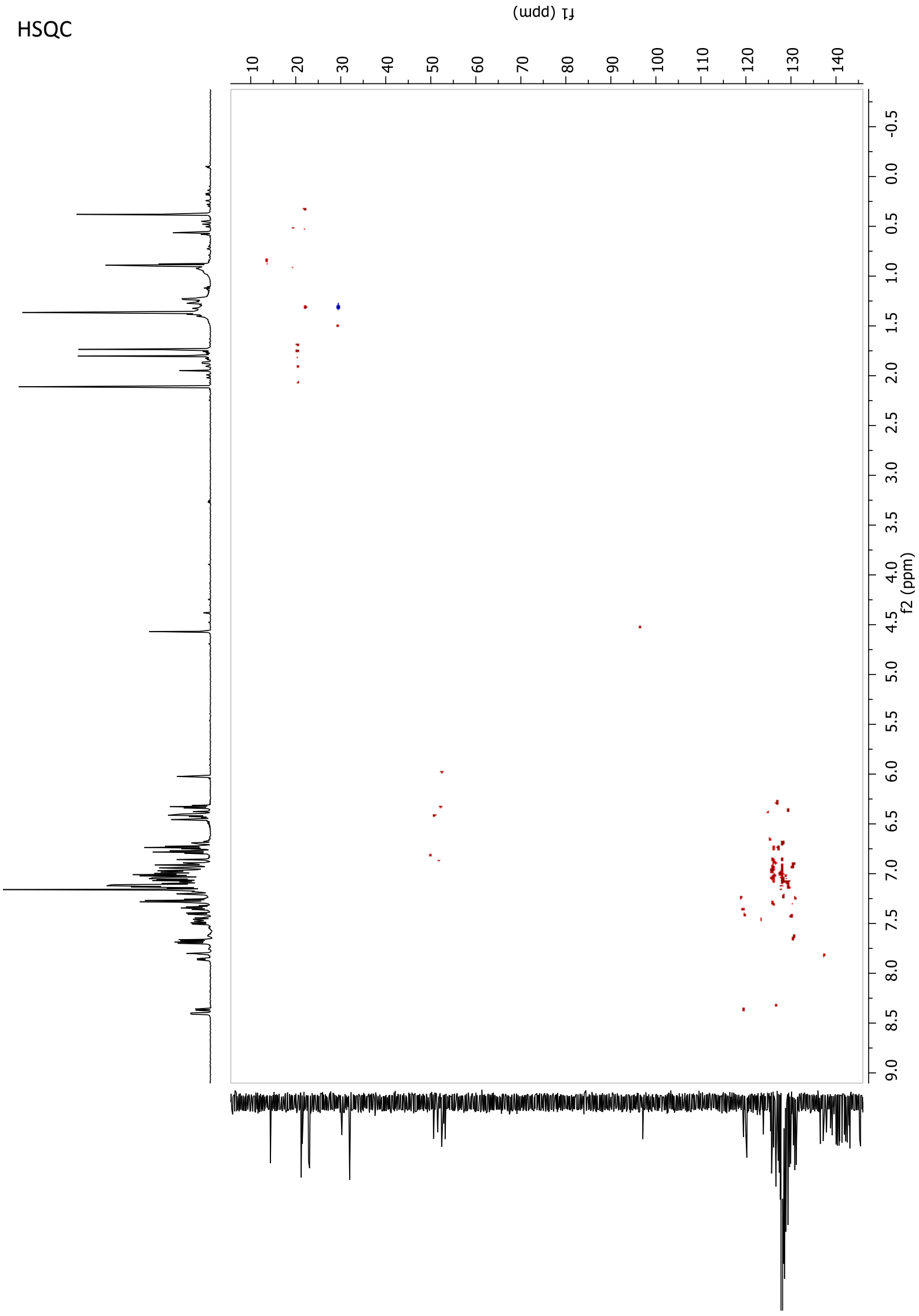




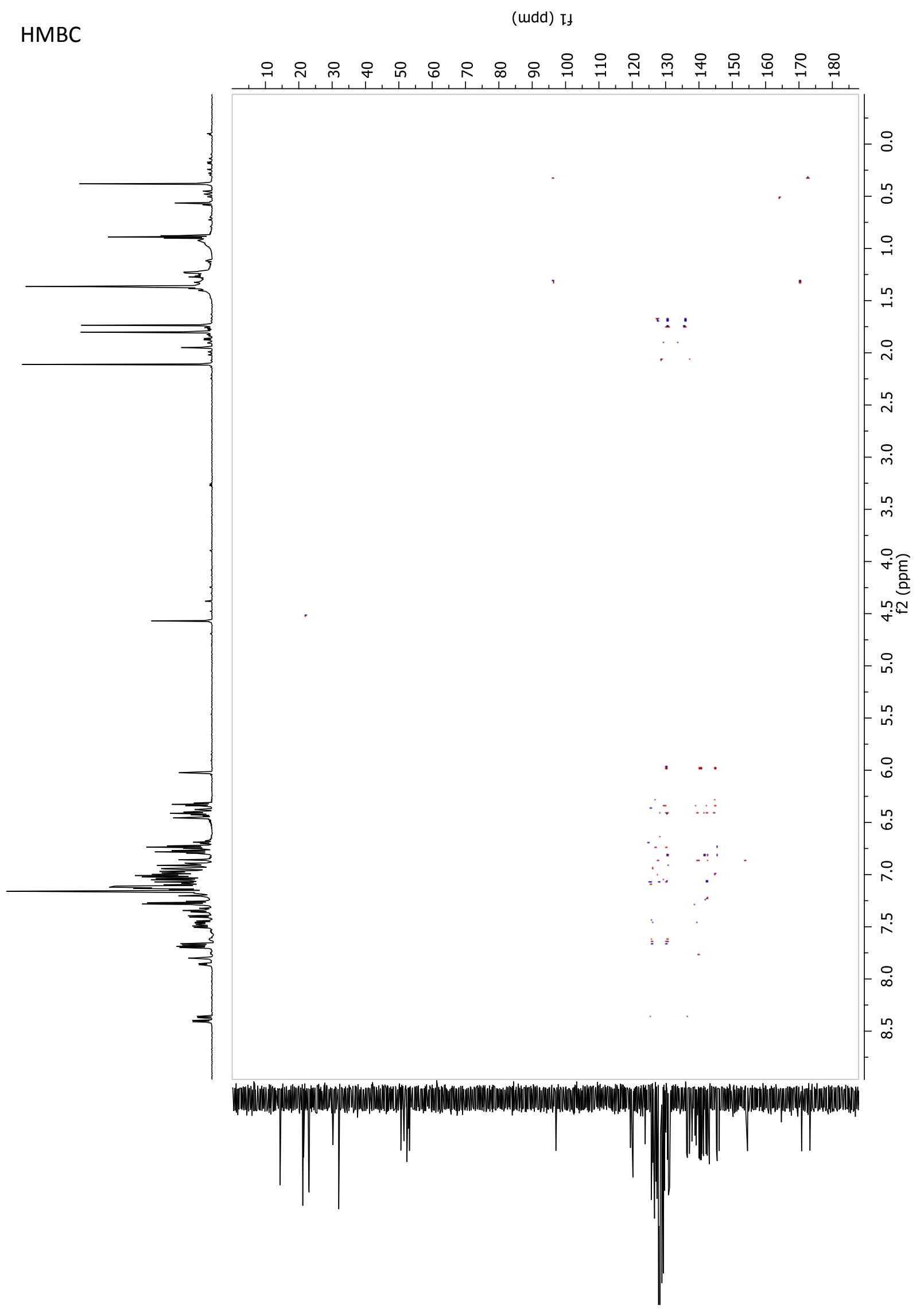


A.12 BDIDIPPAI(PHPh)Cl (53)

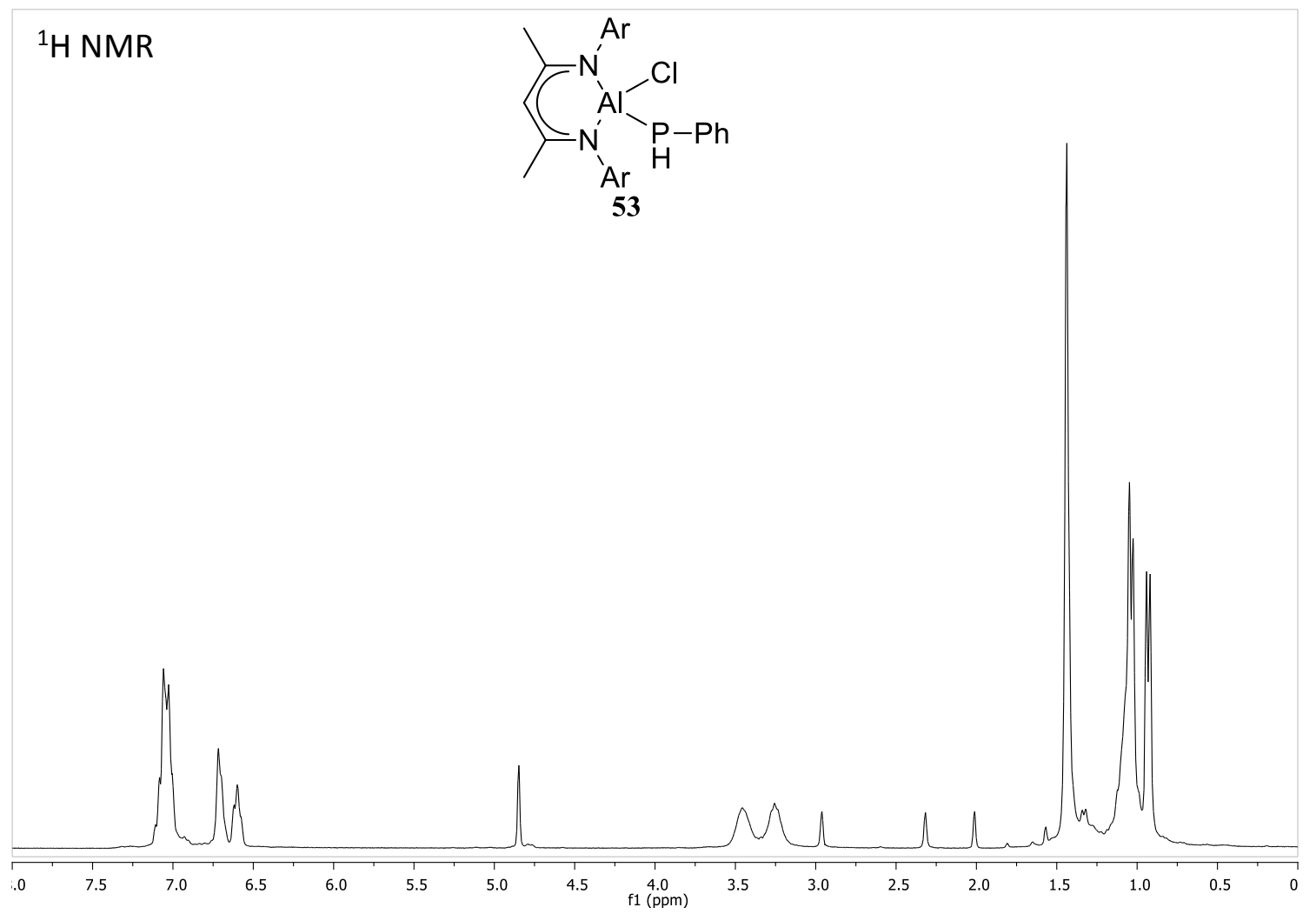

${ }^{13}$ C NMR

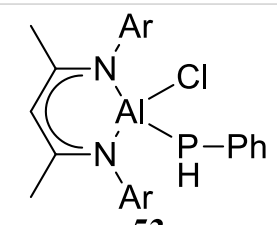

53

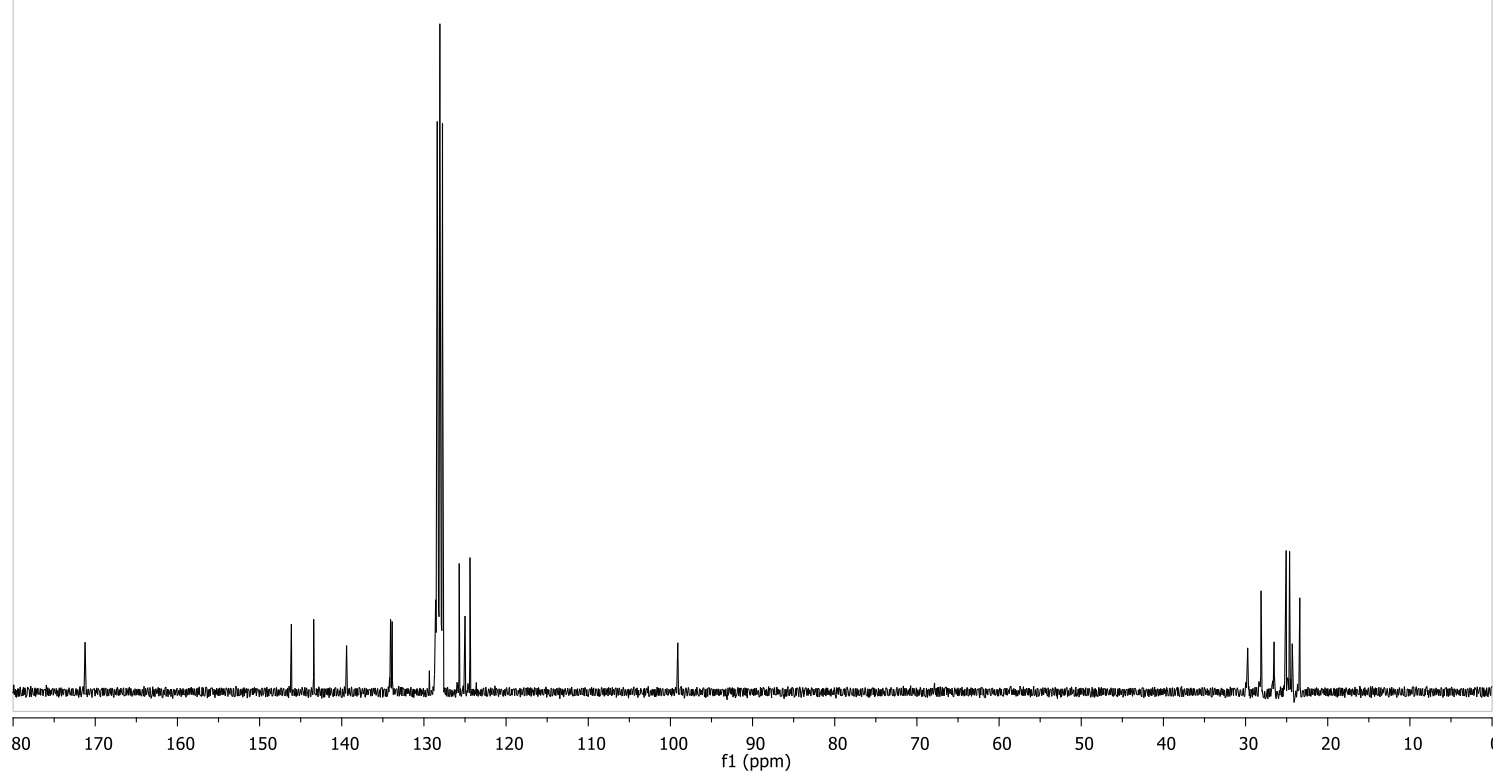



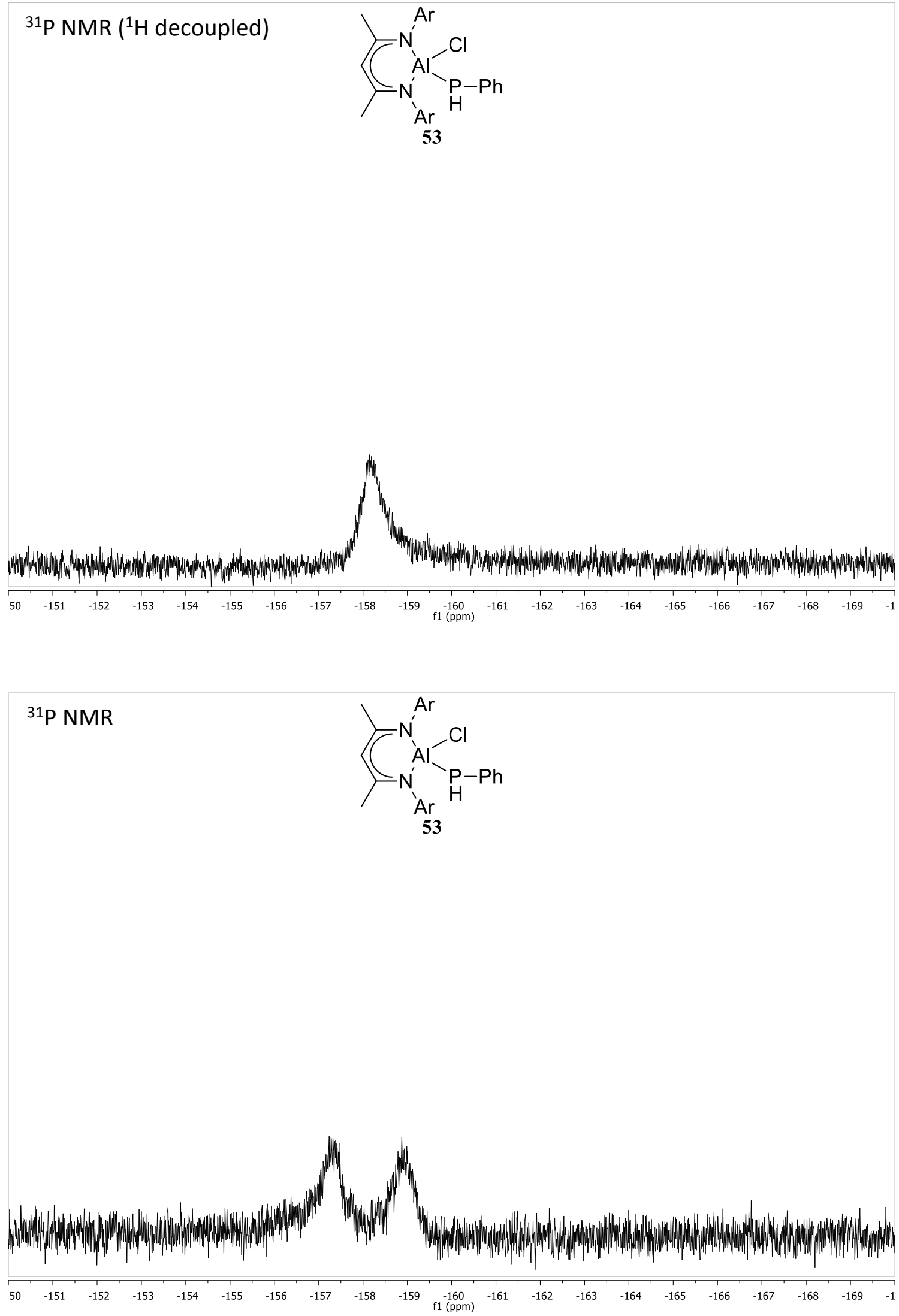


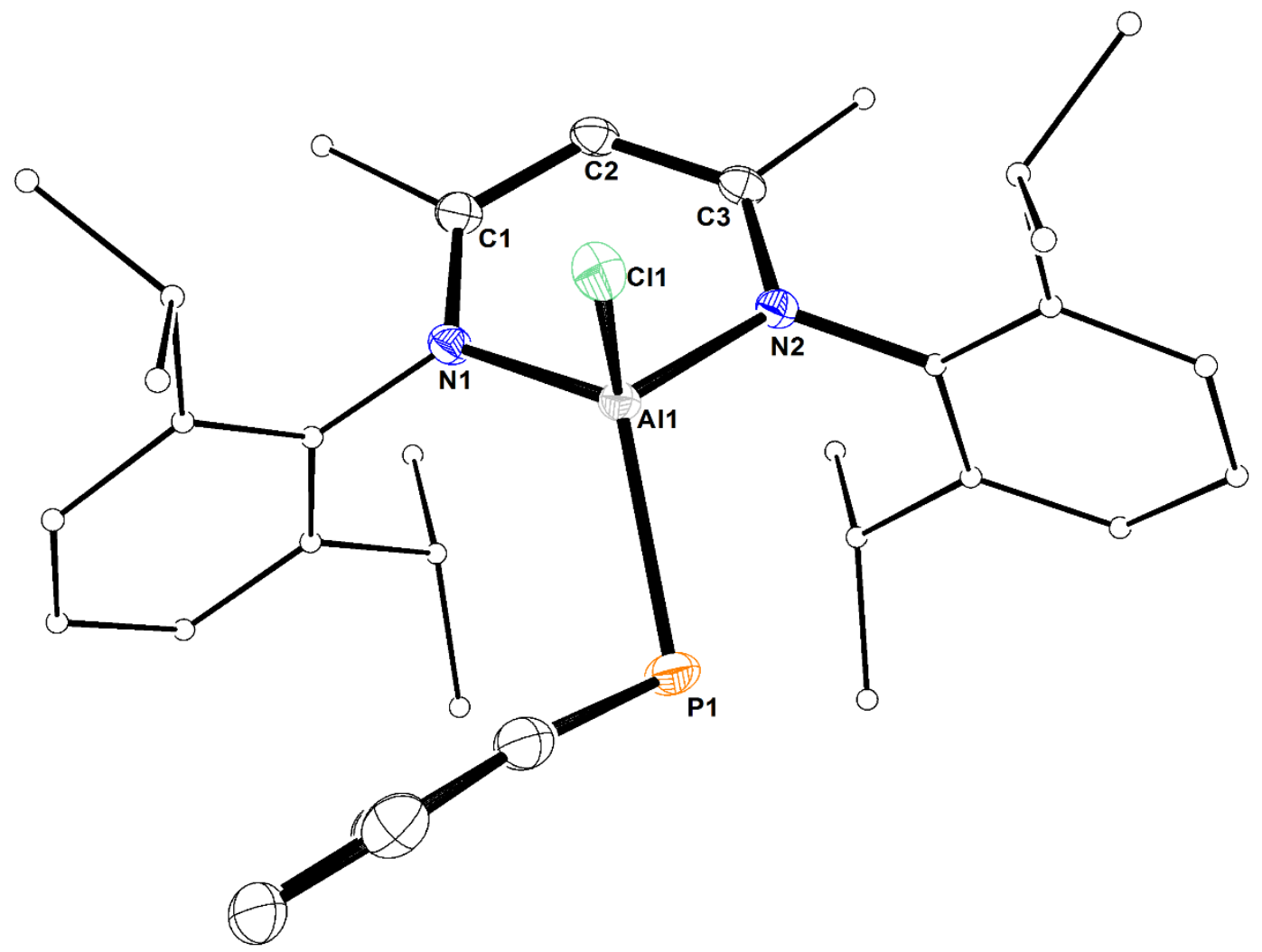

ORTEP plot of $\mathrm{BDI}_{\mathrm{DIPPAI}}(\mathrm{PHPh}) \mathrm{Cl}$ 53. Ellipsoids at 30\%, $\mathrm{H}$ atoms omitted and selected $\mathrm{C}$ atoms in wire frame for clarity. 


\section{A.13 BDIDIPPAl(PHMes)Cl (58)}
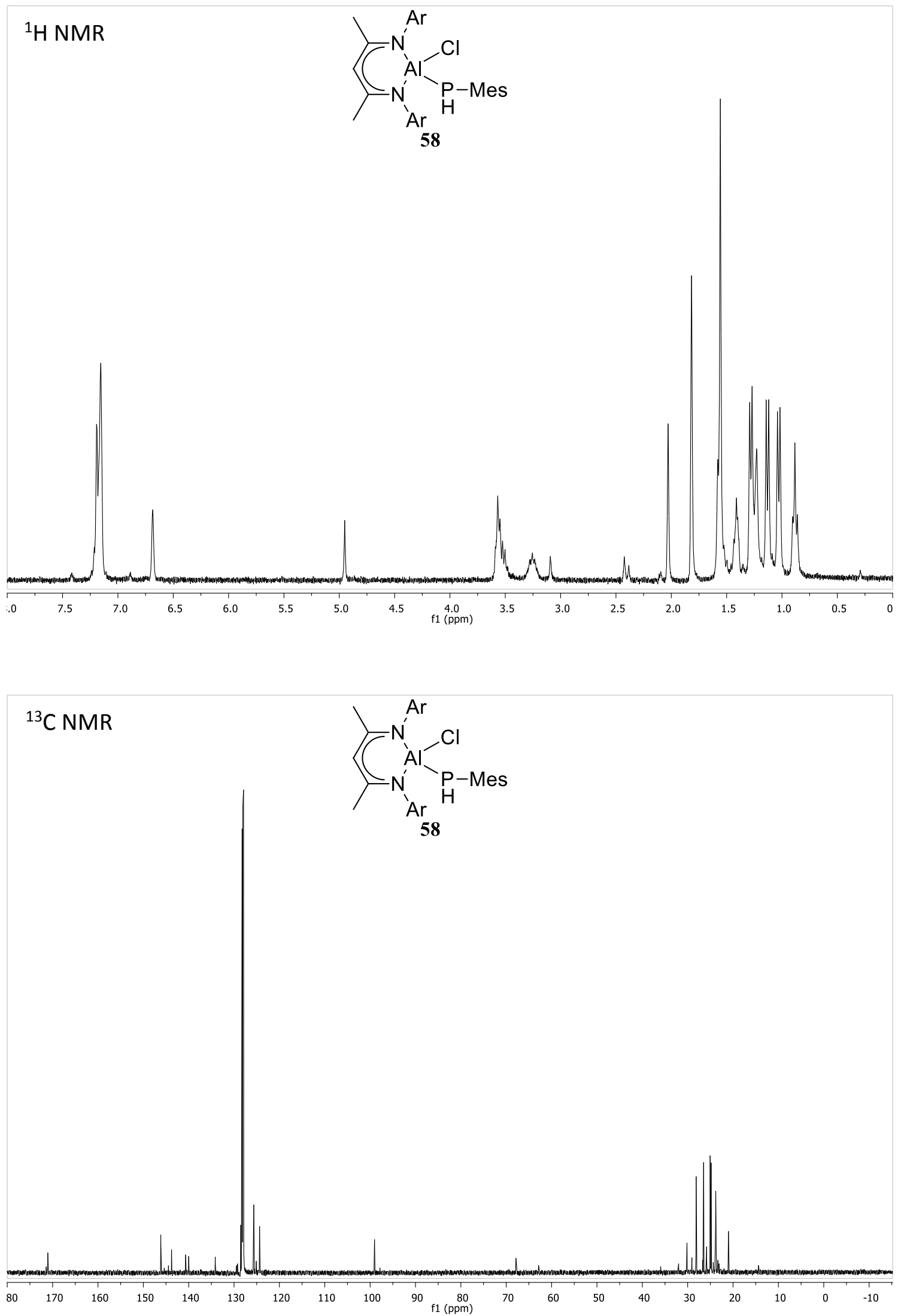


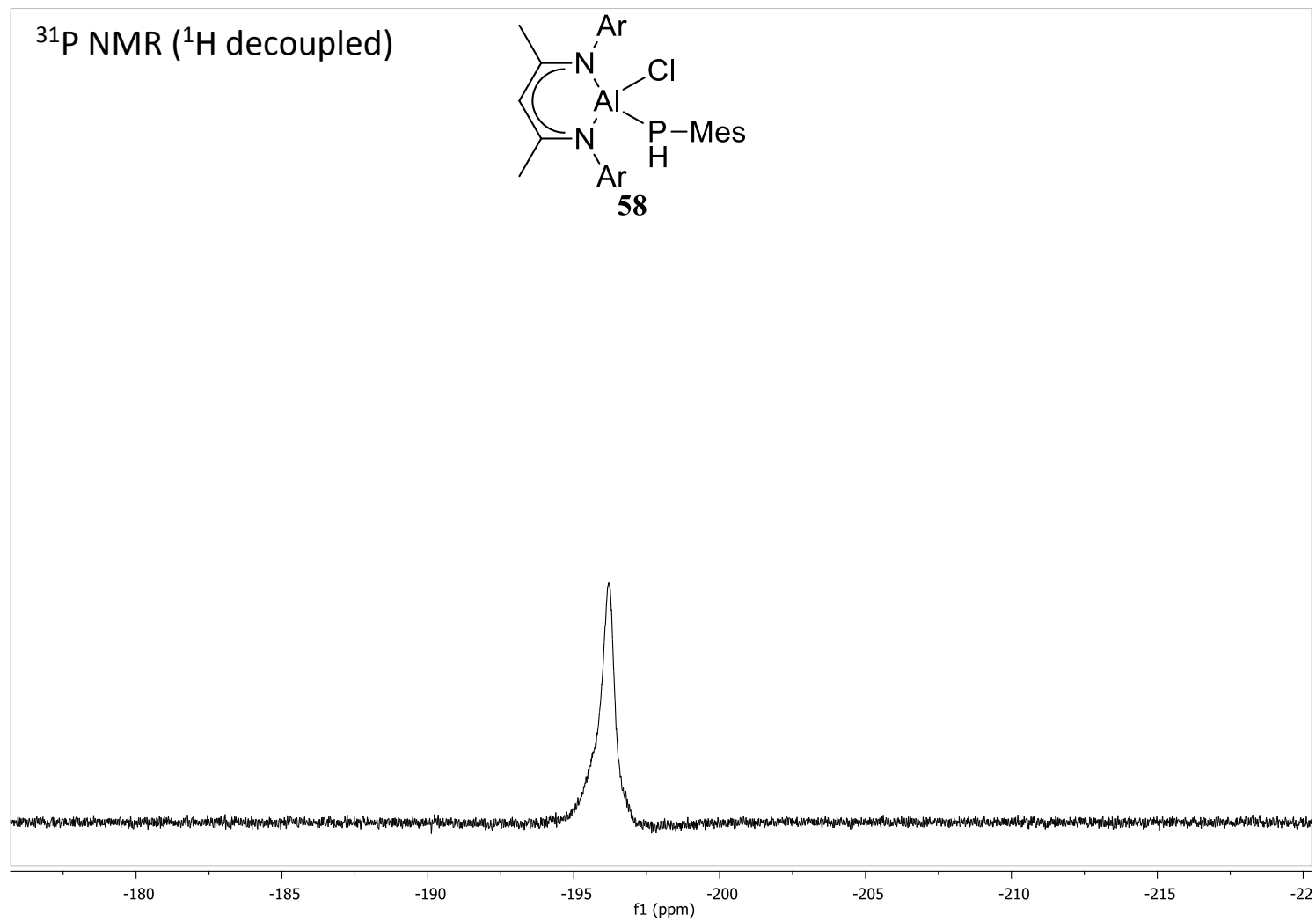

${ }^{31}$ P NMR

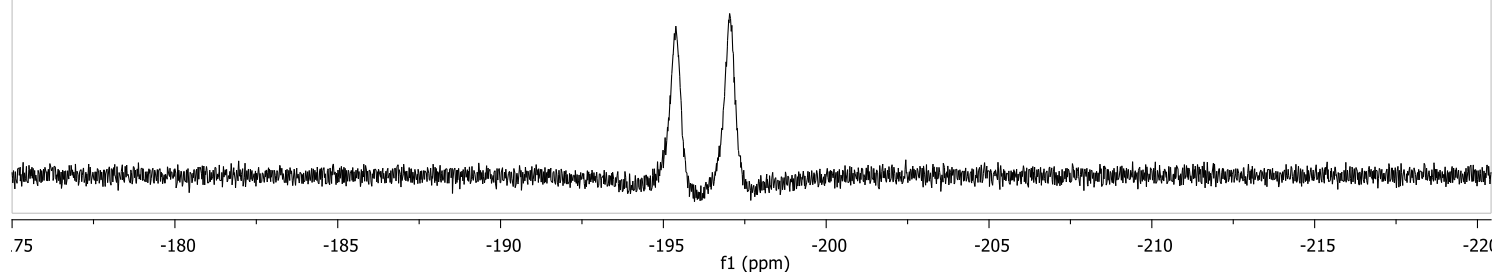




\section{A.14 BDIDIPPGa(PHMes)Cl (59)}
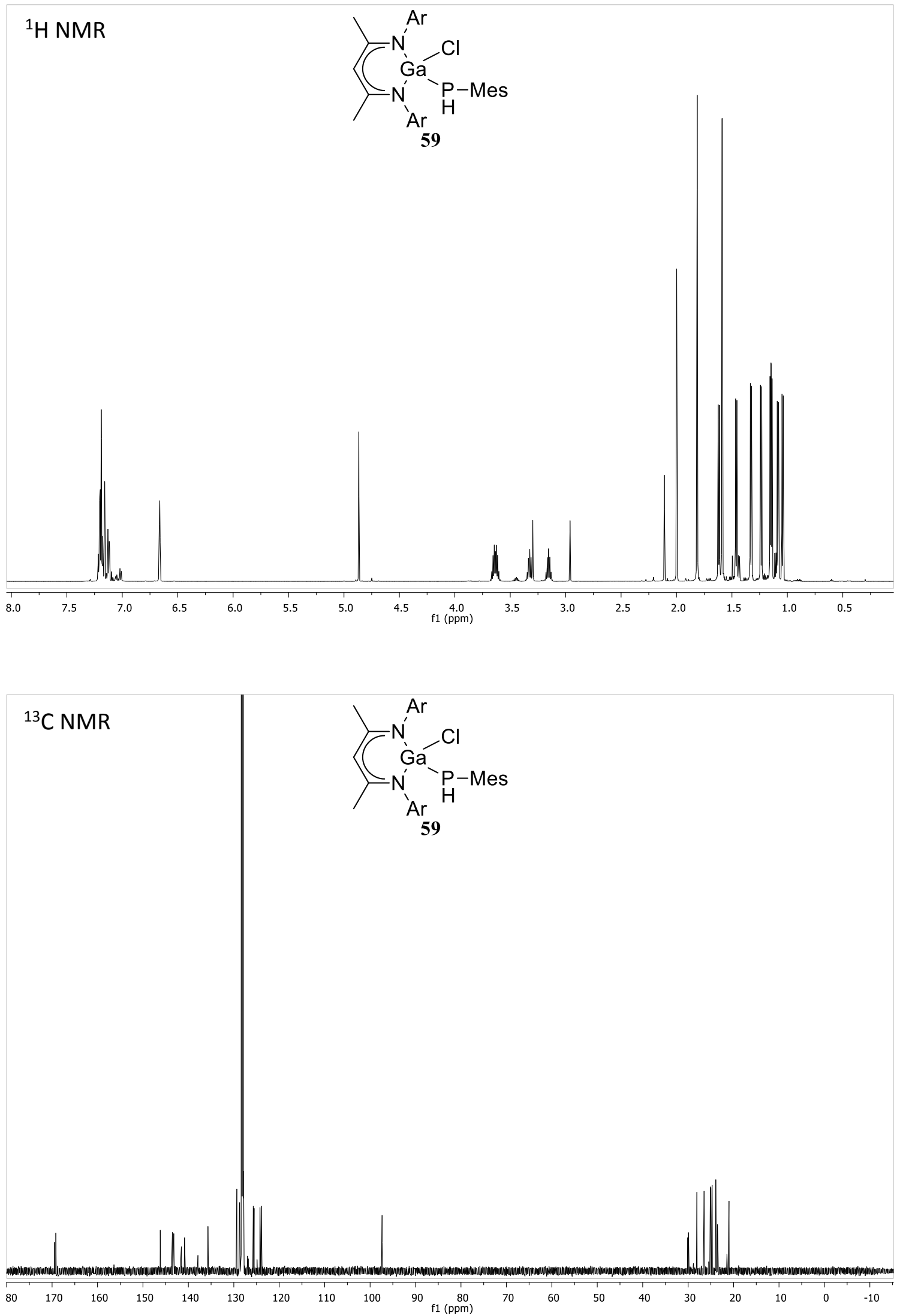


$$
{ }^{31} \text { P NMR }\left({ }^{1} \mathrm{H} \text { decoupled }\right)
$$

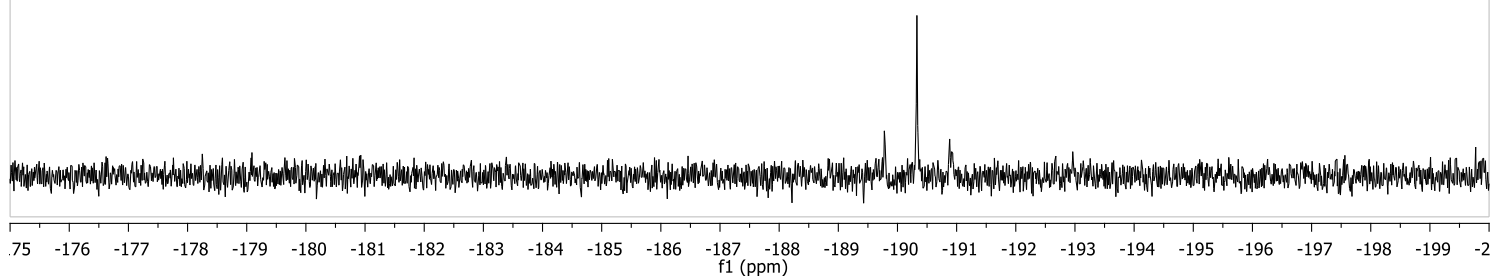

${ }^{31}$ P NMR

59

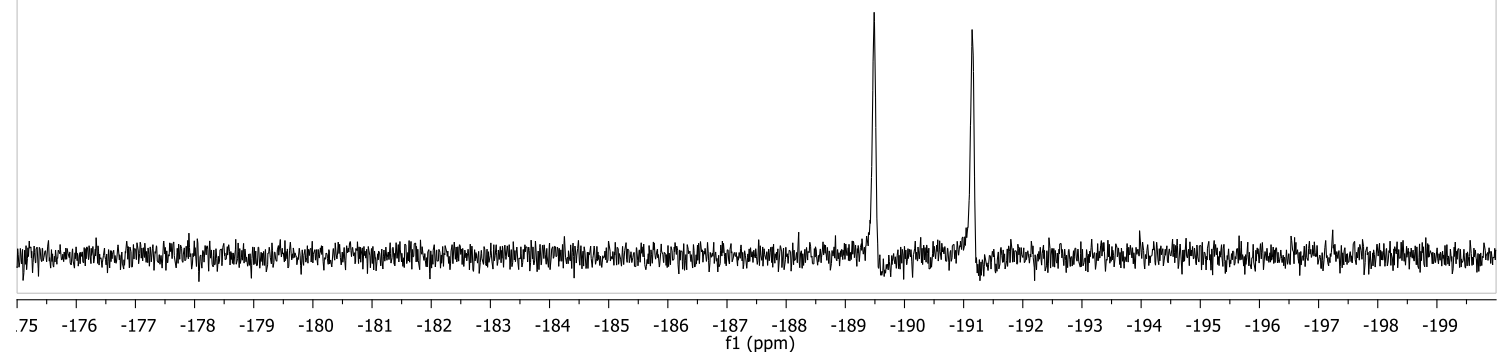




\section{A.15 BDIDIPPAI(PPhTMS)Cl (60)}
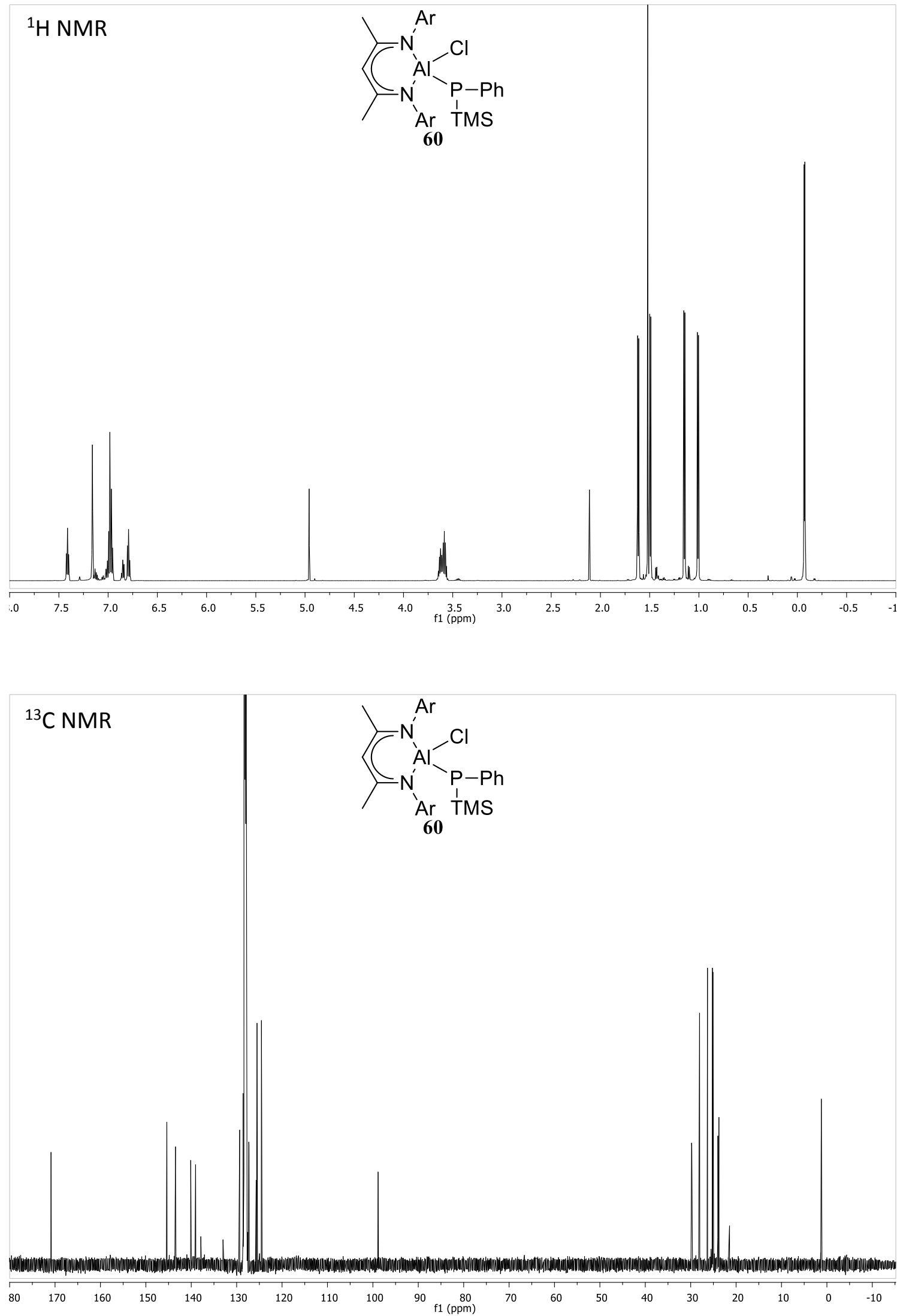
${ }^{31}$ P NMR

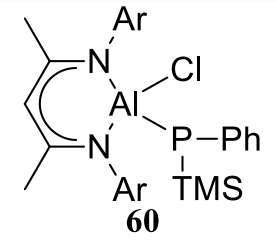

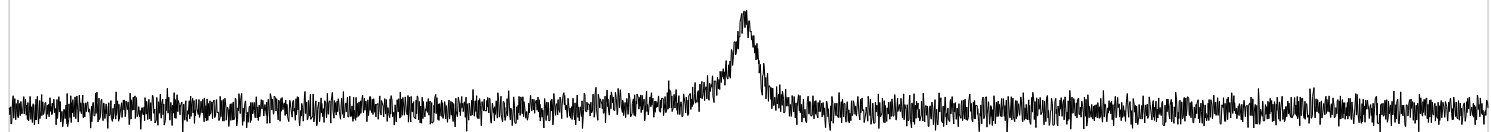
\begin{tabular}{llllllllllllllllllllllllllll}
\hline-141 & -143 & -145 & -147 & -149 & -151 & -153 & -155 & -157 & -159 & -161 & -163 & -165 & -167 & -169 & -171 & -173 & -175 & -177 & -179 \\
\hline
\end{tabular} 


\section{A.16 BDIDIPPAl(PHMes)Et (63)}
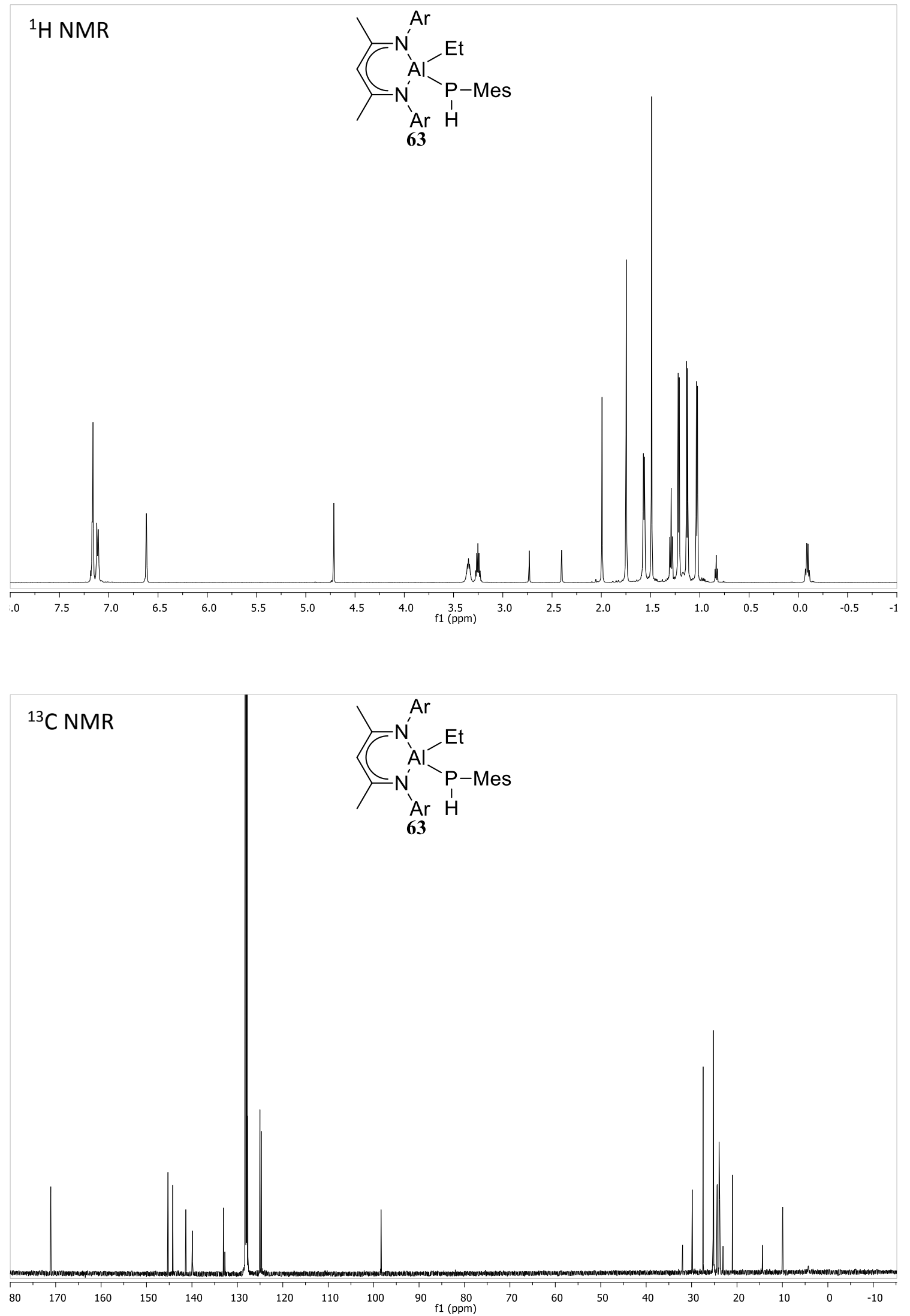

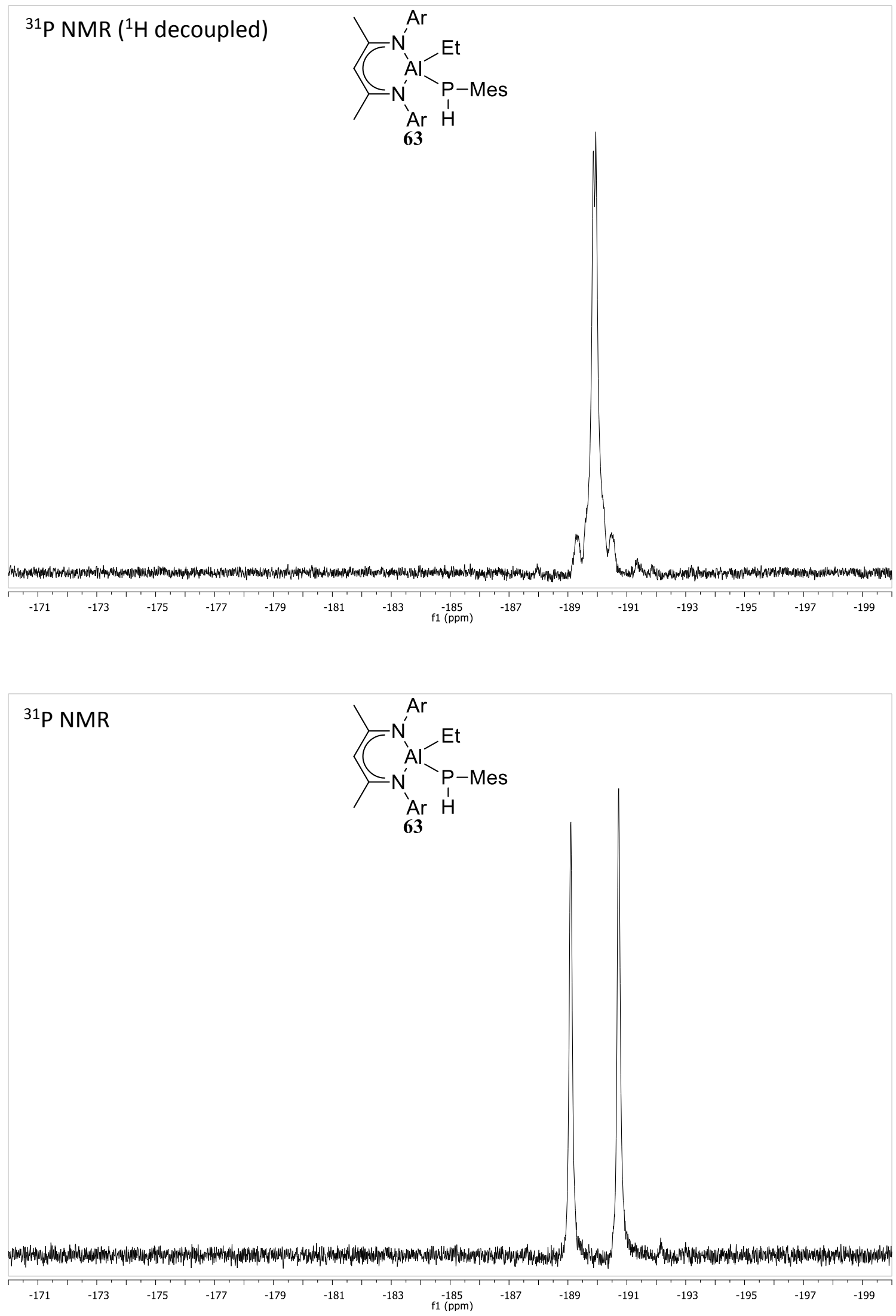
A.17 BDIDIPPGa(H)P(H)Mes (66)
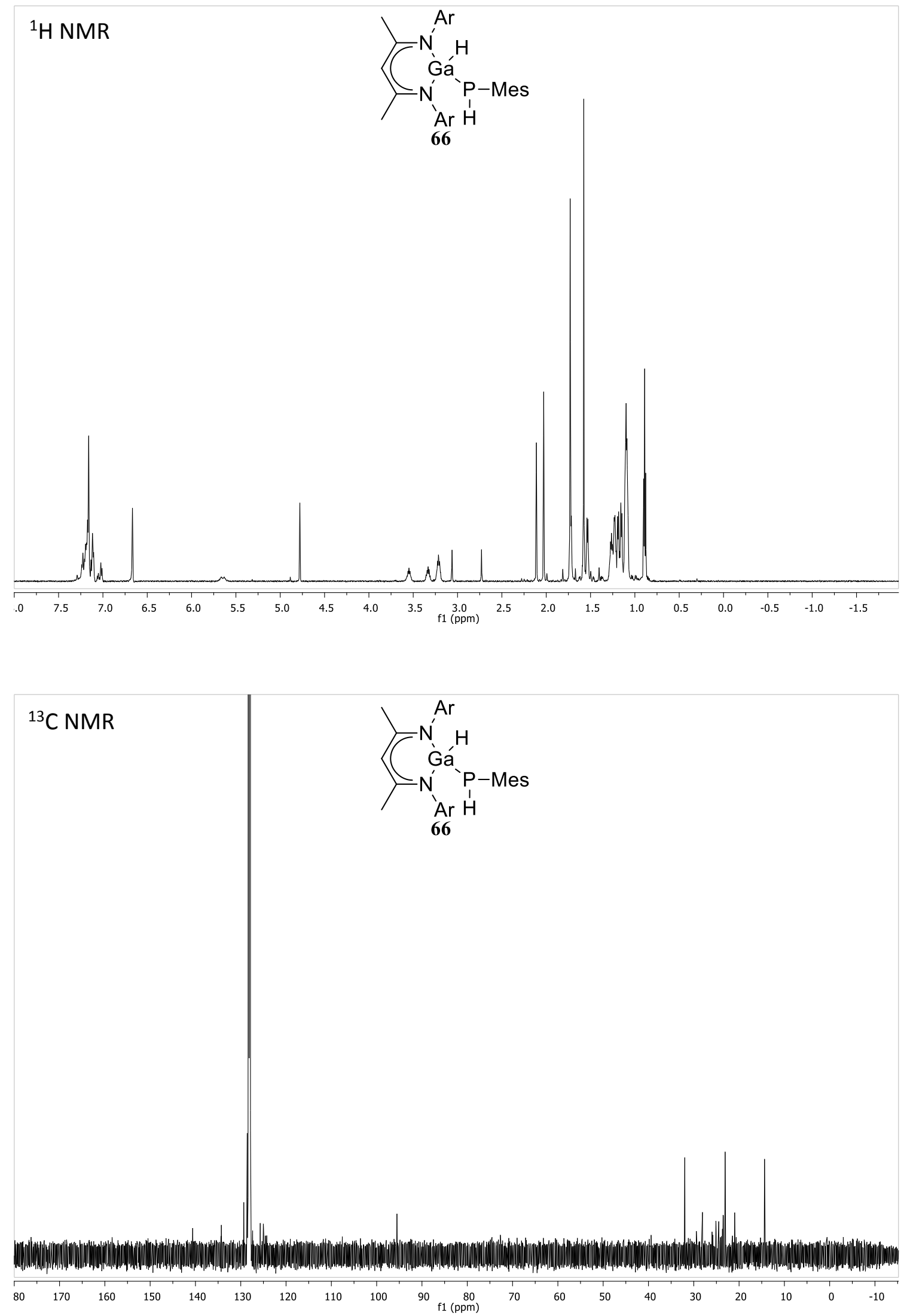


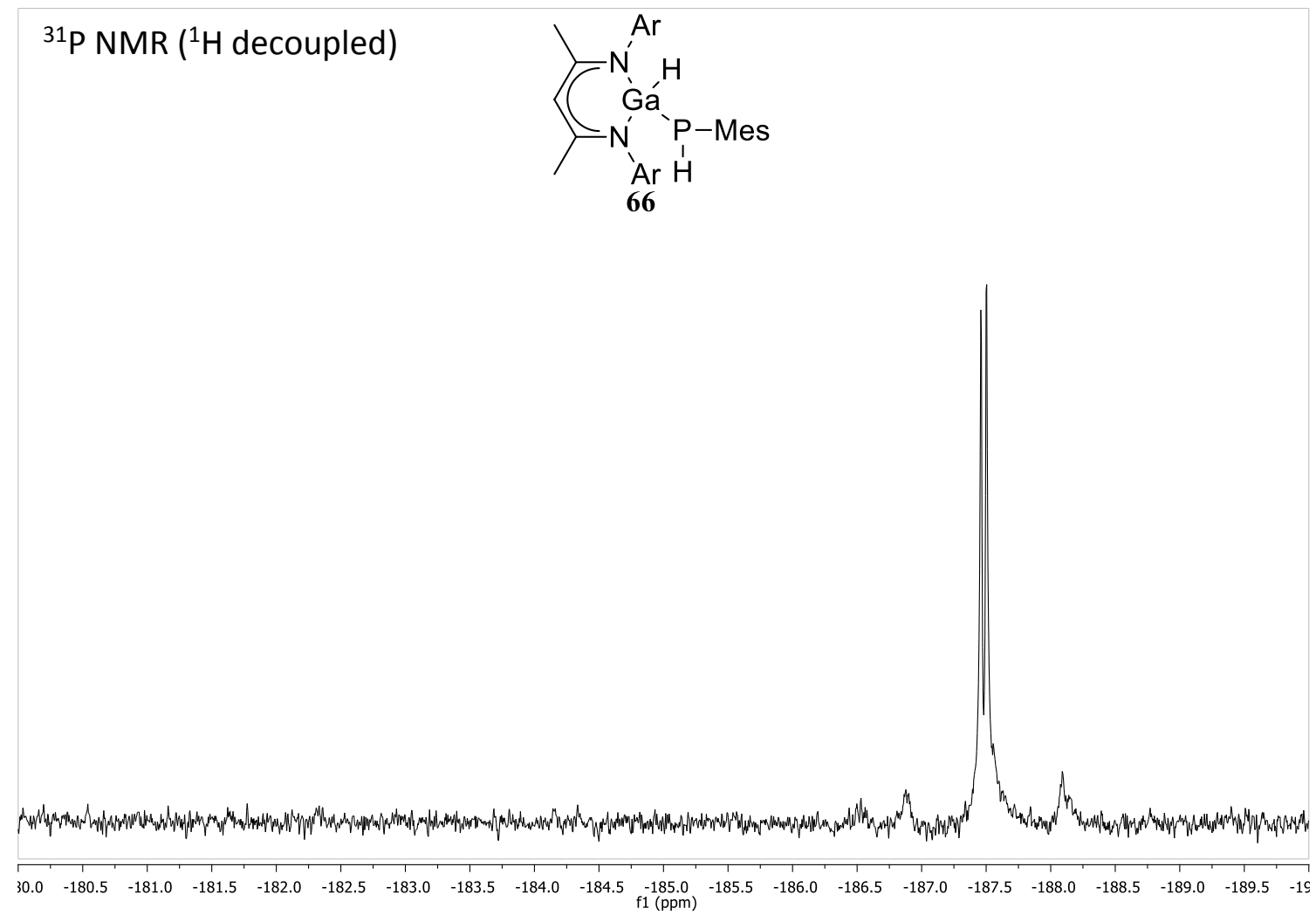

${ }^{31}$ P NMR

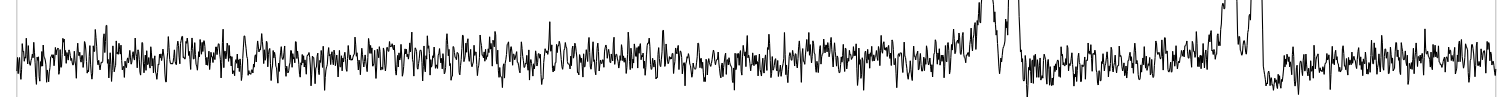
\begin{tabular}{llllllllllllllllllllll}
30.0 & -180.5 & -181.0 & -181.5 & -182.0 & -182.5 & -183.0 & -183.5 & -184.0 & -184.5 & -185.0 & -185.5 & -186.0 & -186.5 & -187.0 & -187.5 & -188.0 & -188.5 & -189.0 & -189.5 & -15 \\
\hline
\end{tabular} 
A.18 ArBDIDIPpAIMe 2 (67)
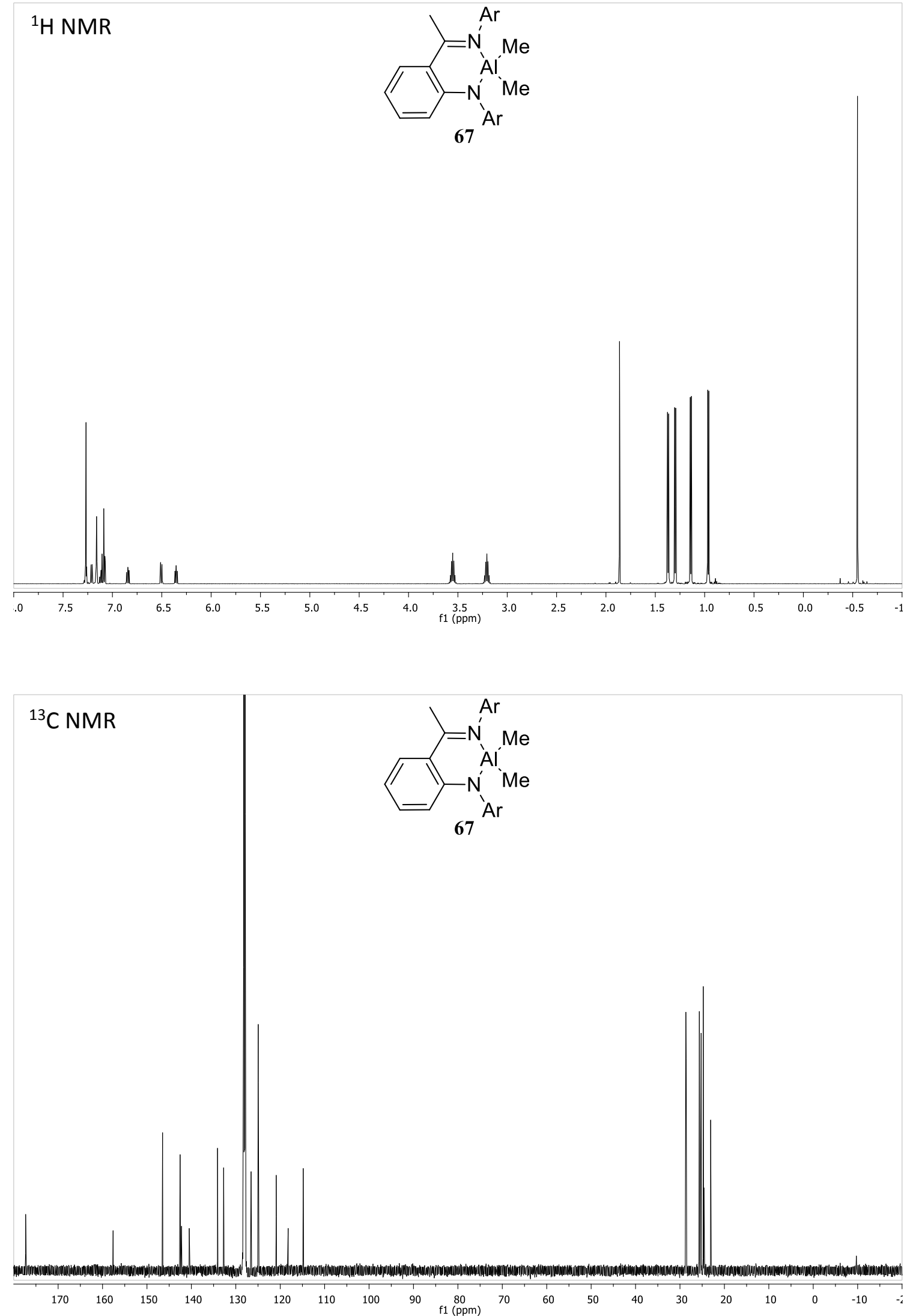


\section{A.19 ArBDI DIPPAll $_{2}$ (68)}
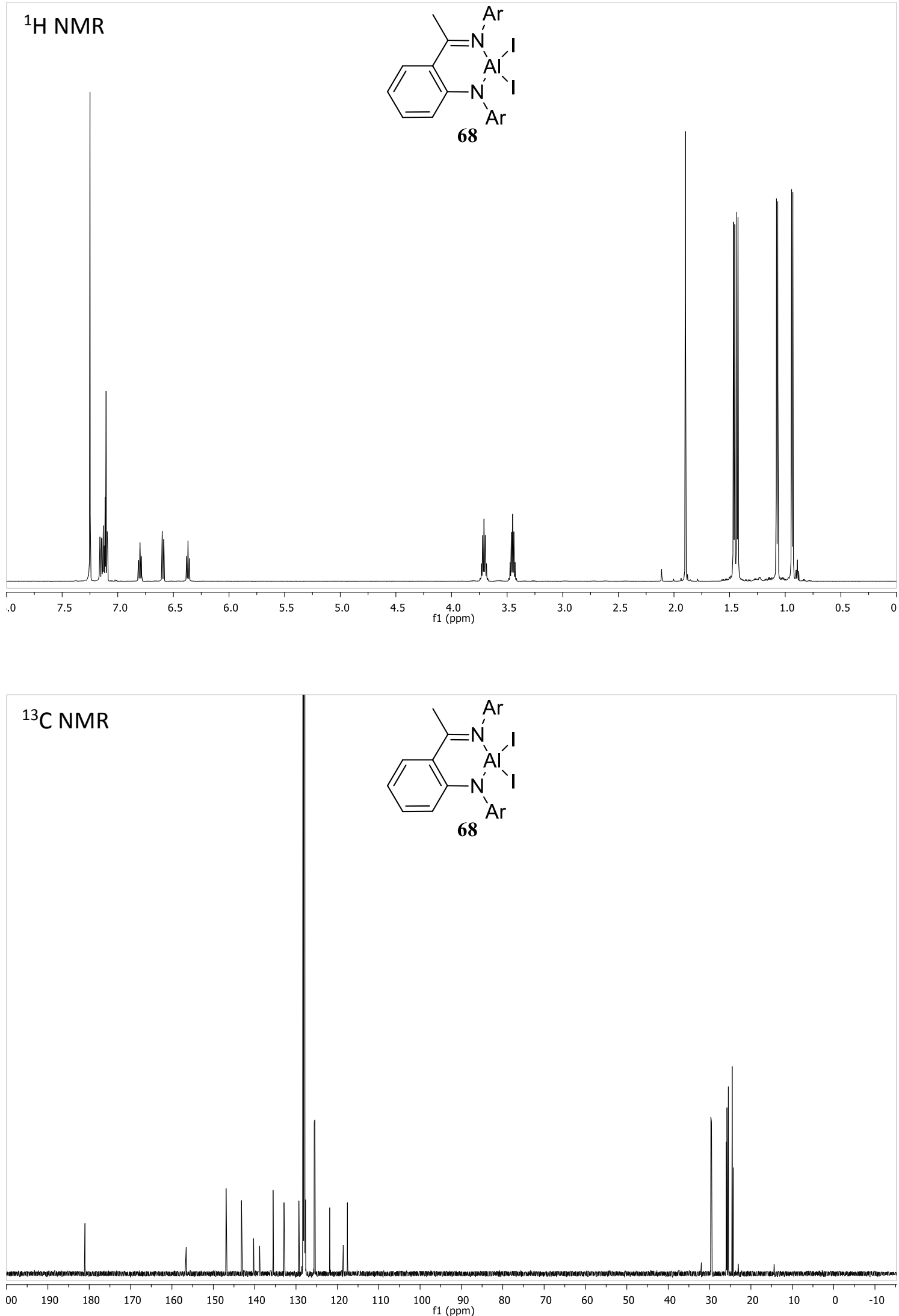
A.20 ArBDIDIPPH.AlMe 3 (70)

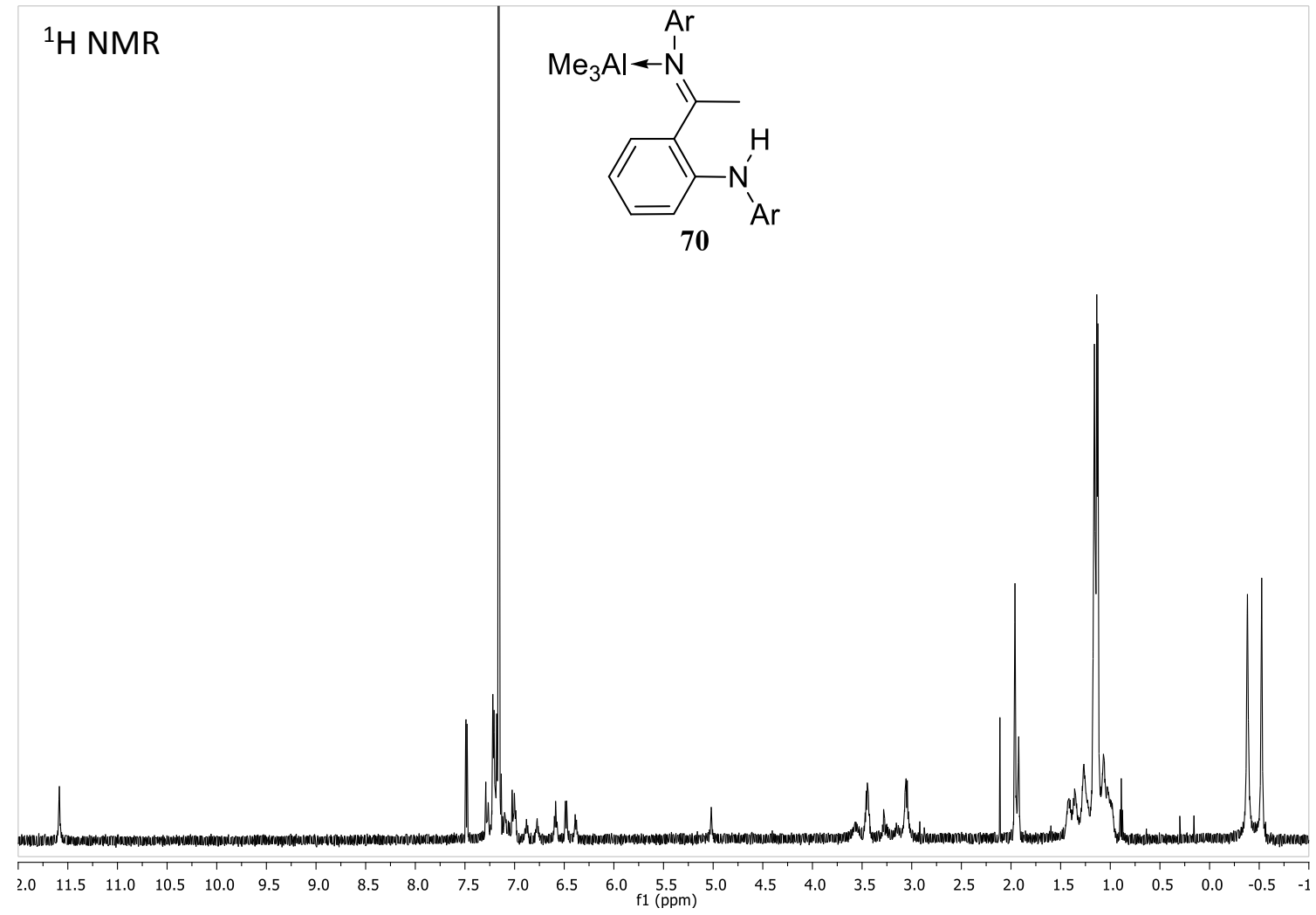

${ }^{1} \mathrm{H}$ NMR - heated to $30^{\circ} \mathrm{C}$

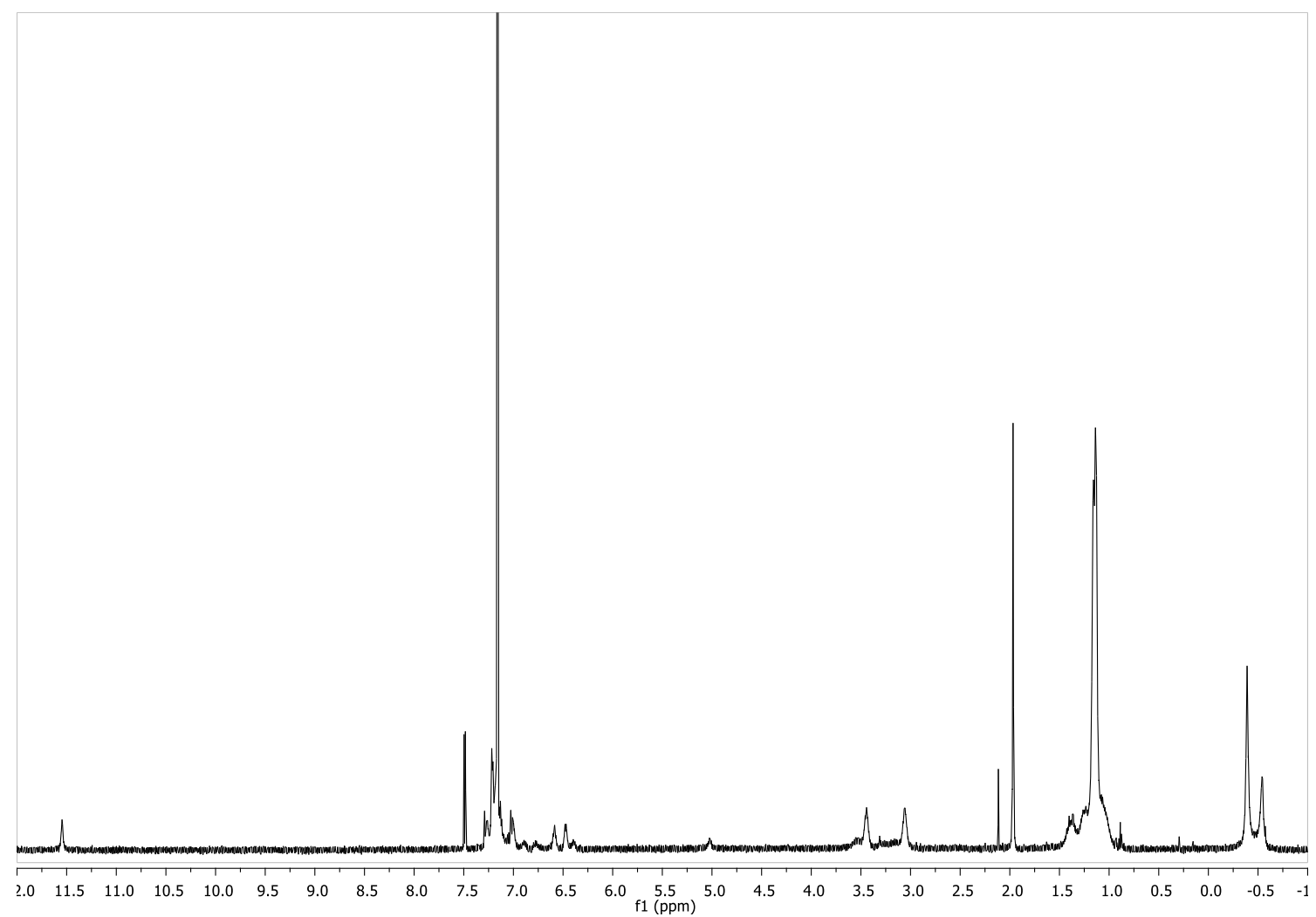


${ }^{1} \mathrm{H}$ NMR - heated to $40{ }^{\circ} \mathrm{C}$

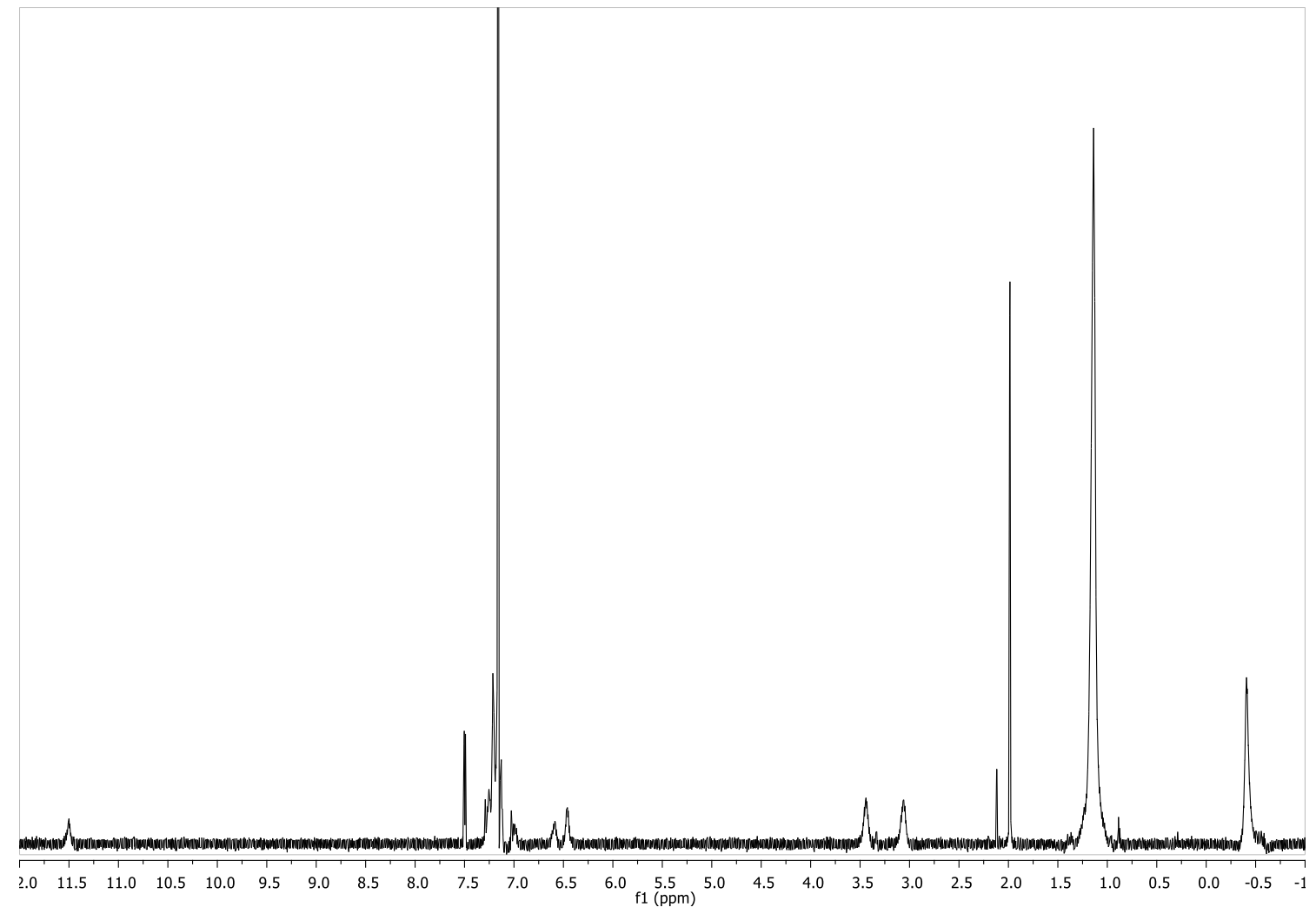


A.21 BDI $\mathrm{Ar} * \mathrm{AlMe}_{2}$ (72)
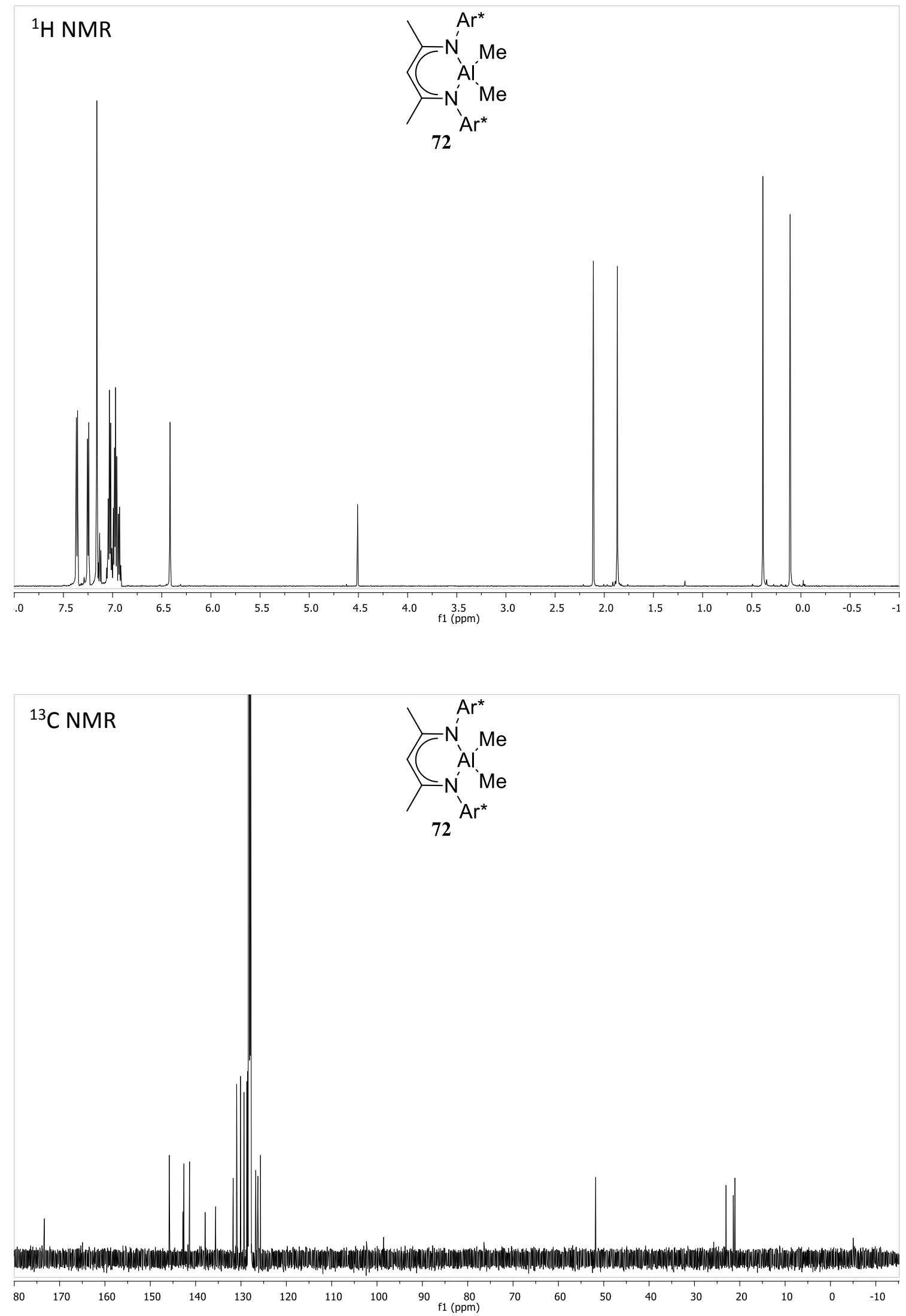


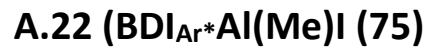

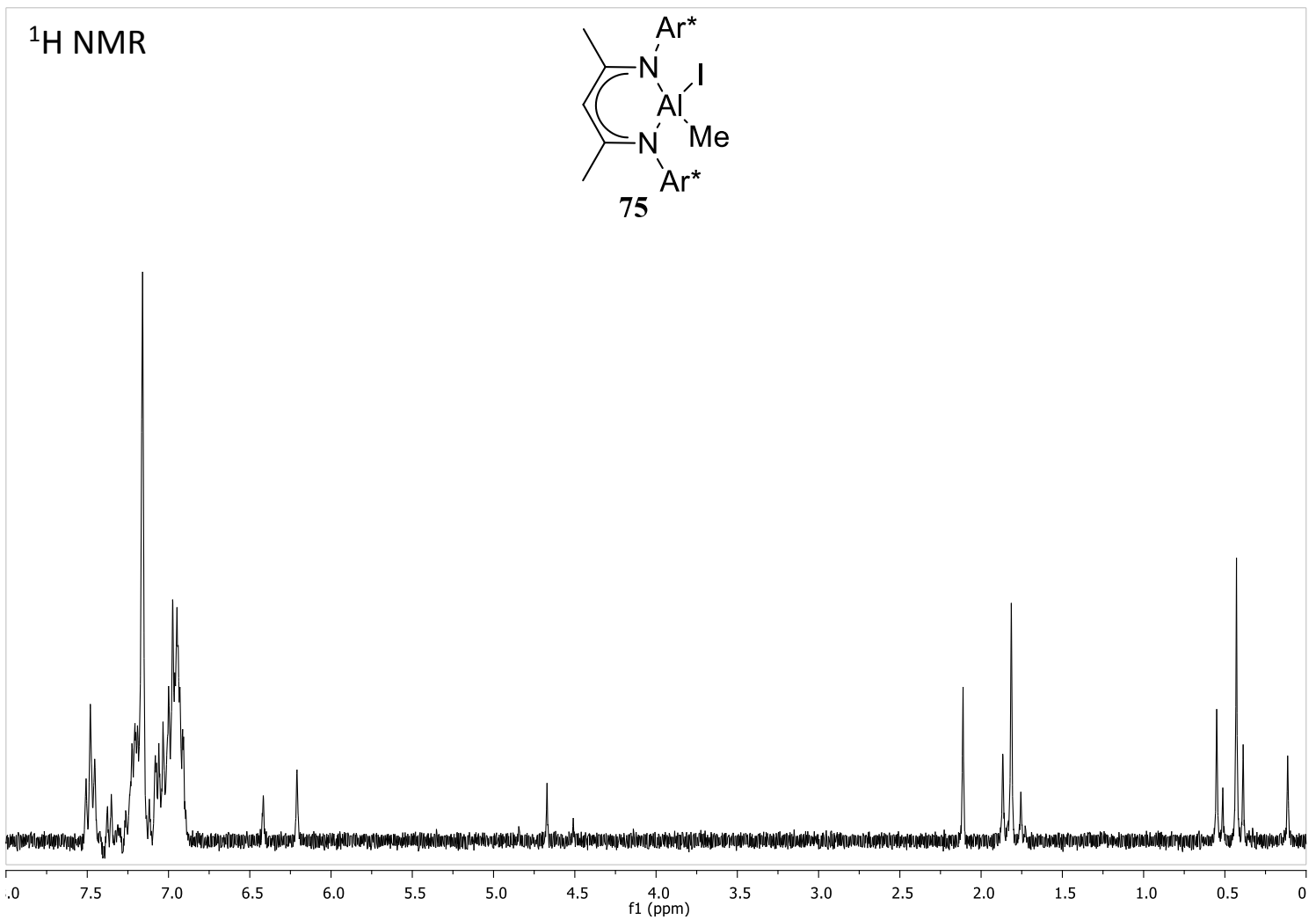


A.23 (BDIDIPPAI(Cl)N(4-NO $2-\mathrm{Ph}) \mathrm{C}(\mathrm{O}) \mathrm{P}(\mathrm{H}) \mathrm{Mes}, 76)$

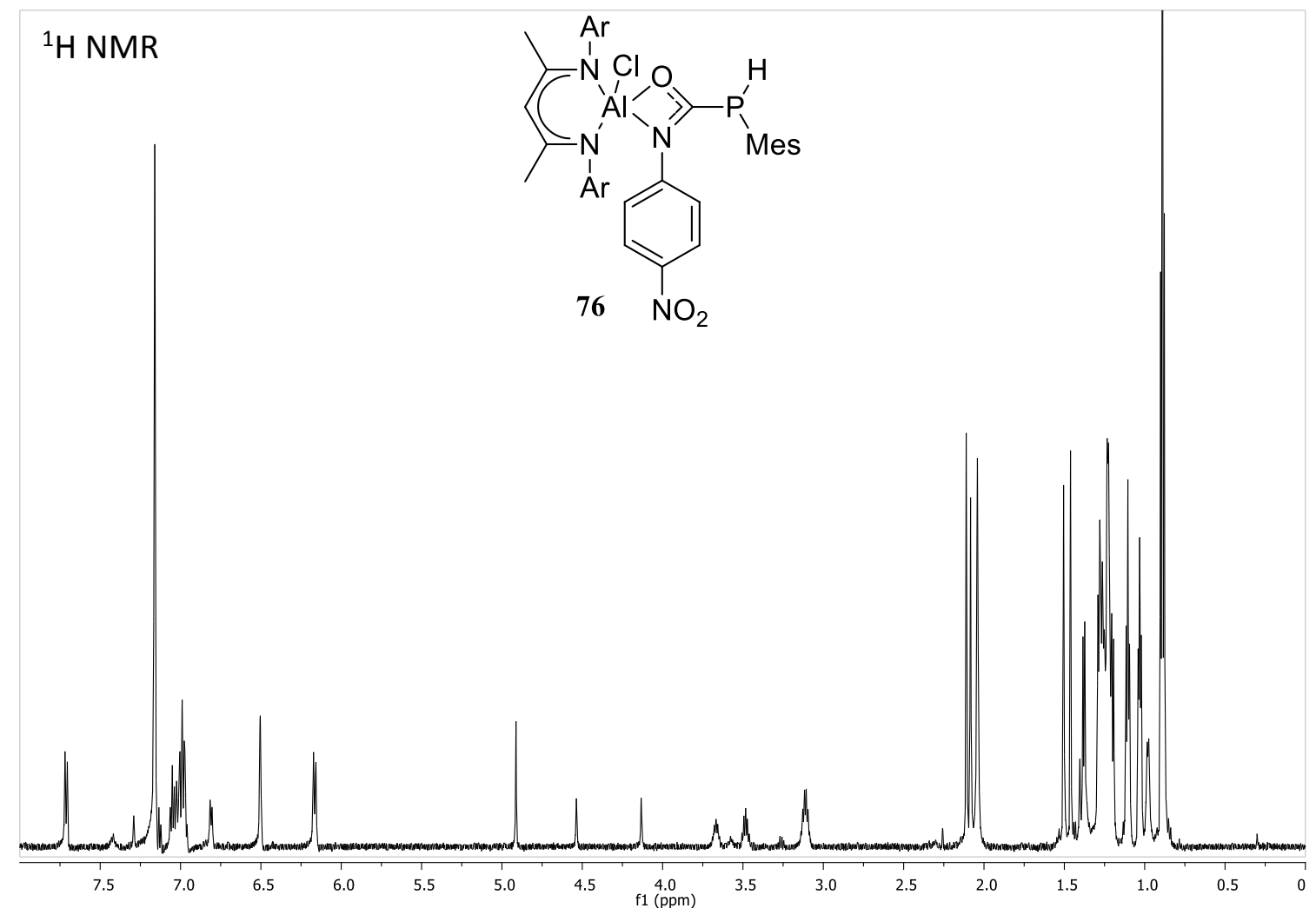

${ }^{31} \mathrm{P}$ NMR $\left({ }^{1} \mathrm{H}\right.$ decoupled $)$
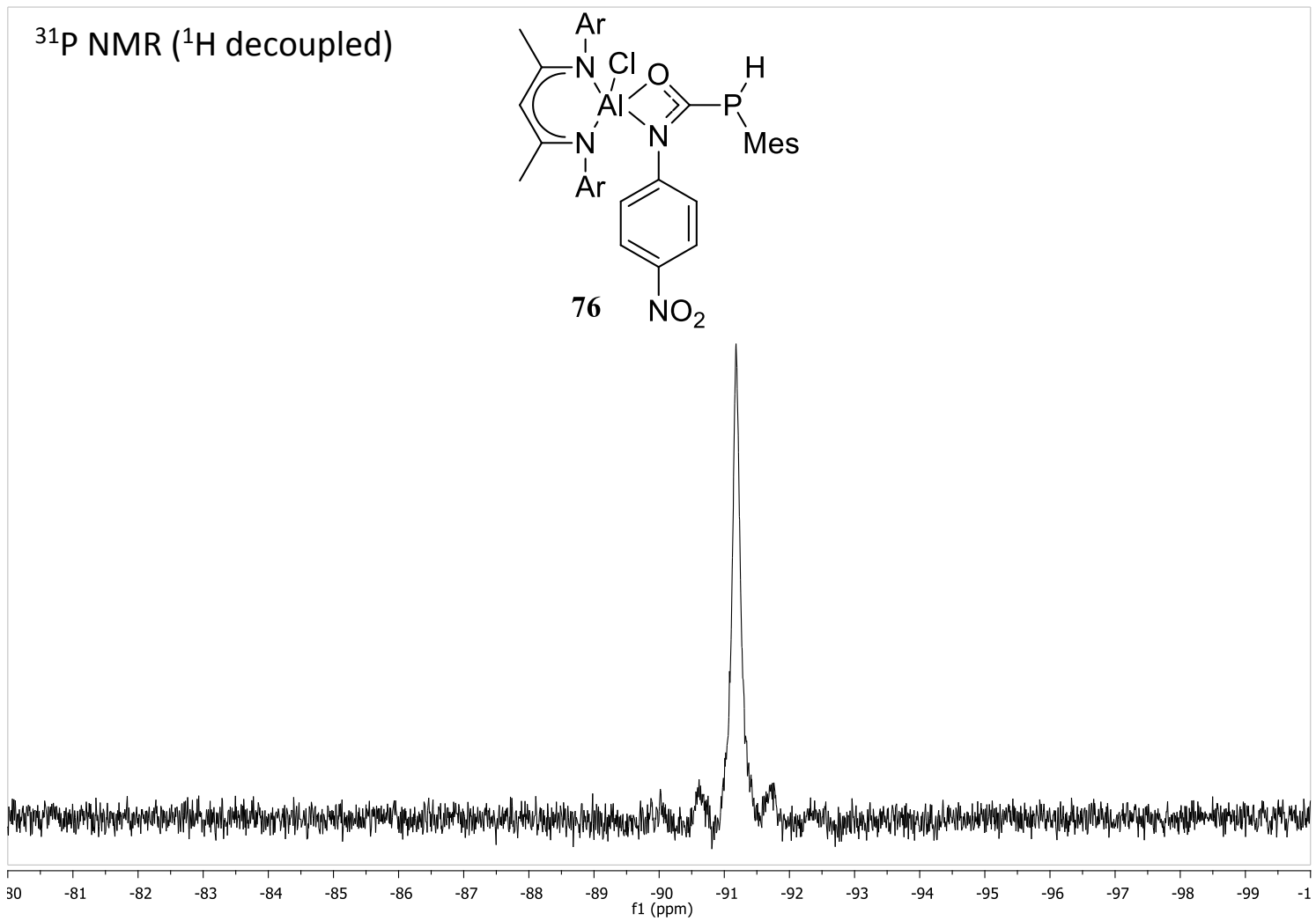


\section{Appendix B: Crystal Data Tables}

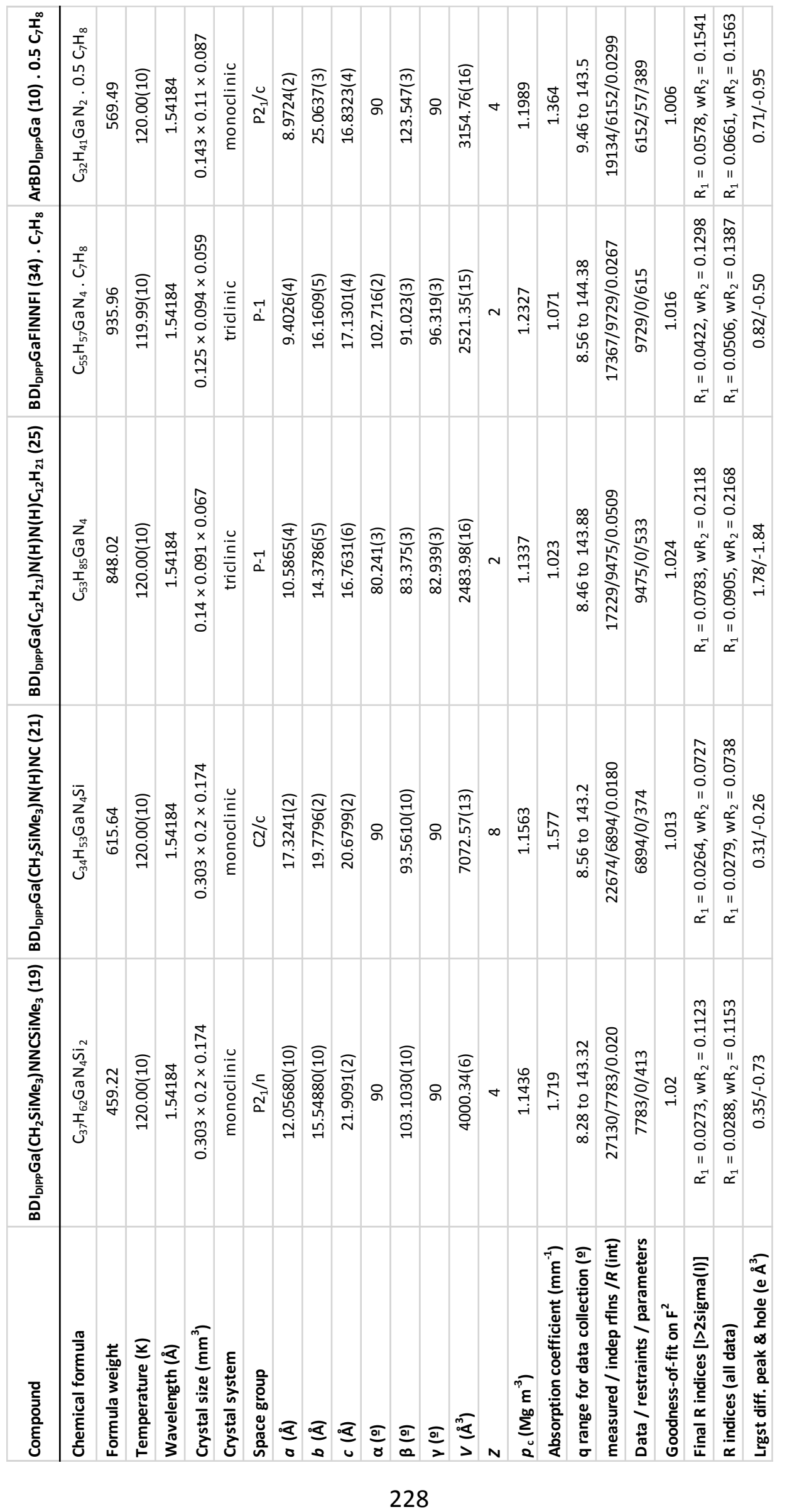




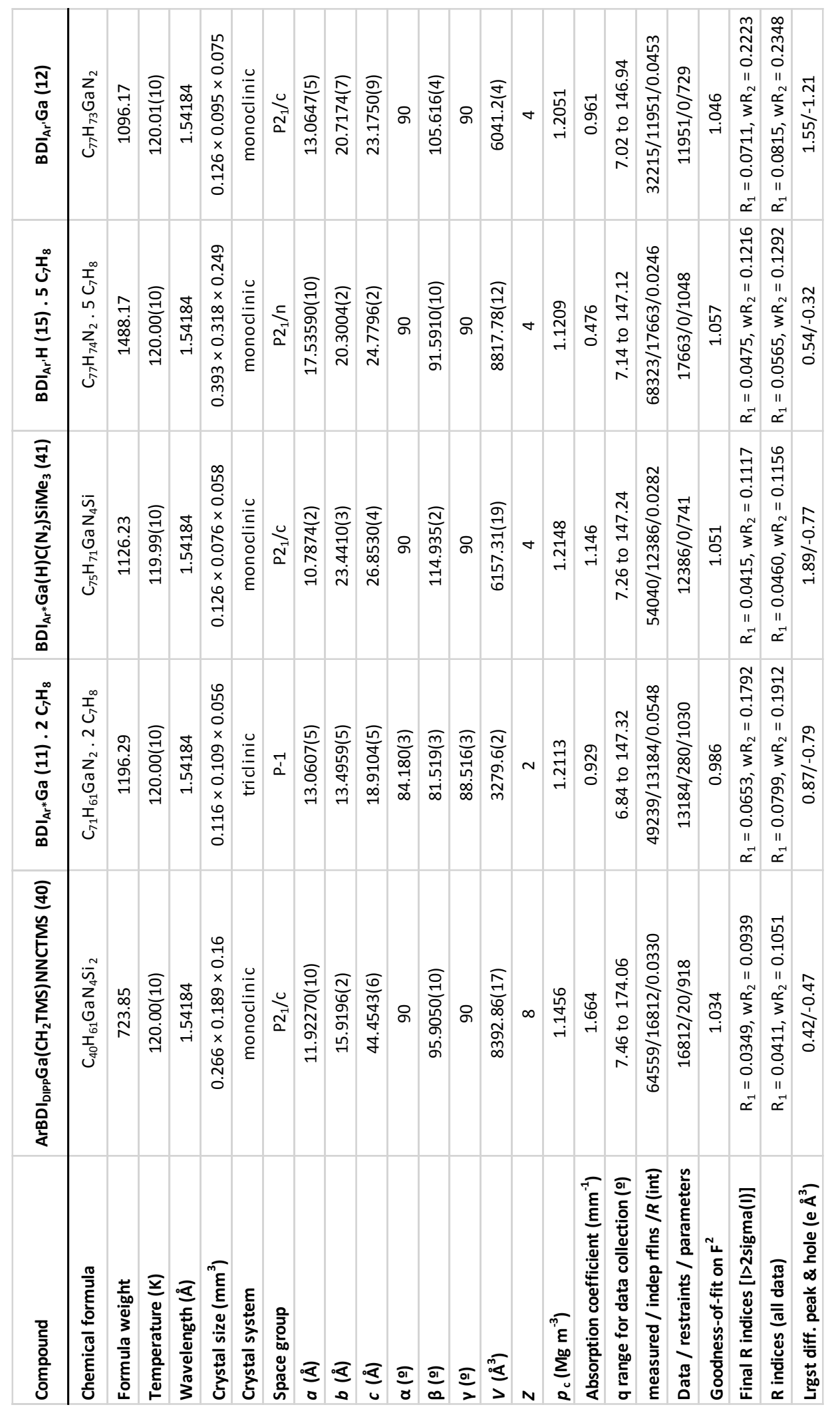




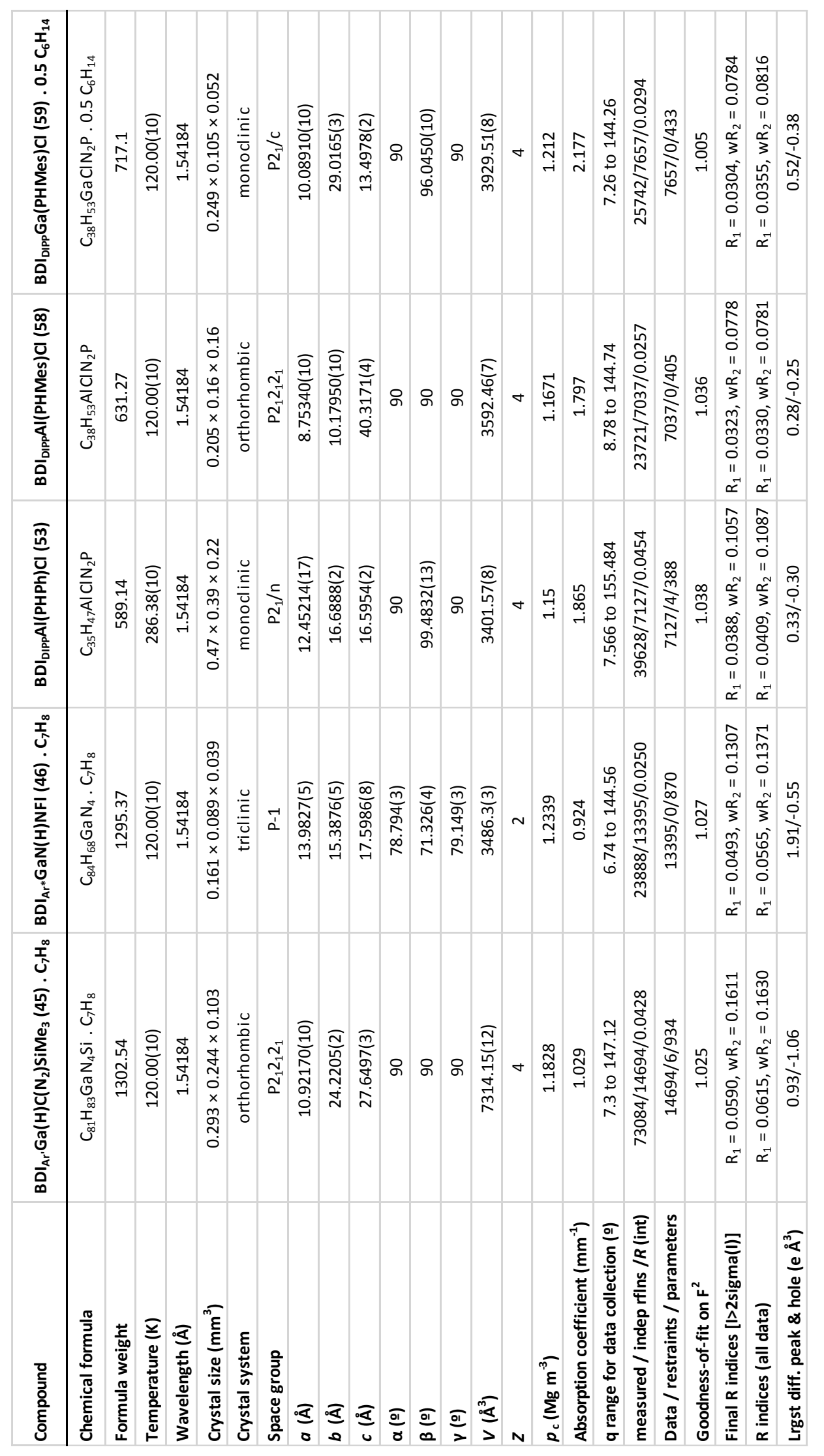




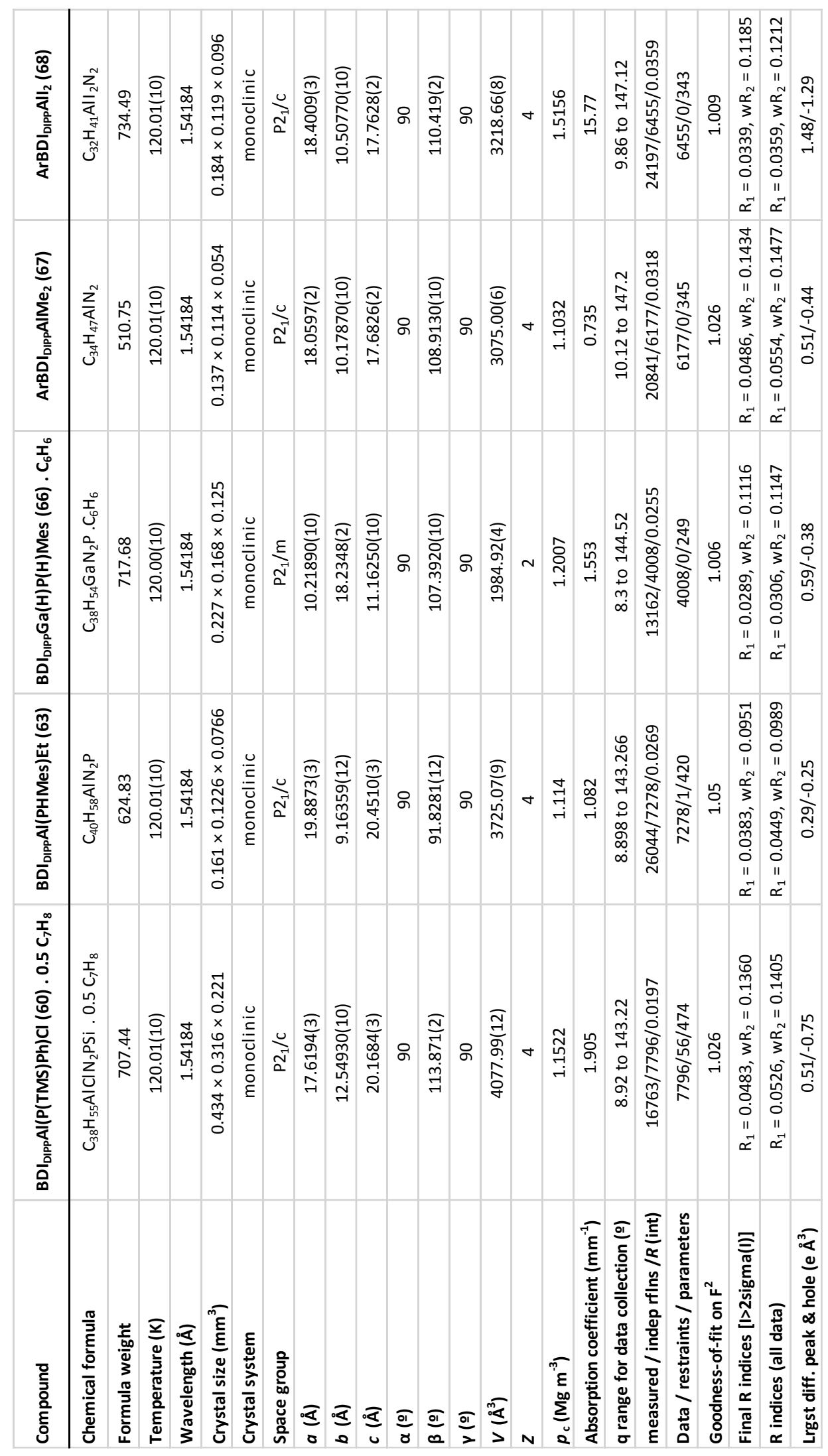




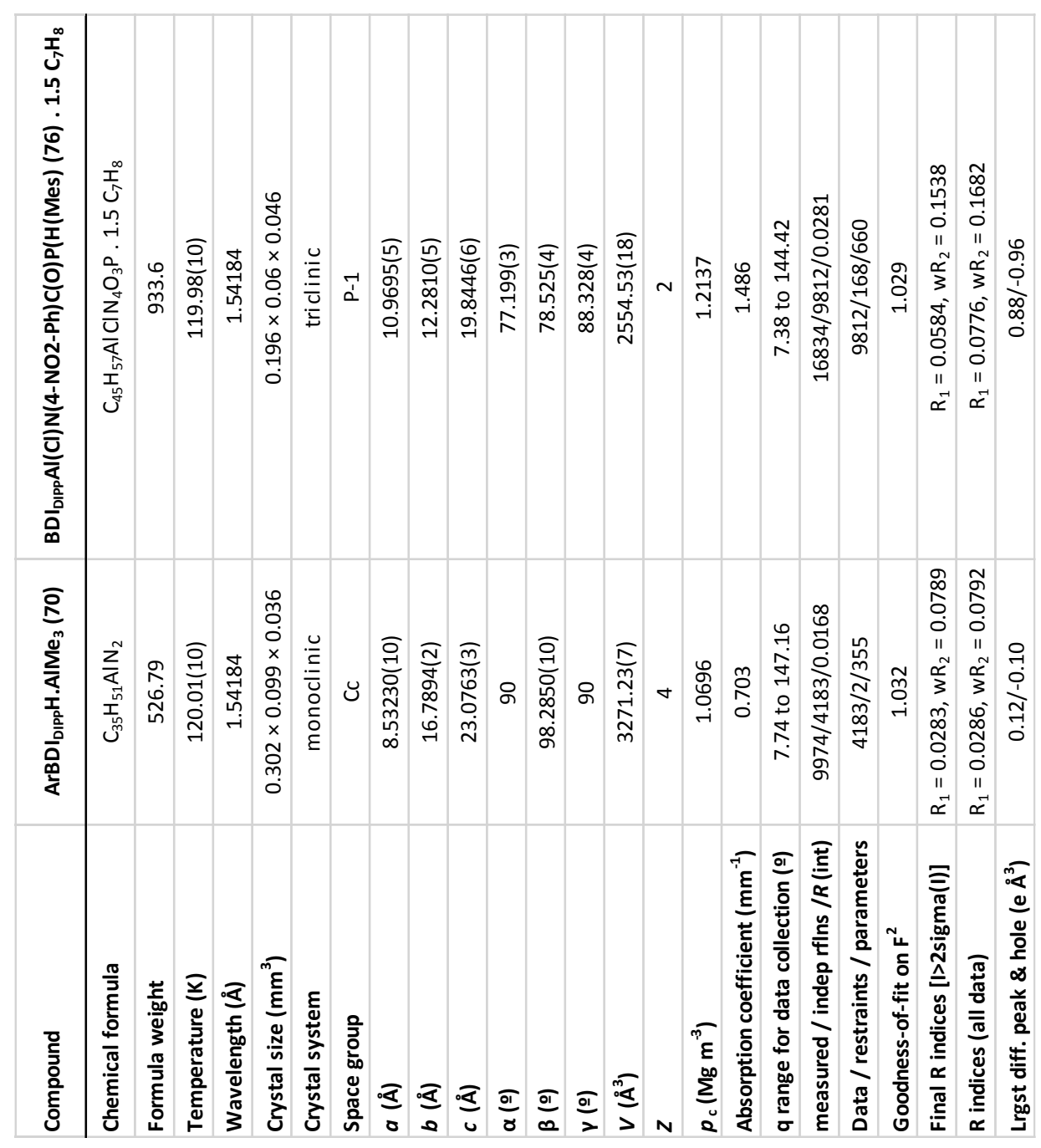




\section{Appendix C: Bibliography}

1. Mann, J. B.; Meek, T. L.; Allen, L. C., Configuration Energies of the Main Group Elements. J. Am. Chem. Soc. 2000, 122 (12), 2780-2783.

2. $\quad$ Alvarez, S., A cartography of the van der Waals territories. Dalton Trans. 2013, 42 (24), 86178636.

3. Rahm, M.; Hoffmann, R.; Ashcroft, N. W., Atomic and lonic Radii of Elements 1-96. Chem. Eur. J. 2016, 22, 14625-14632.

4. Kaltsoyannis, N., Relativistic effects in inorganic and organometallic chemistry. J. Chem. Soc., Dalton Trans. 1997, 1-11.

5. Power, P. P., $\pi$-Bonding and the Lone Pair Effect in Multiple Bonds between Heavier Main Group Elements. Chem. Rev. 1999, 99 (12), 3463-3504.

6. Kutzelnigg, W., Chemical bonding in the higher major group elements. Angew. Chem. 1984, 96, 262-86.

7. Pyykko, P., Relativistic effects in structural chemistry. Chem. Rev. 1988, 88, 563-94.

8. Hardman, N. J.; Eichler, B. E.; Power, P. P., Synthesis and characterization of the monomer $\mathrm{Ga}\{(\mathrm{NDippCMe}) \mathrm{CH}\}$ (Dipp = CHPr-2,6): a low valent gallium() carbene analogue. Chemical Communications 2000, (20), 1991-1992.

9. $\quad$ Al-Rafia, S. M. I.; Lummis, P. A.; Ferguson, M. J.; McDonald, R.; Rivard, E., Low-Coordinate Germylene and Stannylene Heterocycles featuring Sterically Tunable Bis(amido)silyl Ligands. Inorg. Chem. 2010, 49 (20), 9709-9717.

10. Shimoni-Livny, L.; Glusker, J. P.; Bock, C. W., Lone Pair Functionality in Divalent Lead Compounds. Inorg. Chem. 1998, 37 (8), 1853-1867.

11. Kaupp, M.; Schleyer, P. v. R., Ab initio study of structures and stabilities of substituted lead compounds. Why is inorganic lead chemistry dominated by Pbll but organolead chemistry by PbIV? J. Am. Chem. Soc. 1993, 115, 1061-73.

12. Ding, Y.; Roesky, H. W.; Noltemeyer, M.; Schmidt, H.-G.; Power, P. P., Synthesis and Structures of Monomeric Divalent Germanium and Tin Compounds Containing a Bulky Diketiminato Ligandt. Organometallics 2001, 20 (6), 1190-1194.

13. Chen, M.; Fulton, J. R.; Hitchcock, P. B.; Johnstone, N. C.; Lappert, M. F.; Protchenko, A. V., Synthesis and theoretical studies on rare three-coordinate lead complexes. Dalton Trans. 2007, (26), 2770-2778.

14. Serrano, O.; Hoppe, E.; Power, P. P., Synthesis of the Sterically Related Nickel Gallanediyl Complexes [Ni(CO)3(GaAr')] $\left(\mathrm{Ar}^{\prime}=\mathrm{C} 6 \mathrm{H} 3-2,6-(\mathrm{C} 6 \mathrm{H} 3-2,6-\mathrm{iPr} 2) 2\right)$ and $[\mathrm{Ni}(\mathrm{CO}) 3(\mathrm{GaL})]$

$(\mathrm{L}=\mathrm{HC}[\mathrm{C}(\mathrm{CH} 3) \mathrm{N}(\mathrm{C} 6 \mathrm{H} 3-2,6-\mathrm{iPr} 2)] 2)$ : Thermal Decomposition of $\left[\mathrm{Ni}(\mathrm{CO}) 3\left(\mathrm{GaAr}^{\prime}\right)\right]$ to give the Cluster [Ni4(CO)7(GaAr')3]. J. Cluster Sci. 2010, 21 (3), 449-460.

15. Turner, J.; Abdalla, J. A. B.; Bates, J. I.; Tirfoin, R.; Kelly, M. J.; Phillips, N.; Aldridge, S., Formation of sub-valent carbenoid ligands by metal-mediated dehydrogenation chemistry: coordination and activation of H2Ga\{(NDippCMe)2CH\}. Chemical Science 2013, 4 (11), 4245-4250. 16. Blackman, A.; Bottle, S.; Mocerino, M.; Schmid, S.; Willie, U., Chemistry. 1st ed.; John Wiley \& Sons Australia, Ltd: 2008.

17. Silaghi-Dumitrescu, I.; Petrar, P.; King, R. B., Theoretical aspects of main group multiple bonded systems. John Wiley \& Sons Ltd.: 2011; p. 1.

18. Jacobsen, H.; Ziegler, T., Nonclassical double bonds in ethylene analogs: influence of Pauli repulsion on trans bending and .pi.-bond strength. A density functional study. J. Am. Chem. Soc. 1994, 116 (9), 3667-3679.

19. Carter, E. A.; Goddard, W. A., III, Relation between singlet-triplet gaps and bond energies. J. Phys. Chem. 1986, 90 (6), 998-1001.

20. Trinquier, G.; Malrieu, J. P.; Riviere, P., Unusual bonding in trans-bent digermene. J. Am. Chem. Soc. 1982, 104 (17), 4529-33. 
21. Trinquier, G.; Malrieu, J. P., Nonclassical distortions at multiple bonds. J. Am. Chem. Soc. 1987, 109 (18), 5303-15.

22. Malrieu, J. P.; Trinquier, G., Trans-bending at double bonds. Occurrence and extent. J. Am. Chem. Soc. 1989, 111 (15), 5916-21.

23. Pearson, R. G., Concerning jahn-teller effects. Proc. Natl. Acad. Sci. U. S. A. 1975, 72 (6), 2104-6.

24. Fischer, R. C.; Power, P. P., Pi-bonding and the lone pair effect in multiple bonds involving heavier main group elements: developments in the new millennium. Chem Rev 2010, 110 (7), 3877923.

25. Bader, R. F. W., Vibrationally induced perturbations in molecular electron distributions. Can. J. Chem. 1962, 40, 1164-75.

26. Wells, A. F., Structural Inorganic Chemistry. OUP Oxford: 1984; p 1279.

27. Magnusson, E., sp Hybridization reconsidered: effect of substitution on the utilization of $s$ and p orbitals. J. Am. Chem. Soc. 1984, 106 (5), 1185-91.

28. Stürmann, M.; Saak, W.; Weidenbruch, M.; Klinkhammer, K. W., A Heteroleptic Diplumbene and a Magnesium Dibromide Stabilized Plumbylene Dimer. Eur. J. Inorg. Chem. 1999, 1999 (4), 579582.

29. Pearson, R. G., Symmetry rule for predicting molecular structures. J. Amer. Chem. Soc. 1969, 91 (18), 4947-55.

30. Phillips, A. D.; Wright, R. J.; Olmstead, M. M.; Power, P. P., Synthesis and Characterization of 2,6-Dipp2-H3C6SnSnC6H3-2,6-Dipp2 (Dipp = C6H3-2,6-Pri2): A Tin Analog of an Alkyne. J. Am. Chem. Soc. 2002, 124, 5930-5931.

31. Fischer, R. C.; Pu, L.; Fettinger, J. C.; Brynda, M. A.; Power, P. P., Very Large Changes in Bond Length and Bond Angle in a Heavy Group 14 Element Alkyne Analogue by Modification of a Remote Ligand Substituent. J. Am. Chem. Soc. 2006, 128 (35), 11366-11367.

32. Takagi, N.; Nagase, S., Tin Analogues of Alkynes. Multiply Bonded Structures vs Singly Bonded Structures. Organometallics 2007, 26 (3), 469-471.

33. Takagi, N.; Nagase, S., Substituent Effects on Germanium-Germanium and Tin-Tin Triple Bonds. Organometallics 2001, 20 (26), 5498-5500.

34. Peng, Y.; Fischer, R. C.; Merrill, W. A.; Fischer, J.; Pu, L.; Ellis, B. D.; Fettinger, J. C.; Herber, R. H.; Power, P. P., Substituent effects in ditetrel alkyne analogues: multiple vs. single bonded isomers. Chemical Science 2010, 1 (4), 461-468.

35. Wehmschulte, R. J.; Power, P. P., Multiple Ga-Ga Bonding Character in Na2[Ga(GaTrip2)3], and a Comparison with Neutral Ga(GaTrip2)3 (Trip=2,4,6-iPr3C6H2). Angew. Chem., Int. Ed. 1998, 37 (22), 3152-3154.

36. Brothers, P. J.; Hübler, K.; Hübler, U.; Noll, B. C.; Olmstead, M. M.; Power, P. P., A New In4 Cluster with Short In-In Bonds in Trigonal-Planar In(InTrip2)3. Angew. Chem., Int. Ed. Engl. 1996, 35 (20), 2355-2357.

37. Gaspar, P. P.; West, R. In Silylenes, Wiley: 1998; pp 2463-2568.

38. Power, P. P., Main-group elements as transition metals. Nature (London, U. K.) 2010, 463, 171-177.

39. Mizuhata, Y.; Sasamori, T.; Tokitoh, N., Stable Heavier Carbene Analogs. Chem. Rev. 2009, 109, 3479-3511.

40. Davidson, P. J.; Lappert, M. F., Stabilization of metals in a low coordinative environment using the bis(trimethylsilyl)methyl ligand. Colored tin(II) and lead(II) alkyls. J. Chem. Soc., Chem. Commun. 1973, 317.

41. Stürmann, M.; Weidenbruch, M.; Klinkhammer, K. W.; Lissner, F.; Marsmann, H., New Plumbylenes and a Plumbylene Dimer with a Short Lead-Lead Separation,1. Organometallics 1998, $17(20), 4425-4428$. 
42. Goldberg, D. E.; Harris, D. H.; Lappert, M. F.; Thomas, K. M., A new synthesis of divalent group 4B alkyls $\mathrm{M}[\mathrm{CH}(\mathrm{SiMe} 3) 2] 2(\mathrm{M}=\mathrm{Ge}$ or $\mathrm{Sn})$, and the crystal and molecular and molecular strcuture of the tin compound. J. Chem. Soc., Chem. Commun. 1976, (7), 261-262.

43. Stender, M.; Phillips, A. D.; Wright, R. J.; Power, P. P., Synthesis and characterization of a digermanium analog of an alkyne. Angew. Chem., Int. Ed. 2002, 41, 1785-1787.

44. Pu, L.; Twamley, B.; Power, P. P., Synthesis and Characterization of 2,6-Trip2H3C6PbPbC6H32,6-Trip2 (Trip = C6H2-2,4,6-i-Pr3): A Stable Heavier Group 14 Element Analogue of an Alkyne. J. Am. Chem. Soc. 2000, 122, 3524-3525.

45. Gauss, J.; Schneider, U.; Ahlrichs, R.; Dohmeier, C.; Schnoeckel, H., 27AI NMR spectroscopic investigation of aluminum(I) compounds: ab initio calculations and experiment. J. Am. Chem. Soc. 1993, 115 (6), 2402-2408.

46. Loos, D.; Baum, E.; Ecker, A.; Schnöckel, H.; Downs, A. J., Hexameric Aggregates in Crystalline (Pentamethylcyclopentadienyl)gallium(I) at 200 K. Angew. Chem., Int. Ed. Engl. 1997, 36 (8), 860862.

47. Beachley, O. T.; Churchill, M. R.; Fettinger, J. C.; Pazik, J. C.; Victoriano, L., Synthesis and crystal and molecular structure of In(C5Me5) - an apparent octahedral cluster. J. Am. Chem. Soc. 1986, 108 (15), 4666-4668.

48. Werner, H.; Otto, H.; Kraus, H. J., Die kristallstruktur von TIC5Me5. J. Organomet. Chem. 1986, 315 (3), C57-C60.

49. Dohmeier, C.; Robl, C.; Tacke, M.; Schnöckel, H., The Tetrameric Aluminum(I) Compound [\{Al(n5-C5Me5)\}4]. Angew. Chem., Int. Ed. Engl. 1991, 30 (5), 564-565.

50. Schulz, S.; Roesky, H. W.; Koch, H. J.; Sheldrick, G. M.; Stalke, D.; Kuhn, A., A Simple Synthesis of [(Cp*Al)4] and Its Conversion to the Heterocubanes [(Cp*AlSe)4] and [(Cp*AlTe)4] (Cp* $=\eta 5-$ C5(CH3)5). Angew. Chem., Int. Ed. Engl. 1993, 32 (12), 1729-1731.

51. Haubrich, S. T.; Power, P. P., Monomeric InC6H3-2,6-Trip2 (Trip =-C6H2-2,4,6-i-Pr3) and Its Manganese Complex (n5-C5H5)(CO)2MnInC6H3-2,6-Trip2: One-Coordinate Indium in the Solid State. J. Am. Chem. Soc. 1998, 120 (9), 2202-2203.

52. Wright, R. J.; Phillips, A. D.; Hardman, N. J.; Power, P. P., The "Diindene" ArInInAr (Ar = C6H32,6-Dipp2, Dipp = C6H3-2,6-Pri2). Dimeric versus Monomeric In(I) Aryls: para-Substituent Effects in Terphenyl Ligands. J. Am. Chem. Soc. 2002, 124 (29), 8538-8539.

53. Niemeyer, M.; Power, P. P., Synthesis and Solid-State Structure of 2,6-Trip2C6H3TI (Trip=2,4,6-iPr3C6H2): A Monomeric Arylthallium(I) Compound with a Singly Coordinated Thallium Atom. Angew. Chem., Int. Ed. 1998, 37 (9), 1277-1279.

54. Wright, R. J.; Phillips, A. D.; Hino, S.; Power, P. P., Synthesis and Reactivity of Dimeric Ar'TITIAr' and Trimeric ( $\left.\mathrm{Ar}^{\prime}{ }^{\prime} \mathrm{TI}\right) 3$ ( $\mathrm{Ar} \mathrm{r}^{\prime}, \mathrm{Ar}{ }^{\prime \prime}$ = Bulky Terphenyl Group) Thallium(I) Derivatives: $\mathrm{TI}(\mathrm{I})-\mathrm{TI}(\mathrm{I})$ Bonding in Species Ligated by Monodentate Ligands. J. Am. Chem. Soc. 2005, 127 (13), 4794-4799. 55. Hardman, N. J.; Wright, R. J.; Phillips, A. D.; Power, P. P., Structures, Bonding, and Reaction Chemistry of the Neutral Organogallium(I) Compounds (GaAr)n ( $n=1$ or 2$)$ ( $A r=$ Terphenyl or Related Ligand): An Experimental Investigation of Ga-Ga Multiple Bonding. J. Am. Chem. Soc. 2003, 125 (9), 2667-2679.

56. Zhu, Z.; Fischer, R. C.; Ellis, B. D.; Rivard, E.; Merrill, W. A.; Olmstead, M. M.; Power, P. P.; Guo, J. D.; Nagase, S.; Pu, L., Synthesis, Characterization and Real Molecule DFT Calculations for Neutral Organogallium(I) Aryl Dimers and Monomers: Weakness of Gallium-Gallium Bonds in Digallenes and Digallynes. Chem.--Eur. J. 2009, 15 (21), 5263-5272.

57. Hardman, N. J.; Wright, R. J.; Phillips, A. D.; Power, P. P., Synthesis and Characterization of the Neutral "Digallene" Ar'GaGaAr' and Its Reduction to Na2Ar'GaGaAr' (Ar'=2,6-Dipp2C6H3, Dipp=2,6-iPr2C6H3). Angew. Chem., Int. Ed. 2002, 41 (15), 2842-2844.

58. Harrison, P. G., 12 - Lead. In Comprehensive Organometallic Chemistry, Wilkinson, G.; Stone, F. G. A.; Abel, E. W., Eds. Pergamon: Oxford, 1982; pp 629-680.

59. Brooker, S.; Buijink, J. K.; Edelmann, F. T., Synthesis, structure, and reactivity of the first stable diaryllead(II) compound. Organometallics 1991, 10 (1), 25-26. 
60. Gruetzmacher, H.; Pritzkow, H.; Edelmann, F. T., Synthesis and structure of a monomeric diarylstannylene. Organometallics 1991, 10 (1), 23-25.

61. Bender; Banaszak Holl, M. M.; Kampf, J. W., Synthesis and Characterization of a Novel Diarylgermylene Containing Electron-Withdrawing Groups. Organometallics 1997, 16 (12), 27432745.

62. Jutzi, P.; Schmidt, H.; Neumann, B.; Stammler, H.-G., Bis(2,4,6-tri-tert-butylphenyl)germylene Reinvestigated: Crystal Structure, Lewis Acid Catalyzed $\mathrm{C}-\mathrm{H}$ Insertion, and Oxidation to an Unstable Germanone. Organometallics 1996, 15 (2), 741-746.

63. Wegner, G. L.; Berger, R. J. F.; Schier, A.; Schmidbaur, H., Ligand-Protected Strain-Free Diarylgermylenes. Organometallics 2001, 20 (3), 418-423.

64. Drost, C.; B. Hitchcock, P.; F. Lappert, M.; J.-M. Pierssens, L., The novel, chelating C, Nbidentate 2,6-bis(dimethylamino) phenyl ligand (R-), showing ambidentate $N, N^{\prime}$-character in $M(R) 2$ $(\mathrm{M}=\mathrm{Ge}, \mathrm{Sn}, \mathrm{Pb})$ and $\mathrm{Sn}(\mathrm{R}) \mathrm{X}[\mathrm{X}=\mathrm{N}(\mathrm{SiMe}) 2, \mathrm{CH}(\mathrm{SiMe} 3) 2, \mathrm{Cl}]$. Chemical Communications 1997, (12), 1141-1142.

65. Al-Ktaifani, M. M.; Hitchcock, P. B.; Lappert, M. F.; Nixon, J. F.; Uiterweerd, P., Specific insertion reactions of a germylene, stannylene and plumbylene into the unique $P-P$ bond of the hexaphospha-pentaprismane cage, P6C4tBu4: Crystal and molecular structures of P6C4tBu4ER2 (E = Ge, Sn, R = N(SiMe3)2; E = Pb, R = (C6H3(NMe2)2 -2,6). Dalton Trans. 2008, (21), 2825-2831.

66. Tajima, T.; Takeda, N.; Sasamori, T.; Tokitoh, N., A Kinetically Stabilized Stannanetellone, a Tin-Tellurium Double-Bonded Compound. Organometallics 2006, 25 (15), 3552-3553.

67. Kano, N.; Tokitoh, N.; Okazaki, R., A Novel 1,2-Aryl Migration in Metallanethione: Unusual Formation of an Aryl(arylthio)plumbylene from a Plumbanethione. Organometallics 1997, 16 (20), 4237-4239.

68. Li, L.; Fukawa, T.; Matsuo, T.; Hashizume, D.; Fueno, H.; Tanaka, K.; Tamao, K., A stable germanone as the first isolated heavy ketone with a terminal oxygen atom. Nature Chemistry 2012, 4, 361.

69. Simons, R. S.; Pu, L.; Olmstead, M. M.; Power, P. P., Synthesis and Characterization of the Monomeric Diaryls M\{C6H3-2,6-Mes2\}2 ( $\mathrm{M}=\mathrm{Ge}$, Sn, or Pb; Mes = 2,4,6-Me3C6H2-) and Dimeric Aryl-Metal Chlorides [M(Cl)\{C6H3-2,6-Mes2\}]2 (M = Ge or Sn). Organometallics 1997, 16 (9), 19201925.

70. Hurni, K. L.; Rupar, P. A.; Payne, N. C.; Baines, K. M., On the Synthesis, Structure, and Reactivity of Tetramesityldigermene. Organometallics 2007, 26 (23), 5569-5575.

71. Fink, M. J.; Michalczyk, M. J.; Haller, K. J.; Michl, J.; West, R., X-ray crystal structures for two disilenes. Organometallics 1984, 3 (5), 793-800.

72. Masamune, S.; Murakami, S.; Snow, J. T.; Tobita, H.; Williams, D. J., Molecular structure of tetrakis(2,6-diethylphenyl)disilene. Organometallics 1984, 3 (2), 333-334.

73. Snow, J. T.; Murakami, S.; Masamune, S.; Williams, D. J., Synthesis and characterization of tetrakis(2,6-diethylphenyl)digermene. Tetrahedron Lett. 1984, 25 (38), 4191-4194.

74. Stürmann, M.; Saak, W.; Marsmann, H.; Weidenbruch, M., Tetrakis(2,4,6-

triisopropylphenyl)diplumbene: A Molecule with a Lead-Lead Double Bond. Angew. Chem., Int. Ed. 1999, 38 (1-2), 187-189.

75. Schäfer, H.; Saak, W.; Weidenbruch, M., Azadigermiridines by Addition of Diazomethane or Trimethylsilyldiazomethane to a Digermene1. Organometallics 1999, 18 (16), 3159-3163.

76. Shepherd, B. D.; Powell, D. R.; West, R., Synthesis, geometrical isomerism, and crystal structure of a highly hindered disilene. Organometallics 1989, 8 (11), 2664-2669.

77. Suzuki, H.; Tokitoh, N.; Okazaki, R.; Harada, J.; Ogawa, K.; Tomoda, S.; Goto, M., Synthesis and Structures of Extremely Hindered and Stable Disilenes. Organometallics 1995, 14 (2), 1016-1022.

78. Kobayashi, M.; Hayakawa, N.; Nakabayashi, K.; Matsuo, T.; Hashizume, D.; Fueno, H.; Tanaka, K.; Tamao, K., Highly Coplanar (E)-1,2-Di(1-naphthyl)disilene Involving a Distinct $\mathrm{CH}-\pi$ Interaction with the Perpendicularly Oriented Protecting Eind Group. Chem. Lett. 2014, 43 (4), 432434. 
79. Pu, L.; Phillips, A. D.; Richards, A. F.; Stender, M.; Simons, R. S.; Olmstead, M. M.; Power, P. P., Germanium and Tin Analogues of Alkynes and Their Reduction Products. J. Am. Chem. Soc. 2003, 125 (38), 11626-11636.

80. Spikes, G. H.; Fettinger, J. C.; Power, P. P., Facile Activation of Dihydrogen by an Unsaturated Heavier Main Group Compound. J. Am. Chem. Soc. 2005, 127 (35), 12232-12233.

81. Lei, H.; Fettinger, J. C.; Power, P. P., Synthesis and Structures of Low-Valent Alkynyl Tin and Germanium Complexes Supported by Terphenyl Ligands: Heavier Group 14 Element Enediyne Analogues. Organometallics 2010, 29 (21), 5585-5590.

82. Summerscales, O. T.; Caputo, C. A.; Knapp, C. E.; Fettinger, J. C.; Power, P. P., The Role of Group 14 Element Hydrides in the Activation of C-H Bonds in Cyclic Olefins. J. Am. Chem. Soc. 2012, 134 (35), 14595-14603.

83. Sasamori, T.; Hironaka, K.; Sugiyama, Y.; Takagi, N.; Nagase, S.; Hosoi, Y.; Furukawa, Y.; Tokitoh, N., Synthesis and Reactions of a Stable 1,2-Diaryl-1,2-dibromodisilene: A Precursor for Substituted Disilenes and a 1,2-Diaryldisilyne. J. Am. Chem. Soc. 2008, 130 (42), 13856-13857. 84. Sugiyama, Y.; Sasamori, T.; Hosoi, Y.; Furukawa, Y.; Takagi, N.; Nagase, S.; Tokitoh, N., Synthesis and Properties of a New Kinetically Stabilized Digermyne: New Insights for a Germanium Analogue of an Alkyne. J. Am. Chem. Soc. 2006, 128 (3), 1023-1031.

85. Bouslikhane, M.; Gornitzka, H.; Escudié, J.; Ranaivonjatovo, H., New routes to diarsenes and arsaphosphenes involving fluorinated arsines. J. Organomet. Chem. 2001, 619 (1), 275-279.

86. Bouslikhane, M.; Gornitzka, H.; Ranaivonjatovo, H.; Escudié, J., From the New Arsaalkene $\operatorname{ArAsC}(\mathrm{Br}) \mathrm{SiMe} 3$ to the First Stable Arsaallene, ArAsCCR2 (Ar = 2,4,6-Tri-tert-butylphenyl, CR2 = Fluorenylidene). Organometallics 2002, 21 (8), 1531-1533.

87. Ahlemann, J.-T.; Künzel, A.; Roesky, H. W.; Noltemeyer, M.; Markovskii, L.; Schmidt, H.-G., Synthesis and Structure of the First Stable Iminoarsane. Inorg. Chem. 1996, 35 (23), 6644-6645.

88. Lee, V. Y.; Aoki, S.; Kawai, M.; Meguro, T.; Sekiguchi, A., Stibasilene Sb=Si and Its Lighter Homologues: A Comparative Study. J. Am. Chem. Soc. 2014, 136 (17), 6243-6246.

89. Cowley, A. H.; Lasch, J. G.; Norman, N. C.; Pakulski, M., Synthesis and structure of a diarsene: the first compound with an unsupported arsenic-arsenic double bond. J. Am. Chem. Soc. 1983, 105 (16), 5506-5507.

90. Tokitoh, N.; Arai, Y.; Okazaki, R.; Nagase, S., Synthesis and Characterization of a Stable Dibismuthene: Evidence for a Bi-Bi Double Bond. Science 1997, 277 (5322), 78-80.

91. Takahiro, S.; Yoshimitsu, A.; Nobuhiro, T.; Renji, O.; Yukio, F.; Masahiro, K.; Shigeru, N.; Norihiro, T., Syntheses, Structures and Properties of Kinetically Stabilized Distibenes and Dibismuthenes, Novel Doubly Bonded Systems between Heavier Group 15 Elements. Bull. Chem. Soc. Jpn. 2002, 75 (4), 661-675.

92. Sasamori, T.; Takeda, N.; Tokitoh, N., Synthesis of a stable stibabismuthene; the first compound with an antimony-bismuth double bond. Chemical Communications 2000, (15), 13531354.

93. Tokitoh, N.; Arai, Y.; Sasamori, T.; Okazaki, R.; Nagase, S.; Uekusa, H.; Ohashi, Y., A Unique Crystalline-State Reaction of an Overcrowded Distibene with Molecular Oxygen: The First Example of a Single Crystal to a Single Crystal Reaction with an External Reagent. J. Am. Chem. Soc. 1998, 120 (2), 433-434.

94. Sasamori, T.; Takeda, N.; Fujio, M.; Kimura, M.; Nagase, S.; Tokitoh, N., Synthesis and Structure of the First Stable Phosphabismuthene. Angew. Chem., Int. Ed. 2002, 41 (1), 139-141.

95. Twamley, B.; Sofield, C. D.; Olmstead, M. M.; Power, P. P., Homologous Series of Heavier Element Dipnictenes 2,6-Ar2H3C6E=EC6H3-2,6-Ar2 (E = P, As, Sb, Bi; Ar = Mes = C6H2-2,4,6-Me3; or Trip $=$ C6H2-2,4,6-iPr3) Stabilized by m-Terphenyl Ligands. J. Am. Chem. Soc. 1999, 121 (14), 33573367.

96. Wolf, R.; Fischer, J.; Fischer, R. C.; Fettinger, J. C.; Power, P. P., Reactions of Terphenylbismuth Dihalides with $\mathrm{KSi}(\mathrm{SiMe} 3) 3, \mathrm{~K} 2 \mathrm{Si2}(\mathrm{SiMe} 3) 4$ and $\mathrm{Na2}[\mathrm{Fe}(\mathrm{CO})] 4$ : Reduction vs. Metathesis. Eur. J. Inorg. Chem. 2008, 2008 (16), 2515-2521. 
97. Twamley, B.; P. Power, P., Unsymmetric dipnictenes-synthesis and characterization of MesP=EC6H3-2,6-Trip2 (E = As or Sb; Mes = C6H2-2,4,6-Me3, Trip = C6H2-2,4,6-Pri3). Chemical Communications 1998, (18), 1979-1980.

98. Šimon, P.; de Proft, F.; Jambor, R.; Růžička, A.; Dostál, L., Monomeric Organoantimony(I) and Organobismuth(I) Compounds Stabilized by an NCN Chelating Ligand: Syntheses and Structures. Angew. Chem., Int. Ed. 2010, 49 (32), 5468-5471.

99. Vránová, I.; Alonso, M.; Lo, R.; Sedlák, R.; Jambor, R.; Růžička, A.; Proft, F. D.; Hobza, P.; Dostál, L., From Dibismuthenes to Three- and Two-Coordinated Bismuthinidenes by Fine Ligand Tuning: Evidence for Aromatic BiC3N Rings through a Combined Experimental and Theoretical Study. Chem.--Eur. J. 2015, 21 (47), 16917-16928.

100. Vránová, I.; Alonso, M.; Jambor, R.; Růžička, A.; Turek, J.; Dostál, L., Different Products of the Reduction of (N),C,N-Chelated Antimony(III) Compounds: Competitive Formation of Monomeric Stibinidenes versus 1H-2,1-Benzazastiboles. Chem.--Eur. J. 2017, 23 (10), 2340-2349.

101. Lappert, M.; Protchenko, A.; Power, P.; Seebe, A., Metal Amide Chemistry. Wiley: 2008.

102. Coles, M. P., The role of the bis-trimethylsilylamido ligand, [N\{SiMe3\}2]-, in main group chemistry. Part 1: Structural chemistry of the s-block elements. Coord. Chem. Rev. 2015, 297-298, 223.

103. Coles, M. P., The role of the bis-trimethylsilylamido ligand, [N\{SiMe3\}2]-, in main group chemistry. Part 2: Structural chemistry of the metallic p-block elements. Coord. Chem. Rev. 2015, 297-298, 24-39.

104. Kays, D. L., Extremely bulky amide ligands in main group chemistry. Chem. Soc. Rev. 2016, 45 (4), 1004-1018.

105. Wright, R. J.; Brynda, M.; Fettinger, J. C.; Betzer, A. R.; Power, P. P., Quasi-Isomeric Gallium Amides and Imides GaNR2 and RGaNR ( $R=$ Organic Group): Reactions of the Digallene, $\mathrm{Ar}^{\prime} \mathrm{GaGaAr}$ $\left(\mathrm{Ar}^{\prime}=\mathrm{C} 6 \mathrm{H} 3-2,6-(\mathrm{C} 6 \mathrm{H} 3-2,6-\mathrm{Pri2}) 2\right)$ with Unsaturated Nitrogen Compounds. J. Am. Chem. Soc. 2006, 128 (38), 12498-12509.

106. Wright, R. J.; Brynda, M.; Power, P. P., A Monomeric Thallium(I) Amide in the Solid State: Synthesis and Structure of TIN(Me)ArMes2 (ArMes2 = C6H3-2,6-Mes2). Inorg. Chem. 2005, 44 (10), 3368-3370.

107. Waezsada, S. D.; Belgardt, T.; Noltemeyer, M.; Roesky, H. W., [2,6-iPr2C6H3(Me3Si)NTI]4-A Covalent Thallium(I)-Nitrogen Compound with Weak Arene-Thallium Interactions. Angew. Chem., Int. Ed. Engl. 1994, 33 (13), 1351-1352.

108. Dange, D.; Li, J.; Schenk, C.; Schnöckel, H.; Jones, C., Monomeric Group 13 Metal(I) Amides: Enforcing One-Coordination Through Extreme Ligand Steric Bulk. Inorg. Chem. 2012, 51 (23), 1305013059.

109. Roesky, H. W., Renaissance of aluminum chemistry. An. Acad. Nac. Cienc. Exactas, Fis. Nat. (Buenos Aires) 2005, 57, 71-75.

110. Saur, I.; Alonso, S. G.; Barrau, J., Three-coordinate divalent Group 14 element derivatives and related compounds. Appl. Organomet. Chem. 2005, 19 (4), 414-428.

111. Scheibe, G., Über die Farbe der Di- und Tri-[chinolyl-2]-methane und ihrer Abkömmlinge. Berichte der deutschen chemischen Gesellschaft (A and B Series) 1923, 56 (1), 137-148.

112. Parks, J. E.; Holm, R. H., Synthesis, solution stereochemistry, and electron delocalization properties of bis(.beta.-iminoamino)nickel(II) complexes. Inorg. Chem. 1968, 7 (7), 1408-1416.

113. Feldman, J.; McLain, S. J.; Parthasarathy, A.; Marshall, W. J.; Calabrese, J. C.; Arthur, S. D., Electrophilic Metal Precursors and a $\beta$-Diimine Ligand for Nickel(II)- and Palladium(II)-Catalyzed Ethylene Polymerization. Organometallics 1997, 16 (8), 1514-1516.

114. Cheng, M.; Lobkovsky, E. B.; Coates, G. W., Catalytic Reactions Involving C1 Feedstocks: New High-Activity Zn(II)-Based Catalysts for the Alternating Copolymerization of Carbon Dioxide and Epoxides. J. Am. Chem. Soc. 1998, 120 (42), 11018-11019.

115. Xue, M.; Shen, Q.; Hong, Y. A $\beta$-diimino bivalent rare-earth hydroboron complexes and the preparation method and application thereof. CN104140436, 2014. 
116. Clegg, W.; Cope, E. K.; Edwards, A. J.; Mair, F. S., Structural Characterization of [(2,6Pri2C6H3) NC(Me)C(H)C(Me)N(2,6-Pri2C6H3)K·PhCH3] $\infty$ : A Heavy Alkali Metal Diazapentadienyl Complex. Inorg. Chem. 1998, 37 (9), 2317-2319.

117. Sun, S.; Ouyang, H.; Luo, Y.; Zhang, Y.; Shen, Q.; Yao, Y., Synthesis of $\beta$-diketiminate-ligated bimetallic and monometallic lanthanide amide complexes and their reactivity with isoprene and AlMe3. Dalton Trans. 2013, 42 (46), 16355-16364.

118. Hitchcock, P. B.; Lappert, M. F.; Liu, D.-S., Transformation of the bis(trimethylsilyl)methyl into a $\beta$-diketinimato ligand; the $X$-ray structure of $\left[\mathrm{Li}^{\prime}\left(\mathrm{L}^{\prime} \mathrm{L}^{\prime}\right)\right] 2, \mathrm{SnCl}(\mathrm{Me}) 2\left(\mathrm{~L}^{\prime} \mathrm{L}^{\prime}\right)$ and $\mathrm{SnCl}(\mathrm{Me}) 2(\mathrm{LL})$, $\left[L^{\prime} L^{\prime}=N(R) C(P h) C(H) C(P h) N R, L L=N(H) C(P h) C(H) C(P h) N H, R=S i M e 3\right)$. J. Chem. Soc., Chem. Commun. 1994, (14), 1699-1700.

119. Reynolds, A. M.; Gherman, B. F.; Cramer, C. J.; Tolman, W. B., Characterization of a 1:1 Cu-O2 Adduct Supported by an Anilido Imine Ligand. Inorg. Chem. 2005, 44 (20), 6989-6997.

120. Arrowsmith, M.; Maitland, B.; Kociok-Kohn, G.; Stasch, A.; Jones, C.; Hill, M. S., Mononuclear Three-Coordinate Magnesium Complexes of a Highly Sterically Encumbered $\beta$-Diketiminate Ligand. Inorg. Chem. 2014, 53, 10543-10552.

121. Bourget-Merle, L.; Lappert, M. F.; Severn, J. R., The Chemistry of $\beta$-Diketiminatometal Complexes. Chem. Rev. 2002, 102 (9), 3031-3066.

122. Coles, M. P.; Jordan, R. F., Cationic Aluminum Alkyl Complexes Incorporating Amidinate Ligands. Transition-Metal-Free Ethylene Polymerization Catalysts. J. Am. Chem. Soc. 1997, 119 (34), 8125-8126.

123. Radzewich, C. E.; Guzei, I. A.; Jordan, R. F., Three-Coordinate Cationic Aluminum Alkyl Complexes Incorporating $\beta$-Diketiminate Ligands. J. Am. Chem. Soc. 1999, 121 (37), 8673-8674.

124. Cui, C.; Roesky, H. W.; Schmidt, H.-G.; Noltemeyer, M.; Hao, H.; Cimpoesu, F., Synthesis and Structure of a Monomeric Aluminum(I) Compound [ $\mathrm{HC}(\mathrm{CMeNAr}) 2\} \mathrm{Al}]$ ( $\mathrm{Ar}=2,6-\mathrm{iPr} 2 \mathrm{C} 6 \mathrm{H} 3)$ : A Stable Aluminum Analogue of a Carbene. Angew. Chem., Int. Ed. 2000, 39 (23), 4274-4276.

125. Chu, T.; Korobkov, I.; Nikonov, G. I., Oxidative Addition of $\sigma$ Bonds to an Al(I) Center. J. Am. Chem. Soc. 2014, 136 (25), 9195-9202.

126. Chu, T.; Boyko, Y.; Korobkov, I.; Nikonov, G. I., Transition Metal-like Oxidative Addition of C-F and C-O Bonds to an Aluminum(I) Center. Organometallics 2015, 34 (22), 5363-5365.

127. Chu, T.; Boyko, Y.; Korobkov, I.; Kuzmina, L. G.; Howard, J. A. K.; Nikonov, G. I., Oxidative Addition of Disulfides, Alkyl Sulfides, and Diphosphides to an Aluminum(I) Center. Inorg. Chem. 2016, 55 (17), 9099-9104.

128. Zhu, H.; Chai, J.; Jancik, V.; Roesky, H. W.; Merrill, W. A.; Power, P. P., The Selective Preparation of an Aluminum Oxide and Its Isomeric C-H-Activated Hydroxide. J. Am. Chem. Soc. 2005, 127 (29), 10170-10171.

129. Ganesamoorthy, C.; Blaeser, D.; Woelper, C.; Schulz, S., Temperature-Dependent Electron Shuffle in Molecular Group 13/15 Intermetallic Complexes. Angew. Chem., Int. Ed. 2014, 53 (43), 11587-11591.

130. Ganesamoorthy, C.; Blaeser, D.; Woelper, C.; Schulz, S., Sequential Bi-C bond activation reactions of BiEt3 via insertion reactions of $\mathrm{RE}\{\mathrm{R}=\mathrm{HC}[\mathrm{C}(\mathrm{Me}) \mathrm{N}(2,6-\mathrm{i}-\mathrm{Pr} 2 \mathrm{C} 6 \mathrm{H} 3)] 2 ; \mathrm{E}=\mathrm{Al}, \mathrm{Ga}, \mathrm{In}\}$. Chemical Communications 2014, 50 (82), 12382-12384.

131. Zhu, H.; Oswald, R. B.; Fan, H.; Roesky, H. W.; Ma, Q.; Yang, Z.; Schmidt, H.-G.; Noltemeyer, M.; Starke, K.; Hosmane, N. S., Aluminacyclopropene: Syntheses, Characterization, and Reactivity toward Terminal Alkynes. J. Am. Chem. Soc. 2006, 128 (15), 5100-5108.

132. Ottosson, H.; Eklöf, A. M., Silenes: Connectors between classical alkenes and nonclassical heavy alkenes. Coord. Chem. Rev. 2008, 252 (12), 1287-1314.

133. Liang, C.; Allen, L. C., Group IV double bonds: shape deformation and substituent effects. J. Am. Chem. Soc. 1990, 112 (3), 1039-1041.

134. Breidung, J.; Thiel, W., Anharmonic force field and spectroscopic constants of silene. An ab initio study. Theor. Chem. Acc. 1998, 100 (1-4), 183-190. 
135. Bessac, F.; Frenking, G., Chemical Bonding in Phosphane and Amine Complexes of Main Group Elements and Transition Metals. Inorg. Chem. 2006, 45 (17), 6956-6964.

136. Zhu, H.; Chai, J.; Chandrasekhar, V.; Roesky, H. W.; Magull, J.; Vidovic, D.; Schmidt, H.-G.; Noltemeyer, M.; Power, P. P.; Merrill, W. A., Two Types of Intramolecular Addition of an Al-N Multiple-Bonded Monomer LAINAr' Arising from the Reaction of LAI with N3Ar' $(\mathrm{L}=$ $\left.\mathrm{HC}[(\mathrm{CMe})(\mathrm{NAr})] 2, \mathrm{Ar}^{\prime}=2,6-\mathrm{Ar} 2 \mathrm{C} 6 \mathrm{H} 3, \mathrm{Ar}=2,6-\mathrm{iPr} 2 \mathrm{C} 6 \mathrm{H} 3\right)$. J. Am. Chem. Soc. 2004, 126 (31), $9472-$ 9473.

137. Wright, R. J.; Phillips, A. D.; Allen, T. L.; Fink, W. H.; Power, P. P., Synthesis and Characterization of the Monomeric Imides $\operatorname{Ar}^{\prime} \mathrm{MNAr}^{\prime \prime}$ (M = Ga or In; $\mathrm{Ar}^{\prime}$ or Ar' " = Terphenyl Ligands) with Two-Coordinate Gallium and Indium. J. Am. Chem. Soc. 2003, 125 (7), 1694-1695.

138. Li, J.; Li, X.; Huang, W.; Hu, H.; Zhang, J.; Cui, C., Synthesis, Structure, and Reactivity of a Monomeric Iminoalane. Chem.--Eur. J. 2012, 18 (48), 15263-15266.

139. Krüger, J.; Ganesamoorthy, C.; John, L.; Wölper, C.; Schulz, S., A General Pathway for the Synthesis of Gallastibenes containing Ga=Sb Double Bonds. Chem.--Eur. J. 2018, 24 (36), 9157-9164.

140. Helling, C.; Wölper, C.; Schulz, S., Synthesis of a Gallaarsene $\{\mathrm{HC}[\mathrm{C}(\mathrm{Me}) \mathrm{N}-2,6-\mathrm{i}-\mathrm{Pr2}-$ C6H3]2\}GaAsCp* Containing a Ga=As Double Bond. J. Am. Chem. Soc. 2018, 140 (15), 5053-5056.

141. Hardman, N. J.; Cui, C.; Roesky, H. W.; Fink, W. H.; Power, P. P., Stable, Monomeric Imides of Aluminum and Gallium: Synthesis and Characterization of [\{HC(MeCDippN)2\}MN-2,6-Trip2C6H3] ( $\mathrm{M}=\mathrm{Al}$ or Ga; Dipp=2,6-iPr2C6H3; Trip=2,4,6-iPr3C6H2). Angew. Chem., Int. Ed. 2001, 40 (11), 21722174.

142. Pandey, K. K.; Vishwakarma, R.; Patidar, S. K., Theoretical insights into the nature of bonding in group 13-group 15 compounds [REE'R] $\left(E=B-T l ; E^{\prime}=N-B i ; R=M e, P h, A r\right)$ : Bonding energy analysis. Computational and Theoretical Chemistry 2016, 1076, 23-31.

143. Jones, C.; Stasch, A. In The chemistry of the group 13 metals in the +1 oxidation state, John Wiley \&amp; Sons Ltd.: 2011; p 285.

144. Weetman, C.; Inoue, S., The Road Travelled: After Main-Group Elements as Transition Metals. ChemCatChem 2018, 10 (19), 4213-4228.

145. Jana, A.; Ghoshal, D.; Roesky, H. W.; Objartel, I.; Schwab, G.; Stalke, D., A Germanium(II) Hydride as an Effective Reagent for Hydrogermylation Reactions. J. Am. Chem. Soc. 2009, 131 (3), 1288-1293.

146. Jana, A.; Tavčar, G.; Roesky, H. W.; John, M., Germanium(ii) hydride mediated reduction of carbon dioxide to formic acid and methanol with ammonia borane as the hydrogen source. Dalton Trans. 2010, 39 (40), 9487-9489.

147. Hicks, J.; Vasko, P.; Goicoechea, J. M.; Aldridge, S., Synthesis, structure and reaction chemistry of a nucleophilic aluminyl anion. Nature 2018, 557 (7703), 92-95.

148. Sammakia, T. In Diazomethane, John Wiley \& Sons, Ltd.: 2001; pp 1-7.

149. Davis, P. J.; Harris, L.; Karim, A.; Thompson, A. L.; Gilpin, M.; Moloney, M. G.; Pound, M. J.; Thompson, C., Substituted diaryldiazomethanes and diazofluorenes: structure, reactivity and stability. Tetrahedron Lett. 2011, 52 (14), 1553-1556.

150. Regitz, M.; Maas, G., Diazo Compounds. Properties and Synthesis. Academic: 1986; p 596 pp.

151. Werner, H.; Fluegel, R.; Windmueller, B.; Michenfelder, A.; Wolf, J., Synthesis and Reactions of Stable 16-Electron Osmium(0) Complexes [OsCl(NO)(PR3)2] Including the X-ray Crystal Structure of [OsCl2(NO)(n1-CH:C:CPh2)(P-i-Pr3)2]. Organometallics 1995, 14, 612-18.

152. Werner, H.; Stueer, W.; Laubender, M.; Lehmann, C.; Herbst-Irmer, R., Stable Osmium Hydrido-Carbene Complexes with $\mathrm{CH} 2$ and Secondary Carbenes $\mathrm{CHR}$ as Ligands. Organometallics 1997, 16, 2236-2238.

153. Werner, H.; Stüer, W.; Wolf, J.; Laubender, M.; Weberndörfer, B.; Herbst-Irmer, R.; Lehmann, C., Hydrido(carbene), Hydrido(diazoalkane), Aqua(carbene), and Vinyl(carbene) Complexes of Osmium(II). Eur. J. Inorg. Chem. 1999, 1999 (11), 1889-1897.

154. Christen, D. P. In Dichloro(phenylmethylene)bis(tricyclohexyl)ruthenium, John Wiley \& Sons, Ltd.: 2003; pp 1-17. 
155. Bernal, M. J.; Torres, O.; Martín, M.; Sola, E., Reversible Insertion of Carbenes into Ruthenium-Silicon Bonds. J. Am. Chem. Soc. 2013, 135 (50), 19008-19015.

156. Taubmann, C.; Öfele, K.; Herdtweck, E.; Herrmann, W. A., Complexation of (5H)Dibenzo[a,d]cyclohepten-5-ylidene to Palladium(II) via the Diazo Route and Evidence of C-H $\cdots \mathrm{Pd}$ Interactions. Organometallics 2009, 28 (15), 4254-4257.

157. Barrett, B. J.; Iluc, V. M., An Adaptable Chelating Diphosphine Ligand for the Stabilization of Palladium and Platinum Carbenes. Organometallics 2017, 36 (3), 730-741.

158. Hofmann, P.; Shishkov, I. V.; Rominger, F., Synthesis, Molecular Structures, and Reactivity of Mono- and Binuclear Neutral Copper(I) Carbenes. Inorg. Chem. 2008, 47 (24), 11755-11762.

159. Mindiola, D. J.; Hillhouse, G. L., Synthesis, Structure, and Reactions of a Three-Coordinate Nickel-Carbene Complex, \{1,2-Bis(di-tert-butylphosphino)ethane\}NiCPh2. J. Am. Chem. Soc. 2002, 124 (34), 9976-9977.

160. Iluc, V. M.; Hillhouse, G. L., Three-Coordinate Nickel Carbene Complexes and Their OneElectron Oxidation Products. J. Am. Chem. Soc. 2014, 136 (17), 6479-6488.

161. Bellow, J. A.; Stoian, S. A.; van Tol, J.; Ozarowski, A.; Lord, R. L.; Groysman, S., Synthesis and Characterization of a Stable High-Valent Cobalt Carbene Complex. J. Am. Chem. Soc. 2016, 138 (17), 5531-5534.

162. Tindall, D. J.; Werlé, C.; Goddard, R.; Philipps, P.; Farès, C.; Fürstner, A., Structure and Reactivity of Half-Sandwich $\mathrm{Rh}(+3)$ and $\mathrm{Ir}(+3)$ Carbene Complexes. Catalytic Metathesis of Azobenzene Derivatives. J. Am. Chem. Soc. 2018, 140 (5), 1884-1893.

163. Russell, S. K.; Hoyt, J. M.; Bart, S. C.; Milsmann, C.; Stieber, S. C. E.; Semproni, S. P.; DeBeer, S.; Chirik, P. J., Synthesis, electronic structure and reactivity of bis(imino)pyridine iron carbene complexes: evidence for a carbene radical. Chemical Science 2014, 5 (3), 1168-1174.

164. Rit, A.; Tirfoin, R.; Aldridge, S., Exploiting Electrostatics To Generate Unsaturation: Oxidative $\mathrm{Ge}=\mathrm{E}$ Bond Formation Using a Non $\pi$-Donor Stabilized [R(L)Ge:]+ Cation. Angew. Chem., Int. Ed. 2015, 55 (1), 378-382.

165. Dai, X.; Warren, T. H., Discrete Bridging and Terminal Copper Carbenes in Copper-Catalyzed Cyclopropanation. J. Am. Chem. Soc. 2004, 126 (32), 10085-10094.

166. Iluc, V. M.; Laskowski, C. A.; Hillhouse, G. L., Synthesis of Bis(phosphine) and N-Heterocyclic Carbene Supported $\alpha$-Diazoalkyl Complexes of Copper(I). Organometallics 2009, 28 (20), 6135-6138. 167. Harrold, N. D.; Corcos, A. R.; Hillhouse, G. L., Synthesis, structures, and catalytic reactivity of bis(N-heterocyclic carbene) supported diphenyldiazomethane and 1-azidoadamantane complexes of nickel. J. Organomet. Chem. 2016, 813, 46-54.

168. Ortmann, D. A.; Weberndörfer, B.; Ilg, K.; Laubender, M.; Werner, H., Carbene Iridium(I) and Iridium(III) Complexes Containing the Metal Center in Different Stereochemical Environments. Organometallics 2002, 21 (12), 2369-2381.

169. Chu, J.; Kefalidis, C. E.; Maron, L.; Leng, X.; Chen, Y., Chameleon Behavior of a Newly Synthesized Scandium Nitrilimine Derivative. J. Am. Chem. Soc. 2013, 135 (22), 8165-8168.

170. Uhl, W.; Hannemann, F.; Saak, W.; Wartchow, R., Diazomethane Derivatives Bearing Dialkylaluminium or DialkylgalliumSubstituents - The Isomeric Diazomethane and Nitrile Imine Structures Realized by the Different Coordination Behavior of Aluminium and Gallium. Eur. J. Inorg. Chem. 1999, 1999 (5), 771-776.

171. Emig, N.; Reau, R.; Bertrand, G.; Gabbai, F. P.; Krautscheid, H., The Azide-Nitrilimine Analogy in Aluminum Chemistry. Angew Chem Int Ed Engl 1998, 37 (Copyright (C) 2018 U.S. National Library of Medicine.), 989-992.

172. Uhl, W.; Hannemann, F., The Reaction of Diazomethane Derivatives with the Dielement Compounds R2Al-AIR2 and R2Ga-GaR2 [R = CH(SiMe3)2] - Insertion versus Fragmentation. Eur. J. Inorg. Chem. 1999, 1999 (1), 201-207.

173. Tsui, E. Y.; Müller, P.; Sadighi, J. P., Reactions of a Stable Monomeric Gold(I) Hydride Complex. Angew. Chem., Int. Ed. 2008, 47 (46), 8937-8940. 
174. Dagmar, L.; Hansgeorg, S.; Jürgen, G.; Uwe, S., [Ga(C5H5)]: Synthese, Identifizierung und abinitio-Untersuchungen. Angew. Chem. 1992, 104 (10), 1376-1378.

175. Kuchta, M. C.; Bonanno, J. B.; Parkin, G., A Monovalent Gallium Complex Supported by Tris(3,5-di-tert-butylpyrazolyl)hydroborato Ligation: The Syntheses and Structures of [TpBut2]Ga and Its Gal3 Adduct, [TpBut2] Ga $\rightarrow$ Gal31. J. Am. Chem. Soc. 1996, 118 (44), 10914-10915.

176. Dange, D.; Choong, S. L.; Schenk, C.; Stasch, A.; Jones, C., Synthesis and characterisation of anionic and neutral gallium(i) N-heterocyclic carbene analogues. Dalton Trans. 2012, 41 (31), 93049315.

177. Hardman, N. J.; Power, P. P.; Gorden, J. D.; Macdonald, C. L. B.; Cowley, A. H., Gallium-boron donor-acceptor bonds. Chemical Communications 2001, (18), 1866-1867.

178. Ganesamoorthy, C.; Matthias, M.; Blaser, D.; Wolper, C.; Schulz, S., Lewis acid-base adducts of group 13 elements: synthesis, structure and reactivity toward benzaldehyde. Dalton Trans. 2016, 45 (28), 11437-11444.

179. Burford, N.; Ragogna, P. J.; Robertson, K. N.; Cameron, T. S.; Hardman, N. J.; Power, P. P., Coordination Chemistry Umpolung: A Gallane Ligand on a Phosphine Lewis Acceptor. J. Am. Chem. Soc. 2002, 124 (3), 382-383.

180. Kempter, A.; Gemel, C.; Fischer, R. A., Insertion of Ga(DDP) into the $\mathrm{Au}-\mathrm{Cl}$ Bond of (PPh3)AuCl: A First Structurally Characterized Au-Ga Bond. Inorg. Chem. 2005, 44 (2), 163-165.

181. Kempter, A.; Gemel, C.; Cadenbach, T.; Fischer, R. A., Nickel Olefin Complexes Supported by Gal(DDP). Organometallics 2007, 26 (17), 4257-4264.

182. Chakraborty, U.; Mühldorf, B.; van Velzen, N. J. C.; de Bruin, B.; Harder, S.; Wolf, R., [CpArNi\{Ga(nacnac)\}]: An Open-Shell Nickel(I) Complex Supported by a Gallium(I) Carbenoid (CpAr = $\mathrm{C} 5(\mathrm{C} 6 \mathrm{H} 4-4-\mathrm{Et}) 5$, nacnac $=\mathrm{HC}[\mathrm{C}(\mathrm{Me}) \mathrm{N}-(\mathrm{C6H} 3)-2,6-\mathrm{PPr} 2] 2)$. Inorg. Chem. 2016, 55 (6), 3075-3078.

183. Serrano, O.; Hoppe, E.; Fettinger, J. C.; Power, P. P., Synthesis and characterization of the

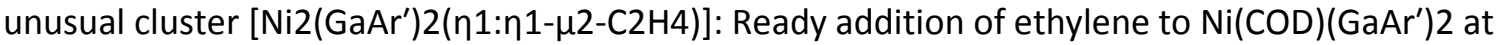
$25^{\circ} \mathrm{C}$ and 1 atmosphere. J. Organomet. Chem. 2011, 696 (10), 2217-2219.

184. Kempter, A.; Gemel, C.; Fischer, R. A., Pt(0) and Pd(0) Olefin Complexes of the Metalloid NHeterocyclic Carbene Analogues [EI(ddp)] (ddp=2-\{(2,6-diisopropylphenyl)amino\}-4-\{(2,6diisopropylphenyl)imino\}-2-pentene; $\mathrm{E}=\mathrm{Al}, \mathrm{Ga}$ ): Ligand Substitution, $\mathrm{H}-\mathrm{H}$ and Si-H Bond Activation, and Cluster Formation. Chem.--Eur. J. 2007, 13 (10), 2990-3000.

185. Prabusankar, G.; Gonzalez-Gallardo, S.; Doddi, A.; Gemel, C.; Winter, M.; Fischer, R. A., Linear Coinage Metal Complexes Stabilized by a Group 13 Metalloid Ligand. Eur. J. Inorg. Chem. 2010, 2010 (28), 4415-4418.

186. Doddi, A.; Gemel, C.; Winter, M.; Fischer, R. A.; Goedecke, C.; Rzepa, H. S.; Frenking, G., LowValent Ge2 and Ge4 Species Trapped by N-Heterocyclic Gallylene. Angew. Chem., Int. Ed. 2013, 52 (1), 450-454.

187. McCrea-Hendrick, M. L.; Caputo, C. A.; Roberts, C. J.; Fettinger, J. C.; Tuononen, H. M.; Power, P. P., Reactions of Terphenyl-Substituted Digallene AriPr4GaGaAriPr4 (AriPr4 = C6H3-2,6(C6H3-2,6-iPr2)2) with Transition Metal Carbonyls and Theoretical Investigation of the Mechanism of Addition. Organometallics 2016, 35 (4), 579-586.

188. Kempter, A.; Gemel, C.; Hardman, N. J.; Fischer, R. A., Insertion of the Ga(I) Bis-imidinate $\mathrm{Ga}(\mathrm{DDP})$ into the Metal Halogen Bonds of Rh(I) Complexes. How Electrophilic Are Coordinated Ga(DDP) Fragments? Inorg. Chem. 2006, 45 (7), 3133-3138.

189. Kempter, A.; Gemel, C.; Cadenbach, T.; Fischer, R. A., Synthesis and Structure of New Compounds with Zn-Ga Bonds: Insertion of the Gallium(I) Bisimidinate $\mathrm{Ga}(\mathrm{DDP})$ into $\mathrm{Zn}-\mathrm{X}(\mathrm{X}=\mathrm{CH} 3$, $\mathrm{Cl})$ and the Homoleptic Complex Cation [Zn(GaCp*)4]2+. Inorg. Chem. 2007, 46 (22), 9481-9487.

190. Kempter, A.; Gemel, C.; Fischer, R. A., Oxidative Addition of Group 13 and 14 Metal Halides and Alkyls to Ga(DDP) (DDP = Bulky Bisimidinate). Inorg. Chem. 2008, 47 (16), 7279-7285.

191. Prabusankar, G.; Kempter, A.; Gemel, C.; Schröter, M. K.; Fischer, R. A., [Sn17\{GaCl(ddp)\}4]: A High-Nuclearity Metalloid Tin Cluster Trapped by Electrophilic Gallium Ligands. Angew. Chem., Int. Ed. 2008, 47 (38), 7234-7237. 
192. Prabusankar, G.; Gemel, C.; Parameswaran, P.; Flener, C.; Frenking, G.; Fischer, R. A., A Short $\mathrm{Bi}=\mathrm{Bi}$ Bond Supported by a Metalloid Group 13 Ligand. Angew. Chem., Int. Ed. 2009, 48 (30), 55265529.

193. Tuscher, L.; Helling, C.; Wölper, C.; Frank, W.; Nizovtsev, A. S.; Schulz, S., A General Route to Metal-Substituted Dipnictenes of the Type [L(X)M]2E2. Chem.--Eur. J. 2018, 24 (13), 3241-3250.

194. Seifert, A.; Scheid, D.; Linti, G.; Zessin, T., Oxidative Addition Reactions of Element-Hydrogen Bonds with Different Polarities to a Gallium(I) Compound. Chem.--Eur. J. 2009, 15 (44), 12114-12120. 195. Herappe-Mejia, E.; Trujillo-Hernandez, K.; Carlos Garduno-Jimenez, J.; Cortes-Guzman, F.; Martinez-Otero, D.; Jancik, V., Synthesis of substituted [small beta]-diketiminate gallium hydrides via oxidative addition of H-O bonds. Dalton Trans. 2015, 44 (38), 16894-16902.

196. Prabusankar, G.; Doddi, A.; Gemel, C.; Winter, M.; Fischer, R. A., P-P Bond Activation of P4 Tetrahedron by Group 13 Carbenoid and its Bis Molybdenum Pentacarbonyl Adduct. Inorg. Chem. 2010, 49 (17), 7976-7980.

197. Prabusankar, G.; Gemel, C.; Winter, M.; Seidel, R. W.; Fischer, R. A., Group 13 Ligand Supported Heavy-Metal Complexes: First Structural Evidence for Gallium-Lead and Gallium-Mercury Bonds. Chem.--Eur. J. 2010, 16 (20), 6041-6047.

198. Bollermann, T.; Cadenbach, T.; Gemel, C.; Freitag, K.; Molon, M.; Gwildies, V.; Fischer, R. A., Homoleptic Hexa and Penta Gallylene Coordinated Complexes of Molybdenum and Rhodium. Inorg. Chem. 2011, 50 (12), 5808-5814.

199. Doddi, A.; Gemel, C.; Seidel, R. W.; Winter, M.; Fischer, R. A., Synthesis and structure of new compounds with Pt-Ga bonds: Insertion of the bulky gallium (I) bisimidinate $\mathrm{Ga}(\mathrm{DDP})$ into Pt-Cl bond. J. Organomet. Chem. 2011, 696 (13), 2635-2640.

200. Ganesamoorthy, C.; Bendt, G.; Blaser, D.; Wolper, C.; Schulz, S., Te-Te and Te-C bond cleavage reactions using a monovalent gallanediyl. Dalton Trans. 2015, 44 (11), 5153-5159.

201. Ganesamoorthy, C.; Bläser, D.; Wölper, C.; Schulz, S., Synthesis of Heterobimetallic Group 13 Compounds via Oxidative Addition Reaction of Gallanediyl LGa and InEt3. Organometallics 2015, 34 (12), 2991-2996.

202. Tuscher, L.; Ganesamoorthy, C.; Bläser, D.; Wölper, C.; Schulz, S., A Gallium-Substituted Distibene and an Antimony-Analogue Bicyclo[1.1.0]butane: Synthesis and Solid-State Structures. Angew. Chem., Int. Ed. 2015, 54 (36), 10657-10661.

203. Ganesamoorthy, C.; Bläser, D.; Wölper, C.; Schulz, S., Temperature-Dependent Electron Shuffle in Molecular Group 13/15 Intermetallic Complexes. Angew. Chem., Int. Ed. 2014, 53 (43), 11587-11591.

204. Caputo, C. A.; Zhu, Z.; Brown, Z. D.; Fettinger, J. C.; Power, P. P., Activation of olefins with low-valent gallium compounds under ambient conditions. Chemical Communications 2011, 47 (26), 7506-7508.

205. Caputo, C. A.; Guo, J.-D.; Nagase, S.; Fettinger, J. C.; Power, P. P., Reversible and Irreversible Higher-Order Cycloaddition Reactions of Polyolefins with a Multiple-Bonded Heavier Group 13 Alkene Analogue: Contrasting the Behavior of Systems with $\pi-\pi, \pi-\pi^{*}$, and $\pi-n+$ Frontier Molecular Orbital Symmetry. J. Am. Chem. Soc. 2012, 134 (16), 7155-7164.

206. Hardman, N. J.; Power, P. P., Dimeric Gallium Oxide and Sulfide Species Stabilized by a Sterically Encumbered $\beta$-Diketiminate Ligand. Inorg. Chem. 2001, 40 (11), 2474-2475.

207. Hardman, N. J.; Power, P. P., Unique structural isomerism involving tetrazole and amide/azide derivatives of gallium. Chemical Communications 2001, (13), 1184-1185.

208. Ganesamoorthy, C.; Helling, C.; Wölper, C.; Frank, W.; Bill, E.; Cutsail, G. E.; Schulz, S., From stable $\mathrm{Sb}$ - and Bi-centered radicals to a compound with a $\mathrm{Ga}=\mathrm{Sb}$ double bond. Nature Communications 2018, 9 (1), 87.

209. Cowley, A. H.; Gabbai, F. P.; Carrano, C. J.; Mokry, L. M.; Bond, M. R.; Bertrand, G., Reactivity of a phosphinylcarbene ( $\lambda 5$-phosphaacetylene) toward Lewis acids: structures of the first carbenegallane complex and a C-gallyl-substituted phosphorus ylide. Angew. Chem. 1994, 106, 584-6 (See also Angew. Chem., Int. Ed. Engl., 1994, 33(5), 578-80). 
210. Nakamura, T.; Suzuki, K.; Yamashita, M., An Isolable Anionic Gallabenzene: Synthesis and Characterization. Organometallics 2015, 34 (10), 1806-1808.

211. Clément, S.; Aly, S. M.; Husson, J.; Fortin, D.; Strohmann, C.; Knorr, M.; Guyard, L.; Abd-ElAziz, A. S.; Harvey, P. D., A-Frame-Containing Organometallic Oligomers Constructed From Homoand Heterobimetallic $\mathrm{M}(\mu-\mathrm{dppm}) 2 \mathrm{M}^{\prime}\left(\mathrm{M} / \mathrm{M}^{\prime}=\mathrm{Pd}, \mathrm{Pt}\right)$ Building Blocks. Eur. J. Inorg. Chem. 2009, 2009 (17), 2536-2546.

212. Fei, N.; Sauter, B.; Gillingham, D., The pKa of Brønsted acids controls their reactivity with diazo compounds. Chemical Communications 2016, 52 (47), 7501-7504.

213. Creary, X., Tosylhydrazone salt pyrolyses: phenyldiazomethanes. Org. Synth. 1986, 64, 20716.

214. Rauniyar, V.; Zhai, H.; Hall, D. G., Catalytic Enantioselective Allyl- and Crotylboration of Aldehydes Using Chiral Diol•SnCl4 Complexes. Optimization, Substrate Scope and Mechanistic Investigations. J. Am. Chem. Soc. 2008, 130 (26), 8481-8490.

215. Zhu, H.; Chai, J.; Stasch, A.; Roesky, Herbert W.; Blunck, T.; Vidovic, D.; Magull, J.; Schmidt, H.-G.; Noltemeyer, M., Reactions of the Aluminum(I) Monomer LAl [L = HC\{(CMe)(NAr)\}2; Ar = 2,6iPr2C6H3] with Imidazol-2-ylidene and Diphenyldiazomethane. A Hydrogen Transfer from the $L$ Ligand to the Central Aluminum Atom and Formation of the Diiminylaluminum Compound LAl(N=CPh2)2. Eur. J. Inorg. Chem. 2004, 2004 (20), 4046-4051.

216. Basato, M.; Tubaro, C.; Biffis, A.; Bonato, M.; Buscemi, G.; Lighezzolo, F.; Lunardi, P.; Vianini, C.; Benetollo, F.; Del Zotto, A., Reactions of Diazo Compounds with Alkenes Catalysed by [RuCl(cod)(Cp)]: Effect of the Substituents in the Formation of Cyclopropanation or Metathesis Products. Chem.--Eur. J. 2009, 15 (6), 1516-1526.

217. Lyubov, D. M.; Cherkasov, A. V.; Fukin, G. K.; Trifonov, A. A., Selective Intermolecular C-H Bond Activation: A Straightforward Synthetic Approach to Heteroalkyl Yttrium Complexes Containing a Bis(pyrazolyl)methyl Ligand. Organometallics 2016, 35 (2), 126-137.

218. Lo, Y.-H.; Lin, Y.-C.; Lee, G.-H.; Wang, Y., Synthesis and Reactivity of the Ruthenium Cyclopropenyl Complex with a Tp Ligand. Organometallics 1999, 18 (6), 982-988.

219. Mao, W.; Xiang, L.; Alvarez Lamsfus, C.; Maron, L.; Leng, X.; Chen, Y., Highly Reactive Scandium Phosphinoalkylidene Complex: $\mathrm{C}-\mathrm{H}$ and $\mathrm{H}-\mathrm{H}$ Bonds Activation. J. Am. Chem. Soc. 2017, 139 (3), 1081-1084.

220. Krebs, A.; Born, W.; Kaletta, B.; Nickel, W.-U.; Rüger, W., Sterisch gehinderte alkene - VI. Auf dem weg zum tetra-tert.butylethen. Tetrahedron Lett. 1983, 24 (44), 4821-4824.

221. Hartzler, H. D., Di-tert-butylvinylidenecarbene, tetra-tert-butylbutatriene, tetra-tertbutylhexapentaene, and tetrakis(di-tert-butylvinylidene)cyclobutane. J. Amer. Chem. Soc. 1971, 93, 4527-31.

222. Shultz, D. A.; Boal, A. K.; Lee, H.; Farmer, G. T., Structure-Property Relationships in Trimethylenemethane-Type Biradicals. 2. Synthesis and EPR Spectral Characterization of Dinitroxide Biradicals. The Journal of Organic Chemistry 1999, 64 (12), 4386-4396.

223. Choong, S. L.; Woodul, W. D.; Stasch, A.; Schenk, C.; Jones, C., A Neutral Gallium(I) NHeterocyclic Carbene Analogue: Synthesis, Characterization and Theoretical Analysis. Aust. J. Chem. 2011, 64 (8), 1173-1176.

224. Singh, S.; Ahn, H. J.; Stasch, A.; Jancik, V.; Roesky, H. W.; Pal, A.; Biadene, M.; Herbst-Irmer, R.; Noltemeyer, M.; Schmidt, H. G., Syntheses, characterization, and X-ray crystal structures of betadiketiminate group 13 hydrides, chlorides, and fluorides. Inorg. Chem. 2006, 45 (4), 1853-60.

225. Jana, A.; Objartel, I.; Roesky, H. W.; Stalke, D., Dehydrogenation of LGeH by a Lewis NHeterocyclic Carbene Borane Pair under the Formation of L'Ge and its Reactions with B(C6F5) 3 and Trimethylsilyl Diazomethane: An Unprecedented Rearrangement of a Diazocompound to an Isonitrile. Inorg. Chem. 2009, 48 (16), 7645-7649.

226. Abdalla, J. A. B.; Caise, A.; Sindlinger, C. P.; Tirfoin, R.; Thompson, A. L.; Edwards, A. J.; Aldridge, S., Structural snapshots of concerted double $\mathrm{E}-\mathrm{H}$ bond activation at a transition metal centre. Nature Chemistry 2017, 9, 1256. 
227. Jana, B.; Uhl, W., New aluminum and gallium complexes of $\beta$-diketiminato and $\beta$-ketiminato ligands. Inorg. Chim. Acta 2017, 455, 61-69.

228. von Hänisch, C.; Hampe, O., [\{Li(thf)3\}2Ga2\{As(SiiPr3)\}4]-A Compound with Gallium=Arsenic Double Bonds. Angew. Chem., Int. Ed. 2002, 41 (12), 2095-2097.

229. Rotter, T.; Kneifel, A. N.; Mayer, P.; Westerhausen, M., Synthesis and characterization of 1,3bis[2,4,6-tri(tert-butyl)phenyl]-2,4-bis[tri(tert-butyl)silyl]-1,3-diinda-2,4-diphosphetane, a dimeric phosphanylidene indane with three-coordinate indium and phosphorus atoms. Inorg. Chem. Commun. 2005, 8 (9), 809-812.

230. Weinrich, S.; Piotrowski, H.; Vogt, M.; Schulz, A.; Westerhausen, M., Dimeric (Tris(tertbutyl)silyl)phosphanyl (Tris(tert-butyl)silyl)phosphanediyl Gallane: A Molecule with a Ga-P-Ga Heteroallyl System. Inorg. Chem. 2004, 43 (12), 3756-3762.

231. Baker, R. J.; Jones, C.; Mills, D. P.; Murphy, D. M.; Hey-Hawkins, E.; Wolf, R., The reactivity of gallium-(i), -(ii) and -(iii) heterocycles towards Group 15 substrates: attempts to prepare galliumterminal pnictinidene complexes. Dalton Trans. 2006, (1), 64-72.

232. Arduengo, A. J.; Calabrese, J. C.; Cowley, A. H.; Dias, H. V. R.; Goerlich, J. R.; Marshall, W. J.; Riegel, B., Carbene-Pnictinidene Adducts. Inorg. Chem. 1997, 36 (10), 2151-2158.

233. Petrie, M. A.; Power, P. P., Synthesis and characterization of the monomeric digallylphosphine and digallylarsine derivatives $\mathrm{MesP}\{\mathrm{Ga}(T r i p) 2\} 2$.Et2O and $\mathrm{PhAs}\{\mathrm{Ga}(T r i p) 2\} 2$. Inorg. Chem. 1993, 32 (8), 1309-1312.

234. Himmel, H.-J.; Downs, A. J.; Greene, T. M., Reactions of Aluminum, Gallium, and Indium (M) Atoms with Phosphine: Generation and Characterization of the Species M.PH3, HMPH2, and H2MPH. Inorg. Chem. 2001, 40 (2), 396-407.

235. Himmel, H.-J.; Downs, A. J.; Green, J. C.; Greene, T. M., Compounds featuring a bond between a Group $13(\mathrm{M})$ and a Group 15 element ( $\mathrm{N}$ or $\mathrm{P}$ ) and with the formulae HmMNHn and HmMPHn: structural aspects and bonding. J. Chem. Soc., Dalton Trans. 2001, (5), 535-545.

236. Lu, J.-S.; Yang, M.-C.; Su, M.-D., Triply Bonded Gallium $\equiv$ Phosphorus Molecules: Theoretical Designs and Characterization. J. Phys. Chem. A 2017, 121 (35), 6630-6637.

237. Cummins, S. J. W. MSc Thesis: The Synthesis of Novel Gallium Carbenes, Nitrenes, Phosphinidenes and Alkoxides. Victoria University of Wellington, Wellington, 2014.

238. Stender, M.; Eichler, B. E.; Hardman, N. J.; Power, P. P.; Prust, J.; Noltemeyer, M.; Roesky, H. W., Synthesis and Characterization of $\mathrm{HC}\{\mathrm{C}(\mathrm{Me}) \mathrm{N}(\mathrm{C} 6 \mathrm{H} 3-2,6-\mathrm{i}-\mathrm{Pr} 2)\} 2 \mathrm{MX2}(\mathrm{M}=\mathrm{Al}, \mathrm{X}=\mathrm{Cl}, \mathrm{I} ; \mathrm{M}=\mathrm{Ga}$, In, $\mathrm{X}=\mathrm{Me}, \mathrm{Cl}, \mathrm{I})$ : Sterically Encumbered $\beta$-Diketiminate Group 13 Metal Derivatives. Inorg. Chem. 2001, 40 (12), 2794-2799.

239. Dhara, D.; Mandal, D.; Maiti, A.; Yildiz, C. B.; Kalita, P.; Chrysochos, N.; Schulzke, C.; Chandrasekhar, V.; Jana, A., Assembly of NHC-stabilized 2-hydrophosphasilenes from Si(iv) precursors: a Lewis acid-base complex. Dalton Trans. 2016, 45 (48), 19290-19298.

240. Petrie, M. A.; Power, P. P., Synthesis and characterization of the monomeric phosphinogallanes But2GaPR' $R^{\prime \prime}\left(R^{\prime}, R^{\prime \prime}=\right.$ bulky aryl or silyl groups) and related compounds. J. Chem. Soc., Dalton Trans. 1993, (11), 1737-1745.

241. Andrews, P. C.; McGrady, J. E.; Nichols, P. J., Decomposition of [2-Pyr(SiMe3)2C]2SbCl into the Stibaalkene [2-Pyr(SiMe3)2C-Sb:C(SiMe3)2-Pyr]: Solid, Solution, and ab Initio Study.

Organometallics 2004, 23 (3), 446-453.

242. Thomas, F.; Schulz, S.; Mansikkamäki, H.; Nieger, M., Unexpected Rearrangement Reaction of Lewis Base Stabilized Group 13/15 Compounds with Group 13 Trialkyls. Organometallics 2003, 22 (17), 3471-3477.

243. Bond Energies. In Encyclopedia of Inorganic Chemistry, King, R. B.; Crabtree, R. H.; Lukehart, C. M.; Atwood, D. A.; Scott, R. A., Eds. 2006.

244. Yang, Y.; Gurubasavaraj, P. M.; Ye, H.; Zhang, Z.; Roesky, H. W.; Jones, P. G., Synthesis, structural characterization, and reactivity of the ethyl substituted aluminum hydroxide and catalytic properties of its derivative. J. Organomet. Chem. 2008, 693 (8), 1455-1461. 
245. Sekiguchi, A.; Izumi, R.; Ihara, S.; Ichinohe, M.; Lee, V. Y., The First Isolable 1,1-

Dilithiogermane and Its Unusual Dimeric Structure-An Effective Reagent for the Preparation of Double-Bonded Derivatives of Group 14 Elements. Angew. Chem., Int. Ed. 2002, 41 (9), 1598-1600.

246. Couret, C.; Escudie, J.; Ranaivonjatovo, H.; Satge, J., New general route to diphosphenes via germylated compounds. Organometallics 1986, 5 (1), 113-117.

247. Steffen, S.; Michael, R.; Eric, M.; Angela, B.; Frank, B., Aluminium Diphosphamethanides: Hidden Frustrated Lewis Pairs. Chem.--Eur. J. 2016, 22 (28), 9508-9512.

248. Welch, G. C.; Juan, R. R. S.; Masuda, J. D.; Stephan, D. W., Reversible, Metal-Free Hydrogen Activation. Science 2006, 314 (5802), 1124-1126.

249. Yang, N.; Xin, L.; Gao, W.; Zhang, J.; Luo, X.; Liu, X.; Mu, Y., Al and Zn complexes bearing $\mathrm{N}, \mathrm{N}, \mathrm{N}$-tridentate quinolinyl anilido-imine ligands: synthesis, characterization and catalysis in I-lactide polymerization. Dalton Trans. 2012, 41 (37), 11454-11463.

250. Shore, S. G.; Parry, R. W., The crystalline compound ammonia-borane,1 H3NBH3. J. Am. Chem. Soc. 1955, 77 (22), 6084-6085.

251. Kuczkowski, A.; Fahrenholz, S.; Schulz, S.; Nieger, M., Reactions of Distibines Sb2R4 and Dibismuthine Bi2Et4 with Trialkyltrieles MR3. Organometallics 2004, 23 (15), 3615-3621.

252. Ewing, W. C.; Carroll, P. J.; Sneddon, L. G., Syntheses and Characterizations of Linear Triborazanes. Inorg. Chem. 2013, 52 (18), 10690-10697.

253. Kumar, A.; Johnson, H. C.; Hooper, T. N.; Weller, A. S.; Algarra, A. G.; Macgregor, S. A., Multiple metal-bound oligomers from Ir-catalysed dehydropolymerisation of H3B-NH3 as probed by experiment and computation. Chemical Science 2014, 5 (6), 2546-2553.

254. Gaumont, A. C.; Carboni, B., Product subclass 16: phosphinoboranes and borane-phosphine complexes. Sci. Synth. 2004, 6, 485-512.

255. Amii, H.; Vranicar, L.; Gornitzka, H.; Bourissou, D.; Bertrand, G., Radical-Type Reactivity of the 1,3-Dibora-2,4-Diphosphoniocyclobutane-1,3-diyl. J. Am. Chem. Soc. 2004, 126 (5), 1344-1345.

256. Rasika, D. H. V.; P., P. P., Synthesis and X-Ray Structure of (2,4,6-Me3C6H2BPC6H11)3: A Boron-Phosphorus Analogue of Borazine. Angew. Chem., Int. Ed. Engl. 1987, 26 (12), 1270-1271.

257. Dou, D.; Wood, G. L.; Duesler, E. N.; Paine, R. T.; Noeth, H., Synthesis and chemistry of diborylphosphanes. Inorg. Chem. 1992, 31 (9), 1695-1702.

258. Geier, S. J.; Gilbert, T. M.; Stephan, D. W., Synthesis and Reactivity of the Phosphinoboranes R2PB(C6F5)2. Inorg. Chem. 2011, 50 (1), 336-344.

259. Schwan, K. C.; Timoskin, A. Y.; Zabel, M.; Scheer, M., Lewis Base Stabilized Phosphanylborane. Chem.--Eur. J. 2006, 12 (18), 4900-4908.

260. Ariane, A.; Manfred, Z.; Manfred, S., Main Group Lewis Acid/Base-Stabilised Phosphanylboranes. Eur. J. Inorg. Chem. 2007, 2007 (15), 2136-2143.

261. Rivard, E.; Merrill, W. A.; Fettinger, J. C.; Wolf, R.; Spikes, G. H.; Power, P. P., Boron-Pnictogen Multiple Bonds: Donor-Stabilized PB and AsB Bonds and a Hindered Iminoborane with a B-N Triple Bond. Inorg. Chem. 2007, 46 (8), 2971-2978.

262. Dou, D.; Linti, G. W.; Chen, T.; Duesler, E. N.; Paine, R. T.; Nöth, H., Synthesis, Structure, and Coordination Chemistry of Aminophosphanylboranes. Inorg. Chem. 1996, 35 (12), 3626-3634.

263. Chen, T.; Duesler, E. N.; Nöth, H.; Paine, R. T., Synthesis and coordination behavior of a zirconocene bis(borylphosphane). J. Organomet. Chem. 2000, 614-615, 99-106.

264. Geier, S. J.; Gilbert, T. M.; Stephan, D. W., Activation of H2 by Phosphinoboranes R2PB(C6F5)2. J. Am. Chem. Soc. 2008, 130 (38), 12632-12633.

265. Marquardt, C.; Hegen, O.; Kahoun, T.; Scheer, M., Oxidation of Substituted Phosphanylboranes with Chalcogens. Chem.--Eur. J. 2017, 23 (18), 4397-4404.

266. Beachley, O. T., Jr.; Tessier-Youngs, C., Synthesis and characterization of organoaluminum compounds containing the (trimethylsilyl)methyl substituent, $\mathrm{Al}(\mathrm{CH} 2 \mathrm{SiMe} 3) 2 \mathrm{Br}, \mathrm{Al}(\mathrm{CH} 2 \mathrm{SiMe} 3) 2 \mathrm{H}$, and (Me3SiCH2)2AlPPh2, and a reinvestigation of the chemistry of Me2AlPPh2 and Et2AlPPh2.

Organometallics 1983, 2, 796-801. 
267. Habereder, T.; Noeth, H.; Paine, R. T., Synthesis and reactivity of new bis(tetramethylpiperidino)(phosphanyl)alumanes. Eur. J. Inorg. Chem. 2007, 4298-4305.

268. Wehmschulte, R. J.; Ruhlandt-Senge, K.; Power, P. P., Synthesis and Characterization of Unassociated Aluminum Monophosphides. Inorg. Chem. 1994, 33 (15), 3205-3207.

269. Klaus, K.; Ingo, K.; Heinrich, N.; Holger, S.-K.; Martin, S.-A.; Thomas, S., The AluminumNitrogen Bond in Monomeric Bis(amino)alanes: A Systematic Experimental Study of Bis(tetramethylpiperidino)alanes and Quantum Mechanical Calculations on the Model System (H2N)2AlY. Eur. J. Inorg. Chem. 1998, 1998 (8), 1095-1114.

270. Ding, S.; Li, J.; Liu, R.; Fu, G.; Zhu, H.; Liu, W.; Ye, Q., N-Geminal P/Al Lewis Pair-Alkyne Dipolar Cycloaddition to the Zwitterionic C2PNAl-Heterocyclopentene. ACS Omega 2017, 2 (6), 24052414.

271. Zijlstra, H. S.; Pahl, J.; Penafiel, J.; Harder, S., "Masked" Lewis-acidity of an aluminum $\alpha-$ phosphinoamide complex. Dalton Trans. 2017, 46 (11), 3601-3610.

272. Bertini, F.; Hoffmann, F.; Appelt, C.; Uhl, W.; Ehlers, A. W.; Slootweg, J. C.; Lammertsma, K., Reactivity of Dimeric P/Al-Based Lewis Pairs toward Carbon Dioxide and tert-Butyl Isocyanate.

Organometallics 2013, 32 (22), 6764-6769.

273. Roters, S.; Appelt, C.; Westenberg, H.; Hepp, A.; Slootweg, J. C.; Lammertsma, K.; Uhl, W., Dimeric aluminum-phosphorus compounds as masked frustrated Lewis pairs for small molecule activation. Dalton Trans. 2012, 41 (30), 9033-9045.

274. Boudreau, J.; Courtemanche, M.-A.; Fontaine, F.-G., Reactivity of Lewis pairs (R2PCH2AIMe2)2 with carbon dioxide. Chemical Communications 2011, 47 (39), 11131-11133.

275. Leung, W.-P.; Chan, C. M. Y.; Wu, B.-M.; Mak, T. C. W., Synthesis and Characterization of Monomeric Amide, Phosphide, and Thiolate Complexes of Gallium and Indium. Organometallics 1996, 15 (24), 5179-5184.

276. Petrie, M. A.; Ruhlandt-Senge, K.; Power, P. P., Detection of a rotation barrier around a bond between heavier Main Group 3 and 5 elements. Inorg. Chem. 1992, 31 (20), 4038-4039.

277. Thomas, F.; Schulz, S.; Nieger, M.; Nättinen, K., Bimetallic Complexes from Amphoteric Group 13/15 Ligands: Syntheses and X-ray Crystal Structures. Chem.--Eur. J. 2002, 8 (8), 1915-1924. 278. Atwood, D. A.; Cowley, A. H.; Jones, R. A.; Mardones, M. A., Synthesis and structure of the first base-free diphosphadigalletane. J. Am. Chem. Soc. 1991, 113 (18), 7050-7052.

279. Schwamm, R. J.; Fulton, J. R.; Coles, M. P.; Fitchett, C. M., Hydrophosphination-type reactivity promoted by bismuth phosphanides: scope and limitations. Dalton Trans. 2017, 46 (7), 2068-2071.

280. Roering, A. J.; Leshinski, S. E.; Chan, S. M.; Shalumova, T.; MacMillan, S. N.; Tanski, J. M.; Waterman, R., Insertion Reactions and Catalytic Hydrophosphination by Triamidoamine-Supported Zirconium Complexes. Organometallics 2010, 29 (11), 2557-2565.

281. Harris, L. M.; Tam, E. C. Y.; Cummins, S. J. W.; Coles, M. P.; Fulton, J. R., The Reactivity of Germanium Phosphanides with Chalcogens. Inorg. Chem. 2017, 56 (5), 3087-3094.

282. Daly, S. R.; Klaehn, J. R.; Boland, K. S.; Kozimor, S. A.; Maclnnes, M. M.; Peterman, D. R.; Scott, B. L., NMR spectroscopy and structural characterization of dithiophosphinate ligands relevant to minor actinide extraction processes. Dalton Trans. 2012, 41 (7), 2163-2175.

283. Sheldrick, G. M., A short history of SHELX. Acta Crystallogr., Sect. A: Found. Crystallogr. 2008, 64 (1), 112-122.

284. Sheldrick, G. M., Crystal structure refinement with SHELXL. Acta Crystallogr., Sect. C: Struct. Chem. 2015, 71 (1), 3-8.

285. Dolomanov, O. V.; Bourhis, L. J.; Gildea, R. J.; Howard, J. A. K.; Puschmann, H., OLEX2: a complete structure solution, refinement and analysis program. J. Appl. Crystallogr. 2009, 42 (2), 339341.

286. Maity, A. K.; Fortier, S.; Griego, L.; Metta-Magaña, A. J., Synthesis of a "Super Bulky" Guanidinate Possessing an Expandable Coordination Pocket. Inorg. Chem. 2014, 53 (15), 8155-8164. 
287. Qian, B.; Ward, D. L.; Smith, M. R., Synthesis, Structure, and Reactivity of $\beta$-Diketiminato Aluminum Complexes. Organometallics 1998, 17 (14), 3070-3076.

288. Hua, G.; Li, Y.; Slawin, A. M. Z.; Woollins, J. D., Stereoselective synthesis of olefins by a reductive coupling reaction. Dalton Trans. 2007, (15), 1477-1480. 